\title{
ANALYSIS OF THE FLAMMABILITY PROPERTIES OF SOLID FUELS
}

\author{
PhD THESIS
}

María de las Nieves Fernández Áñez

Mining Engineer 
Department of Energy and Fuels

School of Mines and Energy

\title{
ANALYSIS OF THE FLAMMABILITY PROPERTIES OF SOLID FUELS
}

\author{
PhD THESIS \\ Autor: \\ María de las Nieves Fernández Áñez. \\ Mining Engineer \\ Supervisor: \\ Javier García Torrent. \\ PhD Mining Engineer
}

2016 



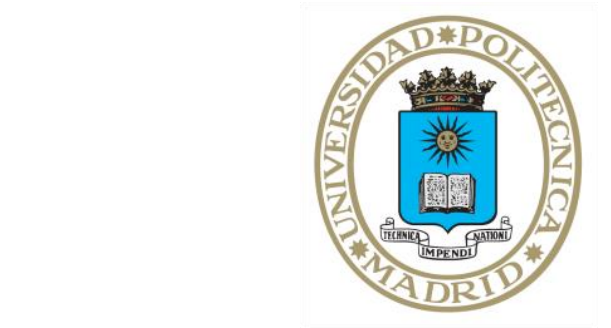

\section{UNIVERSIDAD POLITÉCNICA DE MADRID}

Tribunal nombrado por el Magfo. Y Excmo. Sr. Rector de la Universidad Politécnica de Madrid, el día de de $20 \ldots \ldots$.

Presidente:

Vocal:

Vocal:

Vocal:

Secretario:

Suplente:

Suplente:

Realizado el acto de defensa y lectura de la tesis el día de de 20..... en la E.T.S.I/Facultad 

La presente tesis doctoral es el resultado de las "Becas de investigación de la U.P.M. para la realización del doctorado en sus departamentos e institutos" concedida por la Universidad Politécnica de Madrid. (Resolución de 4 de octubre de 2011) 



\section{ACKNOWLEDGMENTS}

First of all, I would like to thank to my supervisor, Prof. Javier Garcia Torrent, for his guidance during all these years and for helping me to achieve this goal with his experience in this research and in life.

I am extremely grateful to Laboratorio Oficial Madariaga and Lloyd's Register Educational Trust for financial support and for making this possible.

I would also like to thank to the supervisors of my research stays, Prof. Ajit Shenoi and Dr. Herodotos Phylaktou, and to all the people that made these periods easier.

Thanks to the external reviewers of my thesis, Dr. Xinyan Huang and Dr. Bjarne Christian Hagen for their valuable comments.

Thanks to all the people that has collaborated with this research and with all the work associated to it, Ljiljana Medic, Alvaro Ramirez, Laura Rubio, Lucía Montenegro, Vanesa Valiño.

I am also grateful to Gonzalo, Emilio and Mariano for all their help inside and outside the laboratory, I could not have finished this thesis without your help.

Thanks to all the colleagues who have gone through the "432" or near: Amaia, María Jesús, Marcelo, Fernando, Miguel, Miky, Alberto and all the people that used to visit me. Thanks for listening to me in my worst moments and making me laugh when I needed it.

Very special thanks to my mother that has guided me until this end, and will be next to me in every following step. Thanks to my father, that has been by my side during all this long period. And many thanks to my sister, for supporting me in all the bad moments and for believing in me since the beginning.

Thanks to all my friends, from the School of Mines and outside. You have listened to my problems hours and hours and gave me the force that I needed many times. I do not have enough space in this paper for all your names, but you will be always in my heart.

At the end, but always at the beginning of all my thoughts, I would like to thank Javi for listening all my long monologues, helping me with all my problems and put a smile always in my face. 



\section{TABLE OF CONTENTS}

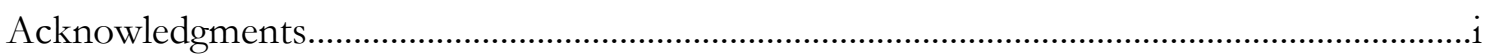

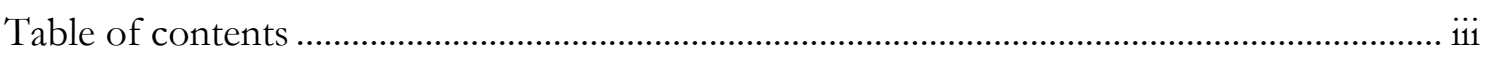

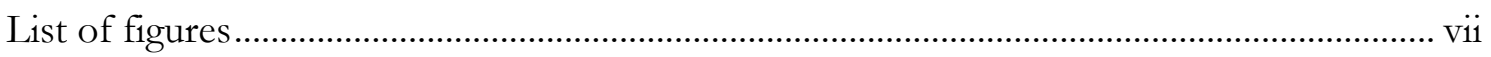

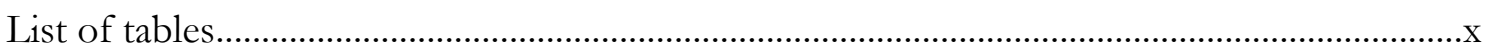

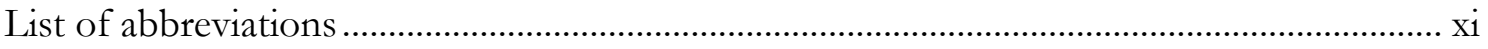

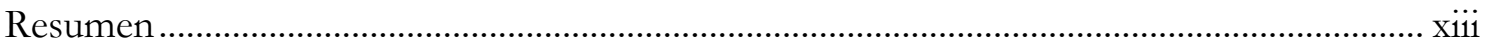

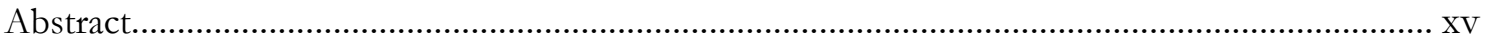

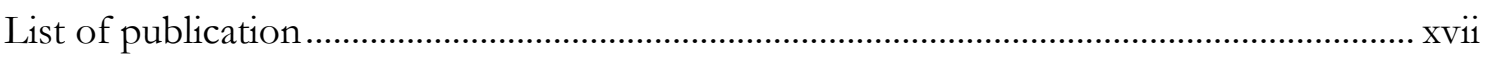

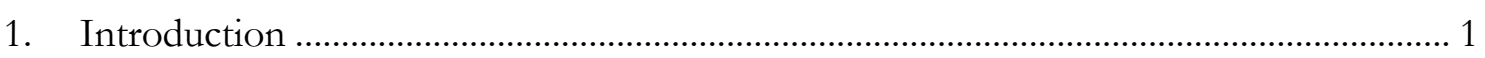

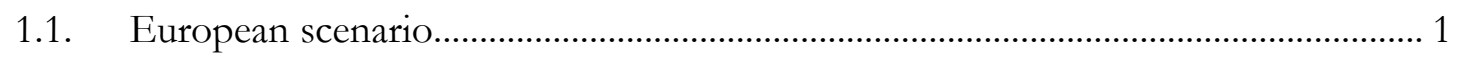

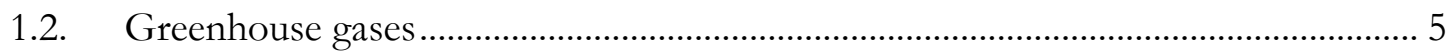

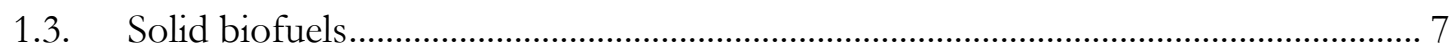

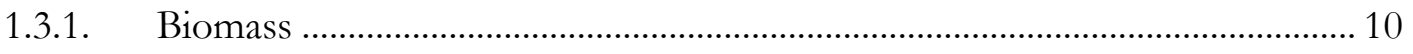

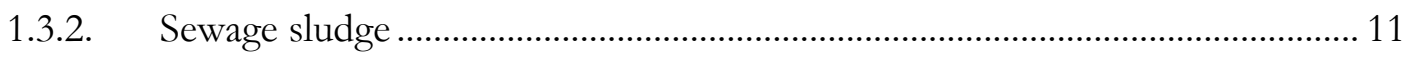

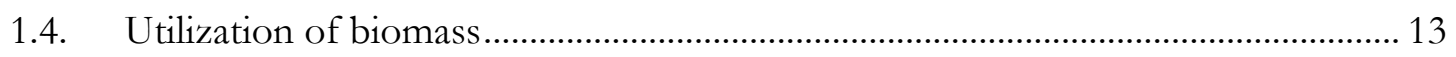

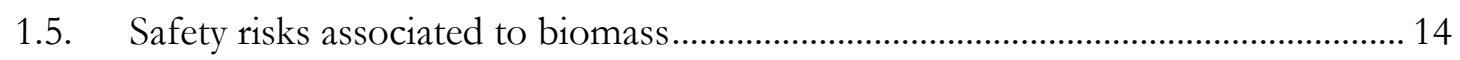

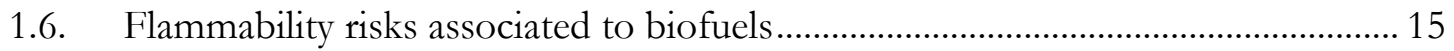

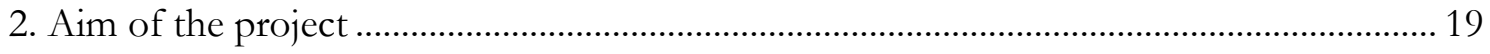

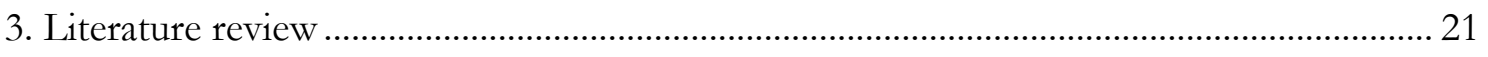

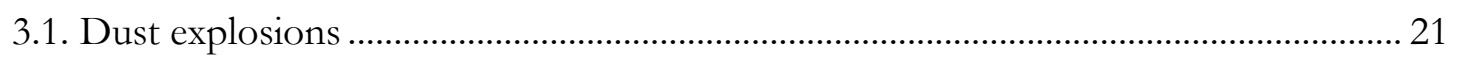

3.1.1. Dust explosibility parameters and assessment .............................................. 22

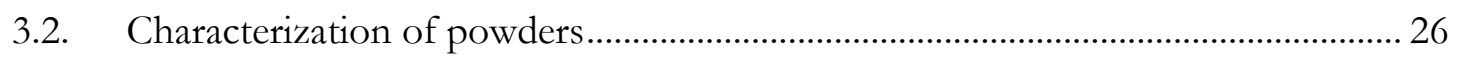

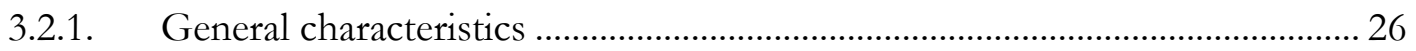

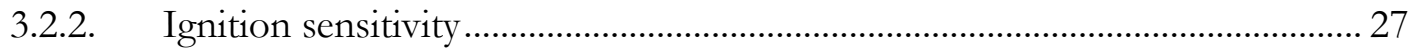

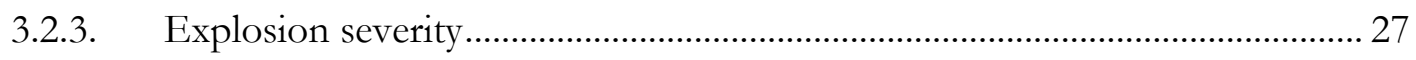

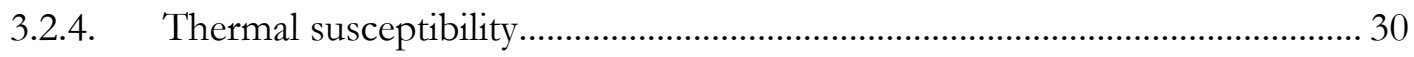




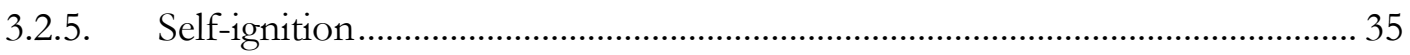

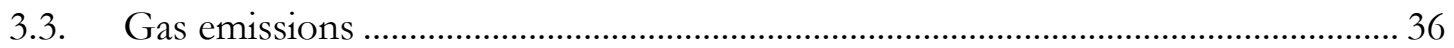

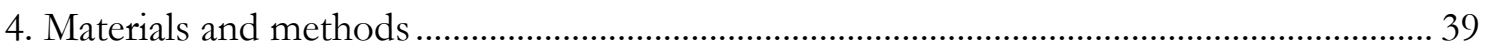

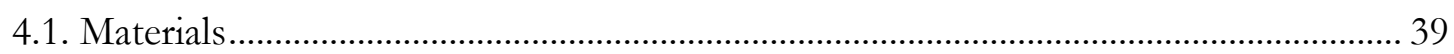

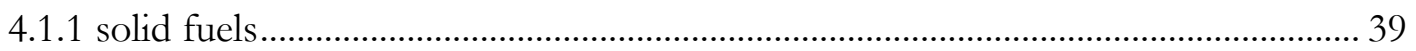

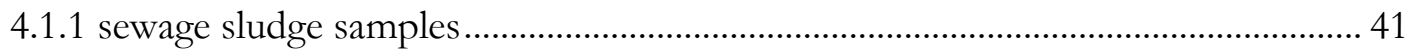

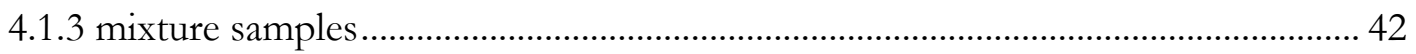

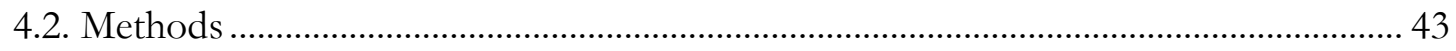

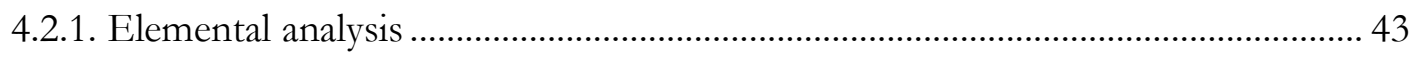

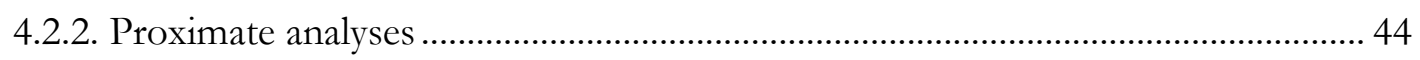

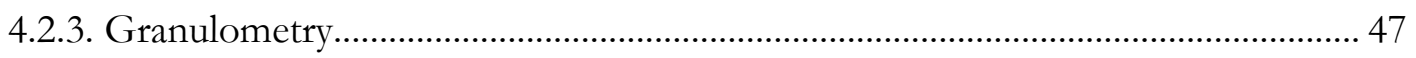

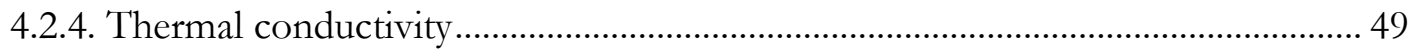

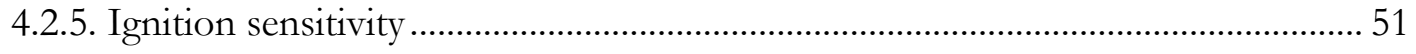

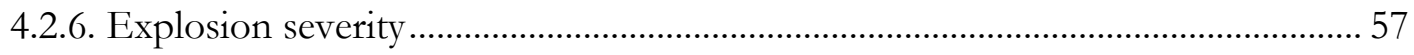

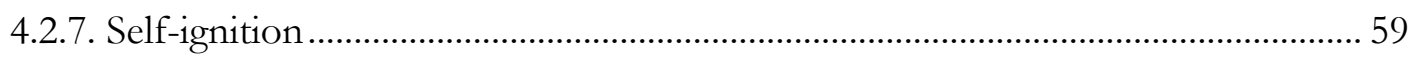

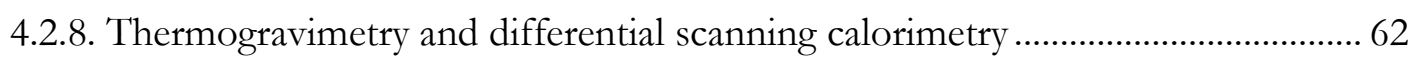

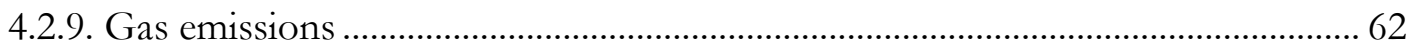

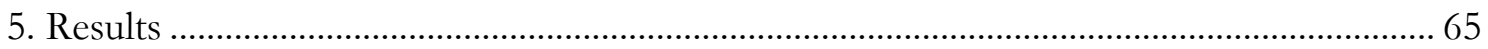

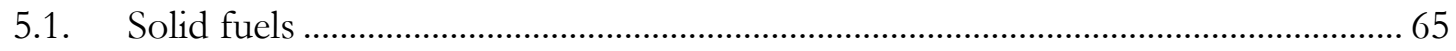

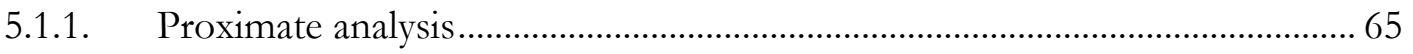

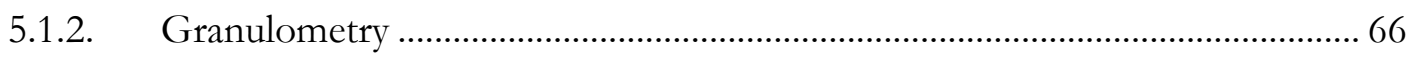

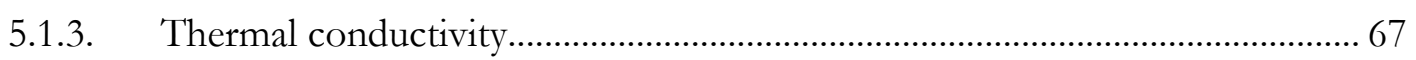

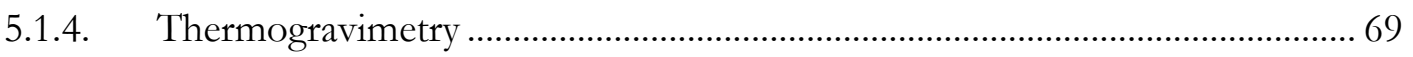

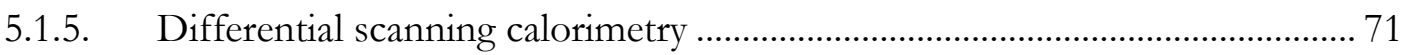

5.1.6. Minimum ignition temperature on a layer............................................................ 76

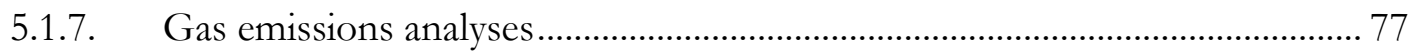

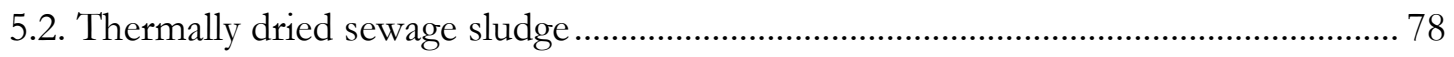

5.2.1. Elemental and proximate analyses................................................................... 78 


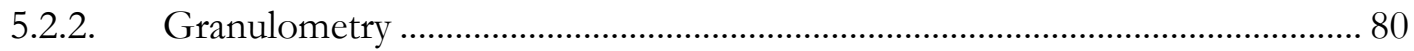

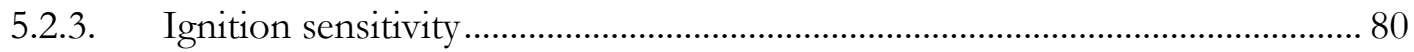

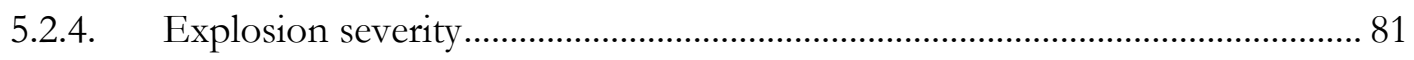

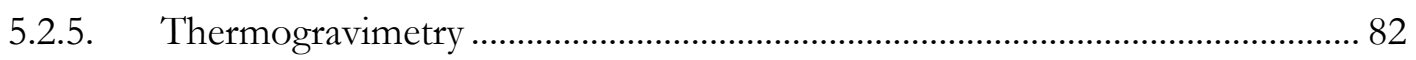

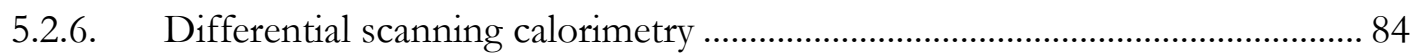

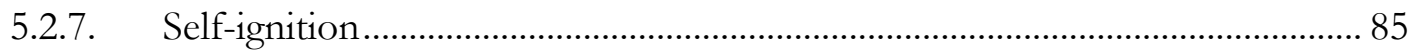

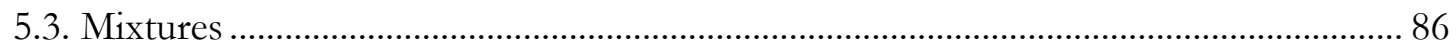

5.3.1. Elemental and proximate analyses............................................................................. 86

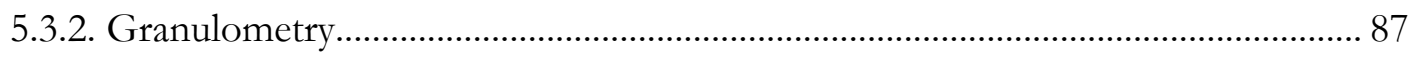

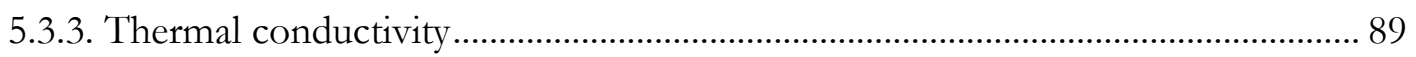

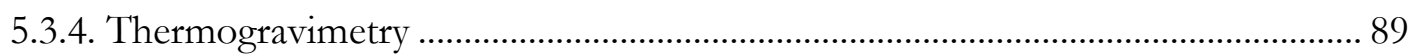

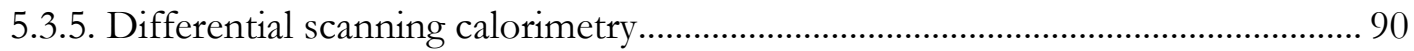

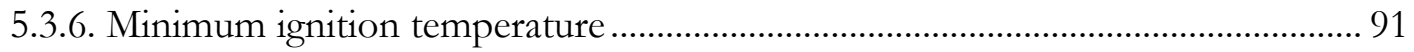

5.3.7. Minimum ignition energy ..................................................................................... 92

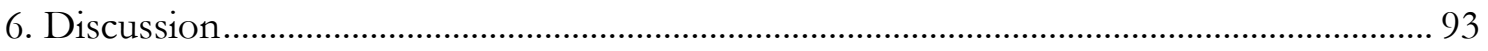

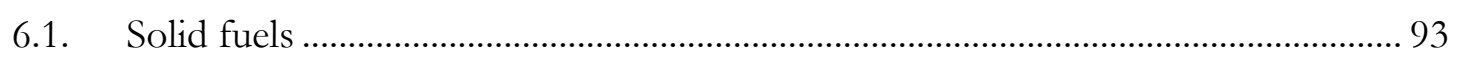

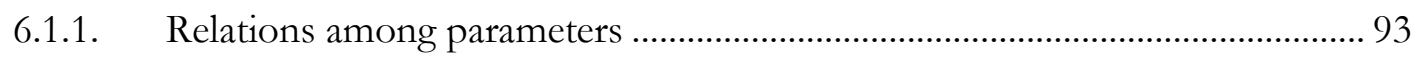

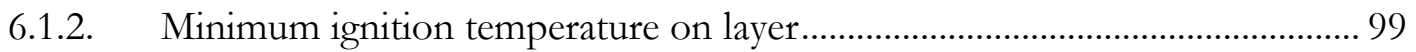

6.1.3. Thermogravimetry - differential scanning calorimetry .................................... 101

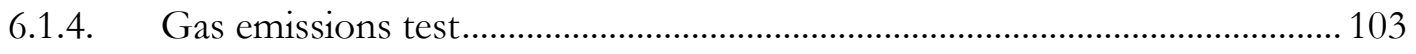

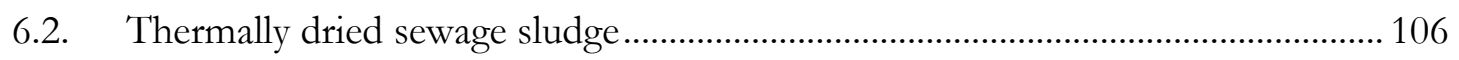

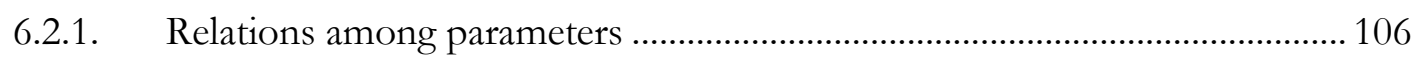

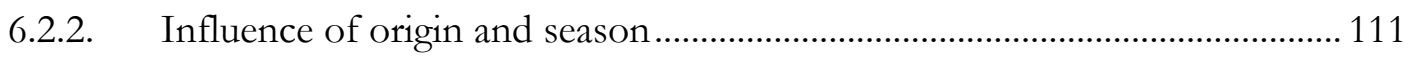

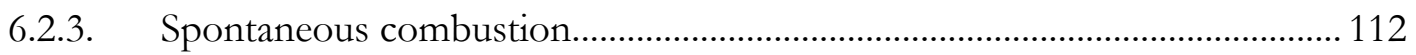

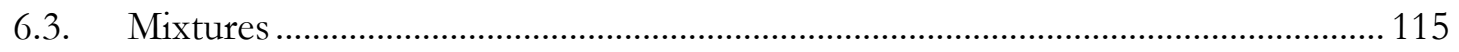

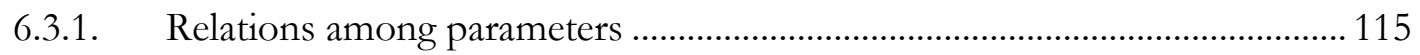

6.3.2. Thermogravimetry and differential scanning calorimetry ............................. 120

6.3.3. Minimum ignition temperature on a layer and minimum ignition energy... 124 


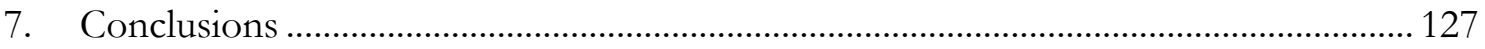

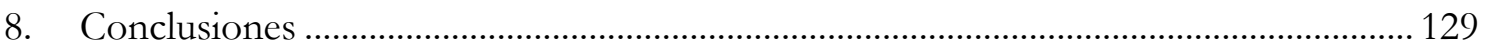

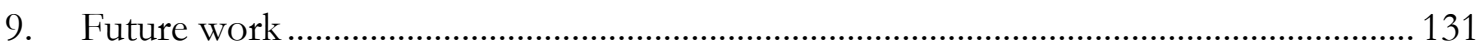

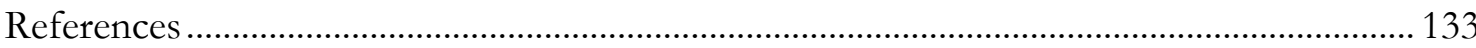

\section{ANNEXES}

Annex I. Documents needed for the "international doctor" mention

Annex II. Results

Annex III. Flammability properties of thermally dried sewage sludge

Annex IV. Determination of spontaneous combustion of thermally dried sewage sludge

Annex V. Detection of incipient self-ignition process in solid fuels through gas emissions methodology 


\section{LIST OF FIGURES}

Figure 1. Role of biomass in meeting Europe's renewable energy targets - European Commission scenario [4].

Figure 2. Current biomass energy growth compared to the growth required to reach the

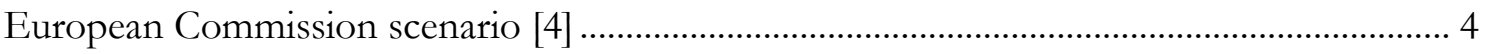

Figure 3. Share of renewable energy in gross final energy consumption [7] ........................... 4

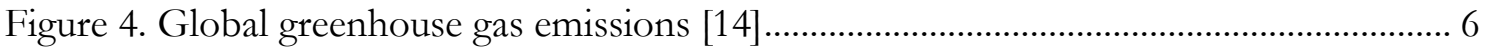

Figure 5. Global carbon emissions from fossil fuels have significantly increased since 1900

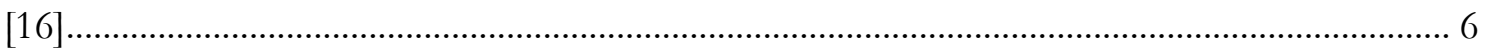

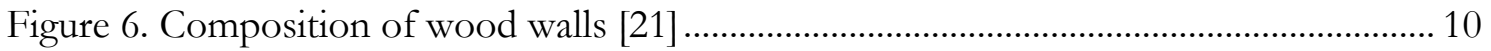

Figure 7. Water associated with sludge particles [25] ............................................................... 12

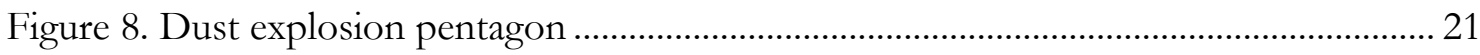

Figure 9. Influence of particle size on the explosibility of dusts [47] ..................................... 23

Figure 10. Example of explosion characteristics [49] ……………............................................ 24

Figure 11. Ignition sources for dust explosions [51] …………….......................................... 24

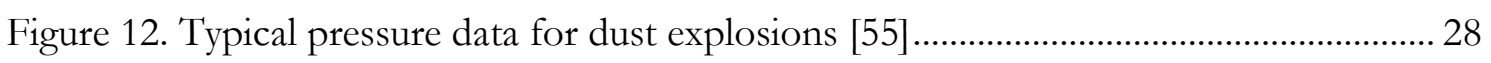

Figure 13. Effect of reduced oxygen concentration on coal dust explosibility [55].............. 29

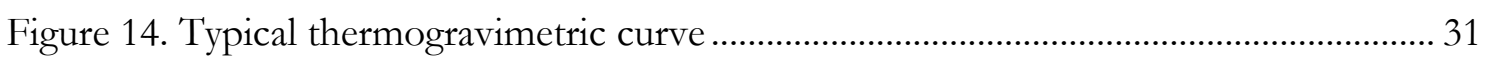

Figure 15. Thermogravimetric curve for biomasses ............................................................... 32

Figure 16. Curve of thermogravimetry with oxygen test ........................................................ 32

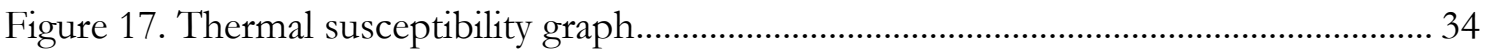

Figure 18. Typical curve of differential scanning calorimetry .................................................... 35

Figure 19. Thermal behaviour of the dust materials in the isothermal oven [83] .................. 36

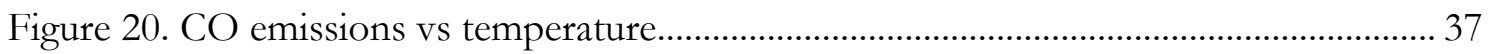

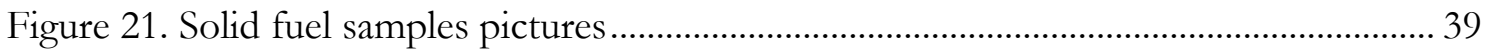

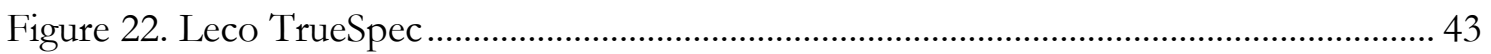

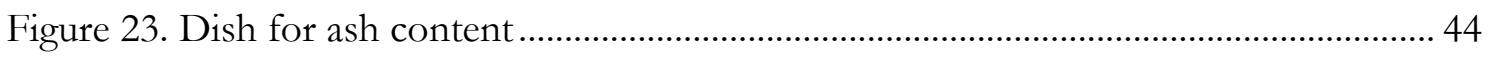

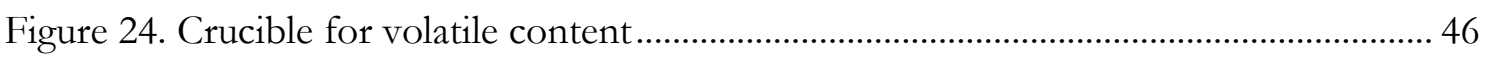

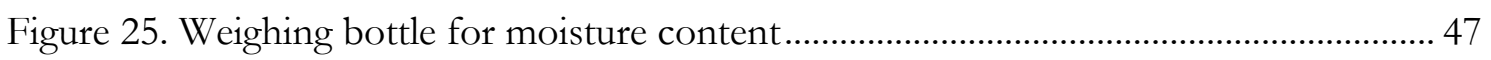

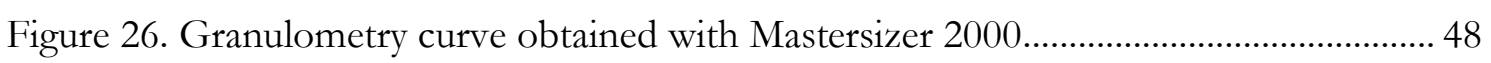

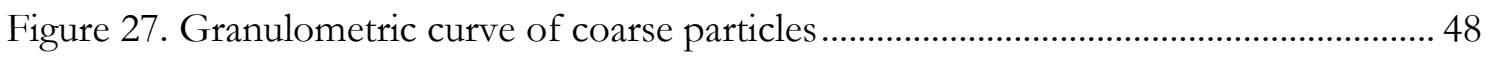

Figure 28. Equipment for determining minimum ignition temperature on layer [98].......... 51

Figure 29. Ring used for minimum ignition temperature on layer [98] ................................. 52 
Figure 30. Correlation between maximum admissible surface temperature and thickness of

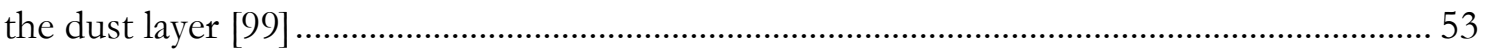

Figure 31. Furnace for minimum ignition temperature on cloud [98] ................................... 54

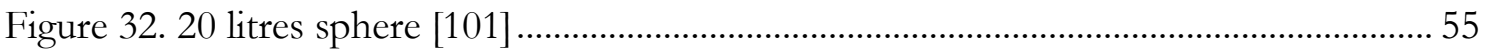

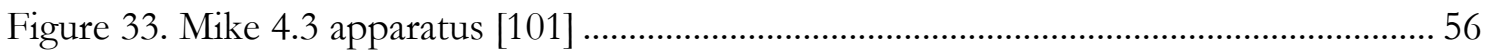

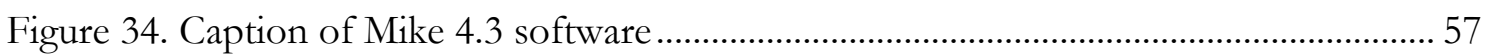

Figure 35. Determination of rate of explosion pressure rise .................................................. 58

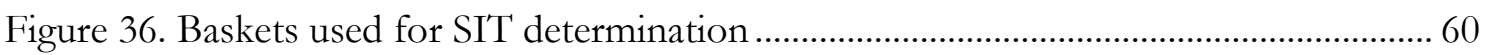

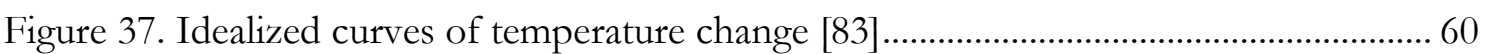

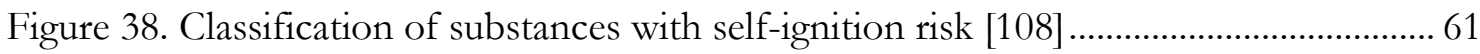

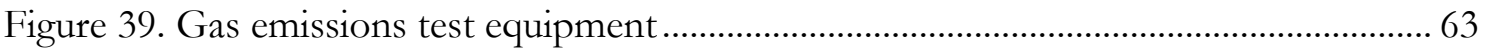

Figure 40. Triangular diagram proximate analyses biomass samples [110] .............................. 65

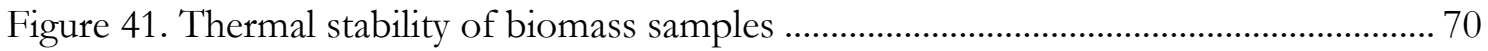

Figure 42. Thermogravimetry with air curves of solid fuels.................................................... 72

Figure 43. Derivative curves of thermogravimetry with air of solid fuels ................................ 73

Figure 44. Thermogravimetry with oxygen curves of solid fuels............................................... 74

Figure 45. Differential scanning calorimetry curves of solid fuels .......................................... 75

Figure 46. Triangular diagram elemental analyses sewage sludge [110] ................................. 79

Figure 47.Triangular diagram proximate analyses sewage sludge [110] ................................... 79

Figure 48. Thermal susceptibility graph thermally dried sewage sludge .................................. 83

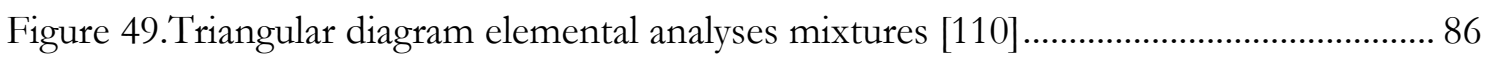

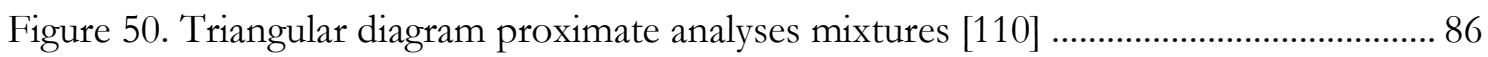

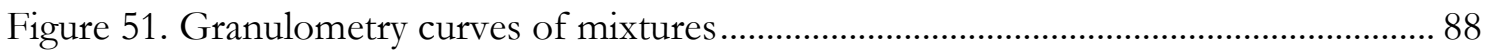

Figure 52. Minimum ignition temperature on a layer of mixtures............................................. 91

Figure 53. Minimum ignition energy of mixtures ....................................................................... 92

Figure 54. Relations between ash content (\%), MLT_1, Tcharact, IET, CST $\left({ }^{\circ} \mathrm{C}\right)$............... 94

Figure 55. Relations between volátiles content $(\%), \mathrm{d} 50(\mu \mathrm{m})$, diffusivity $\left(\mathrm{m}^{2} / \mathrm{s}\right)$, density $(\mathrm{g} / \mathrm{L})$

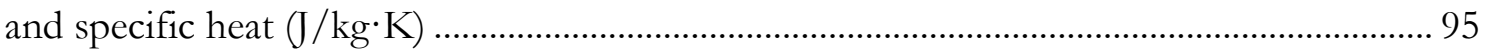

Figure 56. Fixed carbon vs volatiles solid fuels .......................................................................... 96

Figure 57. Relations between ash content (\%), diffusivity $\left(\mathrm{m}^{2} / \mathrm{s}\right)$, MLT_$_{-}$, Tcharact, CST and

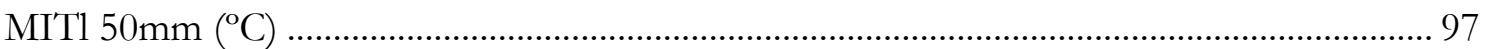

Figure 58. Relations between volatiles and fixed carbon contents $(\%)$, specific heat $(\mathrm{J} / \mathrm{kg} \cdot \mathrm{K})$,

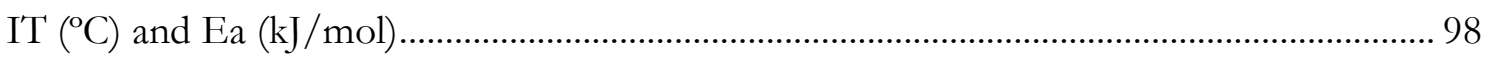

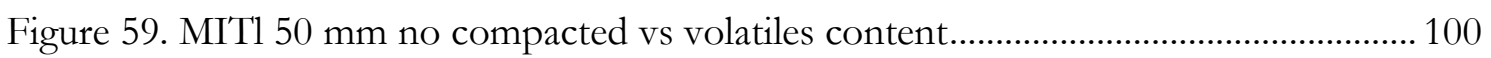


Figure 60. Middle graph SSA vs (MITl $50 \mathrm{~mm}$ no compacted - MITl $50 \mathrm{~mm}$ compacted) 101

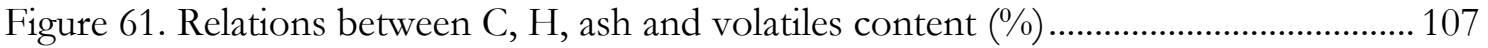

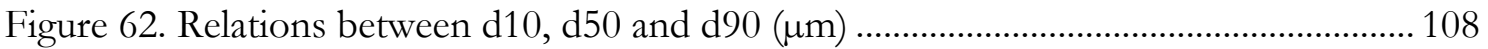

Figure 63. Relations between volátiles and ash contents (\%) and MITl $\left({ }^{\circ} \mathrm{C}\right), \mathrm{MIE}(\mathrm{mJ})$ and $\mathrm{P}_{\max }(\mathrm{bar})$ 109

Figure 64. Relations between medium diameter $(\mu \mathrm{m})$ and $\operatorname{MITl}\left({ }^{\circ} \mathrm{C}\right)$, MIE $(\mathrm{mJ})$ and IT $\left({ }^{\circ} \mathrm{C}\right)$

Figure 65. Thermal stability graph for thermally dried sewage sludge

Figure 66. Extrapolation of SIT. Temperature [1/T] versus size [Log (V/A)] 114

Figure 67. Extrapolation of SIT. Time [log (t)] versus size [Log (V/A)] 114

Figure 68. Relations between particle size parameters $(\mu \mathrm{m})$ 116

Figure 69. Relations between volatiles and ash contents (\%) and density (g/L), diffusivity $\left(\mathrm{m}^{2} / \mathrm{s}\right)$ and $\mathrm{Ea}(\mathrm{kJ} / \mathrm{mol})$

Figure 70. Relations between volatiles content (\%) and MITl50mm, MLT_1, IT, IET, FET and $\operatorname{CST}\left({ }^{\circ} \mathrm{C}\right)$......

Figure 71 . Relations between medium particle size $(\mu \mathrm{m})$, density $(\mathrm{g} / \mathrm{L})$, diffusivity $\left(\mathrm{m}^{2} / \mathrm{s}\right)$, Tcharact, CST and MITl50mm $\left({ }^{\circ} \mathrm{C}\right)$

Figure 72. TG curves estimated and measured for mixtures............................................... 121

Figure 73. DSC curves estimated and measured for mixtures .............................................. 123

Figure 74. Calculated vs measured MIE and MITl 125 


\section{LIST OF TABLES}

Table 1.Physical, chemical and fuel properties of biomass and coal fuels [5]......................... 3

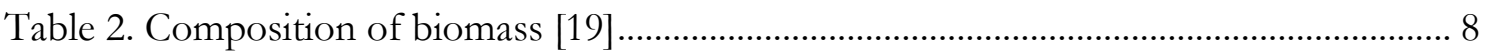

Table 3. Average values of proximate and ultimate analyses of biomass [20] ......................... 9

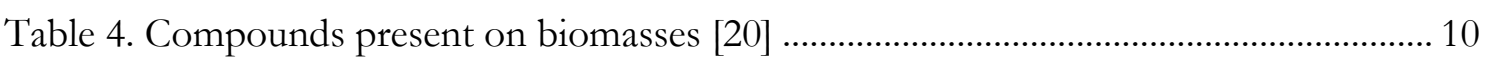

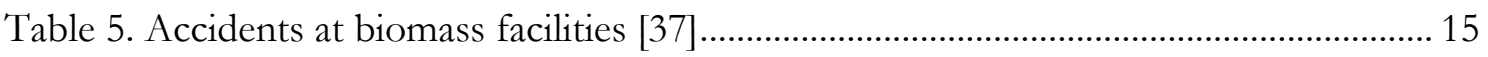

Table 6. Explosion type depending on characteristic constant value....................................... 28

Table 7. Factors influencing the maximum rise of pressure........................................................ 29

Table 8. Self-ignition risk depending on characteristic temperature values ............................. 33

Table 9. Self-ignition risk depending on activation energy values .............................................. 34

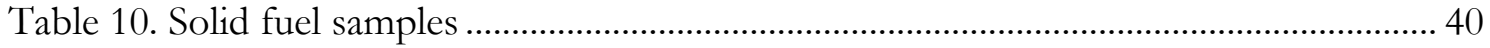

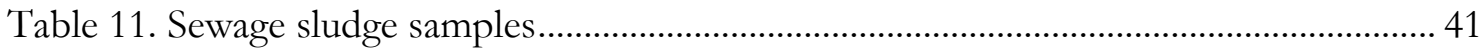

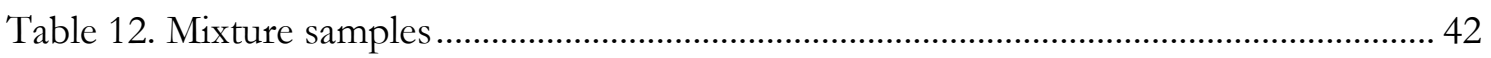

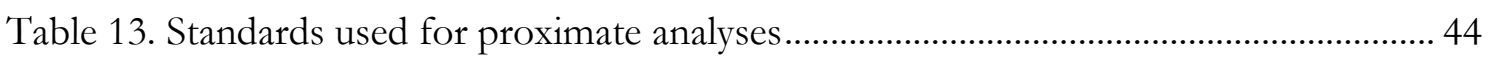

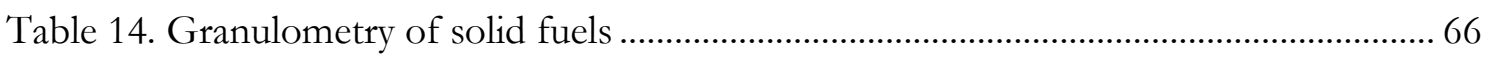

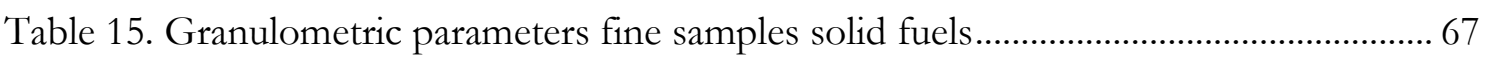

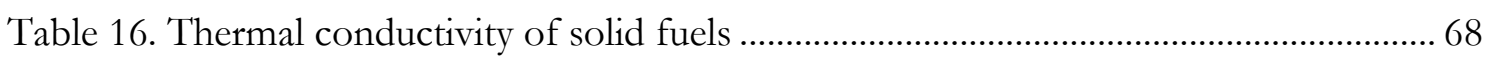

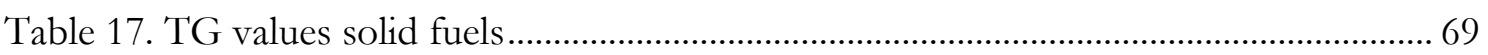

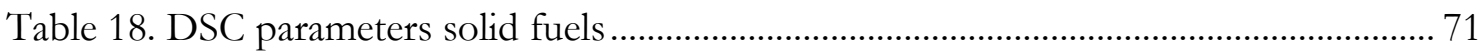

Table 19. Minimum ignition temperature on a layer of solid fuels with different particle sizes .76

Table 20. Gas emissions results for solid fuels ........................................................................... 77

Table 21. Gas emissions results for solid fuels (cont.) ………………………………………..... 78

Table 22. Statistical parameters granulometry sewage sludge.................................................... 80

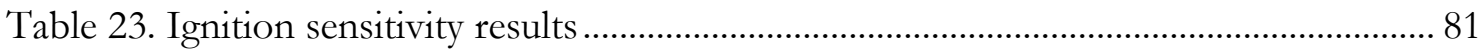

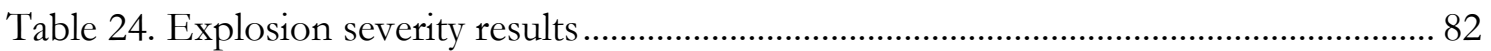

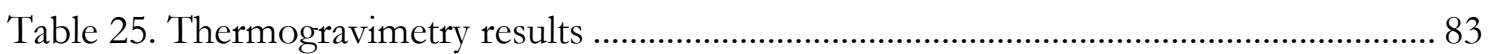

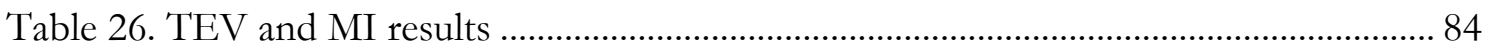

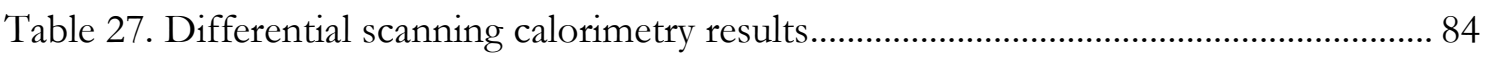

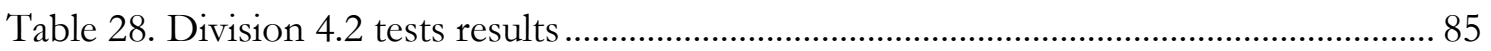

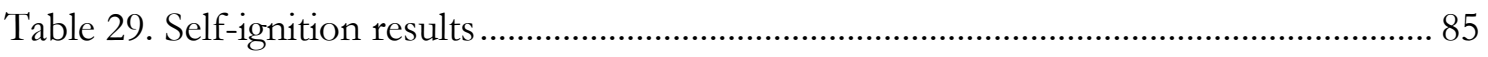

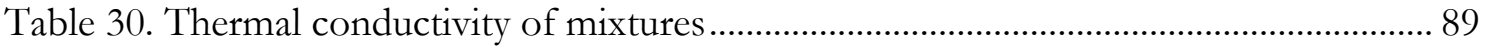

Table 31. Thermogravimetry results for mixtures..................................................................... 90

Table 32. Differential scanning calorimetry results for mixtures............................................. 91 


\section{LIST OF ABBREVIATIONS}

Apparent activation energy (Ea): minimum energy required to start a chemical reaction.

Change of slope temperature (CST): temperature at which the fast exothermic reaction commences.

Characteristic constant (Kmax): constant value used to establish an explosibility classification of dusts depending on the explosion class.

Characteristic oxidation temperature (Tcharact): temperature at which a sudden loss of weight happens in the TG with oxygen stream test.

Explosion severity: characteristics that allow to evaluate the explosion consequences.

Final exothermic temperature (FET): maximum temperature reached during the exothermic reaction.

Ignition sensitivity: characteristics of the powders related to its flammability easiness.

Initial exothermic temperature (IET): minimum temperature at which the exothermic reaction begins.

Limiting oxygen concentration (LOC): minimum percentage of oxygen at which an explosion occurs.

Lower explosibility limit (LEL): lower limit of the range of concentration of airborne dust to which the air-dust is potentially explosive.

Maciejasz index (MI): obtained as a result of a test for the reactivity to oxygen, this index represents the self-ignition risk of a sample. Self-ignition risk is considered when MI $>10$.

Maximum pressure (pmax): difference between the pressure at the ignition moment (normal pressure) and the maximum pressure registered at the pressure-time curve.

Maximum rise of pressure ((dP/dt)max): maximum value of the pressure rise per unit time.

Maximum weight loss temperature (MLT): indicator of the reactivity of the product such as it represents the yield of volatiles due to the pyrolysis process. 
Minimum ignition energy (MIE): lowest energy that is enough to ignite the most flammable mixture of a dust cloud.

Minimum ignition temperature (MIT): lowest temperature at which the dusty simple starts to ignite.

Self-ignition: type of combustion which occurs by self-heating followed by an increase on the dust's temperature and finally its ignition.

Temperature of emission of flammable volatiles (TEV): used to analyse a possible thermal degradation of organic matters generating volatile substances capable of being ignited.

Thermal susceptibility: characteristics used to know the thermal behaviour of solids and to determine their self-combustion tendency. 


\section{RESUMEN}

Actualmente, más del 80\% de la energía utilizada en el mundo procede de la combustión de combustibles fósiles, siendo el carbón el combustible más empleado y su almacenamiento una práctica común. Debido a ello, se han estudiado ampliamente los riesgos asociados a este material, así como sus efectos medioambientales y sobre la salud humana o el riesgo de autoignición y combustión espontánea. Actualmente, como consecuencia de estos riesgos y del agotamiento de las reservas de carbón, se están considerando diversos combustibles alternativos y respetuosos con el medio ambiente para reemplazar al carbón parcial o totalmente, como la biomasa o los residuos.

Estos sólidos combustibles están caracterizados por unas propiedades de inflamación que deben ser cuidadosamente determinadas en cada caso particular debido a su heterogeneidad, pero cuyos valores medios muestran un elevado riesgo de ignición.

El objetivo principal de esta tesis es la determinación de las condiciones de seguridad contra el riesgo de atmósferas explosivas en las industrias relacionadas con el procesamiento de biomasas. Con este objetivo se ha estudiado una gran variedad de biomasas, incluyendo así mismo materiales como lodos de depuradora secados térmicamente.

Se han caracterizado tres grupos de muestras. En primer lugar, un grupo de combustibles sólidos que incluye tanto biomasas como combustibles fósiles, focalizando en las diferencias existentes entre estos grupos así como dentro de los propios grupos. Un segundo grupo que incluye veinte lodos de depuradora secados térmicamente, en el cual se puede observar la variación que provoca la heterogeneidad de este tipo de residuos. Finalmente, se ha estudiado un grupo compuesto por mezclas de carbón, lodos secados térmicamente y pellets de madera torrefactados, debido a su creciente importancia en las técnicas de cocombustión.

Se han estudiado distintos parámetros, incluyendo sensibilidad a la ignición, severidad de la explosión, susceptibilidad térmica y auto-ignición. A través del estudio estadístico de estos parámetros, se han determinado las relaciones existentes entre ellos y la influencia de algunos parámetros comunes, como el tamaño de grano o el contenido en volátiles, en el riesgo de ignición de sólidos combustibles.

Los resultados de esta tesis demuestran que la caracterización de los materiales pulverulentos es indispensable para tener instalaciones seguras y para disminuir los riesgos tanto humanos como económicos. 


\begin{abstract}
Currently, over $80 \%$ of the energy source used in the world comes from the combustion of fossil fuels. Coal is the fossil fuel most used to produce energy, and its storage is a common practice. The associated hazards, its harmful effects to the environment and human health and its self-ignition and spontaneous combustion risks are commonly studied. Due to environmental concerns and depleting reserves of coal, alternative, environmentally friendly fuels such as biomass and waste products are being considered for partial or full coal replacement.
\end{abstract}

The flammability properties that characterize all these solid fuels have to be carefully determined in each single case due to their heterogeneity, but mean values show that they present a high ignition risk.

This thesis aims to determine the safety conditions against explosive atmospheres risks in the facilities related with the biomasses processing. To achieve this goal, a range of biomasses has been studied, including a group of thermally dried sewage sludge.

Three groups of samples have been characterize. First of all a group of solid fuels including different biomasses and fossil fuels, focusing on the differences existing between these groups and also inside the groups. A second group that includes twenty different thermally dried sewage sludge samples, were the variation that provides the heterogeneity of this kind of waste biomasses can be observed. And finally, a group composed by mixtures of coal, thermally dried sewage sludge and torrefied wood pellets, due to their rising importance on co-firing techniques.

Several parameters have been determined, including ignition sensitivity, explosion severity, thermal susceptibility and self-ignition. Through the statistical study of these parameters, different relations have been observed in order to determine the influence of common parameters as particle size or volatiles content on the flammability of solid fuels.

Results of this research show that characterizing dust materials is essential for having safe facilities and for decreasing the risks both human and economical. 


\section{LIST OF PUBLICATION}

This research has led to the following publications:

\section{Journal papers:}

i. Fernandez Anez N., Garcia Torrent J., Medic Pejic L., Grima Olmedo C. "Detection of incipient self-ignition process in solid fuels through gas emissions methodology" Journal of Loss Prevention in the Process Industries 36 (2015) 343-351

ii. Medic Pejic L., Fernandez Anez N., Garcia Torrent J., Ramirez Gomez A. "Determination of spontaneous combustion of thermally dried sewage sludge" Journal of Loss Prevention in the Process Industries 36 (2015) 352-357

iii. Fernandez-Anez N., Garcia-Torrent J., Medic-Pejic L. "Flammability properties of thermally dried sewage sludge" Fuel 134 (2014) 636-643

\section{Conference papers:}

i. Fernandez Anez N., Medic Pejic L., Garcia Torrent J., Ramirez Gomez A. Flammability properties of co-firing fuel mixtures. 10th European Congress of Chemical Engineering, 3rd European Congress of Applied Biotechnology, 5th European Process Intensification Conference (ECCE10 + ECAB3 + EPIC5). Niza, Francia, Septiembre 2015.

ii. Fernandez-Anez N., Slatter D.J.F., Saeed M.A., Phylaktou H.N., Andrews G.E., GarciaTorrent J. Ignition sensitivity of coal/waste/biomass mixtures. 8th International Conference on Sustainable Energy \& Environmental Protection (SEEP2015) Paisley, Glasgow, United Kingdom, Agosto 2015.

iii. Fernandez Añez N., Garcia Torrent J., Medic Pejic L. Ramírez Gómez A. Characterization of gas emissions during heating of solid products. II International Symposium on Handling and Hazards of Materials in Industry (HANHAZ2014) Madrid, Julio 2014

iv. Fernandez Añez N., Garcia Torrent J., Medic Pejic L. Grima Olmedo C. Influence of grain size and compaction of different solid fuels on the layer temperature. II International Symposium on Handling and Hazards of Materials in Industry (HANHAZ2014) Madrid, Julio 2014

v. Medic Pejic L., Fernandez Añez N., Montenegro Mateos L., Garcia Torrent J., Ramirez Gomez A. Characterization of spontaneous combustion of dried sewage sludge. Tenth International Symposium on Hazards, Prevention and Mitigation of Industrial Explosion (X ISHPMIE) Bergen, Noruega, Junio 2014

vi. Fernandez Añez N., Garcia Torrent J., Medic Pejic L., Grima Olmedo C. New tests for the detection of incipient self-ignition process in solid fuels. Tenth International Symposium on Hazards, Prevention and Mitigation of Industrial Explosion (X ISHPMIE) Bergen, Noruega, Junio 2014

vii. Fernandez Añez N., Alvarez Perez A., Garcia Torrent J., Medic Pejic L. CO, CO2 and SO2 emissions during heating process of coke and coal compacted and non-compacted. XII Meeting of the Spanish Coal Group. Madrid, Octubre 2013

viii. $\quad$ Fernandez Añez N., Montenegro Mateos L., Medic Pejic L., Garcia Torrent J. (2013) Flammability properties of dry sewage sludges. 13th International multidisciplinary scientific geoconference SGEM 2013. Albena Co., Bulgaria, 2013 



\section{INTRODUCTION}

\subsection{EUROPEAN SCENARIO}

At the beginning of the 1990's, international efforts start trying to find a solution for climate change. In 1992, the United Nations Framework Convention on Climate Change was established with this objective. However, no specific actions were adopted until the adoption under this Framework of the Kyoto Protocol, an international agreement which commits its Parties by setting internationally binding emission reduction targets. The first commitment period of the Protocol was between 2008 and 2012, and its targets cover the emissions of the six main greenhouse gases (carbon dioxide, methane, nitrous oxide, hydrofluorocarbons, perfluorocarbons and sulphur hexafluoride). The 15 European Countries had a target of reduction of $8 \%$.

It is well-known that the main source of increasing carbon dioxide concentration in the atmosphere is the burning of fossil fuels like oil and coal, along with deforestation of tropical forests [1]. According to the World Meteorological Organization [2], the amount of greenhouse gases in the atmosphere is reaching a higher record every year. Between 1990 and 2012 , a $32 \%$ increase in radiative forcing, the warming effect on our climate due to carbon dioxide and other long-lived gases that trap heat, such as methane and nitrous oxide, was recorded.

Since the beginning of the industrial era in 1750, the global average concentration of $\mathrm{CO}_{2}$ in the atmosphere has increased by $41 \%$, methane by $160 \%$ and nitrous oxide by $20 \%$. Only about half of the $\mathrm{CO}_{2}$ emitted by human activities remains in the atmosphere, with the rest being absorbed in the biosphere and in the oceans.

The US National Oceanic and Atmospheric Administration [3] reported that for the first time in 2013 the barrier of $400 \mathrm{ppm}$ measured of $\mathrm{CO}_{2}$ in the atmosphere was exceeded.

Built under the Kyoto Protocol, in 2008 the European Union's members adopted a climate and energy package consisting on a group of measures to fight against climate change. The Europe's "202020" targets establish that by the year 2020, greenhouse gas emissions should be reduced by 20 percent, renewable energy sources should represent 20 percent of Europe's final energy consumption and energy efficiency should increase by 20 percent. To achieve this goal, biomass can play an important role, as shown in the European Commission scenario (Figure 1) [4]. 
Exhibit 1

Role of biomass in meeting Europe's renewable energy targets -

European Commission scenario

EU-27 final energy consumption ${ }^{1 ;}$ TWh

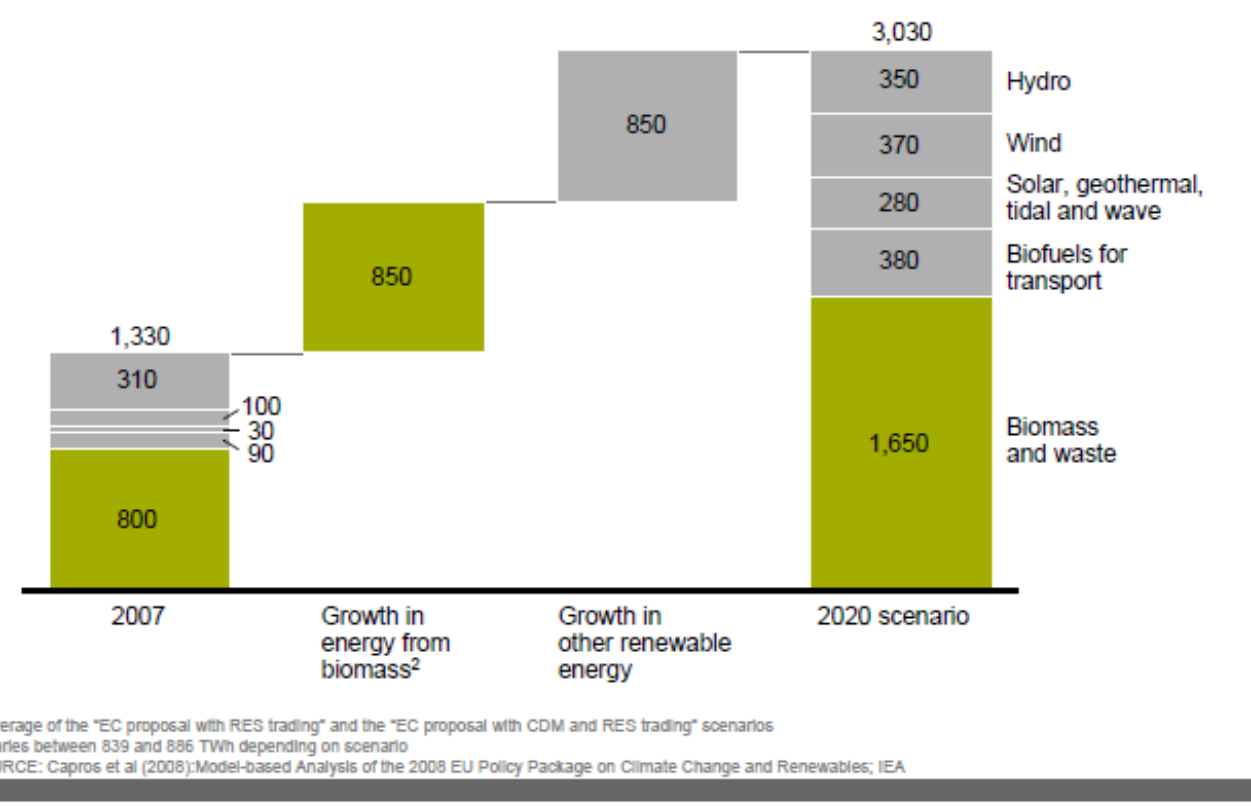

Figure 1. Role of biomass in meeting Europe's renewable energy targets - European Commission scenario [4]

Biomass offers important advantages as a combustion feedstock due to the high volatility of the fuel and the high reactivity of both the fuel and the resulting char. But comparing with solid fossil fuels, biomass contains much less carbon and more oxygen and has a low heating value [5], as can be seen with an easy comparison in Table 1. 
Table 1.Physical, chemical and fuel properties of biomass and coal fuels [5]

\begin{tabular}{|c|c|c|}
\hline Property & Biomass & Coal \\
\hline Fuel density $\left(\mathrm{kg} / \mathrm{m}^{3}\right)$ & $\sim 500$ & $\sim 1300$ \\
\hline Particle size & $\sim 3 \mathrm{~mm}$ & $\sim 100 \mu \mathrm{m}$ \\
\hline C content (\%wt of dry fuel) & $42-54$ & $65-85$ \\
\hline O content (\%wt of dry fuel) & $35-45$ & $2-15$ \\
\hline S content (\%wt of dry fuel) & $\operatorname{Max} 0.5$ & $0.5-7.5$ \\
\hline $\begin{array}{c}\mathrm{SiO}_{2} \text { content }\left(\mathrm{wt}^{0} \% \text { of dry }\right. \\
\text { ash) }\end{array}$ & $23-49$ & $40-60$ \\
\hline $\begin{array}{c}\mathrm{K}_{2} \mathrm{O} \text { content (wt } \% \text { of dry } \\
\text { ash) }\end{array}$ & $4-48$ & $2-6$ \\
\hline $\begin{array}{c}\mathrm{Al}_{2} \mathrm{O}_{3} \text { content }\left(w t^{0} \% \text { of } d r y\right. \\
\text { ash })\end{array}$ & $2.4-9.5$ & $15-25$ \\
\hline $\begin{array}{c}\mathrm{Fe}_{2} \mathrm{O}_{3} \text { content }\left(w \mathrm{t}^{\mathrm{t}} \% \text { of dry }\right. \\
\text { ash) }\end{array}$ & $1.5-8.5$ & $8-18$ \\
\hline Ignition temperature $(\mathrm{K})$ & $418-426$ & $490-595$ \\
\hline Peak temperature & $560-575$ & - \\
\hline Friability & Low & High \\
\hline Dry heating value $(\mathrm{MJ} / \mathrm{kg})$ & $14-21$ & $23-28$ \\
\hline
\end{tabular}

Unfortunately, recent researches show that biomass is not on track to play the important role that the European Commission thought, mainly caused by the uncertainty around several important aspects related with its production and trade [6]. 


\section{Exhibit 2}

Current biomass energy growth compared to the growth required to reach

the European Commission scenario

Final energy consumption from biomass (excluding biofuels); TWh

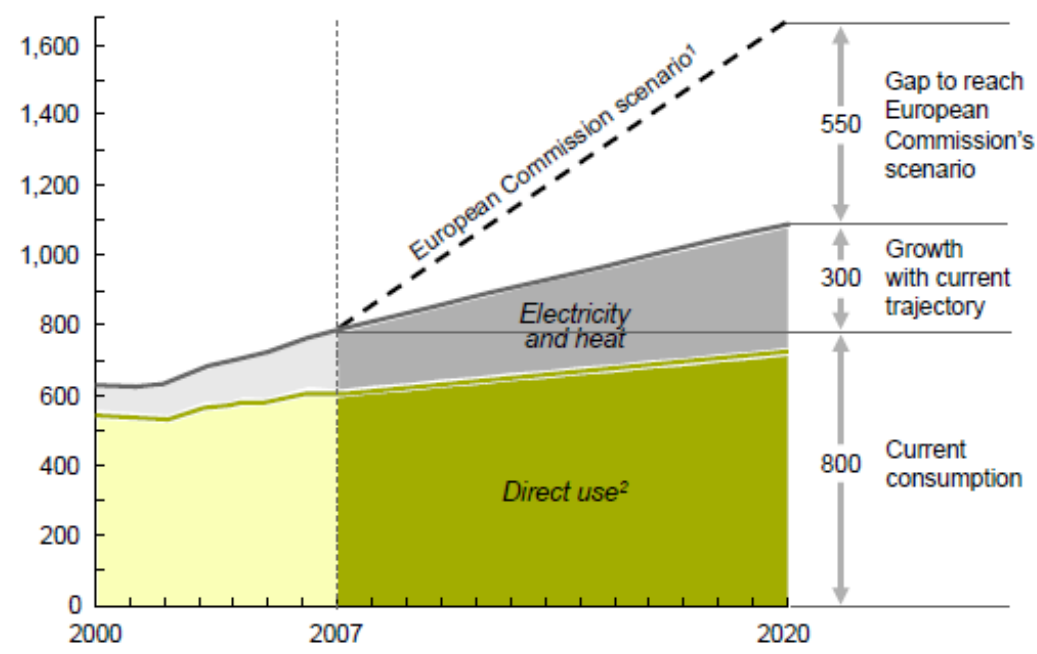

1 Average of the "EC proposal wth RES trading" and the "EC proposal with CDM and RES trading" scenarios

Figure 2. Current biomass energy growth compared to the growth required to reach the European Commission scenario [4]

Anyway, looking at the whole renewable energies group, in 2013, 11 countries have achieved the target of $20 \%$ of renewable energy sources, while only 7 have still less than $10 \%$ (Figure 3) [7].

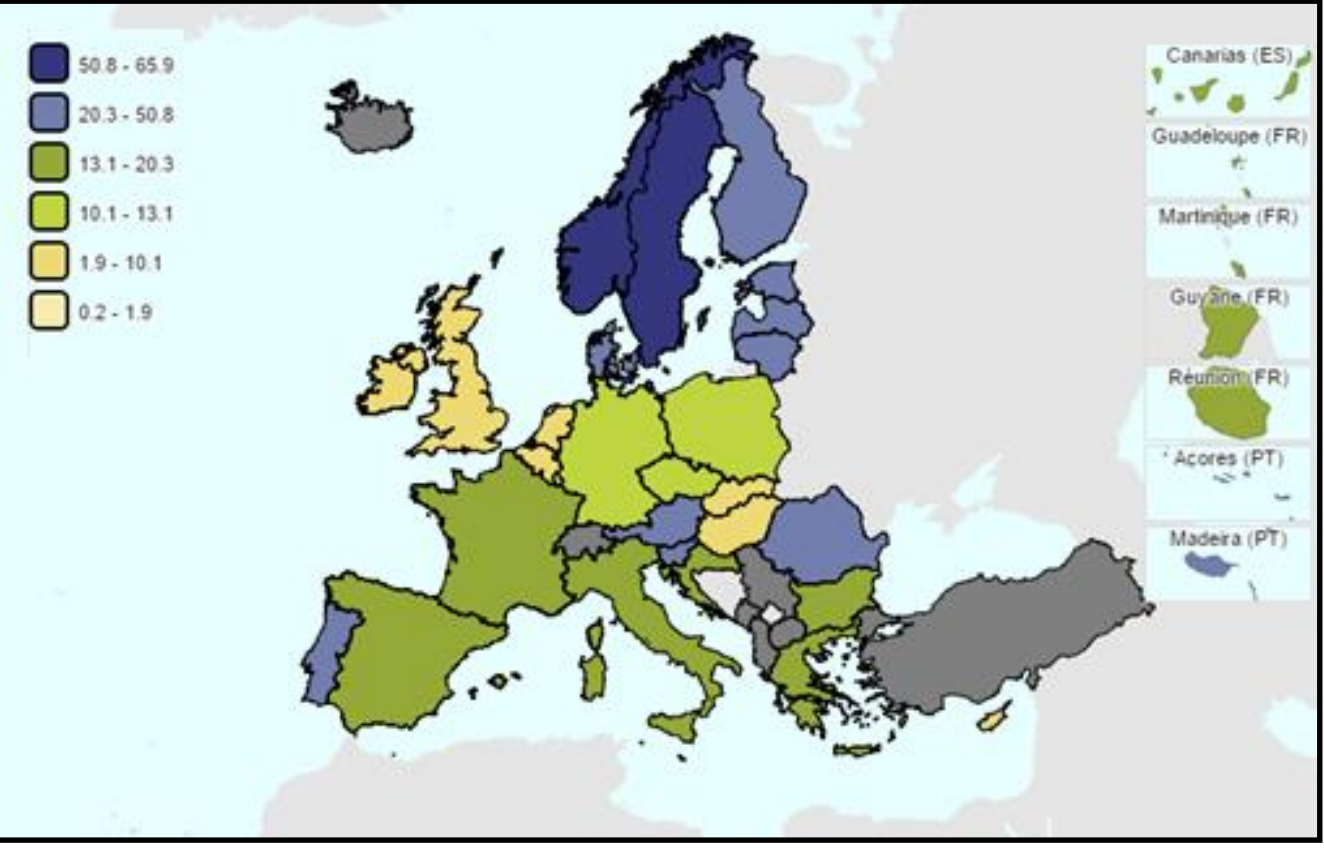

Figure 3. Share of renewable energy in gross final energy consumption [7] 
In 2015, the United Nations Climate Change Conference, COP 21 or CMP 11 was held in Paris. According to the organizing committee at the outset of the talks [8], the expected key result was an agreement to set a goal of limiting global warming to less than 2 degrees Celsius $\left({ }^{\circ} \mathrm{C}\right)$ compared to pre-industrial levels. The agreement calls for zero net anthropogenic greenhouse gas emissions to be reached during the second half of the 21 st century.

To summarize, the European Union and the United Nations are on their way of achieving the goals established to fight against the climate change, even so biomass is not playing the important part that it was supposed to. However, several researchers are nowadays trying to improve the properties of these materials in order to increase its use.

\subsection{GREENHOUSE GASES}

Nowadays, climate change is the main environmental problem, and it is mainly related with the emission of greenhouse gases. A greenhouse gas is "any gas that absorbs infrared radiation in the atmosphere". Currently, five major pollutants are listed as criteria pollutants:

Carbon monoxide is a colourless, odourless gas emitted from combustion processes. CO can cause harmful health effects by reducing oxygen delivery to the body's organs and tissues [9].

Nitrogen oxides are formed when fuel is burned at high temperatures, and come principally from motor vehicle exhaust and stationary sources such electrical utilities and industrial boilers. It can irritate the lungs and lower resistance to respiratory effects. Nitrogen oxides in the air can significantly contribute to a number of environmental effects such as acid rain and eutrophication in coastal waters [10].

Sulphur dioxide is mainly produced by fossil fuel combustion at power plants (73\%) and other industrial facilities (20\%). It is linked with a number of adverse effects on the respiratory system [11].

Ground level or bad ozone is created by chemical reactions between oxides of nitrogen and volatile organic compounds in the presence of sunlight. Breathing it can trigger a variety of health problems and harmful effects on sensitive vegetation and ecosystems [12].

Particulate matter is defined as a complex mixture of extremely small particles and liquid droplets. These particles come in many sizes and shapes and can be made up of hundreds of different chemicals. The main problems caused by these particles include health problems 
because the microscopic solids or liquid droplets can get into the lungs and cause serious health problems. Additionally, this pollution may cause visibility problems [13].

However, the primary greenhouse gas emitted through human activities is carbon dioxide.

At the global scale, the key greenhouse gases emitted by human activities are the ones shown in Figure 4.

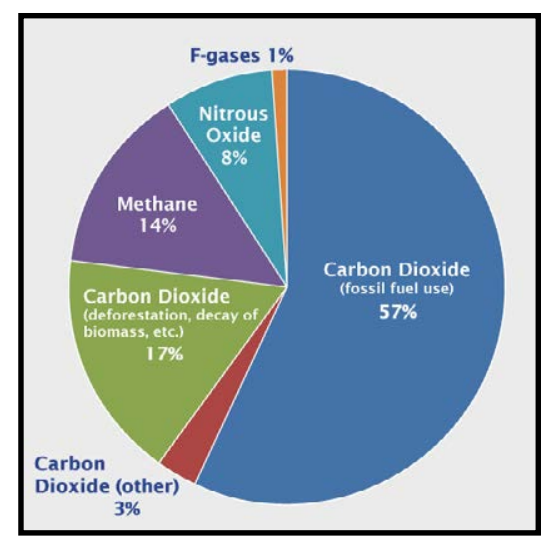

Figure 4. Global greenhouse gas emissions [14]

Carbon dioxide is naturally present in the atmosphere as part of the Earth's carbon cycle, but human activities are altering the carbon cycle, increasing the $\mathrm{CO}_{2}$ emissions mainly since the industrial revolution, as shown in Figure 5. The main human activity that emits this gas is the combustion of fossil fuels for energy and transportation [15].

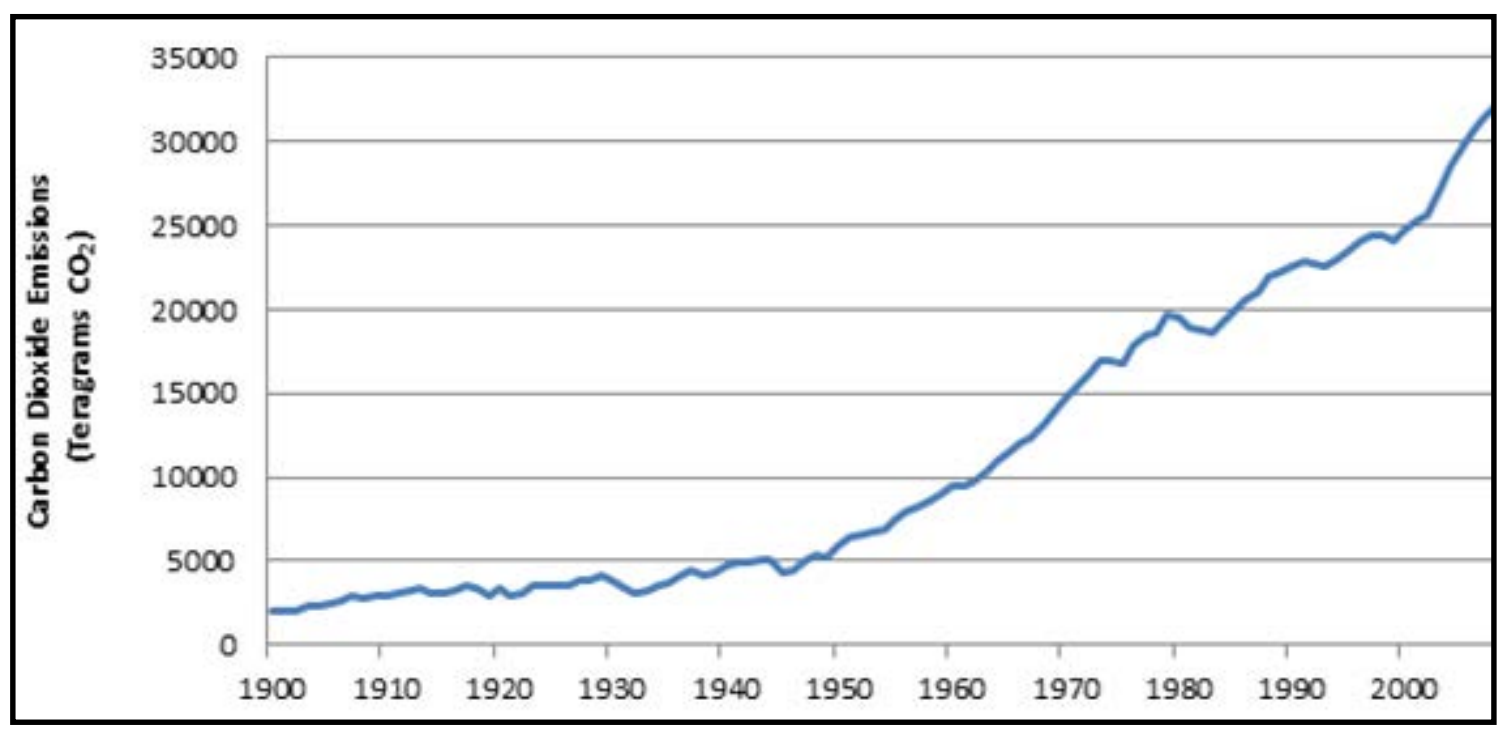

Figure 5. Global carbon emissions from fossil fuels have significantly increased since 1900 [16] This problem may be partially solved by the use of biomass sources. It has been considered that the net $\mathrm{CO}_{2}$ emissions of biomasses are almost null, due to the emissions emitted during 
their processing and use are almost the same as the $\mathrm{CO}_{2}$ absorption they have while they are alive.

However, burning biomass in inappropriate, or badly maintained equipment, or under poor operating conditions can give rise to a number of potential emissions, which includes particulate matter, $\mathrm{NO}_{x}, \mathrm{CO}$ and other carbon containing compounds. The levels of these and other elements depend on many factor, including the environment the material was grown in, the species, any contaminants in the soil, water or air, etc. The chemical composition of different parts of a plant also varies; for example higher levels of minerals in bark, lead to increased ash production, while there is more nitrogen and sulphur in green waste and brash [17].

\subsection{SOLID BIOFUELS}

According to the United Nations Framework Convention on Climate Change [18], the term biomass is defined as:

"non-fossilized and biodegradable organic material originating from plants, animals and micro-organisms.

This shall also include products, by-products, residues and waste from agriculture, forestry and related industries as well as the non-fossilized and biodegradable organic fractions of industrial and municipal wastes".

In other words, biomass is a complex heterogeneous mixture of organic and inorganic matter, containing various inorganic associated solid and fluid phases with different contents and origins. Biomass has highly variable composition and properties, especially with respect to moisture, structural components and inorganic constituents, mainly grouped as shown in Table 2. 
Table 2. Composition of biomass [19]

\begin{tabular}{|c|c|c|}
\hline \multirow[t]{2}{*}{ Organic matter } & $\begin{array}{l}\text { Solid, non- } \\
\text { crystalline }\end{array}$ & $\begin{array}{l}\text { Structural ingredients, namely } \\
\text { cellulose, hemicelluloses, lignin, } \\
\text { extractives, other }\end{array}$ \\
\hline & Solid, crystalline & $\begin{array}{c}\text { Organic mineral such as } \mathrm{Ca}-\mathrm{Mg}- \\
\mathrm{K}-\mathrm{Na} \text { oxalates }\end{array}$ \\
\hline \multirow[b]{2}{*}{$\begin{array}{l}\text { Inorganic } \\
\text { matter }\end{array}$} & Solid, crystalline & $\begin{array}{l}\text { Mineral species from phosphates, } \\
\text { carbonates, silicates, chlorides, } \\
\text { sulphates, oxyhydroxides, nitrates } \\
\text { and other mineral classes }\end{array}$ \\
\hline & $\begin{array}{l}\text { Solid, semi- } \\
\text { crystalline }\end{array}$ & $\begin{array}{c}\text { Poorly crystallized mineraloids of } \\
\text { some silicates, phosphates, } \\
\text { hydroxides, others }\end{array}$ \\
\hline
\end{tabular}

Solid, amorphous

Amorphous phases such as various glasses, silicates, others

Fluid matter

Moisture, gas and gas-liquid inclusions associated with both organic and inorganic matter

This general term includes many different kinds of materials, whose use as fuel cannot be comparable.

According to the origin, biomass can be divided in the following groups [20]:

- Wood and woody biomass, such as stems, branches, foliage, bark, chips, pellets, briquettes, sawdust, sawmill and others from various wood species.

- Herbaceous and agricultural biomass, annual and perennial and field-based or processed-based such as grasses and flowers, straws and other residues (fruits, shells, husks, pits, seeds, etc.)

- Aquatic biomass, including every marine or freshwater macro or micro-algae.

- Animal and buman biomass wastes, for example bones, meat-bone meal or chicken litter.

- Contaminated biomass and industrial biomass wastes (semi-biomass), this group includes municipal solid waste, demolition wood, refuse-derived fuel, sewage sludge, hospital waste, paper-pulp sludge, waste papers and paperboard waste. 
Average values of proximate and ultimate analyses of the different groups of biomasses show the existing differences among them (Table 3).

Table 3. Average values of proximate and ultimate analyses of biomass [20]

\begin{tabular}{|c|c|c|c|c|c|c|c|c|c|}
\hline \multirow{2}{*}{ Group } & \multicolumn{4}{|c|}{ Proximate analysis ( $\%$ d.b.) } & \multicolumn{5}{|c|}{ Elemental analysis ( $\%$ d.a.f.) } \\
\hline & $\mathrm{M}^{*}$ & $\mathrm{VM}^{*}$ & $\mathrm{FC}^{*}$ & $A^{*}$ & $\mathrm{C}$ & $\mathrm{O}$ & $\mathrm{H}$ & $\mathrm{N}$ & S \\
\hline $\begin{array}{c}\text { Wood and } \\
\text { woody }\end{array}$ & 19.3 & 78.0 & 18.5 & 3.5 & 52.1 & 41.2 & 6.2 & 0.4 & 0.08 \\
\hline $\begin{array}{l}\text { Herbaceous } \\
\text { and } \\
\text { agricultural }\end{array}$ & 12.0 & 75.2 & 19.1 & 5.7 & 49.9 & 42.6 & 6.2 & 1.2 & 0.15 \\
\hline $\begin{array}{c}\text { Aquatic } \\
\text { (Marine } \\
\text { macroalgae) }\end{array}$ & 10.7 & 50.5 & 25.9 & 23.6 & 43.2 & 45.8 & 6.2 & 2.2 & 2.60 \\
\hline $\begin{array}{l}\text { Animal } \\
\text { biomass }\end{array}$ & 5.9 & 55.5 & 13.6 & 30.9 & 58.9 & 23.1 & 7.4 & 9.2 & 1.45 \\
\hline $\begin{array}{c}\text { Contaminated } \\
\text { biomass and } \\
\text { wastes }\end{array}$ & 11.6 & 72.0 & 9.4 & 18.6 & 53.6 & 37.0 & 7.3 & 1.7 & 0.46 \\
\hline
\end{tabular}

${ }^{*} \mathrm{M}$ represents the moisture of the sample, VM the volatiles matter, FC is fixed carbon content and $\mathrm{A}$ ash content.

Aquatic and animal biomass are less common than the other groups of biomasses and their use is still not usual. However, each kind of biomass presents advantages and disadvantages, but according to their composition, they may be classified thanks to the compounds they are enriched or depleted in, as resumed in Table 4. 
Table 4. Compounds present on biomasses [20]

\begin{tabular}{|c|c|c|}
\hline Group & Enriched in & Depleted in \\
\hline Wood and woody & Ca, Mg, Mn, VM & A, Cl, N, P, S, Si \\
\hline Herbaceous and agricultural & FC, K, O, VM & C, H, Ca \\
\hline $\begin{array}{c}\text { Contaminated biomass and } \\
\text { wastes }\end{array}$ & A, Al, C, Cl, Fe, H, N, S, Ti & FC, K, P \\
\hline
\end{tabular}

\subsubsection{BIOMASS}

Intrinsically, biomass is a flexible composite of cellulose, hemicelluloses and lignin, which serve to maintain the structural integrity of plant cells and provide the mechanical support and strength for plants (Figure 6).

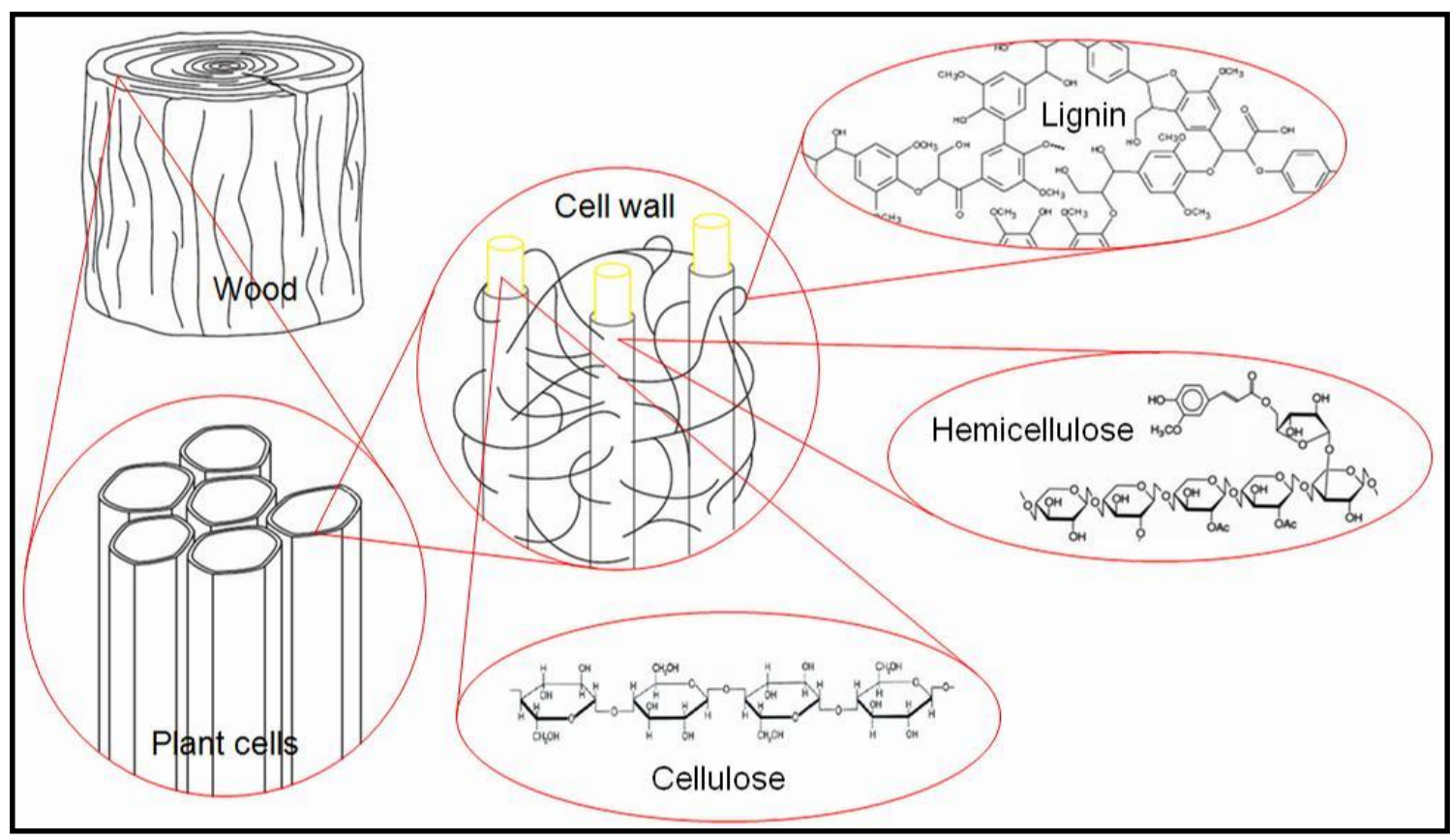

Figure 6. Composition of wood walls [21]

Cellulose is the primary structural component of cell walls in biomass. Its chemical formula is $\left(\mathrm{C}_{6} \mathrm{H}_{10} \mathrm{O}_{5}\right)_{\mathrm{n}}$, and it is a long chain polymer with a high degree of polymerization and a large molecular weight. It presents a crystalline structure, made up of many glucose molecules, which confers it the high strength that makes it the skeletal structure of most terrestrial biomass. 
The high cellulose value is characteristic of some sub-groups such as wood stems and herbaceous and agricultural stalks and fibres. Extremely high values of cellulose are typical of some varieties, namely paper, cotton, flax fibres, sunflower stalks and waste paper pulps. Low contents are present in agricultural pits and wood twigs, barks and leaves, and extremely low in some twigs for different trees [22].

Hemicellulose is another constituent of the cell walls of a plant. Hemicellulose has a random, amorphous structure with little strength. It is a group of carbohydrates with a branched chain structure and a lower degree of polymerization, and may be represented by the generic formula $\left(\mathrm{C}_{5} \mathrm{H}_{8} \mathrm{O}_{4}\right)_{\mathrm{n}}$. Hemicellulose tends to yield more gases and less tar than cellulose [23]

High contents of hemicelluloses are present on wood twigs, leaves and barks, as well as some grasses and corn grains. Herbaceous and agricultural fibres, stalks and pits present low contents, while tree stems, paper, sunflower stalks and cotton seed hairs have extremely low values [22].

Lignin is a complex highly branched polymer and is an integral part of the secondary cell walls of plants. Lignin is the cementing agent for cellulose fibres holding adjacent cells together. The dominant monomeric units in the polymers are benzene rings, which are combined to form the structure.

Extremely high lignin content is typical for apricot pits, olive husks, some shells, tea residue and coconut coir pith, while high lignin contents have been detected on wood barks and herbaceous and agricultural pits, shells and husks. On the other hand, cotton, flax fibres, certain grasses, paper and waste paper pulps present extremely low content of lignin, and herbaceous and agricultural fibres, stalks and grasses present a low content [22].

Vassilev et al [22] observed a negative significant correlation between hemicellulose/cellulose content and the lignin's one. Also a negative correlation is observed with the loose and shaken bulk densities of biomass samples.

\subsubsection{SEWAGE SLUDGE}

Municipal waste constitute around $10 \%$ of total waste generated. The generation of sewage sludge in Europe has slowed down and stabilised at about $520 \mathrm{~kg}$ per capita since 2002 [24].

As a very rough guide, sewage sludge composition is characterised by six groups of components, which are all present mixed in one mixture. 
- Non-toxic organic carbon compounds.

- Nitrogen- and phosphorus- containing components.

- Toxic inorganic and organic pollutants.

- Pathogens and other microbiological pollutants.

- Inorganic compounds.

- Water.

One of the biggest problems associated with the treatment of sewage sludge is the amount of water they have, that is why the sewage sludge might be dried in advance of any possible reuse. The drying process of the sewage sludge is a post-treatment whose objectives are to decrease the amount of water present in it (decreasing the volume of the waste and obtaining drier and manageable products), to obtain an adequate sanitation and to achieve an effective stabilization. In brief, the main objective of the process is to improve the valorisation of the sewage sludge.

Sewage sludge is associated to four types of water as shown in Figure 7. The drying process that allows to remove all these types needs to be at elevated temperatures and it is called thermal drying.

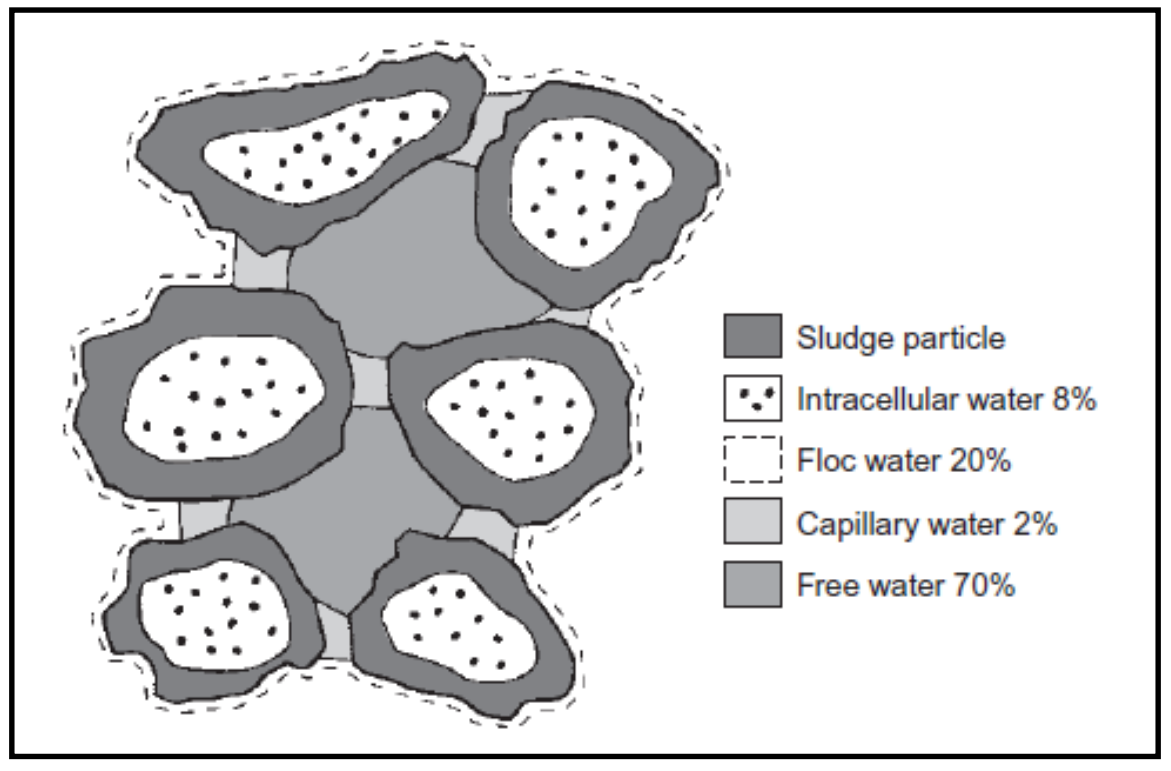

Figure 7. Water associated with sludge particles [25]

The heat transfer from the heating medium to the sludge can be made by three systems: conduction, convection and radiation. However, depending on the design of the dryer, one of them prevails over the other, and the drying process is denominated according to this. 
More simply, the dryers are divided in two groups: direct or indirect. The first ones are those in which the sludge is in direct contact with the combustion gases, while in the second ones the heat input is made through heat interchange surfaces.

Thermally dried sewage sludge final products are round pellets with typical diameters between 2 and 4 millimetres. Their dry matter content is higher than $90 \%$, and they are easily manageable despite they are highly hygroscopic. Fourteen of the EU-15 member states have thermal drying plants as installations for wastewater treatment [26]. Although the dried sludge is reduced in volume and is a pasteurised product, its disposal can still be difficult if it is to be recycled to land or disposed of to landfill. Under certain conditions, it is also possible for the pasteurised product to become recolonised by pathogens. Thermal drying also has a high recovery input, although plants that include anaerobic digesters can reduce this requirement by the use of biogas.

One of the main uses for sewage sludge over the past years has been its agricultural use. This use has reduced farmers' need for mineral fertilisers and has improved soil structure. Nonetheless, sewage sludge contains harmful and potentially hazardous substances, which causes that some actors oppose its use in agriculture [27].

\subsection{UTILIZATION OF BIOMASS}

Biomass is a resource that can appear as several different materials. Some of these materials can be used directly as fuels, while others need a conversion process in order to improve their properties. This conversion into a fuel can follow different processes, whose selection mainly depends on the type and amount of biomass, the final user, environmental issues and economic factors. The conversion from biomass to energy is mainly done by thermochemical or bio-chemical conversion [28].

Thermo-chemical conversion includes three processes: combustion, gasification and pyrolysis.

Combustion is a process in which the fuel is burnt with the oxygen from air to release the stored chemical energy as heat in burners, boilers, internal combustion engines and turbines. Biomass combustion is the oldest form of combustion used by humanity [29]. However, it also present some disadvantages associated with the heterogeneity of raw materials and to their low density. 
It is an exothermic reaction accompanied by large heat generation in which the reaction is spontaneously continued by the heat generated by the reaction [30].

Gasification is a partial oxidation process whereby a carbon source is broken down into carbon monoxide and hydrogen, plus carbon dioxide and hydrocarbon molecules such as methane. The final product of this process is a gas used for electricity generation or as a fuel $[31,32]$.

Pyrolysis is defined as the heating of an organic material in the absence of oxygen. The material does not combust but the chemical compounds that make up that material thermally decompose into combustible gases and charcoal. This process have three products: one liquid (bio-oil), one solid (bio-char) and one gaseous (syngas) [33].

Two main processes are used for bio-chemical conversion of biomasses: fermentation and anaerobic digestion.

Fermentation consists on a series of chemical reactions that convert sugars to ethanol. It is an anaerobic process in which bacteria are added to the biomass material, which feed on the sugars to produce ethanol and carbon dioxide. The ethanol is distilled and dehydrated to obtain a higher concentration of alcohol that can be used as automotive fuel [34].

Anaerobic digestion is a process that produces a gas composed of methane and carbon dioxide. This process consists of three steps: decomposition of plant, conversion of decomposed matter to organic acids and conversion of the acids to methane gas [35].

\subsection{SAFETY RISKS ASSOCIATED TO BIOMASS}

Independently from the final use of it, biomass is going to pass at least through two steps: fuel delivery and fuel storage and handling. The main occupational risks associated to these processes are listed below [36].

\section{Fuel delivery}

- Reversing lorries in a restricted space that may be shared with other activities.

- Large, below ground level fuel storage has risks of falling from height.

- Fuel storage of any kind is considered a confined space and can present fire or asphyxiation hazards. 
- Mechanical augers/conveyors pose hazards from unintentional human contact with their moving parts.

- Pneumatic delivery increases the risk of dust and explosion.

- Wetter fuels tend to give lower risk of dust explosion but greater risk of anaerobic digestion during storage with the emission of $\mathrm{CO}$ and $\mathrm{CO}_{2}$, and greater risk of selfignition.

- Finer fuels tend to give greater risk of dust explosion

Fuel storage and handling

- Explosion

- Fire

- Issues related to the Control of Substances Hazardous to Health Regulations (COSSH)

- Mechanical failure of store walls

- Slips and falls

- Injury from contact with machinery and moving parts

\subsection{FLAMMABILITY RISKS ASSOCIATED TO BIOFUELS}

From March 2011 to January of 2015, 28 accidents related to fires and explosions in industrial biomass facilities and storage areas have been reported worldwide (Table 5). Fires at biomass facilities typically start from boiler fires, spontaneous combustion of fermenting woodchip or sawdust piles, or wood dust explosions.

Table 5. Accidents at biomass facilities [37]

\begin{tabular}{|c|c|c|}
\hline Date & Place & Accident \\
\hline January 2015 & Motril, Spain & $\begin{array}{c}\text { "Major fire" broke out in a pile of biomass } \\
\text { chips. }\end{array}$ \\
\hline January 2015 & $\begin{array}{l}\text { King George V } \\
\text { Graving Dock }\end{array}$ & Wood chip pile ignition \\
\hline December 2014 & Gypsum, Colorado & Conveyor belt at a biomass facility \\
\hline October 2014 & $\begin{array}{l}\text { Burns Lake, British } \\
\text { Columbia }\end{array}$ & $\begin{array}{c}\text { Fire at a wood pellet plant with unknown } \\
\text { origin }\end{array}$ \\
\hline
\end{tabular}


Table 5. Accidents at biomass facilities [37] (cont.)

\begin{tabular}{|c|c|c|}
\hline Date & Place & Accident \\
\hline July 2014 & St. Augustine, Florida & $\begin{array}{l}\text { Smouldering embers in a sawdust drier that } \\
\text { ignited }\end{array}$ \\
\hline June 2014 & Aurangabad, India & $\begin{array}{c}\text { "Major fire" ignited from the base and } \\
\text { other materials stored }\end{array}$ \\
\hline June 2014 & $\begin{array}{l}\text { South Yorkshire, } \\
\text { United Kingdom }\end{array}$ & $\begin{array}{c}\text { Storing chips or biomass power plant } \\
\text { caught fire }\end{array}$ \\
\hline March 2014 & St. Augustine, Florida & Explosion in a wood gas heat exchanger \\
\hline February 2014 & Ironbridge, Shropshire & $\begin{array}{l}\text { Fire broke out in one of the main turbines } \\
\text { of a biomass power facility }\end{array}$ \\
\hline October 2013 & $\begin{array}{l}\text { South Shields, South } \\
\text { Tyneside, United } \\
\text { Kingdom }\end{array}$ & $\begin{array}{c}\text { "Difficult and dangerous" fire erupted in a } \\
\text { conveyer transfer tower at a biomass pellet } \\
\text { storage facility }\end{array}$ \\
\hline June 2013 & $\begin{array}{l}\text { Hexham, United } \\
\text { Kingdom }\end{array}$ & $\begin{array}{l}\text { Wood-burning biomass incinerator caught } \\
\text { on fire }\end{array}$ \\
\hline May 2013 & $\begin{array}{l}\text { Amador County, } \\
\text { California }\end{array}$ & Boiler ruptured in a biomass power plant \\
\hline April 2013 & Shakopee, Minnesota & $\begin{array}{l}\text { Explosion igniting a fire in two of the fuel } \\
\text { storage silos that burned or over a week }\end{array}$ \\
\hline December 2012 & $\begin{array}{l}\text { Copenhagen, } \\
\text { Denmark }\end{array}$ & Wood dust explosion in a wood pellet silo \\
\hline November 2012 & $\begin{array}{l}\text { Nijmegen, } \\
\text { Netherlands }\end{array}$ & $\begin{array}{l}\text { Coal/biomass facility exploded due to } \\
\text { "steam pipe overpressure" }\end{array}$ \\
\hline October 2012 & Sitka, Alaska & Biomass boiler blew up \\
\hline $\begin{array}{l}\text { September } 2012 \\
\left(15^{\text {th }} \text { and } 18^{\text {th }}\right)\end{array}$ & White Pine, Oregon & Sawdust pile burst into flames \\
\hline August 2012 & Avedore, Denmark & $\begin{array}{l}\text { Biomass power incinerator experienced a } \\
\text { fire that began in an electrical conveyor } \\
\text { system and spread to the wood pellet silo }\end{array}$ \\
\hline July 2012 & White Pine, Oregon & $\begin{array}{l}\text { Woodchip pile caught fire due to } \\
\text { spontaneous combustion }\end{array}$ \\
\hline May 2012 & $\begin{array}{l}\text { Copenhagen, } \\
\text { Denmark }\end{array}$ & Wood dust explosion in a wood pellet silo \\
\hline
\end{tabular}


Table 5. Accidents at biomass facilities [37] (cont.)

\begin{tabular}{|c|c|c|}
\hline Date & Place & Accident \\
\hline March 2012 & Blue Lake, California & Pipe explosion in a biomass incinerator \\
\hline February 2012 & $\begin{array}{c}\text { Essex, United } \\
\text { Kingdom }\end{array}$ & Massive fire raged inside a wood pellet silo \\
\hline January 2012 & Sacul, Texas & Explosion in a biomass power incinerator \\
\hline October 2011 & $\begin{array}{c}\text { Port of Tyne, United } \\
\text { Kingdom }\end{array}$ & $\begin{array}{c}\text { "Huge" fire ripped through a storage facility } \\
\text { for wood pellets }\end{array}$ \\
\hline June 2011 & Waycross, Georgia & Wood pellet processing plant exploded \\
\hline May 2011 & Middlebury, Vermont & $\begin{array}{c}\text { Baghouse filter system for a combined heat } \\
\text { and power facility caught fire }\end{array}$ \\
\hline March 2011 & Portsmouth, New & $\begin{array}{c}\text { Friction in a wood pellet crushing machine } \\
\text { started a three alarm fire }\end{array}$ \\
& Hampshire & \\
\hline
\end{tabular}





\section{AIM OF THE PROJECT}

The depletion of fossil fuels has motivated the appearance of a huge range of new fuels that can be grouped under the term biomass. These new fuels are deeply studied in order to find out materials less pollutant but that can produce enough energy to be interesting. Nevertheless, some of the risks associated to these fuels are still unknown, and their production and use can generate many accidents and both human and economic loss. One of the main risks associated to every powdery substance is the flammability risk, which may cause ignitions and/or explosions on industrial facilities. In order to clarify this topic, and to give advice about the correct use, storage and transport of these fuels, flammability parameters of a wide range of solid fuels have been studied in the present thesis.

The main objective of this research is the determination of the safety conditions against explosive atmospheres (ATEX) risks in the facilities related with the biomasses processing.

As specific objectives, the following steps have been followed:

- Study of the operation conditions of different biomasses' processing industries.

- Development of an experimental design for analysing of flammability properties, taking into account that several variables may affect to experimental results, as compaction or granulometry.

- Conducting the tests needed for the complete study of these parameters, including: chemical composition, granulometric analysis, ignition sensitivity, explosion severity, thermal susceptibility, gas emissions.

- Analysis of the different variables that influence these flammability parameters.

- Statistical analysis of the obtained results.

According to the results obtained following these steps, the main parameters that influence the flammability properties of different solid fuels have been determined. Once these parameters are well known, prevention and protection measurements can be implemented in this kind of facilities in order to avoid the ignitability of the dusts. 



\section{LITERATURE REVIEW}

\subsection{DUST EXPLOSIONS}

Even though the most known explosions are those caused by combustible gases, dust explosions are as frequents and damaging as the first ones, and it is important to remark that "both types of explosions have the potential to cause loss of life, personal injury, property damage business interruption, and environmental degradation" [38].

The definition of dust is a much discussed question. It can be considered as the solid particles that can pass through a sieve of $500 \mu \mathrm{m}$. However, for practical purposes dust is defined as "those solid particles that are deposited under the effect of its weight, but can remain suspended for some time". [39] That would surely include any fraction of the particle distribution below $1 \mathrm{~mm}$.

A dust explosion is an uncontrolled rapid combustion propagating itself with generation of heat and gases at high temperatures and pressures.[39]. It can occur in every facility where dust is handled or storage, due to almost all the combustible materials are susceptible to developing the combustion process when achieving a grain size small enough.

A dust explosion occurs when five factors come together to make what has been called the ‘dust explosion pentagon’ [40]:

(i) Presence of combustible dust in finely divided form

(ii) Availability of oxidant

(iii) Presence of an ignition source

(iv) Some degree of confinement

(v) State of mixed reactants

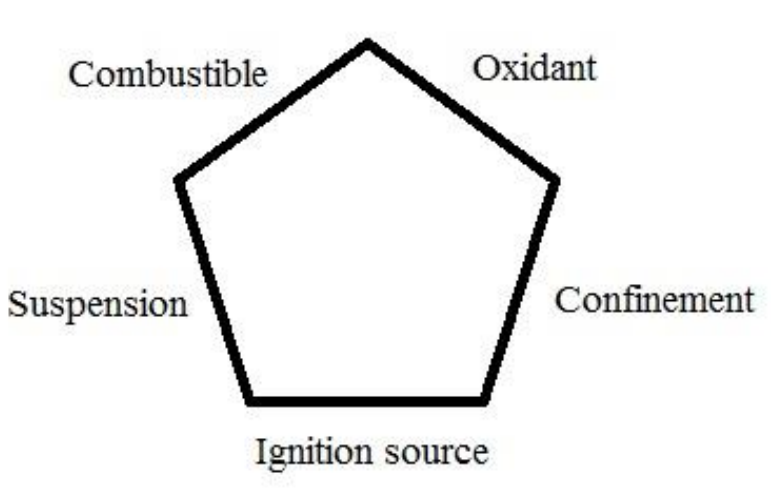

Figure 8. Dust explosion pentagon 


\subsubsection{DUST EXPLOSIBILITY PARAMETERS AND ASSESSMENT}

Several researchers have studied over the years the main parameters that affect the dust explosions risks, and seven characteristics have been determined as the most important ones

\section{Chemical composition}

Chemical composition is one of the main parameters influencing the flammability of solid fuels, mainly in coal samples, due to their rank is an ultimate characteristic for their selfheating tendency, i.e. the lower the rank of the coal, the higher the self-ignition tendency is. A decrease on the rank means an increase on moisture, volatile matter and oxygen and hydrogen content, due to the presence of long chain hydrocarbons. These relations are enhanced with the negative relation between the mineral matter and the self-ignition tendency of coal [41], or the positive one existing with carbon, hydrogen and volatiles contents [42].

Historically, moisture is one of the most important parameters due to its antagonistic effect in the dust explosion propagation mechanism. The study of this parameter is difficult, because depending on the chemical composition of the dust, the moisture may inhibit or promote the ignition of dusts and the severity of the explosion [43]. At lower moisture content, the moisture would mainly consume the reaction heat of dust explosion by temperature rise and phase change. In this situation, because the heat consumption is proportional to the mass of moisture, the measured explosion severity reduces gently and linearly with the rising moisture content. Nevertheless, as the moisture content continues to rise, due to the stronger interparticle cohesion between particles, besides consuming heat, the existence of moisture would also cause the agglomerations of dust particles and, thereby, increase the effective particle size of dusts and weaken dispersion of dust cloud, so that the reduction of explosion becomes more remarkable and even dust cloud cannot ignite.[44]

\section{Particle size}

It is well known that fine particles facilitate the flame propagation [45]. The easiness of ignition of a dust cloud and the severity of the explosion increases when the particle size is smaller [46]. However, if the particles in an organic dust are really small and the devolatilisation no longer control the explosion rate, further particle size reduction will not increase the overall combustion rate further. That is why for many metals the limiting particle 
is considerably smaller than for most organic materials and coals: metals do not produce an homogeneous combustible gas phase by devolatilisation as organic materials do [47].
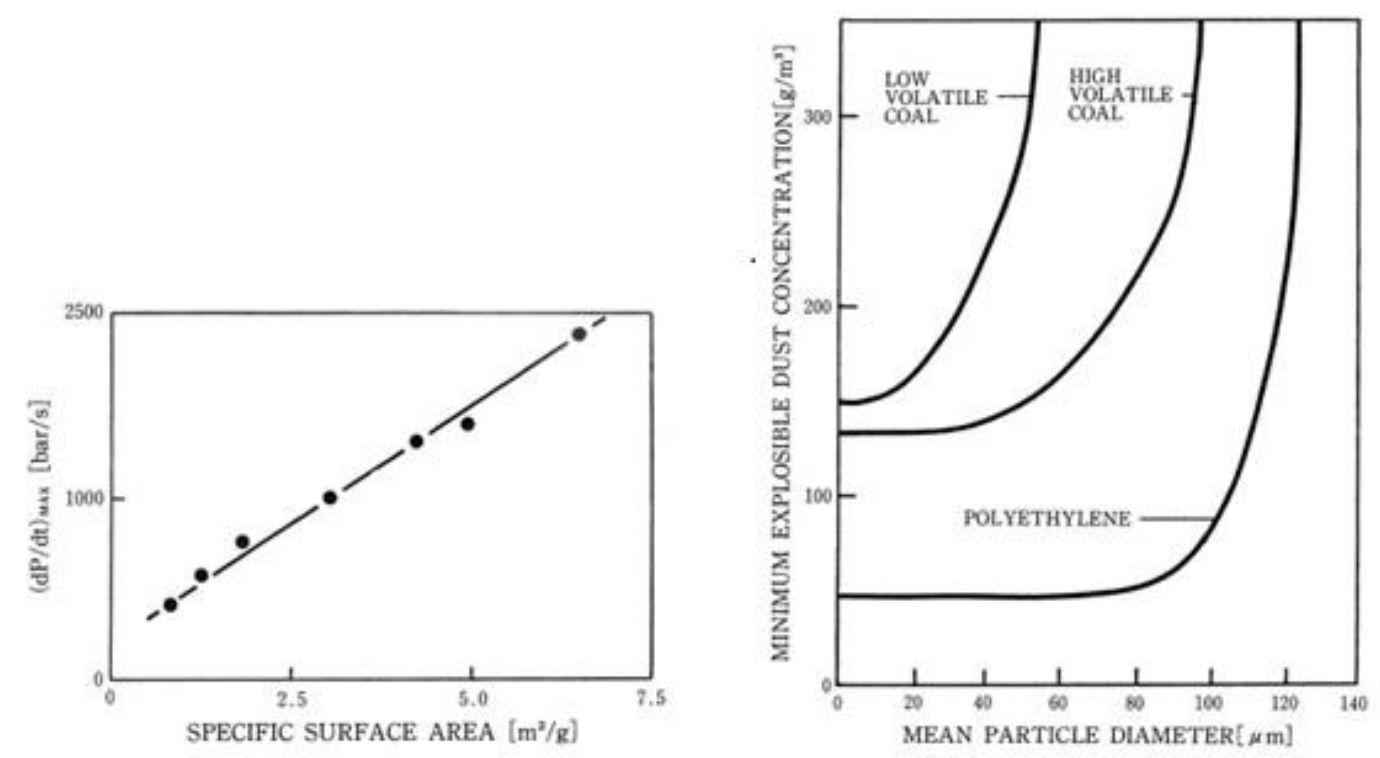

Figure 9. Influence of particle size on the explosibility of dusts [47]

The particle size does not have a significant effect on the amount of residue, whereas the maximum peak temperatures increase as the sample become finer. This may be the result of mineral constituents in liberated for at finer size fraction. [48]

\section{Dust concentration}

The concentration of dust is an important parameter, mainly due to the explosibility limits. This concentration must be in the range formed by the lower explosive limit and the upper explosive limit (flammable range) to be ignitable. In the case of dusts, the upper explosive limit is not very often used, being the lower explosive limit one of the most important parameters to consider when studying the flammability of dusts.

Once the dust concentration is in this range, the severity of the explosion depends on this concentration. The concentration at which the dust starts to be explosible is called the minimum explosive concentration. Just after this concentration, the explosion pressure and the consequences of the explosion are still low. These values increase quickly from this point to a maximum point, and after this it remains almost constant [49], as shown in Figure 10. 


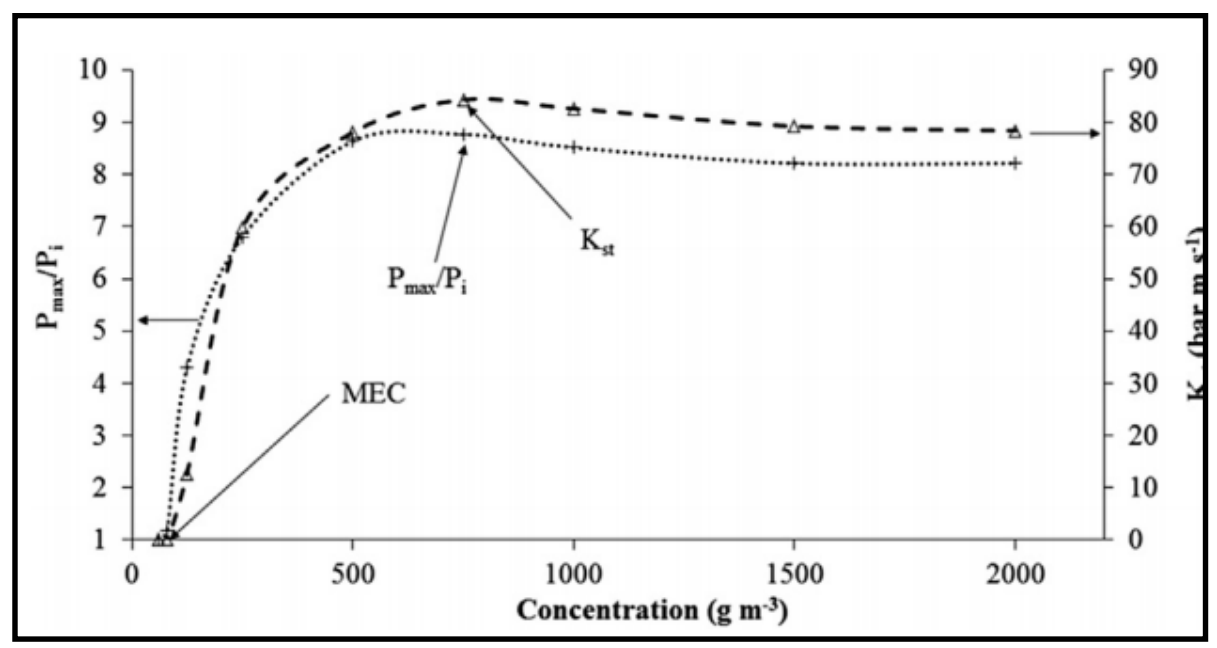

Figure 10. Example of explosion characteristics [49]

Dust concentration has an important influence of the explosion severity for low concentration, being the parameters almost constant after a maximum. This has been observed in all kind of dusts, including biomasses [46] and metallic dusts [50].

\section{Ignition source}

Ignition sources are divided into eight types: flame and direct heat, hot work, electrical sparks, static electricity, impact sparks, self-heating and smouldering, friction sparks, and hot surfaces [40]. The main ignition source causing dust explosions are flame and direct heat, following by friction sparks [51], as shown on Figure 11

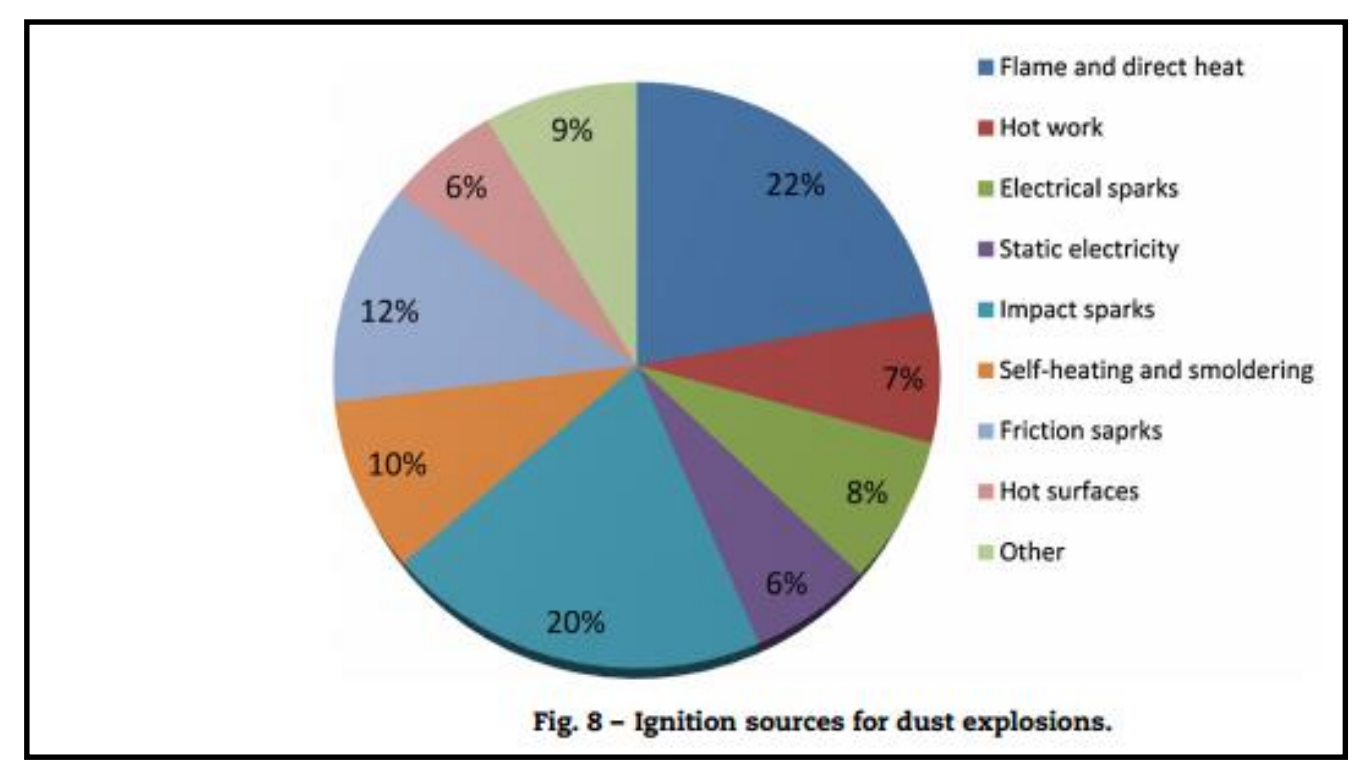

Figure 11. Ignition sources for dust explosions [51] 
To study the possibility of ignition of a source, it is necessary to take into account the energy of the source, the time, the volume of sample affected by this energy and its spatial distribution.

A variation on the location of the ignition source produces a variation on the severity of the explosion. As an example, if an explosion takes place in a silo and it has a vented area, the nearer the ignition to the vented area, the lower the explosion pressure is [52].

The ignition delay is the most controversial parameter of the ignition source, and the explosion severity heavily depends on this parameter [53]. Several researchers have studied this parameter, and their experiments have been conducted with different results. Pilao et al. [54] worked with a 22.7 litres vessel and a 0.4 s of delay, while Cashdollar has worked with a 20 litres vessel and 0.6 s [55] and 0.3 s [56]. Recently, Huéscar Medina et al. [57] published their research working with an ignition delay of $0.6 \mathrm{~s}$ in the $1 \mathrm{~m}^{3}$ vessel.

\section{Initial temperature and pressure}

A higher initial temperature causes a reduction of the mass of air available for combustion and a reduction of the moisture of the sample. These two antagonistic effects finally cause an increase on the explosion severity when increasing the initial temperature [58], effect that is also caused by an increase of initial pressure $[59,60]$. Additionally, when the temperature of the material is higher, smouldering processes start easily and occur quicker [61].

\section{Turbulence}

Turbulence plays a major role in determining the explosion characteristics of a dust. It is important to remark that some turbulence is going to appear always, since pre-ignition turbulence is necessary for suspending the dust clouds [62]. This turbulence causes different effects on ignition sensitivity parameters or on explosion severity [47]. In the case of ignition, turbulence will remove heat from the ignition zone by rapid convection, and ignition of a turbulent dust cloud generally requires higher energies/temperatures. On the other hand, the effect of the turbulence is to increase the violence of explosions.

\section{Gas presence}

Depending on the gas mixed with the dust, the explosion can be prevented or promoted. 
One of the most used procedures to inhibit the explosion of a dust cloud is by inerting this cloud mixing the air with an inert gas until an oxygen concentration lower than the limiting oxygen concentration is obtained, so that there is not enough oxygen for the propagation of a flame [63]. The two most used gases for inerting are nitrogen and carbon dioxide [55].

On the other hand, the explosion severity may increase by adding promoting gases. Sanchirico et al. [64] concluded that an explosion generated by a hybrid mixture would have higher severity than one generated only by the dust involved on the mixture, while Dufaud et al. [65] suggested that the severity would be greater than the ones of both compounds taken separately. One of the most common and dangerous gases that is usually present and generating hybrid mixtures is methane [66].

\subsection{CHARACTERIZATION OF POWDERS}

In any industrial facility, prevention and protection measurements should be design by studying the ignition sources that may be present in the facility and the characteristics of the powdery substances. These characteristics are extremely changeable, so their determination should be done at the beginning of their use.

According to the nature of the characteristics, they may be divided in the following groups:

- General characteristics.

- Ignition sensibility.

- Explosion severity.

- Thermal susceptibility.

- Thermal stability.

- Hazardous materials' transport.

\subsubsection{GENERAL CHARACTERISTICS}

This group is made by two characteristics that have to be associated to the other parameters: moisture of the sample and particle size, whose influence has been previously explained in chapter 3.1.1. 


\subsubsection{IGNITION SENSITIVITY}

The ignition sensitivity group includes every characteristic of the powders related to its flammability easiness. These parameters are used to design the prevention measurements of the industrial facilities. The lower these values, the more sensitive is the studied sample.

Three parameters are included in this group: minimum ignition temperature (MIT), lower explosibility limit (LEL) and minimum ignition energy (MIE).

The minimum ignition temperature is the lowest temperature at which the dusty sample starts to ignite. This test may be determined in two ways: with the dust dispersed as a cloud (minimum ignition temperature on a cloud) or deposited as a layer (minimum ignition temperature on a layer). Both parameters can be expressed in ${ }^{\circ} \mathrm{C}$ and according to their values the maximum superficial temperatures of the equipment are limited. Several researches have studied these parameters $[67,68]$. Polka et al [69] studied the values for several biomasses including corn starch and flour.

The lower explosibility limit is the lower limit of the range of concentration of airborne dust to which the air-dust is potentially explosive. In general, it is expressed in terms of weight units by air volume unit. For many dusts, when particle sizes are lower than $180 \mu \mathrm{m}$ of diameter, the LEL is independent of the particle size. If the diameter is larger, a quick increment on LEL values is observed when increasing the particle size [70]

The minimum ignition energy is the lowest energy that is enough to ignite the most flammable mixture of a dust cloud, determined in $\mathrm{mJ}$. [71]

\subsubsection{EXPLOSION SEVERITY}

These characteristics allow to evaluate the explosion consequences, so they are used to design the protection measurements needed in the facilities.

The parameters included in this group are: maximum pressure of explosion $\left(\mathrm{P}_{\max }\right)$, characteristic constant $\left(\mathrm{K}_{\max }\right)$ and limiting oxygen concentration (LOC)

The maximum pressure is the difference between the pressure at the ignition moment (normal pressure) and the maximum pressure registered at the pressure-time curve. $\mathrm{P}_{\max }$ of a dust-air mixture is sensitive to flow properties. When the effect of turbulence is not taken into account, the theoretical approach may lead to underestimations or over estimations of the design strength of industrial equipment [72]. 


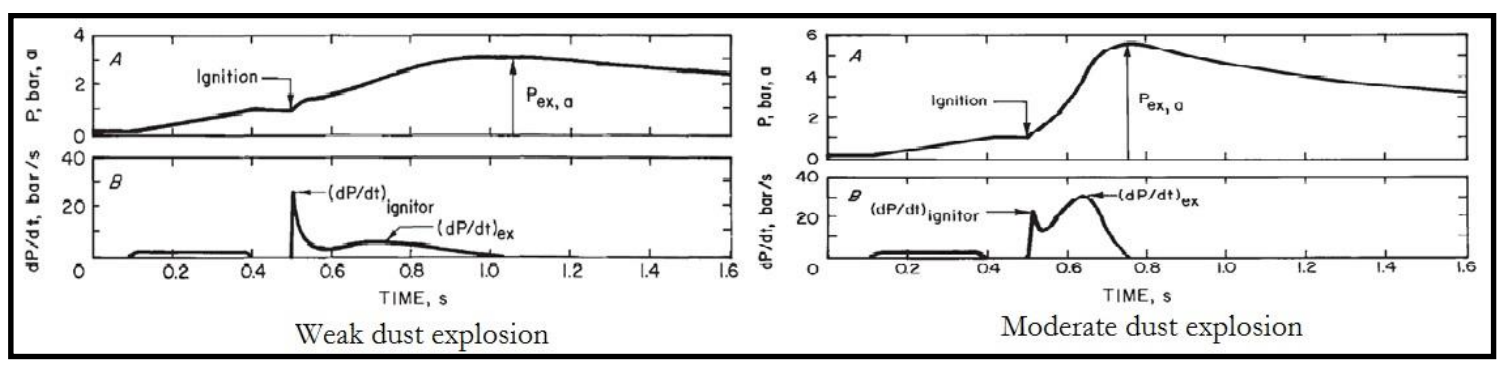

Figure 12. Typical pressure data for dust explosions [55]

The characteristic constant is determined by multiplying the maximum rate of pressure rise by the cubic root of the volume of the enclosure where the explosion occurs.

$$
k_{\max }=\left(\frac{d P}{d t}\right)_{\max } V^{1 / 3}
$$

According to this value, the explosion can be classified in four groups, as shown in Table 6.

Table 6. Explosion type depending on characteristic constant value

\begin{tabular}{|c|c|c|}
\hline Explosion type & $\mathrm{k}_{\max }(\mathrm{m} \cdot \mathrm{bar} / \mathrm{s})$ & Explosion \\
\hline St 0 & 0 & No explosion \\
\hline St 1 & $1-200$ & Weak explosion \\
\hline St 2 & $200-300$ & Strong explosion \\
\hline St 3 & $>300$ & Very strong explosion \\
\hline
\end{tabular}

$\left(\frac{d P}{d t}\right)_{\max }$ is the maximum rise of pressure, and it mainly depends on the combustion speed. This parameter depends on several factors, as the characteristic constant does, being the main the ones detailed in Table 7 [39]. 
Table 7. Factors influencing the maximum rise of pressure

\begin{tabular}{|c|c|}
\hline Factor & Maximum value of $\frac{\boldsymbol{d P}}{\boldsymbol{d} \boldsymbol{t}}$ corresponds to: \\
\hline Particle size & Fine granulometry \\
\hline Dust concentration & Much higher than the minimum explosive \\
\hline Energy of the ignition source & Powerful sources \\
\hline Location of the ignition source & Central locations \\
\hline Initial temperature & High \\
\hline Initial pressure & High \\
\hline Turbulence & High \\
\hline Gases presence & Flammable gases \\
\hline
\end{tabular}

The limiting oxygen concentration is the minimum percentage of oxygen at which an explosion occurs, in volume percent. This parameter depends on the concentration of dust in the atmosphere (Figure 13), but it is determined for the worst situation that can occur.

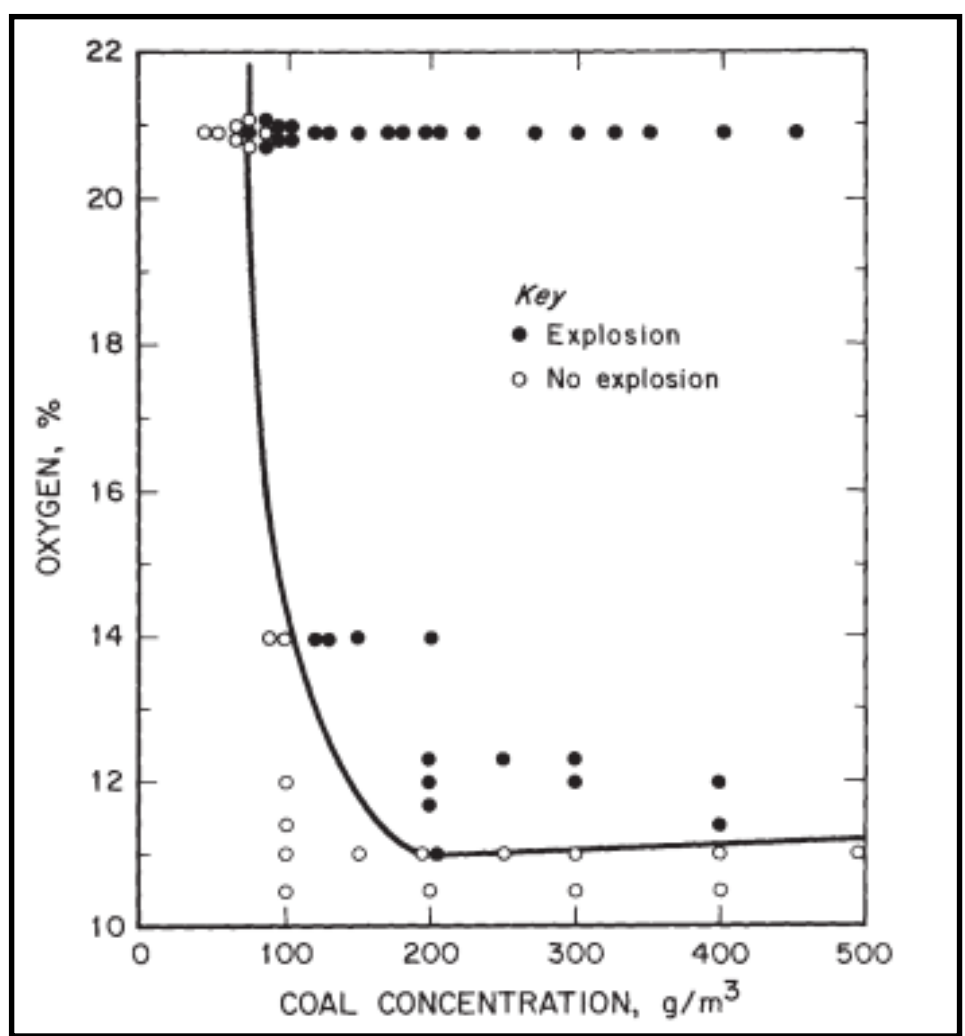

Figure 13. Effect of reduced oxygen concentration on coal dust explosibility [55] 
The LOC measurement is not normally used directly to provide inert levels as a reasonable safety factor should be applied to account for the sensitivity, accuracy and reliability of the plant monitoring system to establish safe inert levels in industrial processes and to set oxygen concentration alarms or interlocks in internal vessels [73]. NFPA 69 [74] recommends keeping the system oxygen concentration at least $2 \%$ lower than measured LOC value when protecting equipment.

\subsubsection{THERMAL SUSCEPTIBILITY}

This group is used to know the thermal behaviour of solids and to determine their selfignition tendency. The parameters of this group are: Maciejasz index (MI), temperature of emission of flammable volatiles (TEV), and those determined by thermogravimetric and differential scanning calorimetric tests.

Maciejasz index is obtained as a result of a test for the reactivity to oxygen, particularly to peroxides. The test consists of attacking the sample with hydrogen peroxide, $\mathrm{H}_{2} \mathrm{O}_{2}$, and then observe its behaviour. If the substance has avidity for oxygen, they will combine each other through an exothermic reaction which will rise the temperature. Maciejasz Index, MI, is an inverse function of the time, $t$, in minutes, necessary for the sample to rise its temperature $65 \mathrm{~K}$ from the initial ambient temperature, when reacts with the oxygen peroxide:

$$
\mathrm{MI}=100 / \mathrm{t}
$$

Self-ignition risk is considered when $\mathrm{MI}>10$.

The temperature of emission of flammable volatiles' test is very useful to analyse a possible thermal degradation of organic matters generating volatile substances capable of being ignited. The testing method consists of heating a portion of the sample at increasing temperatures and then approaches a glowing wire as an ignition source. If the sample produces flammable vapours, these would be more sensitive to ignition than the solid product itself and they can be ignited at lower temperatures.

In Thermogravimetric Analysis (TG) the mass of the sample is measured as a function of its temperature when heated following a programmed heating rate. Figure 14 shows a typical TG plot, with the derivative curve dTG superimposed, where some significant parameters can be defined, such as the combustion induction temperature (IT) and the maximum mass loss temperature (MLT). The MLT is an indicator of the reactivity of the product 
such as it represents the yield of volatiles due to the pyrolysis process: the higher this temperature, the lower the reactivity of the sample.

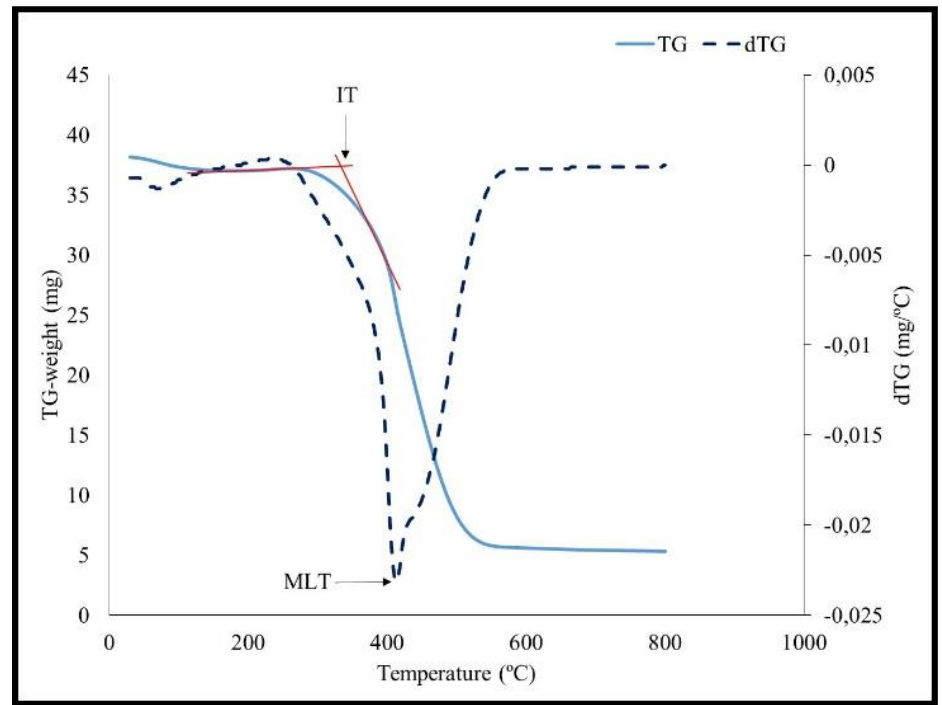

Figure 14. Typical thermogravimetric curve

TG analyses have been widely used to study the kinetics of combustion processes $[75,76]$. The main advantages of this analysis are its rapid assessment of the value and the temperatures at which combustion starts and ends [77]. Thanks to the thermogravimetric curves, the three stages of a combustion process can be easily determined [78]. First of all, the dehydration and drying process, followed by the devolatilisation of the organic matter, where the main weigh of loss occurs. Finally, the inorganic material of the sample is decomposed by the oxidation of the char remaining after the volatiles were removed from the samples. Added to this, TG is an excellent method for accurate determination of the ignition temperature of solid fuels [79].

In the case of the samples studied and due to their structural composition, two points of maximum mass loss, the resultant from the devolatilization of holocellulose (MLT_LV), and that corresponding to the devolatilization of lignin (MLT_HV) are obtained [80], as can be seen in Figure 15. 


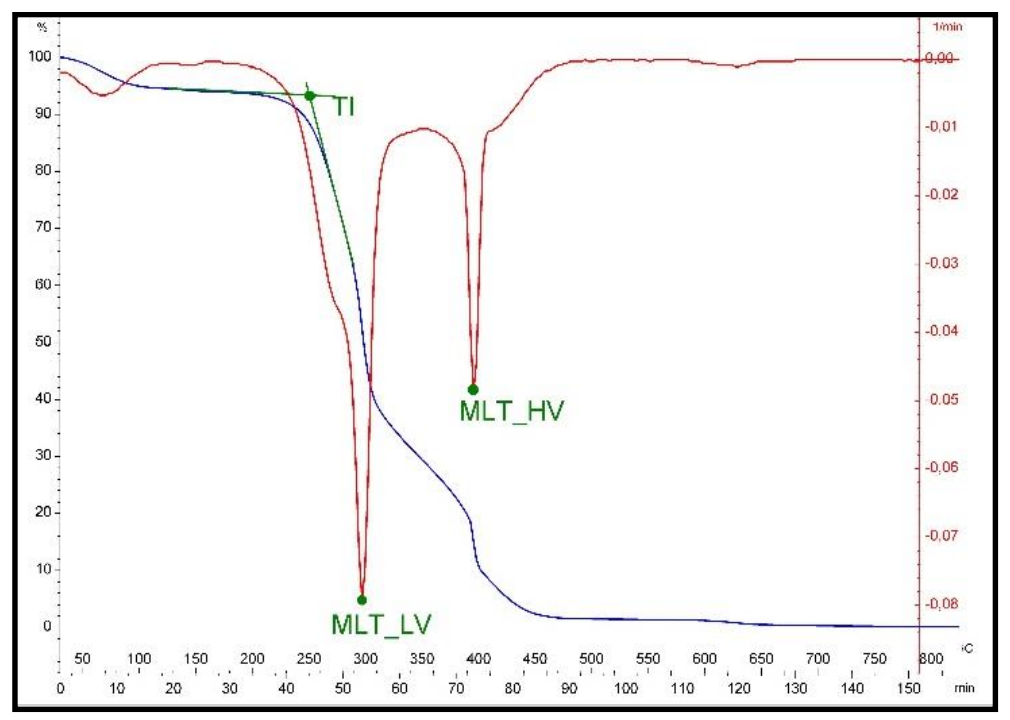

Figure 15. Thermogravimetric curve for biomasses

As a general rule, when an oxygen stream is used instead of air stream, the reaction takes place quicker, and the sample has a peak mass-loss rate at a determined temperature called characteristic oxidation temperature (Tcharact), that is different for each sample (Figure 16).

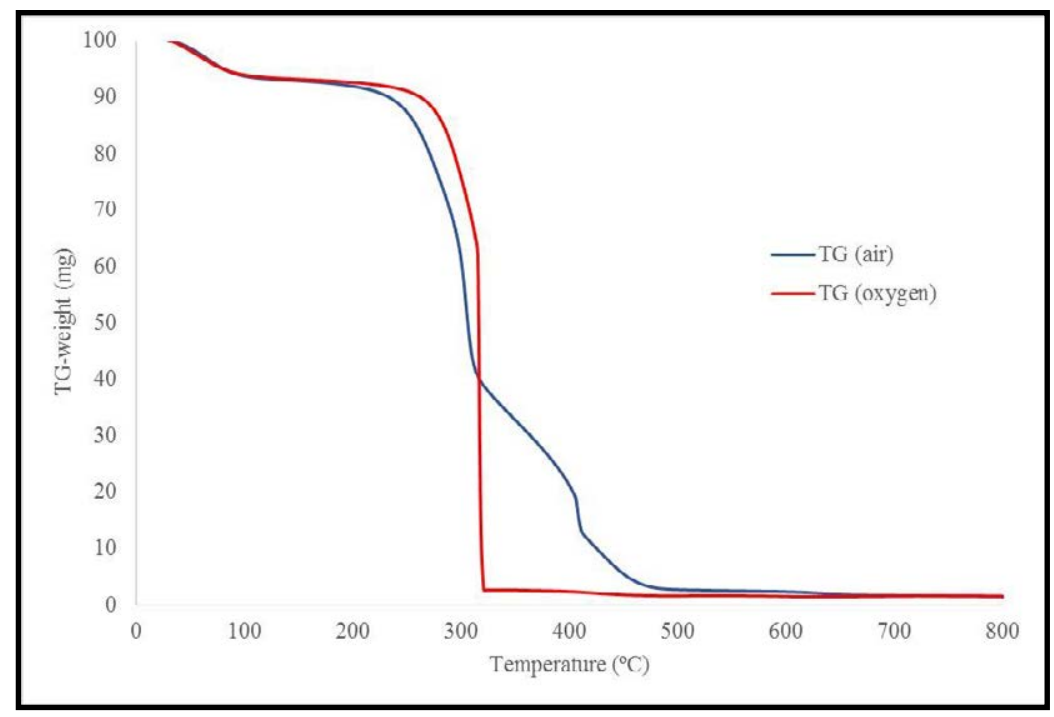

Figure 16. Curve of thermogravimetry with oxygen test

Depending on this parameter samples can be classified by its self-ignition risk, as shown in Table 8. 
Table 8. Self-ignition risk depending on characteristic temperature values

\begin{tabular}{|c|c|}
\hline $\begin{array}{c}\text { Self-ignition risk } \\
\left({ }^{\circ} \mathrm{C}\right)\end{array}$ & $\begin{array}{c}\text { Characteristic temperature } \\
\leq 250\end{array}$ \\
\hline Very high & $250-299$ \\
\hline High & $300-349$ \\
\hline Medium & $\geq 350$ \\
\hline Low & \\
\hline
\end{tabular}

Using data from conventional thermogravimetry analysis with air stream and the mathematic model proposed by Cumming [81], the apparent activation energy of a sample is calculated at the temperature of maximum mass loss of holocellulose.

Cumming's equation relates the apparent activation energy to the rate of mass loss, allowing the estimation of the "apparent activation energy", Ea, from the slope of the least-squares straight line fitted to the chosen test data:

$$
\ln \left(-\frac{1}{W_{\infty}} \cdot \frac{d w}{d t}\right)=-\ln A-\frac{E_{a}}{R \cdot T}
$$

Where: $\quad \mathrm{W}_{\infty}$ : Mass of unburnt sample $(\mathrm{g})$

$\mathrm{dw} / \mathrm{dt}$ : Instant velocity of mass loss $(\mathrm{g} / \mathrm{s})$

A: Frequency factor

Ea: Apparent activation energy $(\mathrm{J} / \mathrm{mol})$

R: Universal gas constant $(8.314 \mathrm{~J} / \mathrm{mol} \mathrm{KT:} \mathrm{Absolute} \mathrm{temperature} \mathrm{(K)}$

Thermodynamic and mathematic basis of Cumming's equation, based on the equations that characterise the first-order reactions, simplifies and makes easier the calculus and use of the value of the apparent activation energy, thus becoming a characteristic parameter of the sample and representative of the ease with which the reaction will be produced.

The value of activation energy (Ea) has been used to classify coal samples according to their self-ignition risk as shown in Table 9. 
Table 9. Self-ignition risk depending on activation energy values

\begin{tabular}{|c|c|}
\hline $\begin{array}{c}\text { Self-ignition risk } \\
\left({ }^{\circ} \mathrm{C}\right)\end{array}$ & $\begin{array}{c}\text { Characteristic temperature } \\
\leq 79\end{array}$ \\
\hline Very high & $80-89$ \\
\hline High & $90-94$ \\
\hline Medium & $\geq 95$ \\
\hline Low & \\
\hline
\end{tabular}

When plotting the values of Ea and Tcaract a thermal susceptibility graph is obtained in which different degrees of reactivity or tendency to self-ignition can be distinguished (Figure 17).

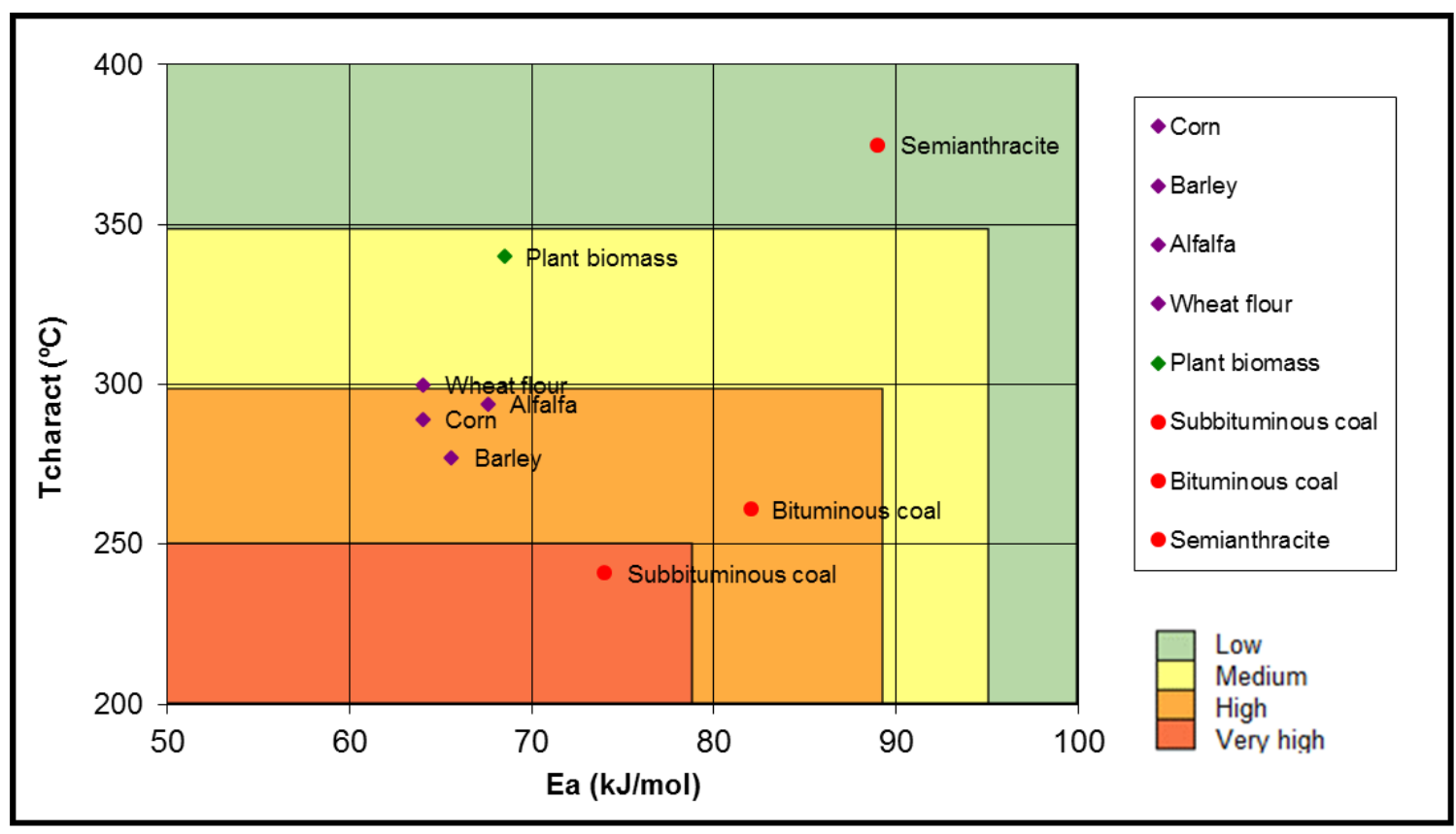

Figure 17. Thermal susceptibility graph

In the case of Differential Scanning Calorimetry (DSC) the sample is heated at a regular rate, previously established and a reference inert product is placed in another crucible. The difference in temperature between the sample and the reference is measured and recorded against the temperature of the oven and the exchanges of heat in the sample are determined. Figure 18 shows a typical DSC record. The parameters used to characterize different substances are the minimum temperature at which the exothermic reaction begins (initial temperature, IET), the maximum temperature reached during the exothermic reaction (final temperature, FET) and the temperature at which the fast exothermic reaction commences (change of slope temperature, CST). 


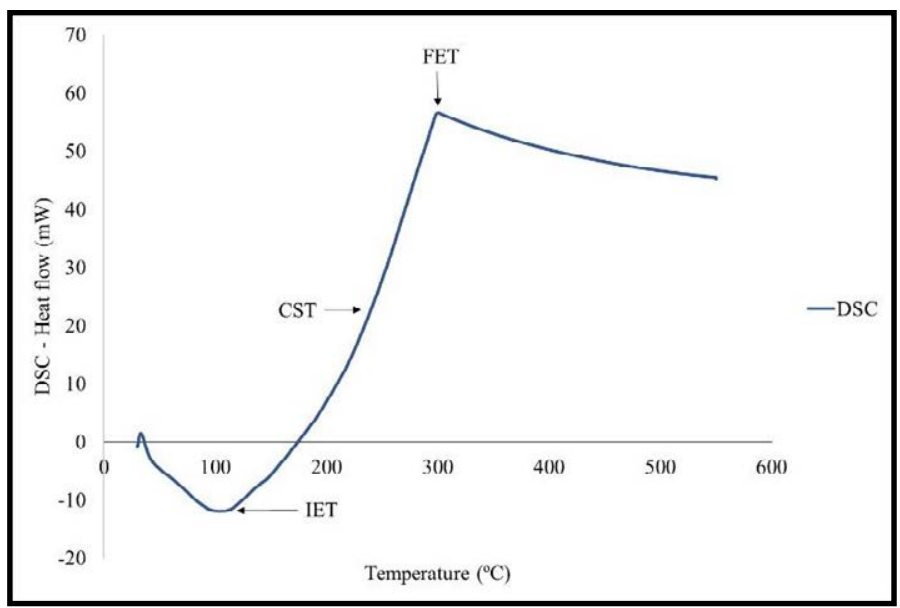

Figure 18. Typical curve of differential scanning calorimetry

\subsubsection{SELF-IGNITION}

The self-ignition temperature is determined in samples of different volumes in an isothermal oven that reproduces environmental temperatures [82]. The temperature in the middle of the sample is recorded against time, and three different curves may be obtained (Figure 19):

A. Subcritical. At an experimental temperature $\mathrm{T}_{\mathrm{A}}$ the sample becomes hotter, approaching the temperature of the oven. The sample does not produce heat by itself and no ignition is observed.

B. Critical. The temperature of the sample slightly surpasses the oven's one for time, but then tends towards the oven temperature.

C. Supercritical. Heat production in the sample surpasses its heat losses. Eventually, non-stationary conditions are reached and the sample temperature increases rapidly over that of the oven and ignition occurs. 


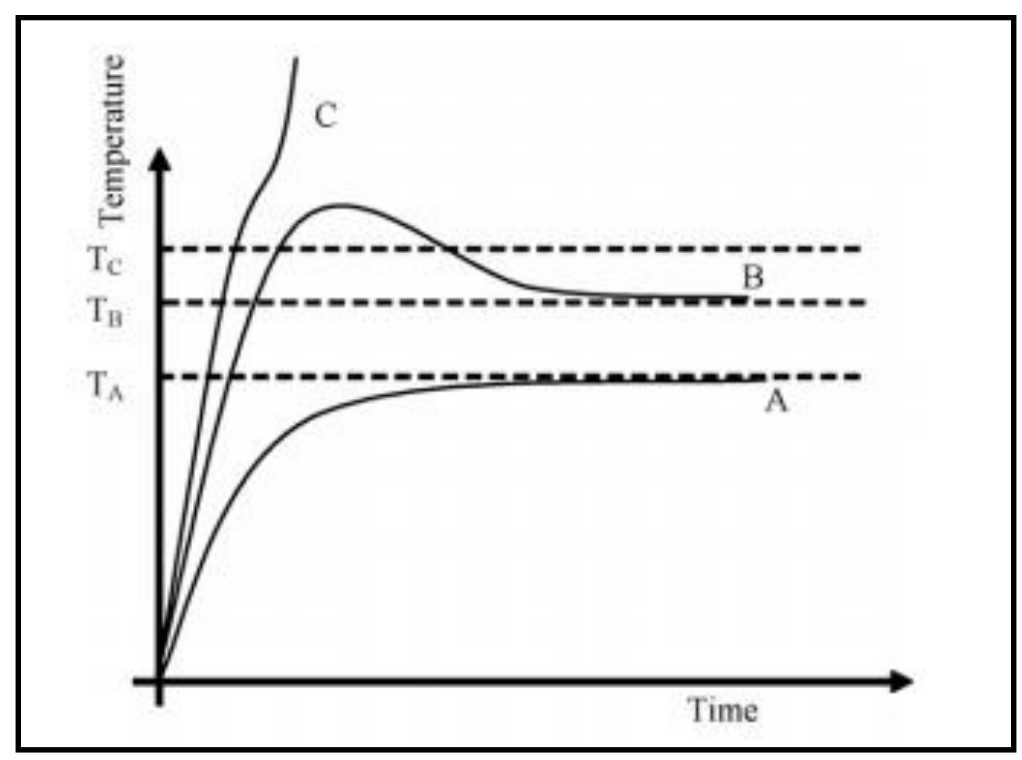

Figure 19. Thermal behaviour of the dust materials in the isothermal oven [83]

According to the Standard EN 15188 [83], the self-ignition temperature (SIT) may be determined as: $S I T=\frac{T_{B}+T_{C}}{2}$

The SIT for dusts and bulk materials increases with a decreasing oxygen content in the surrounding. Wetting can turn a sub-critical into a super-critical deposit and finally lead to an ignition after water vapour evaporated on the particles. Thus, the SIT of a certain volume can be reduced by pouring cater on the surface of a bulk material [84].

\subsection{GAS EMISSIONS}

The self-ignition temperature can be determined in samples of different volumes in an isothermal oven that reproduces environmental temperatures [85], but this technique needs a large amount of sample and a long time for testing. On the other hand, self-ignition properties can be determined by thermogravimetry and differential scanning calorimetry techniques $[75,76]$, which need less amount of sample and provides more information about the combustion process [77].

Also numerical simulations can be used to study the combustion processes of dust materials [86]. The combustion process starts even before the point at which is determined by these analyses, and the first indicator of this combustion is the gas emissions associated to their heating processes. In fact, in the very beginning stage of a self-combustion process, the heating starts to break some chemical bonds in the solid structure, releasing molecules of gases. 
Due to this conviction, experimental research has been carried out in order to develop a new methodology for the detection of the incipient self-ignition processes in solid fuels [87], and it has been implemented in several fuels to study their self-ignition tendency.

It is well known that gas emissions rise when the temperature of the sample rises, i.e. the CO and $\mathrm{CO}_{2}$ emissions are higher when the temperature of the sample is higher. However, this rising is different depending on the composition of the sample, and the starting point of this process can be considered as characteristic parameters for self-ignition detection.

If the $\mathrm{CO}$ or $\mathrm{CO}_{2}$ emissions are plotted vs the temperature of the sample (Figure 20), the starting point of the rise can be considered as the incipient self-ignition temperature.

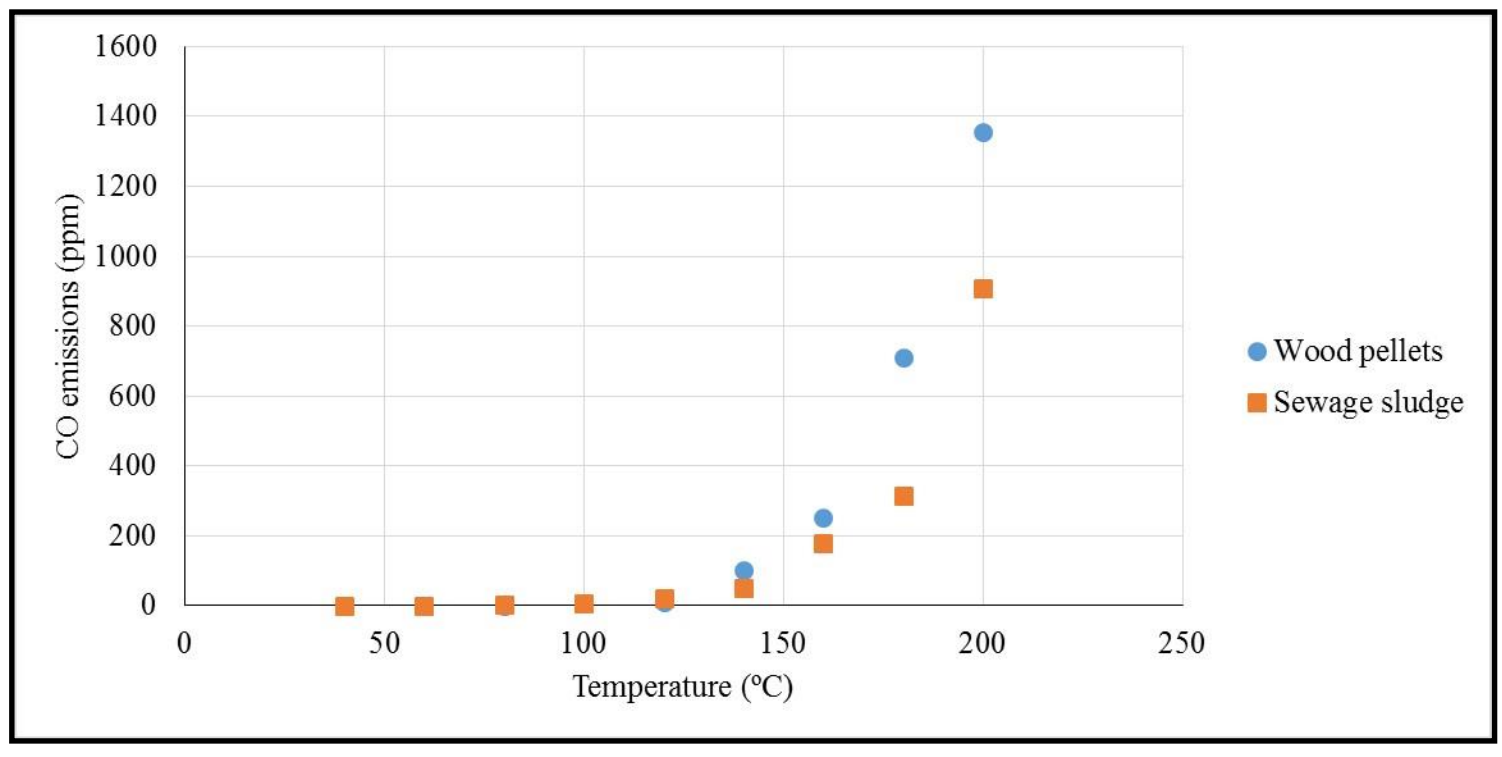

Figure 20. CO emissions vs temperature 



\section{MATERIALS AND METHODS}

\subsection{MATERIALS}

\subsubsection{SOLID FUELS}

Sixteen different samples (Figure 21) have been chosen for this analysis trying to have representative samples of all the groups, as shown on Table 10. Eight of these samples have been studied with two different granulometries.

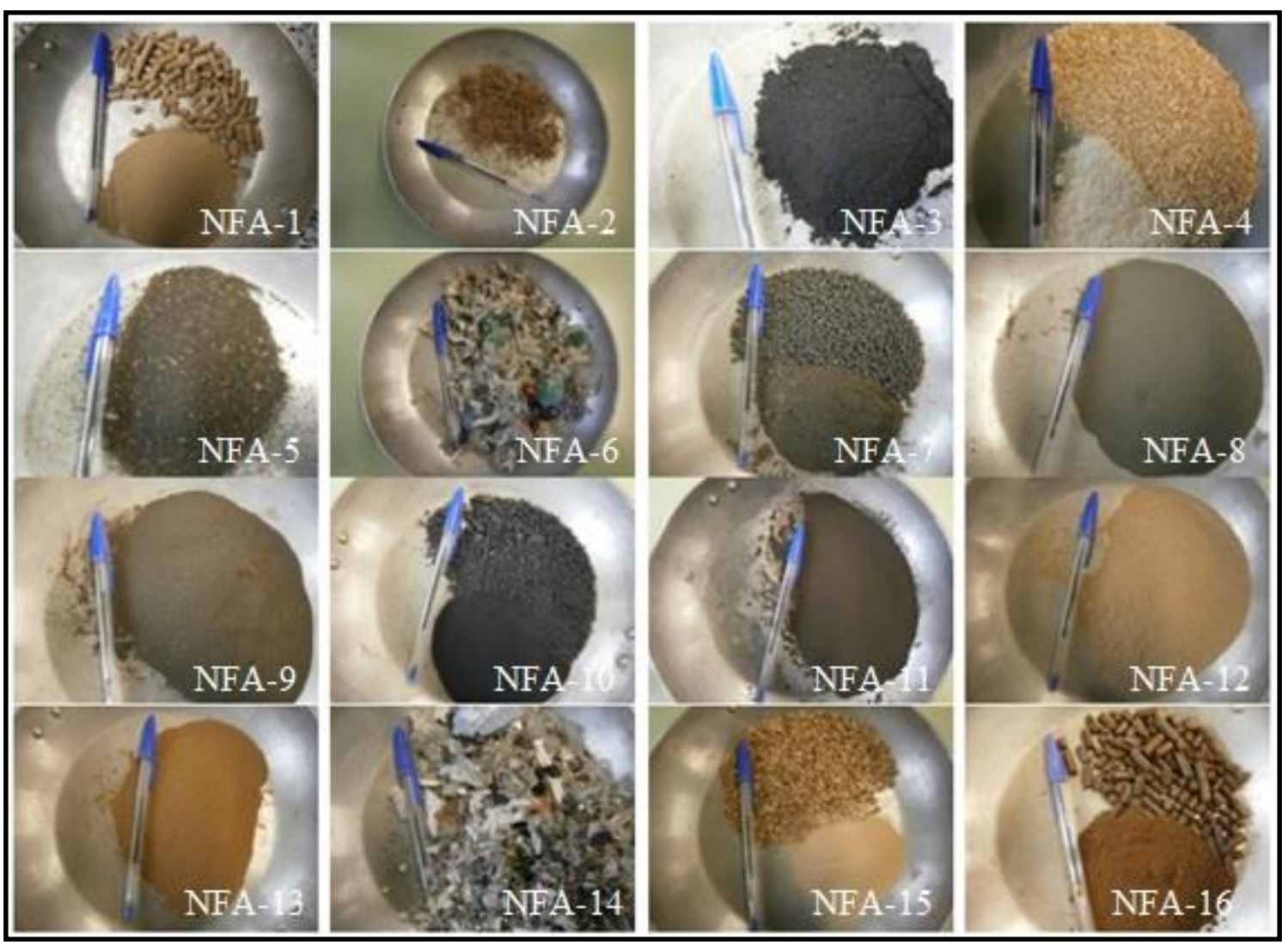

Figure 21. Solid fuel samples pictures 
Table 10. Solid fuel samples

\begin{tabular}{|c|c|c|}
\hline Sample & Grain size & Material \\
\hline NFA-1 & Fine & Wood pellets \\
\hline NFA-1 & Coarse & Wood pellets \\
\hline NFA-2 & Fine & Stubble \\
\hline NFA-3 & Fine & Coal \\
\hline NFA-4 & Fine & Wood chips \\
\hline NFA-4 & Coarse & Wood chips \\
\hline NFA-5 & Fine & Sewage sludge \\
\hline NFA-6 & Fine & Plastic \\
\hline NFA-6 & Coarse & Plastic \\
\hline NFA-7 & Fine & Sewage sludge \\
\hline NFA-7 & Coarse & Sewage sludge \\
\hline NFA-8 & Fine & Sewage sludge \\
\hline NFA-9 & Fine & Sewage sludge \\
\hline NFA-10 & Fine & Coke \\
\hline NFA-10 & Coarse & Coke \\
\hline NFA-11 & Fine & Coal \\
\hline NFA-12 & Fine & Straw \\
\hline NFA-13 & Fine & Almond shell \\
\hline NFA-14 & Fine & Plastic \\
\hline NFA-14 & Coarse & Plastic \\
\hline NFA-15 & Fine & Olive pit \\
\hline NFA-15 & Coarse & Olive pit \\
\hline NFA-16 & Fine & Torrefied wood pellets \\
\hline NFA-16 & Coarse & Torrefied wood pellets \\
\hline
\end{tabular}




\subsubsection{SEWAGE SLUDGE SAMPLES}

Twenty sewage sludge thermally dried samples have been studied. Those samples have been chosen in order to study seasonal and regional variations, so the samples come from different facilities and also from different seasons. The samples have been collected in eight wastewater treatment plants belonging to three regions in Spain: Barcelona, Madrid and Málaga. According to the season when the samples have been collected, they are classified in summer samples or winter samples. If the samples have been collected between May and September, they are classified as summer samples. Otherwise, they have been classified as winter samples. The samples collected are detailed in Table 11

Table 11. Sewage sludge samples

\begin{tabular}{|c|c|c|}
\hline Sample & Origin & Season \\
\hline LRET-101 & Barcelona & Summer \\
\hline LRET-102 & Barcelona & Summer \\
\hline LRET-103 & Barcelona & Winter \\
\hline LRET-104 & Madrid & Summer \\
\hline LRET-105 & Madrid & Summer \\
\hline LRET-106 & Madrid & Summer \\
\hline LRET-107 & Madrid & Winter \\
\hline LRET-108 & Madrid & Winter \\
\hline LRET-110 & Madrid & Winter \\
\hline LRET-111 & Madrid & Winter \\
\hline LRET-112 & Málaga & Winter \\
\hline LRET-113 & Málaga & Winter \\
\hline LRET-114 & Barcelona & Summer \\
\hline LRET-115 & Barcelona & Summer \\
\hline LRET-116 & Barcelona & Winter \\
\hline LRET-117 & Barcelona & Winter \\
\hline LRET-118 & Madrid & Winter \\
\hline LRET-119 & Madrid & Winter \\
\hline LRET-120 & Barcelona & Winter \\
\hline LRET-121 & Madrid & Summer \\
\hline
\end{tabular}




\subsubsection{MIXTURE SAMPLES}

Ten mixture samples using coal (NFA-11), sewage sludge (NFA-7) and torrefied wood pellets (NFA-16) of less than 180 microns have been used in order to study different possibilities of cofiring processes (Table 12).

Table 12. Mixture samples

\begin{tabular}{|c|c|c|c|}
\hline Samples & $\begin{array}{c}\text { Torrefied wood } \\
\text { pellets }(\%)\end{array}$ & $\begin{array}{c}\text { Sewage sludge (\%) } \\
\text { NFA-101 }\end{array}$ Coal (\%) \\
\hline NFA-102 & 0 & 25 & 75 \\
\hline NFA-103 & 0 & 50 & 25 \\
\hline NFA-104 & 25 & 75 & 75 \\
\hline NFA-105 & 50 & 0 & 50 \\
\hline NFA-106 & 75 & 0 & 25 \\
\hline NFA-107 & 25 & 75 & 0 \\
\hline NFA-108 & 50 & 50 & 0 \\
\hline NFA-109 & 75 & 25 & 33.33 \\
\hline NFA-110 & 33.33 & 33.33 & 0 \\
\hline
\end{tabular}




\subsection{METHODS}

\subsubsection{ELEMENTAL ANALYSIS}

Elemental analysis provides the content of carbon, hydrogen, nitrogen and sulphur of the studied materials. It has been determined using a Leco TrueSpec located at Laboratorio de Combustibles y Petroquímica, as the one showed on Figure 22.

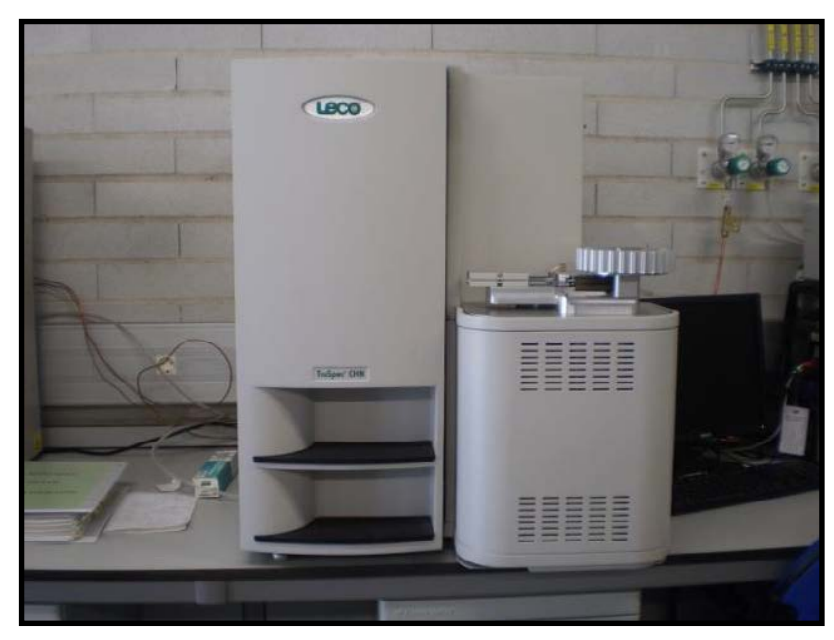

Figure 22. Leco TrueSpec

Carbon, hydrogen and nitrogen contents are determined following the Standard EN 15407 [88], based on the complete oxidation of the materials. The procedure starts with the conversion of $\mathrm{C}, \mathrm{H}$ and $\mathrm{N}$ in their corresponding gases during the combustion in an atmosphere of oxygen of the sample $\left(\mathrm{CO}_{2}, \mathrm{H}_{2} \mathrm{O}\right.$ and $\mathrm{NO}_{\mathrm{x}}$ respectively). The other combustion products are cleaned before the detection of the gases to avoid interferences. $\mathrm{NO}_{x}$ gases are reduced to $\mathrm{N}_{2}$, and this is determined like the $\mathrm{CO}_{2}$ and $\mathrm{H}_{2} \mathrm{O}$ by infrared spectrometry and thermal conductivity

The total sulphur content is determined in solid fuels mainly for environmental and technical reasons. It is determined following the Standard EN 15408 [89] consisting of the combustion at high temperature on a tube furnace and the detection by infrared absorption. The procedure starts by the burning in the tube furnace of a portion of the sample, with the presence of oxygen at least at $1350{ }^{\circ} \mathrm{C}$. During the combustion, sulphur and its compounds are decomposed and oxidized to $\mathrm{SO}_{2}$. This $\mathrm{SO}_{2}$ is detected by the infrared spectrometer. 


\subsubsection{PROXIMATE ANALYSES}

Proximate analyses have been performed according to the standards shown in Table 13. Due to the high ash content of sewage sludge samples, these samples have been analysed according to coal standards and not to biomass standards.

Table 13. Standards used for proximate analyses

\begin{tabular}{|c|c|c|}
\cline { 2 - 3 } \multicolumn{1}{c|}{} & $\begin{array}{c}\text { Coal \& sewage sludge } \\
\text { samples }\end{array}$ & Biomass samples \\
\hline Ash content & UNE 32004 [90] & EN 14775 [91] \\
\hline Volatile content & UNE 32019 [92] & EN 15148 [93] \\
\hline Moisture content & UNE 32002 [94] & EN 14774 [95] \\
\hline
\end{tabular}

Contents have been determined in dry basis, and fixed carbon has been determined as the complementary part to sum 100\% (Fixed carbon $=100-($ Volatiles + Ashes $))$

\subsubsection{ASH CONTENT}

First of all, a laboratory dish is weighted. Between 1 and 2 grams of sample is placed on it and it is weighted empty (Figure 23). The laboratory dish with the sample is placed inside the oven at room temperature.

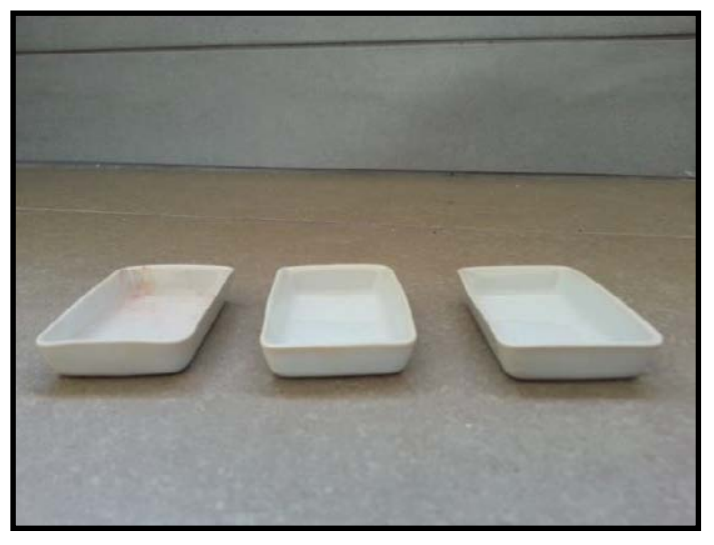

Figure 23. Dish for ash content

The temperature of the oven has to rise under a determinate range, depending on the sample that is tested: 
- For coal: Temperature is raised from room temperature to $250^{\circ} \mathrm{C}$ in 30 minutes, then to $500^{\circ} \mathrm{C}$ in other 30 minutes and finally to $815 \pm 10^{\circ} \mathrm{C}$ in 30 to 60 minutes. Finally, $815{ }^{\circ} \mathrm{C}$ remains for 60 minutes.

- For biomass: Temperature rises from room temperature to $250^{\circ} \mathrm{C}$ in 30 to 50 minutes and it remains at this temperature for 60 minutes. Later, it rises to $550 \pm 10^{\circ} \mathrm{C}$ in 30 minutes and it remains for 120 minutes.

When the heating time finishes, the laboratory dish with the ashes is removed from the oven and cooled for 10 minutes outside and for 15 minutes inside a desiccator with a dehydrating agent.

Ash content is determined with the following equation:

$$
A_{d}=\frac{m_{3}-m_{1}}{m_{2}-m_{1}} \cdot 100 \cdot \frac{100}{100-M_{a d}}
$$

Where $\mathrm{m}_{1}$ is the laboratory dish weight, in grams

$\mathrm{m}_{2}$ is the laboratory dish and the sample weight before heating, in grams

$\mathrm{m}_{3}$ is the laboratory dish and the ash weight after heating, in grams

$\mathrm{M}_{\mathrm{ad}}$ is the moisture of the sample

\subsubsection{VOLATILE CONTENT}

The oven is pre-heated at $900 \pm 10^{\circ} \mathrm{C}$. Before the test procedure, furniture must be cleaned by placing the crucibles in a rack (Figure 24), and inside the oven for 7 minutes. They are removed from the oven and cooled first in a flat surface and later in the desiccator. When it is cold, the crucible and its cover are weighted. Between 1 and 1.01 grams of sample are placed inside the crucible and the crucible, its cover and the sample are weighted. 


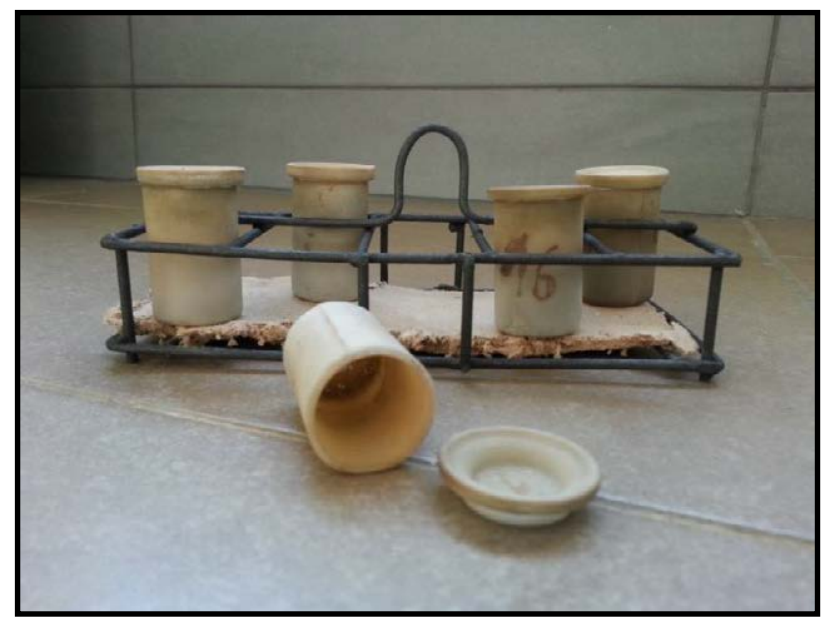

Figure 24. Crucible for volatile content

The crucible is placed in the rack uncovered and the crucible, the rack and the cover are introduced into the oven for 7 minutes. After this time, they are removed and cooled. When they are cold, the crucible, its content and its cover are weighted.

Volatile content is determined with the following equation:

$$
V_{d}=\left(\frac{100\left(m_{2}-m_{3}\right)}{m_{2}-m_{1}}-M_{a d}\right) \cdot\left(\frac{100}{100-M_{a d}}\right)
$$

Where $\mathrm{m}_{1}$ is the crucible weight, in grams

$\mathrm{m}_{2}$ is the crucible and the sample weight before heating, in grams

$\mathrm{m}_{3}$ is the crucible and its content after heating, in grams

$\mathrm{M}_{\mathrm{ad}}$ is the moisture of the sample

\subsubsection{MOISTURE CONTENT}

Before the test, the weighing bottle is dried in an oven at $105 \pm 2{ }^{\circ} \mathrm{C}$.

The oven is preheated at $105 \pm 2{ }^{\circ} \mathrm{C}$. The weighing bottle and its cover (Figure 25) are weighted. Between one and two grams of sample are placed inside the weighing bottle and this with the cover are weighted. 


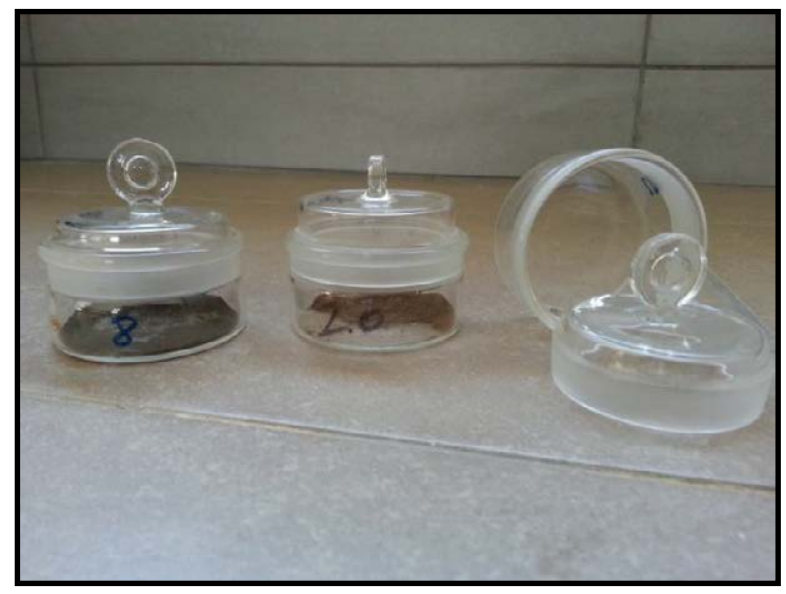

Figure 25. Weighing bottle for moisture content

The weighing bottle is placed in the oven at $105 \pm 2^{\circ} \mathrm{C}$ discovered for at least 60 minutes. Because of the heterogeneity of the biomass samples, they have been placed for at least 2 hours, after that no mass change is observed after future drying. After this time, they are removed and cooled. When they are cold, the weighing bottle, its content and its cover are weighted.

Moisture content is determined with the following equation:

$$
M_{a d}=\frac{m_{2}-m_{3}}{m_{2}-m_{1}} \cdot 100
$$

Where $\mathrm{m}_{1}$ is the weighing bottle and its cover weight, in grams

$\mathrm{m}_{2}$ is the weighing bottle, its cover and the sample weight before drying, in grams $\mathrm{m}_{3}$ is the weighing bottle, its cover and the sample weight after drying, in grams

\subsubsection{GRANULOMETRY}

Granulometry of thin samples have been determined thanks to Mastersizer 2000, which is based on laser diffraction. When the particles of the sample studied cross a beam they cause a Fraunhofer diffraction. The intensity of diffracted light is proportional to the particle size and the diffraction angle varies inversely with it. The software provides a granulometric curve volume (\%) vs particle size, as the sample shown in Figure 26.

Six parameters were obtained through this software:

- The grain diameter where $10 \%$ of the distribution has a smaller particle size: d10.

- The grain diameter where $50 \%$ of the distribution has a smaller particle size: $\mathrm{d} 50$. 
- The grain diameter where $90 \%$ of the distribution has a smaller particle size: $\mathrm{d} 90$.

- Total area of a material per unit of mass: specific surface area (SSA).

- The diameter of the sphere that has the same volume/surface area ratio as the particle of interest: $\mathrm{d}[3,2]$ (surface weighted mean)

- The diameter of the sphere of equal volume to the particle: $\mathrm{d}[4,3]$ (volume weighted mean)

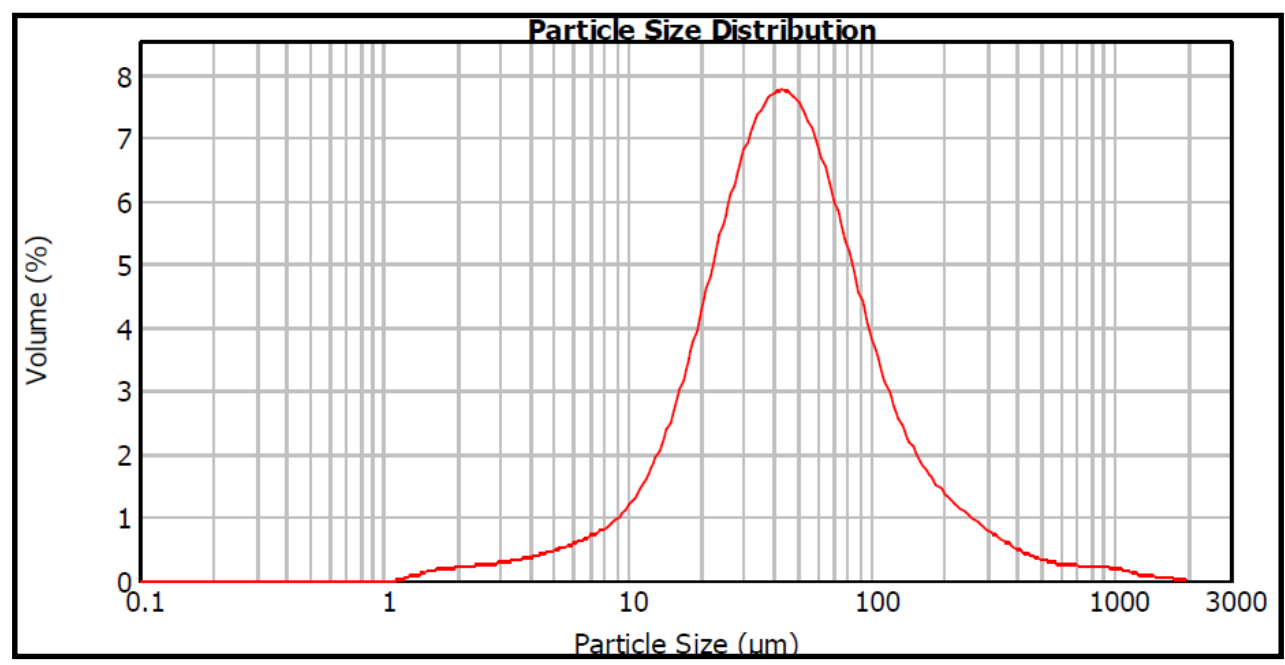

Figure 26. Granulometry curve obtained with Mastersizer 2000

Granulometry of coarse samples have been determined with sieves of different sizes, each sieve having double size than the one that follows it. The amount of sample that pass through each sieve is weighted and recorded, and the accumulative percentage of sample that pass through it is determined. With these data, a granulometric curve as the one shown in Figure 27 is obtained.

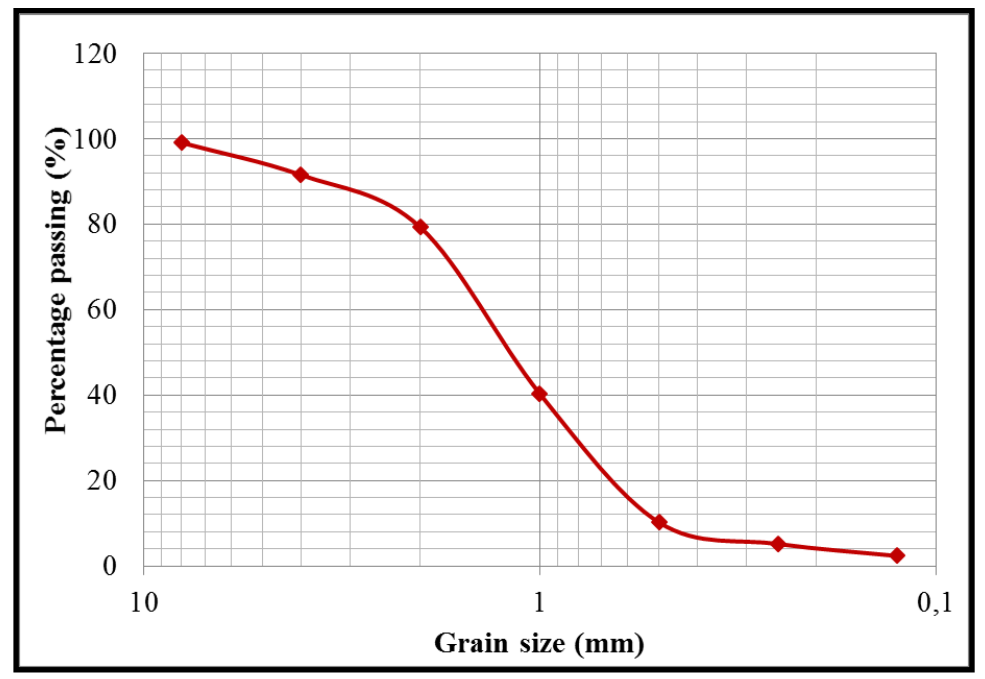

Figure 27. Granulometric curve of coarse particles 


\subsubsection{THERMAL CONDUCTIVITY}

Thermal conductivity has been calculated at $100^{\circ} \mathrm{C}$, so thermal diffusivity and specific heat, which are involved in its determination, have been determined at this temperature. It has been estimated by the following equation.

$$
\lambda=\alpha \cdot \rho \cdot C_{p}
$$

Where $\lambda$ is thermal conductivity $(\mathrm{W} / \mathrm{m} \cdot \mathrm{K})$

$$
\begin{aligned}
& \alpha \text { thermal diffusivity }\left(\mathrm{m}^{2} / \mathrm{s}\right) \\
& \varrho \text { density }\left(\mathrm{kg} / \mathrm{m}^{3}\right) \\
& \mathrm{C}_{\mathrm{p}} \text { specific heat }(\mathrm{J} / \mathrm{kg} \cdot \mathrm{K})
\end{aligned}
$$

\subsubsection{Thermal diffusivity}

Thermal diffusivity has been determined by the procedure described by Wilén et al. [96]: A one-liter cubic volume was filled with the dust sample and placed in an isothermal oven where the temperature was stabilised and lower than the self-ignition temperature for that volume. A thermocouple placed in the centre of the volume was used to record the temperature.

The volume is filled without tamping, tapping, or using any other procedure that could increase the density for the no-compacted test, and compacted with a $10.5 \mathrm{~kg}$ weight for the compacted one.

The thermal diffusivity was estimated following the equation given below (as a result of nondimensional Fourier number):

$$
\frac{\alpha t}{b^{2}}=0.1
$$

Where $\alpha$ is thermal diffusivity

b half edge length

Ta stabilised oven temperature $\left(100^{\circ} \mathrm{C}\right)$

To initial sample temperature 
$\mathrm{t}$ time necessary for the temperature at the centre to reach $\mathrm{T}=(\mathrm{Ta}-0.86(\mathrm{Ta}-\mathrm{To}))$

\subsubsection{Density}

Density for no compacted samples has been determined with a 0.1 litres test tube. The test tube is filled with the dust sample thanks to a funnel located 5 centimetres below the first line of the tube.

Density for compacted samples has been determined by weighting the volume used for determining the thermal diffusivity and dividing it by 1 litre, that is the volume.

\subsubsection{Specific heat}

Specific heat values for the studied samples have been determined with the DSC curves [97], thanks to Equation:

$$
\frac{d H}{d t}=m \cdot c_{p} \cdot \frac{d T}{d t}
$$

Where $\frac{d H}{d t}$ is the energy absorption (W)

$\mathrm{M}$ the mass of the tested sample $(\mathrm{g})$

$\mathrm{C}_{\mathrm{p}}$ the specific heat $(\mathrm{J} / \mathrm{kg} \cdot \mathrm{K})$

$\frac{d T}{d t}$ the heating rate $(\mathrm{K} / \mathrm{s})$

Measures have been done for two temperatures, $80^{\circ} \mathrm{C}$ and $120^{\circ} \mathrm{C}$, trying to avoid the influence of the moisture loss that takes place at $100^{\circ} \mathrm{C}$.

Specific heat follows the following relation with temperature: $c_{P}=a+b \cdot T+c \cdot T^{2}+\cdots$, where $\mathrm{a}, \mathrm{b}$ and $\mathrm{c}$ are constants that are decreasing on value since the degree of the other term is rising. That is why from the third term in advance, terms can be omitted, and it can be considered that the specific heat follows a linear relation with temperature. With this estimation, specific heat at $100{ }^{\circ} \mathrm{C}$ has been determined by a linear interpolation between the values experimentally obtained for $80{ }^{\circ} \mathrm{C}$ and $120^{\circ} \mathrm{C}$. 


\subsubsection{IGNITION SENSITIVITY}

\subsubsection{Minimum ignition temperature layer}

The minimum ignition temperature on a layer is the lowest temperature at which the dusty sample starts to ignite, and it is determined following the Standard EN 50281-2-1 [98], as described below.

The test equipment consists on a round hot surface of $20 \mathrm{~mm}$ diameter, electrically heated. It can reach $400^{\circ} \mathrm{C}$ and its temperature is controlled with two thermocouples located at the middle point of the plate (Figure 28).

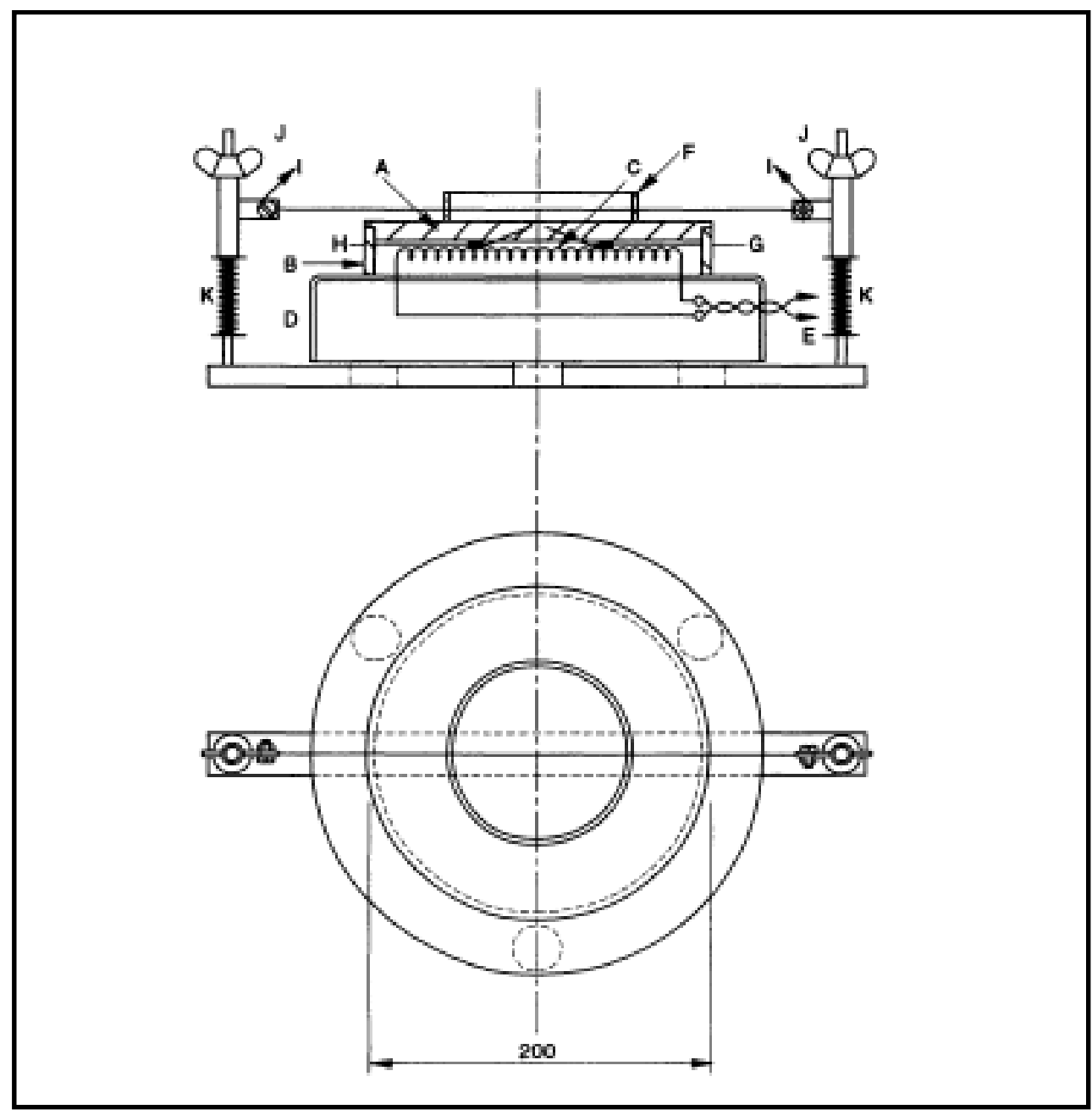

Figure 28. Equipment for determining minimum ignition temperature on layer [98]

One thinner thermocouple (diameter of 0.20 to $0.25 \mathrm{~mm}$ ) should be located 2 or $3 \mathrm{~mm}$ on the plate.

Dust layers are formed with a metallic ring $100 \mathrm{~mm}$ diameter and $5 \mathrm{~mm}$ thickness located in the middle of the plate (Figure 29). Dust is deposited inside the ring with a spatula and 
distributed without compact the sample. Finally, the layer should be screed and all the excess dust should be separated.

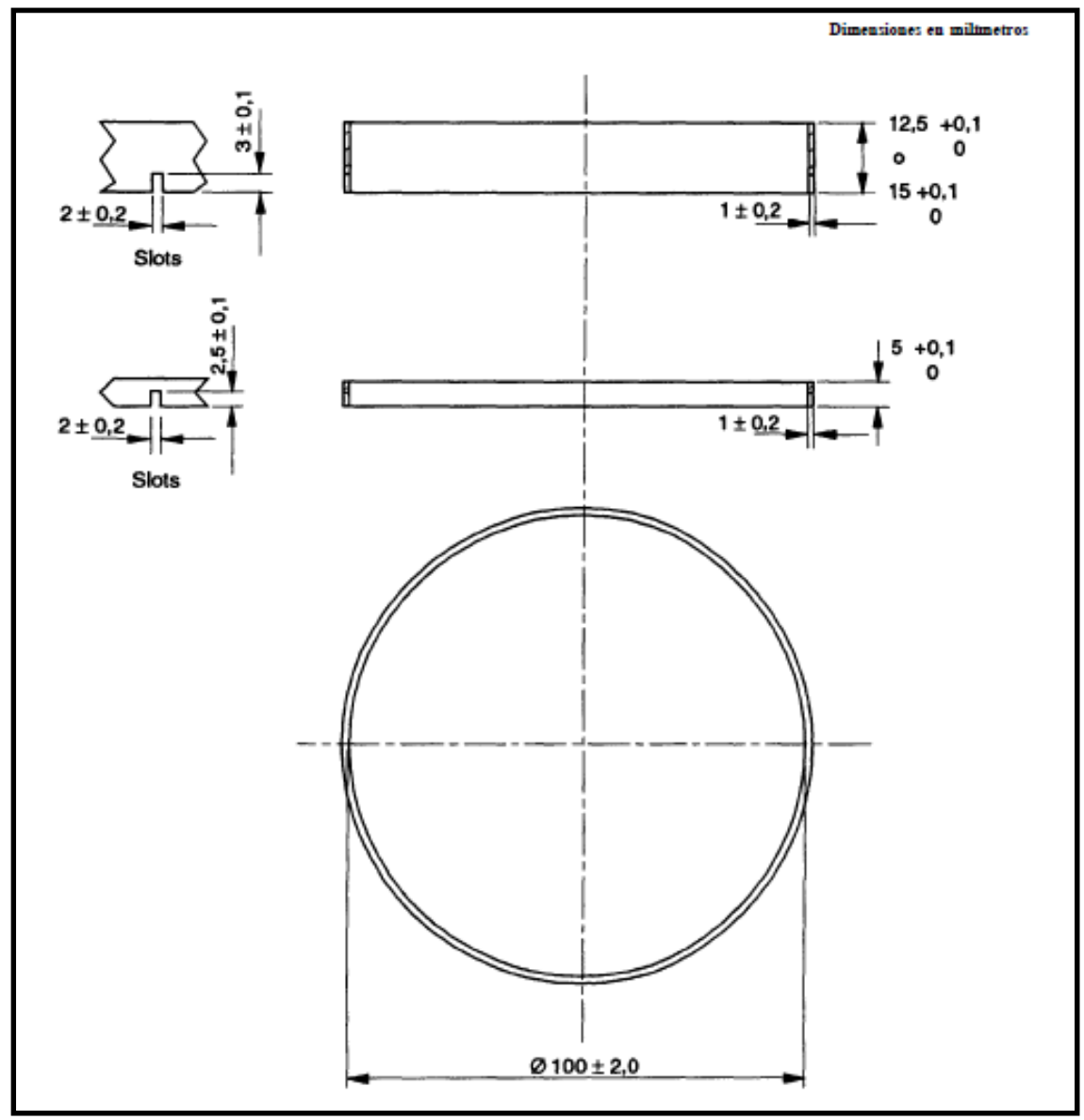

Figure 29. Ring used for minimum ignition temperature on layer [98]

Once the layer is formed, it is consider that ignition occurs if:

- Incandescence or visible flame is shown.

- $450^{\circ} \mathrm{C}$ are reached.

- A $250 \mathrm{~K}$ elevation of the plate temperature is measured.

Test has to be developed for 30 minutes before saying that no ignition appears. Tests have to be carried until a minimum ignition temperature is determined. It is the lowest temperature at which ignition occurs, round to a multiple of $10^{\circ} \mathrm{C}$.

The highest temperature at which ignition does not occur with a difference of $10^{\circ} \mathrm{C}$ with the minimum ignition temperature has to be recorded, and it has to be checked three times. 
This test establishes a standard thickness of the dust layer of $5 \mathrm{~mm}$. But in an industrial facility, the thickness of dust layers is not going to be limited to this value, and different parameters are going to vary the minimum temperature at which a layer may ignite.

A first correlation between the maximum admissible surface temperature and the thickness of a dust layer deposited on this surface depending on the minimum ignition temperature on a layer of 5 millimetres is shown in Standard EN 60079-14 [99] (Figure 30). However, these correlations are done according to different groups, and the values shown are approximations of the real values, which should be determined for each single case. Trying to see this differences, tests have been carried out for dust layers with thickness of 50 millimetres. The procedure previously described for a 5 millimetres layer has been adapted by increasing the time that has to be waited until determining that no ignition occurs to 8 hours. Furthermore, two different compactions have been studied. In the case of no compacted sample, the layer is formed by adding the sample to the ring without tapping or pressing. In the second case, compaction has been performed with a $2.2 \mathrm{~kg}$ round weight, which had the same diameter as the ring. The ring was previously filled of dust and then compacted with the weight.

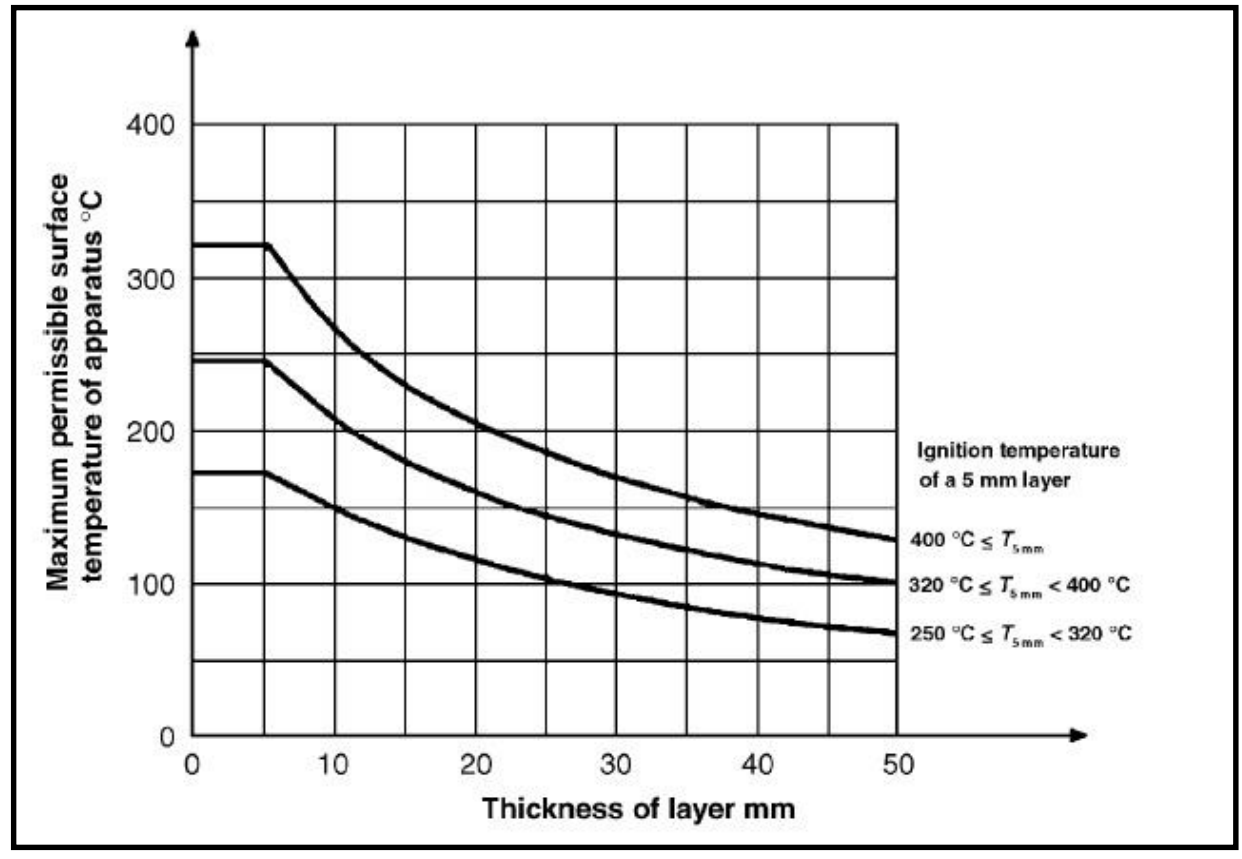

Figure 30. Correlation between maximum admissible surface temperature and thickness of the dust layer [99] 


\subsubsection{Minimum ignition temperature on a cloud}

The minimum ignition temperature on a cloud is determined through the furnace shown in Figure 31, following the procedure described in Standard EN 50281-2-1 [98]. In this furnace a silicon tube is placed vertically with its bottom open to the air. Its top is connected to the dust bowl through a glass adapter. Dust is dispersed in the oven through solenoid valve that releases compressed air.

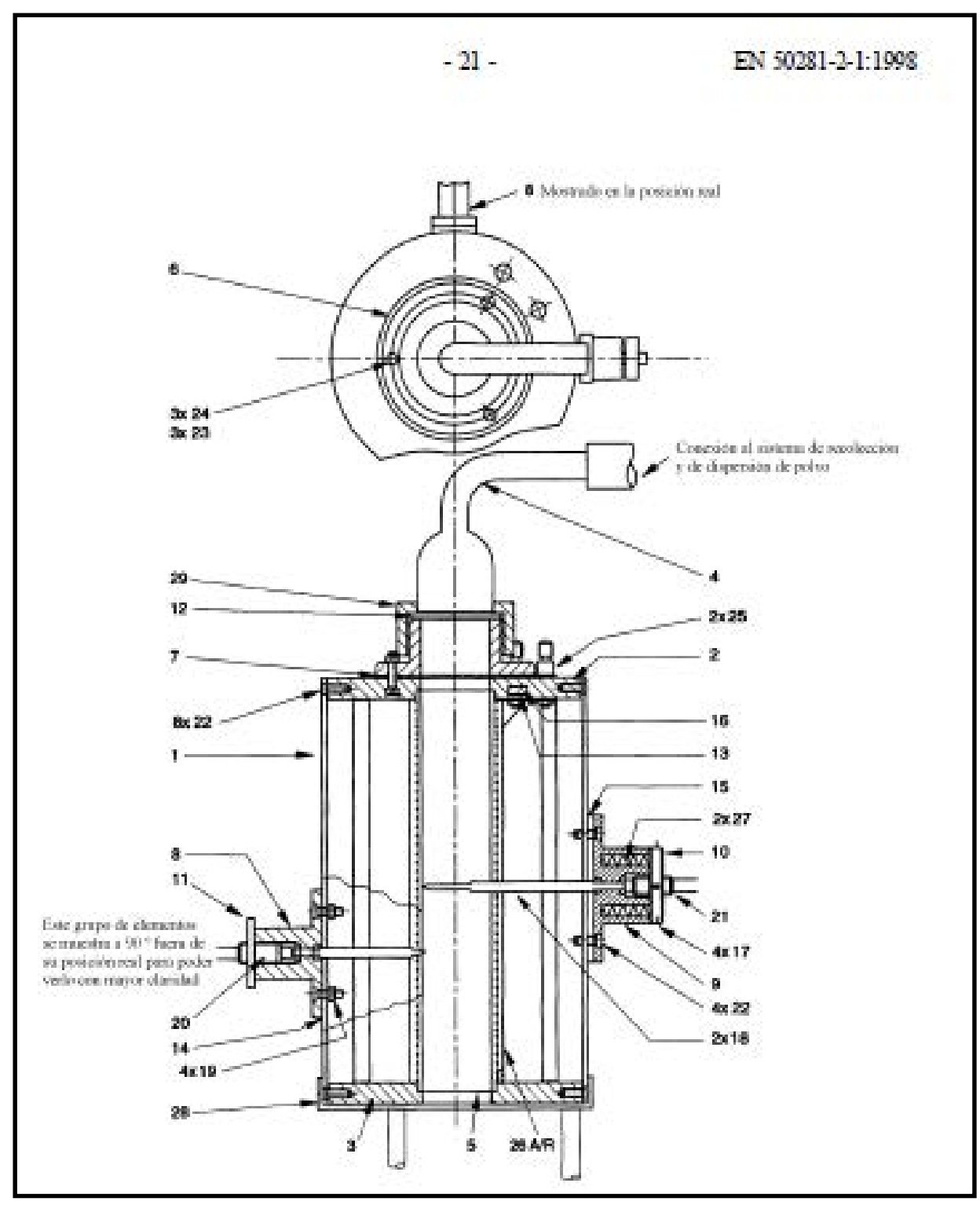

Figure 31. Furnace for minimum ignition temperature on cloud [98]

0.1 grams of dust are placed on the dust bowl and the equipment temperature is adjusted to $500^{\circ} \mathrm{C}$ and air overpressure of $0.1 \mathrm{bar}$. Dust is dispersed. If no ignition occurs, the test has to be done again increasing the temperature of the equipment $50 \mathrm{~K}$ until ignition or until $1000{ }^{\circ} \mathrm{C}$. 
Once ignition appears, dust mass and air pressure have to be varied until the most vigorous explosion is observed. With the same mass and pressure, temperature has to be reduced 20 $\mathrm{K}$ until a temperature where no ignition occurs in 10 times.

Ignition occurs when a visual flame is observed at the bottom of the silicon tube. Sparks without flame is not ignition.

The minimum ignition temperature of a cloud is the minor temperature of the equipment at which ignition occurred, deducting $20 \mathrm{~K}$ for equipment temperatures of more than $300{ }^{\circ} \mathrm{C}$, or deducting $10 \mathrm{~K}$ for equipment temperatures of less or equal to $300{ }^{\circ} \mathrm{C}$.

\subsubsection{Lower explosive limit}

Lower explosive limit is determined with the 20 litres sphere (Figure 32), according to EN 14034-3 [100]. It is defined as the lowest concentration of dust at which the air-dust mixture is explosive.

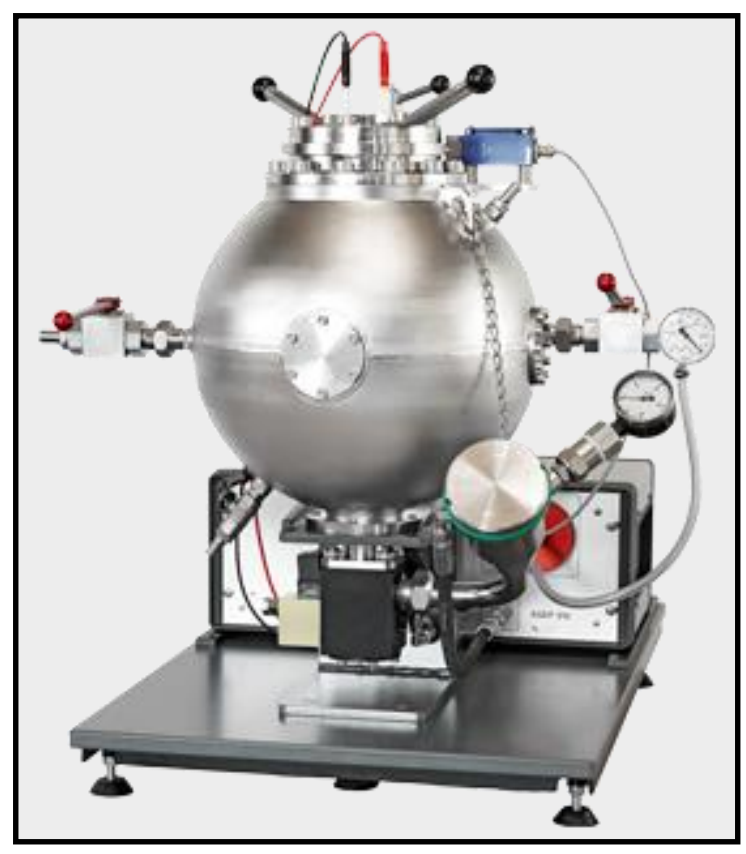

Figure 32. 20 litres sphere [101]

The sample is placed on the dust pot and this pot is pressurized to 20 bars. The 20 litres sphere has to be at ambient pressure. The ignition delay is $(0.6 \pm 0.01) \mathrm{s}$. Pressure is recorded versus time. Explosion pressure $\left(\mathrm{p}_{\mathrm{ex}}\right)$ is the arithmetic mean of the values measured by the pressure sensors. 
This procedure has to be repeated for a dust concentrations interval, from $500 \mathrm{~g} / \mathrm{m}^{3}$ it is decreased with a decrease of $50 \%$. If the concentration has to be increased, it will be done with an increment of $500 \mathrm{~g} / \mathrm{m}^{3}$. The first concentration at which no explosion occurs is the lower explosive limit.

\subsubsection{Minimum ignition energy}

Minimum ignition energy is defined as the minimum amount of energy required to ignite a dust cloud [102]. It is determined following the procedure detailed on Standard EN 13821 [103].

This procedure is done by using a Mike 4.3 apparatus [104] (Figure 33). The apparatus consisted of a vertical cylindrical glass tube with an inner diameter of $68 \mathrm{~mm}$ and a height of $300 \mathrm{~mm}$ giving a volume of $1.2 \mathrm{~L}$. The opposing ignition electrodes (6mm gap) were located half way up the tube. The tube was connected at its base to a $50 \mathrm{ml}$ air reservoir pressurised to 7 bar.

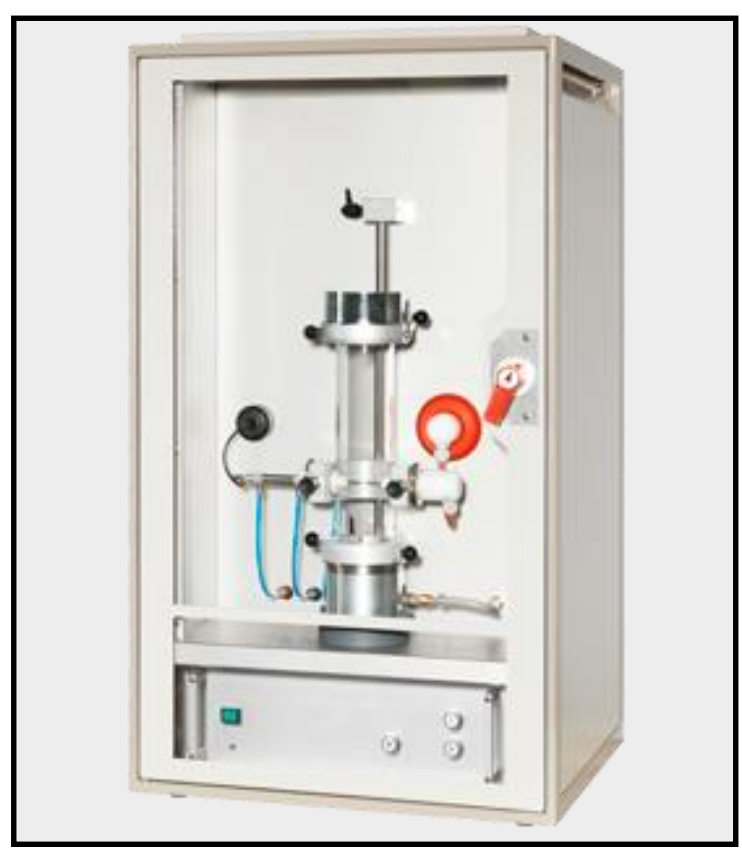

Figure 33. Mike 4.3 apparatus [101]

For each test a known mass of powder was placed in the dispersion cup and the powdered was dispersed into the tube by releasing opening the pressurised air reservoir. The spark was automatically activated with an ignition delay of $120 \mathrm{~ms}$, to allow time for dispersion within the tube. The spark energy could be changed taking values of 1000, 300, 100, 30, 10, 3 and 1 $\mathrm{mJ}$. A visual verification of a propagating flame in the glass tube was required for an 
explosion to have occurred, in accordance with Standard EN 13821. A total of 10 consecutive non-ignitions were required for a given test condition to be considered nonignitable. The MIE was estimated using the probability of ignition as stated below [103].

$$
\log M I E=\log E_{2}-I\left[E_{2}\right] \cdot \frac{\left(\log E_{2}-\log E_{1}\right)}{(N I+I)\left[E_{2}\right]+1}
$$

Where I[E2] was the number of tests with successful ignition at E2 and $(\mathrm{NI}+\mathrm{I})[\mathrm{E} 2]$ stands for the total number of tests at the energy level of E2, and E1 is the highest energy at which no ignition occurs.

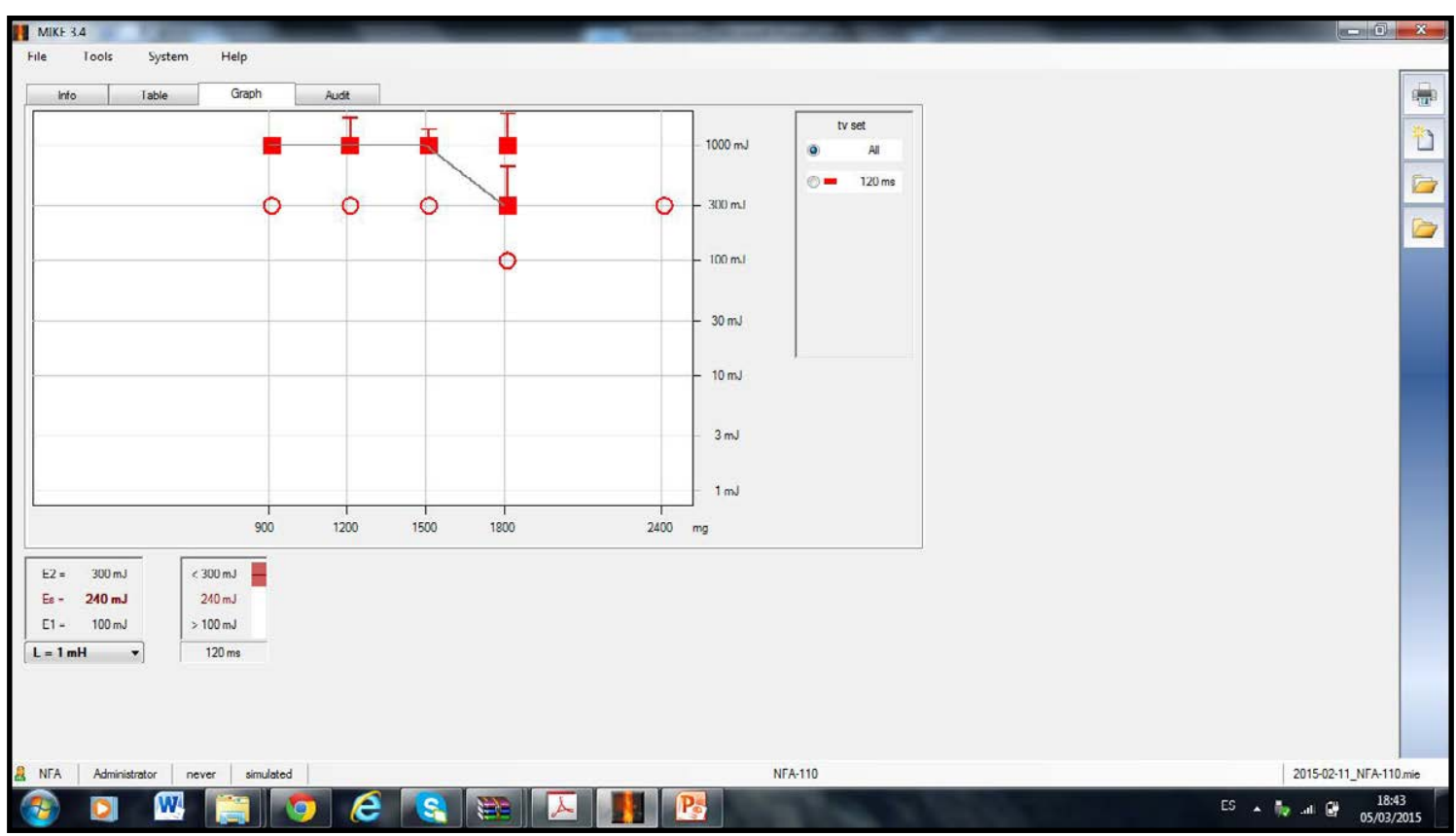

Figure 34. Caption of Mike 4.3 software

\subsubsection{EXPLOSION SEVERITY}

The three parameters of this group are measured with the 20 litre sphere.

\subsubsection{Maximum pressure}

Maximum pressure is determined according to the standard EN 14034-1 [105]. Determination of explosion characteristics of dust clouds. Determination of the maximum explosion pressure $\mathrm{p}_{\max }$ of dust clouds.

The sample is placed on the dust pot and this pot is pressurized to 20 bars. The 20 litres sphere has to be at ambient pressure. The ignition delay is $(0.6 \pm 0.01)$ s. Pressure is recorded 
versus time. Explosion pressure $\left(\mathrm{p}_{\mathrm{ex}}\right)$ is the arithmetic mean of the values measured by the pressure sensors.

This procedure has to be repeated for a dust concentrations interval, from $250 \mathrm{~g} / \mathrm{m}^{3}$ it is increased with an increment of $250 \mathrm{~g} / \mathrm{m}^{3}$, o decreased with a decrease of $50 \%$.

Explosion pressure is determined for all these concentrations, and they are plotted versus concentrations. The maximum value of these explosions pressures is the maximum pressure.

\subsubsection{Rate of explosion pressure rise}

Rate of explosion pressure rise is determined according to the standard EN 14034-2 [106]. Determination of explosion characteristics of dust clouds. Determination of explosion pressure rise $(\mathrm{dp} / \mathrm{dt})_{\max }$ of dust clouds.

The rate of explosion pressure rise is defined as the maximum value of pressure rise per unit of time during explosions in hazardous atmospheres.

The test procedure is exactly the same as the one used to determine the maximum pressure. Once the overpressure of the explosion is plotted versus time, the rate of explosion pressure rise is determined as the slope of the curve that goes from atmospheric pressure (zero overpressure) to the maximum pressure, as shown in the Figure 35, where $\mathrm{Y} 1$ is the overpressure, $\mathrm{Y} 2$ the rate of explosion pressure rise, $\mathrm{X} 1$ time, and $\mathrm{X} 2$ the dust concentration.
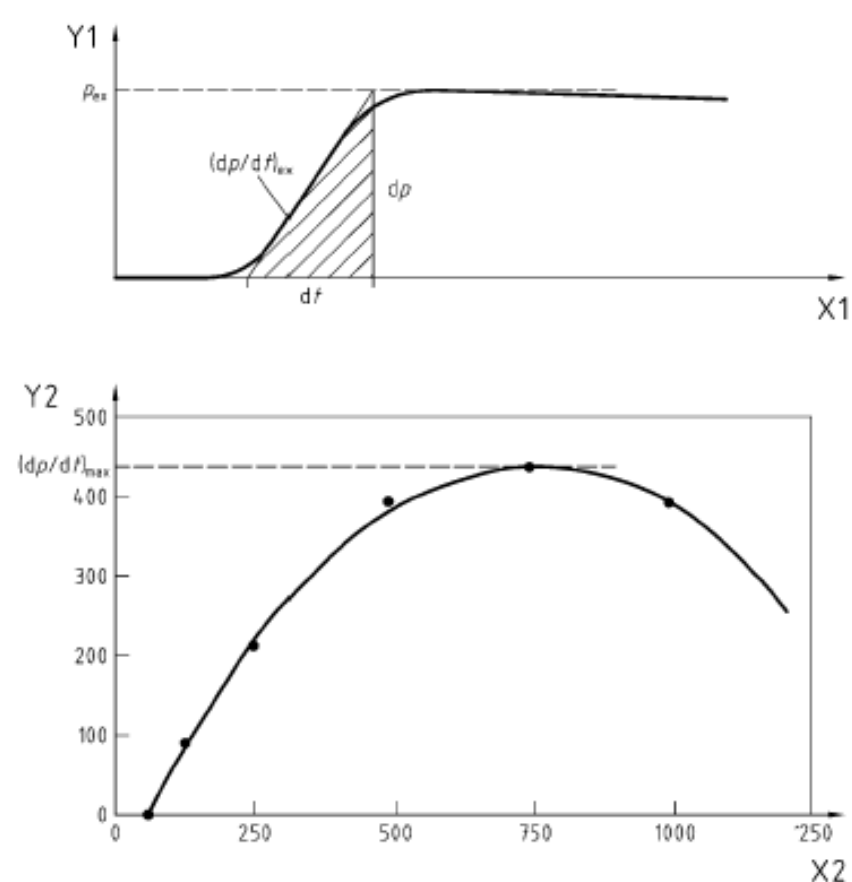

Figure 35. Determination of rate of explosion pressure rise 


\subsubsection{Standard constant}

According to EN 14034-2 [106], the standard constant is a specific characteristics of the dust that is independent of the volume and is determined by the cubic law equation.

$$
(d p / d t)_{\max } \cdot V^{1 / 3}=k_{s t}=k_{\max }
$$

Where $(d p / d t)_{\max }$ is the rate of explosion pressure rise (bar/s)

$$
\begin{aligned}
& \mathrm{V} \text { the volume }\left(\mathrm{m}^{3}\right) \\
& \mathrm{k}_{\max }, \mathrm{k}_{\mathrm{st}} \text { the standard constant }(\mathrm{bar} \cdot \mathrm{m} / \mathrm{s})
\end{aligned}
$$

\subsubsection{Limiting oxygen concentration}

Limiting oxygen concentration is determined according to the standard EN 14034-4 [107].

By increasing the inert gas/air ratio, and varying the dust concentration, the oxygen concentration has to be reduced until the level at which no explosion occurs. This concentration is the limiting oxygen concentration (LOC).

The procedure starts by filling the 20 litres sphere with the inert gas/air mixture, verifying that the oxygen concentration is the one wanted.

The sample is placed on the dust pot and this pot is pressurized to 20 bars. The 20 litres sphere has to be at ambient pressure. The ignition delay is $(0.6 \pm 0.01) \mathrm{s}$. Pressure is recorded versus time. If explosion occurs, the oxygen concentration has to be reduced by $1 \%$.

\subsubsection{SELF-IGNITION}

According to EN 15188 [83], the self-ignition temperature is the maximum temperature at which no ignition of a predetermined volume of dust happens.

This parameter has been determined for four different volumes. To achieve this goal, four cylindrical baskets have been used, of 1500, 350, 150 and $50 \mathrm{~cm}^{3}$, as shown in Figure 36. 


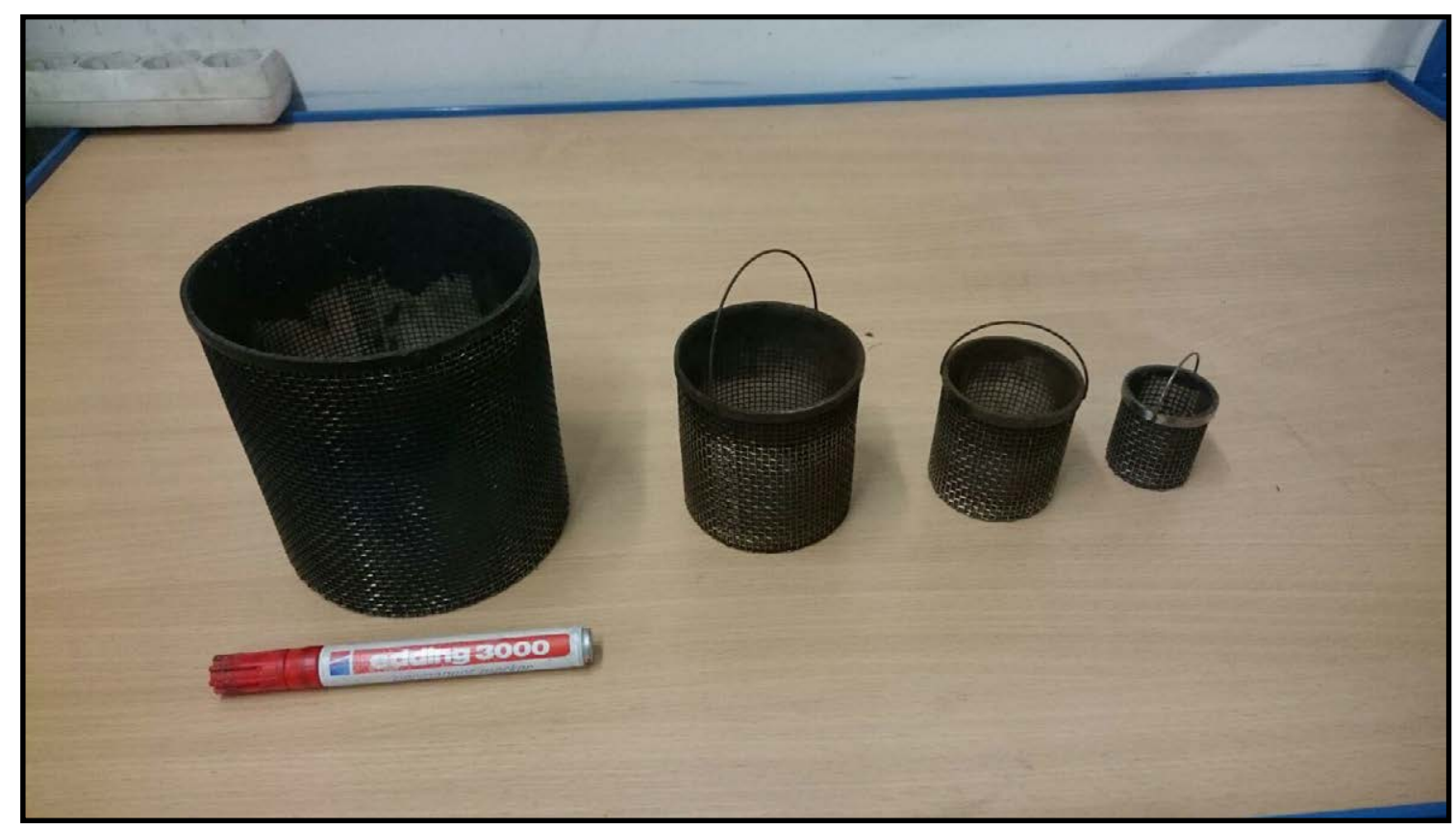

Figure 36. Baskets used for SIT determination

To determine this parameter, the basket is filled with the sample, and one K-type thermocouple is place in the middle of this sample. Two other thermocouples are place in the oven to measure its temperature. The sample is placed inside the oven, and the temperature of the three thermocouples are measured and registered versus time.

Ideally, three different situations may occur, as shown in Figure 37. Normally, a process between two of these situations occur.

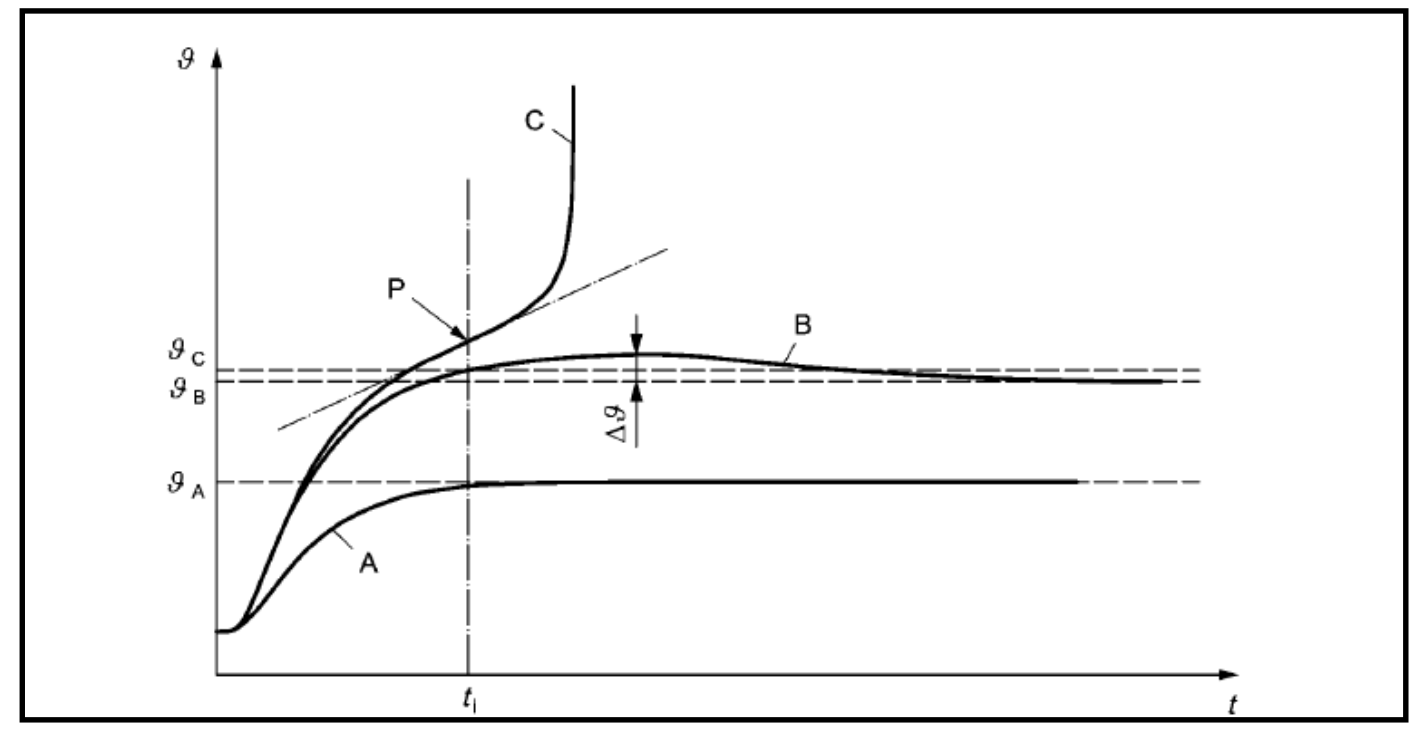

Figure 37. Idealized curves of temperature change [83] 
It is said that ignition occurs if the temperature of the sample exceeds on $60 \mathrm{~K}$ the temperature of the oven. The self-ignition temperature is a phenomenon located between curves B and C.

Additionally, the United Nations establishes a classification for the transport of dangerous materials. It divides these materials in 9 classes, being Class 4 the one that includes the flammable solids, materials that can self-ignite and substances that can emit flammable gases if they contact the water. This class is also divided in 3 subclasses. Class 4.2 includes the material that can self-ignite and it describes the tests needed in order to classify these substances for their transport. This procedure consists on heating different volume baskets in an oven, with different temperatures, as explained in the schedule of Figure 38.

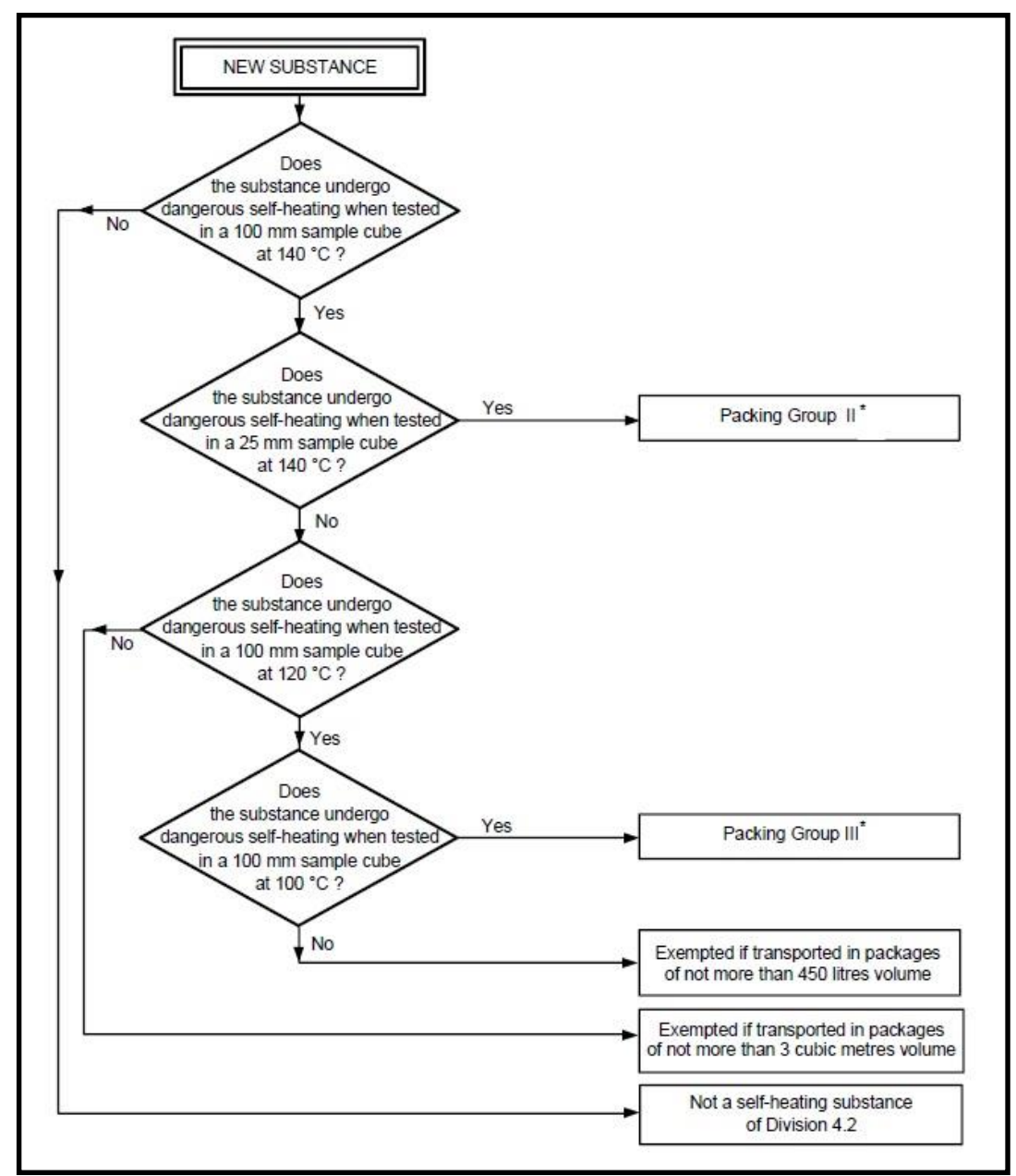

Figure 38. Classification of substances with self-ignition risk [108] 


\subsubsection{THERMOGRAVIMETRY AND DIFFERENTIAL SCANNING CALORIMETRY}

Thermogravimetric (TG) and differential scanning calorimetric (DSC) analyses had been alredy used to assess the risk of self-ignition of different types of coal and biomass materials. TG and DSC analyses had been developed with a Mettler Toledo TG 50.

In TG, the weight of the samples is measured as a function of its temperature. The procedure was developed from $30{ }^{\circ} \mathrm{C}$ to $800{ }^{\circ} \mathrm{C}$ with a heating rate of $5 \mathrm{~K} / \mathrm{min}$. The data obtained is plotted as a weight loss vs temperature graph, and two main parameters are obtained by studying these graphs: initial temperature and maximum loss of weight temperature.

DSC is used to study the heat exchange of the sample during a heating process. The test was developed from $30^{\circ} \mathrm{C}$ to $550{ }^{\circ} \mathrm{C}$, under a heating rate of $20 \mathrm{~K} / \mathrm{min}$. In this case, the obtained graph is a heat flow vs temperature graph in which the different steps of the combustion process can be observed, and three main parameters are obtained: the temperatures at which the exothermic reaction starts and finishes and the temperature of change of slope, at which the slow exothermic reaction starts to accelerate and become a rapid reaction.

\subsubsection{GAS EMISSIONS}

The equipment used to carry out the gas emissions experiments is detailed below (Figure 39):

- $10 \mathrm{~L}$ sealed cylindrical container.

- Isothermal oven P-Selecta.

- $\quad$ Type $\mathrm{K}$ thermocouple.

- Digital temperature display Testo 925.

- 1 L Tedlar sampling bags Sigma-Aldrich.

- Gas analyser Rosemount Analytical NGA-2000. 


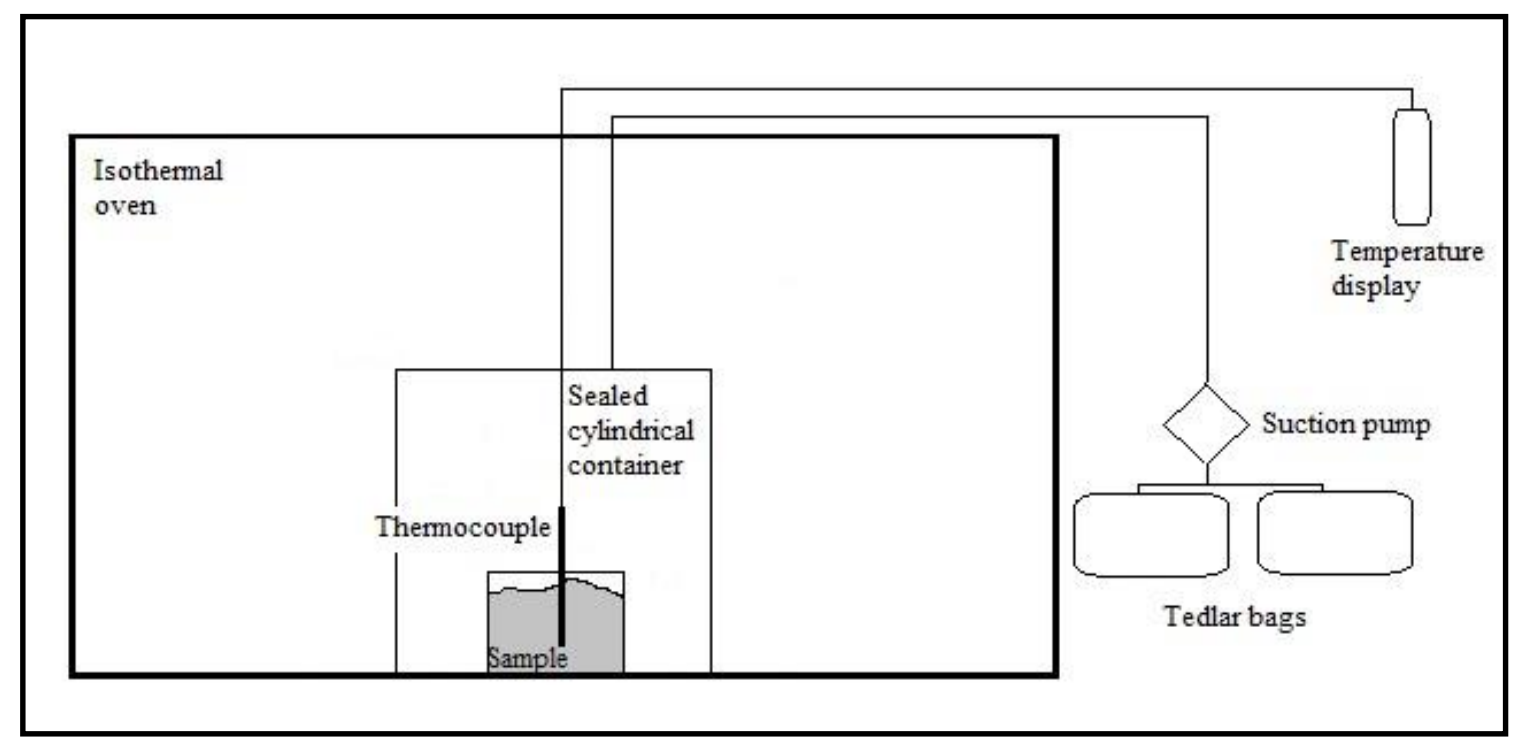

Figure 39. Gas emissions test equipment

The sample is introduced inside a $1000 \mathrm{~cm}^{3}$ cubical wired basket according to different arrangements (compacted and non-compacted) and this basket is introduced inside the sealed container. The container is closed and connected with the temperature display through a K-thermocouple that is placed inside the sample, approximately at its centre. Before introducing the container, the oven is preheated at the tested temperature.

The sealed container is situated inside the oven to carry out the sample heating. The container has a narrow fitting $3 \mathrm{~mm}$ diameter on top where it connects to a plastic tube closed with a Mohr wrench.

Once the desired temperature inside the sample is reached, the plastic tube is connected with the sampling bags by opening the Mohr wrench and they are filled with the gas driven by a suction pump. Due to the small volume of the samples tested, temperature quickly stabilizes and it is considered constant during the sampling time. When the bags are full, they are disconnected from the plastic tub and connected to the analysers. Gases emitted during combustion are measured, starting at the connection between bag and analyser, until gas emission is zero.

The gas analyser Rosemount Analytical NGA-2000 measured emission data of CO and $\mathrm{CO}_{2}$. Also some $\mathrm{H}_{2} \mathrm{O}$ has been observed to condensate inside the tube, but it is not measured because it is not significant for the present research.

The detection limit of the analyser has been determined. It is defined as the lowest quantity of a substance that can be distinguished from the absence of that substance within a stated confidence limit, and calculated: $\mathrm{LOD}=3.3 \cdot \sigma_{\mathrm{D}}$, where $\sigma_{\mathrm{D}}$ is the standard deviation of the 
"blank" measurements. To determine it, 30 measures have been done with the analyser without sample, and the standard deviation of these measures has been determined. The detection limit for $\mathrm{CO}$ is $10.58 \mathrm{ppm}$, and for $\mathrm{CO}_{2}$ is $0.18 \% \mathrm{vol}$.

To determine the point at which emissions started, three different procedures have been tested.

In the first one, the relative percentage of emissions have been determined for each $20 \mathrm{~K}-$ interval. These relative percentages have been calculated according to the following procedure.

First of all, relative differences (RD) for each $20 \mathrm{~K}$ - interval have been calculated as shown in Equation 1.

$$
\mathrm{RD}=\frac{e_{T 2}-e_{T 1}}{e_{T 1}}
$$

Where $\mathrm{e}_{\mathrm{T} 1}$ means the emissions at the lowest temperature of the interval and $\mathrm{e}_{\mathrm{T} 2}$ are the emissions at the highest temperature of the interval.

After that, relative percentages (RP) are determined by Equation 2 as the division between the relative difference of the interval and the sum of all the relative differences of the experiment, multiplied by 100 .

$$
\mathrm{RP}=\frac{R D}{\sum R D_{i}} \cdot 100
$$

The second procedure consists on determining the inflexion point of a third degree curve that has been previously obtained from the numerical results of the test. The inflexion point is the point in which the curve changes from a concave to a convex form, or viceversa. It can be determined by calculating the second derivate of the curve and equalling it to zero.

Finally, the third procedure is based on the environmental limits that have been stablished for this pollutants: $25 \mathrm{ppm}$ for $\mathrm{CO}$ and $0.5 \% \mathrm{vol}$ for $\mathrm{CO}_{2}$ [109]. The emissions temperature is determined as the temperature at which these limits are achieved. 


\section{RESULTS}

\subsection{SOLID FUELS}

\subsubsection{PROXIMATE ANALYSIS}

Looking at the results of proximate analyses (Annex II), different groups are observed on Figure 40. Biomasses are located on the top of the triangle diagram. They have high volatiles content and low ash and fixed carbon content.

The other well-formed group is composed by sewage sludge and plastic samples. Sewage sludge samples have very low fixed carbon content and their ash and volatile contents are similar, being a bit higher the second one. Plastic samples have low ash and fixed carbon contents and they have the highest volatiles content of all the studied samples.

On the other hand, coke and coals samples have high fixed carbon content and they are located in different places. Coke is the most developed sample, so it has the highest fixed carbon content and it is located on the left side of the diagram, almost in the edge. The two coal samples studied are located on the middle of the diagram. The highest the rank of the coal, the highest its fixed carbon content is, so it is located nearer at the bottom of the diagram.

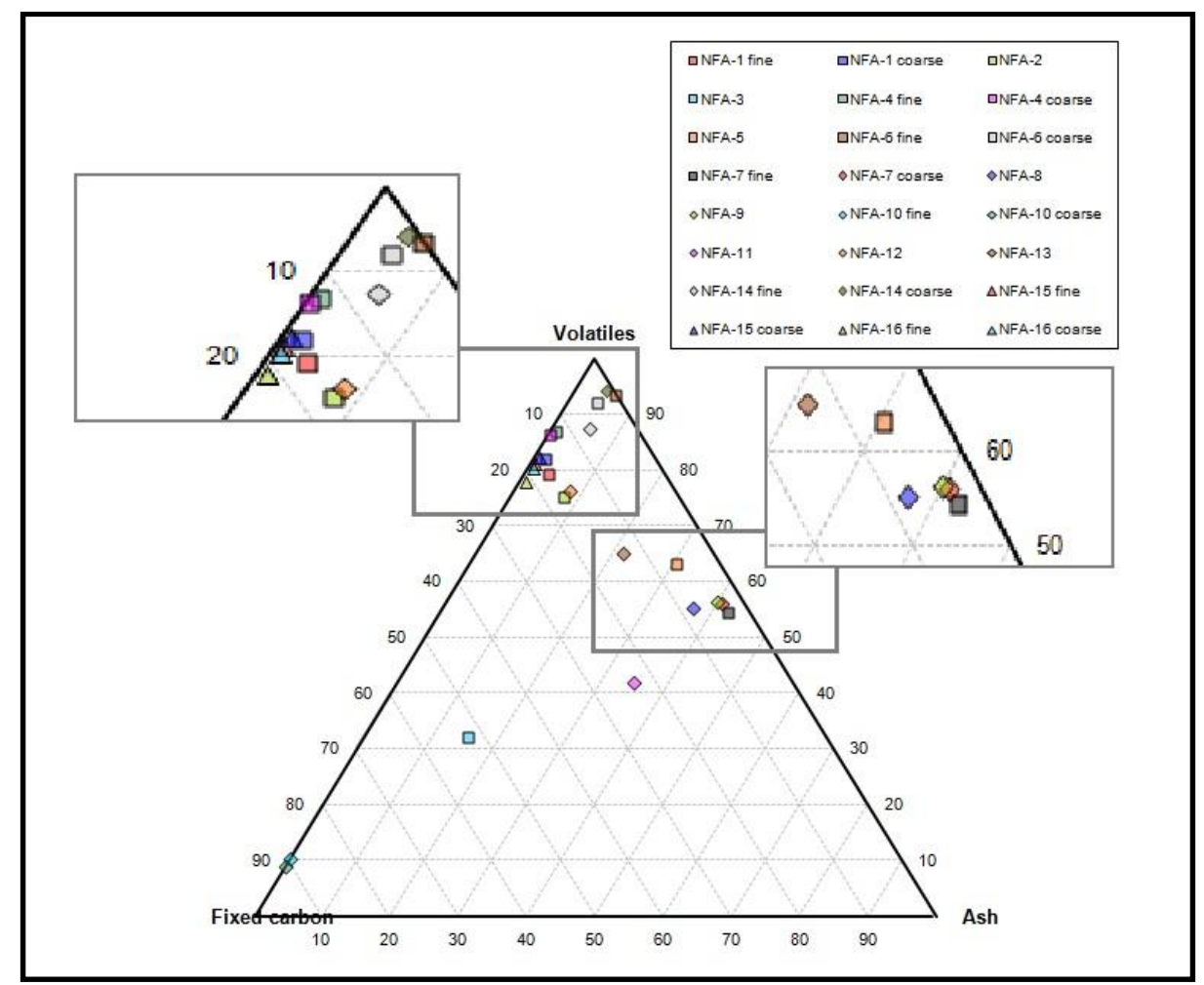

Figure 40. Triangular diagram proximate analyses biomass samples [110] 


\subsubsection{GRANULOMETRY}

The main granulometric parameters of all the studied samples are related in Table 14.

Table 14. Granulometry of solid fuels

\begin{tabular}{|c|c|c|c|}
\hline Sample & $\mathrm{d} 10(\mu \mathrm{m})$ & $\mathrm{d} 50(\mu \mathrm{m})$ & $\mathrm{d} 90(\mu \mathrm{m})$ \\
\hline NFA-1 (F) & 43.4 & 152.9 & 378.9 \\
\hline NFA-1 (C) & 1200.0 & 3000.0 & 5500.0 \\
\hline NFA-2 (C) & 180.0 & 830.0 & 1800.0 \\
\hline NFA-3 (F) & 8.2 & 45.8 & 116.1 \\
\hline NFA-4 (F) & 46.5 & 146.6 & 404.1 \\
\hline NFA-4 (C) & 400.0 & 1100.0 & 1800.0 \\
\hline NFA-5 (F) & 290.5 & 638.2 & 1209.7 \\
\hline NFA-6 (F) & 2000.0 & 4000.0 & 7500.0 \\
\hline NFA-6 (C) & 2800.0 & 9000.0 & 10200.0 \\
\hline NFA-7 (F) & 24.5 & 98.1 & 204.3 \\
\hline NFA-7 (C) & 1000.0 & 1500.0 & 2000.0 \\
\hline NFA-8 (F) & 29.6 & 92.0 & 193.7 \\
\hline NFA-9 (F) & 17.7 & 94.7 & 205.3 \\
\hline NFA-10 (F) & 8.8 & 77.4 & 194.9 \\
\hline NFA-10 (C) & 500.0 & 1200.0 & 3600.0 \\
\hline NFA-11 (F) & 4.4 & 26.8 & 68.2 \\
\hline NFA-12 (F) & 43.7 & 171.2 & 474.5 \\
\hline NFA-13 (F) & 14.8 & 44.3 & 143.0 \\
\hline NFA-14 (F) & 850.0 & 2700.0 & 6500.0 \\
\hline NFA-14 (C) & 3500.0 & 10000.0 & 10900.0 \\
\hline NFA-15 (F) & 20.5 & 68.2 & 196.7 \\
\hline NFA-15 (C) & 800.0 & 1300.0 & 1800.0 \\
\hline NFA-16 (F) & 22.3 & 104.0 & 326.9 \\
\hline NFA-16 (C) & 2300.0 & 3500.0 & 6400.0 \\
\hline
\end{tabular}

Additionally, for the samples with fine particle size three more granulometric parameters were obtained, as shown in Table 15. 
Table 15. Granulometric parameters fine samples solid fuels

\begin{tabular}{|c|c|c|c|}
\hline Sample & $\begin{array}{c}\text { Specific surface area } \\
\left(\mathrm{m}^{2} / \mathrm{g}\right)\end{array}$ & $\begin{array}{c}\text { Surface weighted } \\
\text { mean d }[3,2](\mu \mathrm{m})\end{array}$ & $\begin{array}{c}\text { Vol. Weighted mean } \\
\mathrm{d}[4,3](\mu \mathrm{m})\end{array}$ \\
\hline NFA-1 $(\mathrm{F})$ & 0.069 & 87.5 & 210.5 \\
\hline NFA-3 (F) & 0.307 & 19.5 & 55.3 \\
\hline NFA-4 (F) & 0.065 & 92.9 & 207.1 \\
\hline NFA-5 (F) & 0.012 & 490.3 & 699.6 \\
\hline NFA-7 (F) & 0.125 & 47.8 & 107.5 \\
\hline NFA-8 (F) & 0.119 & 50.3 & 104.2 \\
\hline NFA-9 (F) & 0.179 & 33.5 & 30.6 \\
\hline NFA-10 (F) & 0.258 & 23.2 & 230.3 \\
\hline NFA-11 (F) & 0.620 & 9.7 & 75.3 \\
\hline NFA-12 (F) & 0.076 & 78.5 & 90.7 \\
\hline NFA-13 (F) & 0.227 & 26.5 & 154.8 \\
\hline NFA-15 (F) & 0.155 & 36.7 & \\
\hline NFA-16 (F) & 0.130 & 46.0 & 32.1 \\
\hline
\end{tabular}

\subsubsection{THERMAL CONDUCTIVITY}

Thermal diffusivity of the samples varies between compacted and no-compacted samples. Almost in all the studied samples, thermal diffusivity is higher when the sample is nocompacted than when it is compacted.

Thermal conductivity also varies with compaction. It depends on the thermal diffusivity and on the density of the samples (specific heat does not vary). Thermal conductivity of different samples of the same group (biomass, coal, sewage sludge) varies in different way.

All results are shown in Table 16. 
Table 16. Thermal conductivity of solid fuels

\begin{tabular}{|c|c|c|c|c|c|c|c|}
\hline \multirow{2}{*}{ Sample } & \multirow{2}{*}{$\begin{array}{c}\text { Specific } \\
\text { heat } \\
(\mathrm{J} / \mathrm{kg} \cdot \mathrm{K})\end{array}$} & \multicolumn{2}{|c|}{$\begin{array}{l}\text { Thermal diffusivity } \\
\qquad\left(10^{-7} \mathrm{~m}^{2} / \mathrm{s}\right)\end{array}$} & \multicolumn{2}{|c|}{ Density (g/L) } & \multicolumn{2}{|c|}{$\begin{array}{l}\text { Thermal conductivity } \\
(\mathrm{W} / \mathrm{m} \cdot \mathrm{K})\end{array}$} \\
\hline & & $\begin{array}{c}\text { no } \\
\text { compacted }\end{array}$ & compacted & $\begin{array}{c}\text { no } \\
\text { compacted }\end{array}$ & compacted & $\begin{array}{c}\text { no } \\
\text { compacted }\end{array}$ & compacted \\
\hline NFA-1 (F) & 1524.6 & 2.26 & 2.26 & $670.00\left(^{*}\right)$ & $670.00\left(^{*}\right)$ & $0.231\left(^{*}\right)$ & $0.231\left(^{*}\right)$ \\
\hline NFA-1 (C) & 1524.6 & 2.26 & 2.26 & $670.00\left(^{*}\right)$ & $670.00\left(^{*}\right)$ & $0.231\left(^{*}\right)$ & $0.231\left(^{*}\right)$ \\
\hline NFA-2 (C) & 1952 & 8.59 & 8.59 & 200.00 & 260.00 & 0.335 & 0.436 \\
\hline NFA-3 (F) & 834.45 & 1.49 & 1.21 & 543.27 & 667.47 & 0.068 & 0.067 \\
\hline NFA-4 (F) & 1692.61 & 2.93 & 3.13 & 205.67 & 289.4 & 0.102 & 0.153 \\
\hline NFA-4 (C) & 1692.61 & 2.75 & 3.55 & 199.67 & 260.55 & 0.093 & 0.157 \\
\hline NFA-5 (F) & 1800.4 & 1.59 & 1.53 & 470.67 & 492.35 & 0.135 & 0.136 \\
\hline NFA-6 (F) & 1964.1 & 12.0 & 4.10 & 38.67 & 111.97 & 0.091 & 0.09 \\
\hline NFA-6 (C) & 1964.1 & 41.7 & 9.66 & 33.00 & 61.6 & 0.27 & 0.117 \\
\hline NFA-7 (F) & 1597.1 & 1.38 & 1.10 & 631.33 & 722.07 & 0.139 & 0.127 \\
\hline NFA-7 (C) & 1597.1 & 1.23 & 1.15 & 731.23 & 774.58 & 0.144 & 0.142 \\
\hline NFA-8 (F) & 1203.9 & 1.40 & 1.12 & 693.93 & 725.98 & 0.117 & 0.098 \\
\hline NFA-9 (F) & 1644.6 & 1.22 & 1.01 & 654.67 & 857.78 & 0.131 & 0.142 \\
\hline NFA-10 (F) & 1057.48 & 1.69 & 1.37 & 564.27 & 640.89 & 0.101 & 0.093 \\
\hline NFA-10 (C) & 1057.48 & 1.34 & 1.38 & 642.97 & 688.76 & 0.091 & 0.101 \\
\hline NFA-11 (F) & 1091.3 & 1.58 & 1.41 & 539.33 & 665.69 & 0.093 & 0.102 \\
\hline NFA-12 (F) & 1711.1 & 2.93 & 2.89 & 202.9 & 270.66 & 0.102 & 0.134 \\
\hline NFA-13 (F) & 1995.69 & 2.22 & 1.90 & 261.57 & 337.84 & 0.116 & 0.128 \\
\hline NFA-14 (F) & 2316.8 & 8.59 & 3.91 & 58.00 & 113.63 & 0.115 & 0.103 \\
\hline NFA-14 (C) & 2316.8 & 41.7 & 4.89 & 47.00 & 87.3 & 0.454 & 0.099 \\
\hline NFA-15(F) & 1602.02 & 1.71 & 1.30 & 538.67 & 627.9 & 0.148 & 0.131 \\
\hline NFA-15 (C) & 1602.02 & 1.83 & 1.43 & 585.13 & 607.73 & 0.172 & 0.139 \\
\hline NFA-16 (F) & 1654.9 & 3.89 & 2.16 & 224.93 & 317.96 & 0.145 & 0.114 \\
\hline NFA-16 (C) & 1654.9 & 3.17 & 2.83 & 542.37 & 628.74 & 0.285 & 0.294 \\
\hline
\end{tabular}

${ }^{(*)}$ Data obtained from bibliography [111] 


\subsubsection{THERMOGRAVIMETRY}

Thermogravimetry with air and oxygen curves and the derivative curves of the first ones are shown in Figure 42, Figure 43 and Figure 44, and numeric values in Table 17.

Table 17. TG values solid fuels

\begin{tabular}{|c|c|c|c|c|c|}
\cline { 2 - 6 } \multicolumn{1}{c|}{} & \multicolumn{3}{c|}{ Thermogravimetry } & \multicolumn{2}{c|}{ Characteristics } \\
\hline Sample & MLT_1 & MLT_2 & IT & Ea & Tcharact \\
\hline NFA-1 & 306.0 & 416.7 & 255.2 & 67.3 & 316.1 \\
\hline NFA-2 & 265.1 & 408.8 & 231.0 & 65.3 & 268.4 \\
\hline NFA-3 & - & 393.8 & 374.8 & 80.6 & 271.4 \\
\hline NFA-4 & 313.3 & 438.0 & 267.4 & 66.8 & 324.3 \\
\hline NFA-5 & 277.4 & 313.3 & 242.2 & 69.3 & 272.4 \\
\hline NFA-6 & 285.4 & 430.5 & 216.7 & 69.3 & 224.1 \\
\hline NFA-7 & 252.8 & 400.7 & 227.6 & 67.1 & 251.3 \\
\hline NFA-8 & 254.8 & 394.8 & 228.3 & 67.2 & 261.5 \\
\hline NFA-9 & 247.6 & 387.8 & 216.9 & 66.3 & 234.2 \\
\hline NFA-10 & - & 416.7 & 389.1 & 83.6 & 302.1 \\
\hline NFA-11 & - & 387.8 & 282.2 & 80.6 & 250.0 \\
\hline NFA-12 & 306.5 & 408.7 & 261.9 & 69.2 & 299.2 \\
\hline NFA-13 & 275.3 & 407.3 & 206.0 & 65.2 & 277.6 \\
\hline NFA-14 & 282.8 & 437.2 & 227.3 & 67.4 & 274.3 \\
\hline NFA-15 & 283.3 & 380.1 & 235.3 & 64.4 & 268.3 \\
\hline NFA-16 & 303.9 & 410.0 & 272.7 & 68.3 & 296.7 \\
\hline
\end{tabular}

The first MLT is around $300^{\circ} \mathrm{C}$, and the second one around $400^{\circ} \mathrm{C}$. The less developed samples (sewage sludge) have lower values of MLT, so they are formed by more hemicelluloses than the other biomasses that are mainly formed by cellulose. Around $400^{\circ} \mathrm{C}$ lignin decomposition takes place. 


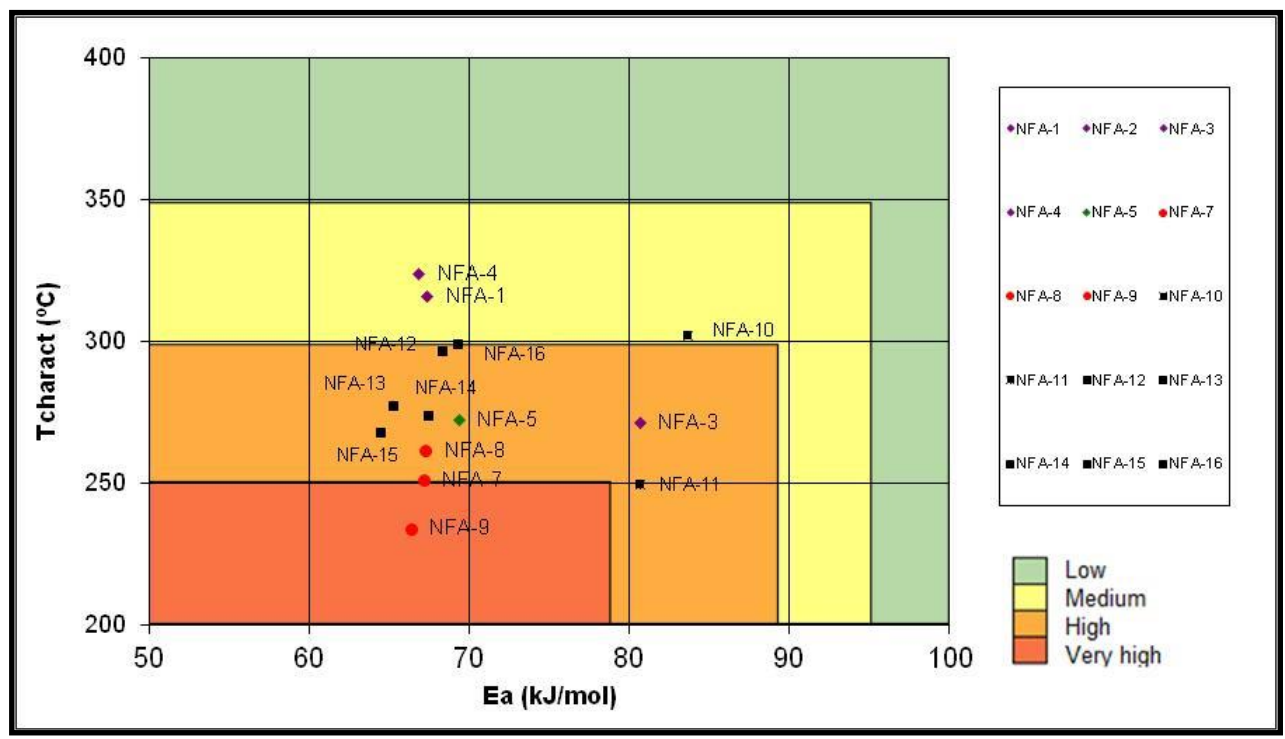

Figure 41. Thermal stability of biomass samples

Looking at the oxidation characteristic temperature, it is observed that in almost all the cases it is lower than the first MLT. Activation energy is an important parameter for coals, but not for biomasses, since only three samples that have activation energy higher than $79 \mathrm{~kJ} / \mathrm{mol}$ are coal and coke samples. In the case of biomasses, oxidation characteristic temperature is the parameter that classifies samples according to their self-ignition risk.

In the susceptibility graph (Figure 41), two biomass samples are located on the medium risk area, and those samples are wood pellets and chips. The only one sample that is located in the very high risk area is one of the sewage sludge. 


\subsubsection{DIFFERENTIAL SCANNING CALORIMETRY}

Differential scanning calorimetry curves are plotted in Figure 45, and numerical values are detailed on Table 18

Table 18. DSC parameters solid fuels

\begin{tabular}{|c|c|c|c|}
\hline Sample & IET & FET & CST \\
\hline NFA-1 & 94.2 & 313.3 & 259.2 \\
\hline NFA-2 & 105.3 & 323.3 & 237.0 \\
\hline NFA-3 & 104.1 & 303.4 & 207.4 \\
\hline NFA-4 & 83.9 & 365.3 & 273.8 \\
\hline NFA-5 & 109.8 & 355.4 & 242.8 \\
\hline NFA-6 & 76.7 & 440.7 & 233.0 \\
\hline NFA-7 & 103.6 & 287.4 & 176.2 \\
\hline NFA-8 & 107.2 & 342.7 & 197.6 \\
\hline NFA-9 & 107.1 & 300.7 & 209.5 \\
\hline NFA-10 & 72.0 & 375.3 & 275.6 \\
\hline NFA-11 & 100.0 & 296.0 & 215.3 \\
\hline NFA-12 & 93.0 & 342.7 & 247.0 \\
\hline NFA-13 & 81.3 & 321.7 & 238.8 \\
\hline NFA-14 & 83.2 & 324.0 & 211.6 \\
\hline NFA-15 & 116.7 & 422.0 & 234.3 \\
\hline NFA-16 & 90.3 & 359.0 & 263.1 \\
\hline
\end{tabular}



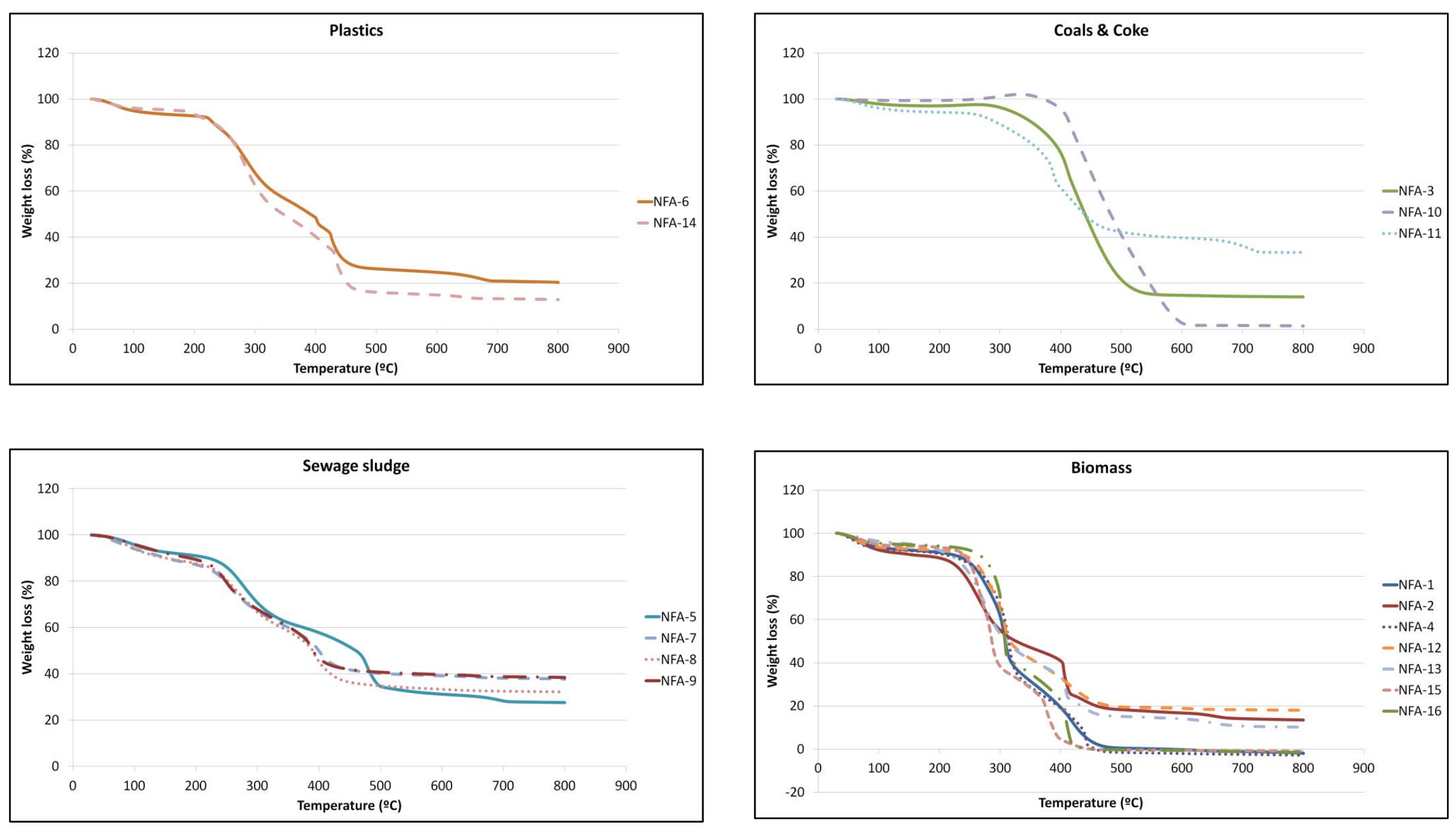

Figure 42. Thermogravimetry with air curves of solid fuels 

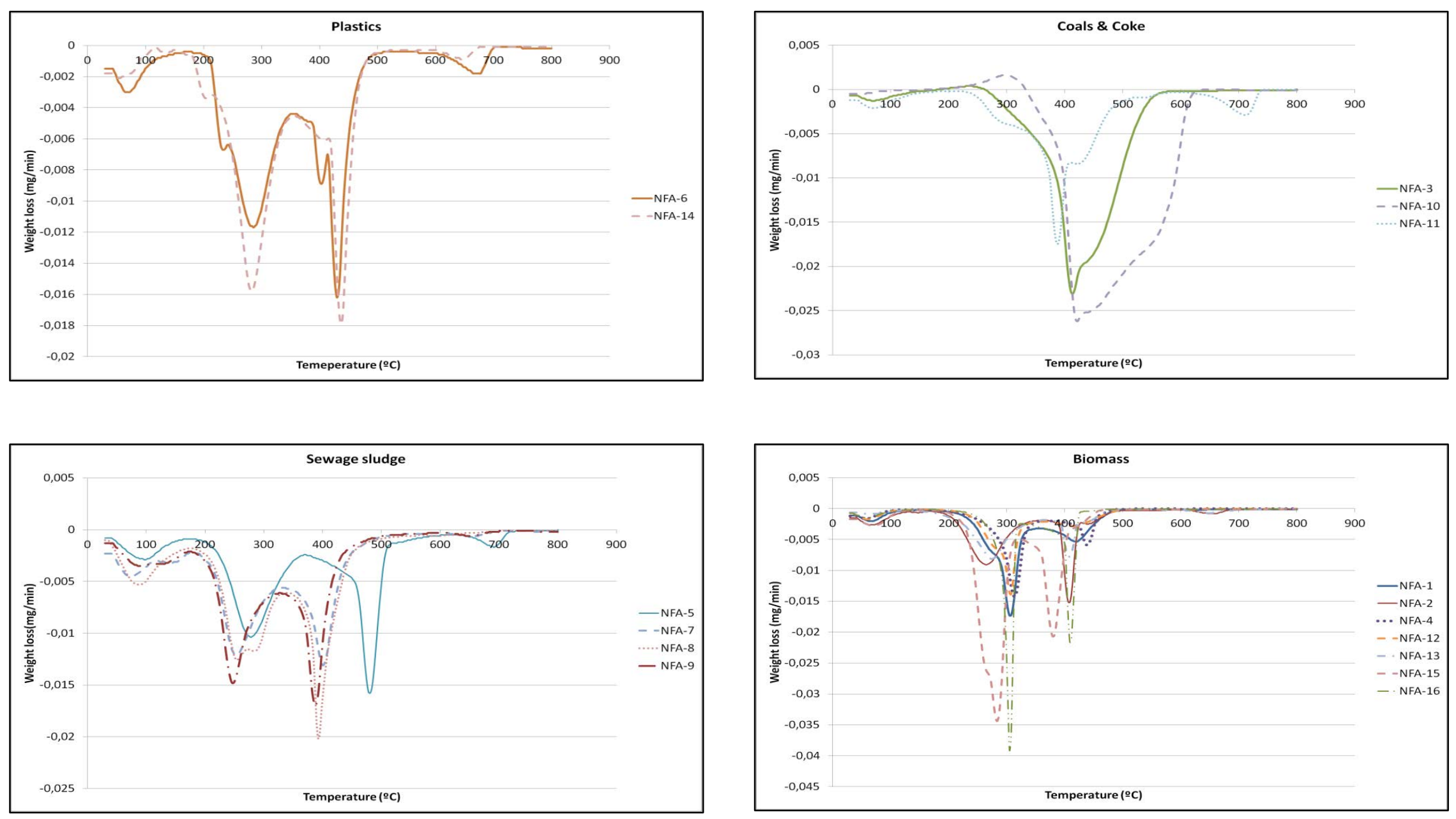

Figure 43. Derivative curves of thermogravimetry with air of solid fuels 

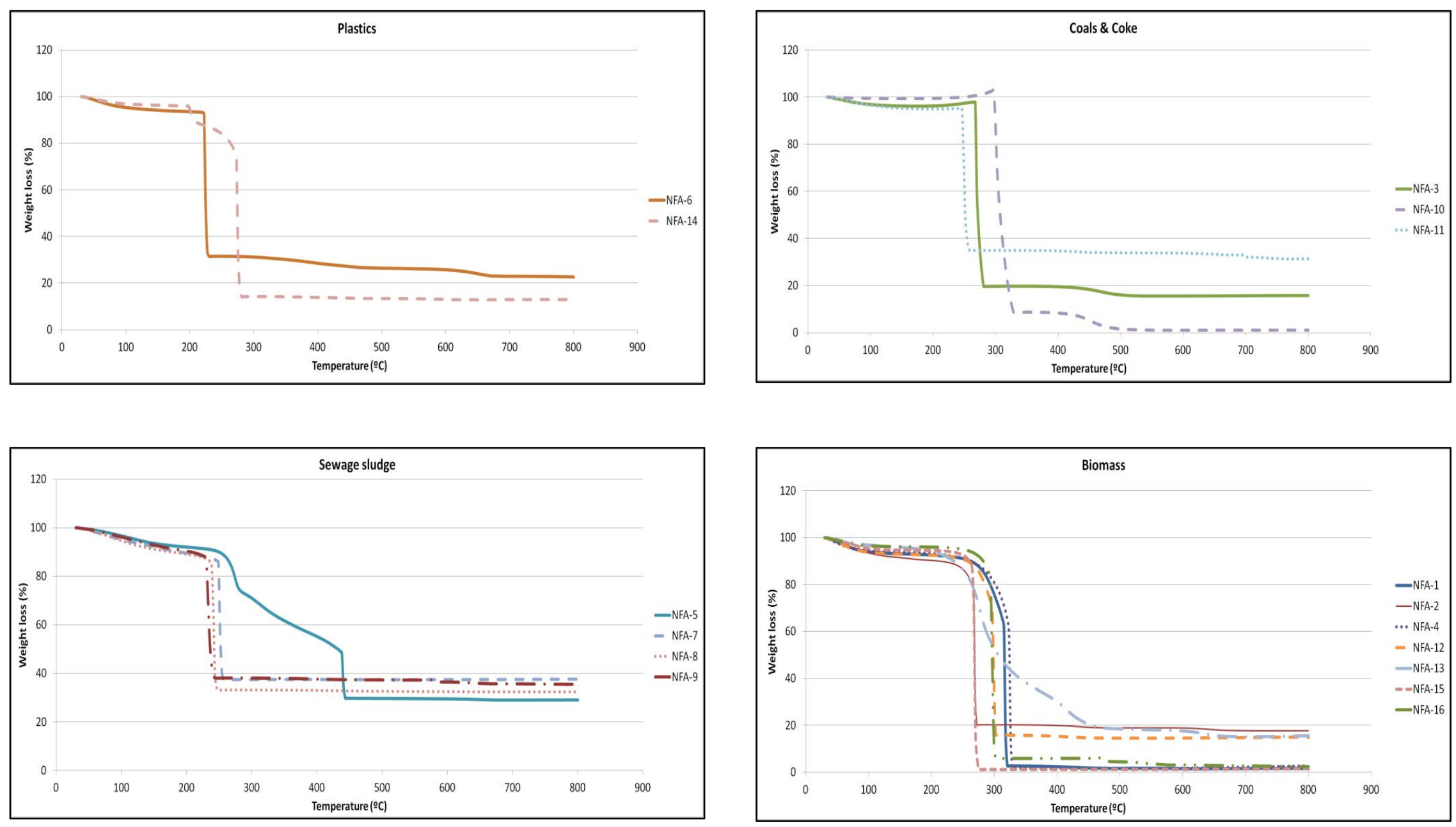

Figure 44. Thermogravimetry with oxygen curves of solid fuels 

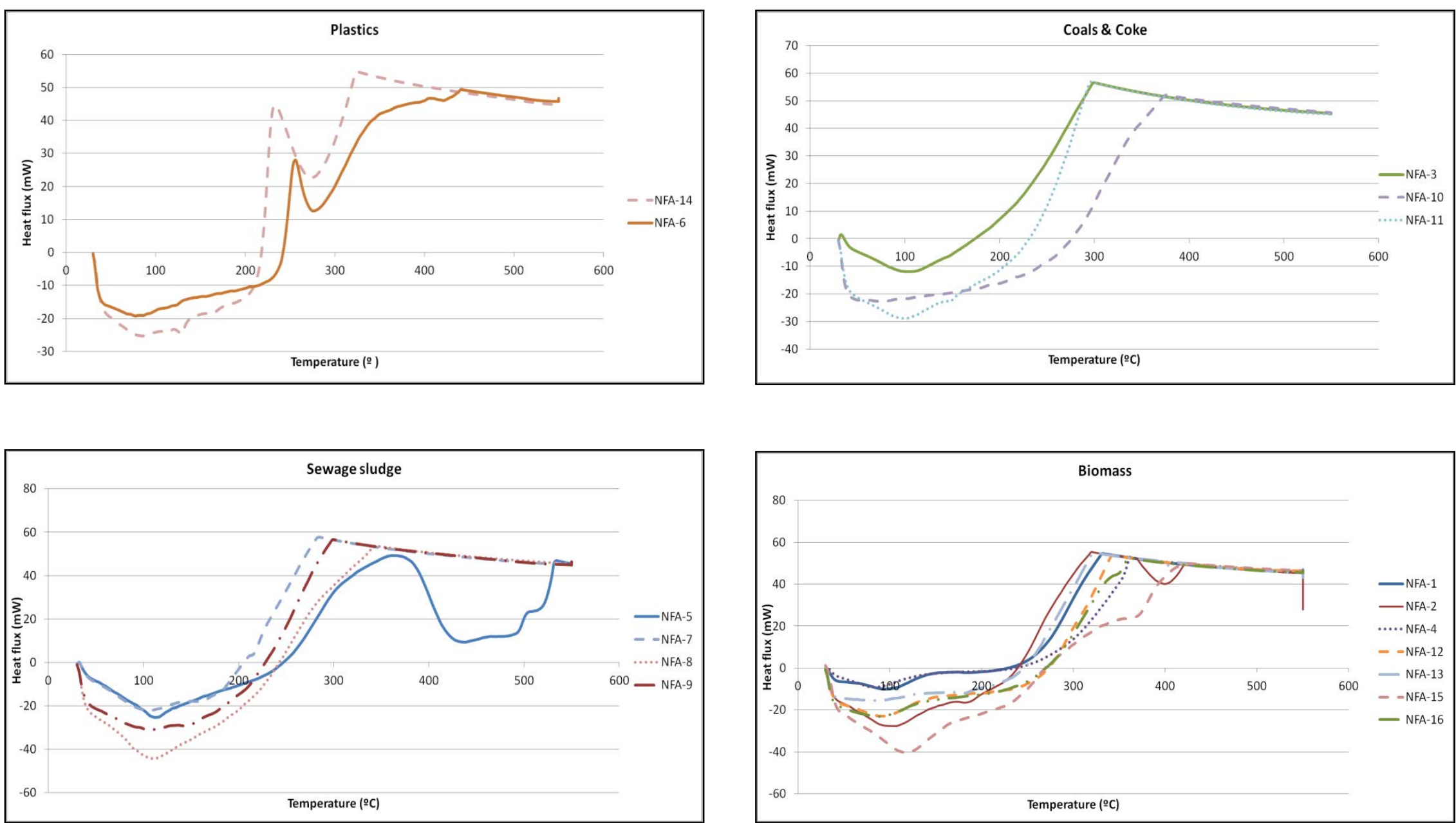

Figure 45. Differential scanning calorimetry curves of solid fuels 


\subsubsection{MINIMUM IGNITION TEMPERATURE ON A LAYER}

Minimum ignition temperature on a layer of 5 millimetres, and on a layer of 50 millimetres both compacted and no compacted have been determined. Six of the samples have been studied for two different granulometries, while the others have been studied only as dusty samples and the results are shown in Table 19.

Table 19. Minimum ignition temperature on a layer of solid fuels with different particle sizes

\begin{tabular}{|c|c|c|c|}
\hline Sample & $\begin{array}{c}\text { MIT layer } 5 \mathrm{~mm} \\
\left({ }^{\circ} \mathrm{C}\right)\end{array}$ & $\begin{array}{l}\text { MIT layer } 50 \mathrm{~mm} \\
\text { no compacted }\left({ }^{\circ} \mathrm{C}\right)\end{array}$ & $\begin{array}{l}\text { MIT layer } 50 \mathrm{~mm} \\
\text { compacted }\left({ }^{\circ} \mathrm{C}\right)\end{array}$ \\
\hline NFA-1 (Fine) & 300 & 250 & 240 \\
\hline NFA-1 (Coarse) & $>400$ & 250 & 250 \\
\hline NFA-3 & $>400$ & 200 & 200 \\
\hline NFA-4 (Fine) & 360 & 270 & 260 \\
\hline NFA-4 (Coarse) & 390 & 270 & 270 \\
\hline NFA-5 & $>400$ & 250 & 240 \\
\hline NFA-7 (Fine) & 260 & 210 & 210 \\
\hline NFA-7 (Coarse) & $>400$ & $>400$ & $>400$ \\
\hline NFA-8 & 310 & 230 & 230 \\
\hline NFA-9 & 280 & 210 & 220 \\
\hline NFA-10 (Fine) & 360 & 240 & 250 \\
\hline NFA-10 (Coarse) & $>400$ & $>400$ & $>400$ \\
\hline NFA-11 & 270 & 200 & 210 \\
\hline NFA-12 & 320 & 250 & 250 \\
\hline NFA-13 & 290 & 230 & 230 \\
\hline NFA-15(Fine) & 300 & 230 & 240 \\
\hline NFA-15 (Coarse) & $>400$ & 320 & 320 \\
\hline NFA-16 (Fine) & 320 & 250 & 250 \\
\hline NFA-16 (Coarse) & 320 & 250 & 250 \\
\hline
\end{tabular}




\subsubsection{GAS EMISSIONS ANALYSES}

Gas emissions tests have been used to determine the range of temperatures at which $\mathrm{CO}$ and $\mathrm{CO}_{2}$ emissions start to rise. This temperature is considered as the minimum between the one obtained with $\mathrm{CO}$ and the one obtained with $\mathrm{CO}_{2}$, which is the one highlighted with bold letters in Table 20.

Table 20. Gas emissions results for solid fuels

\begin{tabular}{|c|c|c|c|c|c|c|c|c|}
\hline \multirow{3}{*}{ Sample } & \multirow{3}{*}{$\begin{array}{l}\text { Particle } \\
\text { size } \\
\text { (Fine / } \\
\text { Coarse) }\end{array}$} & \multirow{3}{*}{$\begin{array}{l}\text { Compacted } \\
\text { / No } \\
\text { compacted }\end{array}$} & \multicolumn{6}{|c|}{ Methods } \\
\hline & & & \multicolumn{2}{|c|}{ Intervals } & \multicolumn{2}{|c|}{ Turning points } & \multicolumn{2}{|c|}{ Standard limits } \\
\hline & & & $\mathrm{CO}$ & $\mathrm{CO}_{2}$ & $\mathrm{CO}$ & $\mathrm{CO}_{2}$ & $\mathrm{CO}$ & $\mathrm{CO}_{2}$ \\
\hline \multirow{3}{*}{ NFA-1 } & \multirow{2}{*}{$\mathrm{F}$} & $\mathrm{C}$ & $120-140$ & $80-100$ & 102 & 100 & 122 & 158 \\
\hline & & $\mathrm{NC}$ & $120-140$ & $80-100$ & 98 & 100 & 123 & 155 \\
\hline & $\mathrm{C}$ & $\mathrm{NC}$ & $120-140$ & $140-160$ & 93 & 133 & 126 & 169 \\
\hline \multirow{2}{*}{ NFA-2 } & \multirow{2}{*}{ C } & $\mathrm{C}$ & $80-100$ & $120-140$ & 91 & 167 & 110 & 175 \\
\hline & & $\mathrm{NC}$ & $100-120$ & $80-100$ & 104 & 100 & 118 & 162 \\
\hline \multirow{2}{*}{ NFA-3 } & \multirow{2}{*}{$\mathrm{F}$} & $\mathrm{C}$ & $80-100$ & $100-120$ & 93 & 117 & 99 & 157 \\
\hline & & $\mathrm{NC}$ & $80-100$ & $80-100$ & 82 & 50 & 80 & 158 \\
\hline \multirow{4}{*}{ NFA-4 } & \multirow{2}{*}{$\mathrm{F}$} & $\mathrm{C}$ & $80-100$ & $140-160$ & 97 & 133 & 104 & 189 \\
\hline & & $\mathrm{NC}$ & $60-80$ & $120-140$ & 62 & 95 & 75 & 172 \\
\hline & \multirow{2}{*}{$\mathrm{C}$} & $\mathrm{C}$ & $60-80$ & $120-140$ & 72 & 50 & 72 & 186 \\
\hline & & $\mathrm{NC}$ & $100-120$ & $120-140$ & 99 & 83 & 92 & 181 \\
\hline \multirow{2}{*}{ NFA-5 } & \multirow{2}{*}{$\mathrm{C}$} & $\mathrm{C}$ & $80-100$ & $40-60$ & 83 & 100 & 121 & 123 \\
\hline & & $\mathrm{NC}$ & $80-100$ & $60-80$ & 96 & 100 & 123 & 113 \\
\hline \multirow{4}{*}{ NFA-6 } & \multirow{2}{*}{$\mathrm{F}$} & $\mathrm{C}$ & $120-140$ & $60-80$ & 99 & 83 & 141 & 175 \\
\hline & & $\mathrm{NC}$ & $100-120$ & $80-100$ & 93 & 74 & 144 & $>200$ \\
\hline & \multirow{2}{*}{$\mathrm{C}$} & $\mathrm{C}$ & $100-120$ & $140-160$ & 106 & 133 & 122 & $>200$ \\
\hline & & $\mathrm{NC}$ & $120-140$ & $120-140$ & 113 & 117 & 121 & 185 \\
\hline \multirow{4}{*}{ NFA-7 } & \multirow{2}{*}{$\mathrm{F}$} & $\mathrm{C}$ & $40-60$ & $80-100$ & 61 & 67 & 99 & 143 \\
\hline & & $\mathrm{NC}$ & $60-80$ & $40-60$ & 42 & 67 & 104 & 145 \\
\hline & \multirow{2}{*}{$\mathrm{C}$} & $\mathrm{C}$ & 100120 & $40-60$ & 85 & 100 & 110 & 144 \\
\hline & & $\mathrm{NC}$ & $80-100$ & $80-100$ & 96 & 83 & 107 & 139 \\
\hline \multirow{2}{*}{ NFA-8 } & \multirow{2}{*}{$\mathrm{F}$} & $\mathrm{C}$ & $80-100$ & $80-100$ & 83 & 67 & 94 & 153 \\
\hline & & $\mathrm{NC}$ & $60-80$ & $40-60$ & 83 & 100 & 102 & 143 \\
\hline \multirow{2}{*}{ NFA-9 } & \multirow{2}{*}{$\mathrm{F}$} & $\mathrm{C}$ & $80-100$ & $80-100$ & 86 & 67 & 94 & 131 \\
\hline & & $\mathrm{NC}$ & $100-120$ & $80-100$ & 95 & 33 & 92 & 131 \\
\hline \multirow{4}{*}{ NFA-10 } & $\mathrm{F}$ & $\mathrm{C}$ & $80-100$ & $100-120$ & 94 & 125 & 95 & 192 \\
\hline & & $\mathrm{NC}$ & $120-140$ & $120-140$ & 101 & 95 & 94 & 194 \\
\hline & $C$ & $\mathrm{C}$ & $120-140$ & $120-140$ & 101 & 100 & 117 & $>200$ \\
\hline & 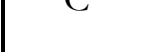 & $\mathrm{NC}$ & $100-120$ & $140-160$ & 108 & 143 & 124 & $>200$ \\
\hline
\end{tabular}


Table 21. Gas emissions results for solid fuels (cont.)

\begin{tabular}{|c|c|c|c|c|c|c|c|c|}
\hline \multirow{3}{*}{ Sample } & \multirow{3}{*}{$\begin{array}{l}\text { Particle } \\
\text { size } \\
\text { (Fine / } \\
\text { Coarse) }\end{array}$} & \multirow{3}{*}{$\begin{array}{c}\text { Compacted } \\
\text { / No } \\
\text { compacted }\end{array}$} & \multicolumn{6}{|c|}{ Methods } \\
\hline & & & \multicolumn{2}{|c|}{ Intervals } & \multicolumn{2}{|c|}{ Turning points } & \multicolumn{2}{|c|}{ Standard limits } \\
\hline & & & $\mathrm{CO}$ & $\mathrm{CO}_{2}$ & $\mathrm{CO}$ & $\mathrm{CO}_{2}$ & $\mathrm{CO}$ & $\mathrm{CO}_{2}$ \\
\hline \multirow{2}{*}{ NFA-11 } & \multirow{2}{*}{$\mathrm{F}$} & $\mathrm{C}$ & 80-100 & $60-80$ & 98 & 100 & 101 & 158 \\
\hline & & NC & $100-120$ & $60-80$ & 83 & 83 & 102 & 154 \\
\hline \multirow{2}{*}{ NFA-12 } & \multirow{2}{*}{$\mathrm{F}$} & $\mathrm{C}$ & $80-100$ & $80-100$ & 96 & 83 & 98 & 166 \\
\hline & & $\mathrm{NC}$ & $80-100$ & $120-140$ & 86 & 67 & 105 & 159 \\
\hline \multirow{2}{*}{ NFA-13 } & \multirow{2}{*}{$\mathrm{F}$} & $\mathrm{C}$ & $100-120$ & $100-120$ & 99 & 100 & 105 & 141 \\
\hline & & $\mathrm{NC}$ & $120-140$ & $120-140$ & 98 & 93 & 93 & 131 \\
\hline \multirow{4}{*}{ NFA-14 } & \multirow{2}{*}{$\mathrm{F}$} & $\mathrm{C}$ & $100-120$ & 160-180 & 108 & 40 & 110 & 186 \\
\hline & & $\mathrm{NC}$ & $60-80$ & $160-180$ & 99 & 133 & 102 & $>200$ \\
\hline & \multirow{2}{*}{$\mathrm{C}$} & $\mathrm{C}$ & $100-120$ & $160-180$ & 112 & 143 & 129 & 193 \\
\hline & & $\mathrm{NC}$ & $160-180$ & $160-180$ & 120 & 167 & 123 & $>200$ \\
\hline \multirow{4}{*}{ NFA-15 } & \multirow{2}{*}{$\mathrm{F}$} & $\mathrm{C}$ & $120-140$ & $140-160$ & 108 & 127 & 121 & 184 \\
\hline & & NC & $100-120$ & $140-160$ & 92 & 122 & 110 & 182 \\
\hline & \multirow{2}{*}{ C } & $\mathrm{C}$ & $100-120$ & $100-120$ & 98 & 111 & 109 & 173 \\
\hline & & $\mathrm{NC}$ & $100-120$ & $100-120$ & 92 & 67 & 107 & 183 \\
\hline \multirow{4}{*}{ NFA-16 } & \multirow{2}{*}{$\mathrm{F}$} & $\mathrm{C}$ & $100-120$ & $140-160$ & 97 & 111 & 81 & 186 \\
\hline & & $\mathrm{NC}$ & $80-100$ & $140-160$ & 76 & 122 & 84 & 171 \\
\hline & \multirow{2}{*}{$\mathrm{C}$} & $\mathrm{C}$ & $100-120$ & $120-140$ & 92 & 95 & 101 & 194 \\
\hline & & $\mathrm{NC}$ & $120-140$ & $160-180$ & 90 & 50 & 64 & $>200$ \\
\hline
\end{tabular}

\subsection{THERMALLY DRIED SEWAGE SLUDGE}

\subsubsection{ELEMENTAL AND PROXIMATE ANALYSES}

Proximate and ultimate analyses (Annex II) were done to the twenty thermally dried sewage sludge samples (Figure 46, Figure 47). Hydrogen, nitrogen and sulphur content values have a low standard deviation, while variations obtained for carbon, ash content, moisture and volatile matter are higher. 


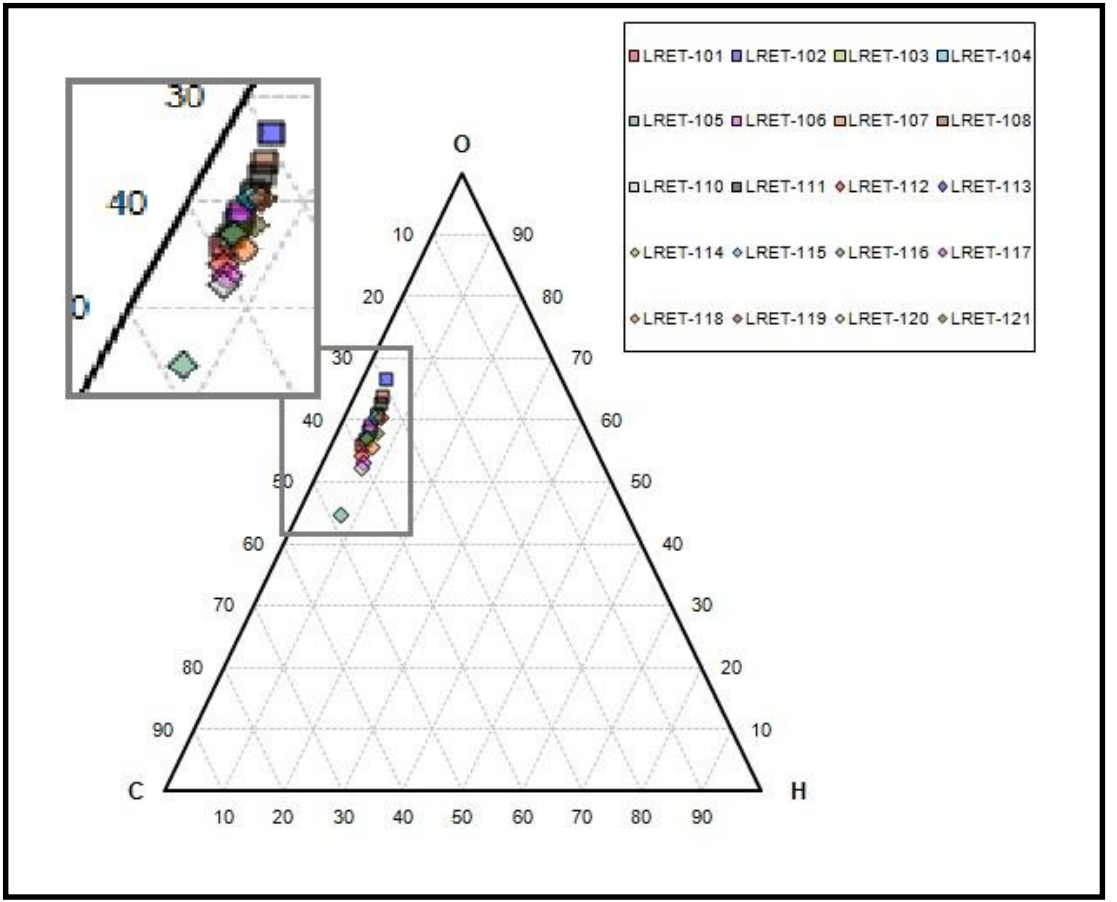

Figure 46. Triangular diagram elemental analyses sewage sludge [110]

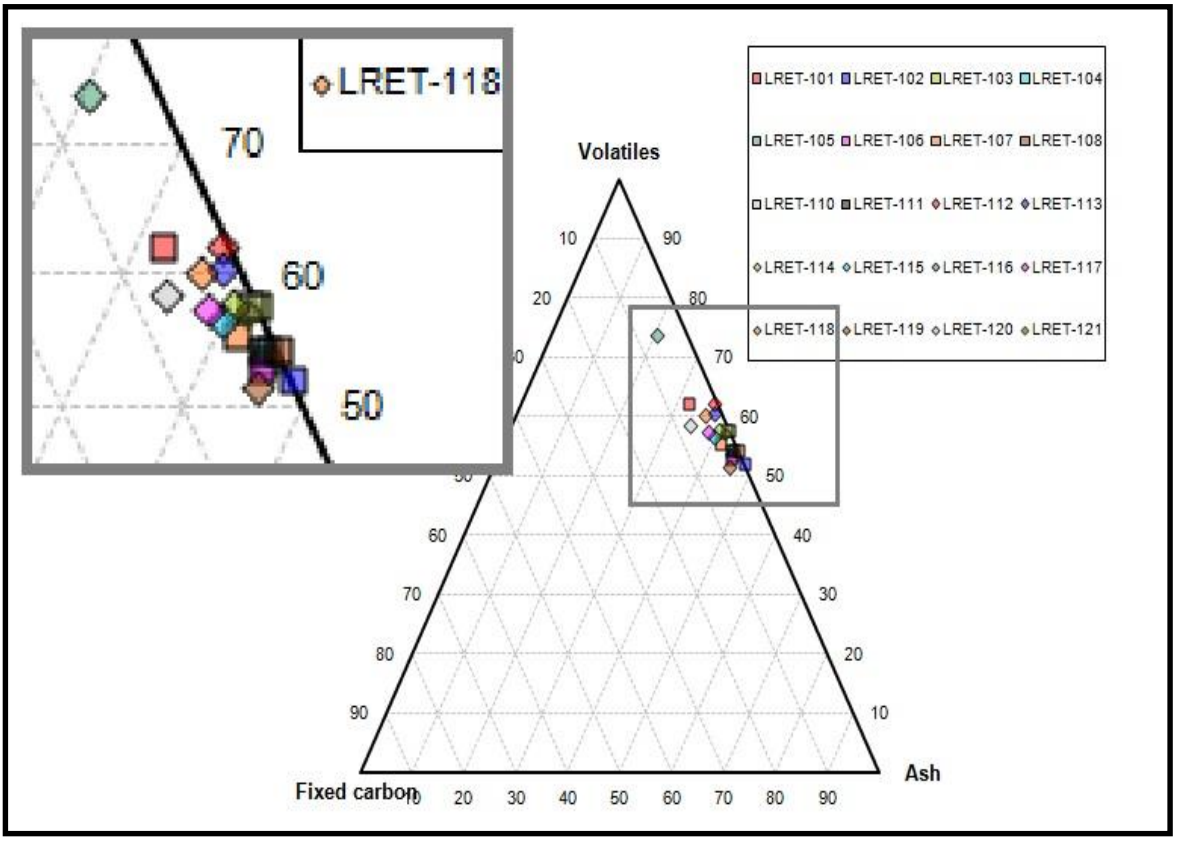

Figure 47.Triangular diagram proximate analyses sewage sludge [110] 


\subsubsection{GRANULOMETRY}

For the twenty samples the granulometry curves were determined, and the three main parameters were obtained, as shown in Table 22. All the studied samples were sieved through a 1 millimetre sieve before testing.

Table 22. Statistical parameters granulometry sewage sludge

\begin{tabular}{|c|c|c|c|}
\hline Parameter & $\mathrm{d} 10(\mu \mathrm{m})$ & $\mathrm{d} 50(\mu \mathrm{m})$ & $\mathrm{d} 90(\mu \mathrm{m})$ \\
\hline LRET-101 & 15.4 & 67.9 & 355.3 \\
\hline LRET-102 & 111.9 & 339.5 & 815.8 \\
\hline LRET-103 & 23.4 & 100.4 & 289.2 \\
\hline LRET-104 & 96.7 & 382.2 & 818.6 \\
\hline LRET-105 & 88.6 & 397.2 & 844.1 \\
\hline LRET-106 & 13.2 & 77.7 & 371.2 \\
\hline LRET-107 & 69.2 & 385.9 & 853.9 \\
\hline LRET-108 & 10.9 & 30.2 & 160.5 \\
\hline LRET-110 & 88.2 & 382.5 & 839.7 \\
\hline LRET-111 & 10.3 & 43.0 & 383.9 \\
\hline LRET-112 & 7.5 & 27.3 & 62.2 \\
\hline LRET-113 & 81.3 & 517.5 & 1150.7 \\
\hline LRET-114 & 69.7 & 298.9 & 664.3 \\
\hline LRET-115 & 152.3 & 492.5 & 1098.7 \\
\hline LRET-116 & 52.3 & 531.6 & 1218.2 \\
\hline LRET-117 & 34.1 & 74.4 & 348.3 \\
\hline LRET-118 & 7.4 & 20.6 & 178.9 \\
\hline LRET-119 & 110.3 & 214.4 & 653.5 \\
\hline LRET-120 & 3.5 & 19.9 & 75.2 \\
\hline LRET-121 & 32.1 & 286.3 & 919.7 \\
\hline
\end{tabular}

\subsubsection{IGNITION SENSITIVITY}

According to the results of the previous tests, ten samples were selected in order to choose the biggest range of values. Ignition sensitivity, explosion severity and thermal stability analyses were developed to those ten samples. These results show high variation in almost all the parameters studied. MITl values have a variation of $150 \mathrm{~K}$, consistent with the observed variation of MITc values, $190 \mathrm{~K}$. The other two parameters included in the ignition 
sensitivity group also have high variations, being of special interest that only three of the ten studied samples have a MIE under $1000 \mathrm{~mJ}$. Results of these tests are shown in Table 23.

Table 23. Ignition sensitivity results

\begin{tabular}{|c|c|c|c|c|}
\hline \multirow{2}{*}{ Sample } & \multicolumn{4}{|c|}{ Ignition sensitivity parameters } \\
\cline { 2 - 5 } & MITl $\left({ }^{\circ} \mathrm{C}\right)$ & MITc $\left({ }^{\circ} \mathrm{C}\right)$ & LEL $(\mathrm{g} / \mathrm{cm} 3)$ & MIE $(\mathrm{mJ})$ \\
\hline LRET-101 & 260 & 460 & 60 & 67 \\
\hline LRET-102 & 360 & 480 & 500 & $>1000$ \\
\hline LRET-103 & 300 & 480 & 60 & $>1000$ \\
\hline LRET-104 & 370 & 440 & 500 & $>1000$ \\
\hline LRET-105 & 370 & 420 & 125 & $>1000$ \\
\hline LRET-107 & 390 & 510 & 30 & $>1000$ \\
\hline LRET-110 & 390 & 510 & 125 & $>1000$ \\
\hline LRET-112 & 240 & 320 & 60 & 170 \\
\hline LRET-117 & 340 & 420 & 60 & 220 \\
\hline LRET-121 & 320 & 460 & 125 & $>1000$ \\
\hline
\end{tabular}

\subsubsection{EXPLOSION SEVERITY}

Explosion severity parameters (Table 24) have a lower range of variation, and the Pmax of the samples do not vary substantially among the studied samples. According to Kmax values, all the samples have the characteristic of "Typical explosion". Finally, the values of the LOC show also a remarkable range of variation, from $13 \%$ to $20 \%$. 
Table 24. Explosion severity results

\begin{tabular}{|c|c|c|c|c|}
\hline \multirow{2}{*}{ Sample } & \multicolumn{4}{|c|}{ Explosion severity parameters } \\
\cline { 2 - 5 } & Pmax (bar) & $\begin{array}{c}\text { Kmax } \\
(\mathrm{bar} \cdot \mathrm{m} / \mathrm{s})\end{array}$ & $\begin{array}{c}(\mathrm{dP} / \mathrm{dt}) \mathrm{max} \\
(\mathrm{bar} / \mathrm{s})\end{array}$ & LOC $(\%)$ \\
\hline LRET-101 & 7.0 & 124 & 458 & 13 \\
\hline LRET-102 & 5.0 & 77 & 285 & 20 \\
\hline LRET-103 & 6.1 & 125 & 462 & 15 \\
\hline LRET-104 & 5.5 & 108 & 399 & 13 \\
\hline LRET-105 & 5.7 & 98 & 361 & 14 \\
\hline LRET-107 & 6.3 & 178 & 654 & 13 \\
\hline LRET-110 & 6.4 & 145 & 633 & 16 \\
\hline LRET-112 & 6.4 & 157 & 577 & 16 \\
\hline LRET-117 & 6.1 & 161 & 592 & 19 \\
\hline LRET-121 & 6.1 & 161 & 591 & \\
\hline
\end{tabular}

\subsubsection{THERMOGRAVIMETRY}

Unlike the previous cases, the variation of the parameters obtained from the thermogravimetric and the differential scanning calorimetry results is lower. The temperatures obtained from these tests do not vary in a range as wide as in the previous cases, so the heating process of all the samples studied can be considered as quite similar.

Results obtained for thermogravimetry tests are shown in Table 25, and the thermal susceptibility graph is shown in Figure 48. 
Table 25. Thermogravimetry results

\begin{tabular}{|c|c|c|c|c|c|}
\cline { 2 - 6 } \multicolumn{1}{c|}{} & \multicolumn{3}{c|}{ Thermogravimetry } & \multicolumn{2}{c|}{ Characteristics } \\
\hline Sample & $\begin{array}{c}\text { MLT_1 } \\
\left({ }^{\circ} \mathrm{C}\right)\end{array}$ & $\begin{array}{c}\text { MLT_2 } \\
\left({ }^{\circ} \mathrm{C}\right)\end{array}$ & IT $\left({ }^{\circ} \mathrm{C}\right)$ & Ea (mJ) & Tcharact $\left({ }^{\circ} \mathrm{C}\right)$ \\
\hline LRET-101 & 295 & 374 & 225 & 70.7 & 309 \\
\hline LRET-103 & 268 & 406 & 240 & 72.0 & 281 \\
\hline LRET-104 & 256 & 417 & 240 & 68.5 & 266 \\
\hline LRET-105 & 260 & 430 & 227 & 69.0 & 264 \\
\hline LRET-107 & 260 & 443 & 226 & 53.3 & 277 \\
\hline LRET-108 & 269 & 406 & 226 & 68.6 & 267 \\
\hline LRET-110 & 260 & 446 & 228 & 69.0 & 267 \\
\hline LRET-112 & 253 & 419 & 203 & 66.6 & 203 \\
\hline LRET-117 & 253 & 409 & 221 & 66.1 & 224 \\
\hline LRET-121 & 253 & 403 & 230 & 66.8 & 218 \\
\hline
\end{tabular}

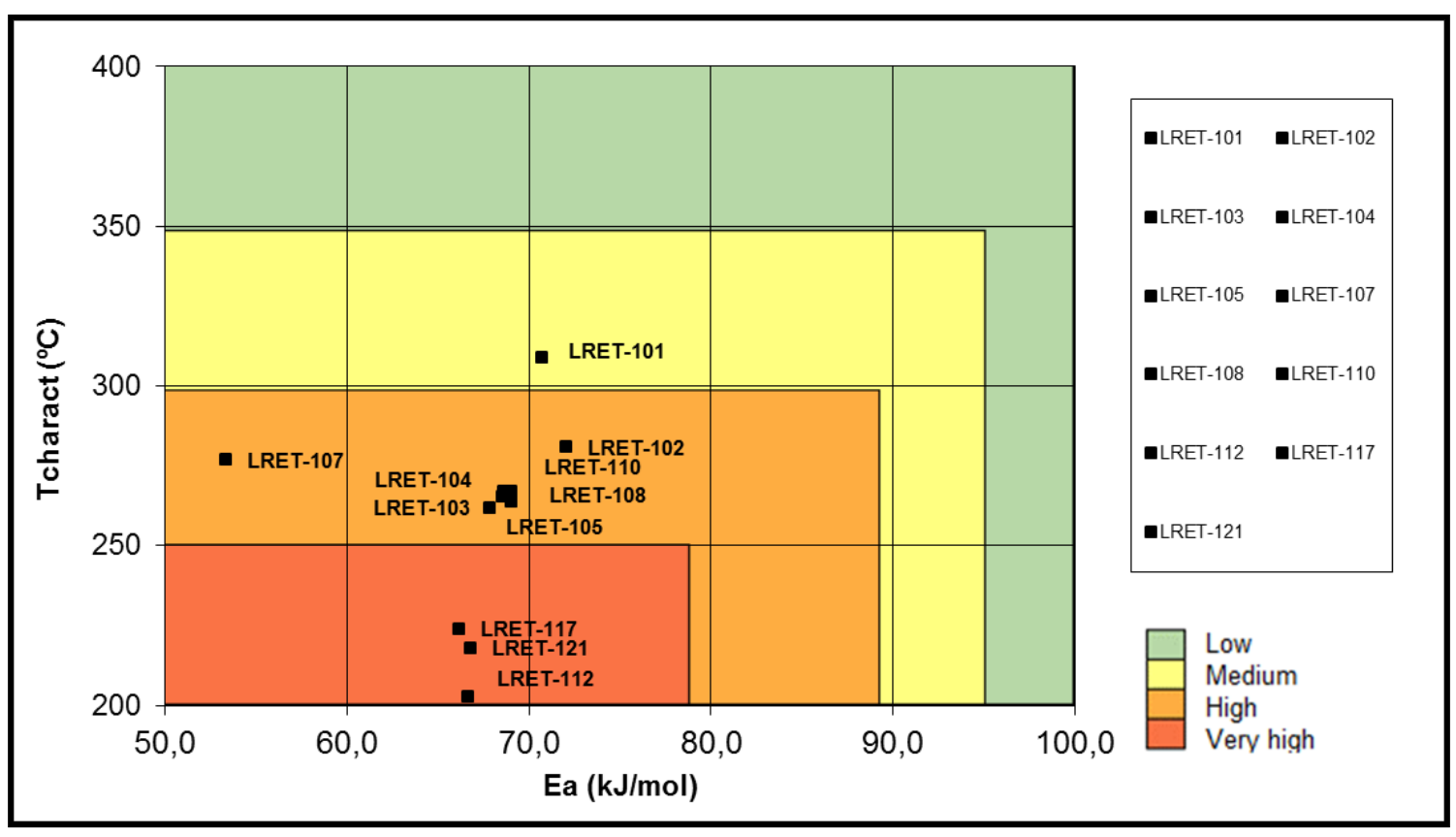

Figure 48. Thermal susceptibility graph thermally dried sewage sludge 
However, one of the most significant differences among the samples studied is the variation of the MI values (Table 26). Only three samples produced a significant reaction, leading to a value higher or equal to 10 , and those samples are not the same as the samples with MIE lower than $1000 \mathrm{~mJ}$.

Table 26. TEV and MI results

\begin{tabular}{|c|c|c|}
\hline Sample & TEV $\left({ }^{\circ} \mathrm{C}\right)$ & MI $\left(\mathrm{s}^{-1}\right)$ \\
\hline LRET-101 & 380 & 0 \\
\hline LRET-102 & 340 & 0 \\
\hline LRET-103 & 310 & 10 \\
\hline LRET-104 & 360 & 3 \\
\hline LRET-105 & 330 & 0 \\
\hline LRET-107 & 320 & 0 \\
\hline LRET-110 & 320 & 7 \\
\hline LRET-112 & 260 & 25 \\
\hline LRET-117 & 330 & 0 \\
\hline LRET-121 & 310 & 0 \\
\hline
\end{tabular}

\subsubsection{DIFFERENTIAL SCANNING CALORIMETRY}

The variation of results among samples for differential scanning calorimetry results is low, and shown in Table 27.

Table 27. Differential scanning calorimetry results

\begin{tabular}{|c|c|c|c|}
\hline Sample & IET $\left({ }^{\circ} \mathrm{C}\right)$ & FET $\left({ }^{\circ} \mathrm{C}\right)$ & CST $\left({ }^{\circ} \mathrm{C}\right)$ \\
\hline LRET-101 & 76 & 296 & 212 \\
\hline LRET-102 & 114 & 345 & 194 \\
\hline LRET-103 & 89 & 305 & 219 \\
\hline LRET-104 & 118 & 317 & 193 \\
\hline LRET-105 & 114 & 304 & 210 \\
\hline LRET-107 & 120 & 303 & 206 \\
\hline LRET-108 & 107 & 273 & 215 \\
\hline LRET-110 & 135 & 299 & 218 \\
\hline LRET-112 & 117 & 288 & 182 \\
\hline LRET-117 & 160 & 387 & 209 \\
\hline LRET-121 & 153 & 319 & 209 \\
\hline
\end{tabular}




\subsubsection{SELF-IGNITION}

According to the data obtained for these ten samples, three of them were selected due to their diversity and thermal stability was studied for them. Two samples, LRET-102 and LRET-110, were analysed according to the Division 4.2 tests and TSI was determined for the third sample, LRET-121. The results for LRET-102 and LRET-110 showed that they were exempted of hazardous classification when transported in packages of less than $3 \mathrm{~m}^{3}$ (Table 28).

Table 28. Division 4.2 tests results

\begin{tabular}{|c|c|c|c|c|c|}
\hline Sample & $\begin{array}{c}\text { Self-heating in } \\
\text { a } 100 \mathrm{~mm} \text { cube } \\
\text { at } 140^{\circ} \mathrm{C}\end{array}$ & $\begin{array}{c}\text { Self-heating in } \\
\text { a } 25 \mathrm{~mm} \text { cube } \\
\text { at } 140^{\circ} \mathrm{C}\end{array}$ & $\begin{array}{c}\text { Self-heating in } \\
\text { a } 100 \mathrm{~mm} \text { cube } \\
\text { at } 120^{\circ} \mathrm{C}\end{array}$ & $\begin{array}{c}\text { Self-heating in } \\
\text { a } 100 \mathrm{~mm} \text { cube } \\
\text { at } 100^{\circ} \mathrm{C}\end{array}$ & Classification \\
\hline LRET-102 & Yes & No & No & - & $\begin{array}{c}\text { Exempted if } \\
\text { transported in } \\
\text { packages } \leq 3 \\
\mathrm{~m}^{3}\end{array}$ \\
\hline LRET-110 & Yes & No & No & - & $\begin{array}{c}\text { Exempted if } \\
\text { transported in } \\
\text { packages } \leq 3 \\
\mathrm{~m}^{3}\end{array}$ \\
\hline
\end{tabular}

A more detailed testing has been done for sample LRET-121 in order to determine its selfignition temperature. Using four different volumes of sample, ranging from $50 \mathrm{~cm}^{3}$ to 1500 $\mathrm{cm}^{3}$ and subjecting the samples to increasing oven temperatures, both the lower temperature leading to an ignition and the higher temperature without ignition can be determined, so that the self-ignition temperature can be defined as the medium value among those temperatures. Test results for sample LRET-121 are shown in Table 29 and their corresponding graphs are plotted on Annex II.

Table 29. Self-ignition results

\begin{tabular}{|c|c|c|c|}
\hline $\begin{array}{c}\text { Sample Volume } \\
\left(\mathrm{cm}^{3}\right)\end{array}$ & $\begin{array}{c}\text { Lower } \\
\text { temperature } \\
\text { leading to ignition } \\
\left({ }^{\circ} \mathrm{C}\right)\end{array}$ & $\begin{array}{c}\text { Higher } \\
\text { temperature } \\
\text { without ignition } \\
\left({ }^{\circ} \mathrm{C}\right)\end{array}$ & $\begin{array}{c}\text { Self ignition } \\
\text { temperature } \\
(\text { SIT }) \\
\left({ }^{\circ} \mathrm{C}\right)\end{array}$ \\
\hline 1500 & 125 & 120 & 122.5 \\
\hline 350 & 140 & 135 & 137.5 \\
\hline 150 & 145 & 140 & 142.5 \\
\hline 50 & 155 & 150 & 152.5 \\
\hline
\end{tabular}




\subsection{MIXTURES}

\subsubsection{ELEMENTAL AND PROXIMATE ANALYSES}

Elemental analysis of the studied mixtures (Annex II) is plotted on Figure 49, where it can be seen that the ten mixtures studied are located almost parallel to one of the sides of the triangle, i.e. the hydrogen content of the samples is almost constant for all of them.

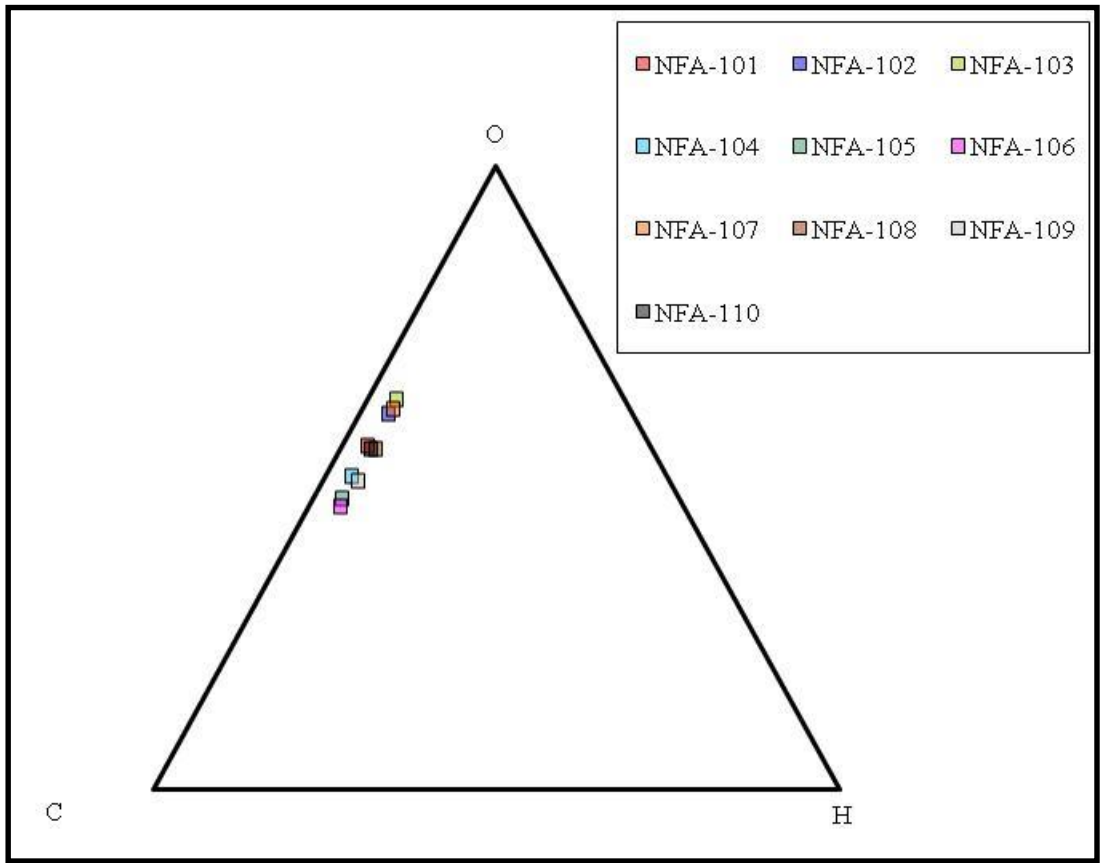

Figure 49.Triangular diagram elemental analyses mixtures [110]

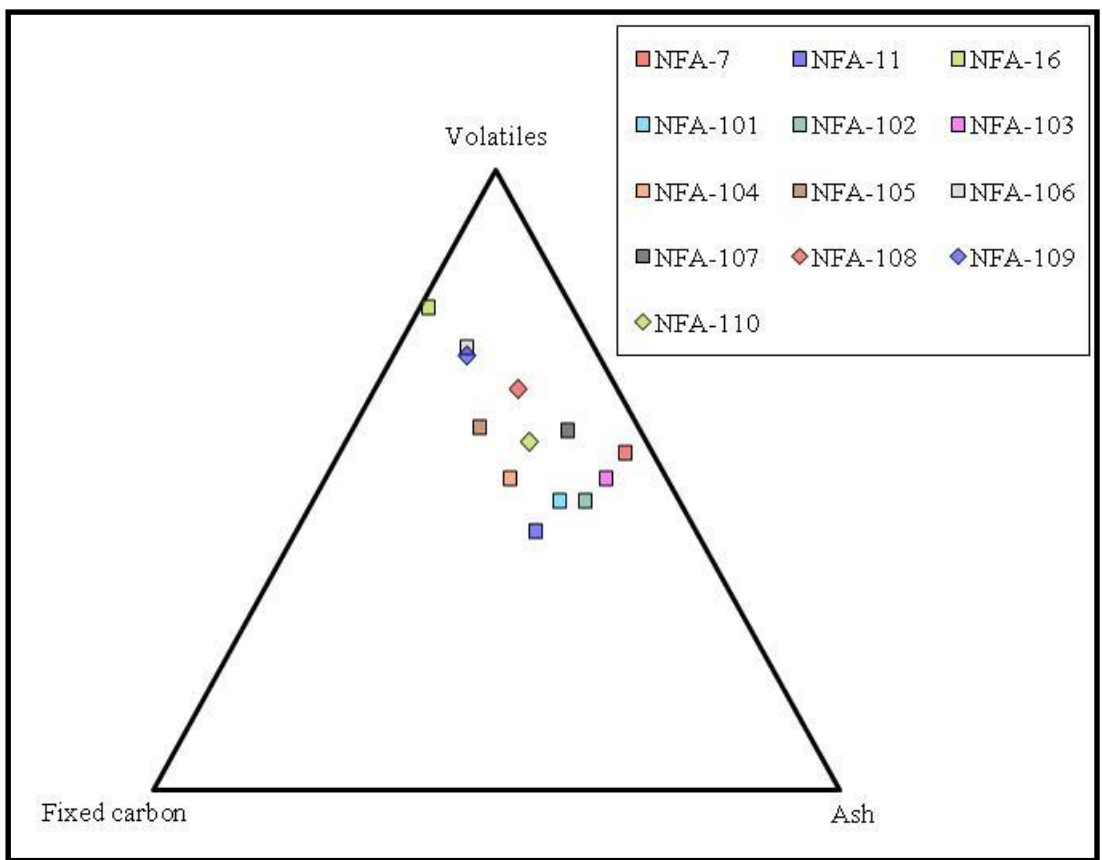

Figure 50. Triangular diagram proximate analyses mixtures [110] 
Proximate analyses were also determined (Annex II), as shown in Figure 50.

\subsubsection{GRANULOMETRY}

Granulometry curves are shown in Figure 51. Coal samples has lower particle size, and it is the responsible of the first peak that can be mainly seen on samples NFA-101 and NFA-104. Both sewage sludge and pellets were sieved under $180 \mu \mathrm{m}$, so the peak of the curves is below this point. The percentage of samples of more than $180 \mu \mathrm{m}$ is caused to the irregularities of the samples. 


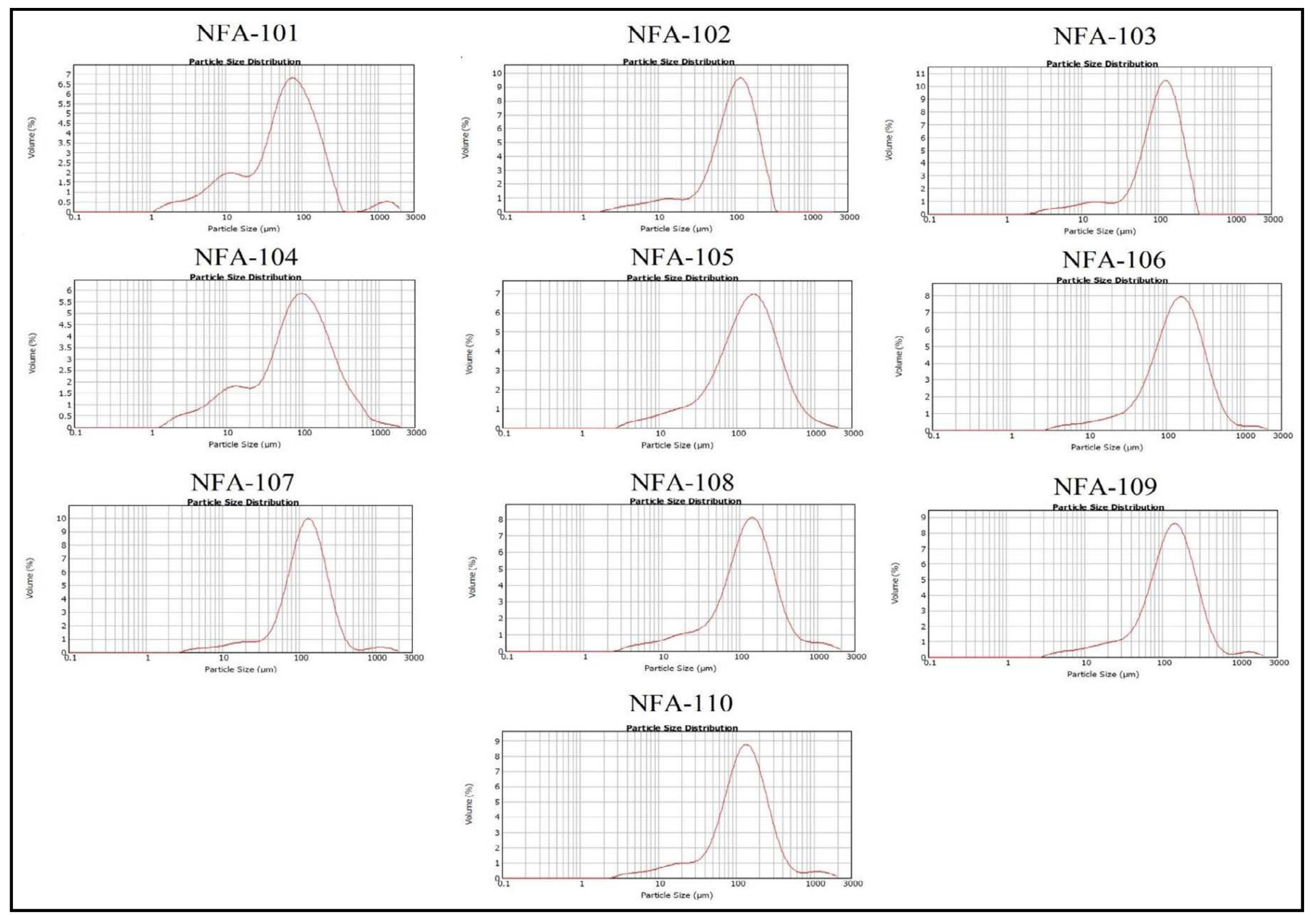

Figure 51. Granulometry curves of mixtures 


\subsubsection{THERMAL CONDUCTIVITY}

The density of the mixtures decreases by adding torrefied wood pellets to the mixtures, due to its lower density. It can also be seen how the density of the samples rises by compacting them. Looking at the thermal diffusivity, it increases with the addition of torrefied wood pellets too, and it is lower for compacted samples than for the no compacted ones. The specific heat could be determined only for no compacted samples, due to the characteristics of the crucibles of the DSC, so the same value is used for compacted and no compacted thermal conductivity. The specific heat increases when adding torrefied wood pellets to coal or sewage sludge, but in decreases when adding sewage sludge to the coal sample. The thermal conductivity of the mixtures of torrefied wood pellets and coal present the highest values of thermal conductivity, and the mixtures of sewage sludge and torrefied wood pellets the lowest ones. All the values obtained in the laboratory are shown on Table 30.

Table 30. Thermal conductivity of mixtures

\begin{tabular}{|c|c|c|c|c|c|c|c|}
\hline & \multirow{2}{*}{ Sample } & $\begin{array}{c}\text { Specific } \\
\text { heat } \\
(\mathrm{J} / \mathrm{kg} \cdot \mathrm{K})\end{array}$ & \multicolumn{2}{|c|}{$\begin{array}{c}\text { Thermal diffusivity } \\
\left(10^{-7} \mathrm{~m}^{2} / \mathrm{s}\right)\end{array}$} & \multicolumn{2}{|c|}{$\begin{array}{c}\text { Density } \\
(\mathrm{g} / \mathrm{L})\end{array}$} & \multicolumn{2}{c|}{$\begin{array}{c}\text { Thermal conductivity } \\
\text { (W/m·K) }\end{array}$} \\
\cline { 3 - 9 } & & compacted & compacted & $\begin{array}{c}\text { no } \\
\text { compacted }\end{array}$ & compacted & $\begin{array}{c}\text { no } \\
\text { compacted }\end{array}$ & compacted \\
\hline NFA-101 & 1463.5 & 1.43 & 1.07 & 535.18 & 707.83 & 0.112 & 0.111 \\
\hline NFA-102 & 1477.8 & 1.36 & 1.12 & 570.41 & 748.33 & 0.115 & 0.124 \\
\hline NFA-103 & 1475.2 & 1.27 & 1.08 & 591.72 & 717.33 & 0.111 & 0.114 \\
\hline NFA-104 & 1327.9 & 1.88 & 1.44 & 429.71 & 567.63 & 0.107 & 0.108 \\
\hline NFA-105 & 2317.3 & 2.24 & 1.63 & 370.80 & 469.77 & 0.192 & 0.177 \\
\hline NFA-106 & 1588.1 & 2.20 & 1.72 & 284.17 & 377.30 & 0.100 & 0.103 \\
\hline NFA-107 & 1745.0 & 1.73 & 1.56 & 469.06 & 564.63 & 0.142 & 0.154 \\
\hline NFA-108 & 2205.7 & 2.09 & 1.59 & 328.89 & 454.03 & 0.151 & 0.159 \\
\hline NFA-109 & 1555.0 & 2.32 & 1.74 & 247.12 & 390.2 & 0.089 & 0.106 \\
\hline NFA-110 & 1444.6 & 1.83 & 1.37 & 402.14 & 532.33 & 0.107 & 0.105 \\
\hline
\end{tabular}

\subsubsection{THERMOGRAVIMETRY}

When the mixtures are formed by sewage sludge and coal, the addition of the first one causes an increase on the values of MLT_1 and MLT_2, which means that the maximum loss of 
weight of the sample takes place later. However, the combustion reaction starts earlier. When the samples are formed by torrefied wood pellets and one of the other materials, the addition of torrefied wood pellets causes a delay on the beginning of the combustion, as well as an increase on the maximum loss of weight temperatures. Looking at the activation energy, only the samples with higher amounts of coal present values of more than $79 \mathrm{~kJ} / \mathrm{mol}$, where the self-ignition area changes.

Table 31. Thermogravimetry results for mixtures

\begin{tabular}{|c|c|c|c|c|c|}
\hline \multirow{2}{*}{ Sample } & \multicolumn{3}{|c|}{ Thermogravimetry } & \multicolumn{2}{c|}{ Characteristics } \\
\cline { 2 - 6 } & MLT_1 $\left({ }^{\circ} \mathrm{C}\right)$ & MLT_2 $\left({ }^{\circ} \mathrm{C}\right)$ & IT $\left({ }^{\circ} \mathrm{C}\right)$ & Ea $(\mathrm{kJ} / \mathrm{mol})$ & Tcharact $\left({ }^{\circ} \mathrm{C}\right)$ \\
\hline NFA-101 & 275.33 & 393.42 & 250.39 & 81.51 & 260.75 \\
\hline NFA-102 & 260.58 & 399.25 & 237.56 & 83.24 & 253.25 \\
\hline NFA-103 & 253.92 & 400.67 & 232.02 & 67.70 & 255.75 \\
\hline NFA-104 & 288.42 & 387.33 & 267.63 & 84.88 & 278.83 \\
\hline NFA-105 & 296.17 & 403.33 & 274.85 & 69.50 & 297.17 \\
\hline NFA-106 & 301.33 & 416.67 & 268.6 & 69.05 & 296.83 \\
\hline NFA-107 & 276.42 & 384.67 & 247.48 & 67.41 & 264.33 \\
\hline NFA-108 & 293.00 & 366.00 & 269.31 & 68.61 & 291.33 \\
\hline NFA-109 & 301.67 & 440.67 & 279.94 & 67.94 & 300.42 \\
\hline NFA-110 & 275.63 & 424.67 & 263.56 & 70.25 & 279.00 \\
\hline
\end{tabular}

\subsubsection{DIFFERENTIAL SCANNING CALORIMETRY}

The starting point of the exothermic reaction is lower when the content of torrefied wood pellets is higher, taking place before the moisture loss in these cases, and after this moment for the mixtures formed by sewage sludge and coal, or with high amounts of one of these materials. On the other hand, the end point of this reaction occurs later with this addition of pellets, the same as the change of slope of the curve. Numerical results of DSC tests are shown on Table 32. 
Table 32. Differential scanning calorimetry results for mixtures

\begin{tabular}{|c|c|c|c|}
\hline Sample & IET $\left({ }^{\circ} \mathrm{C}\right)$ & FET $\left({ }^{\circ} \mathrm{C}\right)$ & CST $\left({ }^{\circ} \mathrm{C}\right)$ \\
\hline NFA-101 & 102.00 & 296.35 & 206.02 \\
\hline NFA-102 & 113.49 & 298.01 & 214.81 \\
\hline NFA-103 & 107.02 & 282.02 & 214.16 \\
\hline NFA-104 & 110.23 & 347.35 & 233.70 \\
\hline NFA-105 & 88.26 & 361.01 & 258.90 \\
\hline NFA-106 & 88.26 & 361.01 & 259.31 \\
\hline NFA-107 & 122.07 & 323.35 & 224.47 \\
\hline NFA-108 & 89.21 & 356.01 & 234.53 \\
\hline NFA-109 & 89.80 & 357.68 & 250.73 \\
\hline NFA-110 & 96.32 & 317.34 & 225.88 \\
\hline
\end{tabular}

\subsubsection{MINIMUM IGNITION TEMPERATURE}

Results are shown on Figure 52. The mixtures formed by coal and sewage sludge present huge similarities while for the other the MITl values increase when the presence of torrefied wood pellets is higher.

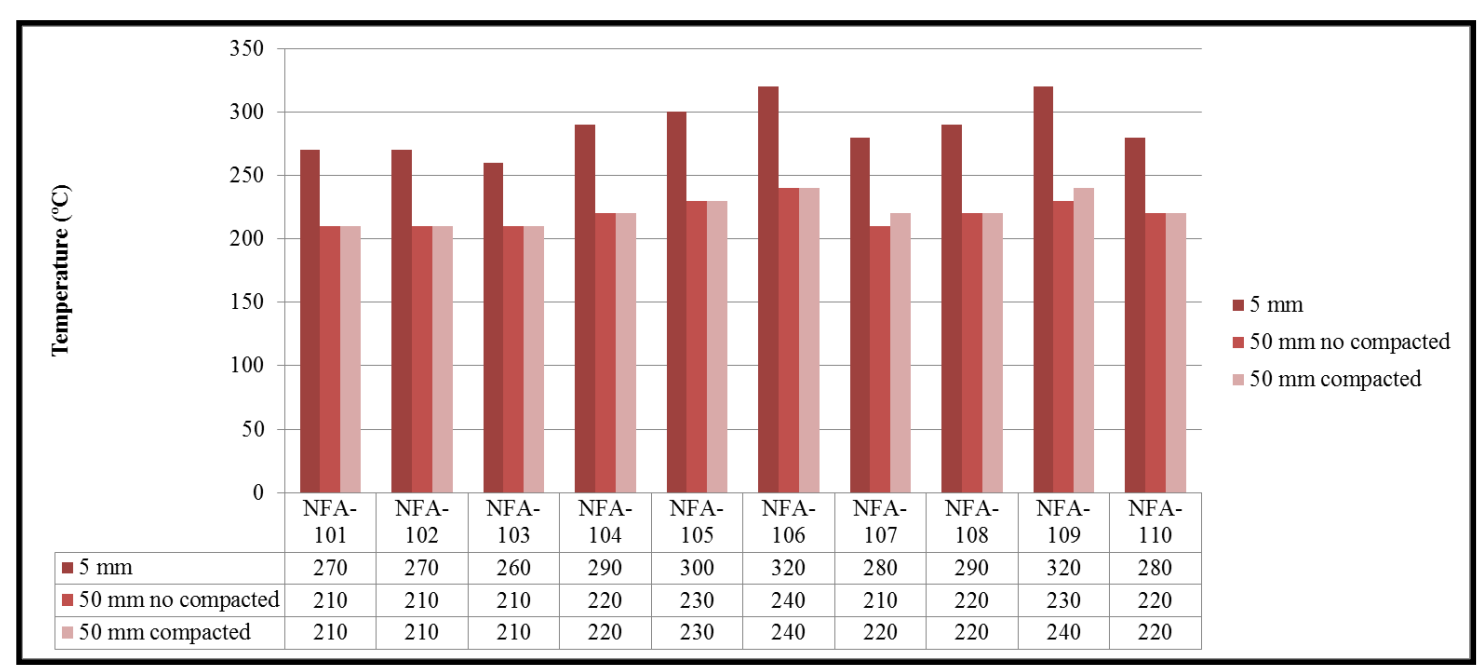

Figure 52. Minimum ignition temperature on a layer of mixtures 


\subsubsection{MINIMUM IGNITION ENERGY}

Minimum ignition energy has been determined for the ten mixtures studied, and results are plotted on Figure 53. Thermally dried sewage sludge and coal have a MIE of $>1000 \mathrm{~mJ}$, while torrefied wood pellets presents a value of $74 \mathrm{~mJ}$. In this case, the mixtures formed by coal and sewage sludge do not ignite with the highest tested energy, $1000 \mathrm{~mJ}$. But when the mixture involves torrefied wood pellets, the energy needed for igniting a cloud is lower until a limit that is the same as for the sample alone $(74 \mathrm{~mJ})$.

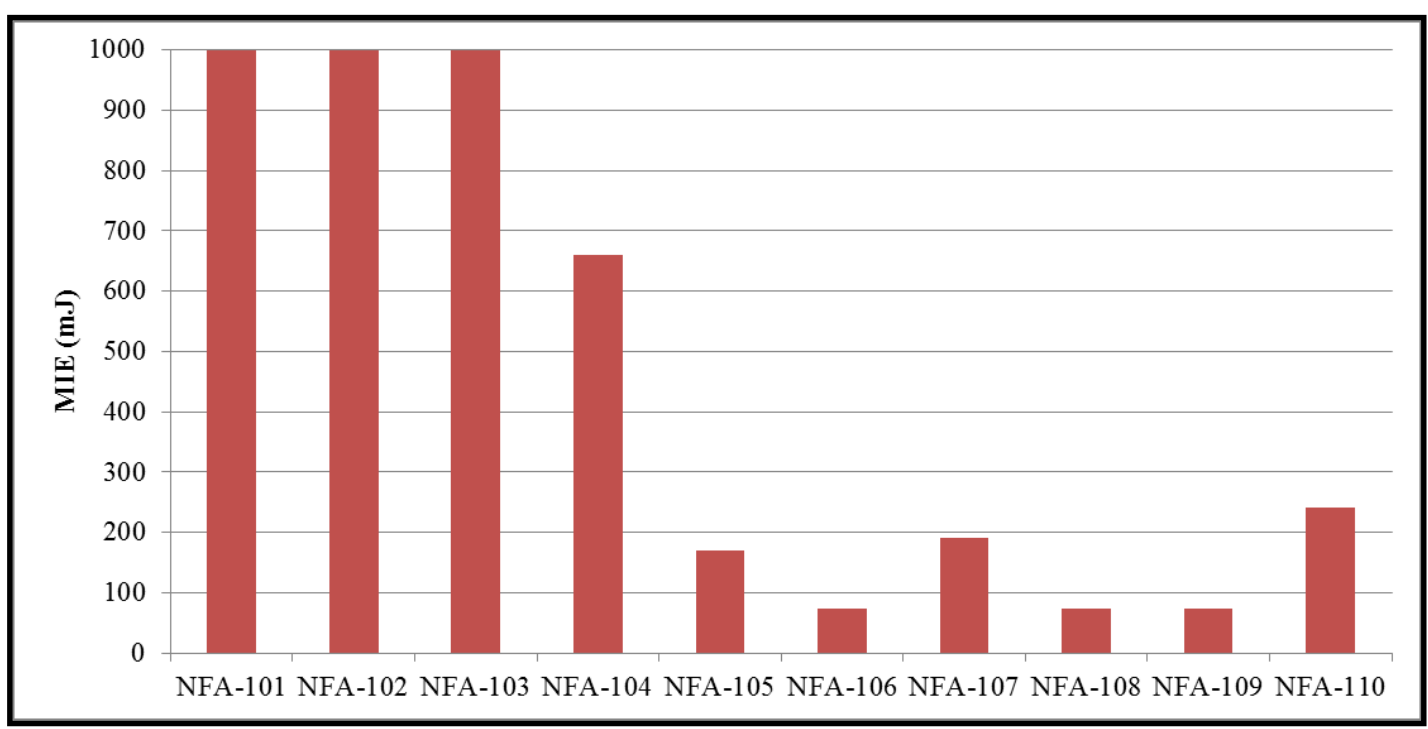

Figure 53. Minimum ignition energy of mixtures 


\section{DISCUSSION}

\subsection{SOLID FUELS}

\subsubsection{RELATIONS AMONG PARAMETERS}

To determine the influence that chemical and physical parameters have on the flammability of solid fuels, a multivariate analysis was developed to the data with the software Statgraphics Centurion XVI. A correlation matrix has been determined, and the significant correlations existing between parameters, with a significant level of $95 \%$, studied. The objective of this analysis was to determine the relations existing and define the parameters that could be easily modified by preventive measures and may cause a decrease on the explosion risk on this kind of industrial plants. With this analysis it is possible to see the similarities of the samples with other materials well-known as coal, and design prevention and protection systems based on those developed and widely experienced in other industrial plants.

Thanks to this study it has been corroborated that ash and volatiles contents are important parameters that influence several thermal and flammability characteristics of solid fuels.

Ash content is mainly related with the temperatures obtained from TG-DSC analyses that explain the combustion process of the solids. The devolatilisation of holocellulose and lignin (MLT_1 and MLT_2), the end of the exothermic process (FET), the temperature of oxidation (Tcharact) and the starting point of the quick exothermic reaction (CST) take place at lower temperature for the samples that present more amount of ash content, sewage sludge samples (30-40 \% d.b.) However, the samples with higher amount of ashes need a higher temperature for the beginning of the exothermic reaction (IET). Finally, the ash content presents a positive significant correlation with densities, due to biomass samples have lower densities and ash contents than sewage sludge. 


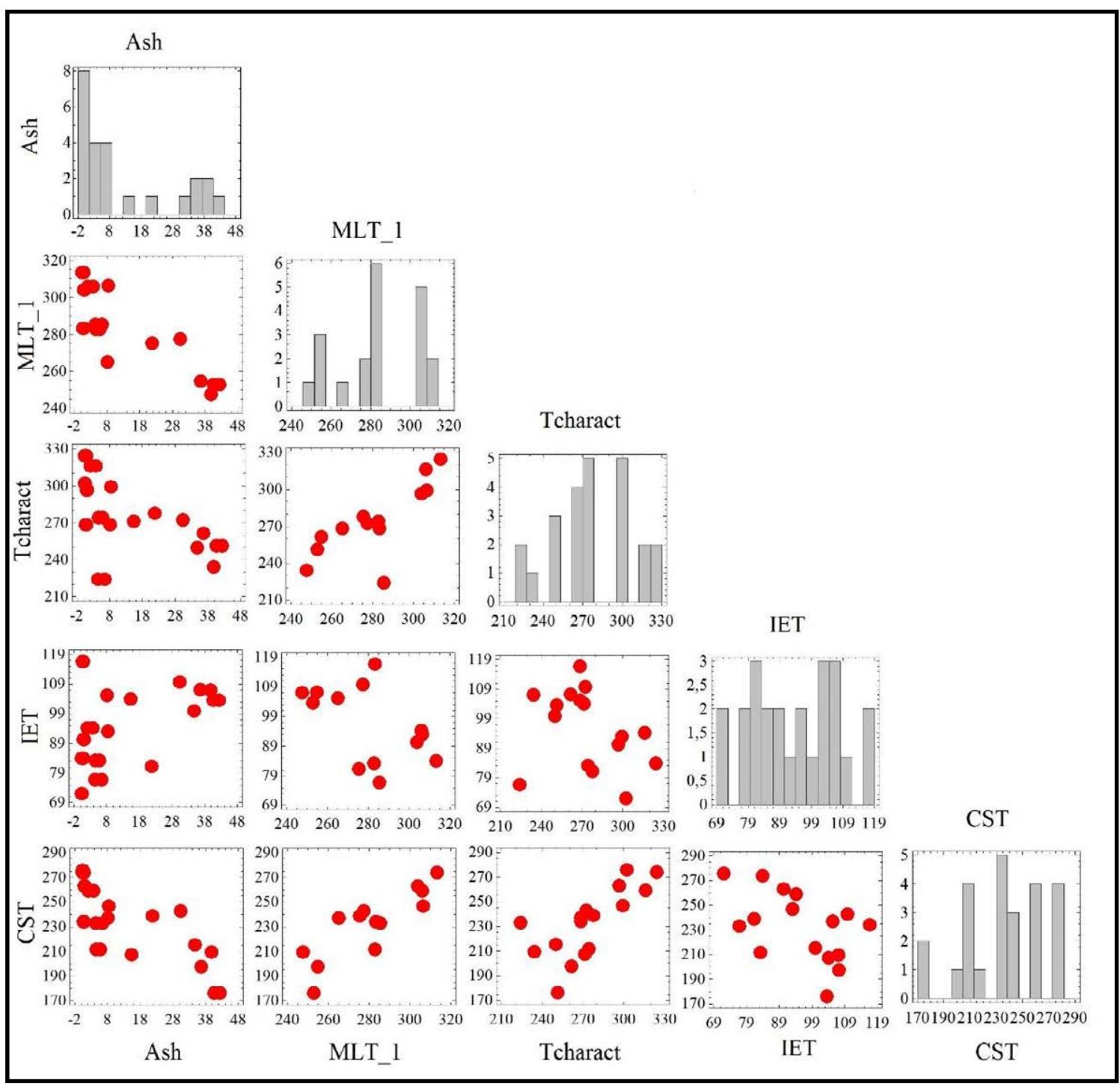

Figure 54. Relations between ash content (\%), MLT_1, Tcharact, IET, CST $\left({ }^{\circ} \mathrm{C}\right)$

Looking at the volatiles content, it is observed that the samples with a high amount of fines (low particle size) are the ones that have less amount of volatiles. This causes a significant correlation with the specific surface area too. Volatiles also show important relations with the thermal properties of the samples. Positive relations with diffusivities and specific heat have been observed, and a negative one with densities. This is because coke, coals and sewage sludge have low amounts of volatiles, low values of diffusivities and specific heat, but high densities values, while the opposite occurs for biomasses. Finally, focusing on the thermal behaviour of the samples, MLT_1, IT and Ea are related to the volatiles content, with a negative correlation the first one and positive the other two. Coals, coke and sewage sludge need higher temperatures for the beginning of the combustion process than biomasses (mainly woody). Coals and coke only present one peak on the dTG curve, so they do not have any MLT_1 value. Even so, the biomasses with lower amount of volatiles (sewage 
sludge) present lower values of MLT_1. This means that they have more amount of hemicellulose than cellulose. The relation existing with $\mathrm{Ea}$ is due to coals and coke, which are the only ones that present Ea values of more than $79 \mathrm{~kJ} / \mathrm{mol}$.

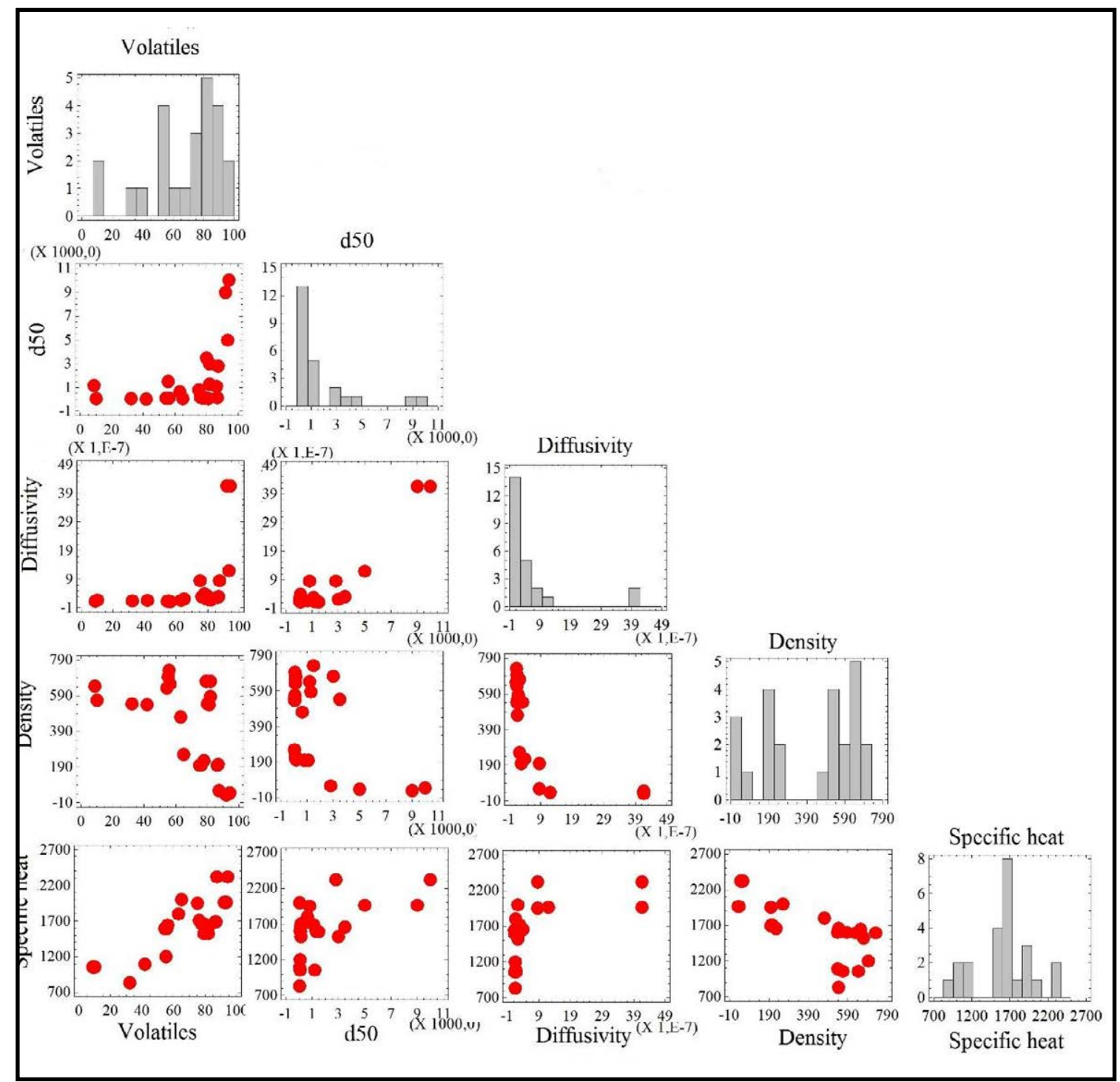

Figure 55. Relations between volatiles content $(\%)$, d50 $(\mu \mathrm{m})$, diffusivity $\left(\mathrm{m}^{2} / \mathrm{s}\right)$, density $(\mathrm{g} / \mathrm{L})$ and specific heat $(\mathrm{J} / \mathrm{kg} \cdot \mathrm{K})$

Fixed carbon content presents also significant correlation with moisture, volatiles, MLT_1, IT, Ea and CST. The relation between fixed carbon and volatiles is caused by coke that have a higher amount of the first one and low of the second one, and its opposite that are the plastics samples (Figure 56). Coke and coals have higher values of IT, CST and Ea and their fixed carbon content is much higher than for biomasses or plastics. 


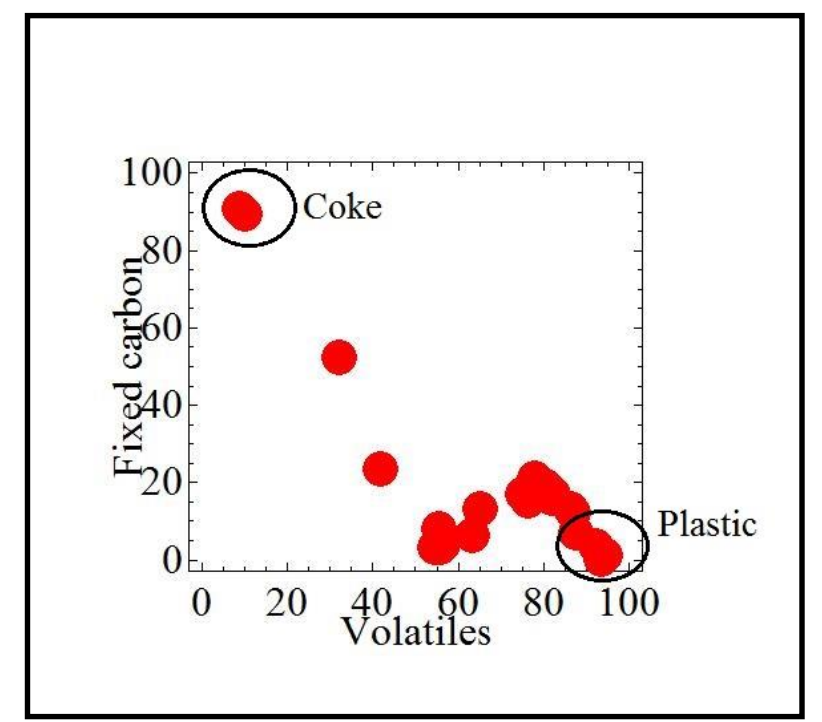

Figure 56. Fixed carbon vs volatiles solid fuels

Particle size parameters are also well-known as main parameters on the study of flammability of dusts. In this case, their main relations are observed with the thermal properties (diffusivities, specific heat and densities). The lower the particle size, more amount of fines the samples has that can fill the pores and increase the density while the amount of air existing decreases, so the diffusivity of the sample do the same.

The flammability temperatures present correlations among them too, being the main ones the existing between MLT_1, IT, Tcharact, IET and CST.

Due to the existence of two groups according to their particle size, and how the influence of dusty materials may vary the risk of an industrial facility, another study has been developed only with the fine particles samples. In this case, also ashes and volatiles contents show their importance on the flammability of biomasses.

Ash content is related with the diffusivity of the samples and with almost all the temperatures studied. Diffusivities present a negative correlation with ashes due to the sewage sludge samples, which present high amounts of ash and low thermal diffusivity, unlike biomasses with low ashes contents and high thermal diffusivities. As in the previous case, the negative relations existing with temperatures (MLT_1, Tcharact, FET, CST, MITl 50mm) show that sewage sludge samples have more reactivity than the other studied biomass samples. 


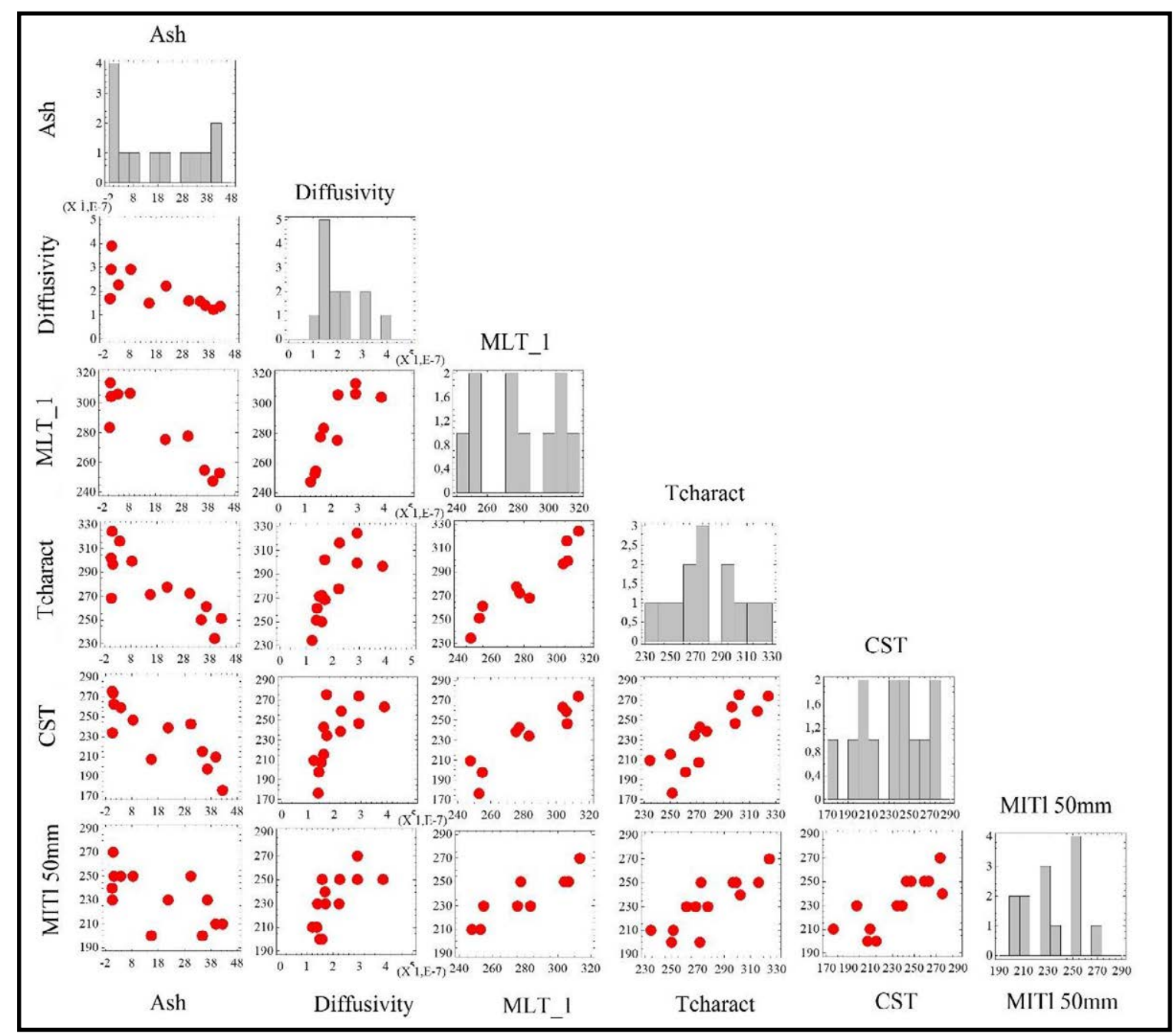

Figure 57. Relations between ash content (\%), diffusivity $\left(\mathrm{m}^{2} / \mathrm{s}\right)$, MLT_1, Tcharact, CST and MITl $50 \mathrm{~mm}\left({ }^{\circ} \mathrm{C}\right)$

Volatiles content present important relations with fixed carbon content, specific surface area, diffusivities, specific heat and only three flammability parameters (MLT_1, IT and Ea). These results are also similar to the ones obtained in the precious case. 


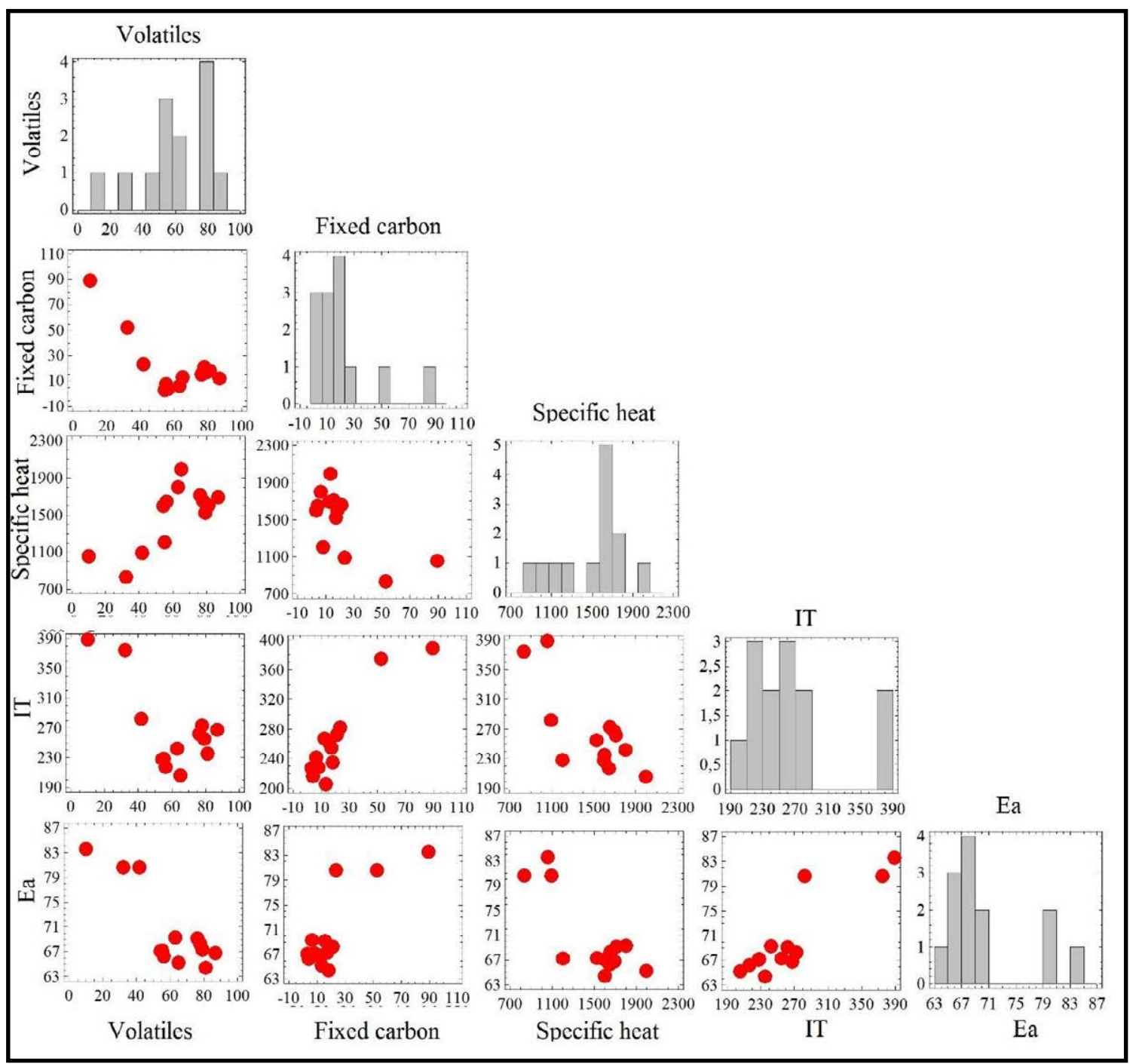

Figure 58. Relations between volatiles and fixed carbon contents (\%), specific heat $(\mathrm{J} / \mathrm{kg} \cdot \mathrm{K})$, IT $\left({ }^{\circ} \mathrm{C}\right)$ and $\mathrm{Ea}(\mathrm{kJ} / \mathrm{mol})$

In this case it is important to observe the influence of the diffusivity on the flammability parameters. When the particle size studied is small, diffusivities present significant relations with several temperatures (MLT_1, Tcharact, CST, MITl 50mm). The samples that present higher thermal diffusivity values are the ones with less densities, torrefied wood pellets, wheat straw, wood chips, wood pellets and almond shells, and they present the higher values of flammability temperatures, and so the combustion of these materials is more difficult and needs more temperature than for sewage sludge, which present lower values of diffusivities.

The flammability temperatures also present important relations when studying fine particle size samples, adding the MITl $50 \mathrm{~mm}$ parameters to the significant relations list. 


\subsubsection{MINIMUM IGNITION TEMPERATURE ON LAYER}

The influence of the thickness in the minimum ignition temperature of a layer is shown in this study. The difference of the values for different granulometries is higher when the layer is finer.

MITl values for a 50 millimetres layer are not influenced by the compaction for the coarse samples. Coarse samples are not significantly compacted with this method, so it does not vary any parameter that affects to the values of the MITl.

Looking at the different pellets, it is shown how pelletizing process affects to the values [112]. On one hand, coke and sewage sludge pellets particles are round and can be squeezed into gaps and voids, generating a higher density and harder pellet [113]. Also the pieces of olive pit are hard and not easy to break. This causes high values of MITl for these samples. On the other hand, wood pellets and torrefied wood pellets are cylindrical and fragile, only with the pressure of two fingers it is possible to break them up. They are formed by thin particles, so once the pellet is broken the propagation is easier.

Finally, for torrefacted wood pellets there is no difference between powder and pellets. In one hand, during torrefaction, the water contained in the biomass as well as superfluous volatiles are released, and the biopolymers (cellulose, hemicellulose and lignin) partly decomposed, giving off various types of volatiles. On the other hand, the higher the torrefaction degree, the higher the proportion of thin particles is [114].

By plotting MITl 50 millimetres vs volatiles content (Figure 59) it can be seen a differentiation on areas depending on the volatiles content.

By a multivariate analysis it can be seen that the main cause of this differentiation is the specific surface area, which represents the area of particles that is in the surface. Coal samples have higher specific surface area since they are round and uniform, and biomass samples are elongated and heterogeneous. Sewage sludge particles shapes are located in the middle of both distributions. This parameter is not determinant for the narrower layers.

While the access of the oxygen to the particles is higher, the temperature needed from the hot surface is lower, and the ignition is easier. Looking at the biomass group, wood chips is the sample with higher MITl due to its heterogeneity, unlike almond shell and olive pit that are more uniform and need less temperature to ignite. 


\section{Discussion}

Also it can be shown how MITl can be increased by increasing the particle size looking at sewage sludge 2, which has higher particle size and is located with biomass samples and not inside the sewage sludge group.

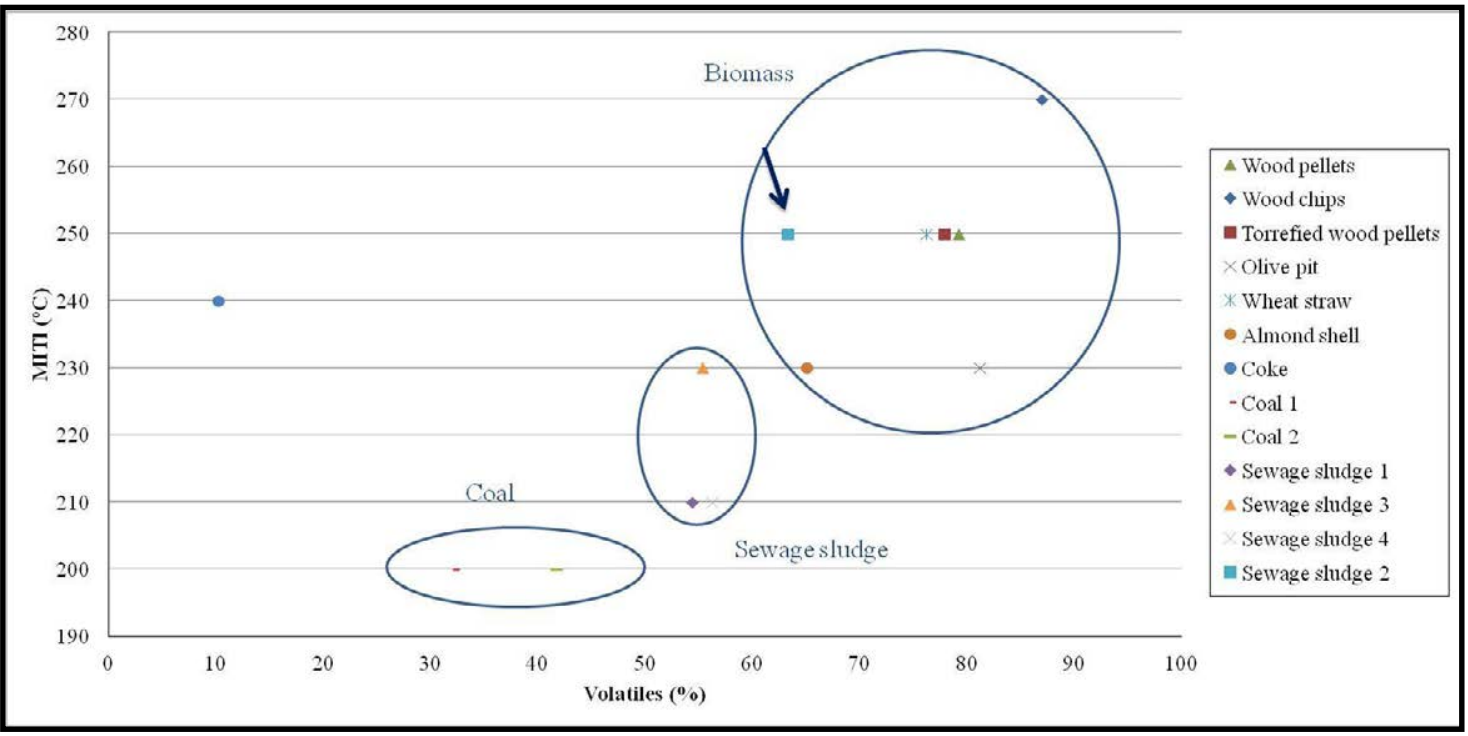

Figure 59. MITl $50 \mathrm{~mm}$ no compacted vs volatiles content

Looking at the thermal diffusivity of the samples, it is shown that the higher the thermal diffusivity, the higher the MITl is. Thermal diffusivity is defined as the ability of a material to conduct thermal energy relative to its ability to store thermal energy. In a substance with high thermal diffusivity, heat moves rapidly through it because the substance conducts heat quickly relative to its volumetric heat capacity. As heat moves rapidly through the substance, it is more difficult for it to reach the temperature for ignition, so the temperature that the hot plate has to supply to the sample for ignition is higher.

Focusing on compaction, it affects in a different way to the different studied samples. In four of the fourteen studied samples, the MITl increases when compacted and it decreases for other four samples, being the same for the other six samples studied. A multivariate analysis has been developed to the data, and it is shown that the factors that most influence this variability are the particles size related factors. According to this analysis, the factor that influences this differentiation the most is the specific surface area (SSA), as can be seen thanks to a middle graph (Figure 60). In the $\mathrm{x}$-axis it is shown the difference between the MITl $50 \mathrm{~mm}$ no compacted and the MITl $50 \mathrm{~mm}$ compacted, in order to shown the variation between both distributions. In the y-axis it is shown the value of specific surface area (SSA). The mean of each group of values decreases when the specific surface area increases, i.e. for higher values of SSA, the MITl of compacted sample is higher than for the no compacted one. 
If the dust has a big specific surface area, and the access of oxygen to the samples is higher, the heat may be dissipated and it is more difficult to ignite the layer, i.e. the MITl is higher for no compacted layer than for compacted. When this specific surface area is lower, the access of oxygen is more difficult and heat cannot be dissipated, so it is easier to ignite the layer. Medium values of specific surface area produce no difference between compacted and no compacted samples.

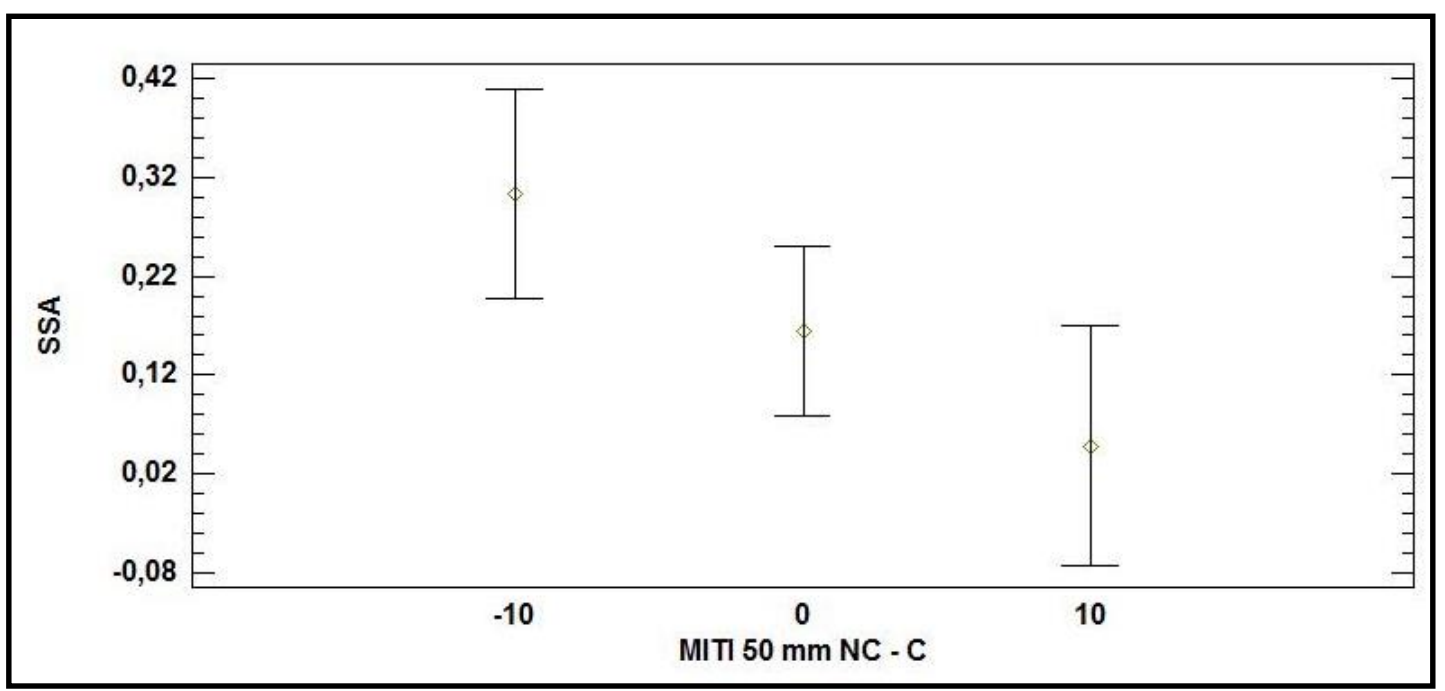

Figure 60. Middle graph SSA vs (MITl $50 \mathrm{~mm}$ no compacted - MITl $50 \mathrm{~mm}$ compacted)

\subsubsection{THERMOGRAVIMETRY - DIFFERENTIAL SCANNING CALORIMETRY}

Thermogravimetric curves present several differences that characterize the thermal behaviour of the studied samples. Looking at the all the curves, it is shown that coke and coals curves present the decrease on the curve later than the other samples, i.e. the combustion of these samples start at higher temperature than for the other studied samples. Focusing on each group, plastics present similarities on the curves and on the values, as well as sewage sludge samples. The coals and coke graphs present some differences, mainly because coke present less residues at the end of the combustion, so the weight loss at the end of the heating process is almost null. The combustion of NFA-11 starts and finishes at lower temperatures, and it have a lot of residues at the end of the process. Biomass samples are divided in two groups according to the residues that they have. Stubble, straw and almond shell leave less residues than the other studied samples. However, all these samples present a temperature of induction to combustion of less than $280^{\circ} \mathrm{C}$ 


\section{Discussion}

These similarities and differences are also observed thanks to the derivative curves. First of all, it is important to notice that plastics, sewage sludge and biomasses present two peaks in this derivative curves while coke and coals present only one. This is due to the composition of the samples, the first peak is originated by the devolatilisation of light compounds as holocellulose, which is not present on coals and coke samples. The curves of the plastics samples present again a lot of similarities, so their thermal behaviour is expected to be almost the same. The group formed by coals and coke is the only one that present one peak, and they also present some differences among them. NFA-11 present a short and narrow peak that represents a quick and short reaction, while the coke's peak is high and width, representing a long combustion reaction. Sewage sludge samples show similar peaks, but sample NFA-5 present both peaks later than the other three studied samples, so the devolatilisation of the materials is more difficult for this sample. Finally, looking at the last group it is shown that both peaks are located in the same range for all the samples. However, the peaks are higher or shorter depending on the composition of the samples. It is important to notice that for the three woody samples, these peaks are higher and more elongated while the materials are more processed, being the shorter for wood chips and the higher for torrefied wood pellets.

When the air stream is substituted by an oxygen one in the thermogravimetry tests, the differences observed among the samples are bigger. In this case, coals and coke are not the last ones on losing the weight, but wood pellets and wood chips are the samples with higher characteristic temperature. The main difference existing among these samples is that not all of them present the expected sudden weight loss. Samples NFA-5, NFA-13 and NFA-14 present a slower loss of weight caused by the chemical composition that they present.

If the samples are plotted on the thermal stability graph (Figure 41), it is shown that 12 of the 16 studied samples are located on the high self-ignition risk area, one in the very high, and the other three in the medium area. The activation energy does not seem to be an important parameter in this study, since the only samples that present a value of more than $79 \mathrm{~kJ} / \mathrm{mol}$ are the coals and the coke.

The study of the DSC curves is focused on the energetic behaviour of the samples during a heating rate. $\mathrm{Al}$ the graphs present similar forms, where the belly of the curve is used to study the energy that the samples need to absorb before the exothermic reaction can starts. The higher the heat flow at the beginning of the exothermic reaction (IET), the higher the amount of energy that the sample needs for starting this exothermic reaction. 
Plastics samples (NFA-6 and NFA-14) present similar reactions where the exothermic reactions start before the complete loss of moisture (before $100^{\circ} \mathrm{C}$ ). They also present a second endothermic reaction just before $300^{\circ} \mathrm{C}$. However, NFA-6 has a component that causes a degradation at the end of the process, which is why the FET of this sample is higher than the NFA-14 ones. Due to the heterogeneity of the samples, and the small particle size needed for this tests, this may be caused by a component that is not present in all the material. Looking at the parameters obtained for coal samples, the similarity among them is obvious. Anyway, NFA-3 has a small endothermic reaction, while for NFA-11 it is bigger. Coke sample exothermic reaction starts really early $\left(\operatorname{IET}=72^{\circ} \mathrm{C}\right)$ and it finishes later than both coal samples. The length of this exothermic reaction makes coke a good material for obtaining energy.

The same quality is observed on the olive pits (NFA-14), but its exothermic reaction starts later and it needs more initial absorption of energy. Biomasses present a large range of values for the parameters obtained from DSC analysis. However, this range is as expected.

\subsubsection{GAS EMISSIONS TEST}

The results clearly indicate that increasing the temperature the total emissions of gas increase, which is fully expected as higher temperature implies an increased rate to the oxidation reaction.

This reaction occurs on the surface of the solid particles of the material, so that since it is an exothermic reaction, a heat source is generated. Upon oxidation of the dust material with the air is a spontaneous exothermic reaction, heat is being released. This phenomenon is called self-heating and is the first step in a process that might finally result in spontaneous combustion. An increase in temperature due to exothermic reaction on the solid surface will produce an increase in the reaction rate, releasing more heat, and this process rapidly accelerates to high temperatures, leading to self-ignition.

The spread of the reaction is affected by the availability of oxygen, and this is related both to particle size and compaction.

More emission from the sample with larger particles could be expected because oxygen in the air would have better access to the surface of the particles. The fine sample behaves somewhat like a compacted sample, because the oxygen access is reduced, but the larger specific surface due to smaller particles will probably have a greater influence on the reaction. 


\section{Discussion}

As for the compaction, it is evident that a compacted sample has a smaller spacing between the particles, which hinders the oxygen access to the area.

Somehow there is a competition between different phenomena (access of oxygen and thermal diffusivity) and temperature will have a decisive influence on which variable predominates. At low temperature, at the time of starting the self-heating, compaction delays the start of the process because it makes access to the solid surface difficult for oxygen: the solid-gas interaction is reduced. However, when the temperature rises enough, the initial oxidation is guaranteed and what influences the development process is the propagation of the reaction, which is now favoured by increasing the thermal conductivity. The self-heating process depends on both the heating and cooling and a high conductivity at the initial time favours heat dissipation and delay the process. Conversely, when the process is underway and the temperature rises, the highest conductivity promotes the heating of the particles close to the heat source.

This change observed with increasing temperature can be seen very well in the DSC curves. Upon reaching the IET (initial temperature exothermic reaction), still at low temperature, the process is still slow and the access of oxygen to the surface is the dominant mechanism for the development of self-heating. However, once the CST (slope change of temperature) is exceeded, the process is faster and will be conditioned by the spread of the reaction, which is favored by a higher thermal conductivity.

By comparing the three methods studying the results obtained by this test, it has been observed in a first look that the third method, the one using the environmental standard methods, provides higher temperatures than the others studied. These values are in many cases also higher than the temperatures obtained from TG-DSC analyses. That is to say that the self-ignition process starts before the environmental limits are achieved.

Looking at the first two methods, both advantages and disadvantages have been observed. The "Inflexion point" method provides an exact number instead of the range of values that the first one does. The values obtained from this method are in most cases inside the range of values determined by the "Interval", only in three of the studied cases the detection can be done in advanced by the second method.

Focusing on the results obtained from the gas emissions test, it is seen that results are different depending on the group of samples we are looking at. The four thermally dried sewage sludge samples studied shown low temperatures in these tests., and $\mathrm{CO}_{2}$ emissions 
are more important in these samples, being emitted before $\mathrm{CO}$ in more cases than in the other studied samples. These results are related to the heterogeneiny of the samples, which produces a first gases emissions at low temperatures that are not observed on the results of the DSC (all of them between 100 and $110^{\circ} \mathrm{C}$ ). The influence of compaction show also two different ways. In one hand, NFA-5 and NFA-9 provide a lower temperature for compacted sample than for no-compacted. On the other hand, NFA-7 thin and NFA-8 show an increase of the temperature when compacting, so the self-ignition of the samples is more difficult. The gas emissions for NFA-7, studied for two granulometries, show how compaction affects in a different way to hard pellets or dust sample. When compacting a fine sample, the air between the particles drastically decrease, and $\mathrm{CO}$ emissions are retarded as $\mathrm{CO}_{2}$ can be emitted in advance. On the other hand, the compaction of the pelletized sample produces a decrease on the exposed surface of the particles, so the complete combustion take place retarded while an incomplete reaction is taking place, i.e. $\mathrm{CO}_{2}$ emissions start before for compacted samples while they start later for no-compacted. Also coarse samples present higher values of the obtained parameters, so their self-ignition starts at higher temperatures.

The two plastic samples studied provide lower results with DSC than with gas emissions test. This is due to the difference on the particle size of the samples. For the DSC the samples are prepared for less than $180 \mu \mathrm{m}$, but the samples tested in the gas emissions analyses were bigger, as explained in advance.

Looking at the fossil fuels, coal samples present lower temperatures than coke, but differences are not significant. The effect of compaction and granulometry on coke is the opposite as the one observed for sewage sludge (NFA-7).

Finally, biomasses present similar results. Woody biomasses present lower values the less developed they are. Compaction affects more to the coarse samples than to the fines, decreasing the detected values by compacting the samples. During compaction, fines can be generated and the self-ignition risk of the sample increases. This influence is not present on the agricultural biomasses (NFA-2 and NFA-12), where compaction has almost not influence. 


\subsection{THERMALLY DRIED SEWAGE SLUDGE}

\subsubsection{RELATIONS AMONG PARAMETERS}

To determine the relationships existing between chemical composition and explosibility parameters and also among the parameters within these two groups, a correlation analysis was done. The objective of this analysis was to determine the relations existing and define the conditions that could be easily modified by preventive measures and may cause a decrease on the explosion risk on this kind of industrial plants. With this analysis it is possible to see the similarity of the samples with other materials well-known as coal and biomass, and design prevention and protection measures based on those developed and widely experienced in other industrial plants.

To carry out these analyses, two groups of parameters have been analysed. In the first group chemical and granulometry parameters were analysed for 20 samples (twenty-sample group). In the second group, besides chemical composition and granulometry, also ignition sensitivity, explosion severity and thermal stability were studied for 10 samples (ten-sample group). From the data obtained from the analyses developed at laboratory, a correlation matrix has been determined in each case, and a Pearson's correlation analysis has been developed to each matrix, with a significant coefficient of 0.05 . Those correlations are studied in two groups, firstly the relationships existing among chemical parameters, and secondly between these parameters and flammability parameters or inside this last group.

a) Chemical composition

Looking only to the chemical parameters determined in this study, two main correlations groups have been observed.

The first group of parameters significantly correlated is formed by four composition parameters: carbon, hydrogen, volatiles and ashes content, as shown in Figure 61. Added to the correlations, also histograms of each one of the parameters are represented, being the $\mathrm{Y}$ axe the frequency of occurrence, the number of samples whose values are included inside the range represented in the $\mathrm{X}$-axe. The correlations existing between carbon, hydrogen and volatiles are positive, unlike that observed between ash content and these three parameters. These correlations are due to the chemical composition of the sewage sludge. The first three parameters represent the organic content of the samples, while the ash content can be assimilated as the inorganic matter contained in the samples. As the organic matter of the samples is higher, the inorganic is lower 


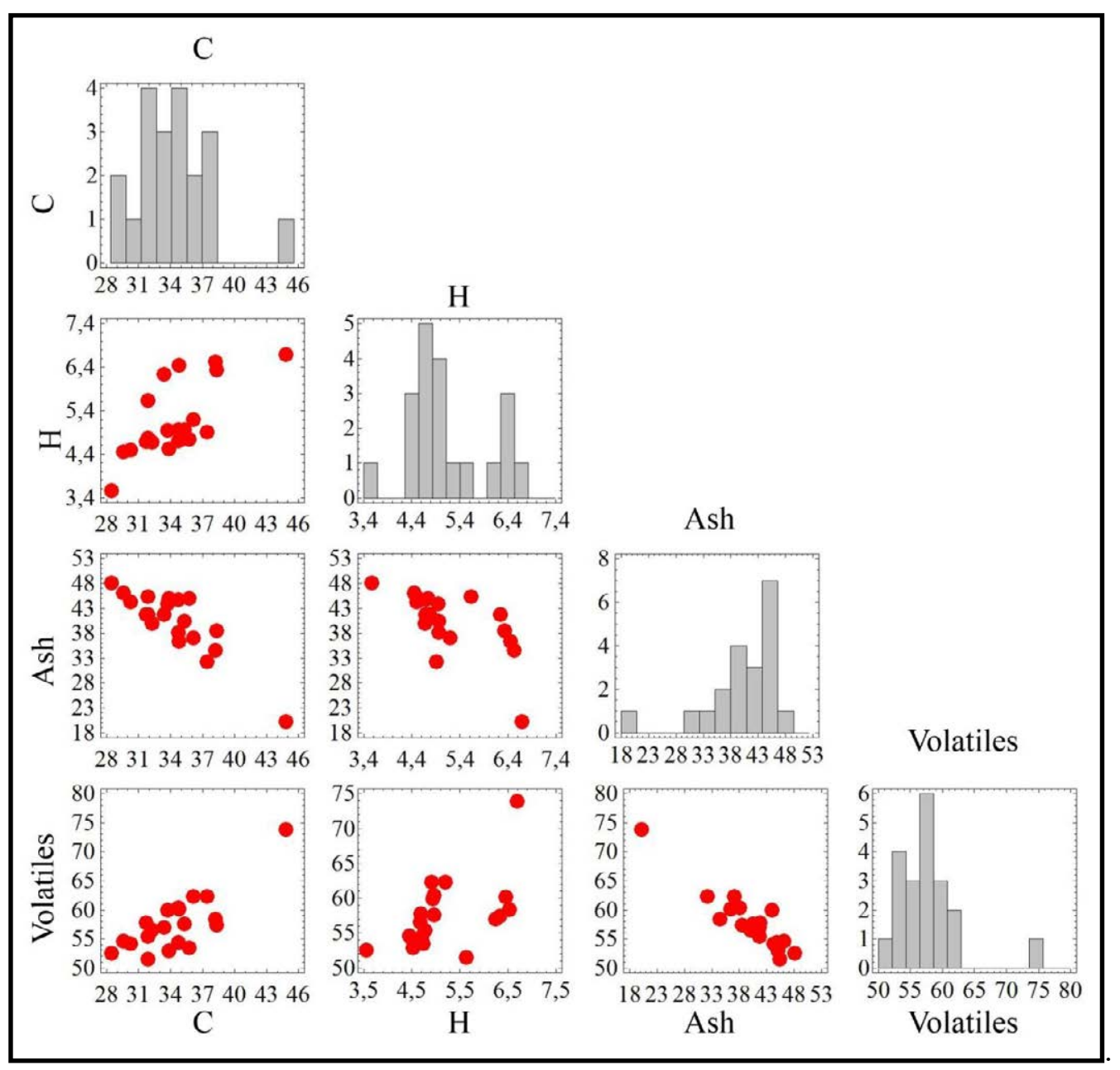

Figure 61. Relations between $\mathrm{C}, \mathrm{H}$, ash and volatiles content (\%)

The second group of significant correlations is observed between the three studied particle size parameters and it means that the tested samples have a high tendency to homogeneity as necessary in this tests. These correlations are illustrated on Figure 62 besides the histograms of each parameter. 


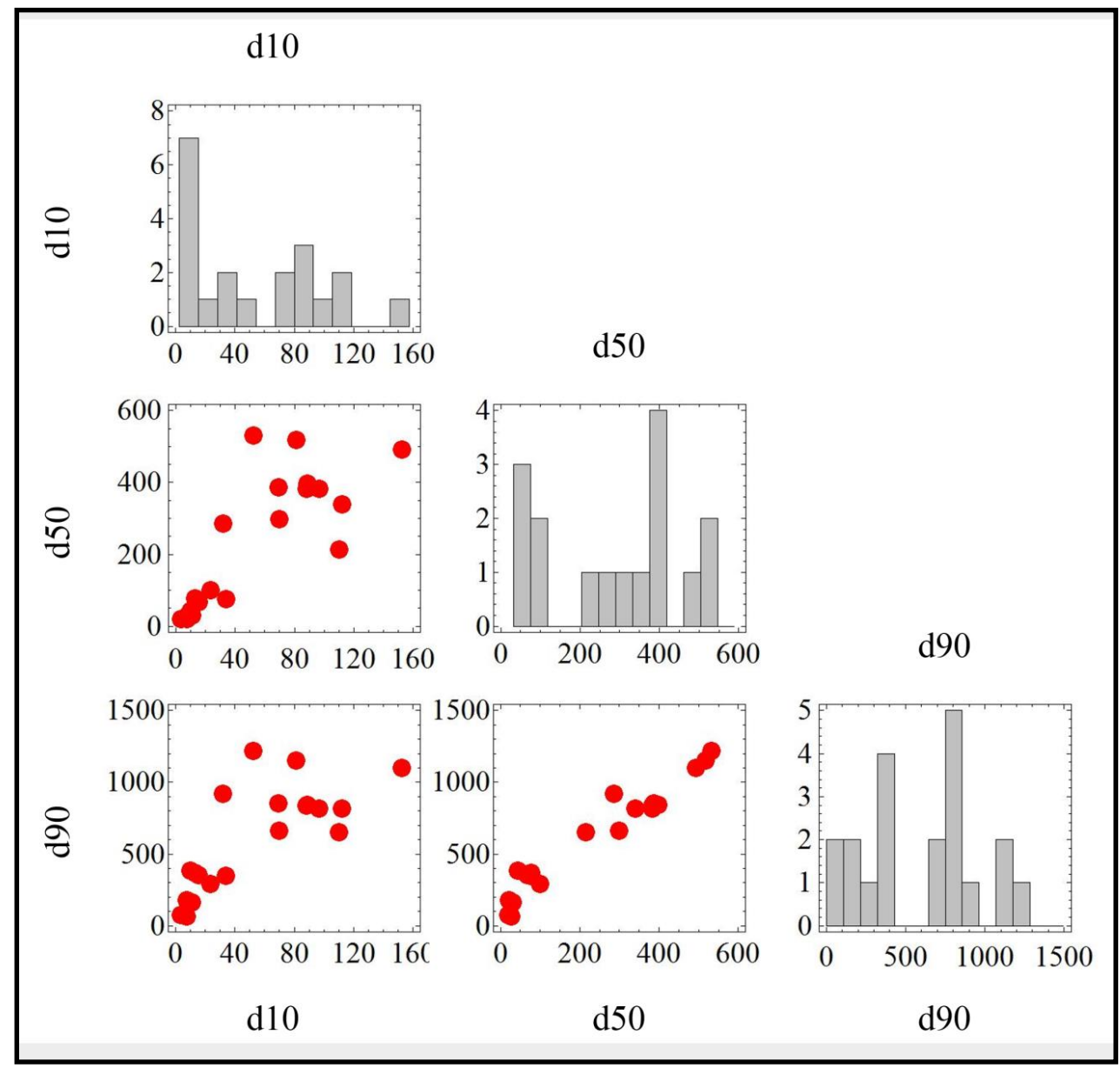

Figure 62. Relations between d10, d50 and d90 $(\mu \mathrm{m})$

b) Chemical composition and flammability

Volatiles and ashes content have a main influence on the flammability and explosibility of dusts. The main relations observed dealing these two parameters are those existing with MITl, MIE and Pmax, as shown in Figure 63. As can be seen by the visible alignment formed by the data, the higher the volatiles content, the easier is the flammability of the samples (lower ignition temperatures and energies) and also higher explosibility (higher explosion pressures). However, ash content has a negative influence on the flammability so that higher ignition temperatures and higher ignition energies are required to ignite sludge samples containing a higher inorganic fraction and the obtained explosion pressure is lower.

The addition of inert dust to some combustible products is usually done to avoid the explosion, and this effect can be explained by these correlations among ashes content and the different parameters shown in Figure 63. These correlations supply a method to decrease the ignition risk of the sewage sludge incorporating into the sample inert dust. 


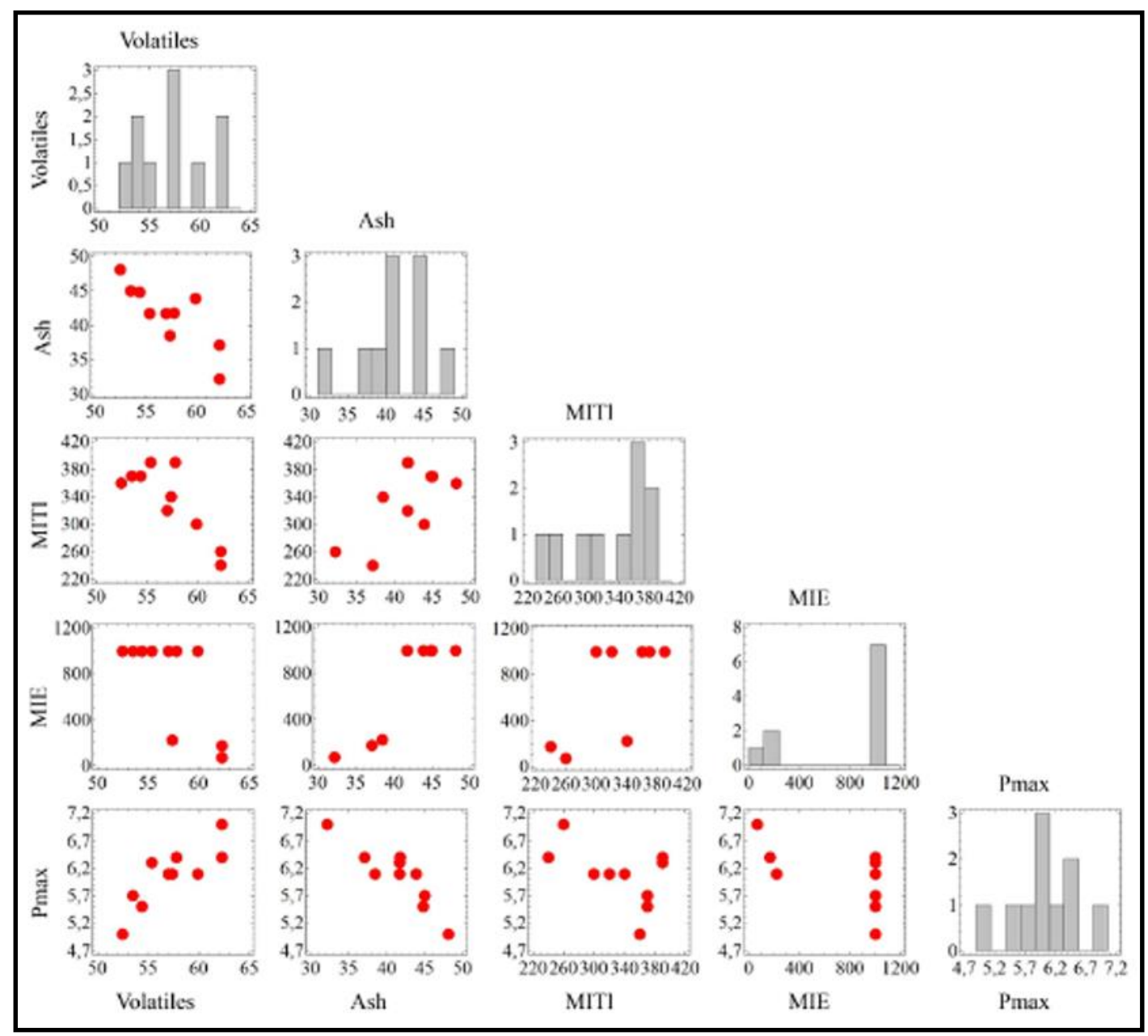

Figure 63. Relations between volátiles and ash contents (\%) and $\mathrm{MITl}\left({ }^{\circ} \mathrm{C}\right), \mathrm{MIE}(\mathrm{mJ})$ and $\mathrm{P}_{\max }(\mathrm{bar})$

Hydrogen and sulphur showed a strong relation to the flammability parameters and this can be explained by the oxidation tendency of these components that are present in the sewage sludge.

Relationships were also observed between the decreasing particle size and an increase on the flammability of dusts and on the explosion severity. These relationships are observed in these samples between the medium diameter (d50) and the MIE, MITl and IT as shown on Figure 64. 


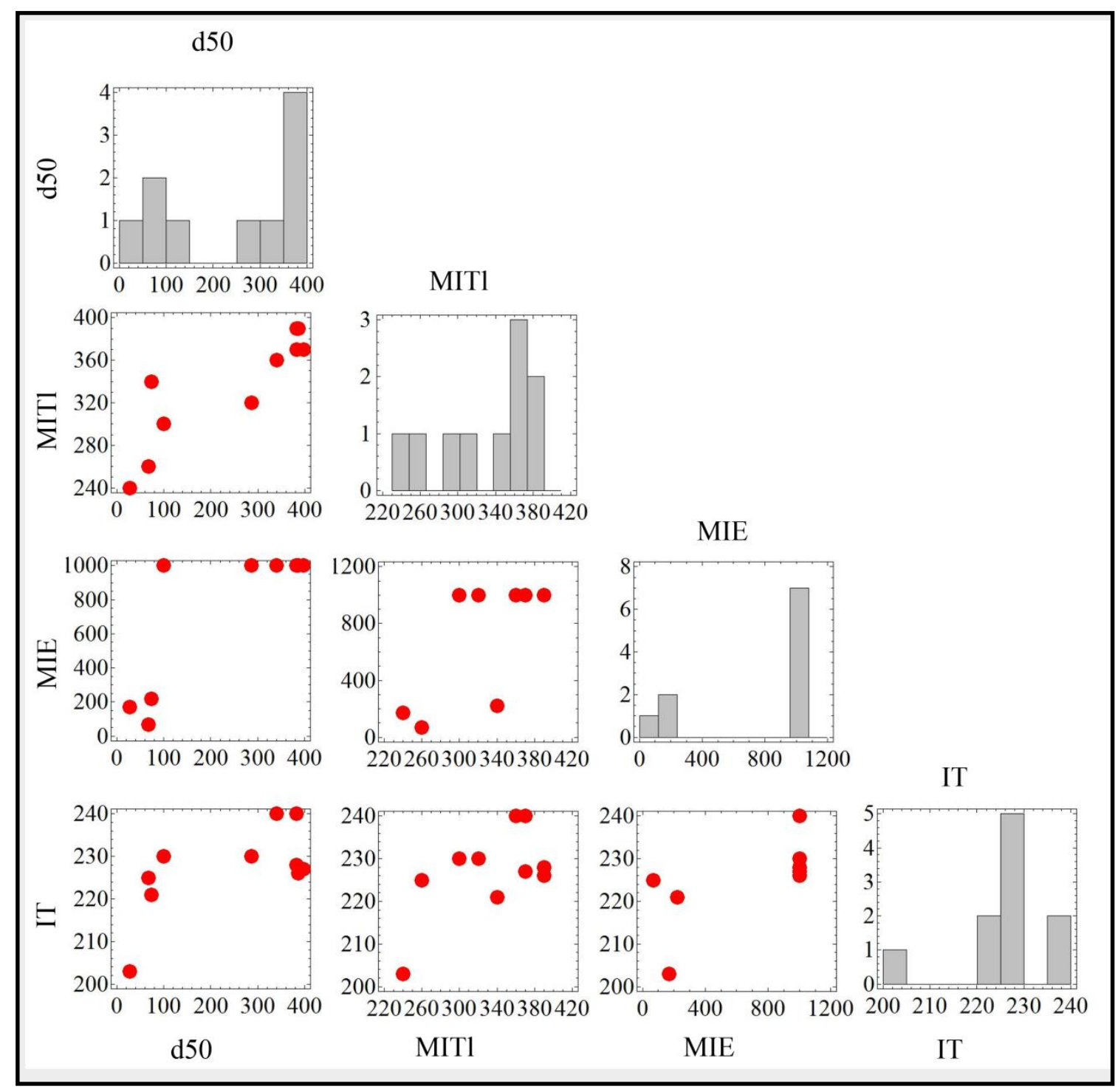

Figure 64. Relations between medium diameter $(\mu \mathrm{m})$ and $\mathrm{MITl}\left({ }^{\circ} \mathrm{C}\right), \mathrm{MIE}(\mathrm{mJ})$ and IT $\left({ }^{\circ} \mathrm{C}\right)$

The relationship existing between particle size and MITl has a double effect. In one hand, when the particle size is bigger, the gaps between the particles full of oxygen are larger, so the ignition easiness is higher. But in the other hand, the ignition is more difficult because the air is less conductive than the own substance. In this case, the second effect is stronger than the first one and by enlarging the particle size it is possible to increase the MITl and the ignition of a dust layer is more difficult. The same effect occurs with the IT, the higher the particle size, the higher the IT so the combustion of the sample starts at higher temperatures. Increasing the particle size and preventing the production of dust of extremely small particle size is also in this case a possibility to prevent the ignition risk in this kind of industrial plants. Correlations with MIE do not lead to a line like in the other cases. Those are significant correlations because samples are grouped in two groups, one for these samples with less than 
$1000 \mathrm{~mJ}$ of MIE and another with more. Generally, the group with more than $1000 \mathrm{~mJ}$ has less volatile content, more ash content, more higher MITl and lower Pmax. These relations are expected, but more samples are needed to ensure them.

In addition, looking at the relations existing among different flammability parameters, it is also observed a significant correlation among several temperatures studied. When a combustible substance is heated by a heat source, it begins to oxidize, and as the temperature increases it oxidizes more rapidly. At a certain point, the heat generated by the oxidation is sufficient to maintain the ignition without the aid of external sources. This point is the selfignition temperature. Therefore, the three temperatures related to this ignition point (MITl, MITc and TEV) vary in the same direction as IT. Correlations related with MIE are similar as in the previous case, forming two groups of samples.

Other relations among temperatures are those more related with the volatile content of the sample. It was found that the higher the volatiles content the more easily it ignites. Because of it, when the Tcharact increases, also other temperatures associated with those volatiles (MITc, MLT and TEV) increase, due to the fact that Tcharact represents the temperature at which a quick combustion occurs. The exothermic reaction starts at lower temperatures as the reactivity of the substances increases (lower MLT) and the ignition of a dust cloud is easier (lower MITc). And in substances in which the quick exothermic reaction starts at low temperatures (lower TCP), the ignition of a cloud of sample is also easier.

Furthermore a relation was observed between ignition sensitivity and explosion severity, so that samples which need less dust concentration to ignite are those that produce the highest explosion pressures.

Finally, looking at the self-ignition risk of the sewage sludge, it was observed that when this risk is higher, the explosion severity is also higher.

\subsubsection{INFLUENCE OF ORIGIN AND SEASON}

A discriminant analysis has been developed based on two different factors: the origin of the samples and the season when they were collected. This analysis was applied to the two groups of data previously described: chemical analysis (twenty-sample group) and flammability data (ten-sample group). In the second analysis, due to the linearity existing among the parameters of these ten samples, a principal component analysis (PCA) was developed. 


\section{Discussion}

In both groups, the discriminant analyses according to the origin of the sample showed that the $100 \%$ of the samples are correctly classified. In the first group, no significant discriminant function is observed. However, in the second group a significant discriminant function is determined, and the moisture of the sample is the main parameter that causes the classification, followed by its sulphur content.

The analysis according to the season shows, that $95 \%$ of the samples included on the twentysample group and $90 \%$ on the ten-sample group are classified in the right group and only one of the samples is incorrectly classified in each case. In the first analysis realized to the twenty-sample data, one significant discriminant function has been determined. In this function, the parameters with more weight are the volatiles content and the carbon content. No significant discriminant function is observed in this case in the analysis done to the twenty-sample data.

\subsubsection{SPONTANEOUS COMBUSTION}

As can be seen in the thermal graph (Figure 65), one sample is placed in the medium risk rone, six samples in the high risk zone and three samples in the very high risk zone.

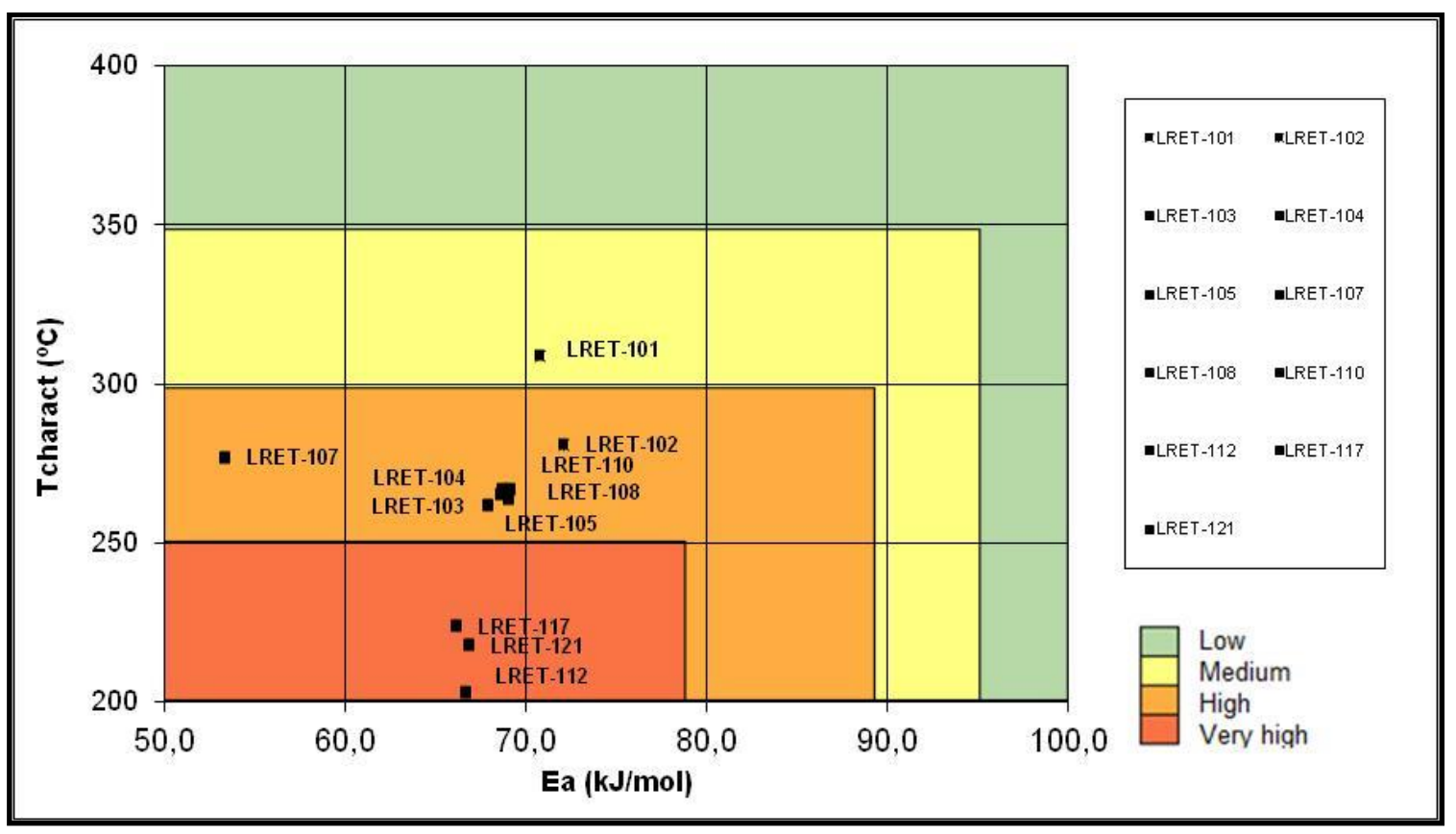

Figure 65. Thermal stability graph for thermally dried sewage sludge

As shown in the analysis, the Ea did not vary in great degree for these, unlike for coals. Coals from different ranges are located in different regions of self-ignition risk, but all the thermally dried sewage sludge and biomass present an activation energy of less than $79 \mathrm{~kJ} / \mathrm{mol}$. This 
situation is also observed for biomasses, which cannot be classify according to their Ea but for their Tcharact. The Ea lower values of biomasses and sewage sludge do not mean a lower risk, but this risk might be determined through Tcharact.

A discriminant analysis has also developed, and it was observed that $100 \%$ of the samples are well classified. Two significant equations are determined where $\mathrm{H}, \mathrm{N}$ and $\mathrm{S}$ are the main parameters causing the differentiation of the samples.

The three samples that are located in the Very high risk, LRET-112, LRET-117 and LRET121, area are those that have a lower difference between IET and CST in the DSC analysis, and the one that is in the Medium risk area is the one with the highest range. This means that the first stage of the self-heating process, consisting of the initial exothermic reaction (slow oxidation) is shorter for samples LRET-112, LRET-117 and LRET-121 than for the other samples. The second stage of the self-heating process that takes place when CST is reached (quick oxidation) starts very near to the initial point of the exothermic reaction.

The three samples that are located inside the very high risk zone are those three with hydrogen contents over $5 \%$ and whose slow combustion reaction is shorter. This location proved that the hydrogen concentration of sewage sludge produces the same effect as the release of volatiles during devolatilisation previously observed in other organic materials, such as different types of coals. For different rank coals, a higher spontaneous combustion risk is observed for low rank coals when volatile contents are higher, as it is the case of subbituminous coals.

This relation is not observed in the other direction for sewage sludge, since the sample that is located in the medium risk (LRET-101) is not the sample with less hydrogen content. This suggests that the hydrogen content is not the only parameter causing this differentiation and it is proved thanks to the discriminant analysis developed. This analysis shows the importance of nitrogen and sulphur content of the samples. It is shown that LRET-101 is the sample with the lowest sulphur content and the highest value of Tcharact, while with LRET-112 the opposite occurs.

Transport classification tests of the two samples tested and the interpolation of results for the third one show that there is no distinction between samples from different origins and that belonging to different spontaneous combustion risk zone. These results indicate that transport classification tests produce a broad grouping of samples, which is a reasonable finding for samples that have some similarities in their composition. 
Figure 66 and Figure 67 represent the size of the sample versus the inverse of temperature and versus time. Extrapolating these results it can be deduced that a volume of $1 \mathrm{~m}^{3}$ will reach self-ignition at $76{ }^{\circ} \mathrm{C}$ after 4.4 months; for $10 \mathrm{~m}^{3}$, the temperature would drop to 62 ${ }^{\circ} \mathrm{C}$, but the required time would increase to 3 years.

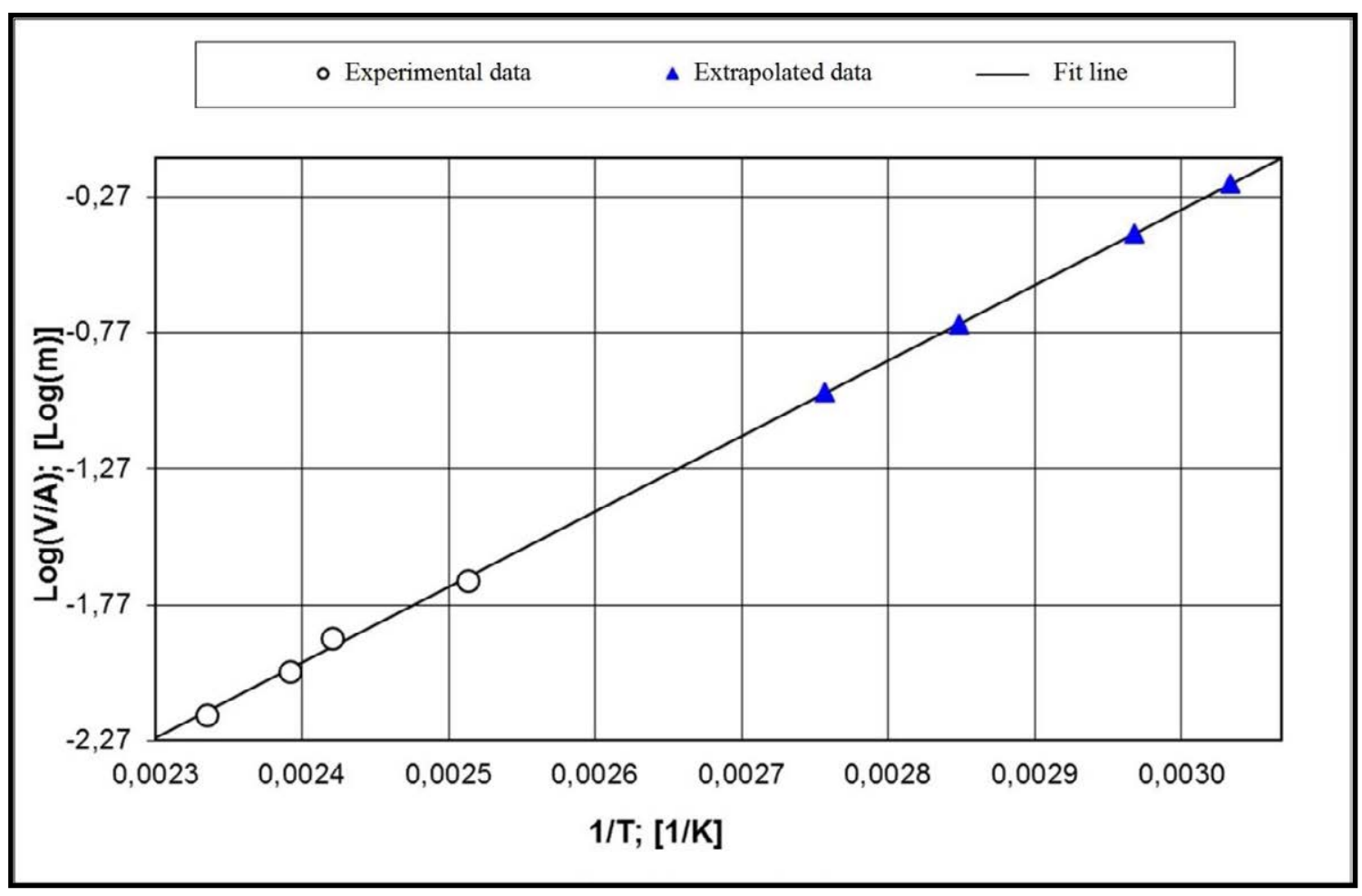

Figure 66. Extrapolation of SIT. Temperature [1/T] versus size [Log (V/A)]

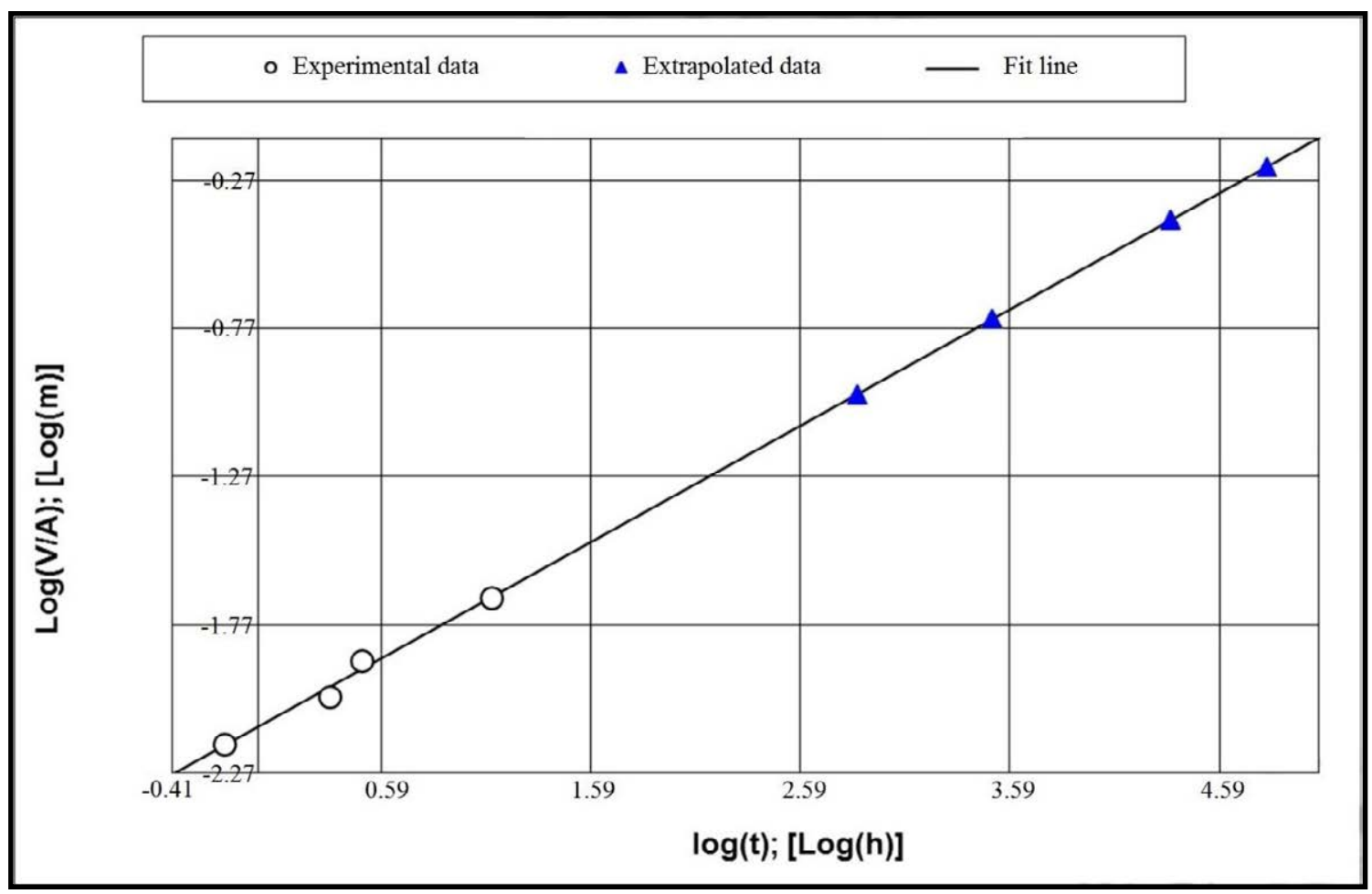

Figure 67. Extrapolation of SIT. Time $[\log (\mathrm{t})]$ versus size $[\log (\mathrm{V} / \mathrm{A})]$ 
These results were also extrapolated to determine the classification of LRET-121 according to ONU N.4 Division 4.2 and results show that this sample is also exempted of classification if it is transported in packages of less than 3 cubic meters.

\subsection{MIXTURES}

\subsubsection{RELATIONS AMONG PARAMETERS}

The main relations existing among chemical parameters of the samples are observed on the study of these mixtures. By a correlation matrix, and a Pearson's sensibility analysis, significant correlations have been observed between carbon and volatiles and ashes contents. Nitrogen and sulphur contents also show a significant correlation with the volatiles content. The correlations existing among the particle size parameters are also observed for these samples. In this case, six parameters are included in the study, and they are correlated among them. 


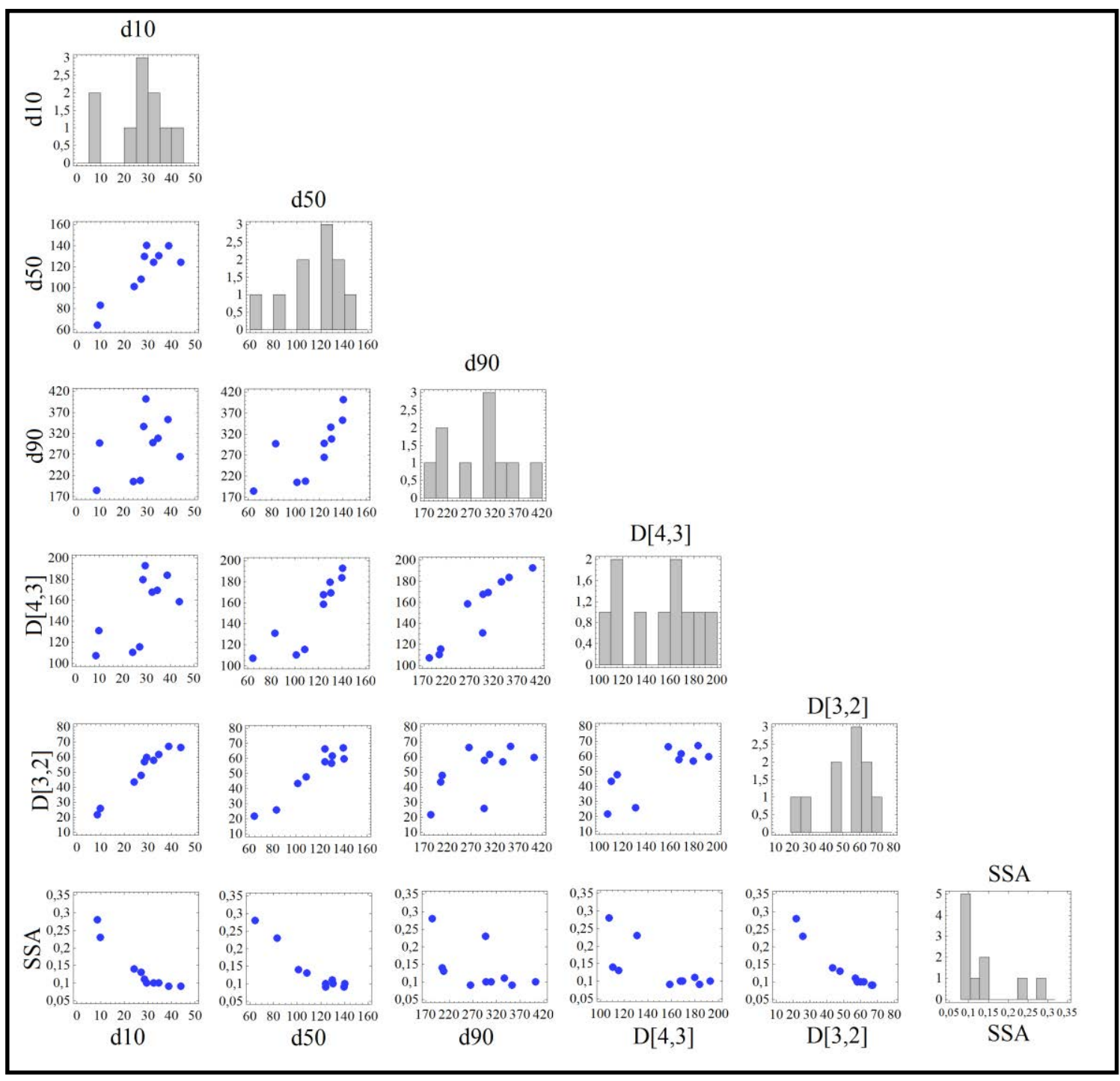

Figure 68. Relations between particle size parameters $(\mu \mathrm{m})$

Once the correlations with flammability parameters are studied, the following main significant correlations have been observed:

Carbon and hydrogen contents do not present any important significant correlations with the studied flammability parameters, being nitrogen and sulphur contents the ones that generate more dependency.

Nitrogen content presents important correlations with density and diffusivity, because the higher the nitrogen content (the lower the torrefied wood pellets content), the higher the density and the lower the diffusitivity. The samples with more coal content are the ones that have higher nitrogen contents. Three of them have a MIE of more than $1000 \mathrm{~mJ}$ and their Tcharact are lower. 
Sulphur content is mainly related with the energies for ignitions, MIE and Ea. When the sulphur content is higher, the energy needed for the ignition of the sample is higher, so it is more difficult to ignite it. Significant relations appear also with density and diffusivity, due to the presence of sulphur on the coal sample.

Secondly, the main relations with volatiles and ashes contents are those existing with diffusivities and densities, MITl, MLT_1, IT, Ea, IET, FET and CST. Diffusivity and density present negative correlations since the lower density the more amount of air is present on the sample, so the bigger the diffusivity is. Relations between volatiles and the MITl parameters (the three of them) are positive. This positive correlation is also observed with MLT_1, IT, Tcharact, FET, CST and diffusivities, while is negative with EMI, Ea, TIE and densities.

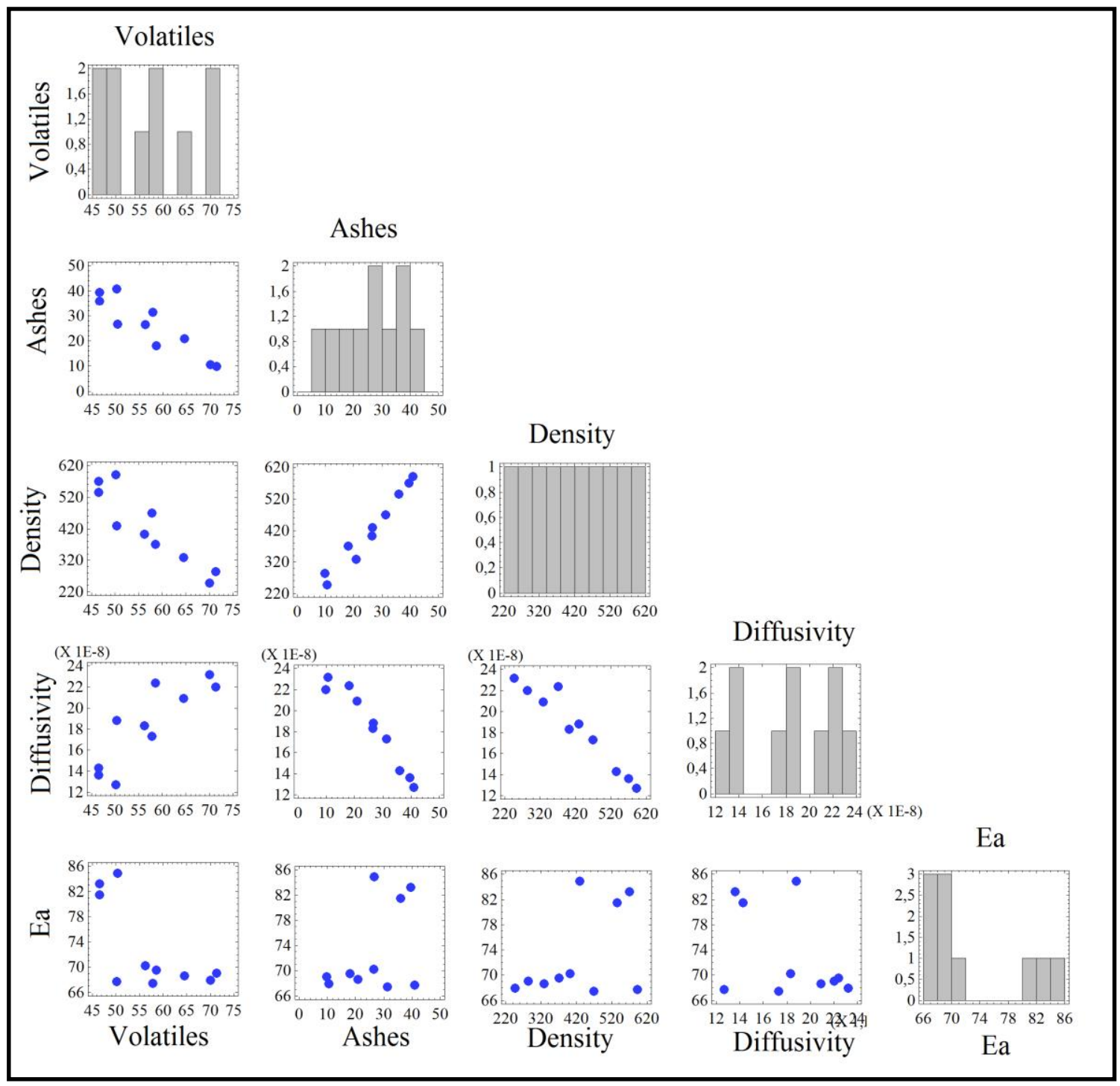

Figure 69. Relations between volatiles and ash contents $(\%)$ and density $(\mathrm{g} / \mathrm{L})$, diffusivity $\left(\mathrm{m}^{2} / \mathrm{s}\right)$ and $\mathrm{Ea}(\mathrm{kJ} / \mathrm{mol})$ 


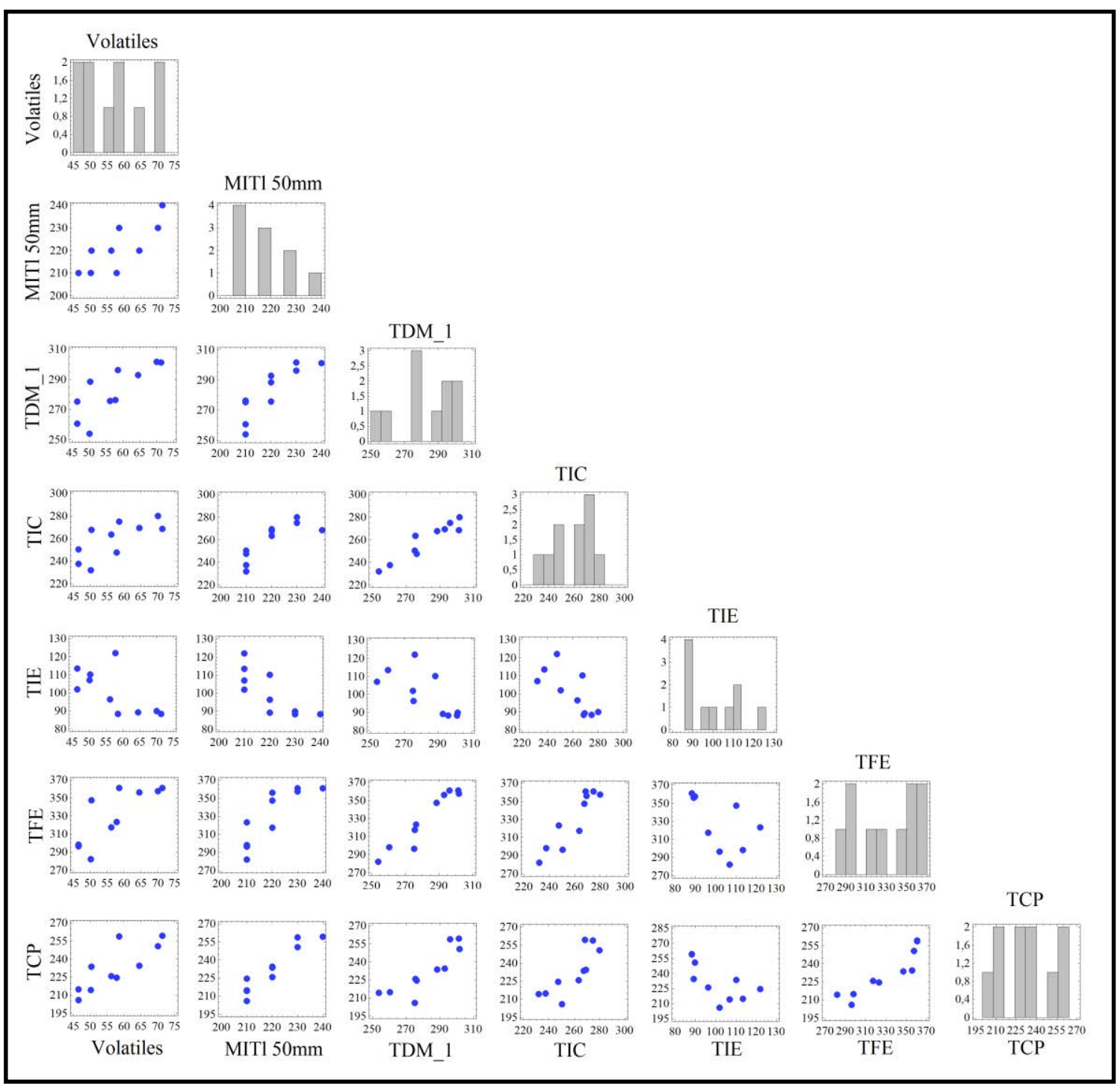

Figure 70. Relations between volatiles content (\%) and MIT150mm, MLT_1, IT, IET, FET and

$$
\operatorname{CST}\left({ }^{\circ} \mathrm{C}\right)
$$

The d50 could represent the particle size of the samples, and its relations are the ones observed with MITl 50 millimetres, MIE, Ea, Tcharact, CST, densities and diffusivities. The relations with the temperatures are all of them positives, so the higher the particle size, the higher the temperatures are and the more difficult the reactions are. On the other hand, with both energies (MIE and Ea), the relations are negative, and the lower the particle size the less energy is necessary to ignite the dust. Finally, the higher the particle size, the higher the diffusivity of the sample, and the lower its density is. 


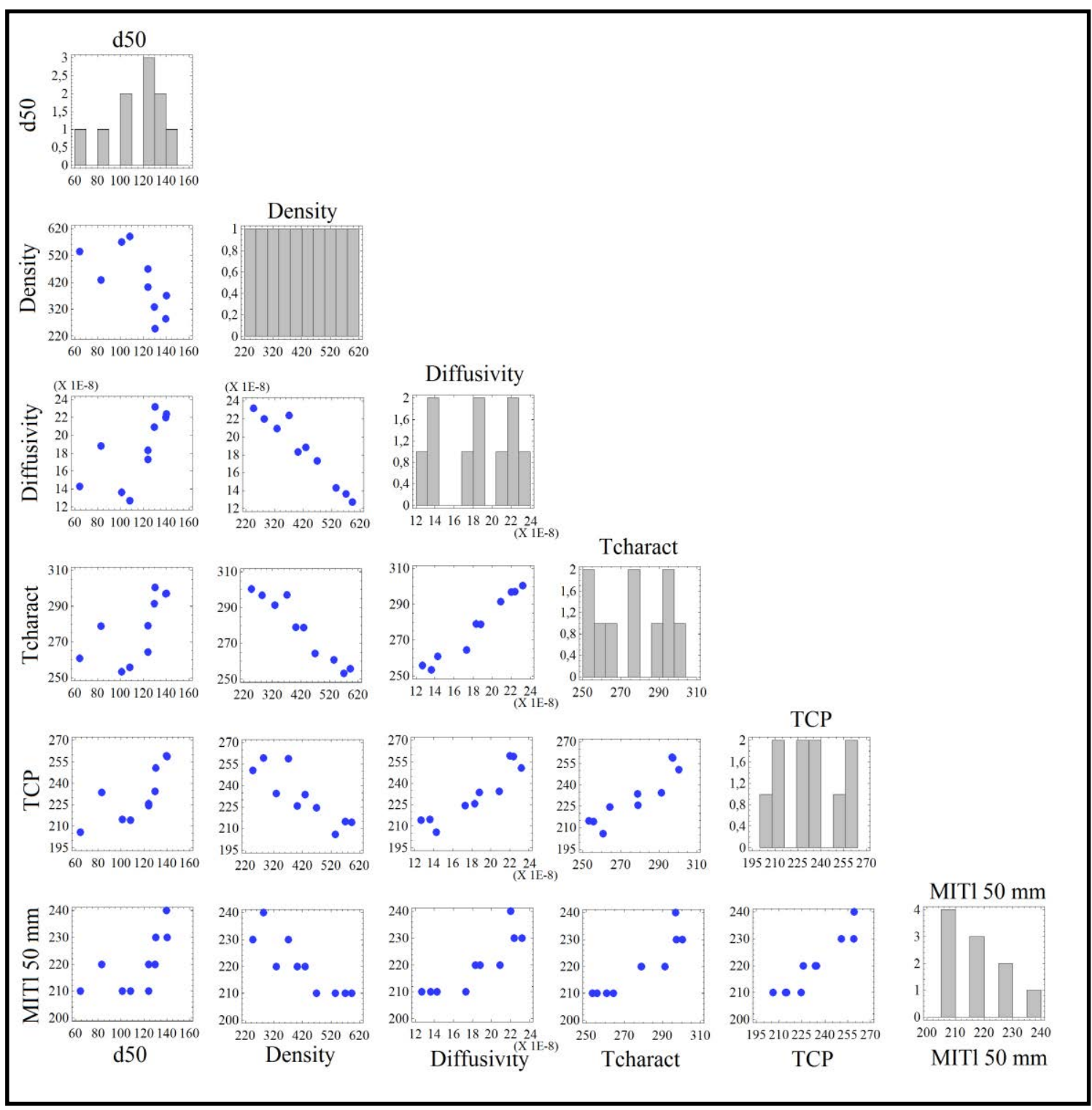

Figure 71 . Relations between medium particle size $(\mu \mathrm{m})$, density $(\mathrm{g} / \mathrm{L})$, diffusivity $\left(\mathrm{m}^{2} / \mathrm{s}\right)$, Tcharact, CST and MITl50mm $\left({ }^{\circ} \mathrm{C}\right)$

The minimum ignition temperature on a layer is related with IT, Tcharact, FET and CST are positive and show the similarities existing among these parameters and the processes they describe. However, this relation is negative with the IET.

Finally, it is important to remark that the MLT_1 present several relations, while MLT_2 does not present any significant correlation with any of the studied parameters. 


\subsubsection{THERMOGRAVIMETRY AND DIFFERENTIAL SCANNING CALORIMETRY}

Thermogravimetry curves show many similarities between the studied samples.

In the samples NFA-101 to NFA-103 it is observed that the IT decreases as the coal content decreases and the sewage sludge's increases.

In the samples in which biomass is added, NFA-104 to 106 and NFA-107 to 109, the IT increases when the torrefied wood pellets content increases, and the other material decreases (coal in the first case and thermally dried sewage sludge in the second one).

For the derivative curve of the thermogravimetry tests, the first peak observed is due to the light volatiles emission. This first peak is characteristic of light organic material, while coal samples do not present it. The higher the peak, the more amounts of light volatiles the sample has. And the narrower the peak is, the easier the reaction of these materials is.

Samples NFA-101 to 103, formed by coal and thermally dried sewage sludge, shown that when the amount of sewage sludge is higher, the first peak rises, and the second one decreases and widens. This means that the light volatiles content is higher when the sewage sludge content is higher, and the heavies are lower. The MLT_1 decreases when the sewage sludge content increases, so the combustion of the sample is easier.

Combining coal and torrefied wood pellets (NFA-104 to 106), the same process occurs but more drastically, due to torrefied wood pellets present tall and narrow peaks. The first peak increases by adding torrefied wood pellets, and the second one decreases. The MLT_1 increases when the torrefied wood pellets content increases.

In the samples formed by thermally dried sewage sludge and torrefied wood pellets (NFA107 to 109) the second peak almost disappears in all the cases, while the first one is taller and narrower while the torrefied wood pellets content is higher.

It is possible to verify the behaviour using the weighted average of normalised weight loss of the blend with the following equation: $W_{\text {blend }}=\sum x_{i} \cdot W_{i}$, where $\mathrm{x}_{\mathrm{i}}$ are the weight percentages of each component in the blend, respectively, and $W_{i}$ are the normalised weight of loss of the materials.

The similarities and differences between the curves obtained from this method (red coloured) and the measured ones (blue) are shown in Figure 72. 


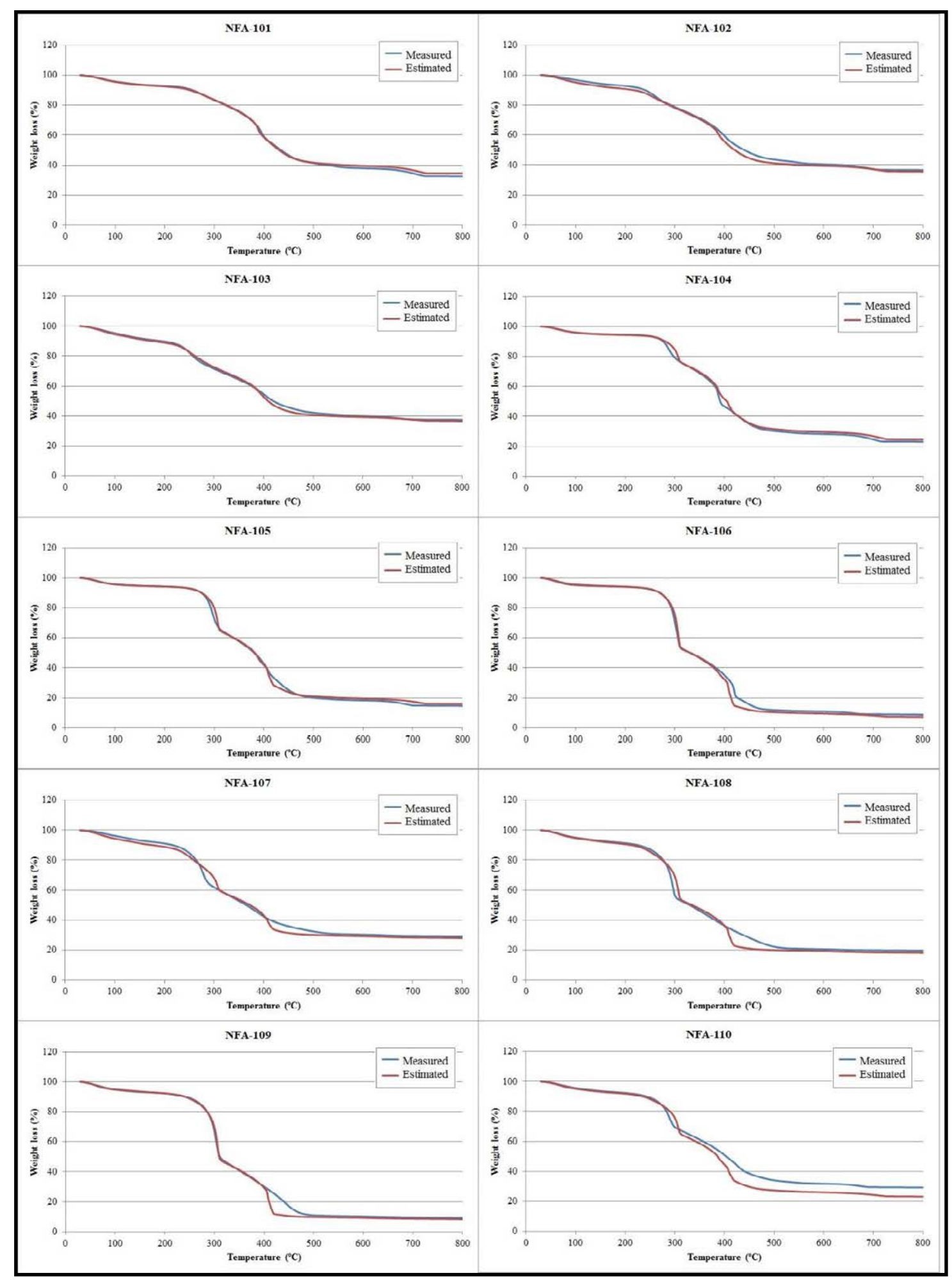

Figure 72. TG curves estimated and measured for mixtures 
Looking at the TGO parameters, the characteristic oxidation temperature does not give much information in these samples, due to the values are almost the same for all the samples. Only one of the studied samples is not located in the high self-ignition risk area according to this parameter, but it is for just $1^{\circ} \mathrm{C}$.

But the influence of the coal on the activation energy is obvious. The Ea is not an important parameter for the biomass samples, because they almost always present Ea values of less than $79 \mathrm{~kJ}$, and are always located in the same area according to it. But in this case, the samples with high amounts of coal present values of more than $79 \mathrm{~kJ}$, and are located on different areas for this parameter.

Finally, DSC curves have been studied. Focusing on the mixtures formed by coal and thermally dried sewage sludge (NFA-101 to 103), the addition of the second component causes an increase on the values of absorbed heat at the beginning of the process, which is to say that samples with more amount of sewage sludge need more energy for starting the exothermic process. However, values obtained from this test (IET, FET and CST) are almost the same in the three samples. The heat emitted by these mixtures is higher than the others, so these mixtures are the betters for producing heat.

In the other two groups, coal and torrefied wood pellets (NFA-104 to 106) and thermally dried sewage sludge and torrefied wood pellets (NFA-107 to NFA-109), by adding the second component the IET decreases while FET and CST increases, so the exothermic reaction starts earlier but not the quick one. The rapid exothermic reaction starts later and finishes later too.

It is important to notice that in all the studied cases, the mixtures curves are not located in the range delimited by the pure components. This can be corroborated by the difference existing between the estimated and the measured curves, as shown in Figure 73. 


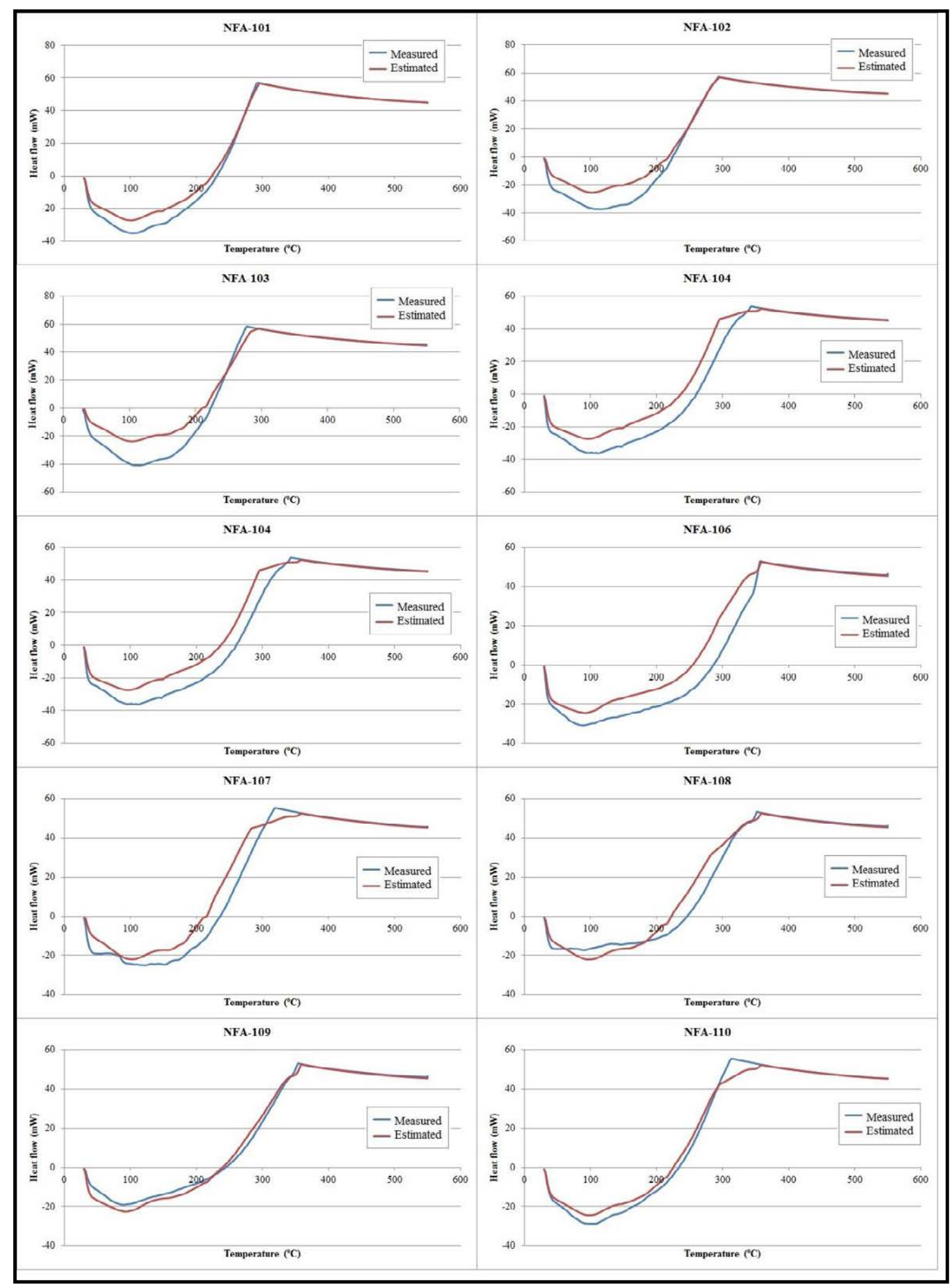

Figure 73. DSC curves estimated and measured for mixtures 


\subsubsection{MINIMUM IGNITION TEMPERATURE ON A LAYER AND MINIMUM IGNITION ENERGY}

The variation of coal and thermally dried sewage sludge in the first three samples studied (NFA-101 to 103) does not affect to MITl or MIE values. The values are almost the same for the three concentrations, and the compaction does not show any influence on the MITl.

The MITl increases and the MIE decreases when torrefied wood pellet is added to coal (NFA-104 to 106). The influence of torrefied wood pellets on the first parameter shows that the higher the amount of pellet in the mixture, the higher the temperature needed for the ignition of a layer of dust (of 5 of 50 millimetres), so it is more difficult for the layer to ignite. On the other hand, the energy needed for the ignition of a cloud of this mixture is lower, and the ignition is easier. Moreover, compaction has not influence on the ignition of wide layers.

The same effect is observed on the mixtures formed by thermally dried sewage sludge and torrefied wood pellets (NFA-106 to 109). The layers are more difficult to ignite when the torrefied wood pellets content is higher, and the cloud is easier to ignite. Moreover, the MIE values for these mixtures are lower than for the ones formed by coal and torrefied wood pellets, being the last to values the same and also the same as the torrefied wood pellets one. Finally, the compaction causes an increase on the minimum ignition temperature of the layers of two of the three studied mixtures, so compaction could help on preventing the ignition of dust layers.

Expected parameters have been determined with the values obtained for the primary components of the mixtures estimating that each component's contribution is the same as the percentage of presence in the mixture, as shown in Figure 74. 


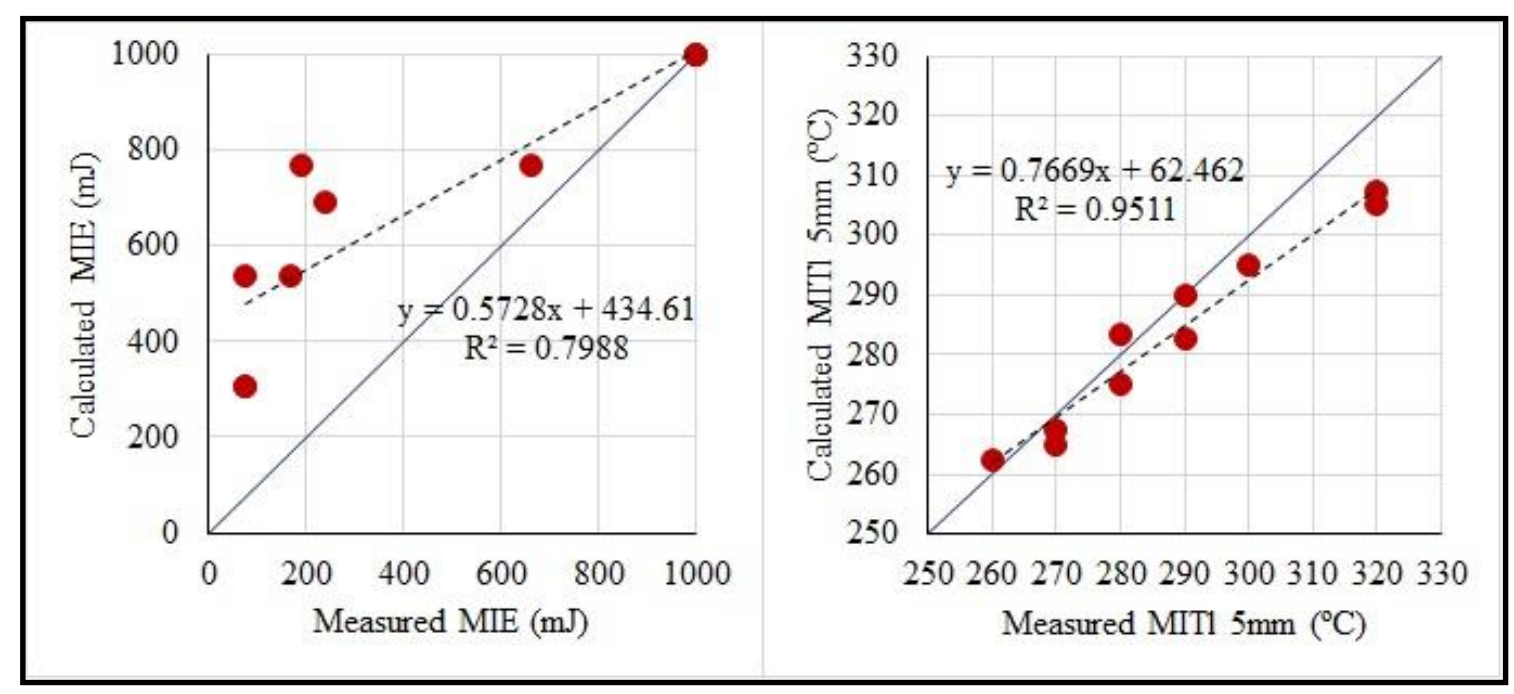

Figure 74. Calculated vs measured MIE and MITl

Calculated values of MIE are higher than the measured ones, i.e. the risk is higher than the calculated depending on the composition of the mixtures, while for the MITl of $5 \mathrm{~mm}$, the expected values are lower than the measured ones. In the case of thicker layers, seven of the ten samples have the same value of measured and calculated MITl $50 \mathrm{~mm}$, while the other three present higher calculated values than the expected ones.

Plotting the calculated vs measured values of the parameters (Figure 74) it can be seen a high correlations between these parameters. These correlations demonstrate that no antagonistic or synergistic effects occur. However, calculated values show that the expected values are not the same as the measured ones, so tests should be done to be sure that all the industrial facilities are designing their protection and prevention measures according to the right parameters. 



\section{CONCLUSIONS}

This research shows flammability data of biomass from agriculture, forestry and waste origin. The variability of these parameters is shown and also how this variability affects to the selfignition tendency of the samples.

- Volatiles and ash contents are the compositional parameters that better represent the variability on the flammability properties of solid fuels. The relations observed between these parameters and the risks allow to design prevention measures and protection systems in the processing facilities in order to avoid flammability risks.

- The importance of particle size over other studied parameters in the reactivity of the samples is observed. The thinner the size, the more reactive the material.

- Pelletization of dusty samples is a good way to reduce their ignition risk, but it is important to take into account that all pellets may become crushed and dust will always be present, so both particle sizes have to be studied and equipment have to be designed for the most dangerous situation.

- Relations between the different measured temperatures showed the high dependency existing between different groups of parameters, and how the ignition, self-ignition and reactivity of the samples are related. It was also observed that the temperatures related with these actions vary together showing the same tendency.

- Looking at the gas emissions tests, it is observed that the total amount of gas emissions from the studied samples heavily depends on the temperature of the sample. Compaction also affects to emissions, but it depends on the particle size and the moisture of the sample. The lower values of these parameters, the more efficient the compaction is.

- The combustion process of the sample is earlier detected by gas emission than by TGDSC emissions. CO emissions are detected at lower temperatures than IT, while it happens occasionally with $\mathrm{CO}_{2}$. This means that $\mathrm{CO}$ emissions are more effective for this methodology. A continuous monitoring of $\mathrm{CO}$ emissions from dust accumulations will allow the early detection of self-heating processes, providing more time for the protective measures to act properly.

- Also different heating stages existing in the combustion process which can be easily detected with the TG-DSC analyses may be also defined with the gas emission test.

- Compaction of the samples is one of the most used methods to avoid self-ignition of coals, but it does not seem to be as effective for biomass samples. Compaction of 
biomasses not always reduces the reactivity of the sample, i.e. the minimum ignition temperature on a layer. It is important to take into account the accessibility of the oxygen to the particles. This accessibility is also influenced by the specific surface area.

- Thermal diffusivity values of dusty samples is the parameter that may determine in advance the ignitability of dust layers, and it can be used to have a first approach to ignition temperatures rank.

- The procedure to evaluate thermal susceptibility based on the activation energy and the characteristic oxidation temperature provides a detailed analysis of samples. However, for the self-ignition risk of biomass samples, activation energy is not as determinant as the characteristic temperature is. Classification according to the activation energy values has been developed for coal samples, and it seems that this parameter is not as important for biomass samples as it was for coals.

- Thermally dried sewage sludge is nowadays been promoted as a new fuel, so their properties are still unknown. These samples present a high self-ignition risk, mainly influenced by their chemical composition, so a deep study of these parameters may provide a guide to design prevention and protection measures to decrease the hazards associated with the handling, transport and storage.

- The thermal behaviour of solid fuels mixtures can be estimated through TG-DSC analyses, since the weighted average of normalised weight loss of the blend provides similar values as the ones experimentally obtained.

- This similarity is not observed for MITl and MIE, for which estimated values differed from the experimental ones. The experimental values provide higher values than the estimated ones. 


\section{CONCLUSIONES}

Esta investigación aporta numerosos datos de inflamabilidad de biomasa procedente tanto de la agricultura, como forestal y residual. Así, se detalla la variabilidad de estos parámetros y como ésta afecta a su posible riesgo de autoignición.

- Los contenidos en volátiles y en cenizas son los parámetros composicionales que mejor representan la variabilidad de las propiedades de inflamabilidad de los sólidos combustibles. Las relaciones observadas entre estos parámetros y el riesgo de ignición permiten diseñar medidas de prevención y protección adecuadas para eliminar o disminuir ese riesgo.

- Se ha observado así mismo la importancia del tamaño de grano en la reactividad de los sólidos combustibles. Cuanto menor es el tamaño de grano, más reactividad presenta el material.

- La pelletización de las muestras de polvo es una buena medida para reducir el riesgo de ignición de este tipo de productos, pero es importante tener en cuenta que los pellets pueden romperse durante su procesamiento y que siempre va a haber presente polvo, por lo que debe estudiarse ambos tamaños de grano. Los equipos de este tipo de instalaciones deben diseñarse siempre para la situación más peligrosa posible.

- Se ha observado la gran dependencia que existe entre los distintos grupos de parámetros a través de las diferentes temperaturas medidas, y como la ignición, autoignición y reactividad de las muestras están ampliamente relacionadas. Las temperaturas que caracterizan estos procesos varían en el mismo sentido.

- Focalizando en los ensayos de emisiones de gases, se ha observado que la emisión de gases durante el calentamiento de este tipo de muestras depende fuertemente de la temperatura de la muestra. Así mismo, la compactación afecta a estas emisiones, pero su sentido depende del tamaño de grano y de la humedad de la muestra. Cuanto más pequeños son estos parámetros, más eficiente es la compactación.

- El proceso de combustión se puede detectar con anterioridad a través de los ensayos de emisiones de gases que a los ensayos de termogravimetría y calorimetría diferencial de barrido. Las emisiones de $\mathrm{CO}$ se pueden detectar antes que la temperatura de inicio del proceso de combustión, y puntualmente ocurre lo mismo con las emisiones de $\mathrm{CO}_{2}$. Esto implica que las emisiones de $\mathrm{CO}$ son más eficientes para este proceso. Así, un continuo monitoreo de emisiones de $\mathrm{CO}$ procedente de las acumulaciones 
de polvo puede permitir una detección precoz de los procesos de autoignición, proporcionando suficiente tiempo para que las medidas de protección implantadas actúen adecuadamente.

- Las diferentes etapas del proceso de calentamiento existentes en los procesos de combustión y ampliamente estudiadas previamente gracias a los ensayos de TG-DSC pueden ser observadas gracias al ensayo de emisiones de gases.

- La compactación de las muestras es uno de los mecanismos más empleados para evitar la autoignición de depósitos de carbón, pero no demuestra la misma eficacia en el caso biomasas. La compactación de biomasas no siempre reduce la reactividad de las muestras, como se ha observado con la temperatura mínima de inflamación en capa. Así, es importante tener en cuenta la accesibilidad del oxígeno a las partículas, la cual a su vez está influenciada por el área superficial de estas partículas.

- La difusividad térmica se puede emplear para determinar el riesgo de inflamabilidad de las capas de polvo, así como para realizar una primera aproximación del rango de temperaturas de ignición.

- El procedimiento empleado para evaluar la susceptibilidad térmica basado en la energía de activación y la temperatura de oxidación característica proporciona un análisis detallado de las muestras. A pesar de ello, se ha observado que la energía de activación no es un parámetro determinante en el caso de las biomasas, a pesar de que sí lo es en el caso de carbones, para los cuales se desarrolló.

- Los lodos de depuradora secados térmicamente son productos cuyas propiedades aún no han sido ampliamente estudiadas dada su novedad como combustible. Este tipo de materiales presenta un elevado riesgo de autoignición, principalmente influenciado por su composición química, por lo que un completo estudio de estos parámetros puede proporcionar una guía para diseñar las medidas de protección y prevención necesarias para disminuir los riesgos asociados con su manejo, transporte y almacenamiento.

- El comportamiento térmico de las mezclas de sólidos combustibles se puede estimar a través de los análisis de TG-DSC, ya que los resultados estimados a través de la media ponderada de sus pesos normalizados proporciona valores similares a los obtenidos experimentalmente.

- En cambio, esta similitud no se observa para los valores de temperatura mínima de inflamación en capa y de energía mínima de ignición, para los que los valores experimentales son mayores que los estimados. 


\section{FUTURE WORK}

- Deepen the influence of pelletization on the ignition risks of biomasses.

- Modification of the $\mathrm{x}$ axis (Ea) for the improvement of the thermal susceptibility graph.

- Study of the influence of the shape of the particles on the explosibility of solid fuels.

- Further study of the double effect that compaction cause on the thermal susceptibility of solid fuels.

- Study of the influence of the different pre-treatments on the self-ignition risk of thermally dried sewage sludge. 



\section{REFERENCES}

[1] International Energy Agency, "Key World Energy Statistics," http://www.iea.org/textbase/nppdf/free/2011/key_world_energy_stats.pdf.2011.

[2] W. M. Organization, "WMO Greenhouse Gas Bulletin," 2013.

[3] National Oceanic and Atmospheric Administration. Earth System Research Laboratory. (2014). Up-to-date weekly average CO2 at Mauna Loa.

[4] M. Hogan, J. Otterstedt, R. Morin, and J. Wilde, "Biomass for heat and power. Opportunity and economics," J. Wilde.-Brussels: European Climate Foundation, 2010.$72 p, 2010$.

[5] A. Demirbas, "Combustion characteristics of different biomass fuels," Progress in energy and combustion science, vol. 30, pp. 219-230, 2004.

[6] European Commission, "Report from the Commission to the European Parliament, the Council, the European economic and social Comittee and the Comittee of the Regions. Renewable energy progress report," Brussels2013.

[7] European Commission. (August 25). Eurostat. Available: ec.europa.eu/eurostat/web/energy/statistics-illustrated

[8] (2015, February). 2015 United Nations Climate Change Conference Available: <span lang="EN-GB" style="font-size:12.0ptAvailable: 11.0ptAvailable: mso-bidilanguage:AR-

SA">https://en.wikipedia.org/wiki/2015_United_Nations_Climate_Change_Conference

[9] United States Environmental Protection Agency (EPA). (2015, November 2015). Carbon monoxide. Available: http://www3.epa.gov/airquality/carbonmonoxide/

[10] United States Environmental Protection Agency (EPA). (2015, November 17). Nitrogen dioxide. Available: http://www3.epa.gov/airtrends/aqtrnd95/no2.html

[11] United States Environmental Protection Agency (EPA). (2015, November 17). Sulfur dioxide. Available: http://www3.epa.gov/airquality/sulfurdioxide/

[12] United States Environmental Protection Agency (EPA). (2015, November 17). Ground level ozone. Available: <span lang="EN-GB" style="font-size:11.0ptAvailable: msobidi-language:AR-SA"> http://www3.epa.gov/ozonepollution/

[13] United States Environmental Protection Agency (EPA). (2015, November 17). Particulate matter (PM). Available: <span lang="EN-GB" style="fontsize:11.0ptAvailable: mso-bidi-language:AR-SA"> http://www3.epa.gov/pm/

[14] B. Metz, O. R. Davidson, P. R. Bosch, R. Dave, and L. A. Meyer, "Contribution of working group III to the fourth assessment report of the intergovernmental panel on climate change," 2007. 
[15] United States Environmental Protection Agency. (EPA). (2015, November 17). Climate change. Available: <span lang="EN-GB" style="font-size:11.0ptAvailable: mso-bidilanguage:AR-SA">http://www3.epa.gov/climatechange/ghgemissions/gases/co2.html

[16] T. A. Boden, G. Marland, and R. J. Andres, "Global, regional, and national fossil-fuel CO2 emissions," Carbon Dioxide Information Analysis Center, Oak Ridge National Laboratory, US Department of Energy, Oak Ridge, Tenn., USA doi, vol. 10, 2009.

[17] Biomass energy centre. (2011, November 17). Emissions. Available: <span lang="ENGB" style="font-size:11.0ptAvailable: mso-bidi-language:ARSA"> $\underline{\text { http://www.biomassenergycentre.org.uk/portal/page? pageid }=77,103200 \& \_d a d=p}$ ortal\&_schema $=$ PORTAL

[18] United Nationas Framework Convention on Climate Change (UNFCCC), http://cdm.unfccc.int/EB/020/eb20repan08.pdf.

[19] S. V. Vassilev, D. Baxter, L. K. Andersen, and C. G. Vassileva, "An overview of the composition and application of biomass ash. Part 1. Phase-mineral and chemical composition and classification," Fuel, vol. 105, pp. 40-76, 2013.

[20] S. V. Vassilev, D. Baxter, L. K. Andersen, and C. G. Vassileva, "An overview of the chemical composition of biomass," Fuel, vol. 89, pp. 913-933, 2010.

[21] Swiss Federal Institute of Technology Zurich (2015, November 19). Transport processes and reactions laboratory - Green chemistry. Available: http://www.ipe.ethz.ch/laboratories/ltr/education/Studienarbeiten/Wood_structure

[22] S. V. Vassilev, D. Baxter, L. K. Andersen, C. G. Vassileva, and T. J. Morgan, "An overview of the organic and inorganic phase composition of biomass," Fuel, vol. 94, pp. $1-33,2012$.

[23] T. Milne, "Pyrolysis - The thermal behavior of biomass below $600 \mathrm{C}, "$ A survey of biomass gasification, vol. 2, pp. 95-132, 1979.

[24] K. Blumenthal, "Generation and treatment of municipal waste," Notes, vol. 2002, p. 2009, 1995.

[25] N. F. Gray, Water technology: an introduction for environmental scientists and engineers: IWA Publishing, 2010.

[26] A. Kelessidis and A. S. Stasinakis, "Comparative study of the methods used for treatment and final disposal of sewage sludge in European countries," Waste Manage, vol. 32, pp. 1186-1195, 2012.

[27] M. Bengtsson and A.-M. Tillman, "Actors and interpretations in an environmental controversy: the Swedish debate on sewage sludge use in agriculture," Resources, Conservation and Recycling, vol. 42, pp. 65-82, 2004.

[28] P. McKendry, "Energy production from biomass (part 2): conversion technologies," Bioresource technology, vol. 83, pp. 47-54, 2002. 
[29] R. P. Overend, "Thermochemical conversion of biomass, in renewable energy sources charged with energy from the sun and originated from earth-moon interaction," Encyclopedia of Life Support Systems, 2004.

[30] S. Yokoyama and Y. Matsumura, "The Asian biomass handbook," Japan Institute of Energy, Japan, 2008.

[31] Biomass enery centre. (2011, November 20). Gasification. Available: http://www.biomassenergycentre.org.uk/portal/page? pageid $=75,17504 \&$ dad=portal\& schema $=$ PORTAL

[32] Bioenergiesysteme GmbH. (November 20). Overview - Biomass gasification. Available: http://www.bios-bioenergy.at/en/biomass-gasification.html

[33] United States Departyment of Agriculture. Agricultural Research Service. (2010, November 20). Biomas Pyrolysis research at the Eastern regional research center. Available: http://www.ars.usda.gov/Main/docs.htm?docid=19898

[34] Biomass Innovation Centre. (2013, December 1). Fermentation. Available: http://www.biomassinnovation.ca/fermentation.html

[35] California energy commission. (2015, December 1). Anaerobic digestion Available: http://www.energy.ca.gov/biomass/anaerobic.html

[36] C. E. Association, Health and safety in biomass systems. Design and operation guide: Carbon Trust, 2011.

[37] E. J. Network. (2015, March 17). Biomass Industry Plays with Fire, Gets Burned.

[38] P. R. Amyotte, "Some myths and realities about dust explosions," Process Safety and Environmental Protection, vol. 92, pp. 292-299, 2014.

[39] J. García Torrent, Seguridad Industrial en Atmósferas Explosivas. Madrid: Laboratorio Oficial J.M. Madariaga, 2003.

[40] T. Abbasi and S. Abbasi, "Dust explosions-Cases, causes, consequences, and control," Journal of Hazardous Materials, vol. 140, pp. 7-44, 2007.

[41] B. B. Beamish and A. Arisoy, "Effect of mineral matter on coal self-heating rate," Fuel, vol. 87, pp. 125-130, 2008.

[42] E. Kaymakci and V. Didari, "Relations between coal properties and spontaneous combustion parameters," Turkish Journal of Engineering and Environmental Sciences, vol. 26, pp. 59-64, 2002.

[43] M. Traoré, O. Dufaud, L. Perrin, S. Chazelet, and D. Thomas, "Dust explosions: How should the influence of humidity be taken into account?," Process Saf Environ, vol. 87, pp. 14-20, 2009.

[44] J. Yuan, W. Wei, W. Huang, B. Du, L. Liu, and J. Zhu, "Experimental investigations on the roles of moisture in coal dust explosion," Journal of the Taiwan Institute of Chemical Engineers, vol. 45, pp. 2325-2333, 2014. 
[45] K. L. Cashdollar, "Coal dust explosibility," Journal of loss prevention in the process industries, vol. 9, pp. 65-76, 1996.

[46] S. Calle, L. Klaba, D. Thomas, L. Perrin, and O. Dufaud, "Influence of the size distribution and concentration on wood dust explosion: Experiments and reaction modelling," Powder technol, vol. 157, pp. 144-148, 2005.

[47] R. K. Eckhoff, "Understanding dust explosions. The role of powder science and technology," J Loss Prevent Proc, vol. 22, pp. 105-116, 2009.

[48] N. E. Altun, C. Hicyilmaz, and M. V. Kök, "Effect of particle size and heating rate on the pyrolysis of Silopi asphaltite," Journal of analytical and applied pyrolysis, vol. 67, pp. 369-379, 2003.

[49] C. H. Medina, H. Phylaktou, G. Andrews, and B. Gibbs, "Explosion characteristics of pulverised torrefied and raw Norway spruce (Picea abies) and Southern pine (Pinus palustris) in comparison to bituminous coal," Biomass and Bioenergy, 2015.

[50] N. Kuai, J. Li, Z. Chen, W. Huang, J. Yuan, and W. Xu, "Experiment-based investigations of magnesium dust explosion characteristics," Journal of Loss Prevention in the Process Industries, vol. 24, pp. 302-313, 2011.

[51] Z. Yuan, N. Khakzad, F. Khan, and P. Amyotte, "Dust explosions: A threat to the process industries," Process Safety and Environmental Protection, vol. 98, pp. 57-71, 2015.

[52] A. Tascón and P. J. Aguado, "CFD simulations to study parameters affecting dust explosion venting in silos," Powder Technology, vol. 272, pp. 132-141, 2015.

[53] Q. Zhang and B. Zhang, "Effect of ignition delay on explosion parameters of corn dust/air in confined chamber," Journal of Loss Prevention in the Process Industries, vol. 33, pp. 23-28, 2015.

[54] R. Pilão, E. Ramalho, and C. Pinho, "Overall characterization of cork dust explosion," Journal of hazardous materials, vol. 133, pp. 183-195, 2006.

[55] K. L. Cashdollar, "Overview of dust explosibility characteristics," Journal of Loss Prevention in the Process Industries, vol. 13, pp. 183-199, 2000.

[56] K. L. Cashdollar and I. A. Zlochower, "Explosion temperatures and pressures of metals and other elemental dust clouds," Journal of Loss Prevention in the Process Industries, vol. 20, pp. 337-348, 2007.

[57] C. H. Medina, B. MacCoitir, H. Sattar, D. J. Slatter, H. N. Phylaktou, G. E. Andrews, et al., "Comparison of the explosion characteristics and flame speeds of pulverised coals and biomass in the ISO standard $1 \mathrm{~m} 3$ dust explosion equipment," Fuel, vol. 151, pp. 91$101,2015$.

[58] S. Mannan, Lees' Loss prevention in the process industries: Hazard identification, assessment and control: Butterworth-Heinemann, 2012. 
[59] R. Pilão, E. Ramalho, and C. Pinho, "Influence of initial pressure on the explosibility of cork dust/air mixtures," Journal of Loss Prevention in the Process Industries, vol. 17, pp. 87-96, 2004.

[60] J. García-Torrent, E. Conde-Lázaro, C. Wilén, and A. Rautalin, "Biomass dust explosibility at elevated initial pressures," Fuel, vol. 77, pp. 1093-1097, 1998.

[61] U. Krause and M. Schmidt, "The influence of initial conditions on the propagation of smouldering fires in dust accumulations," Journal of Loss Prevention in the Process Industries, vol. 14, pp. 527-532, 2001.

[62] G. Zhen and W. Leuckel, "Effects of ignitors and turbulence on dust explosions," Journal of Loss Prevention in the Process Industries, vol. 10, pp. 317-324, 1997.

[63] R. Eckhoff, "Current status and expected future trends in dust explosion research," Journal of loss prevention in the process industries, vol. 18, pp. 225-237, 2005.

[64] R. Sanchirico, A. Di Benedetto, A. Garcia-Agreda, and P. Russo, "Study of the severity of hybrid mixture explosions and comparison to pure dust-air and vapour-air explosions," Journal of Loss Prevention in the Process Industries, vol. 24, pp. 648-655, 2011.

[65] O. Dufaud, L. Perrin, and M. Traore, "Dust/vapour explosions: Hybrid behaviours?," Journal of Loss Prevention in the Process Industries, vol. 21, pp. 481-484, 2008.

[66] A. Garcia-Agreda, A. Di Benedetto, P. Russo, E. Salzano, and R. Sanchirico, "Dust/gas mixtures explosion regimes," Powder Technology, vol. 205, pp. 81-86, 2011.

[67] D. Bideau, O. Dufaud, F. Le Guyadec, L. Perrin, X. Genin, J.-P. Corriou, et al., "Self ignition of layers of powder mixtures: Effect of solid inertants," Powder Technology, vol. 209, pp. 81-91, 2011.

[68] I. Kasalová and K. Balog, "minimum ignition temperatures of food dust clouds determinated by planned experiment," Annals of the Faculty of Engineering Hunedoara, vol. 9, p. 97, 2011.

[69] M. Polka, Z. Salamonowicz, M. Wolinski, and B. Kukfisz, "Experimental analysis of minimal ignition temperatures of a dust layer and clouds on a heated surface of selected flammable dusts," Procedia Engineering, vol. 45, pp. 414-423, 2012.

[70] R. Pilão, E. Ramalho, and C. Pinho, "Influence of particle size on the explosibility of air/cork dust mixtures," in Proceedings of 9th Brazilian Congress of Thermal Engineering and Sciences (CIT02-0689. pdf), 2002, pp. 15-18.

[71] R. Eckhoff, "Minimum ignition energy (MIE) — a basic ignition sensitivity parameter in design of intrinsically safe electrical apparatus for explosive dust clouds," Journal of Loss Prevention in the Process Industries, vol. 15, pp. 305-310, 2002. 
[72] A. Dahoe, K. v. der Nat, M. Braithwaite, and B. Scarlett, "On the sensitivity of the maximum explosion pressure of a dust deflagration to turbulence," KONA Powder and Particle Journal, vol. 19, pp. 178-196, 2001.

[73] M. Mittal, "Limiting oxygen concentration for coal dusts for explosion hazard analysis and safety," Journal of Loss Prevention in the Process Industries, vol. 26, pp. 1106-1112, 2013.

[74] N. F. P. Association, "Standard on explosion prevention systems (NFPA 69)," Quincy, MA: National Fire Protection Association, 2008.

[75] C. Doyle, "Kinetic analysis of thermogravimetric data," Journal of applied polymer science, vol. 5, pp. 285-292, 1961.

[76] J. Jones, K. Henderson, J. Littlefair, and S. Rennie, "Kinetic parameters of oxidation of coals by heat-release measurement and their relevance to self-heating tests," Fuel, vol. 77, pp. 19-22, 1998.

[77] A. Magdziarz and M. Wilk, "Thermogravimetric study of biomass, sewage sludge and coal combustion," Energ Convers Manage, vol. 75, pp. 425-430, 2013.

[78] A. Magdziarz and S. Werle, "Analysis of the combustion and pyrolysis of dried sewage sludge by TGA and MS," Waste management, vol. 34, pp. 174-179, 2014.

[79] Y. Chen, S. Mori, and W.-P. Pan, "Studying the mechanisms of ignition of coal particles by TG-DTA," Thermochimica Acta, vol. 275, pp. 149-158, 1996.

[80] J. Garcia Torrent, N. Fernandez Anez, L. Medic Pejic, and L. Montenegro Mateos, "Assessment of self-ignition risks of solid biofuels by thermal analysis," Fuel, vol. 143, pp. 484-491, 2015.

[81] J. W. Cumming, "Reactivity assessment of coals via a weighted mean activation energy," Fuel, vol. 63, pp. 1436-1440, 1984.

[82] Á. Ramírez, J. García-Torrent, and A. Tascón, "Experimental determination of selfheating and self-ignition risks associated with the dusts of agricultural materials commonly stored in silos," J Hazard Mater, vol. 175, pp. 920-927, 2010.

[83] "EN 15188. Determination of the spontaneous ignition behaviour of dust accumulations," ed, 2007.

[84] C. Lohrer, U. Krause, and J. Steinbach, "Self-ignition of combustible bulk materials under various ambient conditions," Process Safety and Environmental Protection, vol. 83, pp. 145-150, 2005.

[85] J. García-Torrent, A. Ramirez-Gomez, E. Querol-Aragón, C. Grima-Olmedo, and L. Medic-Pejic, "Determination of the risk of self-ignition of coals and biomass materials," J Hazard Mater, vol. 213, pp. 230-235, 2012. 
[86] C. D. Everard, M. Schmidt, K. P. McDonnell, and J. Finnan, "Heating Processes during Storage of Miscanthus Chip Piles and Numerical Simulations to Predict Self-Ignition," $J$ Loss Prevent Proc, 2014.

[87] N. Fernandez Anez, J. Garcia Torrent, L. Medic Pejic, and C. Grima Olmedo, "New tests for the detection of incipient self-ignition process in solid fuels," in Tenth International Symposium on Hazards, Prevention, and Mitigation of Industrial Explosions (X ISHPMIE), Bergen, Norway, 2014, pp. 1431-.

[88] "EN 15407. Solid recovered fuels. Methods of determination of carbon (C), hydrogen (H) and nitrogen (N) content," ed, 2011.

[89] "EN 15408. Solid recovered fuels. Methods for the determination of sulphur (S), chlorine (Cl), fluorine (F) and bromine (Br) content," ed, 2011.

[90] "UNE 32004. Solid mineral fuels. Determination of ash," ed, 1984.

[91] "EN 14775. Solid biofuels. Determination of ash content," ed, 2009.

[92] "UNE 32019. Hard coal and coke - Determination of volatile matter content," ed, 1984.

[93] "EN 15148. Solid biofuels. Determination of the content of volatile matter," ed, 2009.

[94] "UNE 32002. Solid mineral fuels. Determination of moisture in the analysis sample," ed, 1995.

[95] "EN 14774. Solid biofuels. Detemrination of moisture content. Oven dry method," ed, 2009.

[96] C. Wilén, A. Moilanen, A. Rautalin, J. Torrent, E. Conde, R. Lodel, et al., Safe handling of renewable fuels and fuel mixtures: Citeseer, 1999.

[97] J. Collazo, J. A. Pazó, E. Granada, Á. Saavedra, and P. Eguía, "Determination of the specific heat of biomass materials and the combustion energy of coke by DSC analysis," Energy, vol. 45, pp. 746-752, 2012.

[98] "EN 50281-2-1. Electrical apparatus for use in the presence of combustible dust. Part 21: Test methods - Methods for determining the minimum ignition temperatures of dust," ed, 1999.

[99] "EN 60079-14. Explosive atmospheres - Part 14: Electrical installations design, selection and erection," ed, 2010.

[100] B. EN, "14034-3," Determination of Explosion Characteristics of Dust Clouds-Part 3: Determination of the Lower Explosion Limit LEL of Dust Clouds, 2006.

[101] Kühner. (2016, January). Kuhner safety apparatuses. Available: http://safety.kuhner.com/en/product/apparatuses.html

[102] Á. Ramírez, J. García-Torrent, and P. J. Aguado, "Determination of parameters used to prevent ignition of stored materials and to protect against explosions in food industries," J Hazard Mater, vol. 168, pp. 115-120, 2009. 
[103] "EN 13821. Potentially explosive atmopheres. Explosion prevention and protection. Determination of minimum ignition energy of dust/air mixtures," ed, 2002.

[104] A. Janes, J. Chaineaux, D. Carson, and P. A. Le Lore, "MIKE 3 versus HARTMANN apparatus: Comparison of measured minimum ignition energy (MIE)," Journal of hazardous materials, vol. 152, pp. 32-39, 2008.

[105] "EN 14034-1:2004 + A1:2011. Determination of explosion characteristics of dust clouds - Part 1: Determination of the maximum explosion pressure pmax of dust clouds," ed.

[106] "EN 14034-2:2006 + A1:2011. Determination of explosion characteristics of dust clouds - Part 2: Determination of the maximum rate of explosion pressure rise (dp/dt)max of dust clouds," ed.

[107] "EN 14034-4. Determination of explosion characteristics of dust clouds. Determination of the limiting oxygen concnetration LOC of dust clouds," ed, 2004.

[108] United Nations, "Part III. Classification procedures, test methods and criteria relating to class 2, class 3, class 4, division 5.1, class 8 and class 9," 2009.

[109] Instituto Nacional de Seguridad e Higiene en el Trabajo (INSHT), "Límites de exposición profesional para agentes químicos en España, 2015," 2015.

[110] J. M. Warnsloh, "TriAngle: A Microsoft Excel ${ }^{\mathrm{TM}}$ spreadsheet template for the generation of triangular plots," Neues Jahrbuch für Mineralogie-Abhandlungen: Journal of Mineralogy and Geochemistry, vol. 192, pp. 101-105, 2015.

[111] W. Guo, C. J. Lim, X. Bi, S. Sokhansanj, and S. Melin, "Determination of effective thermal conductivity and specific heat capacity of wood pellets," Fuel, vol. 103, pp. 347355, 2013.

[112] W. Stelte, J. K. Holm, A. R. Sanadi, S. Barsberg, J. Ahrenfeldt, and U. B. Henriksen, "Fuel pellets from biomass: The importance of the pelletizing pressure and its dependency on the processing conditions," Fuel, vol. 90, pp. 3285-3290, 2011.

[113] L. Jiang, J. Liang, X. Yuan, H. Li, C. Li, Z. Xiao, et al., "Co-pelletization of sewage sludge and biomass: The density and hardness of pellet," Bioresource technology, vol. 166, pp. 435-443, 2014.

[114] C. Huescar Medina, H. Phylaktou, G. Andrews, and B. Gibbs, "Torrefaction Effects on the Reactivity and Explosibility of Woody Biomass," 2013. 
Annexes 


\section{Annex I. Documents needed for the "International Doctor" mention}




\section{Southampton}

E.T.S. Ingenieros de Minas

Universidad Politécnica de Madrid

Calle Ríos Rosas 21 - 28003 Madrid

Spain

11 October 2013

Dear Sirs,

Ms. Nieves Fernández Áñez

I would like to express my deepest compliments to Ms. Nieves Fernández Áñez who spent three months in our University in the framework of her PhD programme. Her stay started on the 17 July and ended on the 18 October 2013.

During this period, Ms. Fernández accomplished all the goals she targeted. In particular, she was part of the Lloyd's Register Foundation Research Collegium on Coastal Eco-cities. A principal output from her endeavour here is a book which she co-authored.

She separately had several meetings with Professors in different research groups in the University of Southampton which helped her to develop ideas for her PhD. Ms. Fernández also met with several doctoral students in the University of Southampton with similar research interests, exchanging views and sharing knowledge. Finally, she did a literature research using the library facilities available in the University of Southampton.

Ms. Fernández is highly motivated and enthusiastic about everything relating to her research activity. Her stay was clearly productive. It has been a pleasure to host Ms. Fernández in our University.

Yours sincerely
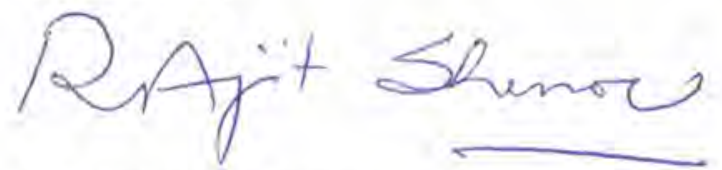

Professor R Ajit Shenoi

Director

email: r.a.shenoi@soton.ac.uk 
E.T.S. Ingenieros de Minas y Energía

Leeds, $15^{\text {th }}$ May 2015

Universidad Politécnica de Madrid (UPM)

Calle Rios Rosas, 21 - 28003 Madrid, Spain

Dear Sirs,

Ms Nieves Fernandez Añez - Leeds University Research Visit

( $1^{\text {st }}$ March $-31^{\text {st }}$ May 2015)

Ms. Fernandez will be completing her research visit with us in a few days and I thought it appropriate to write and inform you of the following:

- She settled in and became an integral and productive part of our research team very quickly, attending weekly meetings with the academic staff and helping daily in the labs.

- She helped out with experimental programmes and learned new laboratory techniques which she has used to build up her existing test data.

- This work has been submitted and accepted for presentation at the $7^{\text {th }}$ International Conference on Sustainable Energy \& Environmental Protection that will take place in Glasgow this August. She will present an oral presentation titled "Ignition sensitivity of coal / waste /biomass mixtures".

- She has been a valued member of our team and has made good suggestions and contributions to the on-going work here and our PhD students have benefited from the interaction with her in both the technical aspects of the work but also in the admirable hard work ethic and reliable arrangements and performance throughout her stay.

- It was a pleasure to have Ms. Fernandez in our Department and her stay has been highly productive and useful to both her and us..

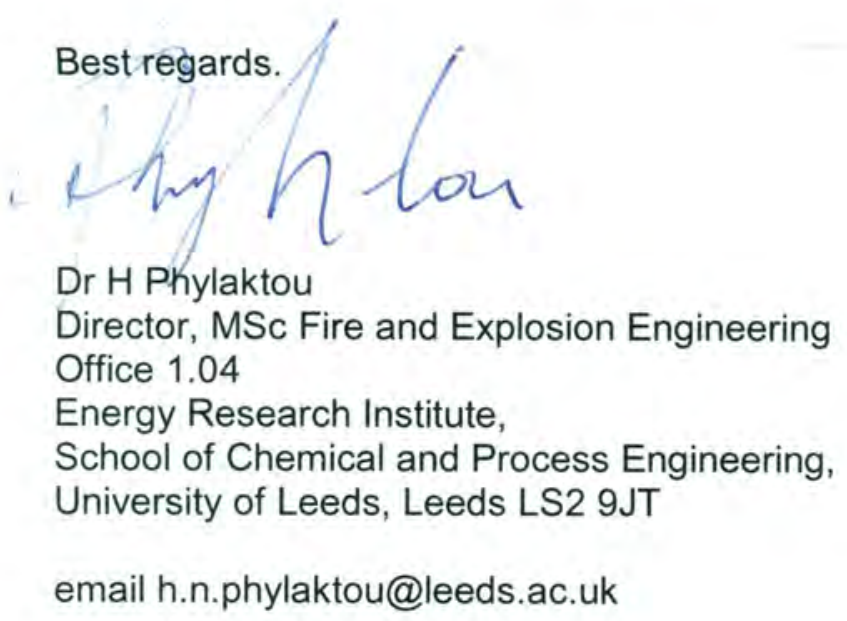




\title{
POLITÉCNICA
}

\section{INFORME EXPERTO EXTERNO / EXTERNAL REVIEWER REPORT (ART. 5B DEL REGLAMENTO DE DEFENSA Y EVALUACIÓN DE LA TESIS DOCTORAL)}

\author{
Nombre del experto/Name of the reviewer \\ Dr Xinyan Huang \\ Categoría/Position \\ Postdoc Research Fellow \\ Universidad a la que pertenece/Departmento, University/Department \\ University of California at Berkeley/Department of Mechanical Engineering
}

Título de la tesis/Title of the Ph.D. Thesis

Analysis of the flammability properties of solid fuels

Nombre del doctorando que presenta la tesis/Name of the Ph.D. candidate

María de las Nieves Fernández Áñez

Especificar los motivos que avalan la calidad de la tesis mencionada para su defensa:

Specify reasons endorsing the quality of the above-mentioned thesis for its defense:

This thesis focuses on the determining the flammability of various biofuels using an experimental approach. This research topic is very difficult and complex, not only involving a large number of experimental methods, but also processing a huge number of data for multi-dimensional analysis. This thesis successfully challenges this fascinating while tough problem, by providing unique and abundant experiment data and proposing novel analytical methodologies.

Sewage sludge, as the major biomass analyzed in this thesis, is an important biomass for potential bioenergy generation. There are very limited studies in the literature to investigate the ignition and flammability criteria for sewage sludge. Even fewer studies are available to investigate the seasonal, regional, and blending effects. This thesis provides vital information regarding the fire safety in sewage sludge utilization, which will benefit the industrial process of sewage sludge in the next few decades.

Moreover, some proposed analysis methods can provide general guidelines for safe utilization of other biomass. Standard tests from different research communities provides different characteristic parameters to quantify and rank the fire risk of fuel. However, correlations among these characteristic parameters are general unknown because of the lack of research in the literature. For the first time, this thesis conducts a systematical study to correlate these standard tests and characteristic parameters by analyzing the fundamental physics behind experimental observations. 


\section{POLITÉCNICA}

¿Qué objetivos se han logrado con la tesis presentada?

What are the contributions of the Ph.D. thesis?

1. This thesis provides a detailed and valuable literature review on the utilizations and fire-safety issues of biomass. The experimental methods and their characteristic parameters are also well reviewed, providing an excellent introduction to a wide audience.

2. Systematic experimental studies are conducted on several biomass, particularly the sewage sludge, and the corresponding characteristic parameters are accurately measured.

3. The physicochemical properties of biomass are quantified through experiments, and the seasonal, regional and blending effects are investigated.

4. The correlations among characteristic parameters are analyzed, and their consistence and inconsistence are found and diccussed.

5. Volatiles and ash contents are identified as best parameters to rank the fire risk of biomass.

6. For the first time, the gas emission is used to successfully quantify the self-ignition risk of biomass.

7. The influence of biomass compaction is investigated and the results show a different trend from coals. This result can provide an important guideline for the production, transportation and process of biomass.

Originalidad del trabajo:

Originality of the work:

In this thesis, there are many novel aspects and not yet addressed in the literature:

- The fire safety of sewage sludge and biomass mixtures including sewage sludge is quantified using various experimental techniques and a novel multi-dimensional analysis.

- Correlations among different experimental methods and characteristic parameters are systematically studied, and interesting patterns among these parameters are revealed.

- Using gas emission (CO and $\mathrm{CO} 2)$ to detect self-ignition is a novel and effective method, and this is proposed in this thesis for the first time.

- The study on the effect of season, region, blending condition, particle size and compaction is original and unique. 


\section{POLITÉCNICA}

Metodología usada / hipótesis contrastadas:

Metodology used / hypotheses tested :

Methodology used:

- A wide range of experimental techniques are used in this thesis, including elemental analysis, proximate analysis, hot-basket test, hot-plate test, explosion test, thermogravimetric analysis, differential scanning calorimetry, and gas-emission analysis.

- Multi-dimensional correlation analysis is used to search the pattern among different parameters.

- For the sensitivity analysis, samples from different regions and seasons as well as with different blending conditions are investigated. Moreover, physical properties such as particle size and compaction conditions are varied for comparison.

Hypotheses tested:

- Whether different experimental techniques and measured parameters give a statistically consistent indication and ranking for the fire risk of different biomass.

- Whether there are some most representative parameters to quantify the fire risk of biomass.

- Whether the effect of season, region, blending condition, particle size and compact condition significantly changes the fire risk.

Observaciones:

Observations:

- Volatiles and ash contents are found to strongly correlate other ignition and flammability properties, and can be used for fast identification of biomass fire risk.

- The self-ignition properties of biomass are not sensitive to compaction, and the apparent activation energy from TGA is found not to be determinant, both very different from coals.

- Pelletization can effectively reduce the first risk of biomass, although the dust explosion risk cannot be completely avoided.

- Using gas emission can detect the fire risk much earlier than other techniques.

- Some characteristic parameters provides a consistent indication, e.g. TG and self-ignition experiments; some do not, e.g. MIT and MIE, because of different physicochemical processes behind these experiments. 


\section{POLITÉCNICA}

Considera que la tesis anteriormente mencionada es apta para su defensa pública? In consideration of all the above, is the $\mathrm{Ph}$.D. Thesis ready for its defense?

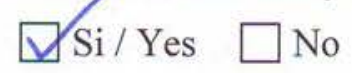

Firma y fecha

Signature and date

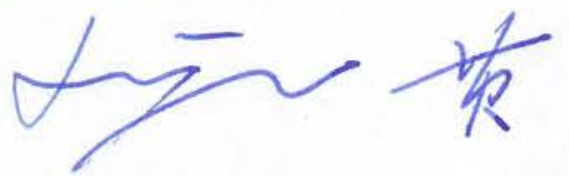

20 February 2016 


\section{Xinyan Huang}

62 Hesse Hall, University of California, Berkeley, CA 94720, USA

Website: https://sites.google.com/site/xinyanfire/
Phone: +1 (510) 643 - 5282

E-mail: xinyan.huang@ berkeley.edu

\section{Professional Experiences}

2015.11 - Present $\quad$ Postdoctoral Research Fellow, University of California at Berkeley

Project: Microgravity Combustion and Fire Safety in Space, funded by NASA and JAXA

\section{Research Interests}

Smouldering Combustion, Ignition and Flame Spread, Wildland Fire, Microgravity Combustion and Clean Energy

\section{Education}

2012 - $2015 \quad$ Ph.D. in Mechanical Engineering, Imperial College London, UK

Thesis: Fundamental Study of Smouldering Combustion of Peat in Wildfires

Adviser: Guillermo Rein

2010 - $2012 \quad$ M.S. in Mechanical Engineering, University of California at San Diego, USA

Thesis: Mechanisms of Ignition and Spread of Electrical Wire Fires

Adviser: Forman Williams

$2006-2010 \quad$ B.S. in Thermal Science and Power Engineering, Southeast University, China

Thesis: Design and Analysis of the Parabolic Trough Solar Collector

\section{Other Research Experiences}

$\begin{array}{lll}2013.8-2013.9 & \text { Visiting Scholar } & \text { State Key Lab of Fire Science, USTC, China } \\ 2013.6-2013.7 & \text { Visiting Scholar } & \text { National University of Singapore } \\ 2012.9-2015.9 & \text { Research \& Teaching Assistant } & \text { ME Department, Imperial College London } \\ 2012.6-2012.9 & \text { Student Research Assistant } & \text { NASA Lewis Research Center \& UC San Diego } \\ 2010.9-2012.6 & \text { Research \& Teaching Assistant } & \text { MAE Department, UC San Diego } \\ 2011.6-2011.9 & \text { Visiting Scholar } & \text { Lab of Space Tech., Hokkaido University, Japan } \\ 2009.3-2010.6 & \text { Internship } & \text { Sanle Electronic Co., China } \\ 2008.9-2010.8 & \text { Undergraduate Research Assistant } & \text { Solar Research Center, Southeast University }\end{array}$

\section{Scholarly \& Professional Services}

Member $\quad$ Editorial Board of Fire Technology - Springer (2016 - 2019)

Member New Technologies Subcommittee, International Association of Fire Safety Science (2014 - )

Website Editor IAFSS (2012-), Combustion Institute British Section (2014 - 2015)

Team Leader National Undergraduate Technology Innovation Project (2010)

\section{Membership of Professional Societies}

Combustion Institute (CI); International Association for Fire Safety Science (IAFSS); Institution of Physics (IOP); International Association of Wildland Fire (IAWF); Association for Fire Ecology (AFE). 


\section{Prizes and Awards}

$\begin{array}{lll}2015 & \text { Best Student Seminar in Thermofluid } & \text { Imperial College London } \\ 2015 & \text { Excellent Poster Award (co-author) } & 10^{\text {th }} \text { AOAFST Fire Symposium } \\ 2015 & \text { TREE Grant } & \text { Association for Fire Ecology (AFE) } \\ 2015 & \text { Best Poster Award } & 2^{\text {nd }} \text { European Fire Symposium } \\ 2015 & \text { Watts Award for Outstanding Reviewer } & \text { Fire Technology } \\ 2015 & \text { Honorable Mention } & 5^{\text {th }} \text { Int. Conference of FESP, Dublin } \\ 2015 & \text { Research Student Grant } & \text { Int. Association of Wildland Fire } \\ 2014 & \text { Qatar Petroleum Medal and Prize for PhD Research } & \text { Qatar Petroleum } \\ & \text { Excellence in Clean Fossil Fuels } & \\ 2014 & \text { Award for Outstanding Student Abroad } & \text { China Scholarship Council } \\ 2014 & \text { Best Student Poster Award } & 11^{\text {th }} \text { IAFSS International Symposium } \\ 2014 & \text { Best Fire Image Award (co-author) } & 11^{\text {th }} \text { IAFSS International Symposium } \\ 2013 & \text { International Mobility Award } & \text { Santander } \\ 2012 & \text { Exceptional Overseas Scholarship } & \text { Imperial College London } \\ 2011 & \text { Overseas Research Scholarship } & \text { Hokkaido University, Japan } \\ 2011 & \text { Best Student Poster Award (co-author) } & 10^{\text {th }} \text { IAFSS International Symposium } \\ 2011 & \text { Best Fire Image Award (co-author) } & 10^{\text {th }} \text { IAFSS International Symposium } \\ 2010 & \text { Best B.S. Thesis Award } & \text { Southeast University } \\ 2006 & 1^{\text {st } \text { Prize in National High School Physics Competition }} & \text { Chinese Ministry of Education }\end{array}$

\section{Journal Publications}

$\diamond$ X. Huang, K. Li, H. Zhang (2015) Modelling Bench-Scale Fire on Engineered Wood: Effects of Flame and Physicochemical Properties, Proceedings of the Combustion Institute (under review).

$\diamond$ K. Miyamoto, X. Huang, N. Hashimoto, C. Fernandez-Pello, O. Fujita (2015) Flammability Limit of Polyethylene Insulated Wires under Varying Oxygen Concentration and External Radiation, Proceedings of the Combustion Institute (under review).

$\diamond$ H. Wan, J. Ji, K. Li, X. Huang, J. Sun, Y. Zhang (2015) Effect of Air Entrainment on Flame Height of Multiple Fires in Open Space, Proceedings of the Combustion Institute (under review).

$\diamond$ G. Rein, X. Huang, F. Restuccia, T. McArdle (2015) O-Revealer: Novel technology for demining in peatlands by controlled smouldering combustion, Experimental Thermal and Fluid Science (under review).

1. X. Huang, G. Rein (2016) Interactions of Earth Atmospheric Oxygen and Fuel Moisture in Smouldering Wildfires, Science of the Total Environment (in press).

2. X. Huang, F. Restuccia, M. Gramola, G. Rein (2016) Experimental Study of the Formation and Collapse of an Overhang in the Surface Spread of Smouldering Peat Fires, Combustion and Flame (in press).

3. X. Huang, G. Rein (2016) Thermochemical Conversion of Biomass in Smouldering Combustion across Scales: the Roles of Heterogeneous Kinetics, Oxygen and Transport Phenomena, Bioresource Technology 207: 409-421. [appeared on the Journal Cover on May, 2016]

4. S. Wang, X. Huang, H. Chen, N. Liu, G. Rein (2015) Ignition of Low-density Expandable Polystyrene Foam by a Hot Particle, Combustion and Flame, 162 (11): 4112-4118.

5. D. Wu, X. Huang, F. Norman, F. Verplaetsen, J. Berghmansa, E. Van den Bulcka (2015) Experimental investigation on the self-ignition behavior of coal dust accumulations in oxy-fuel combustion system, Fuel, 160: 245-254.

6. X. Huang, G. Rein (2015) Computational Study of Critical Moisture and Depth of Burn in Peat Fires, International Journal of Wildland Fire, 24: 798-808. 
7. X. Huang, G. Rein, H. Chen (2015) Computational Smouldering Combustion: Predicting the Roles of Moisture and Inert Contents in Peat Wildfires, Proceedings of the Combustion Institute, 35 (3): 2673-2681.

8. K. Li, X. Huang, C.M. Fleischmann, G. Rein, J. Ji (2014) Pyrolysis of Medium-Density Fiberboard: Optimized Search for Kinetic Scheme and Parameters via a Genetic Algorithm Driven by Kissinger's Method, Energy Fuels, 28: 6130-6139.

9. X. Huang, M. J. Gollner (2014) Correlations for Evaluation of Flame Spread over an Inclined Fuel Surface, Fire Safety Science, 11: 222-233.

10. X. Huang, G. Rein (2014) Smouldering Combustion of Peat: Inverse Modelling of the Thermal and Oxidative Degradation Kinetics, Combustion and Flame 161 (6): 1633-1644. [Most downloaded article for 90 days]

11. X. Huang, Y. Nakamura, F. A. Williams (2013) Ignition-to-Spread Transition of Externally Heated Electrical Wire, Proceedings of the Combustion Institute, 34 (2): 2505-2512.

12. M. J. Gollner, X. Huang, J. Cobian, A. S. Rangwala, F. A. Williams (2013) Experimental Study of Upward Flame Spread of an Inclined Fuel Surface, Proceedings of the Combustion Institute, 34 (2): 2531-2538.

13. J. Wang, X. Huang*, G. Gong, M. Hao (2011) A Systematic Study of the Residual Gas Effect on Vacuum Solar Receiver, Energy Conversion and Management, 52: 2367-2372.

14. G. Gong, X. Huang*, J. Wang, M. Hao (2010) An Optimized Model and Test of the China's First High Temperature Parabolic Trough Solar Receiver, Solar Energy, 84: 2230-2245.

\section{Invited Talks/Seminars}

1. Experimental Study on the Two-Dimensional Spread of Smouldering Peat Fires Department of Mechanical Engineering, Imperial College London, 28 May 2015.

2. Smoldering Wildland Fires: Ignition, Spread and Extinction Department of Fire Protection Engineering, University of Maryland College Park, 20 Aug 2014.

3. Computational Modelling and Experimental Studies of Smouldering Peat Fires State Key Lab of Fire Science, University of Science and Technology of China, 13 Sep 2013.

\section{Selected Conference Communications}

1. K. Miyamoto, X. Huang, N. Hashimoto, C. Fernandez-Pello, O. Fujita Opposed Flame Spread over Polyethylene Insulated Wires under Varying External Radiations and Oxygen Concentrations, 46th International Conference on Environmental Systems, Vienna, Austria, 10-14 Jul 2016.

2. X. Huang, G. Rein, Computational Study of Smouldering Combustion of Peat in Wildfires, 8th International Seminar on Fire and Explosion Hazards (ISFEH), Hefei, China, 25-28 Apr 2016.

3. X. Huang, F. Restuccia, M. Gramola, G. Rein, Experimental Study on the Surface Spread of Smouldering Peat Fires, 5th International Fire Behavior and Fuels Conference, Portland, USA, 11-14 Apr 2016.

4. X. Huang, G. Rein, Computational Smoldering Combustion: Interactions of Atmospheric Oxygen and Fuel Moisture in Peat Fires, Western States Section Combustion Institute (WSSCI) Spring 2016 Meeting, Seattle, USA, 21-22 Mar 2016.

5. X. Huang, G. Rein, Computational smouldering combustion in peat fires: ignition, spread and extinction, 6th International Fire Ecology and Management Congress, San Antonio, Texas, USA, 16-20 Nov 2015.

6. S. Wang, X. Huang, H. Chen, N. Liu, G. Rein, Hot-Particle Ignition of Low-density Expandable Polystyrene Foam, 10th Asia-Oceania Symposium on Fire Science and Technology (AOSFST), Tsukuba, Japan, 5-7 Oct 2015. $\Rightarrow$ [Received Excellent Poster Award]

7. K. Li , X. Huang, Optimized Search for Pyrolysis Kinetics Scheme and Parameters via a Genetic Algorithm Driven by Kissinger's Method, 10th Asia-Oceania Symposium on Fire Science and Technology (AOSFST), Tsukuba, Japan, 5-7 Oct 2015. 
8. G. Rein, X. Huang, F. Restuccia, T. McArdle, P. Idoux, O-Revealer: Novel Technology for Demining in Peatlands by the Controlled Use of Smouldering Combustion, 25th International Colloquium on the Dynamics of Explosions and Reactive Systems (ICDERS), Leeds, UK, 2-7 Aug 2015.

9. X. Huang, G. Rein, Peat fires: Combining an In-depth Spread Model with Laboratory Experiments, 5th International Conference of Fire Effects on Soil Properties, Dublin, Ireland, 14-17 Jul 2015.

10. X. Huang, F. Restuccia, M. Gramola, G. Rein, Experimental Study on the Depth of Burn and Two-Dimensional Smouldering Fire Spread in Peatlands: the Role of Moisture Content and Wind, 5th International Conference of Fire Effects on Soil Properties, Dublin, Ireland, 14-17 Jul 2015.

11. K. Li, X. Huang, H. Zhang, J. Ji, Modelling the Bench-Scale Fire Experiments of Medium Density Fibreboard, 2nd European Symposium on Fire Safety Science, Nicosia, Cyprus, 16-18 Jun 2015.

12. X. Huang, F. Restuccia, M. Gramola, G. Rein, Experimental Study on the Two-Dimensional Spread of Smouldering Peat Fires, 2nd European Symposium on Fire Safety Science, Nicosia, Cyprus, 16-18 Jun 2015.

$\Rightarrow$ [Received Best Poster Award]

13. X. Huang, G. Rein, Computational Smouldering Wildfires: Depth of Burn and Super Critical Moisture at the Indepth Fire Spread over Peat Soils, 35th International Symposium on Combustion, San Francisco, USA, 3-8 Aug 2014.

14. G. Rein, X. Huang, Quenching the Reactive Earth: the Accidental Burning of Fossil Fuels and Geoengineering, Topics in Combustion Modelling, Fitzwilliam College of Cambridge, UK, 10 Jun 2014.

15. X. Huang, G. Rein, Computational Modelling of Smouldering Peat Fires: Predicting the Role of Moisture and Inert Contents, 11th International Symposium on Fire Safety Science, University of Canterbury, New Zealand, 9-14 Feb 2014. $\Rightarrow$ [Received Best Student Poster Award]

16. X. Huang, G. Rein, Smouldering Combustion of Peat: Inverse Modelling of Degradation Kinetics, IOP Current Research in Combustion, Loughborough University, UK, 24 Sep 2013.

17. X. Huang, G. Rein, Smouldering Combustion of Soil Organic Matter: Inverse Modelling of the Thermal and Oxidative Degradation Kinetics, 6th European Combustion Meeting, Lund, Sweden, 25-28 Jun 2013.

18. X. Huang, G. Rein, Computational Smouldering Wildfires: Combustion of Organic Soil and Inverse Kinetics Modelling, European Geosciences Union General (EGU) Assembly, Vienna, Austria, 7-12 Apr 2013.

19. X. Huang, Y. Nakamura, F. A. Williams, An Experimental Study of Flame Spread over Electrical Wire in OxygenEnriched Atmospheres, Western States Section of the Combustion Institute, Spring Technical Meeting, Arizona State University, USA, 19-20 Mar 2012.

20. M. J. Gollner, X. Huang, J. Cobian, A. S. Rangwala, F. A. Williams, Burning of Inclined Fuel Surfaces, Western States Section of the Combustion Institute, Spring Technical Meeting, Arizona State University, USA, 19-20 Mar 2012.

21. X. Huang, Y. Nakamura, F. A. Williams, An Experimental Study on Ignition of Electrical Wire, Western States Section of the Combustion Institute, Fall Technical Meeting, UC Riverside, USA, 16-18 Oct 2011.

22. M. J. Gollner, X. Huang, A. S. Rangwala, F. A. Williams, Effects of Inclination on Upward Flame Spread, Western States Section of the Combustion Institute, Fall Technical Meeting, UC Riverside, USA, Oct 2011.

23. M. J. Gollner, X. Huang, F. A. Williams, A. S. Rangwala, An experimental study of flame spread over inclined fuels, 10th International Symposium on Fire Safety Science, Maryland, 19-24 Jun 2011.

$\Rightarrow$ [Received Best Student Poster Award]

24. M. J. Gollner, X. Huang, F. A. Williams, A. S. Rangwala, Buoyancy-enhanced flame spread over continuous surfaces, 7th U.S. National Meeting of the Combustion Institute, Georgia Institute of Technology, Atlanta, USA, 20-23 Mar 2011.

25. X. Huang, G. Gong, J. Wang, M. Hao, Heat Loss Analysis and Modeling on End Structures of the Parabolic Trough Solar Receivers, 9th International Conference on Sustainable Energy Technologies, Shanghai, China, 24-27 Aug 2010. 
26. X. Huang, J. Wang, G. Gong, Testing and Analysis on the Thermal Properties of a New High Temperature Parabolic Trough Receiver, 10th ASME International Colloquium on Environmentally Preferred Advanced Power Generation, 2010, Costa Mesa, CA, USA, 9-11 Feb 2010.

\section{Journal Referee / Peer Review $(\times 75)$}

Proceedings of the Combustion Institute $(\times 23)$; Fire Technology $(\times 23$, Outstanding Reviewer); Fire Safety Journal $(\times 3)$; Energy Conversion and Management $(\times 16)$; Fire Safety Science $(\times 4)$; Int. Journal of Heat and Mass Transfer $(\times 1)$; Journal of Analytical and Applied Pyrolysis $(\times 1)$; Energy \& Fuel $(\times 1)$; Fire and Material $(\times 1)$; Building Simulation $(\times 1)$; Journal of Thermal Analysis and Calorimetry $(\times 1)$.

\section{Experiences as a Teaching Assistant / Tutor}

Imperial College (2012-2015): Heat Transfer Lab; Heat Transfer; Thermofluid Lab; Experimental Reporting Skills UC San Diego (2010-2012): Fluid Mechanics; Thermodynamics; Aerospace System and Design

\section{Student Advising Experiences}

2015 Shiyu Jing (BS student, UC Berkeley): Ignition delay for cylindrical fuels

2015 Meng Qu (BS student, UC Berkeley) \& SH Jiao Tong Univ.): Flammability of polyethylene wires

2015 Jiayun Song (PhD student, USTC): The Wind Effect on Landing Distribution of Firebrands

2015 Kyosuke Miyamoto (MSc student, Hokkaido Univ.): Wire Fire under External Radiation and Opposed Flow

2014 Michela Gramola (BS student, Cambridge): 2D Spread Behavior in Smoldering Wildfires

2014 Pierre Idoux (MSc student, Imperial): Novel Demining Technology with Controlled Smoldering Fires

2013 Tom McArdle (MEng student, Imperial): Peat Fires in Mine Field

\section{Skills and Interests}

Computer $\quad \mathrm{C}++$, Matlab, Solidworks, ANSYS-Fluent, FDS, Gpyro, Python

Language Chinese (native), Japanese (in study)

Hobbies Hiking, Badminton, Swimming, Musical, Science friction 
POLITÉCNICA

INFORME EXPERTO EXTERNO / EXTERNAL REVIEWER REPORT (ART. 5B DEL REGLAMENTO DE DEFENSA Y EVALUACIÓN DE LA TESIS DOCTORAL)

\begin{tabular}{|l|}
\hline Nombre del experto/Name of the reviewer: Dr. Bjarne Christian Hagen \\
\hline Categoria/Position: Associate professor \\
\hline Universidad a la que pertenece/Departmento, University/Department: \\
Stord Haugesund University College \\
Faculty of Technology/Business/Maritime Education \\
Department of Engineering
\end{tabular}

Título de la tesis/Title of the Ph.D. Thesis:

ANALYSIS OF THE FLAMMABILITY PROPERTIES OF SOLID FUELS

Nombre del doctorando que presenta la tesis/Name of the Ph.D. candidate:

María de las Nieves Fernández Áñez

Especificar los motivos que avalan la calidad de la tesis mencionada para su defensa:

Specify reasons endorsing the quality of the above-mentioned thesis for its defense:

The thesis is presented in a very good manner. The different parts of thesis are well written and well documented.

The introduction is interesting and shows the importance of the work done in the thesis. The literature review is substantial and reflects on both previous and ongoing research. The referencelist is also forming a good base for the thesis.

The materials and method used for analysis are very well described. The number of materials samples and different test methods are significant and quite impressive.

The number of samples and tests are also followed up with a detailed analysis where the important constituencies are identified. Here there are several interesting findings that are properly discusses.

Over all the thesis represents a substantial work, covering numerous materials and test methods and identifies the importance of specific constituencies related to flammability. 


\section{POLITÉCNICA}

¿Qué objetivos se han logrado con la tesis presentada?

What are the contributions of the Ph.D. thesis?

The main contributions of the thesis are the combinations of a large number of samples which are subjected to a large number of test methods. The understanding of materials subjected to different test is lacking and seldom reported on in the literature.

The number of materials and tests combined with a statistical analysis gives an interesting insight in the importance of specific material values that is important for flammability.

Originalidad del trabajo:

Originality of the work:

The number of materials and tests combined with a statistical analysis gives an interesting insight in the importance of specific material values that is important for flammability.

The approach and analysis are interesting and original, and contributes to the understanding of material properties. 


\section{POLITÉCNICA}

Metodología usada / hipótesis contrastadas:

Metodology used / hypotheses tested :

The methodology used is well founded and very interesting. The materials and test methods used are well documented and cover a substantial range of interesting aspects regarding flammability.

In the thesis it is chosen to use "Aim of the Project" instead of a hypothesis. Due to the scope of the work and amount of samples and test methods, using "Aim of the Project" is understandable.

However, it would increase the readability of the thesis and the understanding of the work if a clearer hypothesis was introduced in the thesis.

Observaciones:

Observations:

Over all the work and thesis are very well performed and written. There are some minor issues that could increase the quality of the thesis even more:

- There are some minor errors in the language and the expressions used which easily can be edited and corrected.

- Some figure texts are on the wrong page. Make sure the layout is correct and make a pdf-fil.

- There are some issues around some of the figures. One example: Figure 73: How are the results "estimated"? This is not very clear, and could be explained. Why are the estimated values "always" higher than the measured values? This could also be elaborated on. 


\section{POLITÉCNICA}

Considera que la tesis anteriormente mencionada es apta para su defensa pública? In consideration of all the above, is the Ph.D. Thesis ready for its defence?

$$
\bigotimes \text { Si / Yes } \square \text { No }
$$

Firma y fecha

Signature and date: 29.02.2016

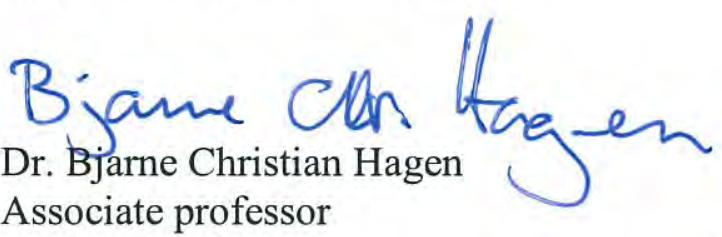

Stord Haugesund University College

Faculty of Technology/Business/Maritime Education

Department of Engineering

$$
\text { HOOSKOLE }
$$


CV FOR Bjarne Christian Hagen

\begin{tabular}{|c|c|}
\hline NAVN & Hagen, Bjarne Christian \\
\hline Academic title & $\mathrm{PhD}$ \\
\hline Position & Associate professor \\
\hline Degrees & $\begin{array}{l}\text { PhD from University of Bergen, Norway } 2013 \\
\text { Master of Science From University of Maryland, USA } 1994 \\
\text { Bachelor of Science - Fire Protection From University of Maryland, } \\
\text { USA } 1993 \\
\text { Bachelor of engineering - Civil engineering from Bergen } \\
\text { ingeniørhøgskolen, Norway } 1990\end{array}$ \\
\hline Experience & $\begin{array}{l}1995 \text { - dd Lecturer at Stord Haugesund university college. } \\
\text { Lecturing at the fire safety bachelor program, } \\
\text { advising students at the Master in Technical safety. } \\
1998 \text { - dd Senior engineer at Rogaland Brann og Sikkerhet } \\
\text { Consulting and designing building with focus on fire } \\
\text { safety. } \\
\text { 2002-2003 Senior engineer at Gassco } \\
\text { Focus on technical safety, environment and } \\
\text { contingency planning }\end{array}$ \\
\hline
\end{tabular}




\section{Publications:}

Bjarne Chr. Hagen

Hagen, Bjarne Chr; Frette, Vidar; Kleppe, Gisle; Arntzen, Bjørn Johan.

Transition from smoldering to flaming fire in short cotton samples with asymmetrical boundary conditions. Fire safety journal 2015 ;Volum 71. s. 69-78

$\mathrm{HSH}$ UiB

Hagen, Bjarne Chr.

Onset of smoldering and transition to flaming fire. : University of Bergen 2013 (ISBN 97882-308-2336-1)

HSH UiB

Hagen, Bjarne Chr; Frette, Vidar; Kleppe, Gisle; Arntzen, Bjørn Johan.

Effects of heat flux scenarios on smoldering in cotton. Fire safety journal 2013 ;Volum 61.

S. $144-159$

$\mathrm{HSH}$ UiB

Hagen, Bjarne Chr; Frette, Vidar; Kleppe, Gisle; Arntzen, Bjørn Johan.

Ignition of cotton by different heat flux scenarios. 10th international Fire Safety

Symposium; 2011-06-19 - 2011-06-24

$\mathrm{HSH}$ UiB

Hagen, Bjarne Chr; Frette, Vidar; Kleppe, Gisle; Arntzen, Bjørn Johan.

Onset of smoldering in cotton: Effects of density. Fire safety journal 2011 ;Volum 46.(3) s. 73-80

$\mathrm{HSH}$ UiB

Halrynjo, Frode Himle; Husted, Bjarne Paulsen; Hagen, Bjarne Chr; Arntzen, Bjørn Johan.

Optimal gas firefighting training objects. 10th International Symposium on Fire Safety

Science; 2011-06-19 - 2011-06-24

$\mathrm{HSH}$ UiB

Kolstad, Einar Arthur; Husted, Bjarne Bruun Paulsen; Hagen, Bjarne Chr.

Case study of a BLEVE in single containment LNG-tank. 10th International Symposium on Fire Safety Science; 2011-06-19 - 2011-06-24

$\mathrm{HSH}$ 
Husted, Bjarne Paulsen; Hagen, Bjarne Chr; Sommerlund-Thorsen, K.

Best practice in the use of CFD for fire simulation. 12th International Fire Science \&

Engineering Conference; 2010-07-05 - 2010-07-07

$\mathrm{HSH}$

\section{Hagen, Bjarne Chr.}

Brannteknisk rømningsanalyse. Tapir Akademisk Forlag 2008 (ISBN 9788251922784) 147 s.

$\mathrm{HSH}$

\section{Hagen, Bjarne Christian.}

Grunnleggende brannteknikk. Haugesund: Eget forlag 2004 (ISBN 8299664519$) 356$ s.

$\mathrm{HSH}$

\section{Hagen, Bjarne Christian.}

Flammer og adiabatisk flammetemperatur. Haugesund: Bjarne Chr.Hagen 2003 (ISBN $8299664500) 24 \mathrm{~s}$.

$\mathrm{HSH}$

Hagen, Bjarne C.; Milke, James A..

The use of gaseous fire signatures as a mean to detect fires. Fire safety journal $2000 \mathrm{~s}$. 55-68

$\mathrm{HSH}$

\section{Hagen, Bjarne Christian; Log, Torgrim.}

Evaluation of the stress of the firefighters. Seventh international fire science and engineering conference.; 1997

$\mathrm{HSH}$ 
Annex II. Results 
1. Proximate analysis solid fuels

2. Granulometric curves solid fuels

3. Gases emissions solid fuels

$\mathrm{CO}$ emissions

$\mathrm{CO}_{2}$ emissions

4. Results of interval method gas emissions test

5. Graphs of inflexion points method gas emissions test

6. Elemental analysis thermally dried sewage sludge

7. Proximate analysis thermally dried sewage sludge

8. Thermogravimetric curves thermally dried sewage sludge

9. Thermogravimetric with oxygen stream curves thermally dried sewage sludge

10. Differential scanning calorimetry curves thermally dried sewage sludge

11. Self-ignition temperature thermally dried sewage sludge (LRET-121)

12. Elemental analysis of mixtures

13. Proximate analysis mixtures 


\section{Proximate analysis solid fuels}

\begin{tabular}{|c|c|c|c|c|}
\hline Sample & Moisture $(\%)$ & Ashes $(\%)$ & Volatiles $(\%)$ & $\begin{array}{c}\text { Fixed carbon } \\
(\%)\end{array}$ \\
\hline NFA-1 fine & 7.28 & 3.73 & 79.20 & 17.07 \\
\hline NFA-1 coarse & 7.27 & 2.01 & 81.87 & 16.12 \\
\hline NFA-2 & 8.85 & 8.08 & 75.05 & 16.87 \\
\hline NFA-3 & 4.30 & 15.40 & 32.10 & 52.50 \\
\hline NFA-4 fine & 7.76 & 0.90 & 86.91 & 12.19 \\
\hline NFA-4 coarse & 7.84 & 0.30 & 86.36 & 13.34 \\
\hline NFA-5 & 7.37 & 30.45 & 63.22 & 6.33 \\
\hline NFA-6 fine & 1.13 & 6.39 & 93.50 & 0.11 \\
\hline NFA-6 coarse & 2.00 & 4.37 & 92.09 & 3.54 \\
\hline NFA-7 fine & 9.21 & 42.45 & 54.40 & 3.15 \\
\hline NFA-7 coarse & 8.99 & 40.69 & 55.88 & 3.43 \\
\hline NFA-8 & 9.68 & 36.71 & 55.32 & 7.97 \\
\hline NFA-9 & 7.77 & 39.89 & 56.25 & 3.86 \\
\hline NFA-10 fine & 0.75 & 0.41 & 10.19 & 89.40 \\
\hline NFA-10 coarse & 0.74 & 0.31 & 8.71 & 90.98 \\
\hline NFA-11 & 5.35 & 34.82 & 41.72 & 23.46 \\
\hline NFA-12 & 8.83 & 8.42 & 76.14 & 15.44 \\
\hline NFA-13 & 8.09 & 21.72 & 65.03 & 13.25 \\
\hline NFA-14 fine & 3.11 & 5.70 & 87.40 & 6.90 \\
\hline NFA-14 coarse & 1.79 & 4.56 & 94.21 & 1.23 \\
\hline NFA-15 fine & 4.46 & 0.58 & 81.19 & 18.23 \\
\hline NFA-15 coarse & 15.33 & 0.82 & 82.06 & 17.12 \\
\hline NFA-16 fine & 4.15 & 1.05 & 77.89 & 21.06 \\
\hline NFA-16 coarse & 3.53 & 0.90 & 80.18 & 18.92 \\
\hline
\end{tabular}




\section{Granulometric curves solid fuels}

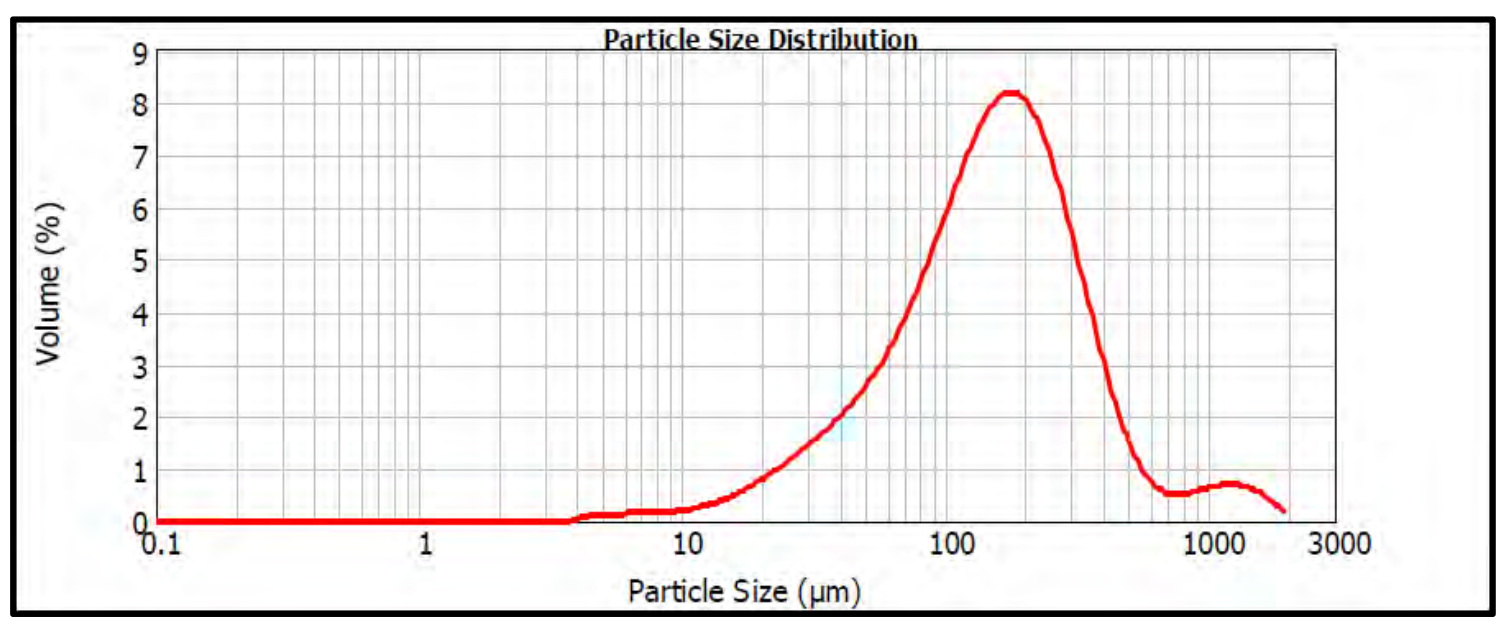

Figure 2-1. Granulometric curve NFA-1 fine

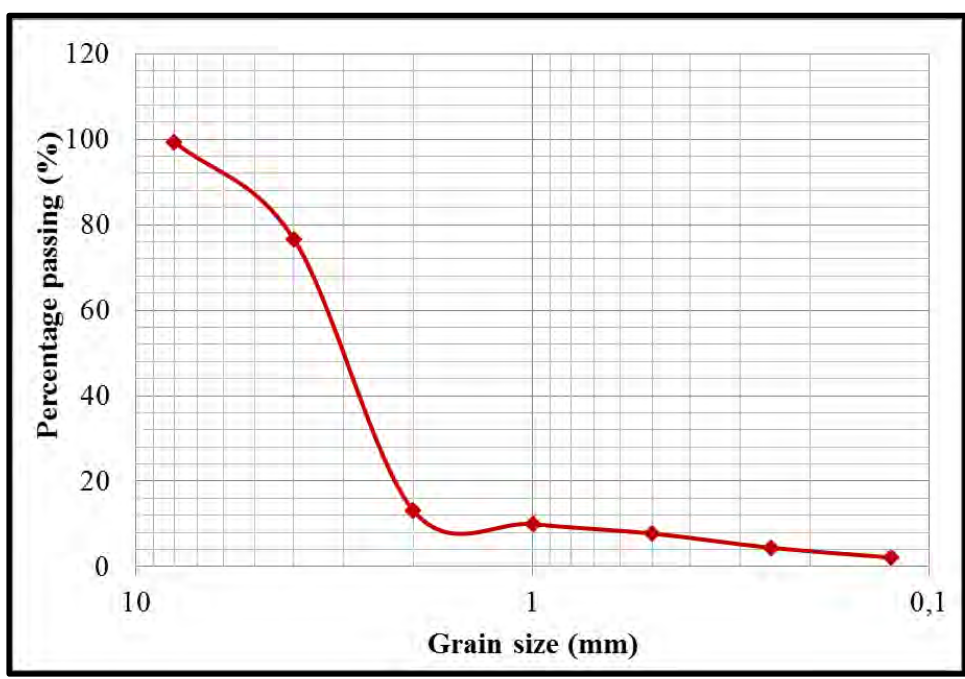

Figure 2-2. Granulometric curve NFA-1 coarse

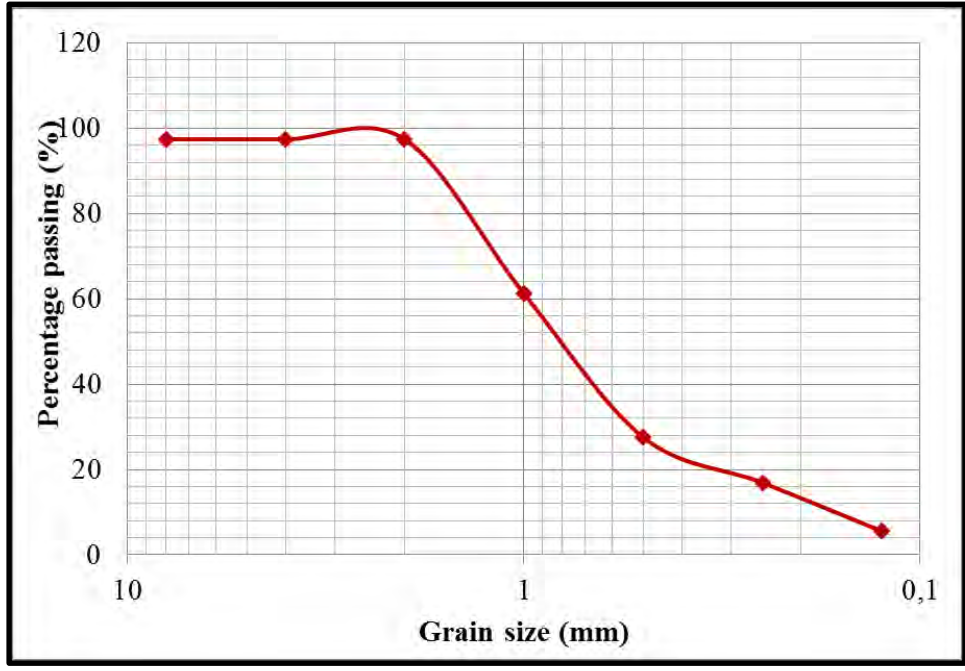

Figure 2-3. Granulometric curve NFA-2 


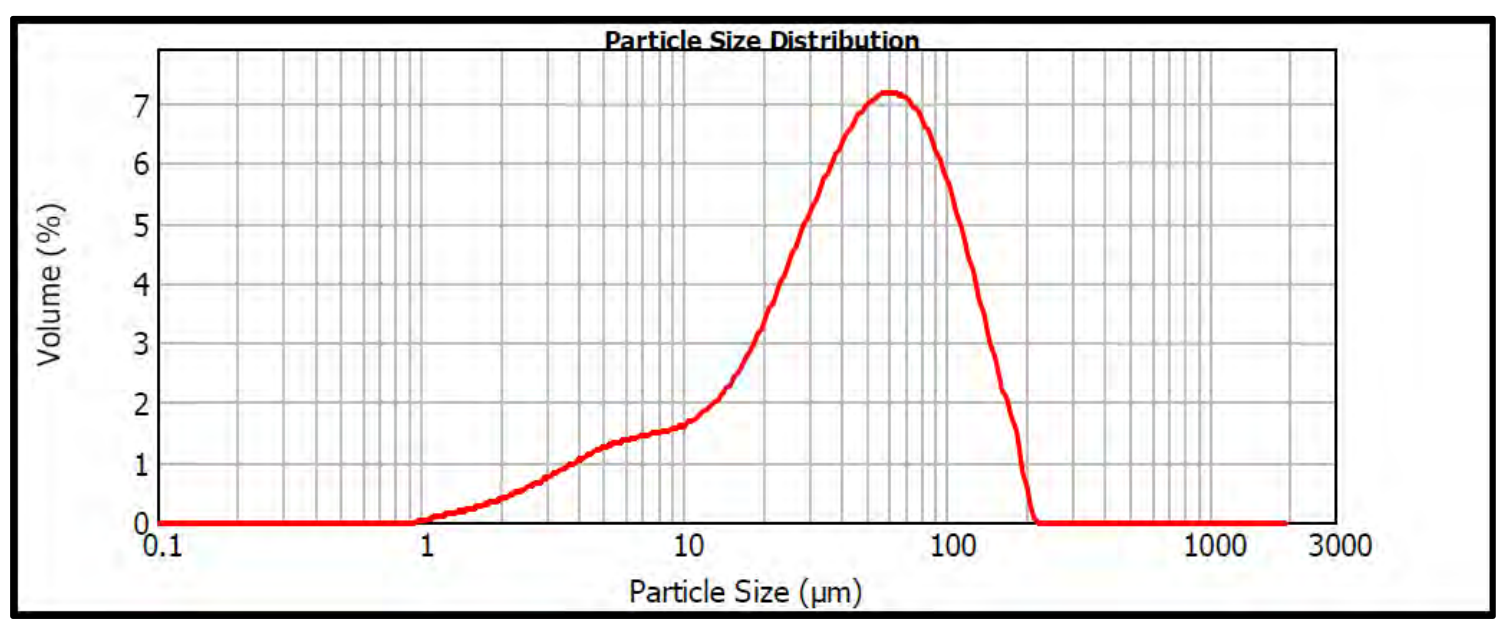

Figure 2-4. Granulometric curve NFA-3

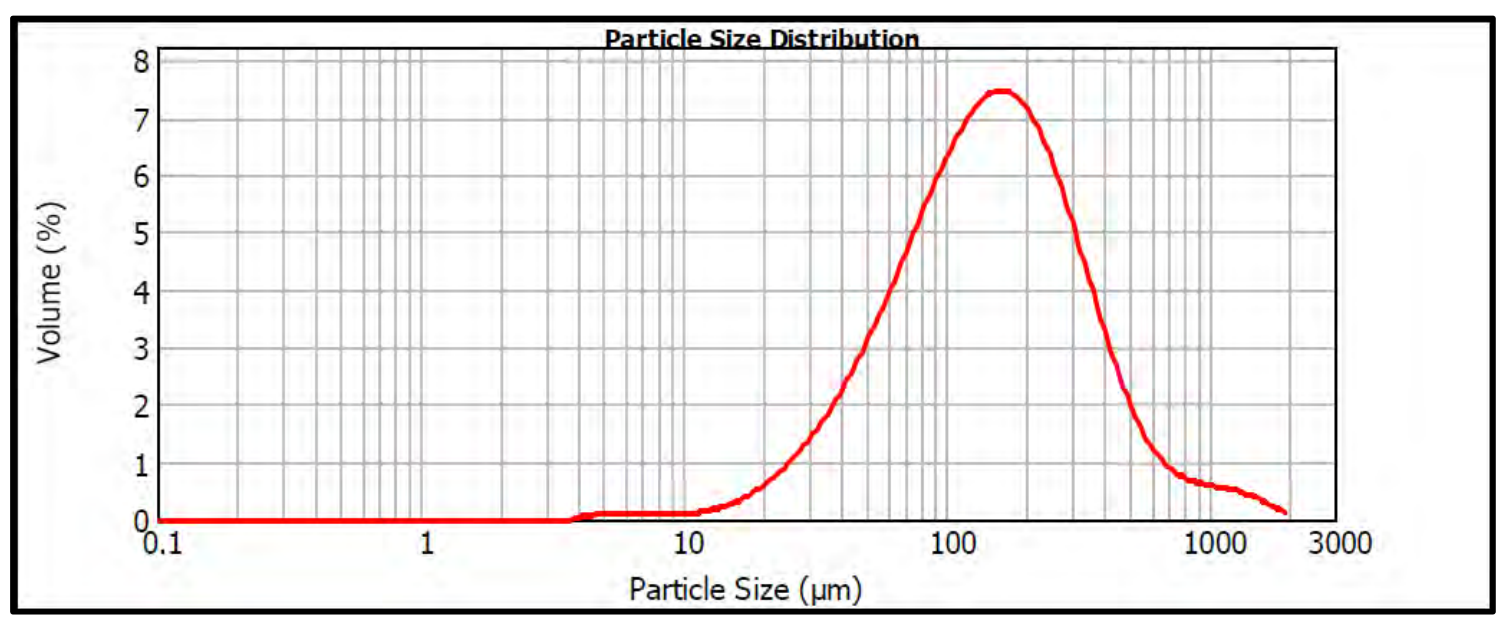

Figure 2-5. Granulometric curve NFA-4 fine

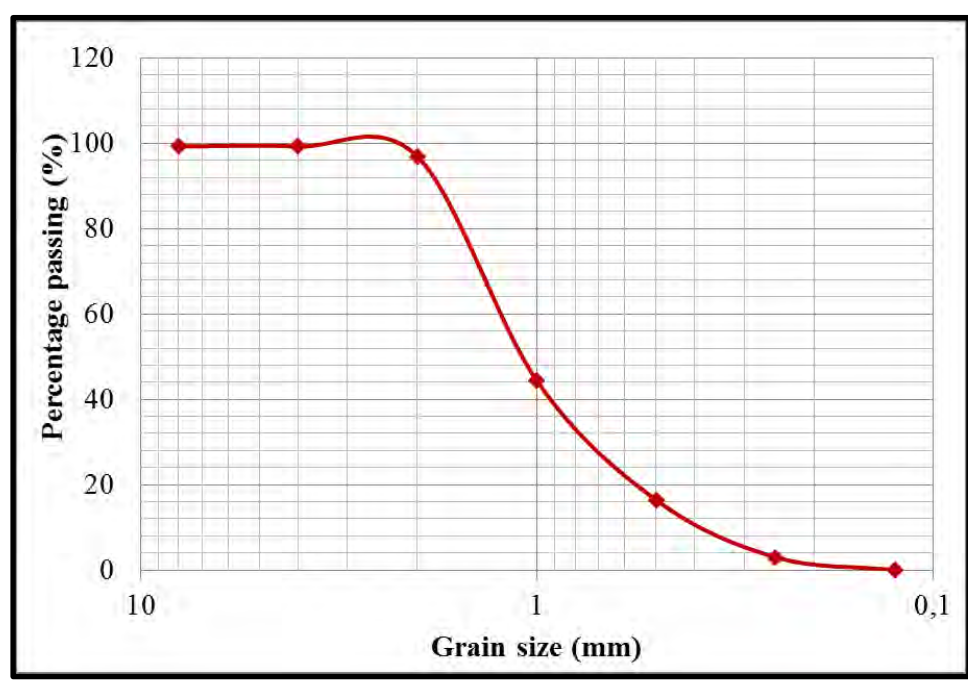

Figure 2-6. Granulometric curve NFA-4 coarse 


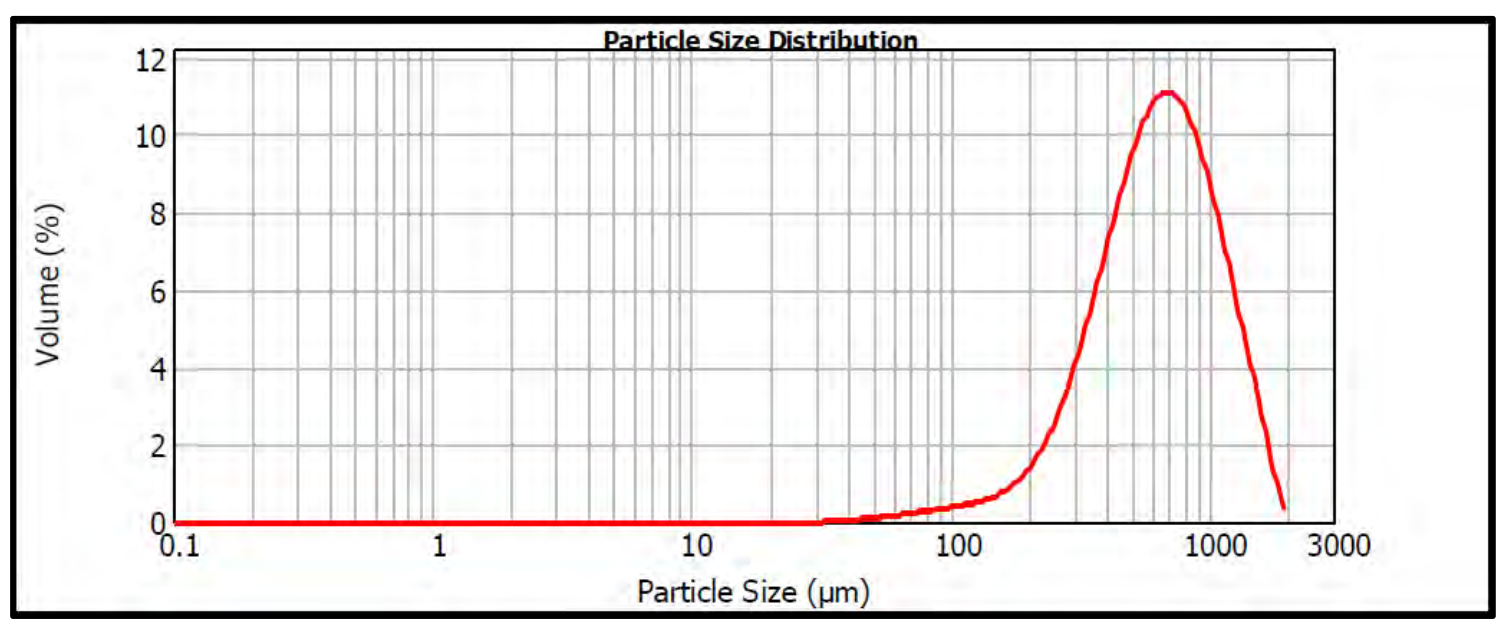

Figure 2-7. Granulometric curve NFA-5

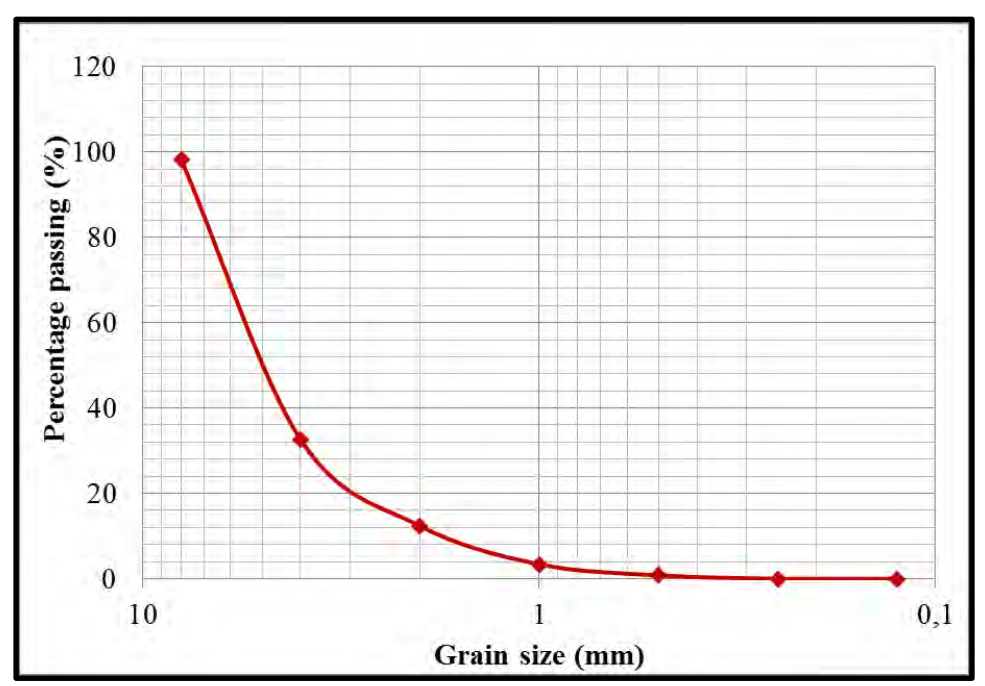

Figure 2-8. Granulometric curve NFA-6 fine

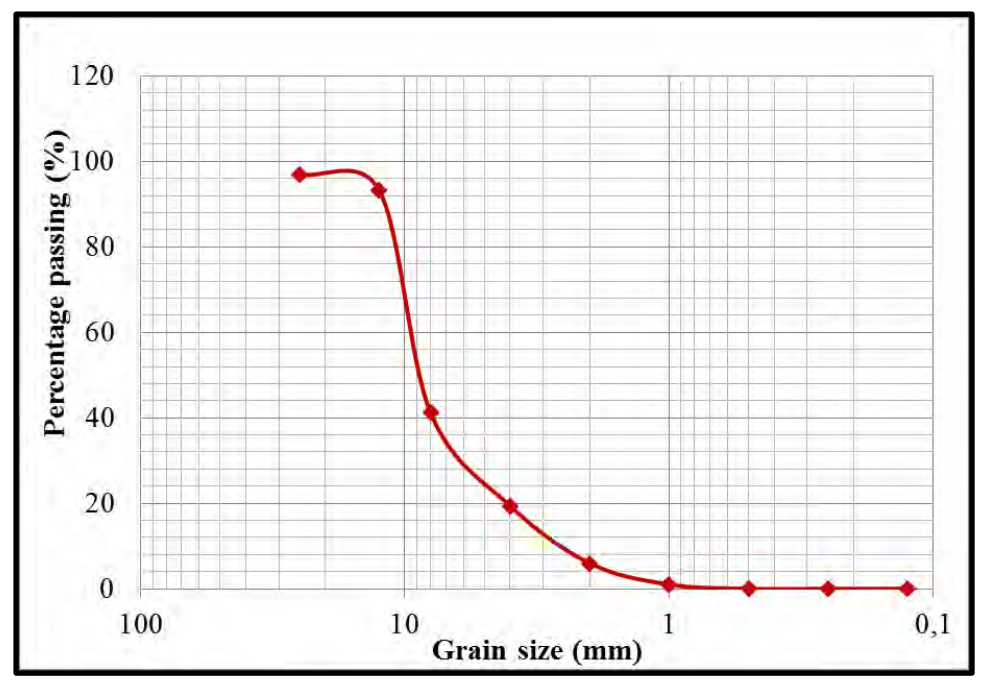

Figure 2-9. Granulometric curve NFA-6 coarse 


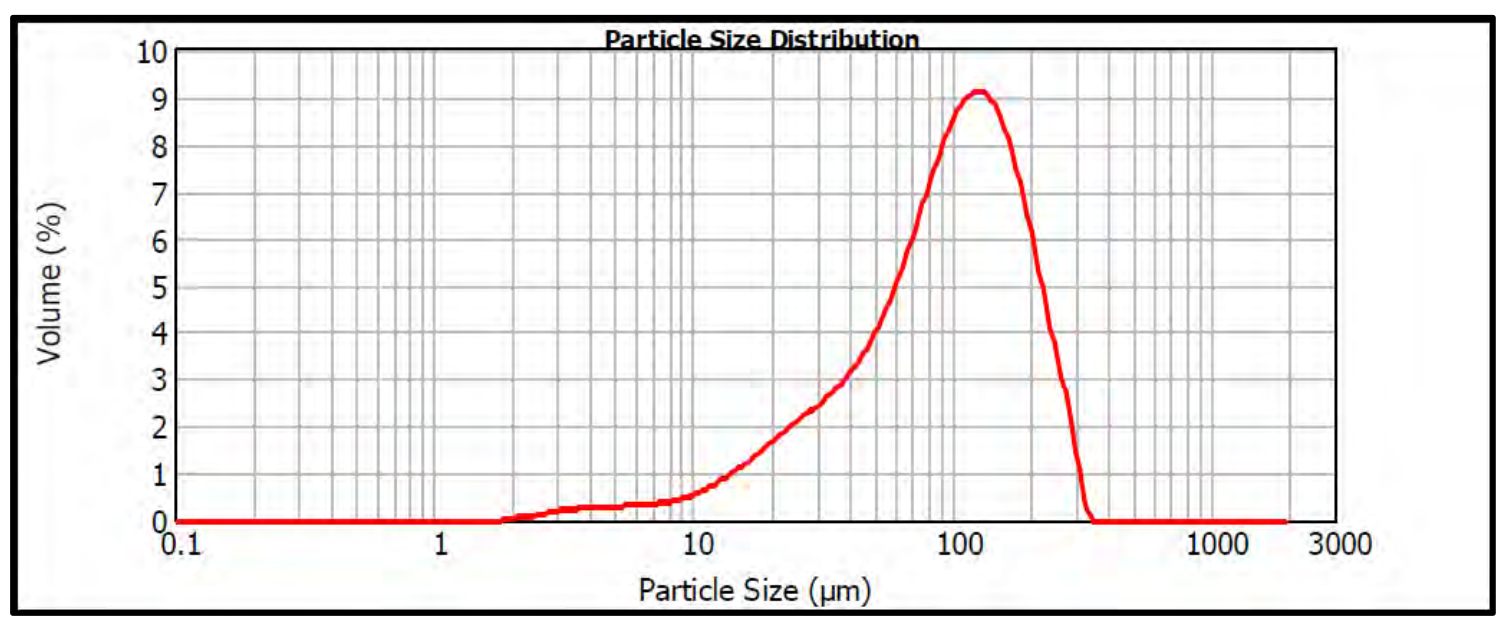

Figure 2-10. Granulometric curve NFA-7 fine

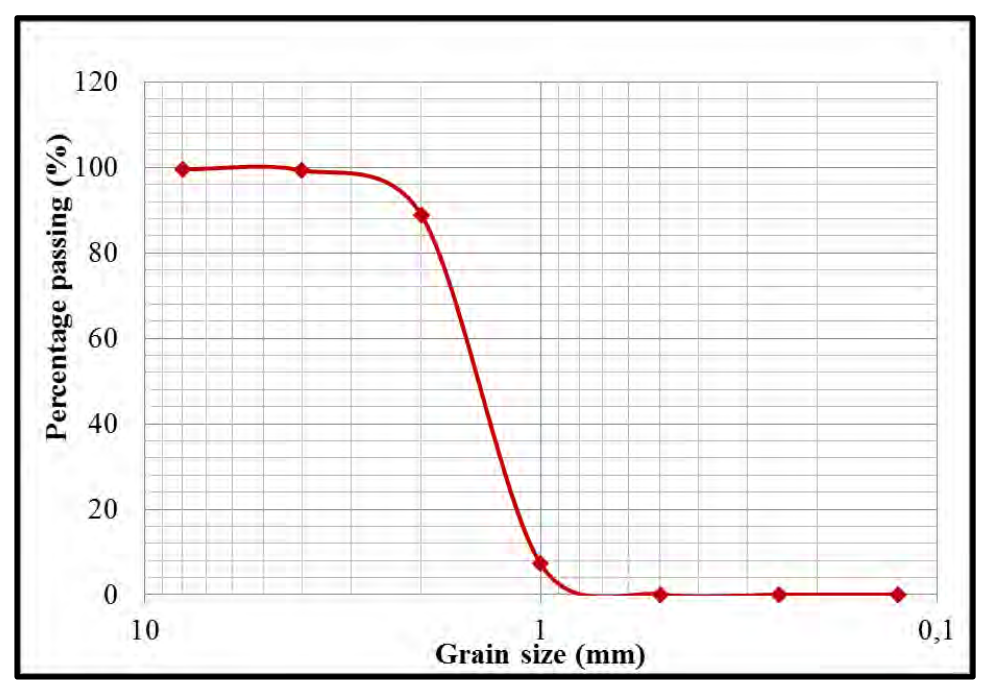

Figure 2-11. Granulometric curve NFA-7 coarse

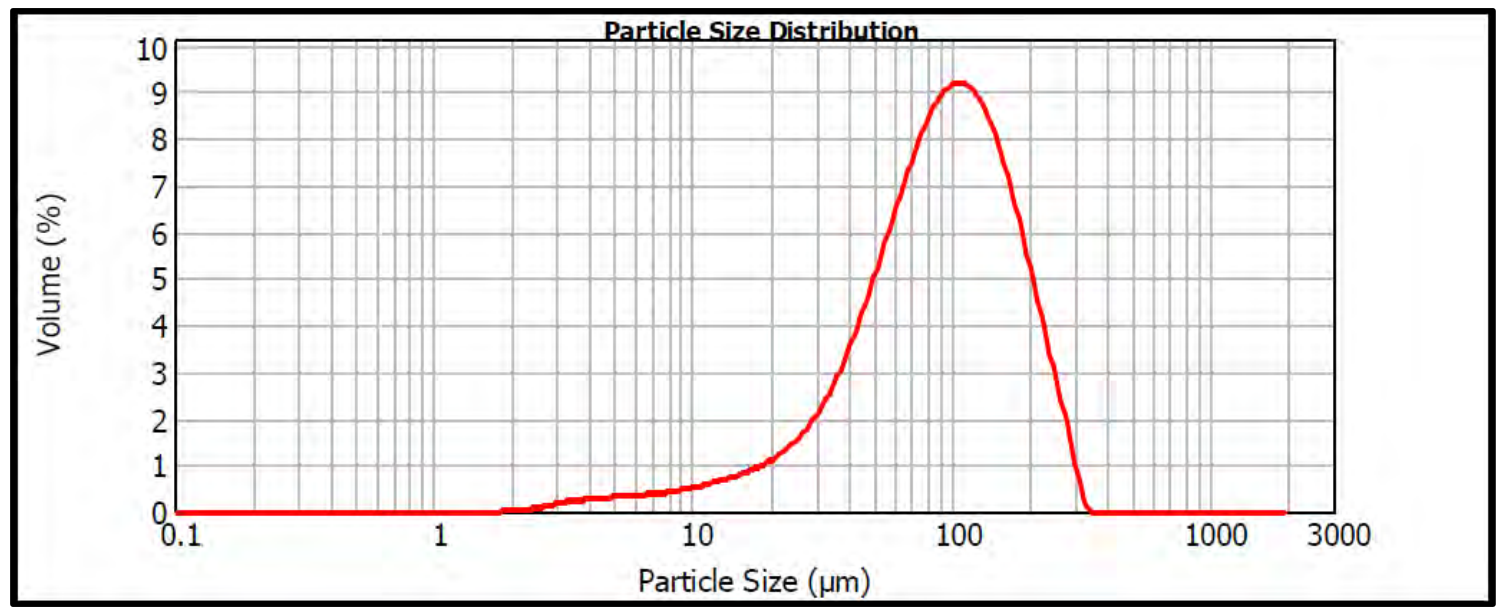

Figure 2-12.Granulometric curve NFA-8 


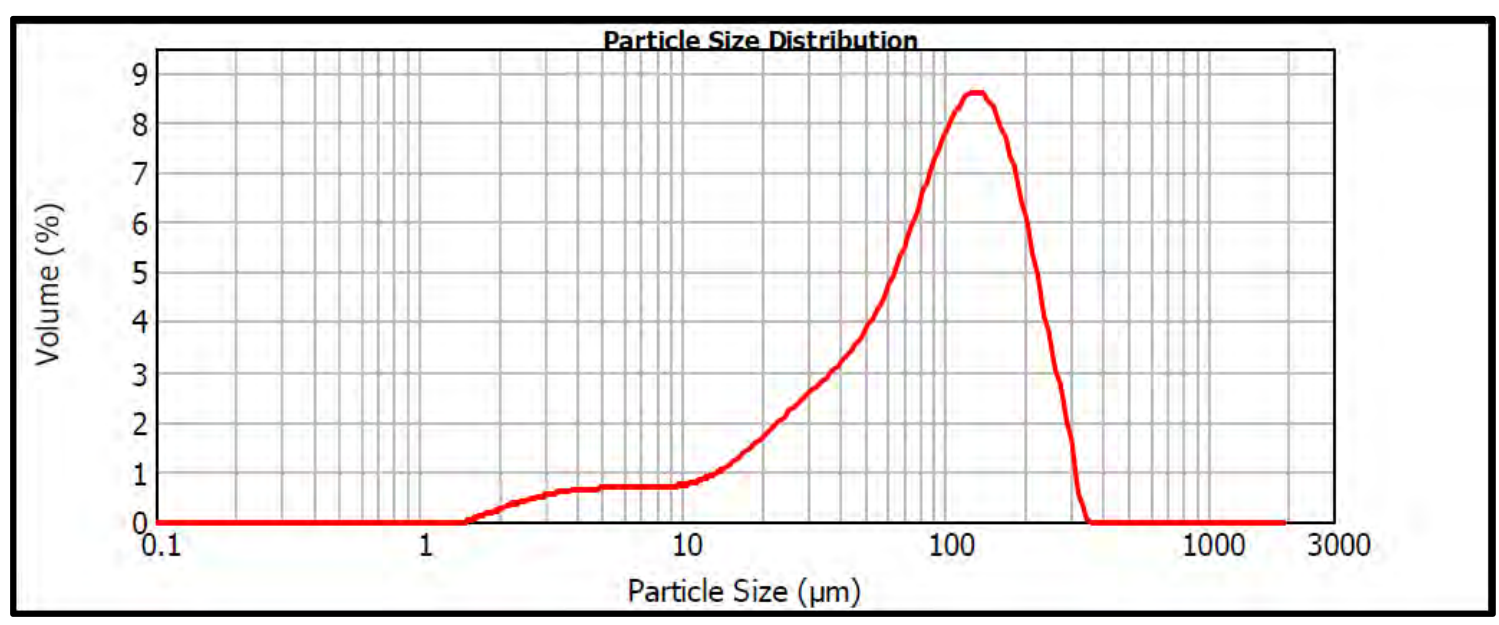

Figure 2-13. Granulometric curve NFA-9

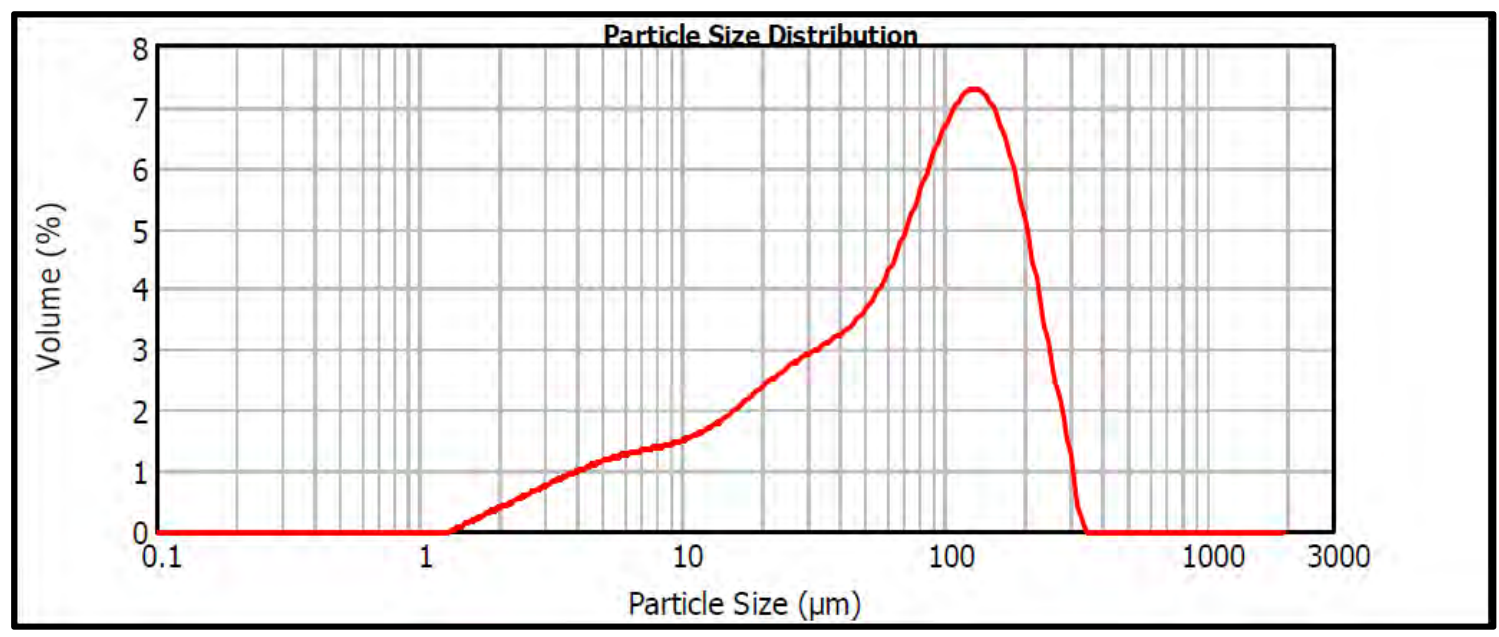

Figure 2-14. Granulometric curve NFA-10 fine

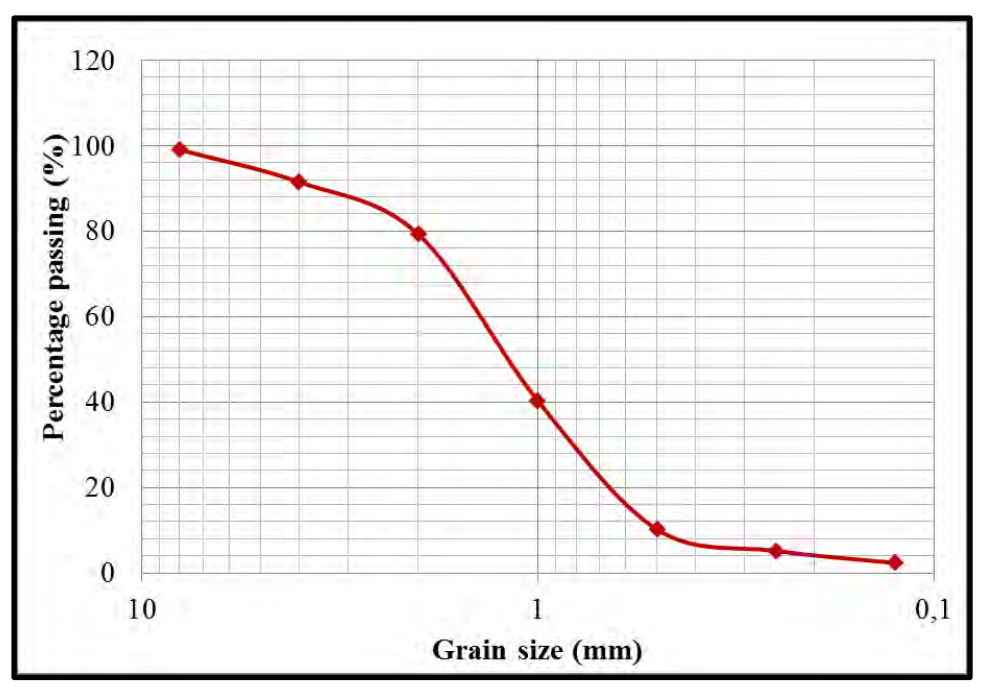

Figure 2-15. Granulometric curve NFA-10 coarse 


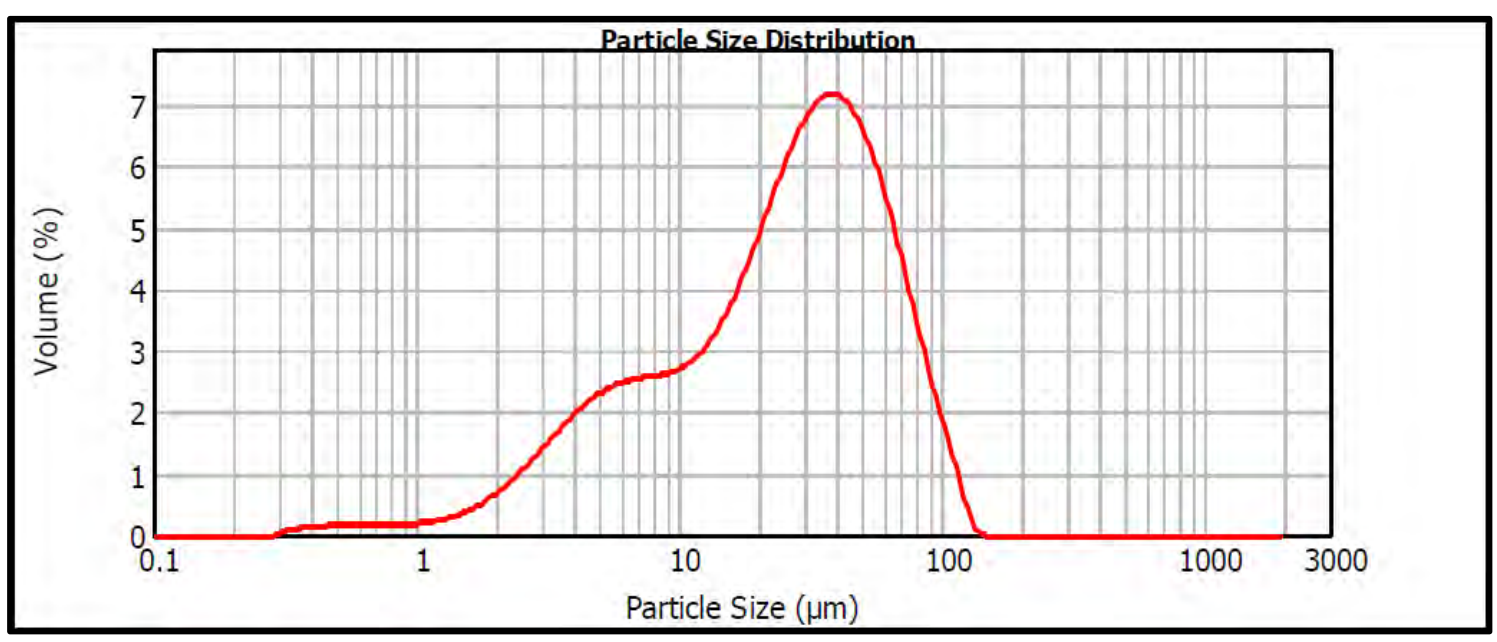

Figure 2-16. Granulometric curve NFA-11

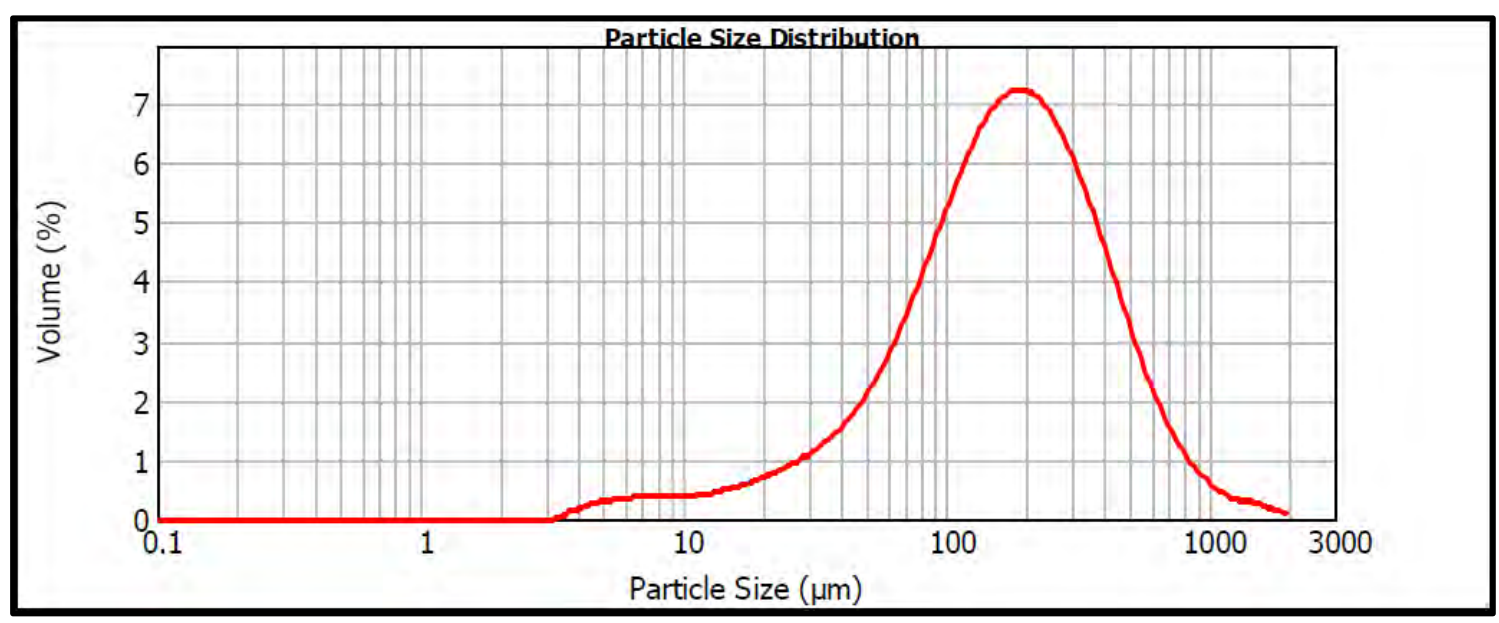

Figure 2-17. Granulometric curve NFA-12

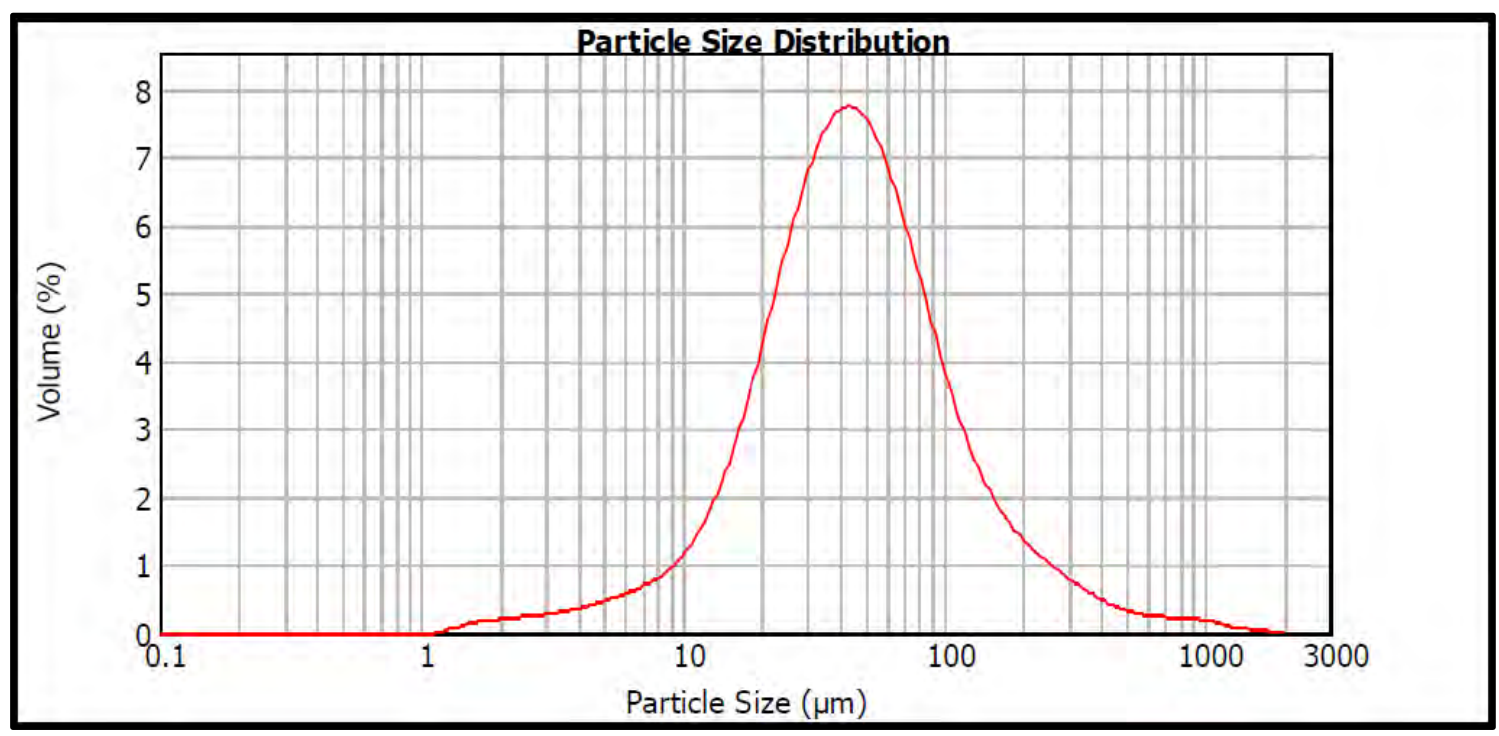

Figure 2-18. Granulometric curve NFA-13 


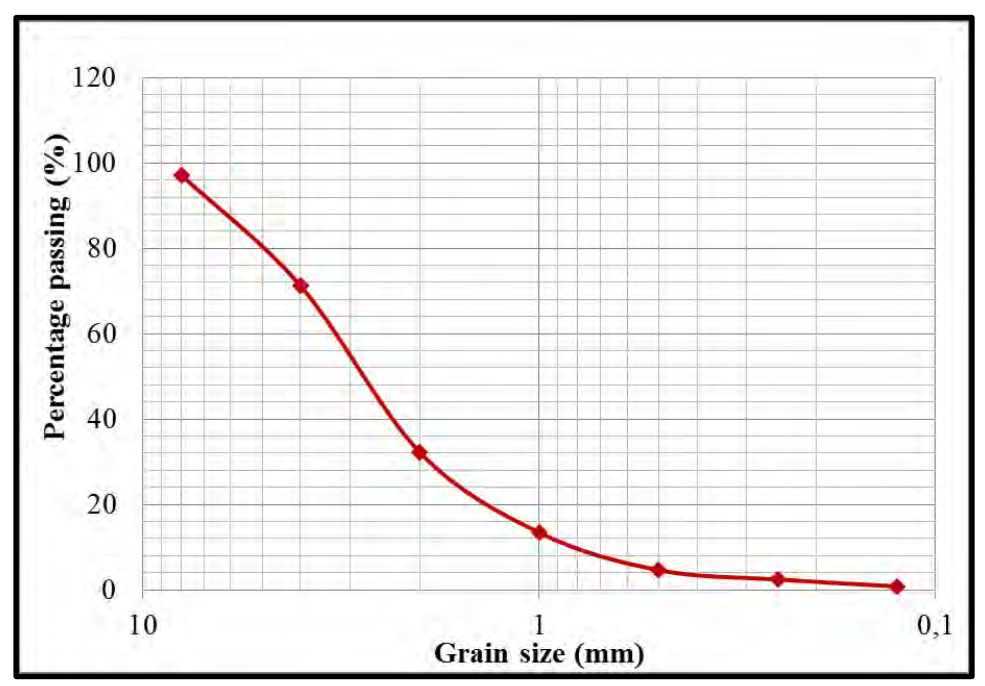

Figure 2-19. Granulometric curve NFA-14 fine

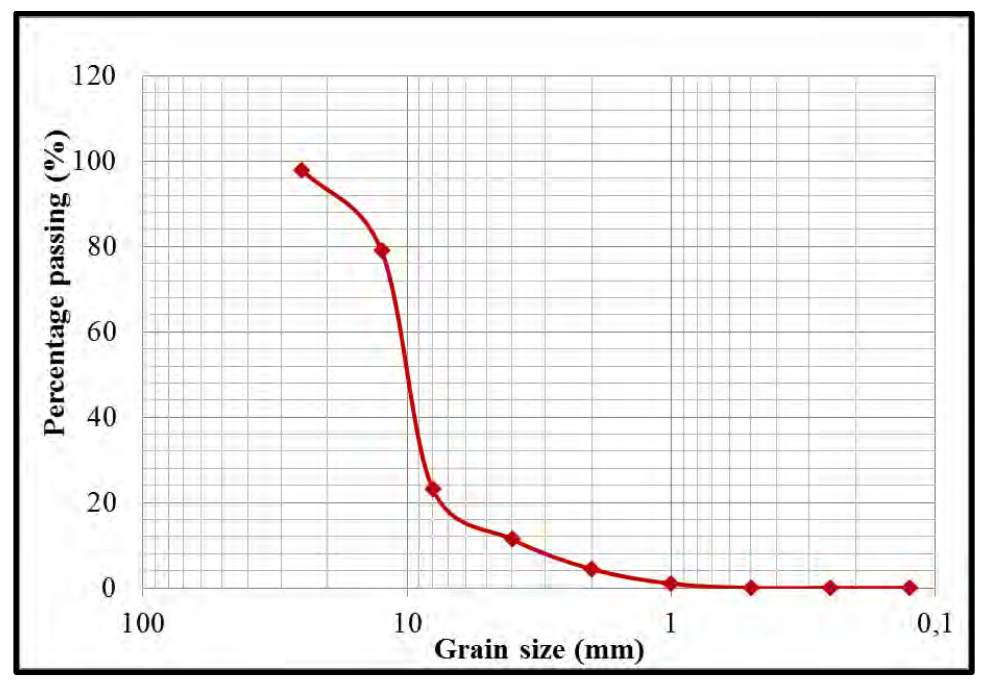

Figure 2-20. Granulometric curve NFA-14 coarse

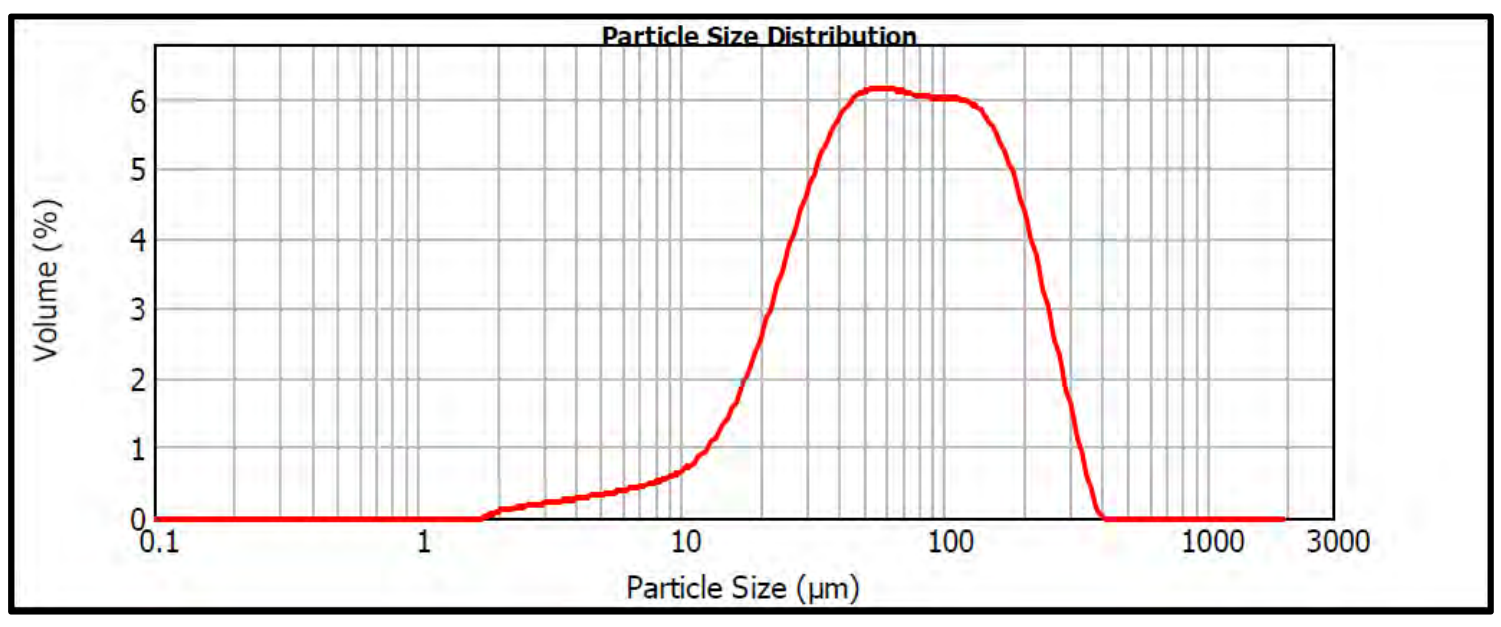

Figure 2-21. Granulometric curve NFA-15 fine 


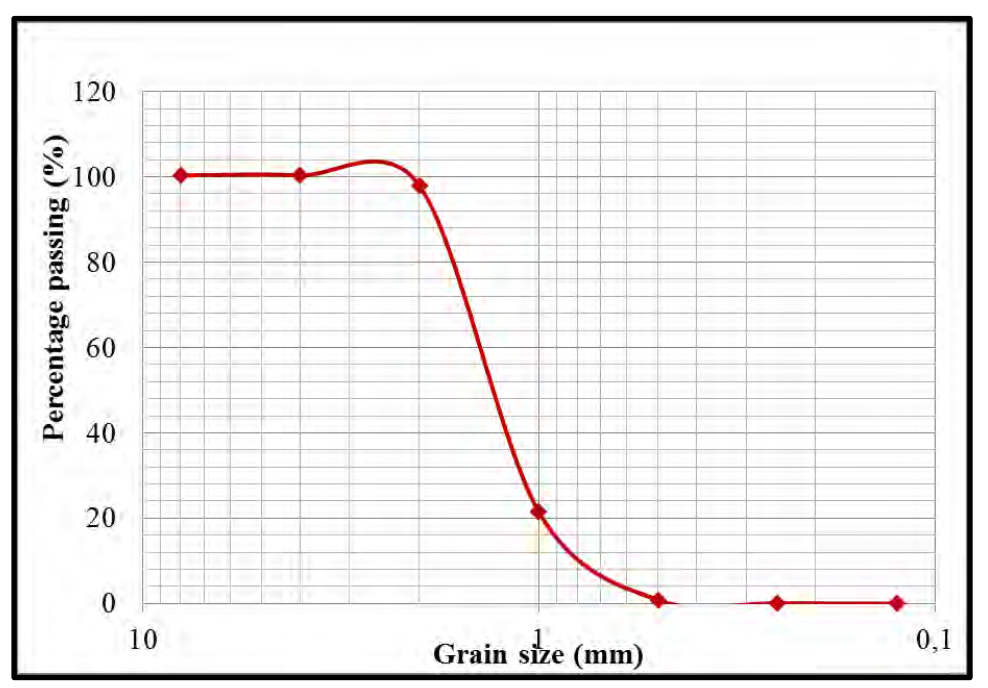

Figure 2-22. Granulometric curve NFA-15 coarse

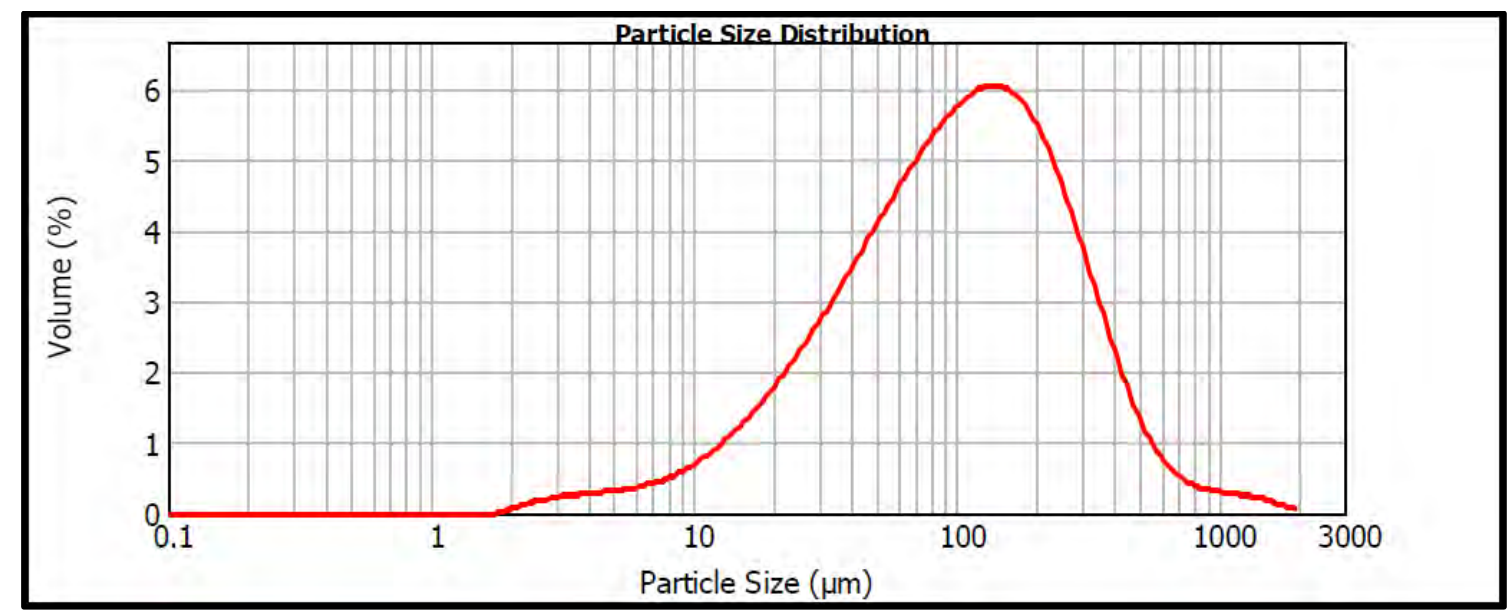

Figure 2-23. Granulometric curve NFA-16 fine

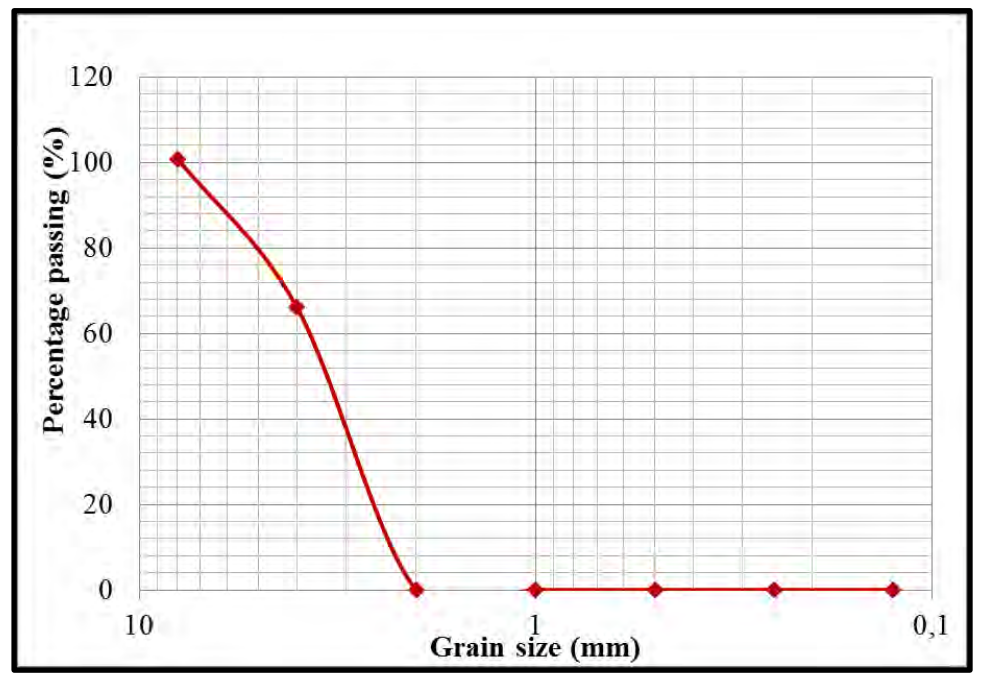

Figure 2-24. Granulometric curve NFA-16 coarse 


\section{Gases emissions solid fuels}

CO emissions

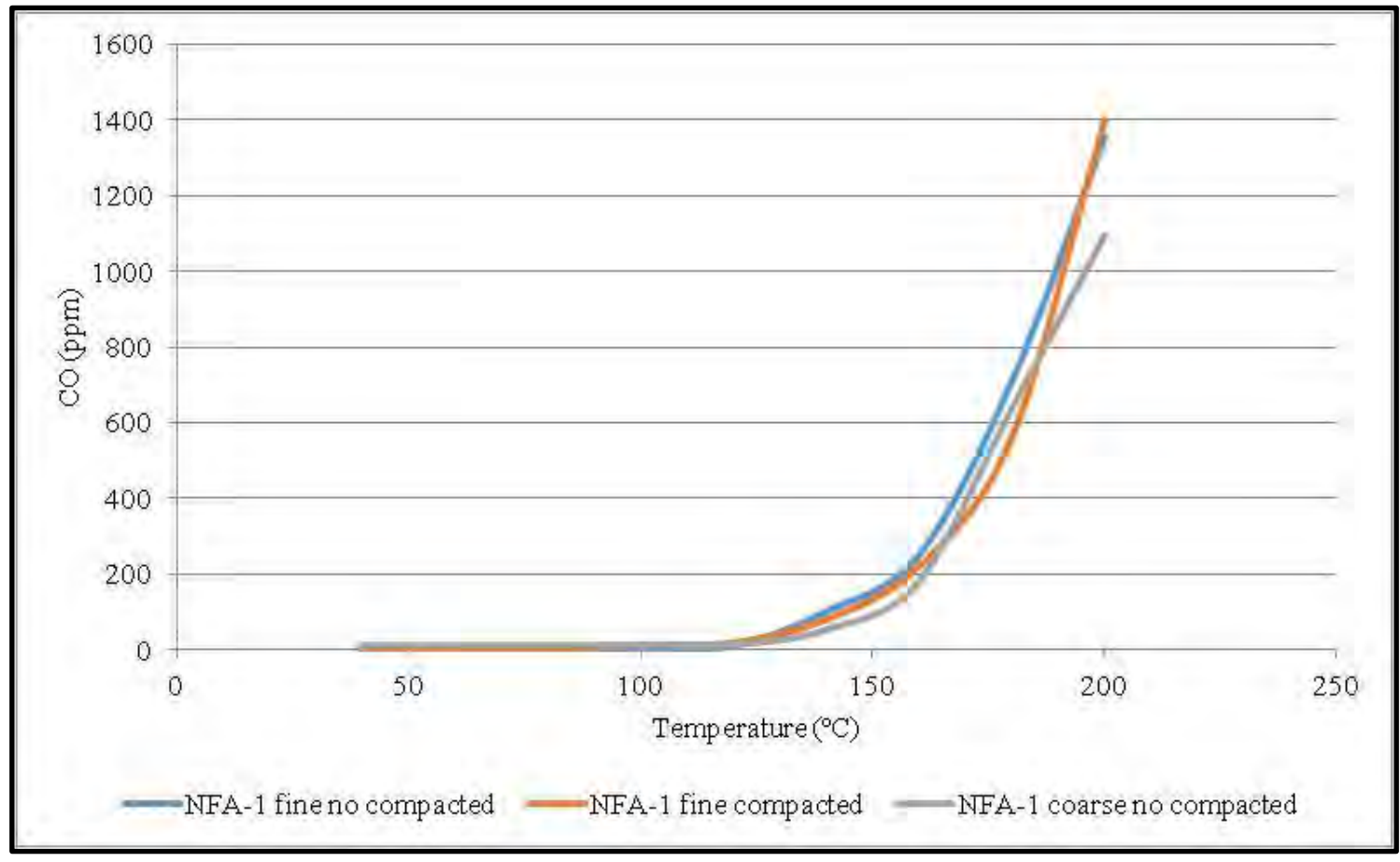

Figure 3-1. NFA-1

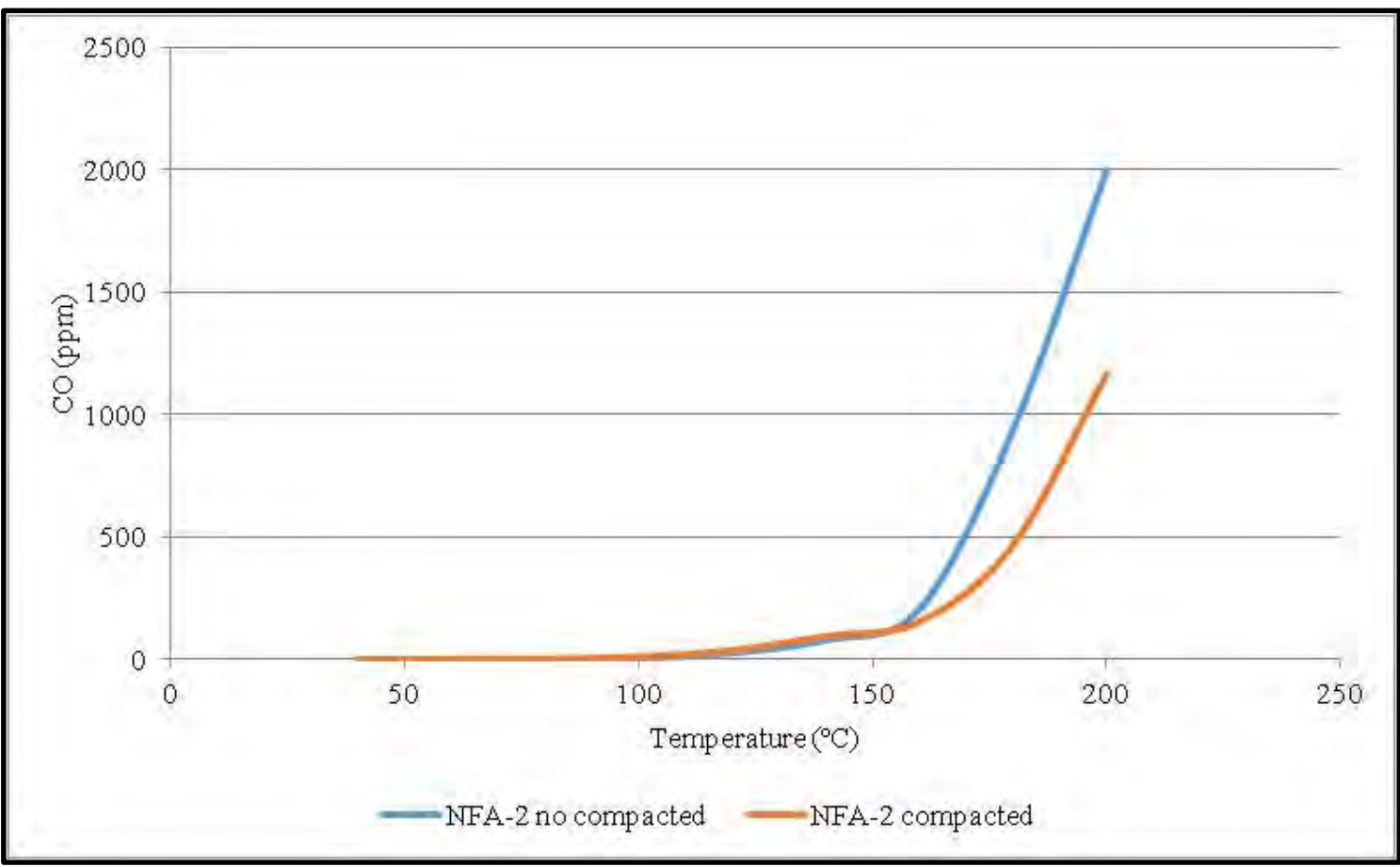

Figure 3-2. NFA-2 


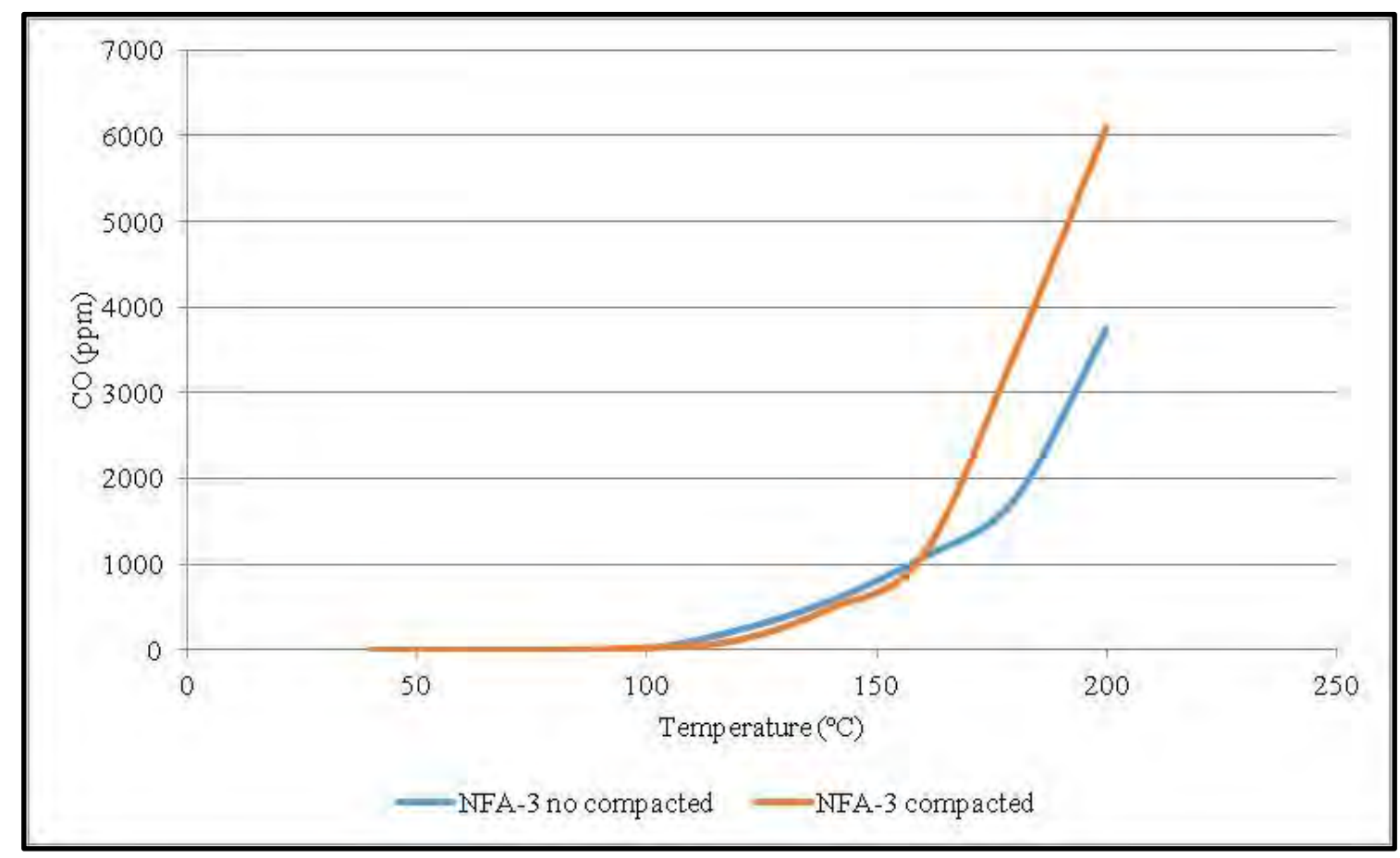

Figure 3-3. NFA-3

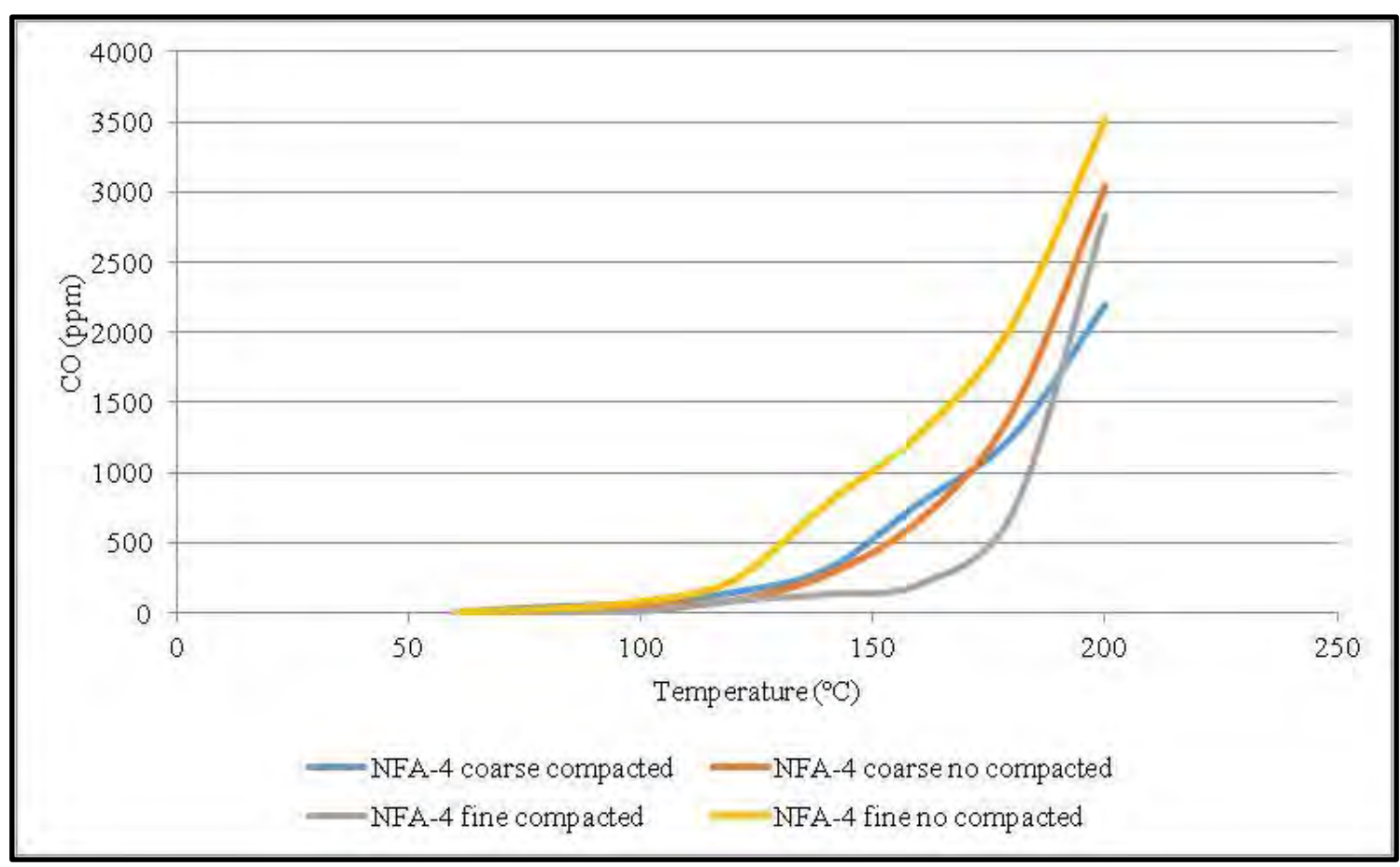

Figure 3-4. NFA-4 


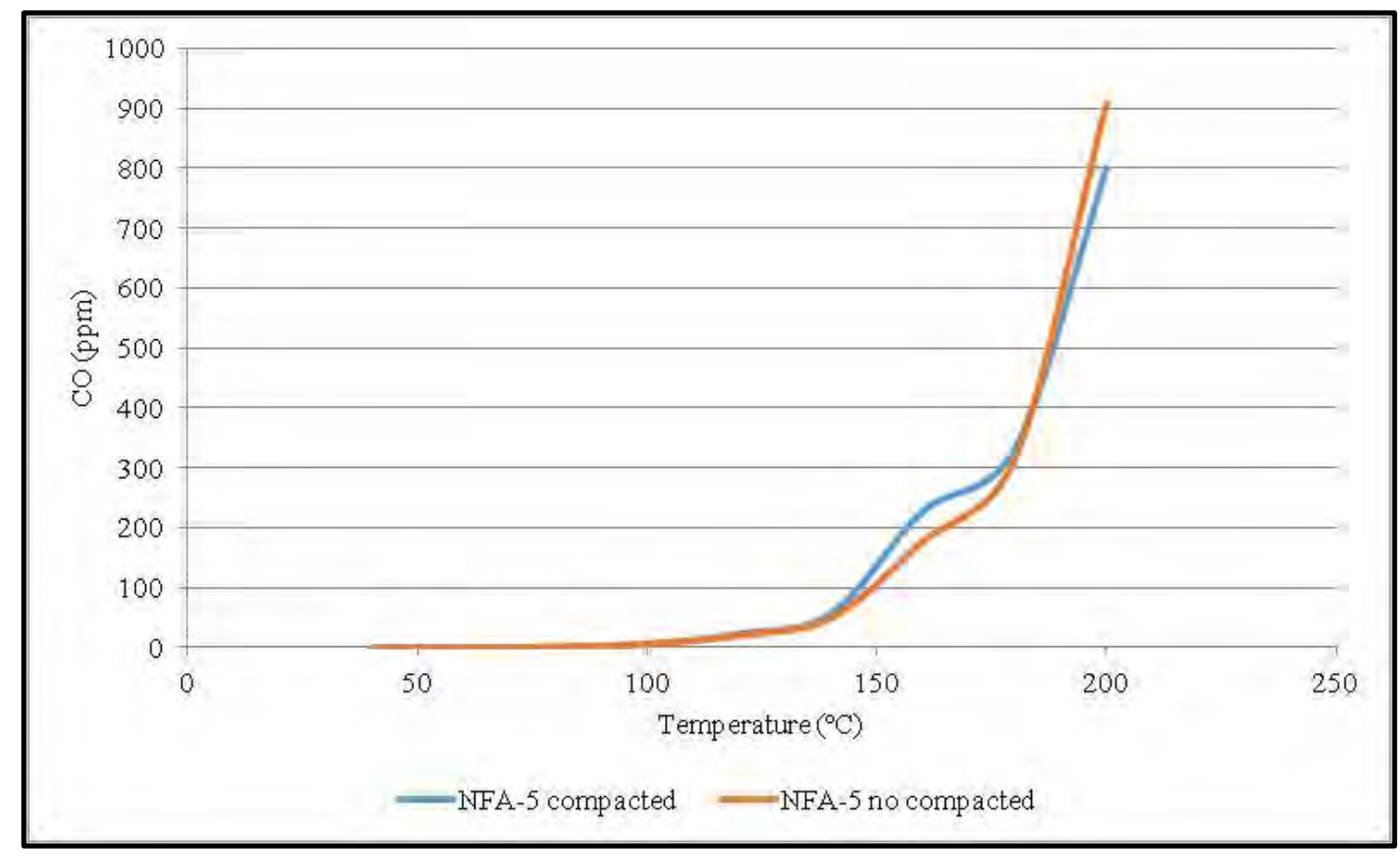

Figure 3-5. NFA-5

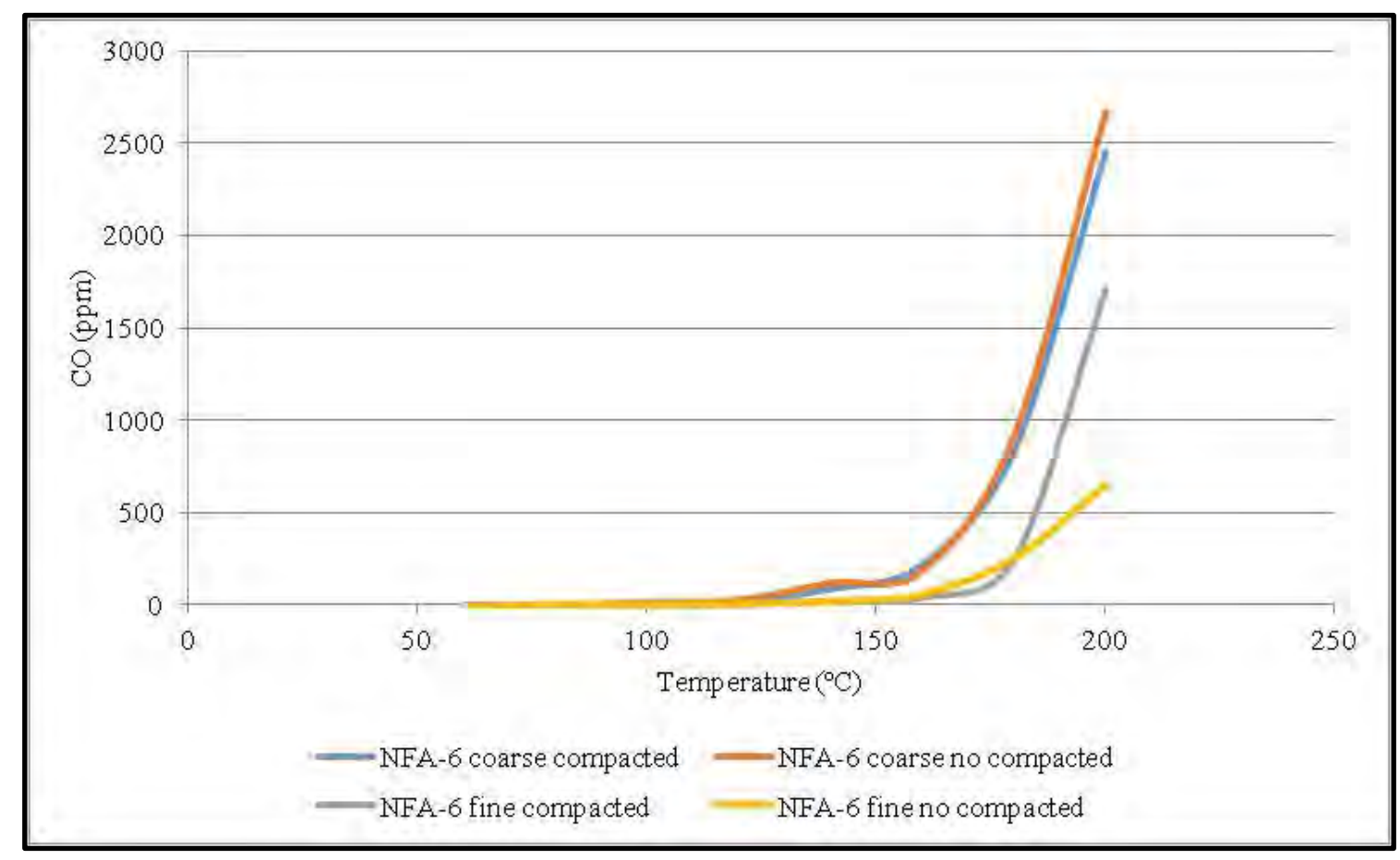

Figure 3-6. NFA-6 


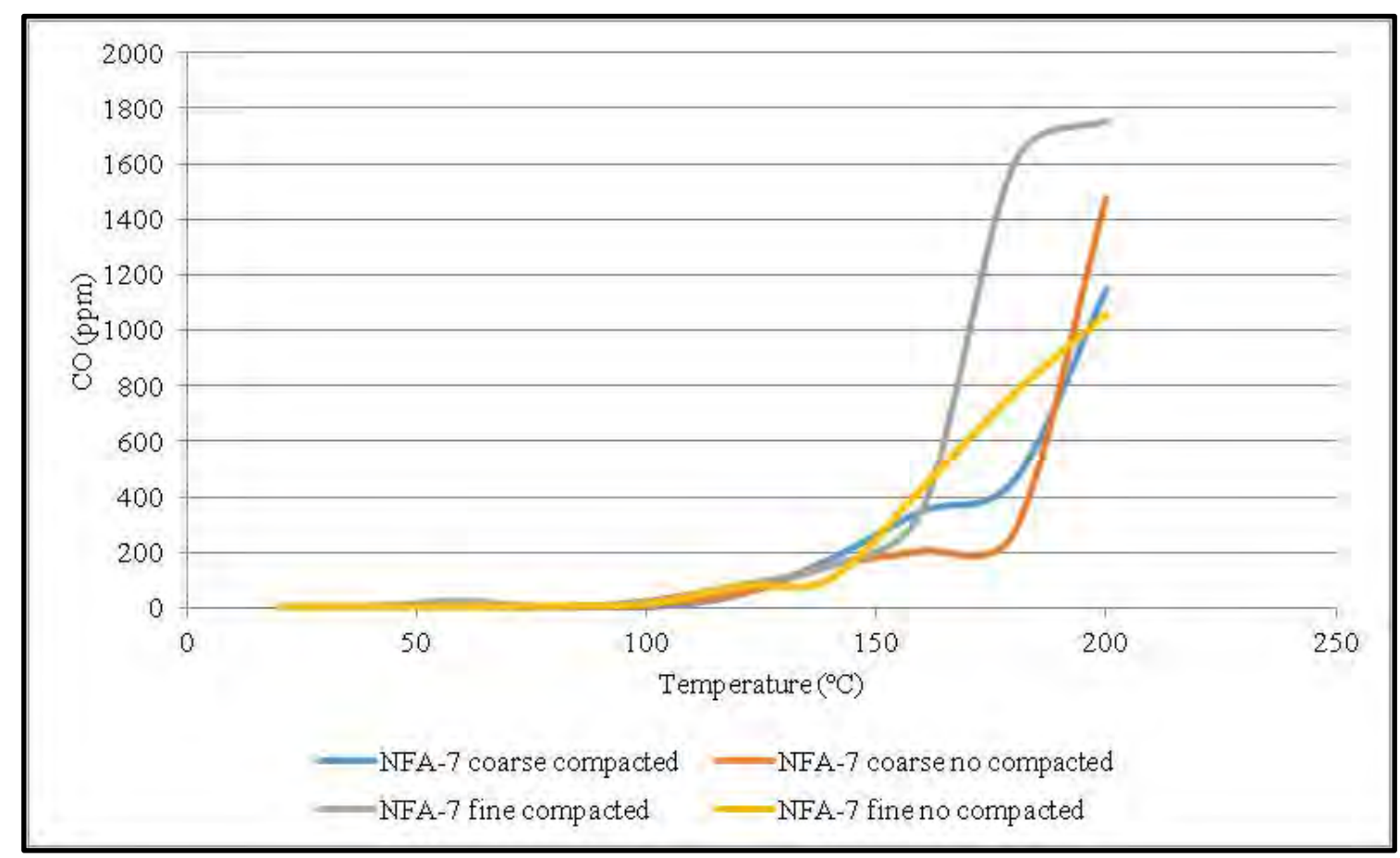

Figure 3-7. NFA-7

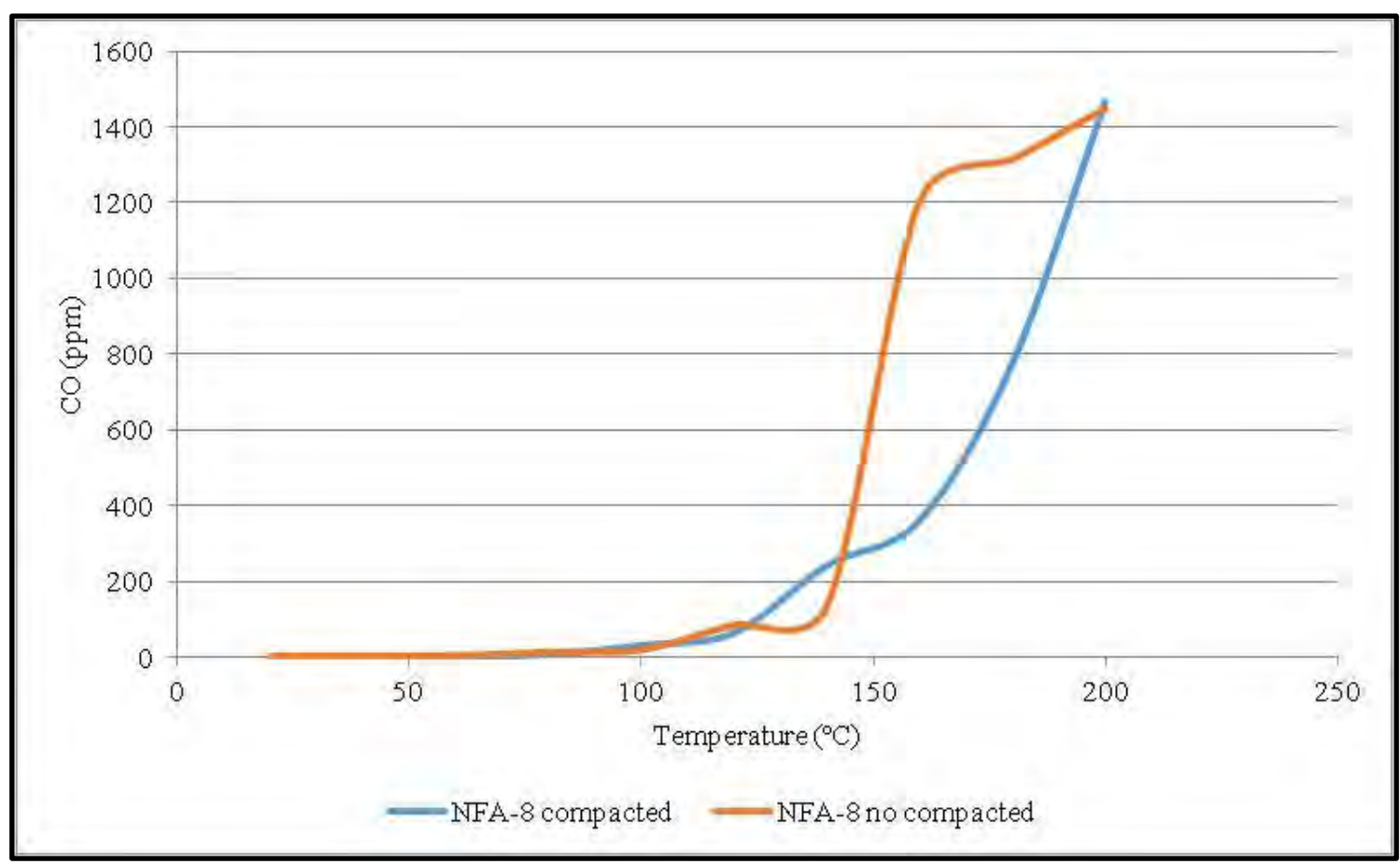

Figure 3-8. NFA-8 


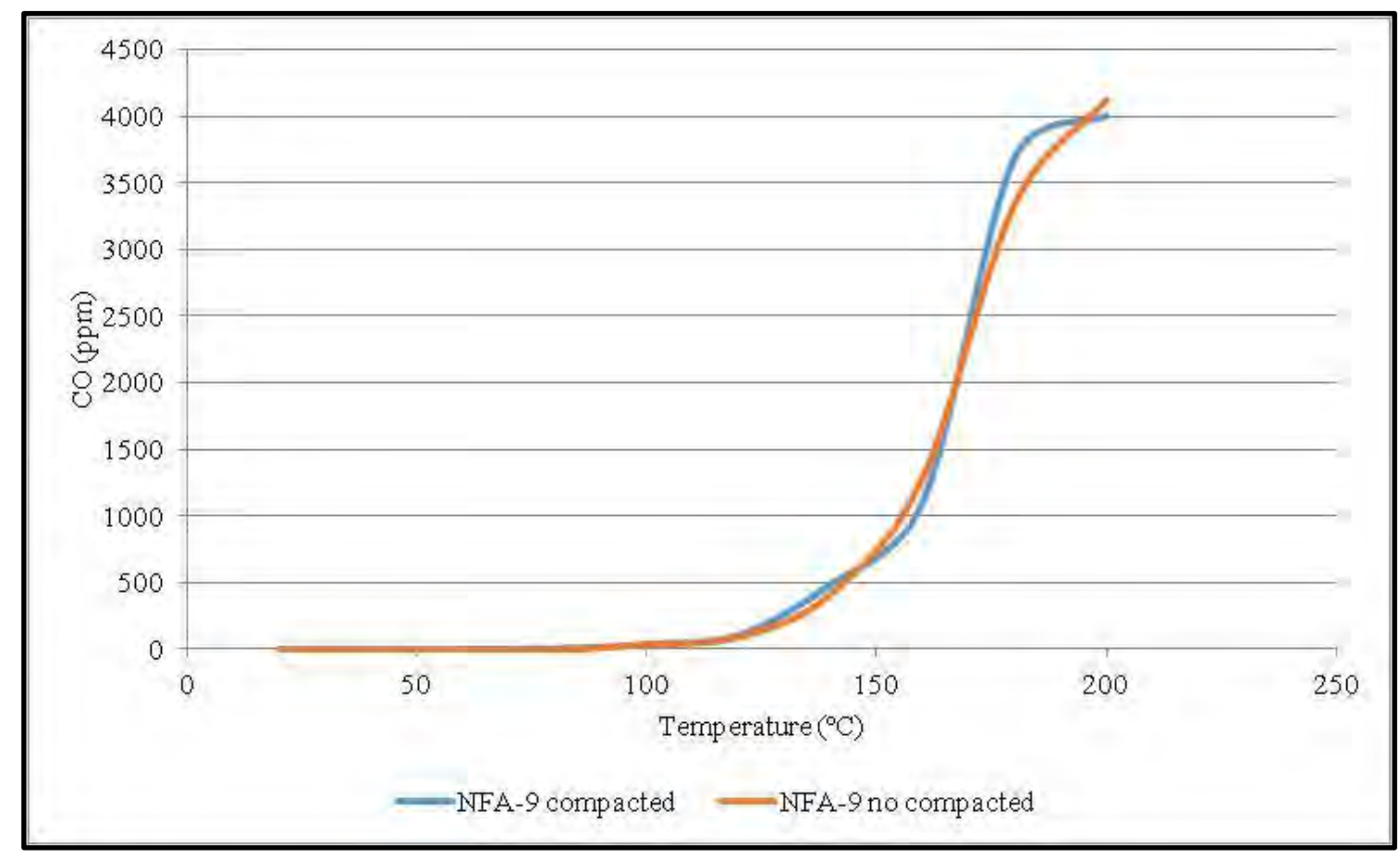

Figure 3-9. NFA-9

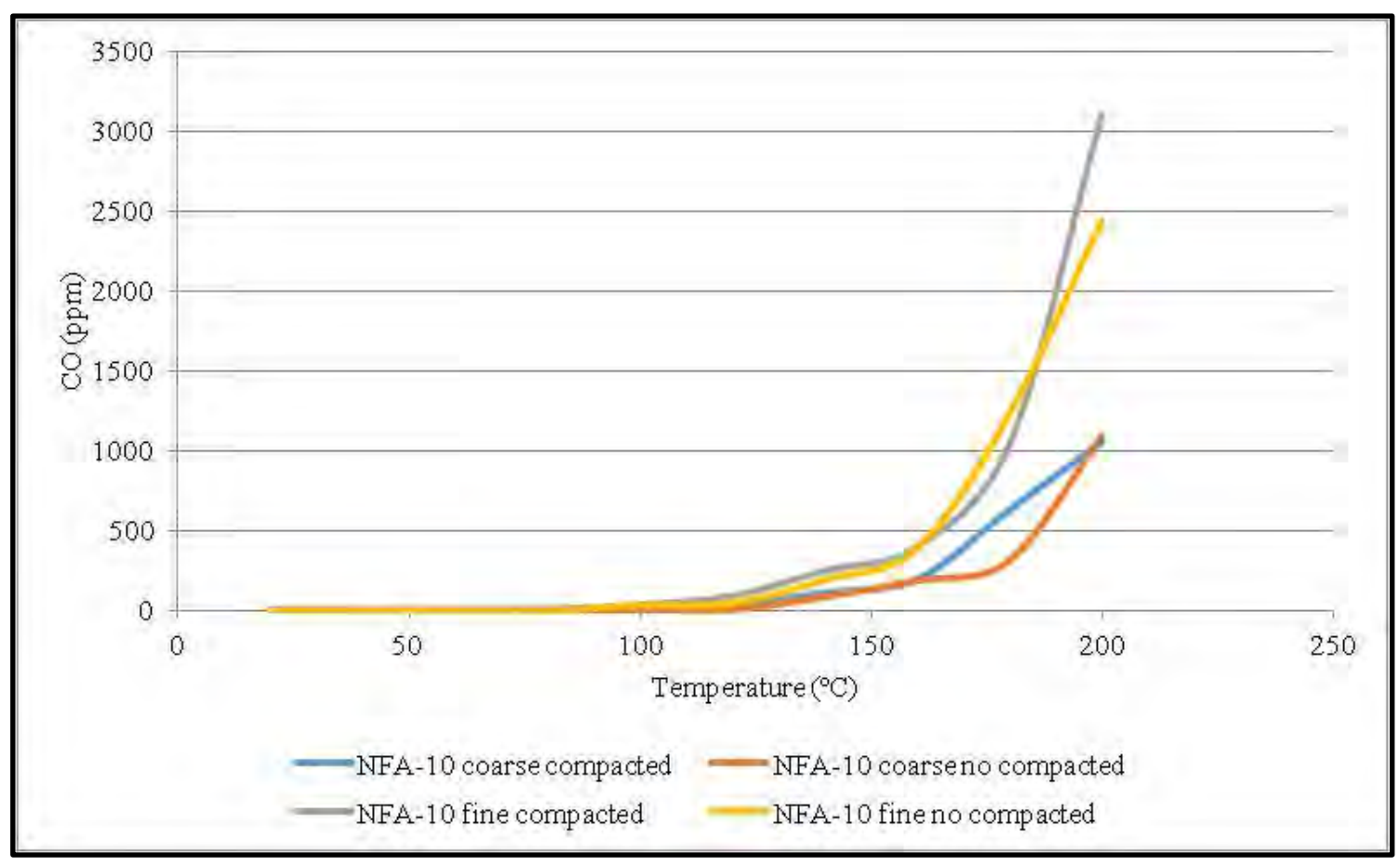

Figure 3-10. NFA-10 


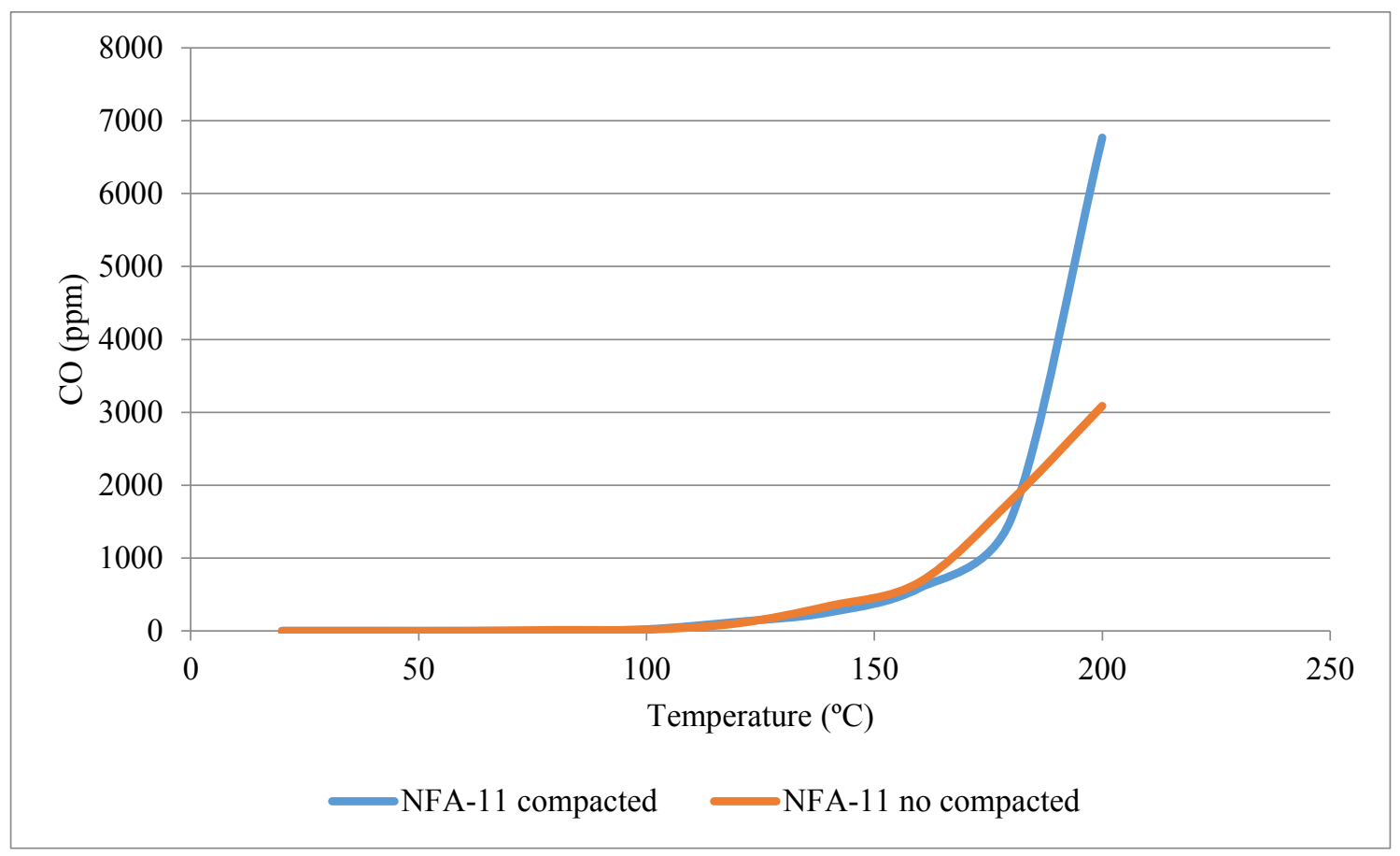

Figure 3-11. NFA-11

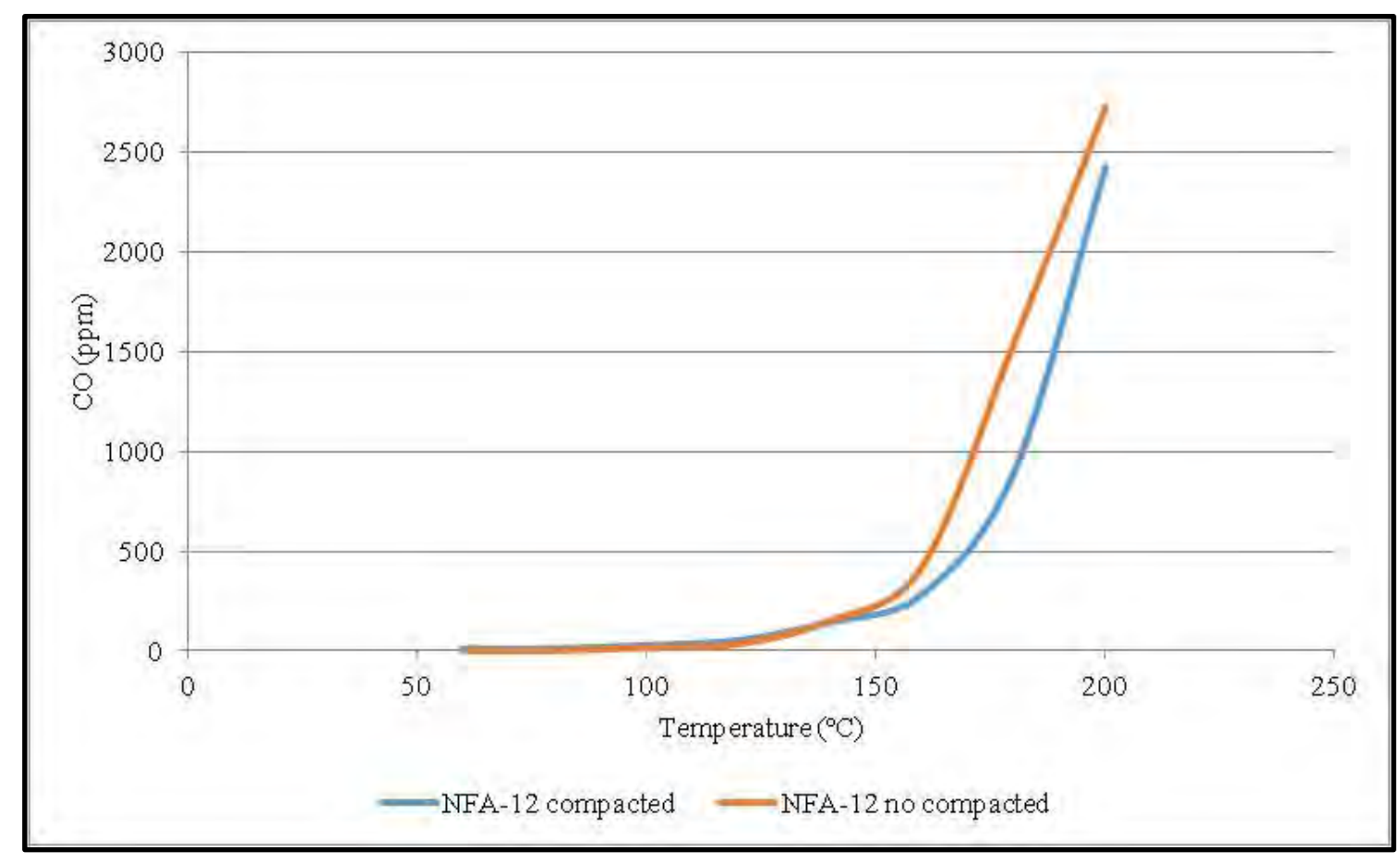

Figure 3-12. NFA-12 


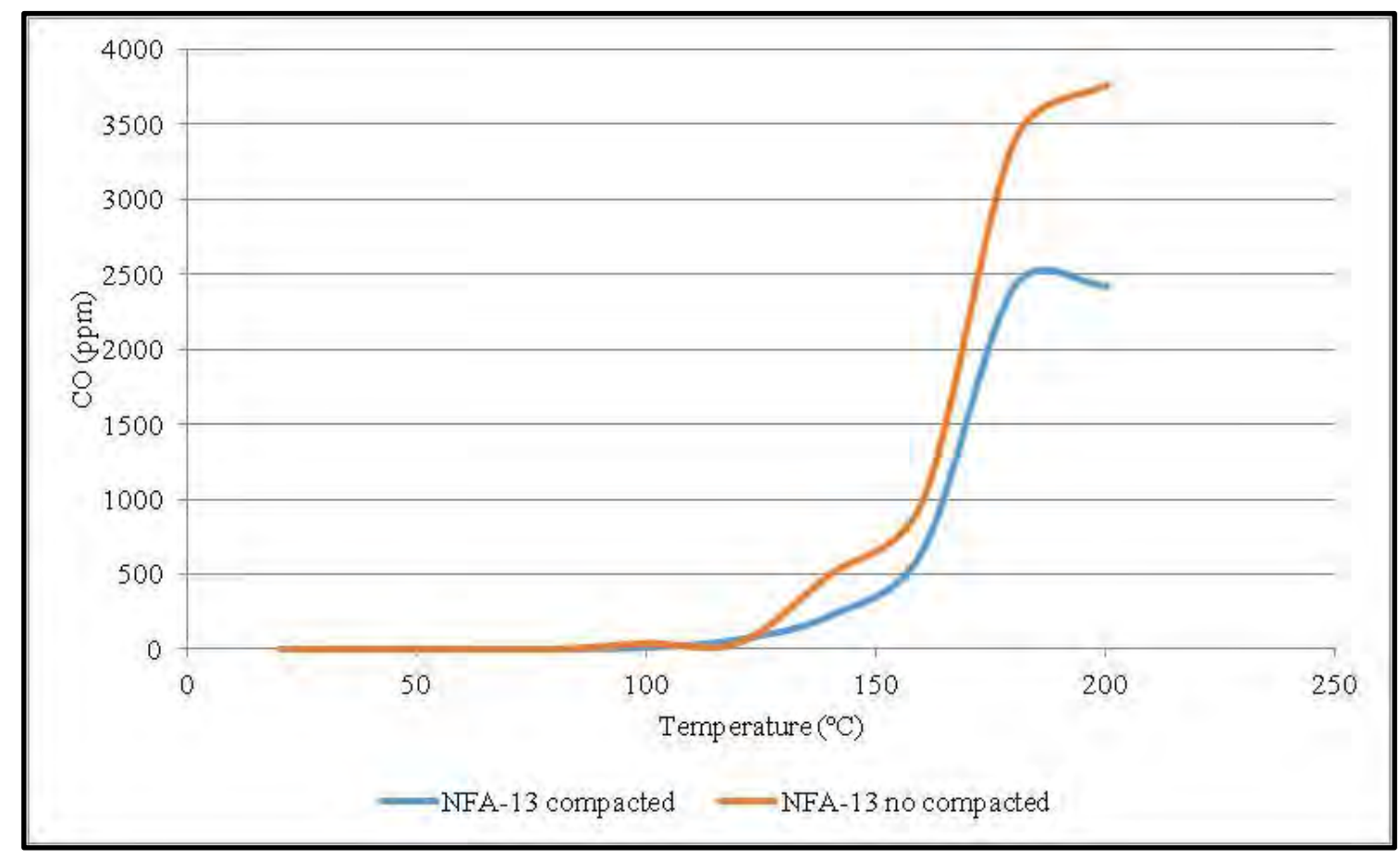

Figure 3-13. NFA-13

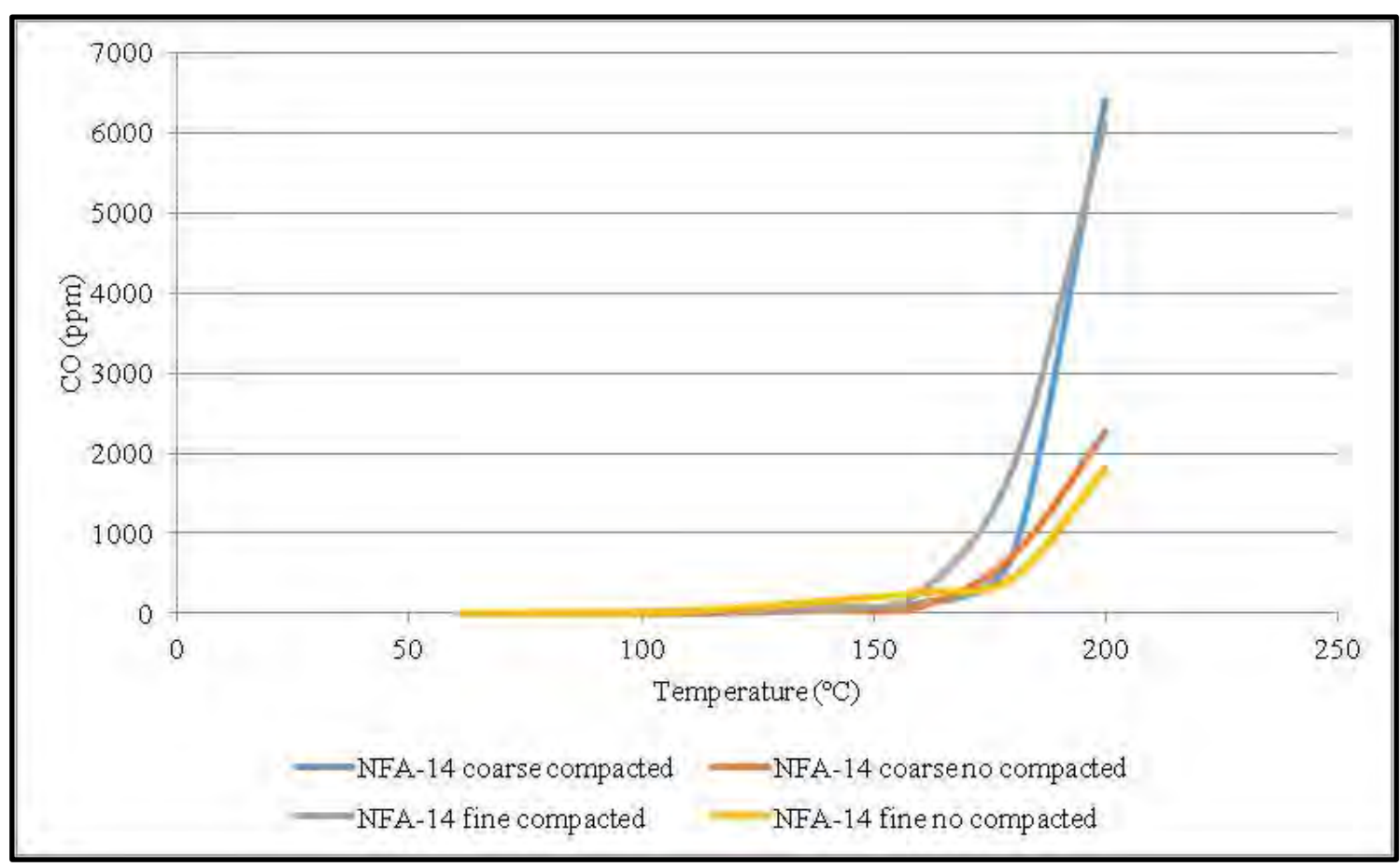

Figure 3-14. NFA-14 


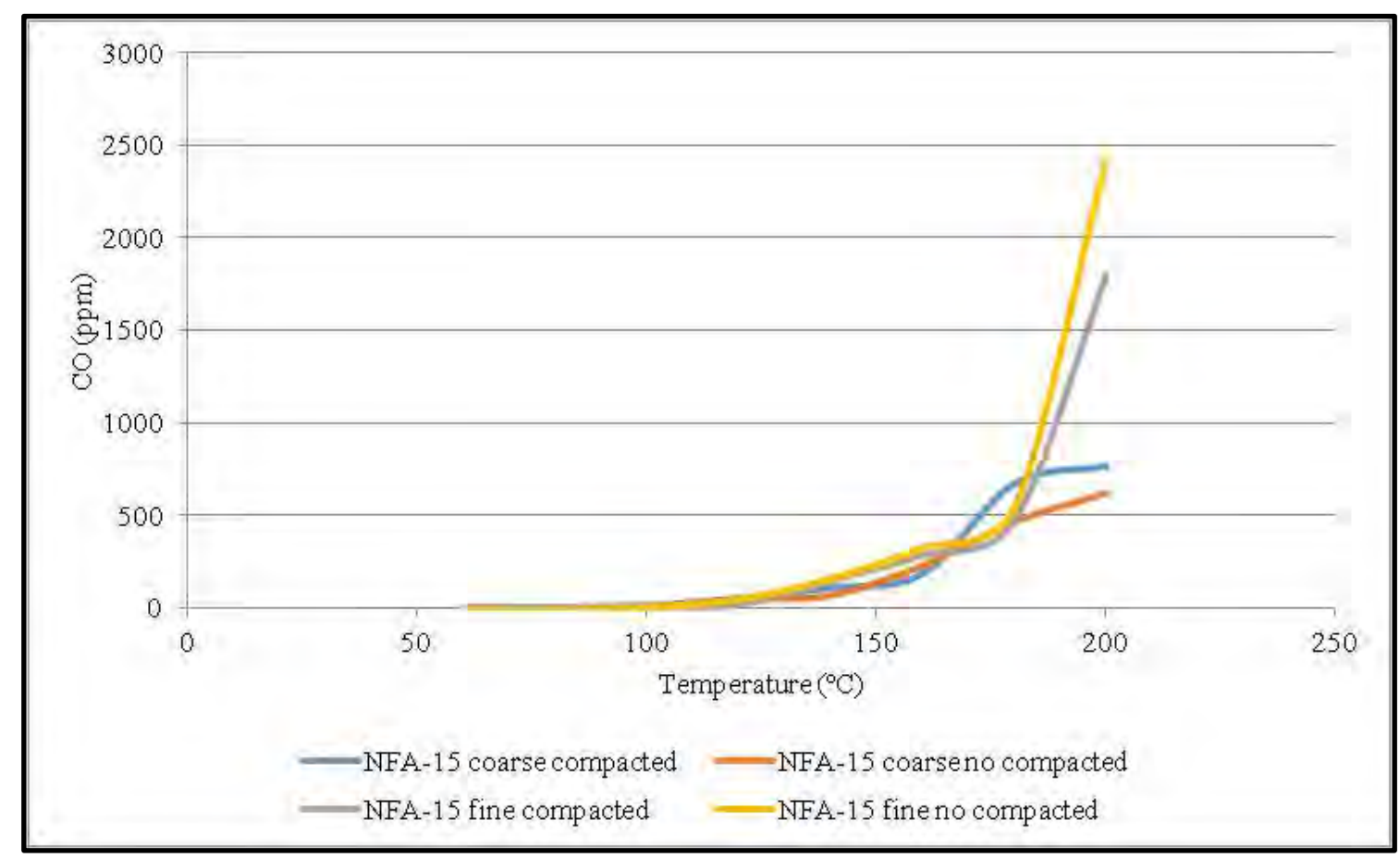

Figure 3-15. NFA-15

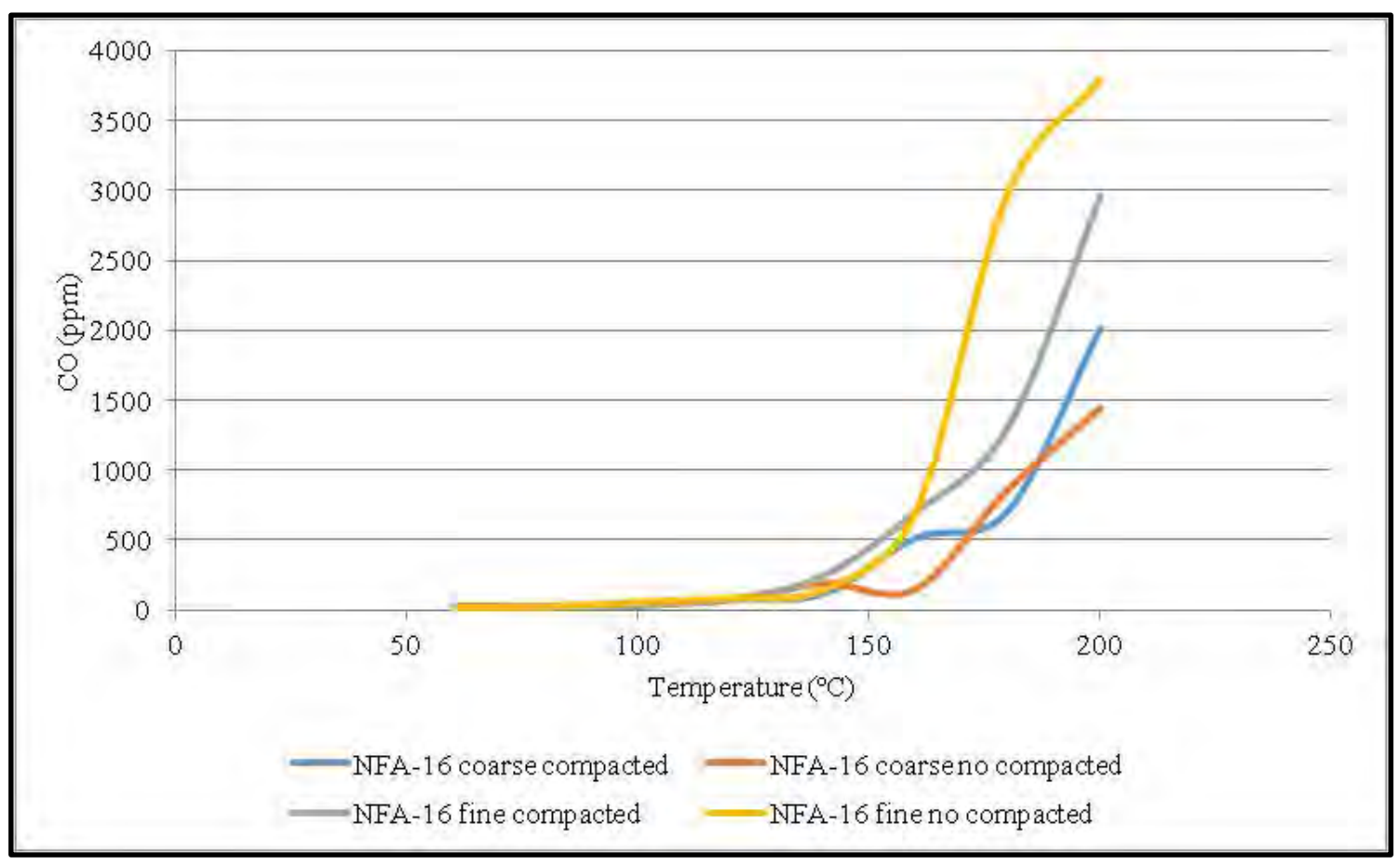

Figure 3-16. NFA-16 
$\mathrm{CO}_{2}$ emissions

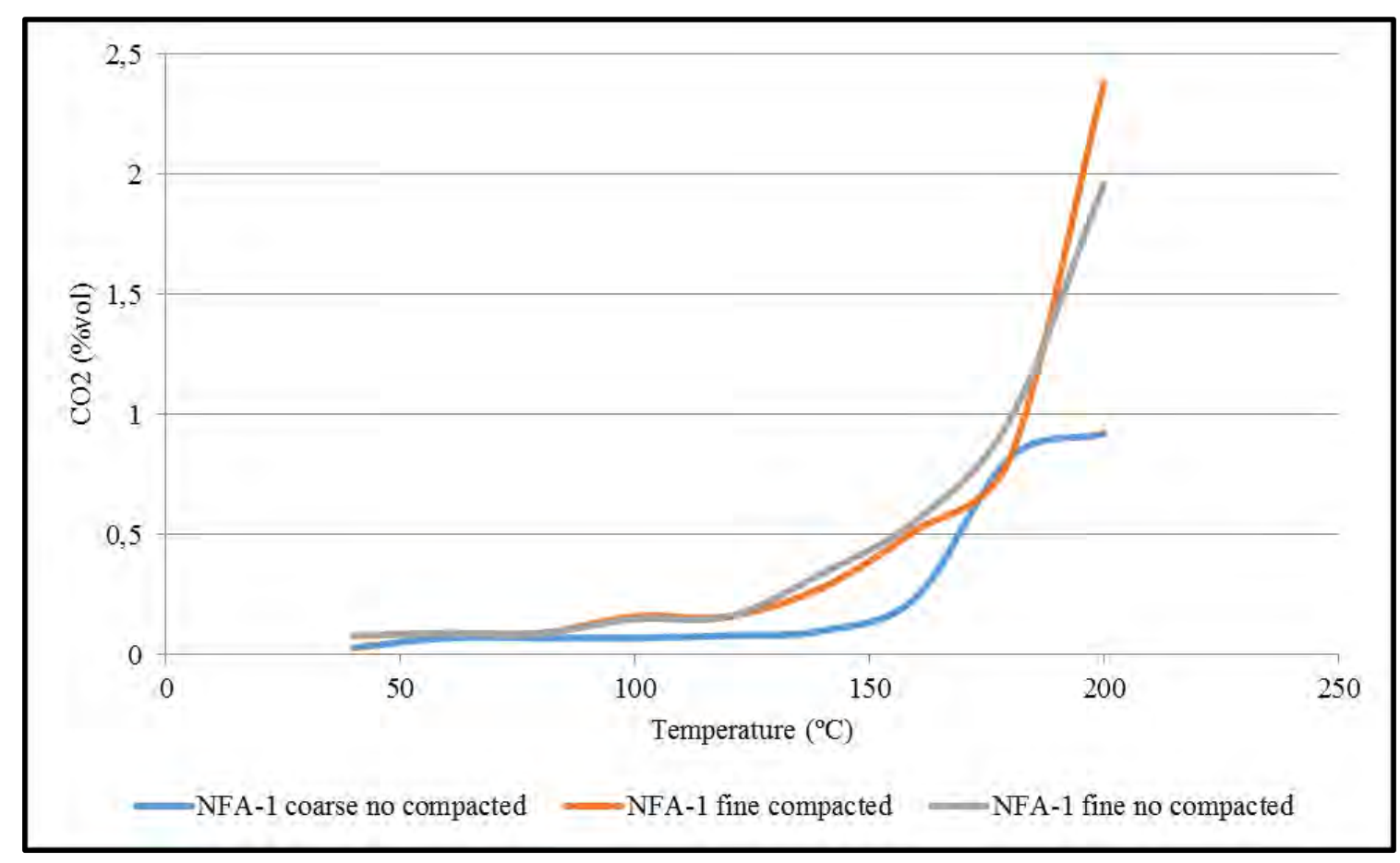

Figure 3-17. NFA-1

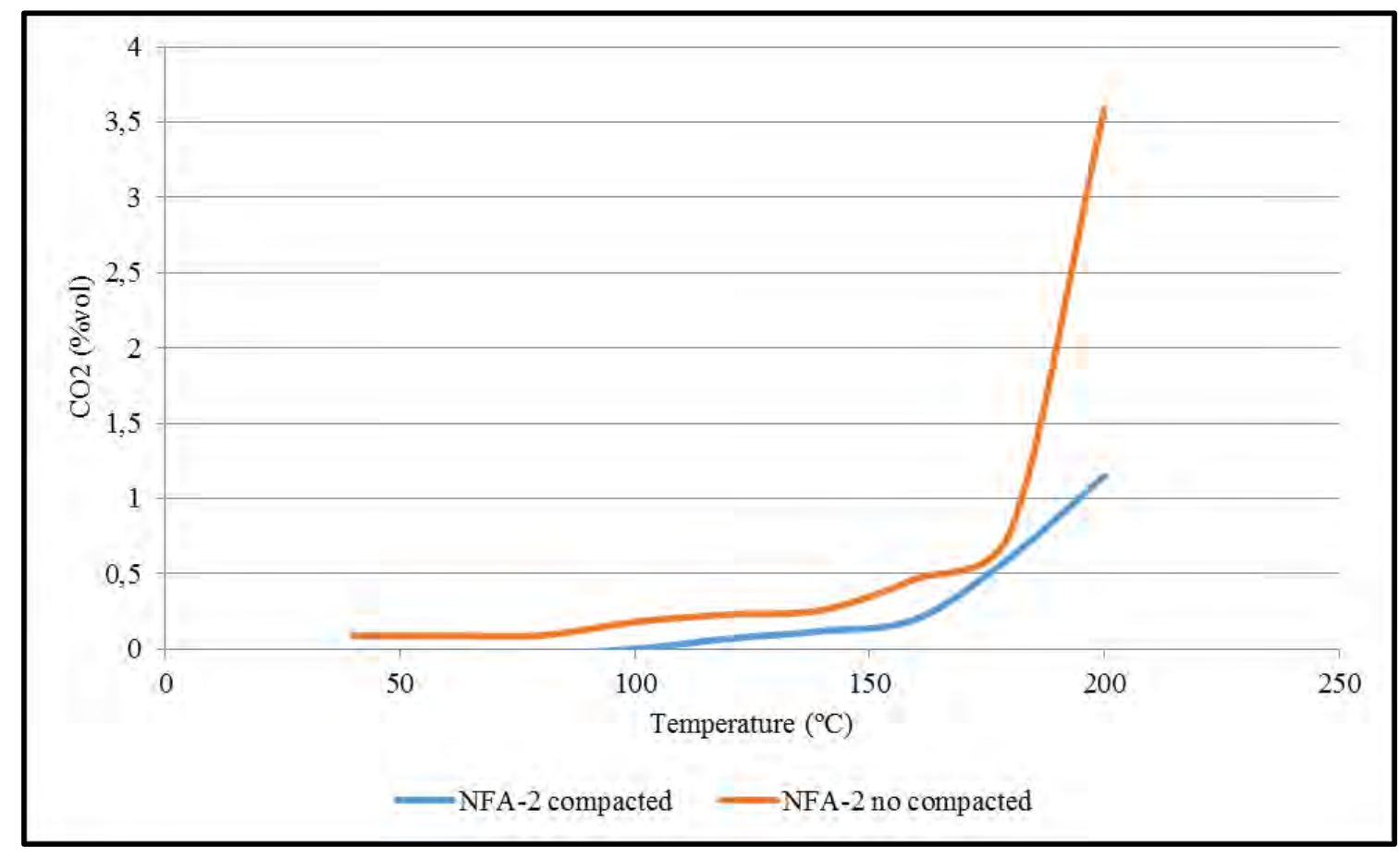

Figure 3-18. NFA-2 


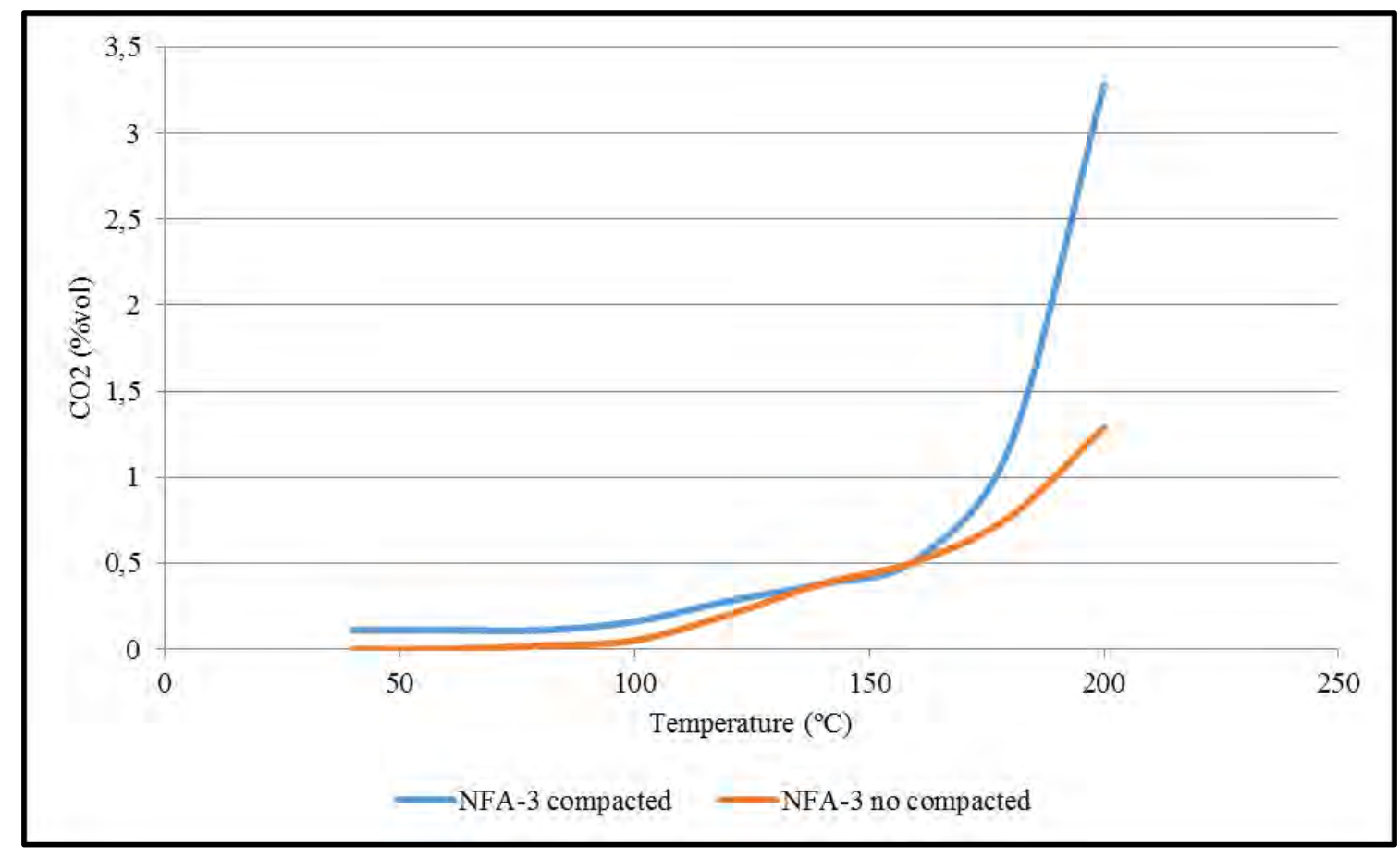

Figure 3-19.NFA-3

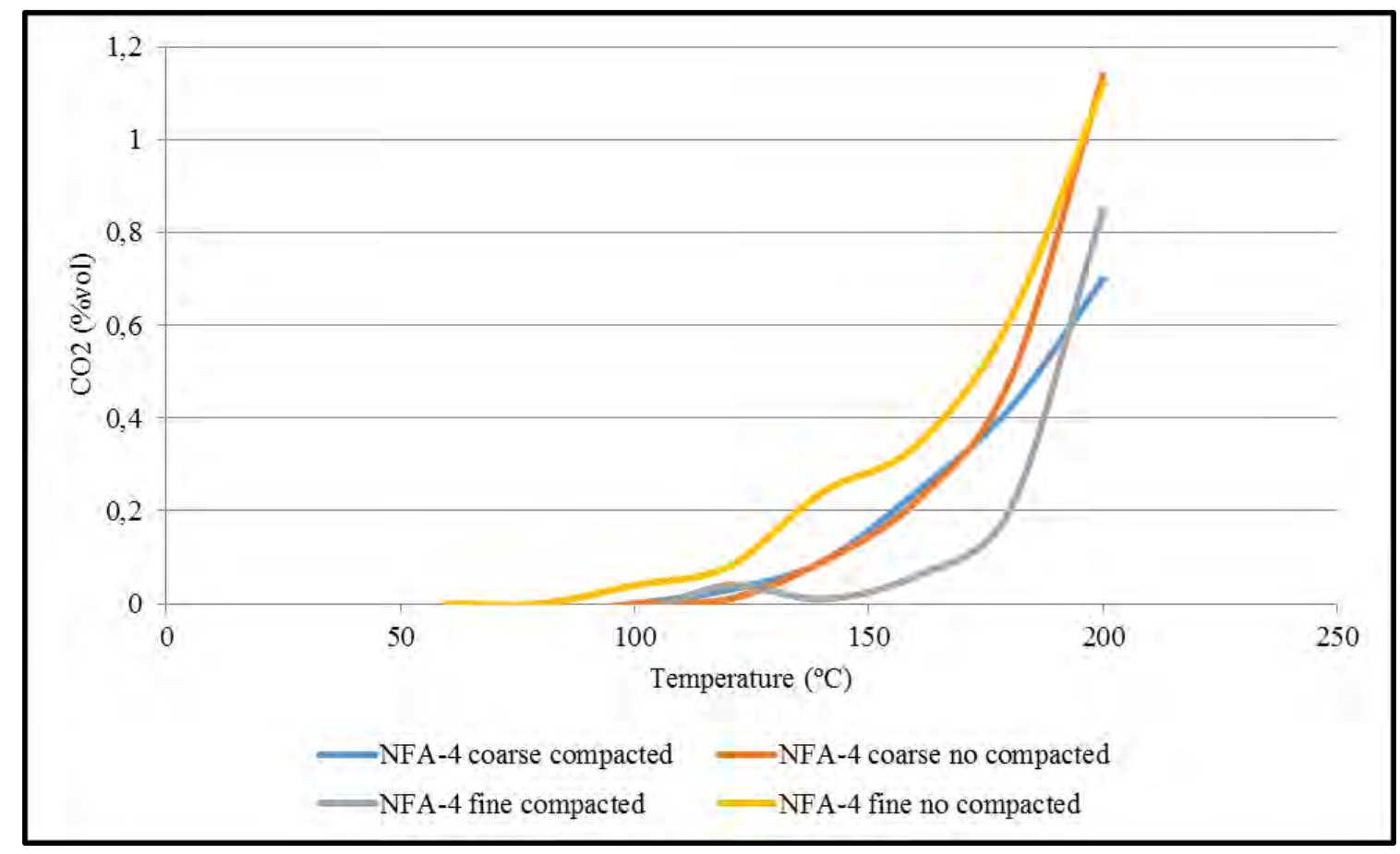

Figure 3-20. NFA-4 


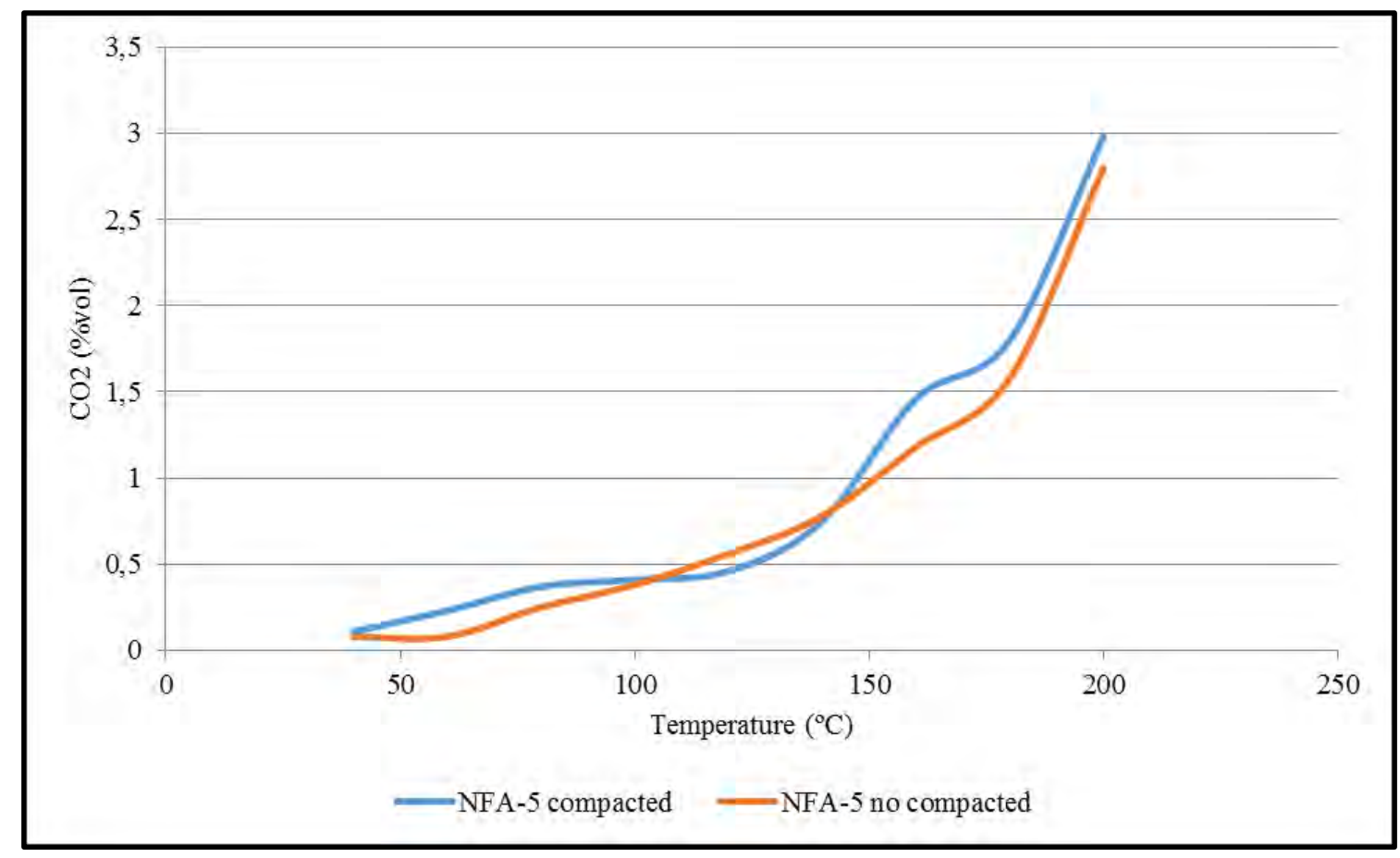

Figure 3-21. NFA-5

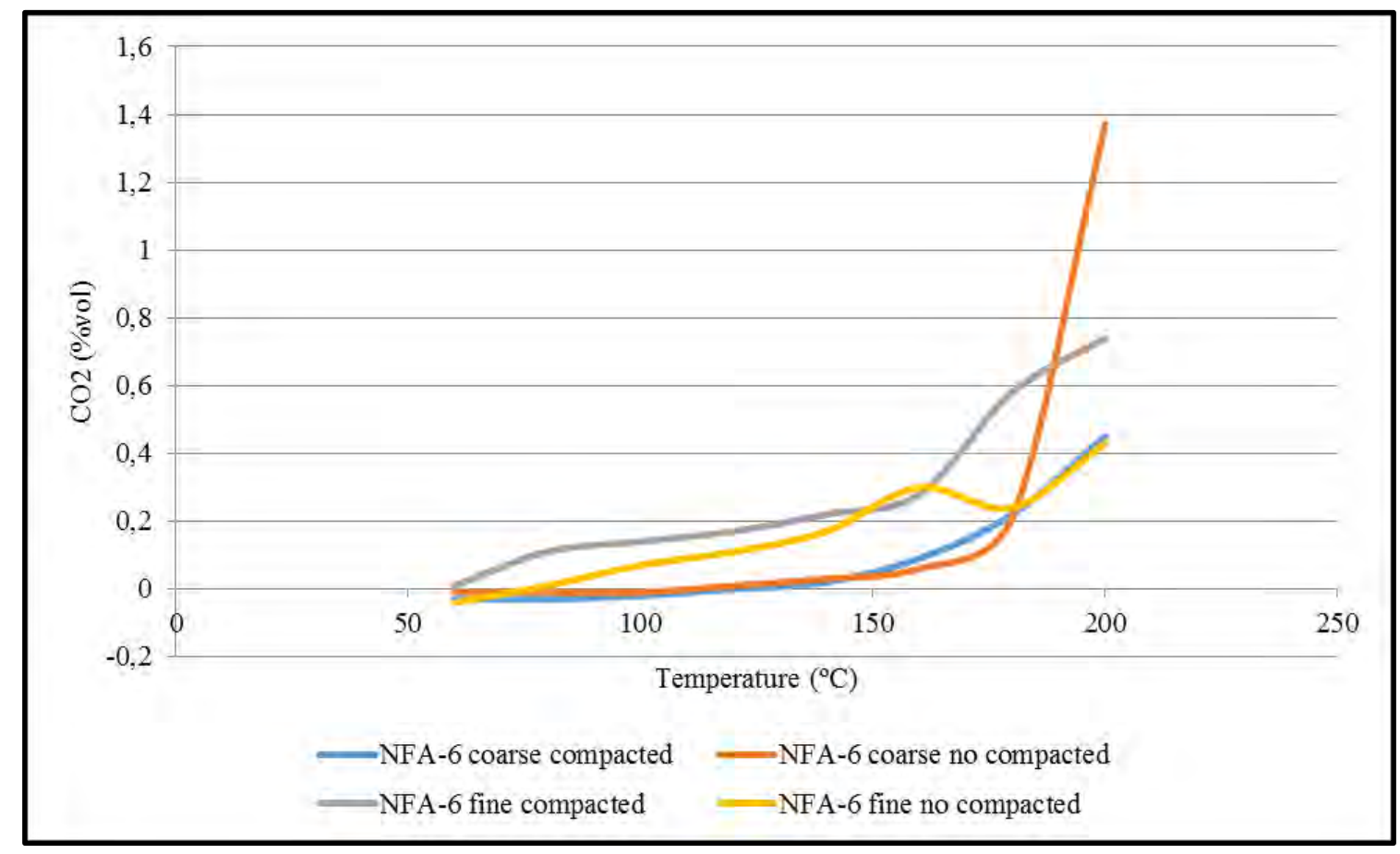

Figure 3-22. NFA-6 


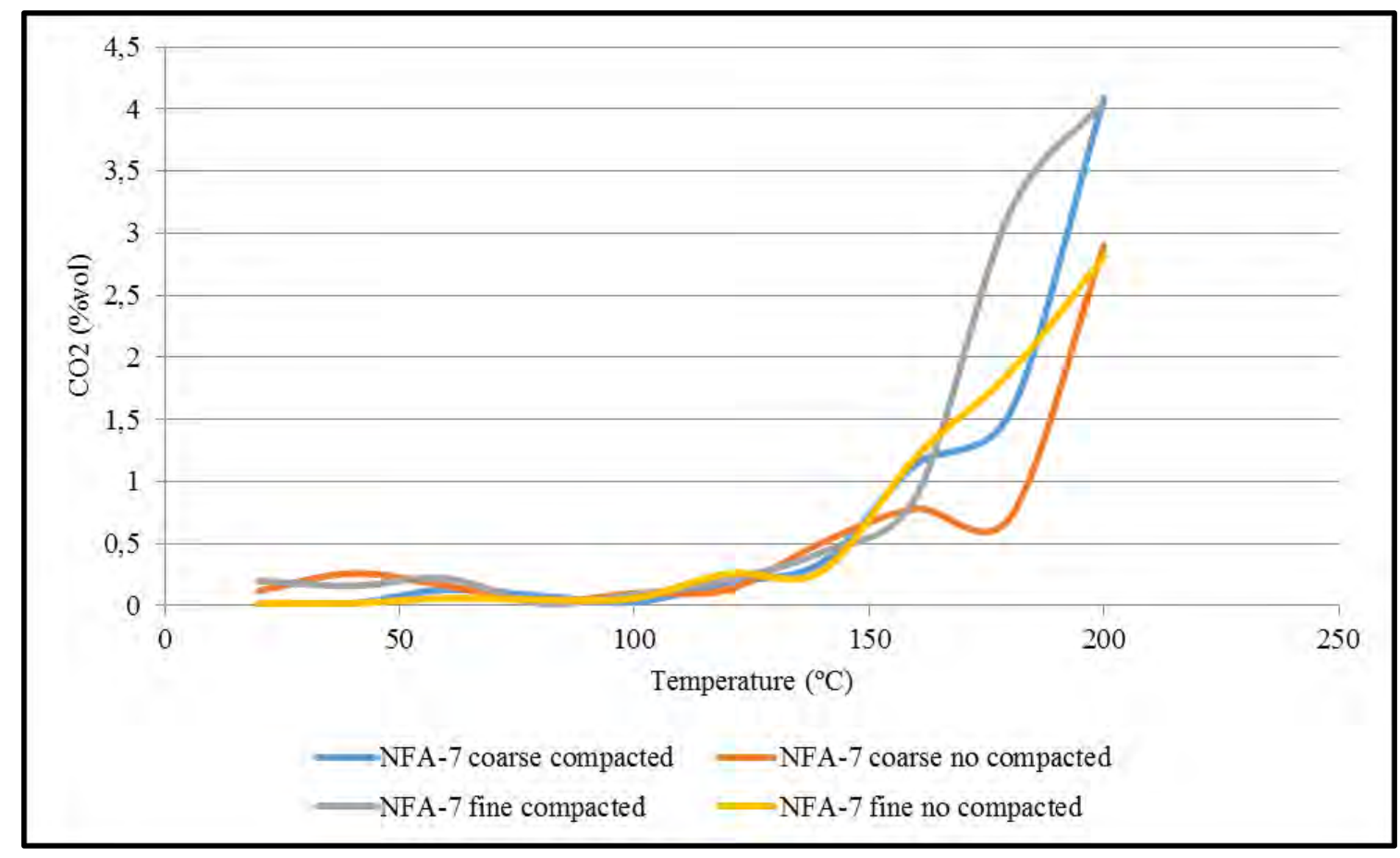

Figure 3-23. NFA-7

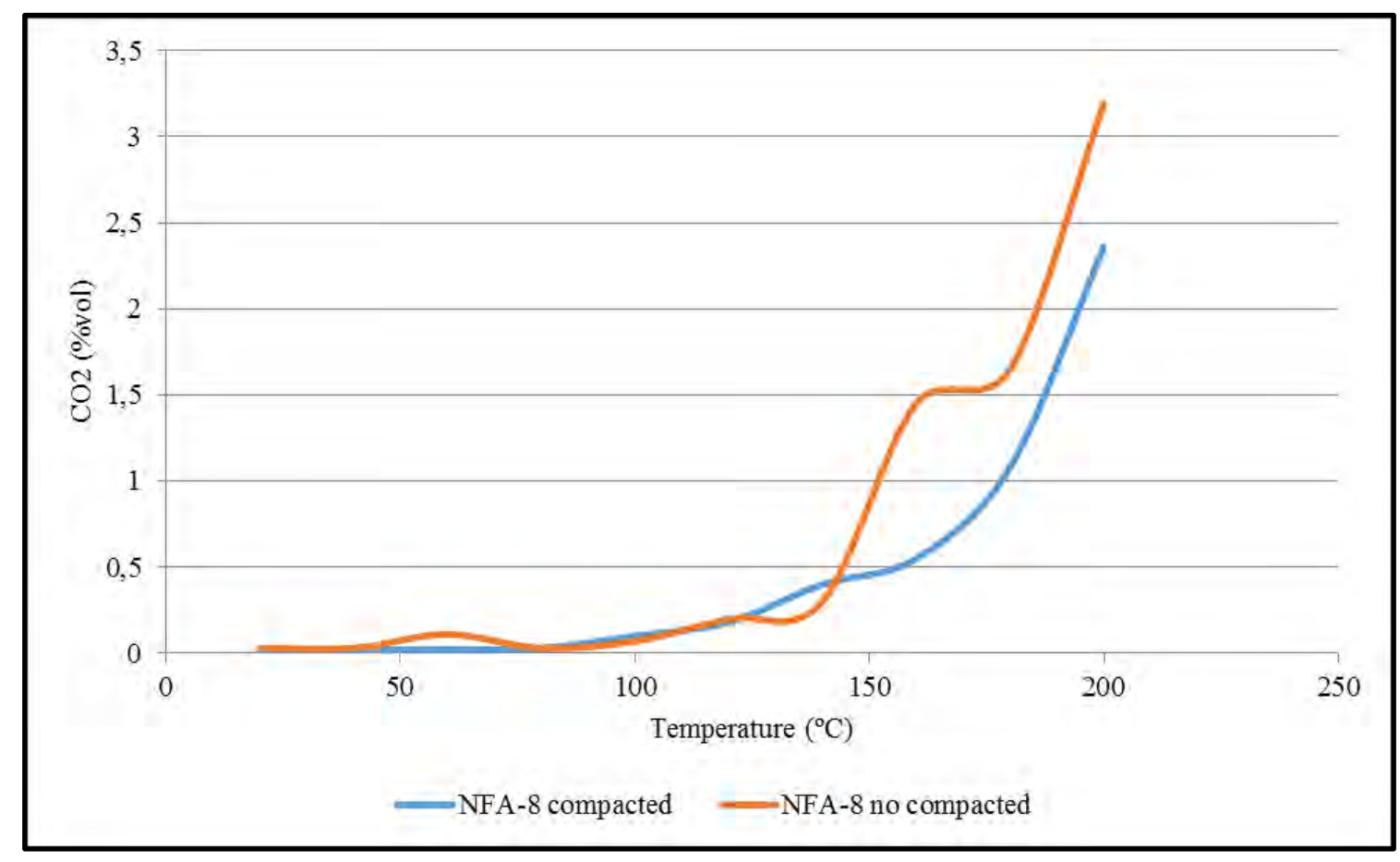

Figure 3-24. NFA-8 


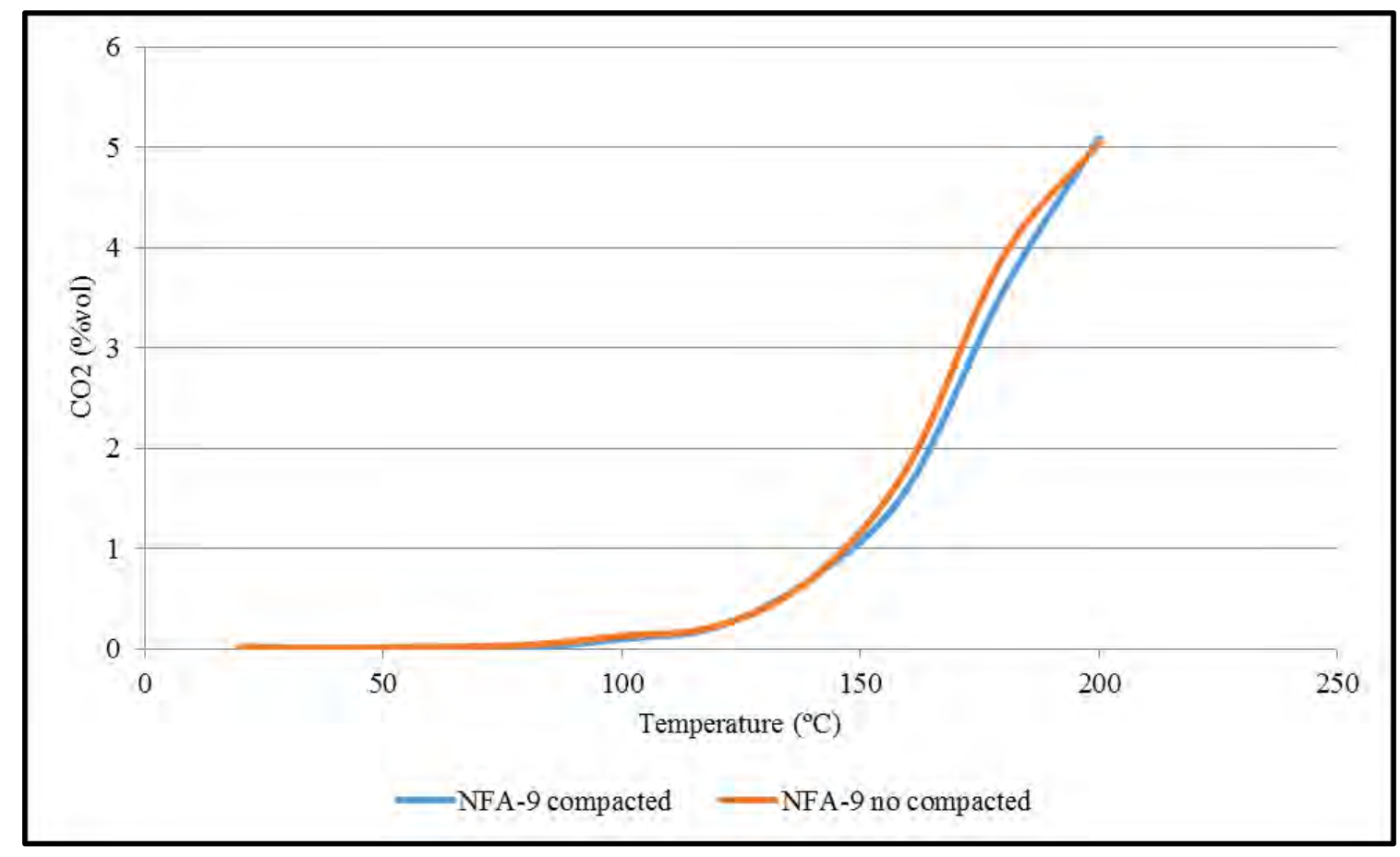

Figure 3-25. NFA-9

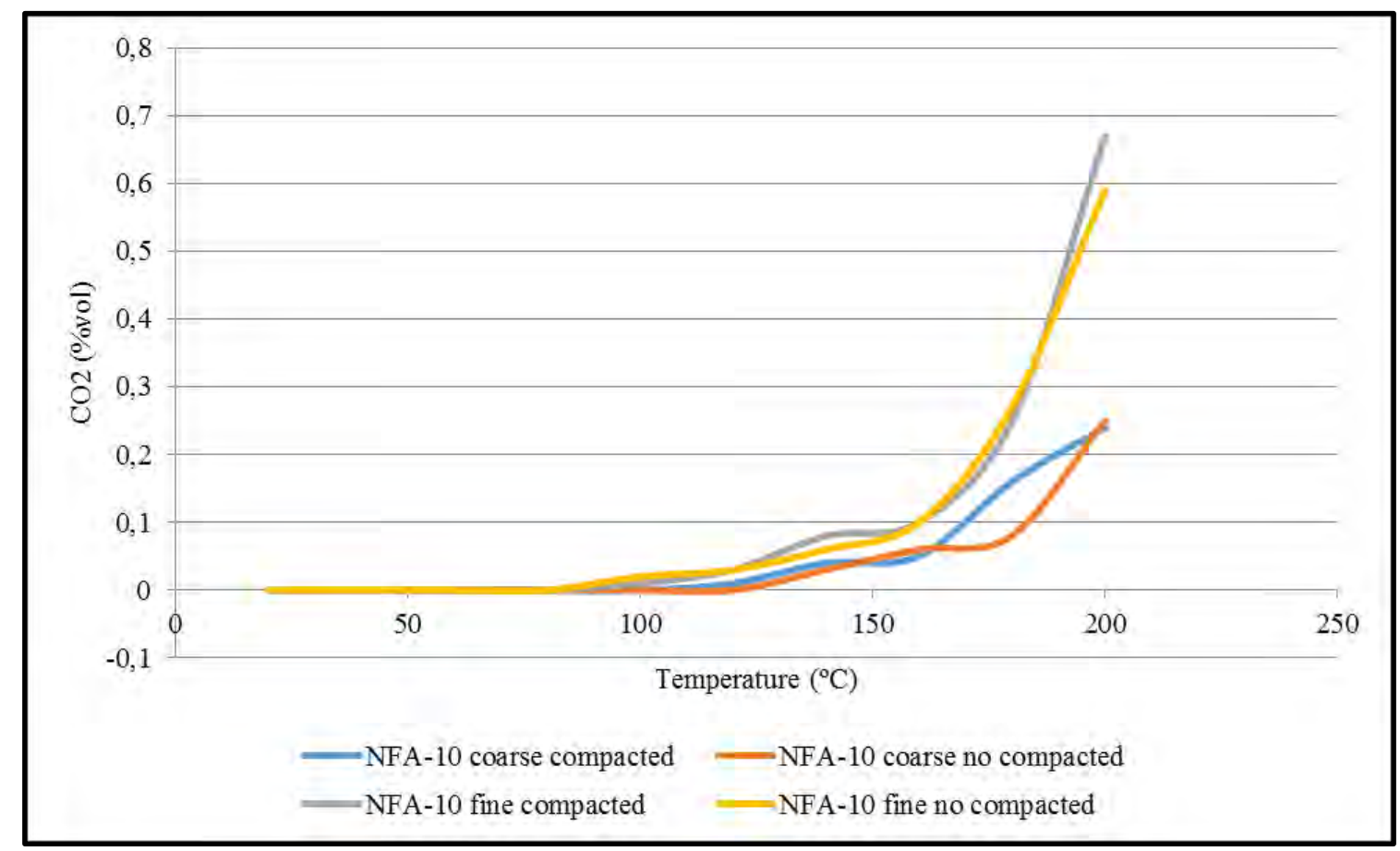

Figure 3-26. NFA-10 


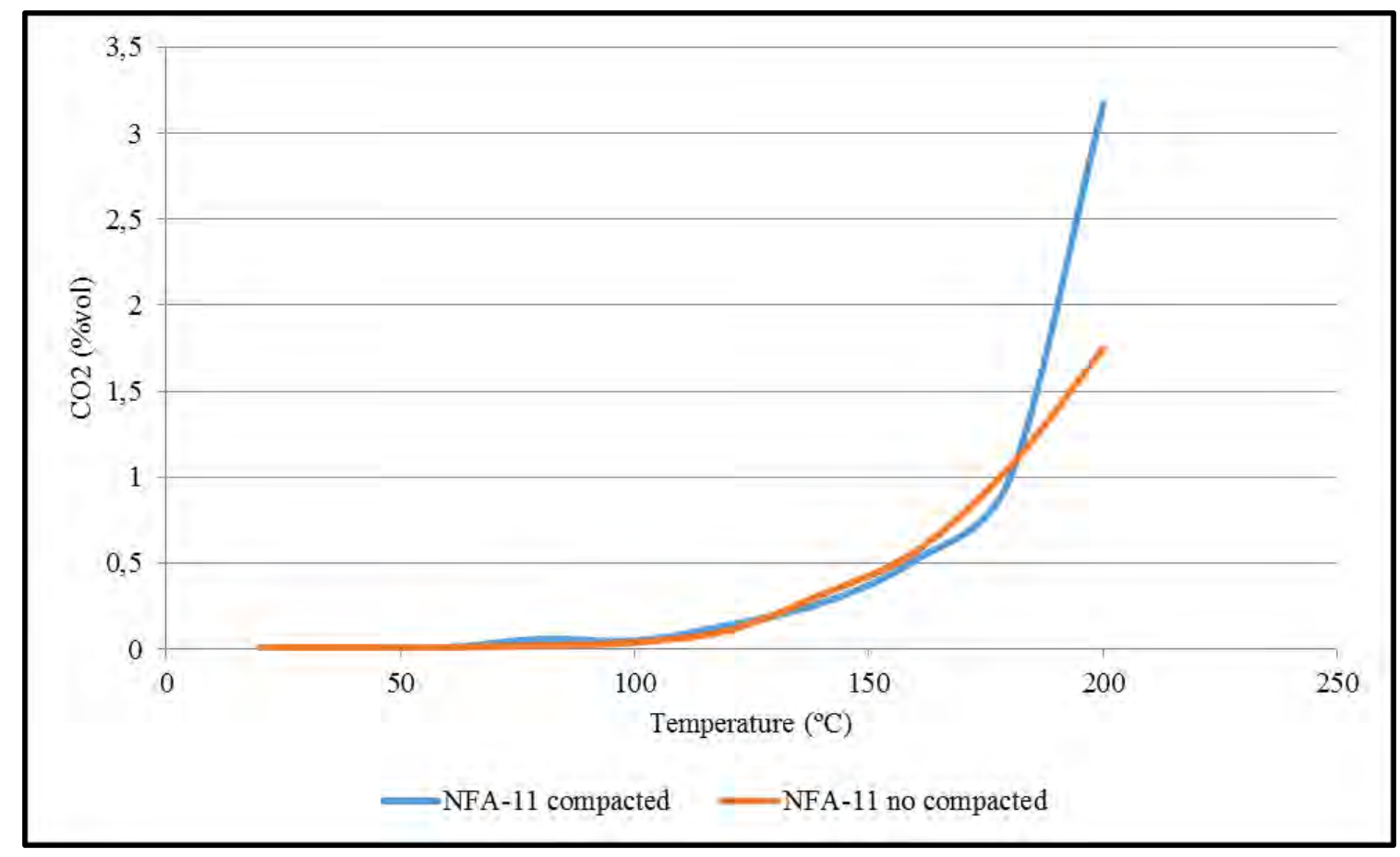

Figure 3-27. NFA-11

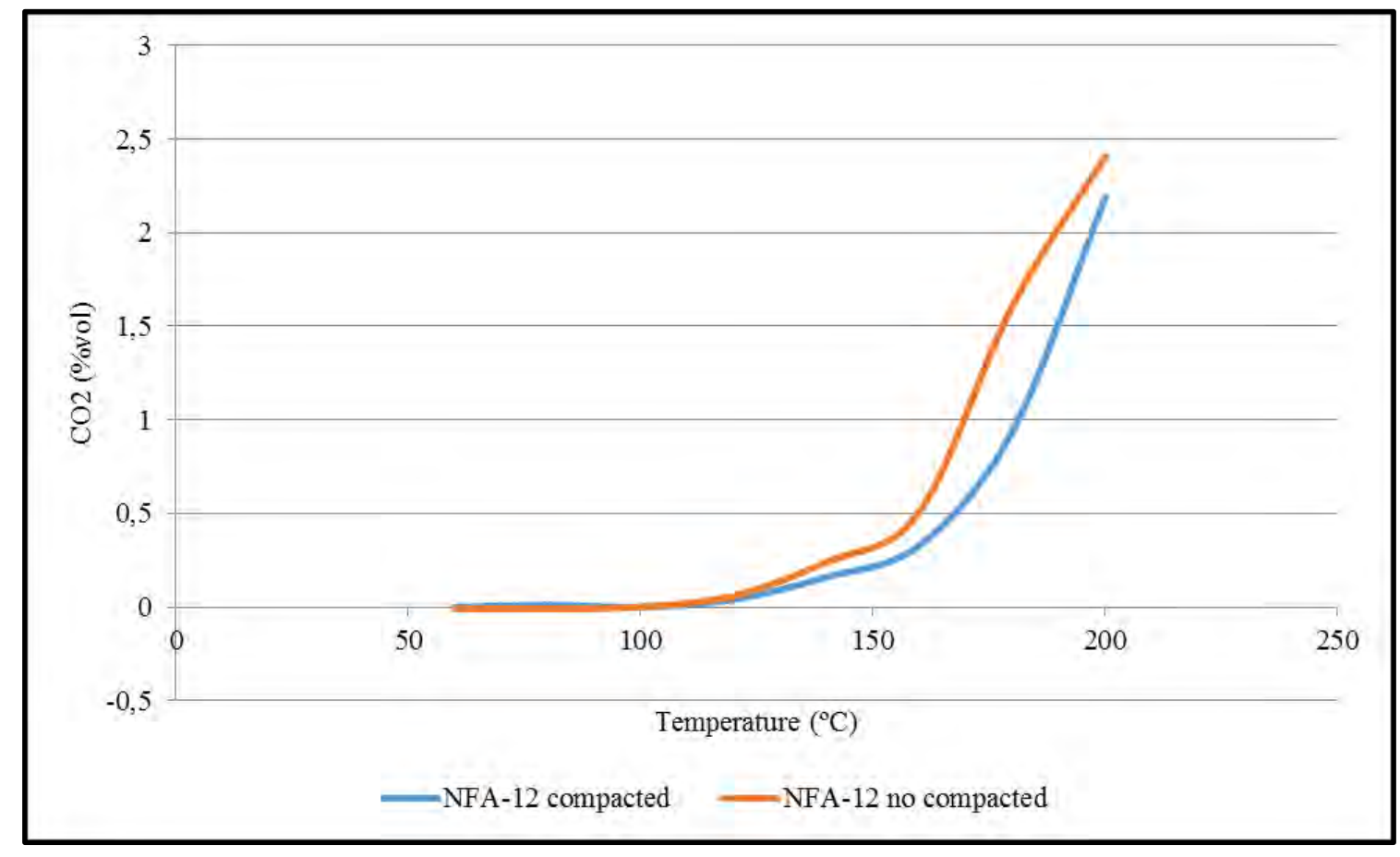

Figure 3-28. NFA-12 


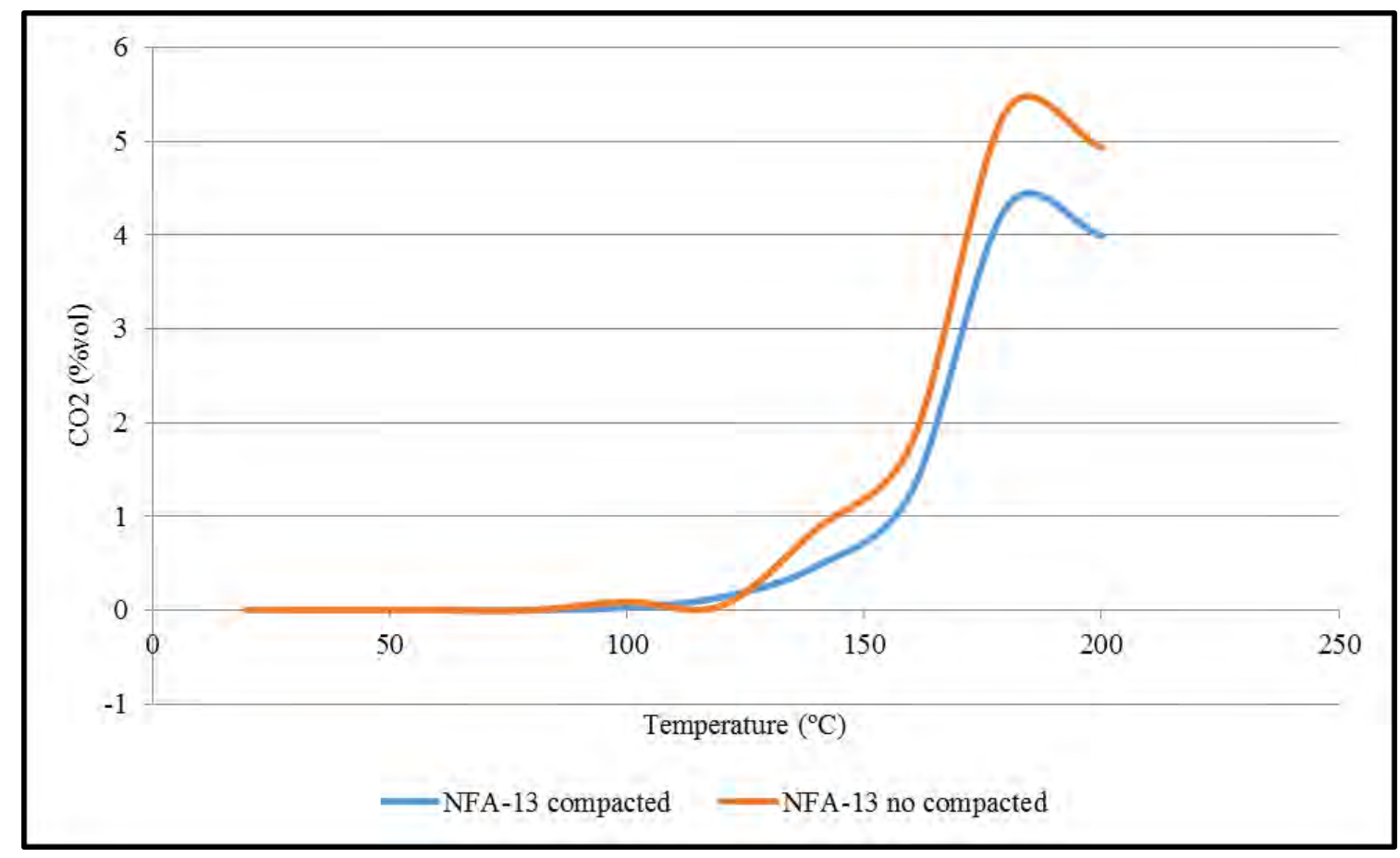

Figure 3-29. NFA-13

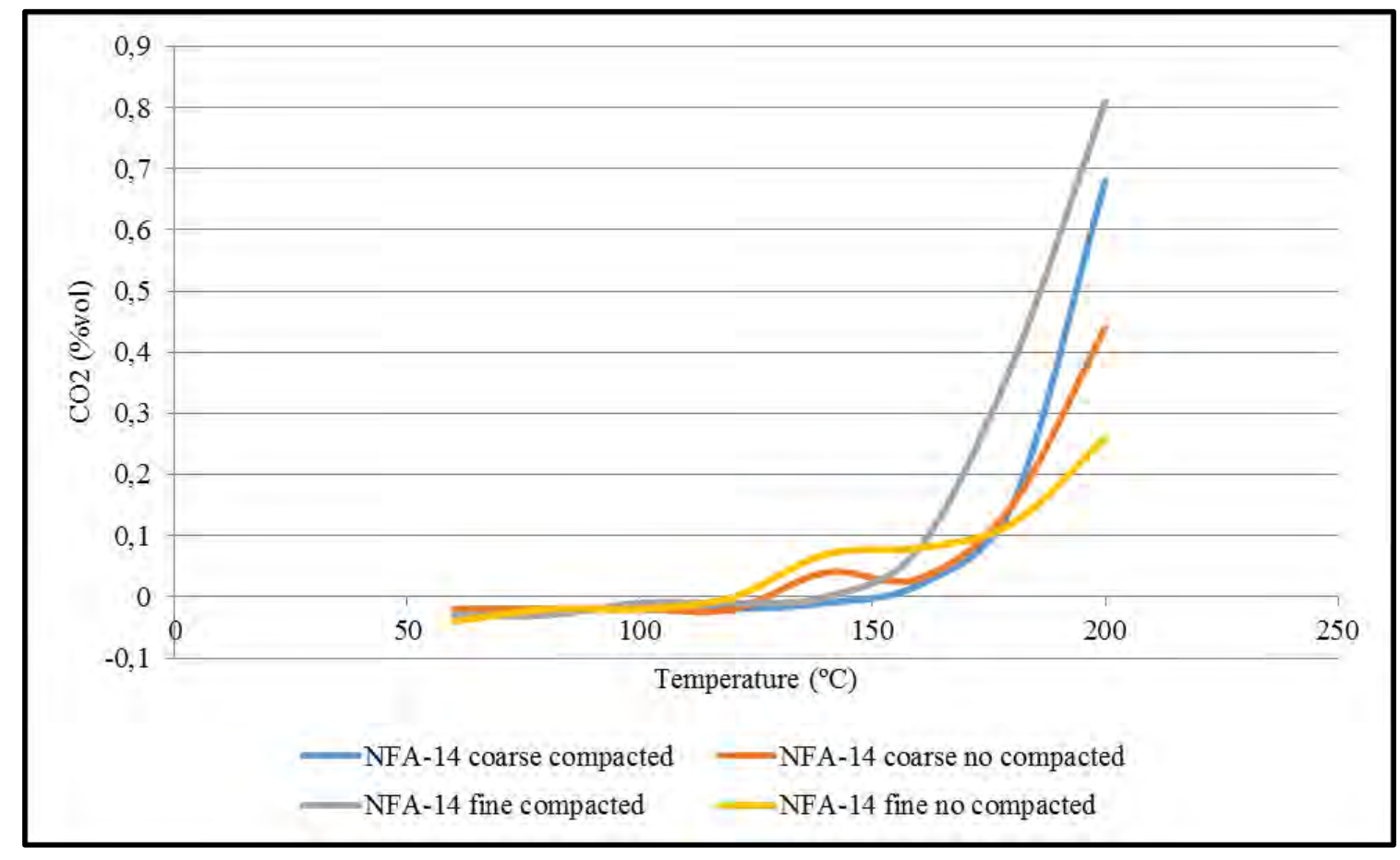

Figure 3-30. NFA-14 


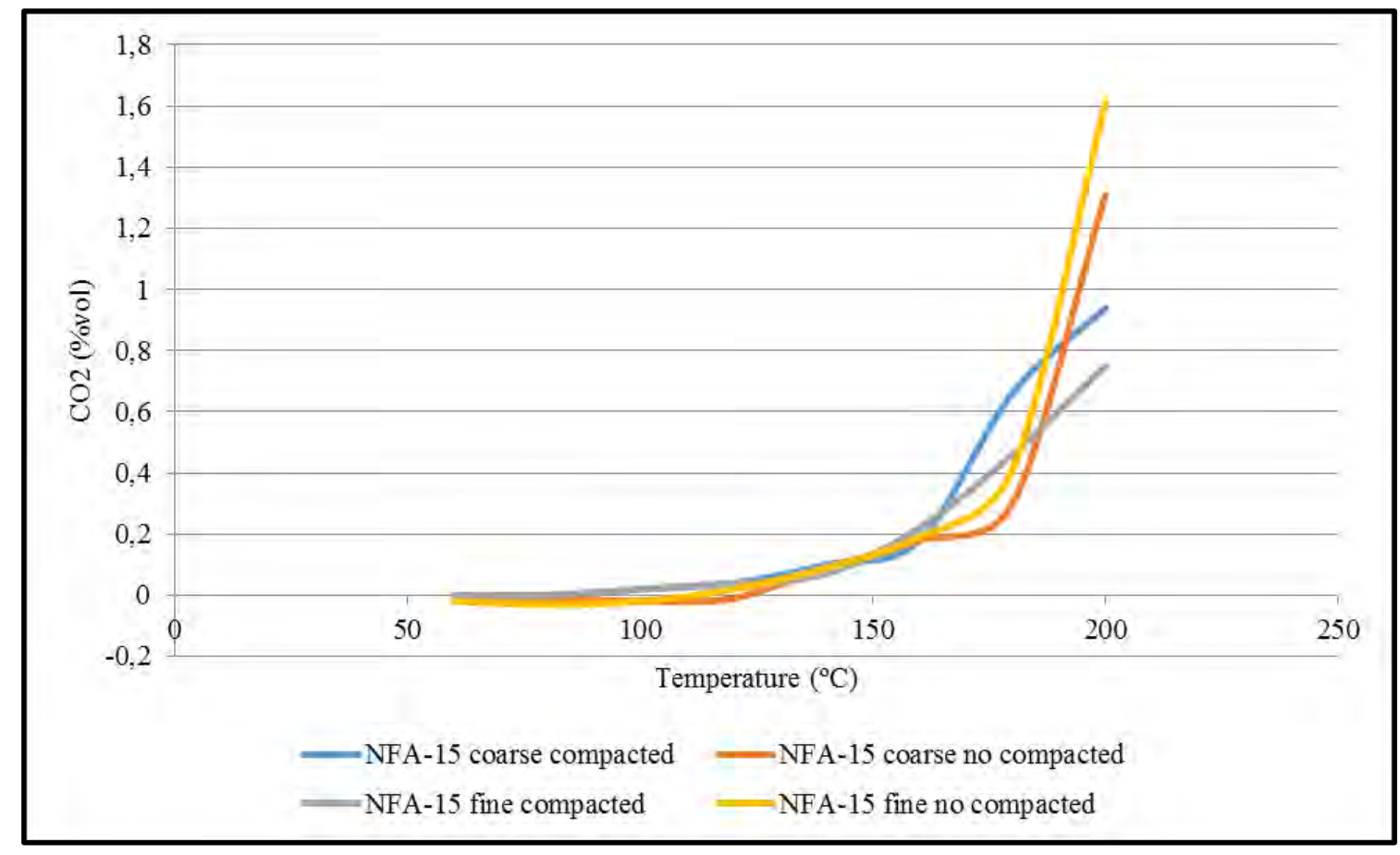

Figure 3-31. NFA-15

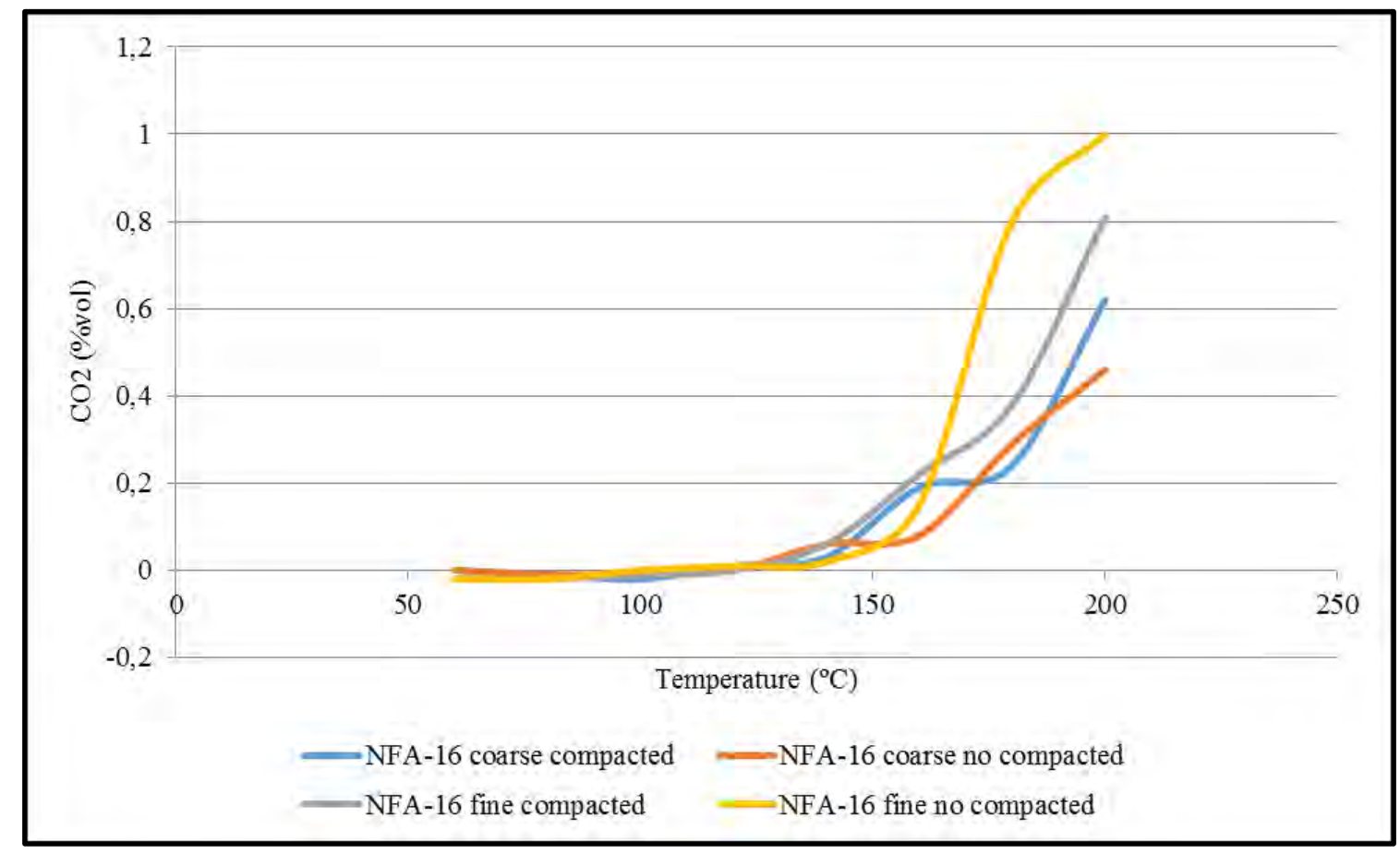

Figure 3-32. NFA-16 


\section{Results of interval method gas emissions test}

NFA-1 coarse no-compacted

\begin{tabular}{|c|c|c|}
\hline $\begin{array}{c}\text { Temperature } \\
\text { range }\left({ }^{\circ} \mathrm{C}\right)\end{array}$ & $\mathrm{RD}(-)$ & $\mathrm{RP}(\%)$ \\
\hline $40-60$ & 0,00 & 0,00 \\
\hline $60-80$ & 0,00 & 0,00 \\
\hline $80-100$ & 0,20 & 2,22 \\
\hline $100-120$ & 0,08 & 0,93 \\
\hline $120-140$ & 2,94 & $\mathbf{3 2 , 6 5}$ \\
\hline $140-160$ & 2,51 & 27,85 \\
\hline $160-180$ & 2,56 & 28,40 \\
\hline $180-200$ & 0,72 & 7,95 \\
\hline Sum & 9,00 & 100,00 \\
\hline
\end{tabular}

NFA-1 fine no compacted

NFA-1 fine compacted

\begin{tabular}{|c|c|c|}
\hline $\begin{array}{c}\text { Temperature } \\
\text { range }\left({ }^{\circ} \mathrm{C}\right)\end{array}$ & $\mathrm{RD}(-)$ & $\mathrm{RP}(\%)$ \\
\hline $40-60$ & 0,00 & 0,00 \\
\hline $60-80$ & 0,00 & 0,00 \\
\hline $80-100$ & 0,00 & 0,00 \\
\hline $100-120$ & 1,39 & 9,74 \\
\hline $120-140$ & 8,62 & $\mathbf{6 0 , 5 8}$ \\
\hline $140-160$ & 1,48 & 10,42 \\
\hline $160-180$ & 1,83 & 12,88 \\
\hline $180-200$ & 0,91 & 6,37 \\
\hline Sum & 14,23 & 100,00 \\
\hline
\end{tabular}

\begin{tabular}{|c|c|c|}
\hline $\begin{array}{c}\text { Temperature } \\
\text { range }\left({ }^{\circ} \mathrm{C}\right)\end{array}$ & $\mathrm{RD}(-)$ & $\mathrm{RP}(\%)$ \\
\hline $40-60$ & 0,00 & 0,00 \\
\hline $60-80$ & 0,00 & 0,00 \\
\hline $80-100$ & 0,00 & 0,00 \\
\hline $100-120$ & 0,50 & 5,73 \\
\hline $120-140$ & 3,42 & $\mathbf{3 9 , 1 3}$ \\
\hline $140-160$ & 1,77 & 20,27 \\
\hline $160-180$ & 1,55 & 17,79 \\
\hline $180-200$ & 1,49 & 17,08 \\
\hline Sum & 8,73 & 100,00 \\
\hline
\end{tabular}

NFA-2 no compacted

NFA-2 compacted

\begin{tabular}{|c|c|c|}
\hline $\begin{array}{c}\text { Temperature } \\
\text { range }\left({ }^{\circ} \mathrm{C}\right)\end{array}$ & $\mathrm{RD}(-)$ & $\mathrm{RP}(\%)$ \\
\hline $40-60$ & 0,00 & 0,00 \\
\hline $60-80$ & 0,00 & 0,00 \\
\hline $80-100$ & 0,00 & 0,00 \\
\hline $100-120$ & 3,91 & $\mathbf{3 2 , 3 7}$ \\
\hline $120-140$ & 1,91 & 15,83 \\
\hline $140-160$ & 1,57 & 12,99 \\
\hline $160-180$ & 3,56 & 29,45 \\
\hline $180-200$ & 1,13 & 9,37 \\
\hline Sum & 12,08 & 100,00 \\
\hline
\end{tabular}

\begin{tabular}{|c|c|c|}
\hline $\begin{array}{c}\text { Temperature } \\
\text { range }\left({ }^{\circ} \mathrm{C}\right)\end{array}$ & $\mathrm{RD}(-)$ & $\mathrm{RP}(\%)$ \\
\hline $40-60$ & 0,00 & 0,00 \\
\hline $60-80$ & 0,50 & 4,45 \\
\hline $80-100$ & 2,67 & $\mathbf{2 3 , 7 1}$ \\
\hline $100-120$ & 2,45 & 21,83 \\
\hline $120-140$ & 1,50 & 13,34 \\
\hline $140-160$ & 0,63 & 5,62 \\
\hline $160-180$ & 2,01 & 17,84 \\
\hline $180-200$ & 1,49 & 13,22 \\
\hline Sum & 11,25 & 100,00 \\
\hline
\end{tabular}


NFA-3 no compacted

\begin{tabular}{|c|c|c|}
\hline $\begin{array}{c}\text { Temperature } \\
\text { range }\left({ }^{\circ} \mathrm{C}\right)\end{array}$ & $\mathrm{RD}(-)$ & $\mathrm{RP}(\%)$ \\
\hline $40-60$ & 0,00 & 0,00 \\
\hline $60-80$ & 0,00 & 0,00 \\
\hline $80-100$ & 22,00 & $\mathbf{6 2 , 0 6}$ \\
\hline $100-120$ & 9,41 & 26,54 \\
\hline $120-140$ & 1,43 & 4,03 \\
\hline $140-160$ & 0,86 & 2,42 \\
\hline $160-180$ & 0,63 & 1,77 \\
\hline $180-200$ & 1,13 & 3,18 \\
\hline Sum & 35,45 & 100,00 \\
\hline
\end{tabular}

NFA-4 coarse no compacted

\begin{tabular}{|c|c|c|}
\hline $\begin{array}{c}\text { Temperature } \\
\text { range }\left({ }^{\circ} \mathrm{C}\right)\end{array}$ & $\mathrm{RD}(-)$ & $\mathrm{RP}(\%)$ \\
\hline $40-60$ & 0,00 & 0,00 \\
\hline $60-80$ & 0,00 & 0,00 \\
\hline $80-100$ & 0,00 & 0,00 \\
\hline $100-120$ & 0,95 & $\mathbf{1 3 , 8 2}$ \\
\hline $120-140$ & 2,18 & 31,58 \\
\hline $140-160$ & 1,47 & 21,28 \\
\hline $160-180$ & 1,17 & 17,00 \\
\hline $180-200$ & 1,13 & 16,33 \\
\hline Sum & 6,90 & 100,00 \\
\hline
\end{tabular}

NFA-4 fine no compacted

\begin{tabular}{|c|c|c|}
\hline $\begin{array}{c}\text { Temperature } \\
\text { range }\left({ }^{\circ} \mathrm{C}\right)\end{array}$ & $\mathrm{RD}(-)$ & $\mathrm{RP}(\%)$ \\
\hline $40-60$ & 0,64 & 5,98 \\
\hline $60-80$ & 2,20 & $\mathbf{2 0 , 6 2}$ \\
\hline $80-100$ & 1,76 & 16,50 \\
\hline $100-120$ & 1,84 & 17,22 \\
\hline $120-140$ & 2,28 & 21,39 \\
\hline $140-160$ & 0,64 & 5,95 \\
\hline $160-180$ & 0,61 & 5,70 \\
\hline $180-200$ & 0,71 & 6,65 \\
\hline Sum & 10,67 & 100,00 \\
\hline
\end{tabular}

NFA-3 compacted

\begin{tabular}{|c|c|c|}
\hline $\begin{array}{c}\text { Temperature } \\
\text { range }\left({ }^{\circ} \mathrm{C}\right)\end{array}$ & $\mathrm{RD}(-)$ & $\mathrm{RP}(\%)$ \\
\hline $40-60$ & 0,00 & 0,00 \\
\hline $60-80$ & 0,00 & 0,00 \\
\hline $80-100$ & 50,80 & $\mathbf{8 2 , 4 1}$ \\
\hline $100-120$ & 3,51 & 5,70 \\
\hline $120-140$ & 3,16 & 5,13 \\
\hline $140-160$ & 1,25 & 2,03 \\
\hline $160-180$ & 2,15 & 3,49 \\
\hline $180-200$ & 0,77 & 1,24 \\
\hline Sum & 61,65 & 100,00 \\
\hline
\end{tabular}

NFA-4 coarse compacted

\begin{tabular}{|c|c|c|}
\hline $\begin{array}{c}\text { Temperature } \\
\text { range }\left({ }^{\circ} \mathrm{C}\right)\end{array}$ & $\mathrm{RD}(-)$ & $\mathrm{RP}(\%)$ \\
\hline $40-60$ & 0,00 & 0,00 \\
\hline $60-80$ & 12,00 & $\mathbf{6 6 , 9 1}$ \\
\hline $80-100$ & 0,62 & 3,43 \\
\hline $100-120$ & 1,27 & 7,08 \\
\hline $120-140$ & 1,15 & 6,39 \\
\hline $140-160$ & 1,54 & 8,61 \\
\hline $160-180$ & 0,61 & 3,41 \\
\hline $180-200$ & 0,75 & 4,17 \\
\hline Sum & 17,93 & 100,00 \\
\hline
\end{tabular}

NFA-4 fine compacted

\begin{tabular}{|c|c|c|}
\hline $\begin{array}{c}\text { Temperature } \\
\text { range }\left({ }^{\circ} \mathrm{C}\right)\end{array}$ & $\mathrm{RD}(-)$ & $\mathrm{RP}(\%)$ \\
\hline $40-60$ & 0,00 & 0,00 \\
\hline $60-80$ & 0,00 & 0,00 \\
\hline $80-100$ & 1,75 & $\mathbf{1 1 , 5 3}$ \\
\hline $100-120$ & 6,91 & 45,50 \\
\hline $120-140$ & 0,54 & 3,56 \\
\hline $140-160$ & 0,53 & 3,49 \\
\hline $160-180$ & 2,47 & 16,29 \\
\hline $180-200$ & 2,98 & 19,64 \\
\hline Sum & 15,18 & 100,00 \\
\hline
\end{tabular}


NFA-5 no compacted

\begin{tabular}{|c|c|c|}
\hline $\begin{array}{c}\text { Temperature } \\
\text { range }\left({ }^{\circ} \mathrm{C}\right)\end{array}$ & $\mathrm{RD}(-)$ & $\mathrm{RP}(\%)$ \\
\hline $40-60$ & 0,00 & 0,00 \\
\hline $60-80$ & 0,00 & 0,00 \\
\hline $80-100$ & 5,00 & $\mathbf{3 5 , 5 7}$ \\
\hline $100-120$ & 2,37 & 16,84 \\
\hline $120-140$ & 1,48 & 10,49 \\
\hline $140-160$ & 2,55 & 18,17 \\
\hline $160-180$ & 0,77 & 5,50 \\
\hline $180-200$ & 1,89 & 13,44 \\
\hline Sum & 14,06 & 100,00 \\
\hline
\end{tabular}

NFA-6 coarse no compacted

\begin{tabular}{|c|c|c|}
\hline $\begin{array}{c}\text { Temperature } \\
\text { range }\left({ }^{\circ} \mathrm{C}\right)\end{array}$ & $\mathrm{RD}(-)$ & $\mathrm{RP}(\%)$ \\
\hline $40-60$ & 0,00 & 0,00 \\
\hline $60-80$ & 0,00 & 0,00 \\
\hline $80-100$ & 0,00 & 0,00 \\
\hline $100-120$ & 1,00 & 4,40 \\
\hline $120-140$ & 4,27 & $\mathbf{1 8 , 8 1}$ \\
\hline $140-160$ & 0,58 & 2,54 \\
\hline $160-180$ & 3,99 & 17,56 \\
\hline $180-200$ & 12,88 & 56,69 \\
\hline Sum & 22,72 & 100,00 \\
\hline
\end{tabular}

NFA-6 fine no compacted

\begin{tabular}{|c|c|c|}
\hline $\begin{array}{c}\text { Temperature } \\
\text { range }\left({ }^{\circ} \mathrm{C}\right)\end{array}$ & $\mathrm{RD}(-)$ & $\mathrm{RP}(\%)$ \\
\hline $40-60$ & 0,00 & 0,00 \\
\hline $60-80$ & 0,00 & 0,00 \\
\hline $80-100$ & 0,67 & 4,49 \\
\hline $100-120$ & 5,00 & $\mathbf{3 3 , 6 9}$ \\
\hline $120-140$ & 2,00 & 13,47 \\
\hline $140-160$ & 2,22 & 14,97 \\
\hline $160-180$ & 3,38 & 22,77 \\
\hline $180-200$ & 1,57 & 10,61 \\
\hline Sum & 14,84 & 100,00 \\
\hline
\end{tabular}

NFA-5 compacted

\begin{tabular}{|c|c|c|}
\hline $\begin{array}{c}\text { Temperature } \\
\text { range }\left({ }^{\circ} \mathrm{C}\right)\end{array}$ & $\mathrm{RD}(-)$ & $\mathrm{RP}(\%)$ \\
\hline $40-60$ & 0,00 & 0,00 \\
\hline $60-80$ & 0,00 & 0,00 \\
\hline $80-100$ & 5,00 & $\mathbf{3 5 , 2 6}$ \\
\hline $100-120$ & 2,83 & 19,98 \\
\hline $120-140$ & 1,48 & 10,43 \\
\hline $140-160$ & 3,00 & 21,18 \\
\hline $160-180$ & 0,46 & 3,21 \\
\hline $180-200$ & 1,41 & 9,94 \\
\hline Sum & 14,18 & 100,00 \\
\hline
\end{tabular}

NFA-6 coarse compacted

\begin{tabular}{|c|c|c|}
\hline $\begin{array}{c}\text { Temperature } \\
\text { range }\left({ }^{\circ} \mathrm{C}\right)\end{array}$ & $\mathrm{RD}(-)$ & $\mathrm{RP}(\%)$ \\
\hline $40-60$ & 0,00 & 0,00 \\
\hline $60-80$ & 0,00 & 0,00 \\
\hline $80-100$ & 0,00 & 0,00 \\
\hline $100-120$ & 17,00 & $\mathbf{6 2 , 8 9}$ \\
\hline $120-140$ & 3,61 & 13,36 \\
\hline $140-160$ & 1,57 & 5,79 \\
\hline $160-180$ & 2,91 & 10,77 \\
\hline $180-200$ & 1,94 & 7,19 \\
\hline Sum & 27,03 & 100,00 \\
\hline
\end{tabular}

NFA-6 fine compacted

\begin{tabular}{|c|c|c|}
\hline $\begin{array}{c}\text { Temperature } \\
\text { range }\left({ }^{\circ} \mathrm{C}\right)\end{array}$ & $\mathrm{RD}(-)$ & $\mathrm{RP}(\%)$ \\
\hline $40-60$ & 0,00 & 0,00 \\
\hline $60-80$ & 0,50 & 3,06 \\
\hline $80-100$ & 0,67 & 4,08 \\
\hline $100-120$ & 0,00 & 0,00 \\
\hline $120-140$ & 3,80 & $\mathbf{2 3 , 2 8}$ \\
\hline $140-160$ & 0,83 & 5,11 \\
\hline $160-180$ & 4,55 & 27,85 \\
\hline $180-200$ & 5,98 & 36,61 \\
\hline Sum & 16,32 & 100,00 \\
\hline
\end{tabular}


NFA-7 coarse no compacted

\begin{tabular}{|c|c|c|}
\hline $\begin{array}{c}\text { Temperature } \\
\text { range }\left({ }^{\circ} \mathrm{C}\right)\end{array}$ & $\mathrm{RD}(-)$ & $\mathrm{RP}(\%)$ \\
\hline $40-60$ & 0,07 & 0,56 \\
\hline $60-80$ & 0,17 & 1,30 \\
\hline $80-100$ & 2,15 & $\mathbf{1 6 , 2 4}$ \\
\hline $100-120$ & 3,67 & 27,78 \\
\hline $120-140$ & 2,06 & 15,55 \\
\hline $140-160$ & 0,33 & 2,52 \\
\hline $160-180$ & 0,34 & 2,54 \\
\hline $180-200$ & 4,43 & 33,50 \\
\hline Sum & 13,22 & 100,00 \\
\hline
\end{tabular}

NFA-7 fine no compacted

\begin{tabular}{|c|c|c|}
\hline $\begin{array}{c}\text { Temperature } \\
\text { range }\left({ }^{\circ} \mathrm{C}\right)\end{array}$ & $\mathrm{RD}(-)$ & $\mathrm{RP}(\%)$ \\
\hline $40-60$ & 0,53 & 3,04 \\
\hline $60-80$ & 5,50 & $\mathbf{3 1 , 5 7}$ \\
\hline $80-100$ & 1,25 & 7,17 \\
\hline $100-120$ & 5,43 & 31,15 \\
\hline $120-140$ & 0,38 & 2,15 \\
\hline $140-160$ & 3,19 & 18,29 \\
\hline $160-180$ & 0,79 & 4,51 \\
\hline $180-200$ & 0,37 & 2,12 \\
\hline Sum & 17,42 & 100,00 \\
\hline
\end{tabular}

NFA-8 no compacted

\begin{tabular}{|c|c|c|}
\hline $\begin{array}{c}\text { Temperature } \\
\text { range }\left({ }^{\circ} \mathrm{C}\right)\end{array}$ & $\mathrm{RD}(-)$ & $\mathrm{RP}(\%)$ \\
\hline $40-60$ & 0,30 & 1,78 \\
\hline $60-80$ & 3,62 & $\mathbf{2 1 , 4 4}$ \\
\hline $80-100$ & 0,51 & 3,01 \\
\hline $100-120$ & 3,64 & 21,59 \\
\hline $120-140$ & 0,60 & 3,53 \\
\hline $140-160$ & 7,99 & 47,42 \\
\hline $160-180$ & 0,09 & 0,55 \\
\hline $180-200$ & 0,11 & 0,67 \\
\hline Sum & 16,86 & 100,00 \\
\hline
\end{tabular}

NFA-7 coarse compacted

\begin{tabular}{|c|c|c|}
\hline $\begin{array}{c}\text { Temperature } \\
\text { range }\left({ }^{\circ} \mathrm{C}\right)\end{array}$ & $\mathrm{RD}(-)$ & $\mathrm{RP}(\%)$ \\
\hline $40-60$ & 1,14 & 5,56 \\
\hline $60-80$ & 0,67 & 3,25 \\
\hline $80-100$ & 0,36 & 1,75 \\
\hline $100-120$ & 12,82 & $\mathbf{6 2 , 4 4}$ \\
\hline $120-140$ & 2,76 & 13,45 \\
\hline $140-160$ & 0,98 & 4,75 \\
\hline $160-180$ & 0,32 & 1,57 \\
\hline $180-200$ & 1,48 & 7,23 \\
\hline Sum & 20,54 & 100,00 \\
\hline
\end{tabular}

NFA-7 fine compacted

\begin{tabular}{|c|c|c|}
\hline $\begin{array}{c}\text { Temperature } \\
\text { range }\left({ }^{\circ} \mathrm{C}\right)\end{array}$ & $\mathrm{RD}(-)$ & $\mathrm{RP}(\%)$ \\
\hline $40-60$ & 2,46 & $\mathbf{1 2 , 6 2}$ \\
\hline $60-80$ & 0,89 & 4,57 \\
\hline $80-100$ & 8,14 & 41,79 \\
\hline $100-120$ & 2,22 & 11,41 \\
\hline $120-140$ & 0,87 & 4,48 \\
\hline $140-160$ & 1,32 & 6,76 \\
\hline $160-180$ & 3,49 & 17,90 \\
\hline $180-200$ & 0,09 & 0,48 \\
\hline Sum & 19,49 & 100,00 \\
\hline
\end{tabular}

NFA-8 compacted

\begin{tabular}{|c|c|c|}
\hline $\begin{array}{c}\text { Temperature } \\
\text { range }\left({ }^{\circ} \mathrm{C}\right)\end{array}$ & $\mathrm{RD}(-)$ & $\mathrm{RP}(\%)$ \\
\hline $40-60$ & 0,00 & 0,00 \\
\hline $60-80$ & 0,00 & 0,00 \\
\hline $80-100$ & 3,00 & $\mathbf{3 2 , 2 8}$ \\
\hline $100-120$ & 1,03 & 11,10 \\
\hline $120-140$ & 2,74 & 29,47 \\
\hline $140-160$ & 0,49 & 5,27 \\
\hline $160-180$ & 1,14 & 12,31 \\
\hline $180-200$ & 0,89 & 9,57 \\
\hline Sum & 9,29 & 100,00 \\
\hline
\end{tabular}


NFA-9 no compacted

\begin{tabular}{|c|c|c|}
\hline $\begin{array}{c}\text { Temperature } \\
\text { range }\left({ }^{\circ} \mathrm{C}\right)\end{array}$ & $\mathrm{RD}(-)$ & $\mathrm{RP}(\%)$ \\
\hline $40-60$ & 0,00 & 0,00 \\
\hline $60-80$ & 0,00 & 0,00 \\
\hline $80-100$ & 0,00 & 0,00 \\
\hline $100-120$ & 1,28 & $\mathbf{1 5 , 1 1}$ \\
\hline $120-140$ & 3,30 & 38,94 \\
\hline $140-160$ & 2,06 & 24,36 \\
\hline $160-180$ & 1,59 & 18,82 \\
\hline $180-200$ & 0,23 & 2,76 \\
\hline Sum & 8,46 & 100,00 \\
\hline
\end{tabular}

NFA-10 coarse no compacted

\begin{tabular}{|c|c|c|}
\hline $\begin{array}{c}\text { Temperature } \\
\text { range }\left({ }^{\circ} \mathrm{C}\right)\end{array}$ & $\mathrm{RD}(-)$ & $\mathrm{RP}(\%)$ \\
\hline $40-60$ & 0,00 & 0,00 \\
\hline $60-80$ & 0,00 & 0,00 \\
\hline $80-100$ & 0,00 & 0,00 \\
\hline $100-120$ & 1,67 & $\mathbf{1 0 , 5 2}$ \\
\hline $120-140$ & 9,88 & 62,33 \\
\hline $140-160$ & 1,16 & 7,33 \\
\hline $160-180$ & 0,66 & 4,20 \\
\hline $180-200$ & 2,48 & 15,63 \\
\hline Sum & 15,84 & 100,00 \\
\hline
\end{tabular}

NFA-10 fine no compacted

\begin{tabular}{|c|c|c|}
\hline $\begin{array}{c}\text { Temperature } \\
\text { range }\left({ }^{\circ} \mathrm{C}\right)\end{array}$ & $\mathrm{RD}(-)$ & $\mathrm{RP}(\%)$ \\
\hline $40-60$ & 0,00 & 0,00 \\
\hline $60-80$ & 0,00 & 0,00 \\
\hline $80-100$ & 0,00 & 0,00 \\
\hline $100-120$ & 0,31 & 4,09 \\
\hline $120-140$ & 3,22 & $\mathbf{4 1 , 9 1}$ \\
\hline $140-160$ & 1,02 & 13,30 \\
\hline $160-180$ & 2,14 & 27,91 \\
\hline $180-200$ & 0,98 & 12,78 \\
\hline Sum & 7,68 & 100,00 \\
\hline
\end{tabular}

NFA-9 compacted

\begin{tabular}{|c|c|c|}
\hline $\begin{array}{c}\text { Temperature } \\
\text { range }\left({ }^{\circ} \mathrm{C}\right)\end{array}$ & $\mathrm{RD}(-)$ & $\mathrm{RP}(\%)$ \\
\hline $40-60$ & 0,00 & 0,00 \\
\hline $60-80$ & 0,00 & 0,00 \\
\hline $80-100$ & 10,67 & $\mathbf{5 3 , 3 4}$ \\
\hline $100-120$ & 2,00 & 10,00 \\
\hline $120-140$ & 3,64 & 18,19 \\
\hline $140-160$ & 1,26 & 6,29 \\
\hline $160-180$ & 2,35 & 11,75 \\
\hline $180-200$ & 0,09 & 0,43 \\
\hline Sum & 20,00 & 100,00 \\
\hline
\end{tabular}

NFA-10 coarse compacted

\begin{tabular}{|c|c|c|}
\hline $\begin{array}{c}\text { Temperature } \\
\text { range }\left({ }^{\circ} \mathrm{C}\right)\end{array}$ & $\mathrm{RD}(-)$ & $\mathrm{RP}(\%)$ \\
\hline $40-60$ & 0,00 & 0,00 \\
\hline $60-80$ & 0,00 & 0,00 \\
\hline $80-100$ & 0,00 & 0,00 \\
\hline $100-120$ & 0,00 & 0,00 \\
\hline $120-140$ & 2,47 & $\mathbf{3 9 , 2 6}$ \\
\hline $140-160$ & 0,81 & 12,86 \\
\hline $160-180$ & 2,32 & 36,91 \\
\hline $180-200$ & 0,69 & 10,97 \\
\hline Sum & 6,28 & 100,00 \\
\hline
\end{tabular}

NFA-11 fine compacted

\begin{tabular}{|c|c|c|}
\hline $\begin{array}{c}\text { Temperature } \\
\text { range }\left({ }^{\circ} \mathrm{C}\right)\end{array}$ & $\mathrm{RD}(-)$ & $\mathrm{RP}(\%)$ \\
\hline $40-60$ & 0,00 & 0,00 \\
\hline $60-80$ & 0,00 & 0,00 \\
\hline $80-100$ & 7,00 & 47,44 \\
\hline $100-120$ & 1,72 & 11,65 \\
\hline $120-140$ & 1,80 & 12,23 \\
\hline $140-160$ & 0,61 & 4,17 \\
\hline $160-180$ & 1,62 & 11,01 \\
\hline $180-200$ & 1,99 & 13,51 \\
\hline Sum & 14,76 & 100,00 \\
\hline
\end{tabular}


NFA-11 no compacted

\begin{tabular}{|c|c|c|}
\hline $\begin{array}{c}\text { Temperature } \\
\text { range }\left({ }^{\circ} \mathrm{C}\right)\end{array}$ & $\mathrm{RD}(-)$ & $\mathrm{RP}(\%)$ \\
\hline $40-60$ & 0,00 & 0,00 \\
\hline $60-80$ & 0,00 & 0,00 \\
\hline $80-100$ & 0,50 & 4,57 \\
\hline $100-120$ & 4,83 & 44,19 \\
\hline $120-140$ & 2,25 & 20,55 \\
\hline $140-160$ & 0,97 & 8,90 \\
\hline $160-180$ & 1,66 & 15,15 \\
\hline $180-200$ & 0,73 & 6,64 \\
\hline Sum & 10,94 & 100,00 \\
\hline
\end{tabular}

NFA-12 no compacted

\begin{tabular}{|c|c|c|}
\hline $\begin{array}{c}\text { Temperature } \\
\text { range }\left({ }^{\circ} \mathrm{C}\right)\end{array}$ & $\mathrm{RD}(-)$ & $\mathrm{RP}(\%)$ \\
\hline $40-60$ & 0,00 & 0,00 \\
\hline $60-80$ & 0,00 & 0,00 \\
\hline $80-100$ & 2,33 & $\mathbf{2 0 , 4 6}$ \\
\hline $100-120$ & 0,95 & 8,33 \\
\hline $120-140$ & 2,97 & 26,08 \\
\hline $140-160$ & 1,74 & 15,28 \\
\hline $160-180$ & 2,64 & 23,13 \\
\hline $180-200$ & 0,77 & 6,72 \\
\hline Sum & 11,40 & 100,00 \\
\hline
\end{tabular}

NFA-13 no compacted

\begin{tabular}{|c|c|c|}
\hline $\begin{array}{c}\text { Temperature } \\
\text { range }\left({ }^{\circ} \mathrm{C}\right)\end{array}$ & $\mathrm{RD}(-)$ & $\mathrm{RP}(\%)$ \\
\hline $40-60$ & 0,00 & 0,00 \\
\hline $60-80$ & 0,00 & 0,00 \\
\hline $80-100$ & 0,00 & 0,00 \\
\hline $100-120$ & 0,08 & 0,53 \\
\hline $120-140$ & 11,02 & $\mathbf{7 5 , 4 9}$ \\
\hline $140-160$ & 0,95 & 6,54 \\
\hline $160-180$ & 2,44 & 16,69 \\
\hline $180-200$ & 0,11 & 0,76 \\
\hline Sum & 14,60 & 100,00 \\
\hline
\end{tabular}

NFA-11 compacted

\begin{tabular}{|c|c|c|}
\hline $\begin{array}{c}\text { Temperature } \\
\text { range }\left({ }^{\circ} \mathrm{C}\right)\end{array}$ & $\mathrm{RD}(-)$ & $\mathrm{RP}(\%)$ \\
\hline $40-60$ & 0,00 & 0,00 \\
\hline $60-80$ & 0,00 & 0,00 \\
\hline $80-100$ & 21,00 & $\mathbf{6 3 , 6 1}$ \\
\hline $100-120$ & 4,64 & 14,04 \\
\hline $120-140$ & 1,05 & 3,18 \\
\hline $140-160$ & 1,33 & 4,02 \\
\hline $160-180$ & 1,60 & 4,85 \\
\hline $180-200$ & 3,40 & 10,30 \\
\hline Sum & 33,01 & 100,00 \\
\hline
\end{tabular}

NFA-12 compacted

\begin{tabular}{|c|c|c|}
\hline $\begin{array}{c}\text { Temperature } \\
\text { range }\left({ }^{\circ} \mathrm{C}\right)\end{array}$ & $\mathrm{RD}(-)$ & $\mathrm{RP}(\%)$ \\
\hline $40-60$ & 0,00 & 0,00 \\
\hline $60-80$ & 0,00 & 0,00 \\
\hline $80-100$ & 2,00 & $\mathbf{2 0 , 9 3}$ \\
\hline $100-120$ & 0,89 & 9,30 \\
\hline $120-140$ & 1,82 & 19,08 \\
\hline $140-160$ & 0,95 & 9,95 \\
\hline $160-180$ & 2,18 & 22,79 \\
\hline $180-200$ & 1,72 & 17,95 \\
\hline Sum & 9,56 & 100,00 \\
\hline
\end{tabular}

NFA-13 compacted

\begin{tabular}{|c|c|c|}
\hline $\begin{array}{c}\text { Temperature } \\
\text { range }\left({ }^{\circ} \mathrm{C}\right)\end{array}$ & RD (-) & RP $(\%)$ \\
\hline $40-60$ & 0,00 & 0,00 \\
\hline $60-80$ & 0,00 & 0,00 \\
\hline $80-100$ & 0,00 & 0,00 \\
\hline $100-120$ & 4,91 & $\mathbf{4 0 , 9 7}$ \\
\hline $120-140$ & 2,48 & 20,67 \\
\hline $140-160$ & 1,91 & 15,92 \\
\hline $160-180$ & 2,69 & 22,43 \\
\hline $180-200$ & 0,00 & 0,01 \\
\hline Sum & 11,98 & 100,00 \\
\hline
\end{tabular}


NFA-14 coarse no compacted

\begin{tabular}{|c|c|c|}
\hline $\begin{array}{c}\text { Temperature } \\
\text { range }\left({ }^{\circ} \mathrm{C}\right)\end{array}$ & $\mathrm{RD}(-)$ & $\mathrm{RP}(\%)$ \\
\hline $40-60$ & 0,00 & 0,00 \\
\hline $60-80$ & 0,00 & 0,00 \\
\hline $80-100$ & 0,00 & 0,00 \\
\hline $100-120$ & 0,00 & 0,00 \\
\hline $120-140$ & 0,95 & 8,32 \\
\hline $140-160$ & 1,00 & 8,72 \\
\hline $160-180$ & 7,36 & $\mathbf{6 4 , 1 5}$ \\
\hline $180-200$ & 2,16 & 18,81 \\
\hline Sum & 11,47 & 100,00 \\
\hline
\end{tabular}

NFA-14 fine no compacted

\begin{tabular}{|c|c|c|}
\hline $\begin{array}{c}\text { Temperature } \\
\text { range }\left({ }^{\circ} \mathrm{C}\right)\end{array}$ & $\mathrm{RD}(-)$ & $\mathrm{RP}(\%)$ \\
\hline $40-60$ & 0,00 & 0,00 \\
\hline $60-80$ & 1,60 & $\mathbf{1 5 , 0 0}$ \\
\hline $80-100$ & 0,38 & 3,61 \\
\hline $100-120$ & 3,17 & 29,69 \\
\hline $120-140$ & 1,19 & 11,13 \\
\hline $140-160$ & 0,60 & 5,66 \\
\hline $160-180$ & 0,70 & 6,52 \\
\hline $180-200$ & 3,03 & 28,38 \\
\hline Sum & 10,66 & 100,00 \\
\hline
\end{tabular}

NFA-15 coarse no compacted

\begin{tabular}{|c|c|c|}
\hline $\begin{array}{c}\text { Temperature } \\
\text { range }\left({ }^{\circ} \mathrm{C}\right)\end{array}$ & $\mathrm{RD}(-)$ & $\mathrm{RP}(\%)$ \\
\hline $40-60$ & 0,00 & 0,00 \\
\hline $60-80$ & 0,00 & 0,00 \\
\hline $80-100$ & 0,00 & 0,00 \\
\hline $100-120$ & 3,55 & $\mathbf{4 6 , 8 5}$ \\
\hline $120-140$ & 0,42 & 5,55 \\
\hline $140-160$ & 2,25 & 29,78 \\
\hline $160-180$ & 1,03 & 13,56 \\
\hline $180-200$ & 0,32 & 4,26 \\
\hline Sum & 7,57 & 100,00 \\
\hline
\end{tabular}

NFA-14 coarse compacted

\begin{tabular}{|c|c|c|}
\hline $\begin{array}{c}\text { Temperature } \\
\text { range }\left({ }^{\circ} \mathrm{C}\right)\end{array}$ & $\mathrm{RD}(-)$ & $\mathrm{RP}(\%)$ \\
\hline $40-60$ & 0,00 & 0,00 \\
\hline $60-80$ & 0,00 & 0,00 \\
\hline $80-100$ & 0,00 & 0,00 \\
\hline $100-120$ & 9,00 & $\mathbf{3 3 , 5 6}$ \\
\hline $120-140$ & 3,20 & 11,93 \\
\hline $140-160$ & 1,95 & 7,28 \\
\hline $160-180$ & 4,86 & 18,13 \\
\hline $180-200$ & 7,80 & 29,10 \\
\hline Sum & 26,82 & 100,00 \\
\hline
\end{tabular}

NFA-14 fine compacted

\begin{tabular}{|c|c|c|}
\hline $\begin{array}{c}\text { Temperature } \\
\text { range }\left({ }^{\circ} \mathrm{C}\right)\end{array}$ & $\mathrm{RD}(-)$ & $\mathrm{RP}(\%)$ \\
\hline $40-60$ & 0,00 & 0,00 \\
\hline $60-80$ & 0,00 & 0,00 \\
\hline $80-100$ & 0,00 & 0,00 \\
\hline $100-120$ & 4,13 & $\mathbf{2 6 , 0 1}$ \\
\hline $120-140$ & 0,76 & 4,77 \\
\hline $140-160$ & 2,58 & 16,29 \\
\hline $160-180$ & 6,02 & 37,93 \\
\hline $180-200$ & 2,38 & 15,00 \\
\hline Sum & 15,86 & 100,00 \\
\hline
\end{tabular}

NFA-15 coarse compacted

\begin{tabular}{|c|c|c|}
\hline $\begin{array}{c}\text { Temperature } \\
\text { range }\left({ }^{\circ} \mathrm{C}\right)\end{array}$ & $\mathrm{RD}(-)$ & $\mathrm{RP}(\%)$ \\
\hline $40-60$ & 0,00 & 0,00 \\
\hline $60-80$ & 0,00 & 0,00 \\
\hline $80-100$ & 0,00 & 0,00 \\
\hline $100-120$ & 5,00 & $\mathbf{5 1 , 1 5}$ \\
\hline $120-140$ & 1,19 & 12,15 \\
\hline $140-160$ & 0,72 & 7,40 \\
\hline $160-180$ & 2,72 & 27,86 \\
\hline $180-200$ & 0,14 & 1,44 \\
\hline Sum & 9,78 & 100,00 \\
\hline
\end{tabular}


NFA-15 fine no compacted

\begin{tabular}{|c|c|c|}
\hline $\begin{array}{c}\text { Temperature } \\
\text { range }\left({ }^{\circ} \mathrm{C}\right)\end{array}$ & $\mathrm{RD}(-)$ & $\mathrm{RP}(\%)$ \\
\hline $40-60$ & 0,00 & 0,00 \\
\hline $60-80$ & 0,00 & 0,00 \\
\hline $80-100$ & 0,00 & 0,00 \\
\hline $100-120$ & 8,40 & $\mathbf{5 2 , 6 9}$ \\
\hline $120-140$ & 2,38 & 14,95 \\
\hline $140-160$ & 1,04 & 6,55 \\
\hline $160-180$ & 0,67 & 4,23 \\
\hline $180-200$ & 3,44 & 21,59 \\
\hline Sum & 15,94 & 100,00 \\
\hline
\end{tabular}

NFA-16 coarse no compacted

\begin{tabular}{|c|c|c|}
\hline $\begin{array}{c}\text { Temperature } \\
\text { range }\left({ }^{\circ} \mathrm{C}\right)\end{array}$ & $\mathrm{RD}(-)$ & $\mathrm{RP}(\%)$ \\
\hline $40-60$ & 0,00 & 0,00 \\
\hline $60-80$ & 0,08 & 0,89 \\
\hline $80-100$ & 0,39 & 4,55 \\
\hline $100-120$ & 0,77 & 8,90 \\
\hline $120-140$ & 1,71 & $\mathbf{1 9 , 7 9}$ \\
\hline $140-160$ & 0,21 & 2,41 \\
\hline $160-180$ & 4,81 & 55,67 \\
\hline $180-200$ & 0,67 & 7,79 \\
\hline Sum & 8,64 & 100,00 \\
\hline
\end{tabular}

NFA-16 fine no compacted

\begin{tabular}{|c|c|c|}
\hline $\begin{array}{c}\text { Temperature } \\
\text { range }\left({ }^{\circ} \mathrm{C}\right)\end{array}$ & $\mathrm{RD}(-)$ & $\mathrm{RP}(\%)$ \\
\hline $40-60$ & 0,00 & 0,00 \\
\hline $60-80$ & 1,00 & 8,53 \\
\hline $80-100$ & 1,83 & $\mathbf{1 5 , 6 4}$ \\
\hline $100-120$ & 0,61 & 5,18 \\
\hline $120-140$ & 0,68 & 5,82 \\
\hline $140-160$ & 4,01 & 34,24 \\
\hline $160-180$ & 3,32 & 28,27 \\
\hline $180-200$ & 0,27 & 2,32 \\
\hline Sum & 11,73 & 100,00 \\
\hline
\end{tabular}

NFA-15 fine compacted

\begin{tabular}{|c|c|c|}
\hline $\begin{array}{c}\text { Temperature } \\
\text { range }\left({ }^{\circ} \mathrm{C}\right)\end{array}$ & $\mathrm{RD}(-)$ & $\mathrm{RP}(\%)$ \\
\hline $40-60$ & 0,00 & 0,00 \\
\hline $60-80$ & 0,18 & 1,54 \\
\hline $80-100$ & 0,56 & 4,71 \\
\hline $100-120$ & 0,50 & 4,24 \\
\hline $120-140$ & 6,24 & $\mathbf{5 2 , 9 3}$ \\
\hline $140-160$ & 0,89 & 7,54 \\
\hline $160-180$ & 0,66 & 5,62 \\
\hline $180-200$ & 2,76 & 23,41 \\
\hline Sum & 11,78 & 100,00 \\
\hline
\end{tabular}

NFA-16 coarse compacted

\begin{tabular}{|c|c|c|}
\hline $\begin{array}{c}\text { Temperature } \\
\text { range }\left({ }^{\circ} \mathrm{C}\right)\end{array}$ & $\mathrm{RD}(-)$ & $\mathrm{RP}(\%)$ \\
\hline $40-60$ & 0,00 & 0,00 \\
\hline $60-80$ & 0,89 & 9,07 \\
\hline $80-100$ & 0,35 & 3,60 \\
\hline $100-120$ & 2,22 & $\mathbf{2 2 , 6 2}$ \\
\hline $120-140$ & 0,50 & 5,10 \\
\hline $140-160$ & 3,60 & 36,76 \\
\hline $160-180$ & 0,39 & 3,93 \\
\hline $180-200$ & 1,86 & 18,93 \\
\hline Sum & 9,80 & 100,00 \\
\hline
\end{tabular}

NFA-16 fine compacted

\begin{tabular}{|c|c|c|}
\hline $\begin{array}{c}\text { Temperature } \\
\text { range }\left({ }^{\circ} \mathrm{C}\right)\end{array}$ & $\mathrm{RD}(-)$ & $\mathrm{RP}(\%)$ \\
\hline $40-60$ & 0,00 & 0,00 \\
\hline $60-80$ & 0,60 & 7,19 \\
\hline $80-100$ & 0,67 & 7,99 \\
\hline $100-120$ & 0,95 & $\mathbf{1 1 , 3 8}$ \\
\hline $120-140$ & 2,13 & 25,50 \\
\hline $140-160$ & 1,86 & 22,35 \\
\hline $160-180$ & 0,87 & 10,44 \\
\hline $180-200$ & 1,26 & 15,14 \\
\hline Sum & 8,34 & 100,00 \\
\hline
\end{tabular}




\section{5. $\mathrm{CO}_{2}$ emissions}

NFA-1 coarse no-compacted

\begin{tabular}{|c|c|c|}
\hline $\begin{array}{c}\text { Temperature } \\
\text { range }\left({ }^{\circ} \mathrm{C}\right)\end{array}$ & $\mathrm{RD}(-)$ & $\mathrm{RP}(\%)$ \\
\hline $40-60$ & 0,00 & 0,00 \\
\hline $60-80$ & 0,00 & 0,00 \\
\hline $80-100$ & 0,00 & 0,00 \\
\hline $100-120$ & 0,14 & 3,30 \\
\hline $120-140$ & 0,25 & 5,77 \\
\hline $140-160$ & 1,40 & $\mathbf{3 2 , 3 2}$ \\
\hline $160-180$ & 2,42 & 55,79 \\
\hline $180-200$ & 0,12 & 2,82 \\
\hline Sum & 4,33 & 100,00 \\
\hline
\end{tabular}

NFA-1 fine no compacted

\begin{tabular}{|c|c|c|}
\hline $\begin{array}{c}\text { Temperature } \\
\text { range }\left({ }^{\circ} \mathrm{C}\right)\end{array}$ & $\mathrm{RD}(-)$ & $\mathrm{RP}(\%)$ \\
\hline $40-60$ & 0,13 & 2,85 \\
\hline $60-80$ & 0,00 & 0,00 \\
\hline $80-100$ & 0,67 & $\mathbf{1 5 , 2 2}$ \\
\hline $100-120$ & 0,07 & 1,52 \\
\hline $120-140$ & 1,13 & 25,68 \\
\hline $140-160$ & 0,65 & 14,77 \\
\hline $160-180$ & 0,75 & 17,12 \\
\hline $180-200$ & 1,00 & 22,83 \\
\hline Sum & 4,38 & 100,00 \\
\hline
\end{tabular}

NFA-2 no compacted

\begin{tabular}{|c|c|c|}
\hline $\begin{array}{c}\text { Temperature } \\
\text { range }\left({ }^{\circ} \mathrm{C}\right)\end{array}$ & $\mathrm{RD}(-)$ & $\mathrm{RP}(\%)$ \\
\hline $40-60$ & 0,00 & 0,00 \\
\hline $60-80$ & 0,00 & 0,00 \\
\hline $80-100$ & 1,00 & $\mathbf{1 5 , 4 4}$ \\
\hline $100-120$ & 0,28 & 4,29 \\
\hline $120-140$ & 0,13 & 2,01 \\
\hline $140-160$ & 0,81 & 12,47 \\
\hline $160-180$ & 0,66 & 10,18 \\
\hline $180-200$ & 3,60 & 55,61 \\
\hline Sum & 6,48 & 100,00 \\
\hline
\end{tabular}

NFA-1 fine compacted

\begin{tabular}{|c|c|c|}
\hline $\begin{array}{c}\text { Temperature } \\
\text { range }\left({ }^{\circ} \mathrm{C}\right)\end{array}$ & $\mathrm{RD}(-)$ & $\mathrm{RP}(\%)$ \\
\hline $40-60$ & 0,13 & 2,51 \\
\hline $60-80$ & 0,00 & 0,00 \\
\hline $80-100$ & 0,78 & $\mathbf{1 5 , 5 9}$ \\
\hline $100-120$ & 0,00 & 0,00 \\
\hline $120-140$ & 0,75 & 15,03 \\
\hline $140-160$ & 0,86 & 17,18 \\
\hline $160-180$ & 0,58 & 11,56 \\
\hline $180-200$ & 1,90 & 38,13 \\
\hline Sum & 4,99 & 100,00 \\
\hline
\end{tabular}

NFA-2 compacted

\begin{tabular}{|c|c|c|}
\hline $\begin{array}{c}\text { Temperature } \\
\text { range }\left({ }^{\circ} \mathrm{C}\right)\end{array}$ & $\mathrm{RD}(-)$ & $\mathrm{RP}(\%)$ \\
\hline $40-60$ & 0,00 & 0,00 \\
\hline $60-80$ & 0,00 & 0,00 \\
\hline $80-100$ & 0,00 & 0,00 \\
\hline $100-120$ & 0,00 & 0,00 \\
\hline $120-140$ & 0,71 & $\mathbf{1 6 , 5 5}$ \\
\hline $140-160$ & 0,67 & 15,45 \\
\hline $160-180$ & 2,05 & 47,50 \\
\hline $180-200$ & 0,89 & 20,51 \\
\hline Sum & 4,32 & 100,00 \\
\hline
\end{tabular}


NFA-3 no compacted

\begin{tabular}{|c|c|c|}
\hline $\begin{array}{c}\text { Temperature } \\
\text { range }\left({ }^{\circ} \mathrm{C}\right)\end{array}$ & $\mathrm{RD}(-)$ & $\mathrm{RP}(\%)$ \\
\hline $40-60$ & 0,00 & 0,00 \\
\hline $60-80$ & 0,00 & 0,00 \\
\hline $80-100$ & 1,50 & $\mathbf{2 1 , 6 5}$ \\
\hline $100-120$ & 3,00 & 43,31 \\
\hline $120-140$ & 0,90 & 12,99 \\
\hline $140-160$ & 0,34 & 4,94 \\
\hline $160-180$ & 0,51 & 7,36 \\
\hline $180-200$ & 0,68 & 9,75 \\
\hline Sum & 6,93 & 100,00 \\
\hline
\end{tabular}

NFA-4 coarse no compacted

\begin{tabular}{|c|c|c|}
\hline $\begin{array}{c}\text { Temperature } \\
\text { range }\left({ }^{\circ} \mathrm{C}\right)\end{array}$ & $\mathrm{RD}(-)$ & $\mathrm{RP}(\%)$ \\
\hline $40-60$ & 0,00 & 0,00 \\
\hline $60-80$ & 0,00 & 0,00 \\
\hline $80-100$ & 0,00 & 0,00 \\
\hline $100-120$ & 0,00 & 0,00 \\
\hline $120-140$ & 8,00 & $\mathbf{6 6 , 6 6}$ \\
\hline $140-160$ & 1,44 & 12,04 \\
\hline $160-180$ & 1,18 & 9,85 \\
\hline $180-200$ & 1,38 & 11,46 \\
\hline Sum & 12,00 & 100,00 \\
\hline
\end{tabular}

NFA-4 fine no compacted

\begin{tabular}{|c|c|c|}
\hline $\begin{array}{c}\text { Temperature } \\
\text { range }\left({ }^{\circ} \mathrm{C}\right)\end{array}$ & $\mathrm{RD}(-)$ & $\mathrm{RP}(\%)$ \\
\hline $40-60$ & 0,00 & 0,00 \\
\hline $60-80$ & 0,00 & 0,00 \\
\hline $80-100$ & 0,00 & 0,00 \\
\hline $100-120$ & 0,00 & 0,00 \\
\hline $120-140$ & 5,67 & $\mathbf{6 2 , 4 1}$ \\
\hline $140-160$ & 0,53 & 5,87 \\
\hline $160-180$ & 0,39 & 4,33 \\
\hline $180-200$ & 2,49 & 27,39 \\
\hline Sum & 9,08 & 100,00 \\
\hline
\end{tabular}

NFA-3 compacted

\begin{tabular}{|c|c|c|}
\hline $\begin{array}{c}\text { Temperature } \\
\text { range }\left({ }^{\circ} \mathrm{C}\right)\end{array}$ & $\mathrm{RD}(-)$ & $\mathrm{RP}(\%)$ \\
\hline $40-60$ & 0,00 & 0,00 \\
\hline $60-80$ & 0,00 & 0,00 \\
\hline $80-100$ & 0,45 & 9,13 \\
\hline $100-120$ & 0,75 & $\mathbf{1 5 , 0 6}$ \\
\hline $120-140$ & 0,36 & 7,17 \\
\hline $140-160$ & 0,37 & 7,40 \\
\hline $160-180$ & 1,27 & 25,49 \\
\hline $180-200$ & 1,78 & 35,74 \\
\hline Sum & 4,98 & 100,00 \\
\hline
\end{tabular}

NFA-4 coarse compacted

\begin{tabular}{|c|c|c|}
\hline $\begin{array}{c}\text { Temperature } \\
\text { range }\left({ }^{\circ} \mathrm{C}\right)\end{array}$ & $\mathrm{RD}(-)$ & $\mathrm{RP}(\%)$ \\
\hline $40-60$ & 0,00 & 0,00 \\
\hline $60-80$ & 0,00 & 0,00 \\
\hline $80-100$ & 0,00 & 0,00 \\
\hline $100-120$ & 0,00 & 0,00 \\
\hline $120-140$ & 2,00 & $\mathbf{3 9 , 3 4}$ \\
\hline $140-160$ & 1,67 & 32,79 \\
\hline $160-180$ & 0,75 & 14,75 \\
\hline $180-200$ & 0,67 & 13,11 \\
\hline Sum & 5,08 & 100,00 \\
\hline
\end{tabular}

NFA-4 fine compacted

\begin{tabular}{|c|c|c|}
\hline $\begin{array}{c}\text { Temperature } \\
\text { range }\left({ }^{\circ} \mathrm{C}\right)\end{array}$ & $\mathrm{RD}(-)$ & $\mathrm{RP}(\%)$ \\
\hline $40-60$ & 0,00 & 0,00 \\
\hline $60-80$ & 0,00 & 0,00 \\
\hline $80-100$ & 0,00 & 0,00 \\
\hline $100-120$ & 0,00 & 0,00 \\
\hline $120-140$ & 0,75 & 6,62 \\
\hline $140-160$ & 5,00 & $\mathbf{4 4 , 1 2}$ \\
\hline $160-180$ & 2,33 & 20,59 \\
\hline $180-200$ & 3,25 & 28,68 \\
\hline Sum & 11,33 & 100,00 \\
\hline
\end{tabular}


NFA-5 no compacted

\begin{tabular}{|c|c|c|}
\hline $\begin{array}{c}\text { Temperature } \\
\text { range }\left({ }^{\circ} \mathrm{C}\right)\end{array}$ & $\mathrm{RD}(-)$ & $\mathrm{RP}(\%)$ \\
\hline $40-60$ & 0,00 & 0,00 \\
\hline $60-80$ & 2,13 & $\mathbf{4 1 , 3 8}$ \\
\hline $80-100$ & 0,52 & 10,13 \\
\hline $100-120$ & 0,47 & 9,22 \\
\hline $120-140$ & 0,39 & 7,65 \\
\hline $140-160$ & 0,51 & 9,99 \\
\hline $160-180$ & 0,34 & 6,60 \\
\hline $180-200$ & 0,77 & 15,04 \\
\hline Sum & 5,14 & 100,00 \\
\hline
\end{tabular}

NFA-6 coarse no compacted

\begin{tabular}{|c|c|c|}
\hline $\begin{array}{c}\text { Temperature } \\
\text { range }\left({ }^{\circ} \mathrm{C}\right)\end{array}$ & $\mathrm{RD}(-)$ & $\mathrm{RP}(\%)$ \\
\hline $40-60$ & 0,00 & 0,00 \\
\hline $60-80$ & 0,00 & 0,00 \\
\hline $80-100$ & 0,00 & 0,00 \\
\hline $100-120$ & 0,00 & 0,00 \\
\hline $120-140$ & 2,00 & $\mathbf{1 8 , 1 4}$ \\
\hline $140-160$ & 1,00 & 9,07 \\
\hline $160-180$ & 2,50 & 22,68 \\
\hline $180-200$ & 5,52 & 50,11 \\
\hline Sum & 11,02 & 100,00 \\
\hline
\end{tabular}

NFA-6 fine no compacted

\begin{tabular}{|c|c|c|}
\hline $\begin{array}{c}\text { Temperature } \\
\text { range }\left({ }^{\circ} \mathrm{C}\right)\end{array}$ & $\mathrm{RD}(-)$ & $\mathrm{RP}(\%)$ \\
\hline $40-60$ & 0,00 & 0,00 \\
\hline $60-80$ & 10,00 & $\mathbf{8 0 , 6 4}$ \\
\hline $80-100$ & 0,27 & 2,20 \\
\hline $100-120$ & 0,21 & 1,73 \\
\hline $120-140$ & 0,29 & 2,37 \\
\hline $140-160$ & 0,27 & 2,20 \\
\hline $160-180$ & 1,07 & 8,64 \\
\hline $180-200$ & 0,28 & 2,22 \\
\hline Sum & 12,40 & 100,00 \\
\hline
\end{tabular}

NFA-5 compacted

\begin{tabular}{|c|c|c|}
\hline $\begin{array}{c}\text { Temperature } \\
\text { range }\left({ }^{\circ} \mathrm{C}\right)\end{array}$ & $\mathrm{RD}(-)$ & $\mathrm{RP}(\%)$ \\
\hline $40-60$ & 1,09 & $\mathbf{2 4 , 8 2}$ \\
\hline $60-80$ & 0,61 & 13,85 \\
\hline $80-100$ & 0,11 & 2,46 \\
\hline $100-120$ & 0,12 & 2,77 \\
\hline $120-140$ & 0,63 & 14,34 \\
\hline $140-160$ & 0,95 & 21,54 \\
\hline $160-180$ & 0,23 & 5,30 \\
\hline $180-200$ & 0,66 & 14,92 \\
\hline Sum & 4,40 & 100,00 \\
\hline
\end{tabular}

NFA-6 coarse compacted

\begin{tabular}{|c|c|c|}
\hline $\begin{array}{c}\text { Temperature } \\
\text { range }\left({ }^{\circ} \mathrm{C}\right)\end{array}$ & $\mathrm{RD}(-)$ & $\mathrm{RP}(\%)$ \\
\hline $40-60$ & 0,00 & 0,00 \\
\hline $60-80$ & 0,00 & 0,00 \\
\hline $80-100$ & 0,00 & 0,00 \\
\hline $100-120$ & 0,00 & 0,00 \\
\hline $120-140$ & 0,00 & 0,00 \\
\hline $140-160$ & 3,50 & $\mathbf{5 8 , 4 3}$ \\
\hline $160-180$ & 1,44 & 24,11 \\
\hline $180-200$ & 1,05 & 17,45 \\
\hline Sum & 5,99 & 100,00 \\
\hline
\end{tabular}

NFA-6 fine compacted

\begin{tabular}{|c|c|c|}
\hline $\begin{array}{c}\text { Temperature } \\
\text { range }\left({ }^{\circ} \mathrm{C}\right)\end{array}$ & $\mathrm{RD}(-)$ & $\mathrm{RP}(\%)$ \\
\hline $40-60$ & 0,00 & 0,00 \\
\hline $60-80$ & 0,00 & 0,00 \\
\hline $80-100$ & 6,00 & $\mathbf{6 7 , 6 2}$ \\
\hline $100-120$ & 0,57 & 6,44 \\
\hline $120-140$ & 0,55 & 6,15 \\
\hline $140-160$ & 0,76 & 8,62 \\
\hline $160-180$ & 0,20 & 2,25 \\
\hline $180-200$ & 0,79 & 8,92 \\
\hline Sum & 8,87 & 100,00 \\
\hline
\end{tabular}


NFA-7 coarse no compacted

\begin{tabular}{|c|c|c|}
\hline $\begin{array}{c}\text { Temperature } \\
\text { range }\left({ }^{\circ} \mathrm{C}\right)\end{array}$ & $\mathrm{RD}(-)$ & $\mathrm{RP}(\%)$ \\
\hline $40-60$ & 0,38 & 3,68 \\
\hline $60-80$ & 0,81 & 7,77 \\
\hline $80-100$ & 2,33 & $\mathbf{2 2 , 3 1}$ \\
\hline $100-120$ & 0,30 & 2,87 \\
\hline $120-140$ & 2,92 & 27,95 \\
\hline $140-160$ & 0,53 & 5,06 \\
\hline $160-180$ & 0,09 & 0,86 \\
\hline $180-200$ & 3,08 & 29,50 \\
\hline Sum & 10,46 & 100,00 \\
\hline
\end{tabular}

NFA-7 fine no compacted

\begin{tabular}{|c|c|c|}
\hline $\begin{array}{c}\text { Temperature } \\
\text { range }\left({ }^{\circ} \mathrm{C}\right)\end{array}$ & $\mathrm{RD}(-)$ & $\mathrm{RP}(\%)$ \\
\hline $40-60$ & 2,00 & $\mathbf{1 9 , 7 6}$ \\
\hline $60-80$ & 0,17 & 1,65 \\
\hline $80-100$ & 0,20 & 1,98 \\
\hline $100-120$ & 3,33 & 32,93 \\
\hline $120-140$ & 0,08 & 0,76 \\
\hline $140-160$ & 3,29 & 32,45 \\
\hline $160-180$ & 0,57 & 5,60 \\
\hline $180-200$ & 0,49 & 4,89 \\
\hline Sum & 10,12 & 100,00 \\
\hline
\end{tabular}

NFA-8 no compacted

\begin{tabular}{|c|c|c|}
\hline $\begin{array}{c}\text { Temperature } \\
\text { range }\left({ }^{\circ} \mathrm{C}\right)\end{array}$ & $\mathrm{RD}(-)$ & $\mathrm{RP}(\%)$ \\
\hline $40-60$ & 2,67 & $\mathbf{2 2 , 2 4}$ \\
\hline $60-80$ & 0,73 & 6,07 \\
\hline $80-100$ & 1,33 & 11,12 \\
\hline $100-120$ & 1,86 & 15,49 \\
\hline $120-140$ & 0,50 & 4,17 \\
\hline $140-160$ & 3,83 & 31,97 \\
\hline $160-180$ & 0,14 & 1,15 \\
\hline $180-200$ & 0,93 & 7,78 \\
\hline Sum & 11,99 & 100,00 \\
\hline
\end{tabular}

NFA-7 coarse compacted

\begin{tabular}{|c|c|c|}
\hline $\begin{array}{c}\text { Temperature } \\
\text { range }\left({ }^{\circ} \mathrm{C}\right)\end{array}$ & $\mathrm{RD}(-)$ & $\mathrm{RP}(\%)$ \\
\hline $40-60$ & 5,50 & $\mathbf{3 2 , 4 7}$ \\
\hline $60-80$ & 0,38 & 2,27 \\
\hline $80-100$ & 0,63 & 3,69 \\
\hline $100-120$ & 5,33 & 31,48 \\
\hline $120-140$ & 0,84 & 4,97 \\
\hline $140-160$ & 2,26 & 13,32 \\
\hline $160-180$ & 0,36 & 2,12 \\
\hline $180-200$ & 1,64 & 9,67 \\
\hline Sum & 16,94 & 100,00 \\
\hline
\end{tabular}

NFA-7 fine compacted

\begin{tabular}{|c|c|c|}
\hline $\begin{array}{c}\text { Temperature } \\
\text { range }\left({ }^{\circ} \mathrm{C}\right)\end{array}$ & $\mathrm{RD}(-)$ & $\mathrm{RP}(\%)$ \\
\hline $40-60$ & 0,38 & 3,38 \\
\hline $60-80$ & 0,91 & 8,19 \\
\hline $80-100$ & 3,50 & $\mathbf{3 1 , 5 5}$ \\
\hline $100-120$ & 1,33 & 12,02 \\
\hline $120-140$ & 1,05 & 9,44 \\
\hline $140-160$ & 1,05 & 9,43 \\
\hline $160-180$ & 2,60 & 23,46 \\
\hline $180-200$ & 0,28 & 2,53 \\
\hline Sum & 11,09 & 100,00 \\
\hline
\end{tabular}

NFA-8 compacted

\begin{tabular}{|c|c|c|}
\hline $\begin{array}{c}\text { Temperature } \\
\text { range }\left({ }^{\circ} \mathrm{C}\right)\end{array}$ & $\mathrm{RD}(-)$ & $\mathrm{RP}(\%)$ \\
\hline $40-60$ & 0,00 & 0,00 \\
\hline $60-80$ & 0,50 & 6,78 \\
\hline $80-100$ & 2,33 & $\mathbf{3 1 , 6 2}$ \\
\hline $100-120$ & 0,80 & 10,84 \\
\hline $120-140$ & 1,22 & 16,56 \\
\hline $140-160$ & 0,38 & 5,08 \\
\hline $160-180$ & 0,96 & 13,06 \\
\hline $180-200$ & 1,19 & 16,06 \\
\hline Sum & 7,38 & 100,00 \\
\hline
\end{tabular}


NFA-9 no compacted

\begin{tabular}{|c|c|c|}
\hline $\begin{array}{c}\text { Temperature } \\
\text { range }\left({ }^{\circ} \mathrm{C}\right)\end{array}$ & $\mathrm{RD}(-)$ & $\mathrm{RP}(\%)$ \\
\hline $40-60$ & 1,00 & 9,89 \\
\hline $60-80$ & 1,00 & 9,89 \\
\hline $80-100$ & 2,25 & $\mathbf{2 2 , 2 6}$ \\
\hline $100-120$ & 0,77 & 7,61 \\
\hline $120-140$ & 2,09 & 20,65 \\
\hline $140-160$ & 1,56 & 15,47 \\
\hline $160-180$ & 1,15 & 11,36 \\
\hline $180-200$ & 0,29 & 2,86 \\
\hline Sum & 10,11 & 100,00 \\
\hline
\end{tabular}

NFA-10 coarse no compacted

\begin{tabular}{|c|c|c|}
\hline $\begin{array}{c}\text { Temperature } \\
\text { range }\left({ }^{\circ} \mathrm{C}\right)\end{array}$ & $\mathrm{RD}(-)$ & $\mathrm{RP}(\%)$ \\
\hline $40-60$ & 0,00 & 0,00 \\
\hline $60-80$ & 0,00 & 0,00 \\
\hline $80-100$ & 0,00 & 0,00 \\
\hline $100-120$ & 0,00 & 0,00 \\
\hline $120-140$ & 0,00 & 0,00 \\
\hline $140-160$ & 1,00 & $\mathbf{2 8 , 9 2}$ \\
\hline $160-180$ & 0,33 & 9,64 \\
\hline $180-200$ & 2,13 & 61,45 \\
\hline Sum & 3,46 & 100,00 \\
\hline
\end{tabular}

NFA-10 fine no compacted

\begin{tabular}{|c|c|c|}
\hline $\begin{array}{c}\text { Temperature } \\
\text { range }\left({ }^{\circ} \mathrm{C}\right)\end{array}$ & $\mathrm{RD}(-)$ & $\mathrm{RP}(\%)$ \\
\hline $40-60$ & 0,00 & 0,00 \\
\hline $60-80$ & 0,00 & 0,00 \\
\hline $80-100$ & 0,00 & 0,00 \\
\hline $100-120$ & 0,50 & 9,90 \\
\hline $120-140$ & 1,00 & $\mathbf{1 9 , 7 9}$ \\
\hline $140-160$ & 0,67 & 13,20 \\
\hline $160-180$ & 1,70 & 33,65 \\
\hline $180-200$ & 1,19 & 23,46 \\
\hline Sum & 5,05 & 100,00 \\
\hline
\end{tabular}

NFA-9 compacted

\begin{tabular}{|c|c|c|}
\hline $\begin{array}{c}\text { Temperature } \\
\text { range }\left({ }^{\circ} \mathrm{C}\right)\end{array}$ & $\mathrm{RD}(-)$ & $\mathrm{RP}(\%)$ \\
\hline $40-60$ & 0,00 & 0,00 \\
\hline $60-80$ & 0,00 & 0,00 \\
\hline $80-100$ & 9,00 & $\mathbf{5 8 , 6 8}$ \\
\hline $100-120$ & 1,20 & 7,82 \\
\hline $120-140$ & 2,23 & 14,52 \\
\hline $140-160$ & 1,27 & 8,26 \\
\hline $160-180$ & 1,22 & 7,94 \\
\hline $180-200$ & 0,43 & 2,78 \\
\hline Sum & 15,34 & 100,00 \\
\hline
\end{tabular}

NFA-10 coarse compacted

\begin{tabular}{|c|c|c|}
\hline $\begin{array}{c}\text { Temperature } \\
\text { range }\left({ }^{\circ} \mathrm{C}\right)\end{array}$ & $\mathrm{RD}(-)$ & $\mathrm{RP}(\%)$ \\
\hline $40-60$ & 0,00 & 0,00 \\
\hline $60-80$ & 0,00 & 0,00 \\
\hline $80-100$ & 0,00 & 0,00 \\
\hline $100-120$ & 0,00 & 0,00 \\
\hline $120-140$ & 3,00 & $\mathbf{5 0 , 4 2}$ \\
\hline $140-160$ & 0,25 & 4,20 \\
\hline $160-180$ & 2,20 & 36,97 \\
\hline $180-200$ & 0,50 & 8,40 \\
\hline Sum & 5,95 & 100,00 \\
\hline
\end{tabular}

NFA-10 fine compacted

\begin{tabular}{|c|c|c|}
\hline $\begin{array}{c}\text { Temperature } \\
\text { range }\left({ }^{\circ} \mathrm{C}\right)\end{array}$ & $\mathrm{RD}(-)$ & $\mathrm{RP}(\%)$ \\
\hline $40-60$ & 0,00 & 0,00 \\
\hline $60-80$ & 0,00 & 0,00 \\
\hline $80-100$ & 0,00 & 0,00 \\
\hline $100-120$ & 2,00 & $\mathbf{2 8 , 1 8}$ \\
\hline $120-140$ & 1,67 & 23,49 \\
\hline $140-160$ & 0,25 & 3,52 \\
\hline $160-180$ & 1,50 & 21,14 \\
\hline $180-200$ & 1,68 & 23,67 \\
\hline Sum & 7,10 & 100,00 \\
\hline
\end{tabular}


NFA-11 no compacted

\begin{tabular}{|c|c|c|}
\hline $\begin{array}{c}\text { Temperature } \\
\text { range }\left({ }^{\circ} \mathrm{C}\right)\end{array}$ & $\mathrm{RD}(-)$ & $\mathrm{RP}(\%)$ \\
\hline $40-60$ & 0,00 & 0,00 \\
\hline $60-80$ & 1,00 & $\mathbf{1 2 , 5 8}$ \\
\hline $80-100$ & 1,00 & 12,58 \\
\hline $100-120$ & 1,75 & 22,01 \\
\hline $120-140$ & 1,91 & 24,01 \\
\hline $140-160$ & 0,78 & 9,83 \\
\hline $160-180$ & 0,86 & 10,81 \\
\hline $180-200$ & 0,65 & 8,19 \\
\hline Sum & 7,95 & 100,00 \\
\hline
\end{tabular}

NFA-12 no compacted

\begin{tabular}{|c|c|c|}
\hline $\begin{array}{c}\text { Temperature } \\
\text { range }\left({ }^{\circ} \mathrm{C}\right)\end{array}$ & $\mathrm{RD}(-)$ & $\mathrm{RP}(\%)$ \\
\hline $40-60$ & 0,00 & 0,00 \\
\hline $60-80$ & 0,00 & 0,00 \\
\hline $80-100$ & 0,00 & 0,00 \\
\hline $100-120$ & 0,00 & 0,00 \\
\hline $120-140$ & 3,00 & 44,26 \\
\hline $140-160$ & 1,13 & 16,60 \\
\hline $160-180$ & 2,16 & 31,82 \\
\hline $180-200$ & 0,50 & 7,33 \\
\hline Sum & 6,78 & 100,00 \\
\hline
\end{tabular}

NFA-13 no compacted

\begin{tabular}{|c|c|c|}
\hline $\begin{array}{c}\text { Temperature } \\
\text { range }\left({ }^{\circ} \mathrm{C}\right)\end{array}$ & $\mathrm{RD}(-)$ & $\mathrm{RP}(\%)$ \\
\hline $40-60$ & 0,00 & 0,00 \\
\hline $60-80$ & 0,00 & 0,00 \\
\hline $80-100$ & 0,00 & 0,00 \\
\hline $100-120$ & 0,44 & 2,23 \\
\hline $120-140$ & 16,40 & $\mathbf{8 2 , 1 6}$ \\
\hline $140-160$ & 1,05 & 5,24 \\
\hline $160-180$ & 1,99 & 9,99 \\
\hline $180-200$ & 0,08 & 0,38 \\
\hline Sum & 19,96 & 100,00 \\
\hline
\end{tabular}

NFA-11 compacted

\begin{tabular}{|c|c|c|}
\hline $\begin{array}{c}\text { Temperature } \\
\text { range }\left({ }^{\circ} \mathrm{C}\right)\end{array}$ & $\mathrm{RD}(-)$ & $\mathrm{RP}(\%)$ \\
\hline $40-60$ & 0,00 & 0,00 \\
\hline $60-80$ & 5,00 & $\mathbf{4 1 , 9 2}$ \\
\hline $80-100$ & 0,17 & 1,40 \\
\hline $100-120$ & 1,80 & 15,09 \\
\hline $120-140$ & 0,93 & 7,79 \\
\hline $140-160$ & 0,93 & 7,76 \\
\hline $160-180$ & 0,90 & 7,58 \\
\hline $180-200$ & 2,20 & 18,46 \\
\hline Sum & 11,93 & 100,00 \\
\hline
\end{tabular}

NFA-12 compacted

\begin{tabular}{|c|c|c|}
\hline $\begin{array}{c}\text { Temperature } \\
\text { range }\left({ }^{\circ} \mathrm{C}\right)\end{array}$ & $\mathrm{RD}(-)$ & $\mathrm{RP}(\%)$ \\
\hline $40-60$ & 0,00 & 0,00 \\
\hline $60-80$ & 0,00 & 0,00 \\
\hline $80-100$ & 1,00 & $\mathbf{1 2 , 1 3}$ \\
\hline $100-120$ & 0,00 & 0,00 \\
\hline $120-140$ & 3,00 & 36,40 \\
\hline $140-160$ & 1,06 & 12,89 \\
\hline $160-180$ & 1,85 & 22,43 \\
\hline $180-200$ & 1,33 & 16,14 \\
\hline Sum & 8,24 & 100,00 \\
\hline
\end{tabular}

NFA-13 compacted

\begin{tabular}{|c|c|c|}
\hline $\begin{array}{c}\text { Temperature } \\
\text { range }\left({ }^{\circ} \mathrm{C}\right)\end{array}$ & $\mathrm{RD}(-)$ & $\mathrm{RP}(\%)$ \\
\hline $40-60$ & 0,00 & 0,00 \\
\hline $60-80$ & 0,00 & 0,00 \\
\hline $80-100$ & 0,00 & 0,00 \\
\hline $100-120$ & 3,67 & $\mathbf{3 6 , 0 0}$ \\
\hline $120-140$ & 2,36 & 23,15 \\
\hline $140-160$ & 1,70 & 16,71 \\
\hline $160-180$ & 2,39 & 23,43 \\
\hline $180-200$ & 0,07 & 0,71 \\
\hline Sum & 10,18 & 100,00 \\
\hline
\end{tabular}


NFA-14 coarse no compacted

\begin{tabular}{|c|c|c|}
\hline $\begin{array}{c}\text { Temperature } \\
\text { range }\left({ }^{\circ} \mathrm{C}\right)\end{array}$ & $\mathrm{RD}(-)$ & $\mathrm{RP}(\%)$ \\
\hline $40-60$ & 0,00 & 0,00 \\
\hline $60-80$ & 0,00 & 0,00 \\
\hline $80-100$ & 0,00 & 0,00 \\
\hline $100-120$ & 0,00 & 0,00 \\
\hline $120-140$ & 0,00 & 0,00 \\
\hline $140-160$ & 0,25 & 4,04 \\
\hline $160-180$ & 4,00 & $\mathbf{6 4 , 6 9}$ \\
\hline $180-200$ & 1,93 & 31,27 \\
\hline Sum & 6,18 & 100,00 \\
\hline
\end{tabular}

NFA-14 fine no compacted

\begin{tabular}{|c|c|c|}
\hline $\begin{array}{c}\text { Temperature } \\
\text { range }\left({ }^{\circ} \mathrm{C}\right)\end{array}$ & $\mathrm{RD}(-)$ & $\mathrm{RP}(\%)$ \\
\hline $40-60$ & 0,00 & 0,00 \\
\hline $60-80$ & 0,00 & 0,00 \\
\hline $80-100$ & 0,00 & 0,00 \\
\hline $100-120$ & 0,00 & 0,00 \\
\hline $120-140$ & 0,00 & 0,00 \\
\hline $140-160$ & 0,14 & 7,89 \\
\hline $160-180$ & 0,50 & $\mathbf{2 7 , 6 3}$ \\
\hline $180-200$ & 1,17 & 64,47 \\
\hline Sum & 1,81 & 100,00 \\
\hline
\end{tabular}

NFA-15 coarse no compacted

\begin{tabular}{|c|c|c|}
\hline $\begin{array}{c}\text { Temperature } \\
\text { range }\left({ }^{\circ} \mathrm{C}\right)\end{array}$ & $\mathrm{RD}(-)$ & $\mathrm{RP}(\%)$ \\
\hline $40-60$ & 0,00 & 0,00 \\
\hline $60-80$ & 0,00 & 0,00 \\
\hline $80-100$ & 0,00 & 0,00 \\
\hline $100-120$ & 1,00 & $\mathbf{1 7 , 8 1}$ \\
\hline $120-140$ & 0,75 & 13,36 \\
\hline $140-160$ & 2,14 & 38,17 \\
\hline $160-180$ & 1,09 & 19,43 \\
\hline $180-200$ & 0,63 & 11,23 \\
\hline Sum & 5,61 & 100,00 \\
\hline
\end{tabular}

NFA-14 coarse compacted

\begin{tabular}{|c|c|c|}
\hline $\begin{array}{c}\text { Temperature } \\
\text { range }\left({ }^{\circ} \mathrm{C}\right)\end{array}$ & $\mathrm{RD}(-)$ & $\mathrm{RP}(\%)$ \\
\hline $40-60$ & 0,00 & 0,00 \\
\hline $60-80$ & 0,00 & 0,00 \\
\hline $80-100$ & 0,00 & 0,00 \\
\hline $100-120$ & 0,00 & 0,00 \\
\hline $120-140$ & 0,00 & 0,00 \\
\hline $140-160$ & 0,00 & 0,00 \\
\hline $160-180$ & 6,50 & $\mathbf{6 4 , 7 8}$ \\
\hline $180-200$ & 3,53 & 35,22 \\
\hline Sum & 10,03 & 100,00 \\
\hline
\end{tabular}

NFA-14 fine compacted

\begin{tabular}{|c|c|c|}
\hline $\begin{array}{c}\text { Temperature } \\
\text { range }\left({ }^{\circ} \mathrm{C}\right)\end{array}$ & $\mathrm{RD}(-)$ & $\mathrm{RP}(\%)$ \\
\hline $40-60$ & 0,00 & 0,00 \\
\hline $60-80$ & 0,00 & 0,00 \\
\hline $80-100$ & 0,00 & 0,00 \\
\hline $100-120$ & 0,00 & 0,00 \\
\hline $120-140$ & 0,00 & 0,00 \\
\hline $140-160$ & 0,00 & 0,00 \\
\hline $160-180$ & 3,75 & $\mathbf{7 6 , 8 2}$ \\
\hline $180-200$ & 1,13 & 23,18 \\
\hline Sum & 4,88 & 100,00 \\
\hline
\end{tabular}

NFA-15 coarse compacted

\begin{tabular}{|c|c|c|}
\hline $\begin{array}{c}\text { Temperature } \\
\text { range }\left({ }^{\circ} \mathrm{C}\right)\end{array}$ & $\mathrm{RD}(-)$ & $\mathrm{RP}(\%)$ \\
\hline $40-60$ & 0,00 & 0,00 \\
\hline $60-80$ & 0,00 & 0,00 \\
\hline $80-100$ & 0,00 & 0,00 \\
\hline $100-120$ & 1,00 & $\mathbf{1 5 , 6 5}$ \\
\hline $120-140$ & 1,50 & 23,47 \\
\hline $140-160$ & 0,80 & 12,52 \\
\hline $160-180$ & 2,67 & 41,73 \\
\hline $180-200$ & 0,42 & 6,64 \\
\hline Sum & 6,39 & 100,00 \\
\hline
\end{tabular}


NFA-15 fine no compacted

\begin{tabular}{|c|c|c|}
\hline $\begin{array}{c}\text { Temperature } \\
\text { range }\left({ }^{\circ} \mathrm{C}\right)\end{array}$ & $\mathrm{RD}(-)$ & $\mathrm{RP}(\%)$ \\
\hline $40-60$ & 0,00 & 0,00 \\
\hline $60-80$ & 0,00 & 0,00 \\
\hline $80-100$ & 0,00 & 0,00 \\
\hline $100-120$ & 0,00 & 0,00 \\
\hline $120-140$ & 0,00 & 0,00 \\
\hline $140-160$ & 1,11 & $\mathbf{2 1 , 3 8}$ \\
\hline $160-180$ & 1,16 & 22,29 \\
\hline $180-200$ & 2,93 & 56,33 \\
\hline Sum & 5,20 & 100,00 \\
\hline
\end{tabular}

NFA-16 coarse no compacted

\begin{tabular}{|c|c|c|}
\hline $\begin{array}{c}\text { Temperature } \\
\text { range }\left({ }^{\circ} \mathrm{C}\right)\end{array}$ & $\mathrm{RD}(-)$ & $\mathrm{RP}(\%)$ \\
\hline $40-60$ & 0,00 & 0,00 \\
\hline $60-80$ & 0,00 & 0,00 \\
\hline $80-100$ & 0,00 & 0,00 \\
\hline $100-120$ & 0,00 & 0,00 \\
\hline $120-140$ & 0,00 & 0,00 \\
\hline $140-160$ & 0,33 & 9,40 \\
\hline $160-180$ & 2,63 & $\mathbf{7 4 , 0 6}$ \\
\hline $180-200$ & 0,59 & 16,54 \\
\hline Sum & 3,54 & 100,00 \\
\hline
\end{tabular}

NFA-16 fine no compacted

\begin{tabular}{|c|c|c|}
\hline $\begin{array}{c}\text { Temperature } \\
\text { range }\left({ }^{\circ} \mathrm{C}\right)\end{array}$ & $\mathrm{RD}(-)$ & $\mathrm{RP}(\%)$ \\
\hline $40-60$ & 0,00 & 0,00 \\
\hline $60-80$ & 0,00 & 0,00 \\
\hline $80-100$ & 0,00 & 0,00 \\
\hline $100-120$ & 0,00 & 0,00 \\
\hline $120-140$ & 1,00 & 8,28 \\
\hline $140-160$ & 6,50 & $\mathbf{5 3 , 7 9}$ \\
\hline $160-180$ & 4,33 & 35,86 \\
\hline $180-200$ & 0,25 & 2,07 \\
\hline Sum & 12,08 & 100,00 \\
\hline
\end{tabular}

NFA-15 fine compacted

\begin{tabular}{|c|c|c|}
\hline $\begin{array}{c}\text { Temperature } \\
\text { range }\left({ }^{\circ} \mathrm{C}\right)\end{array}$ & $\mathrm{RD}(-)$ & $\mathrm{RP}(\%)$ \\
\hline $40-60$ & 0,00 & 0,00 \\
\hline $60-80$ & 0,00 & 0,00 \\
\hline $80-100$ & 0,00 & 0,00 \\
\hline $100-120$ & 0,00 & 0,00 \\
\hline $120-140$ & 0,00 & 0,00 \\
\hline $140-160$ & 1,00 & 19,87 \\
\hline $160-180$ & 0,67 & 13,25 \\
\hline $180-200$ & 3,37 & 66,89 \\
\hline Sum & 5,03 & 100,00 \\
\hline
\end{tabular}

NFA-16 coarse compacted

\begin{tabular}{|c|c|c|}
\hline $\begin{array}{c}\text { Temperature } \\
\text { range }\left({ }^{\circ} \mathrm{C}\right)\end{array}$ & $\mathrm{RD}(-)$ & $\mathrm{RP}(\%)$ \\
\hline $40-60$ & 0,00 & 0,00 \\
\hline $60-80$ & 0,00 & 0,00 \\
\hline $80-100$ & 0,00 & 0,00 \\
\hline $100-120$ & 0,00 & 0,00 \\
\hline $120-140$ & 2,00 & $\mathbf{2 1 , 7 9}$ \\
\hline $140-160$ & 5,33 & 58,10 \\
\hline $160-180$ & 0,26 & 2,87 \\
\hline $180-200$ & 1,58 & 17,25 \\
\hline Sum & 9,18 & 100,00 \\
\hline
\end{tabular}

NFA-16 fine compacted

\begin{tabular}{|c|c|c|}
\hline $\begin{array}{c}\text { Temperature } \\
\text { range }\left({ }^{\circ} \mathrm{C}\right)\end{array}$ & $\mathrm{RD}(-)$ & $\mathrm{RP}(\%)$ \\
\hline $40-60$ & 0,00 & 0,00 \\
\hline $60-80$ & 0,00 & 0,00 \\
\hline $80-100$ & 0,00 & 0,00 \\
\hline $100-120$ & 0,00 & 0,00 \\
\hline $120-140$ & 0,00 & 0,00 \\
\hline $140-160$ & 2,67 & $\mathbf{5 8 , 9 3}$ \\
\hline $160-180$ & 0,73 & 16,07 \\
\hline $180-200$ & 1,13 & 25,00 \\
\hline Sum & 4,53 & 100,00 \\
\hline
\end{tabular}




\section{Graphs of inflexion points method gas emissions test}

NFA-1 coarse no compacted

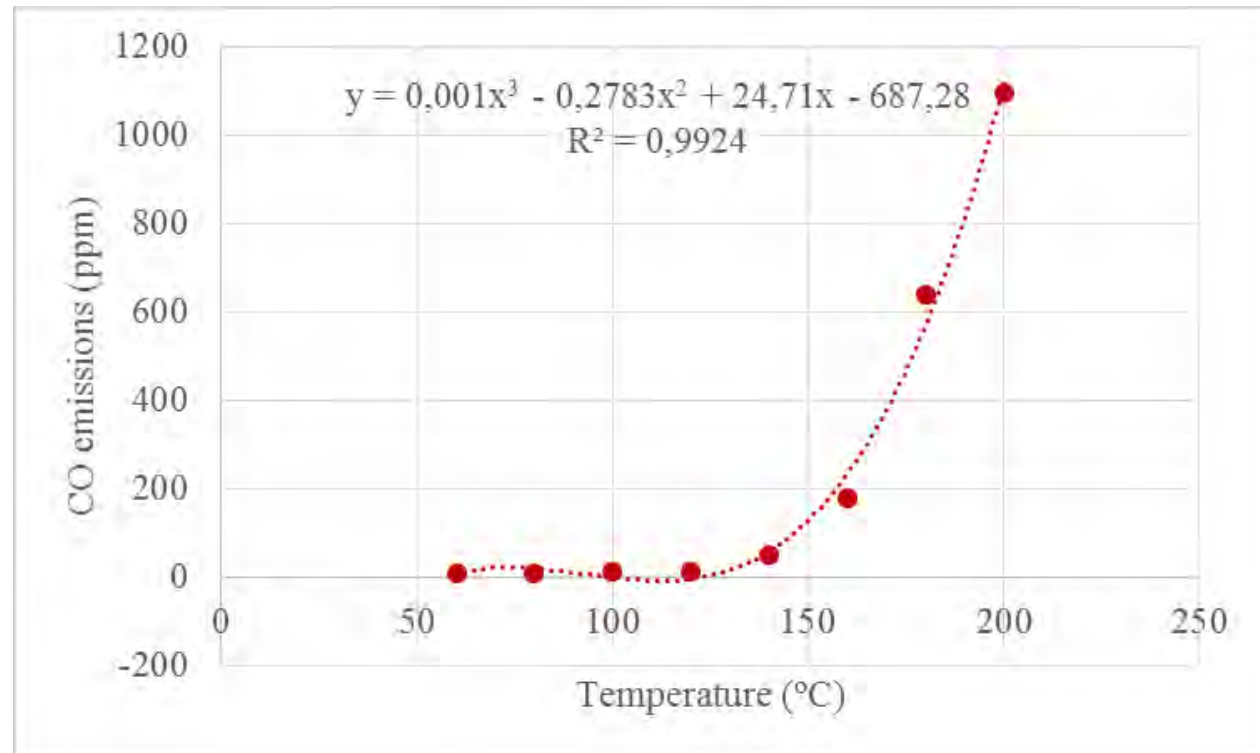

NFA-1 fine no compacted

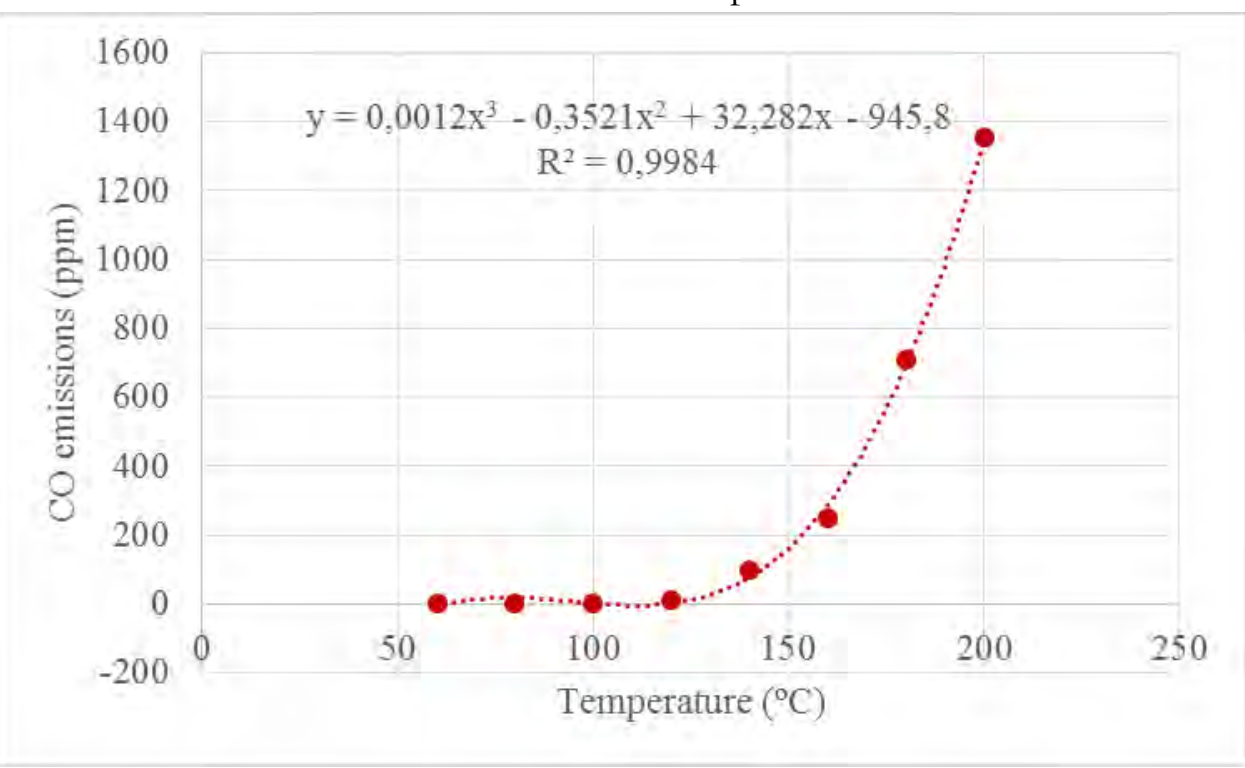

NFA-1 fine compacted

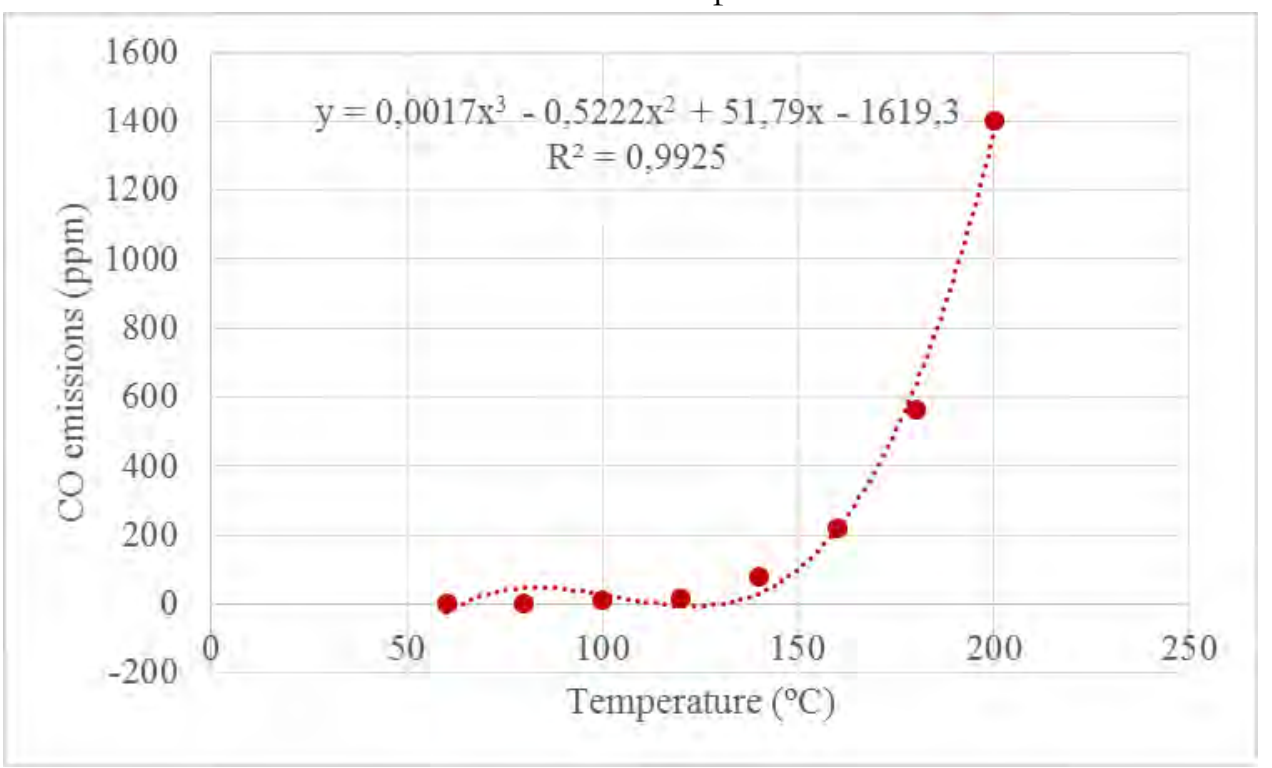


NFA-2 no compacted

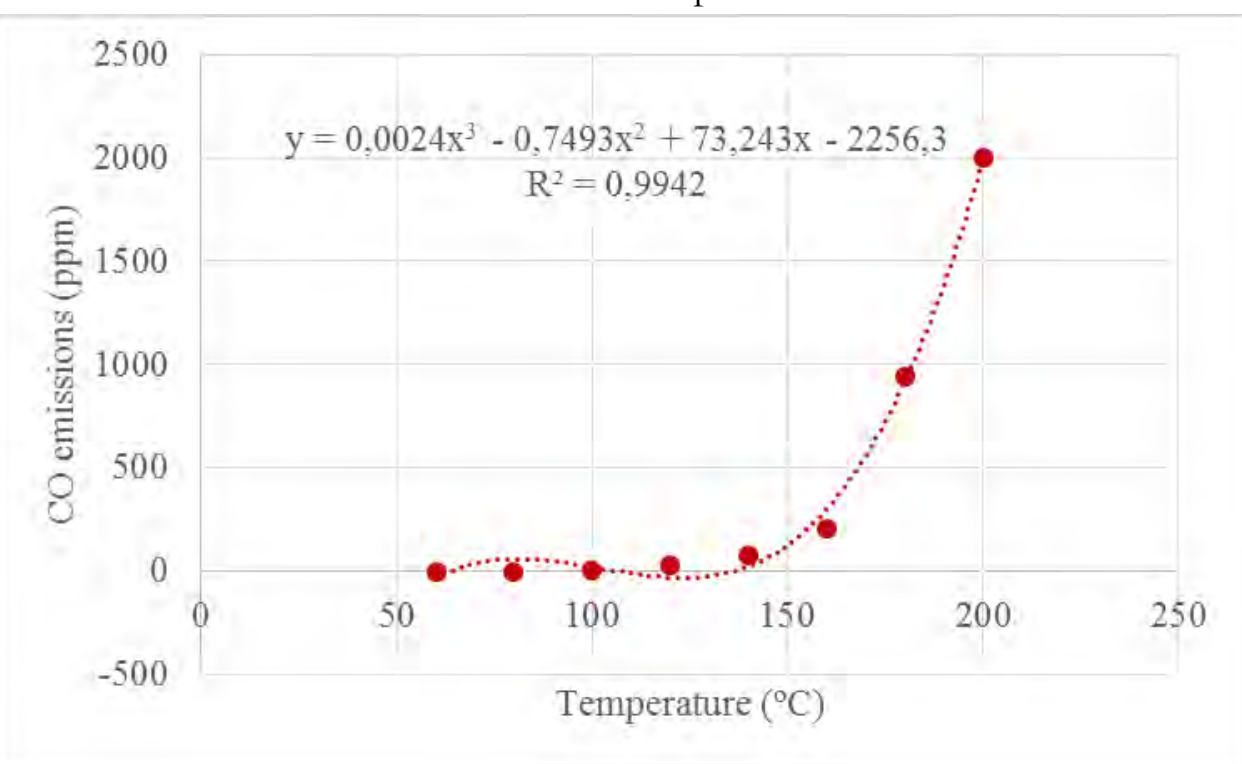

NFA-3 no compacted

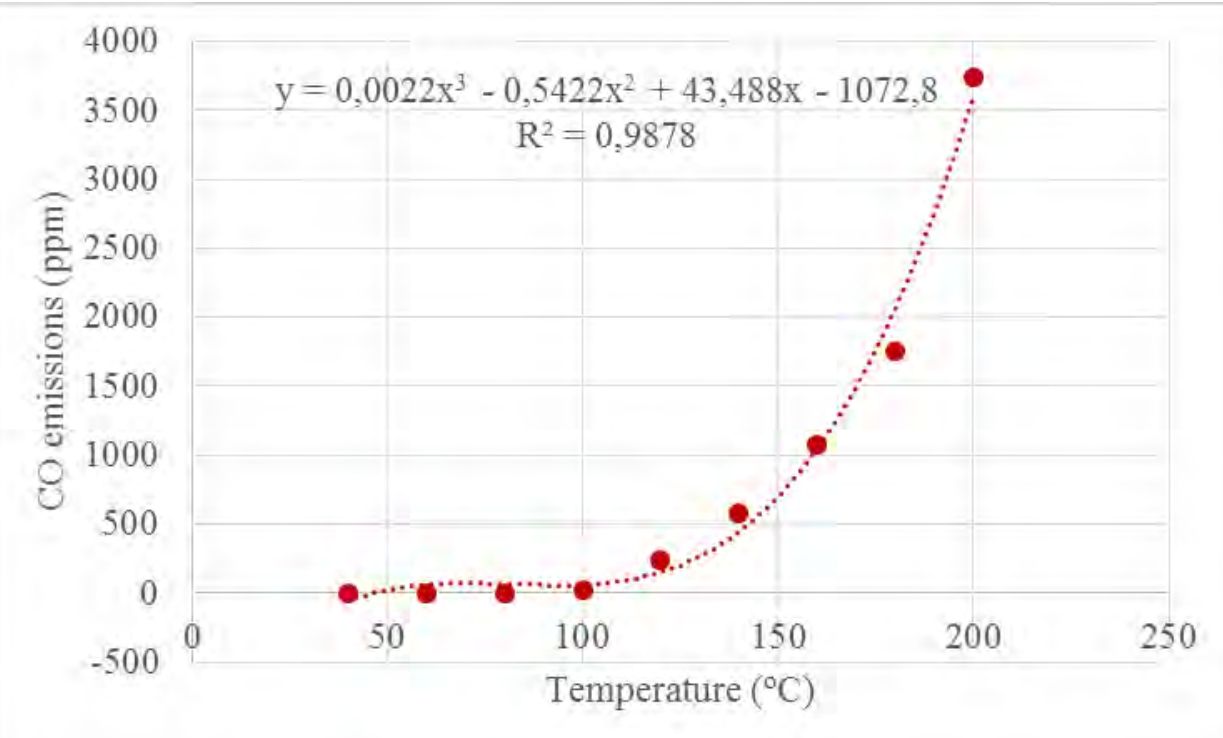

NFA-4 coarse no compacted
NFA-2 compacted

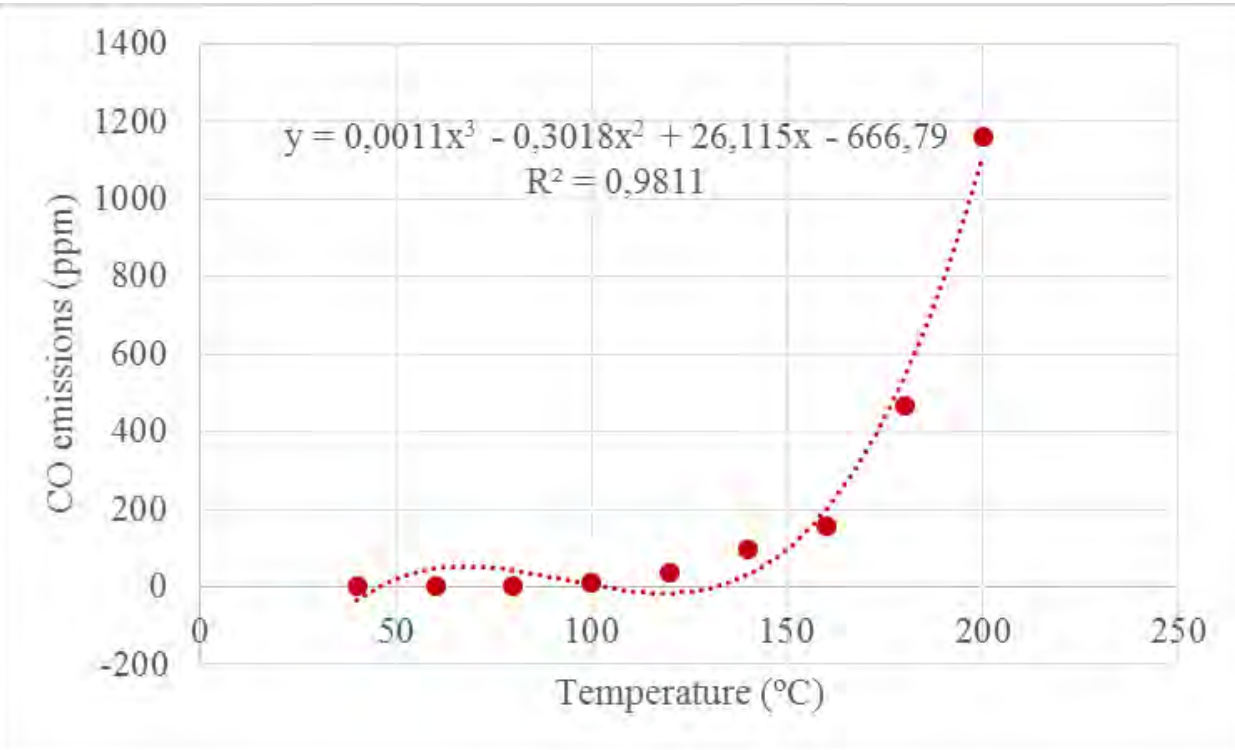

NFA-3 compacted

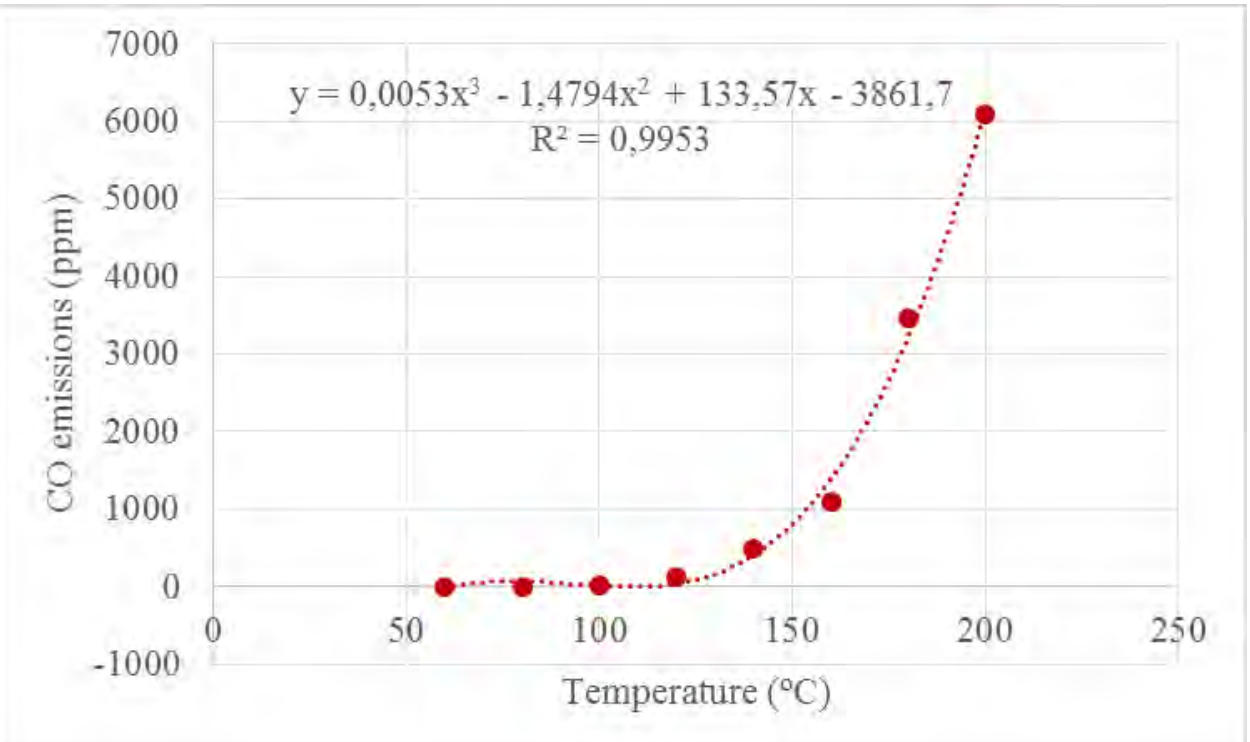



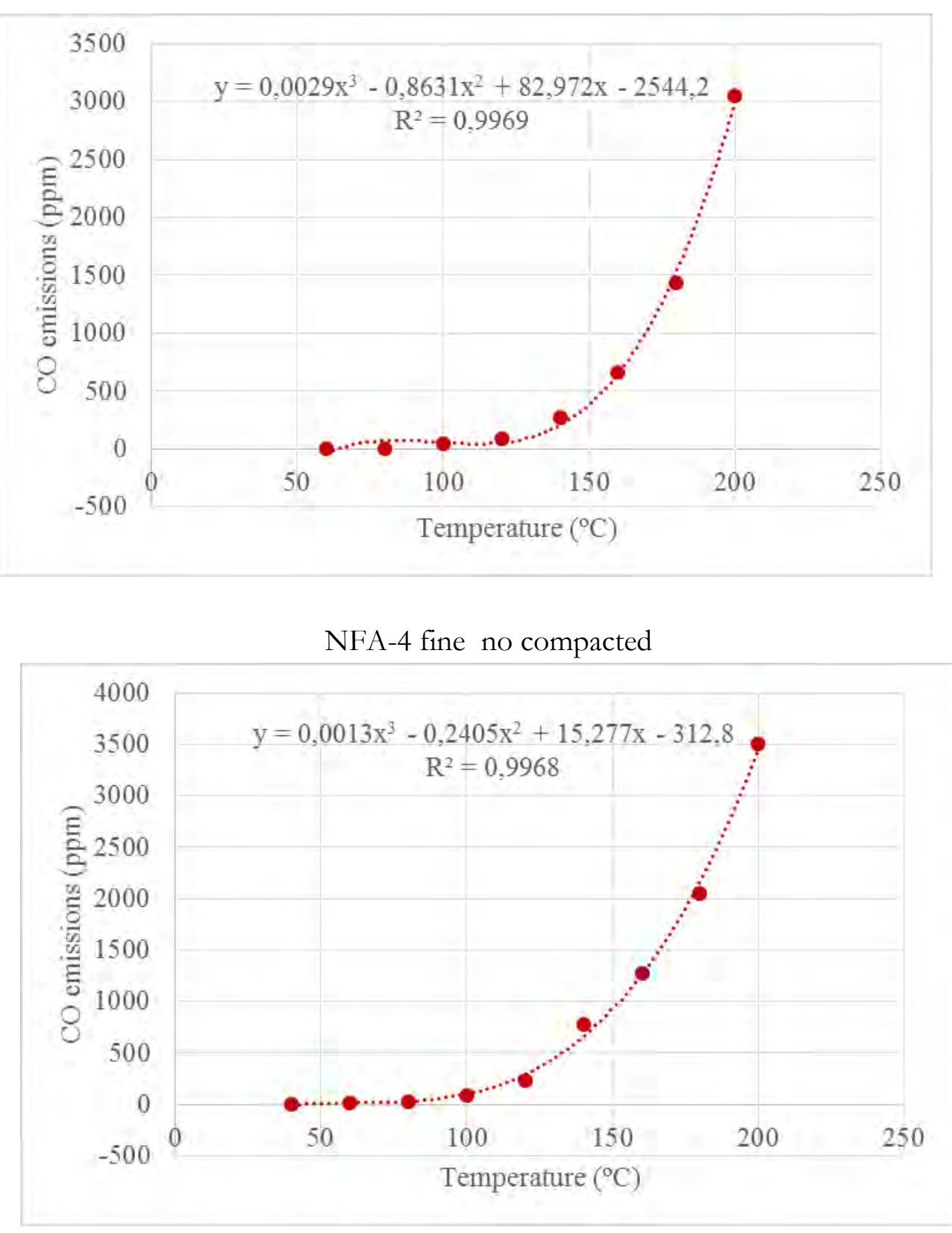

NFA-5 no compacted
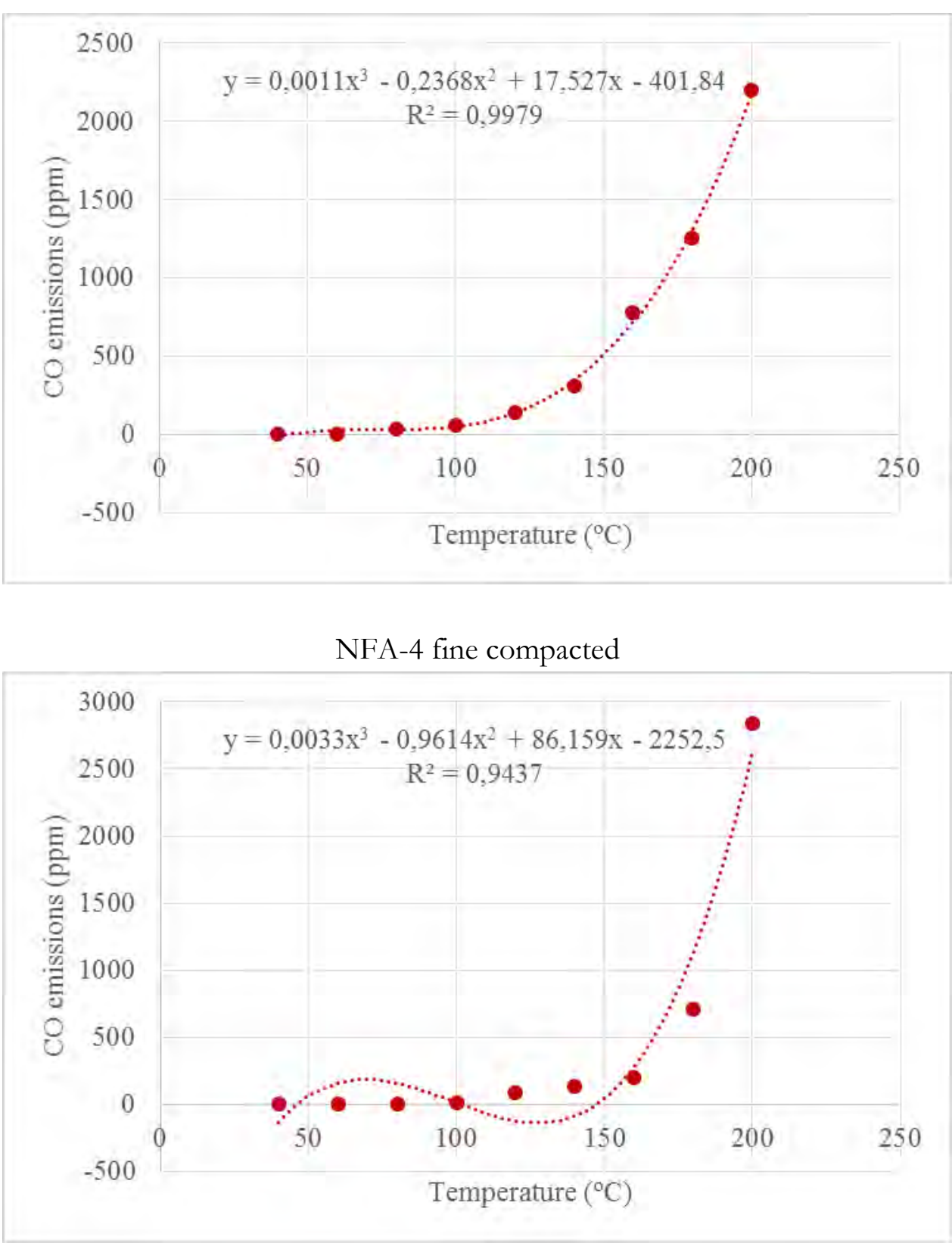

NFA-5 compacted 

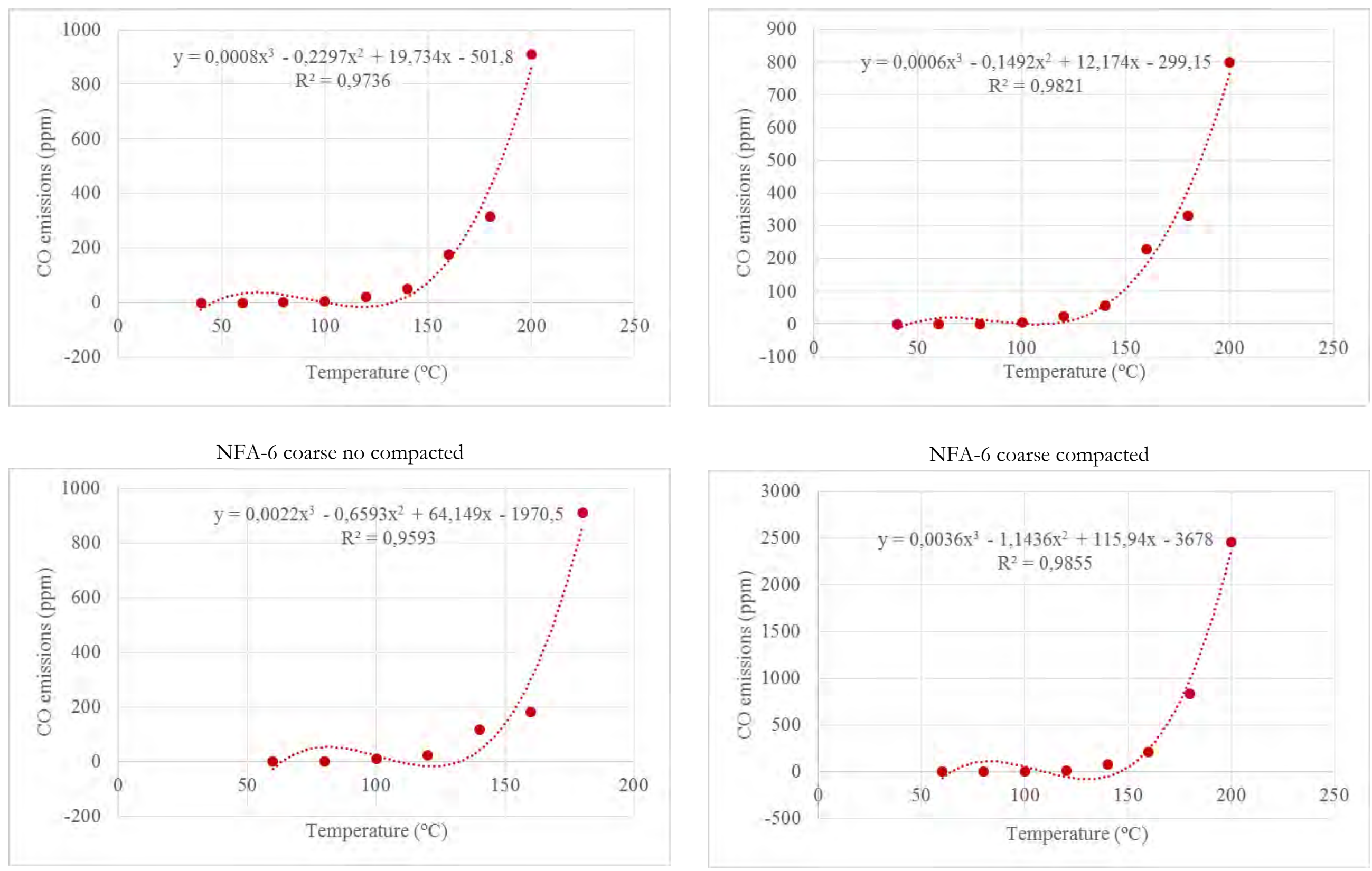

NFA-6 fine no compacted

NFA-6 fine compacted 


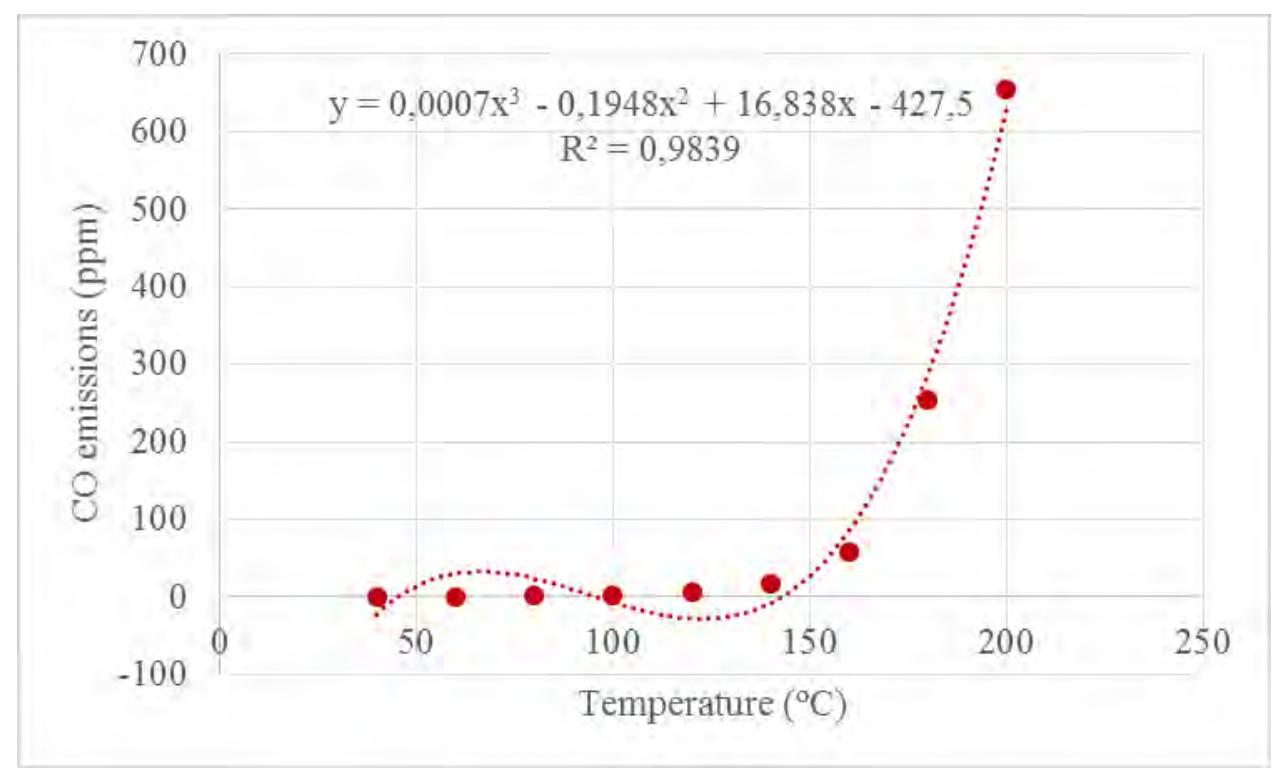

NFA-7 coarse no compacted

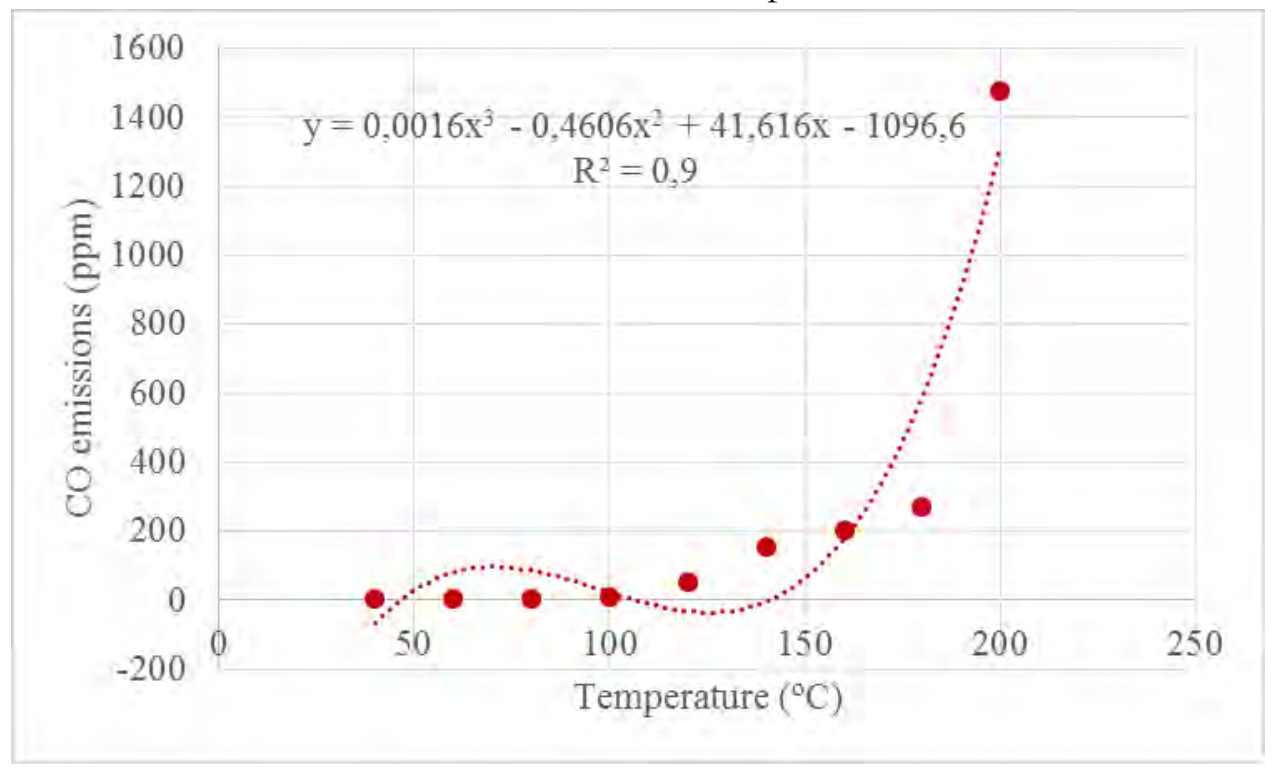

NFA-7 fine no compacted

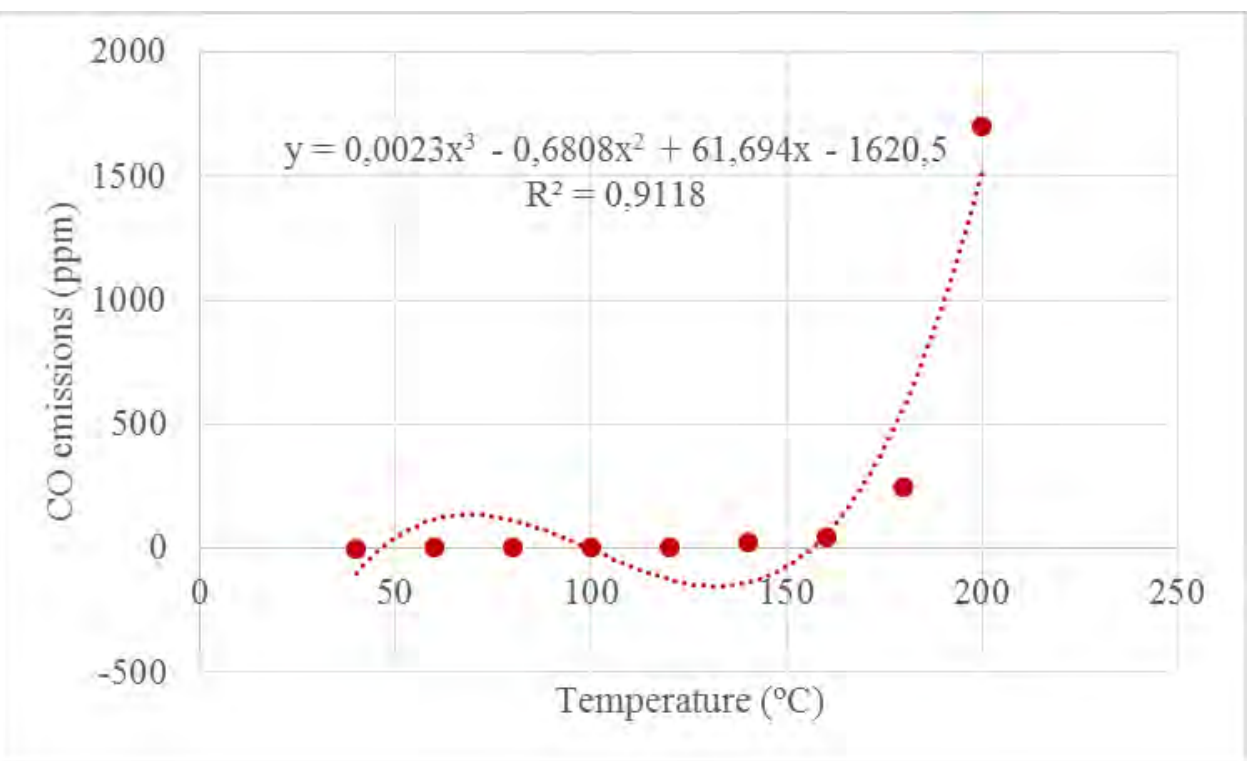

NFA-7 coarse compacted

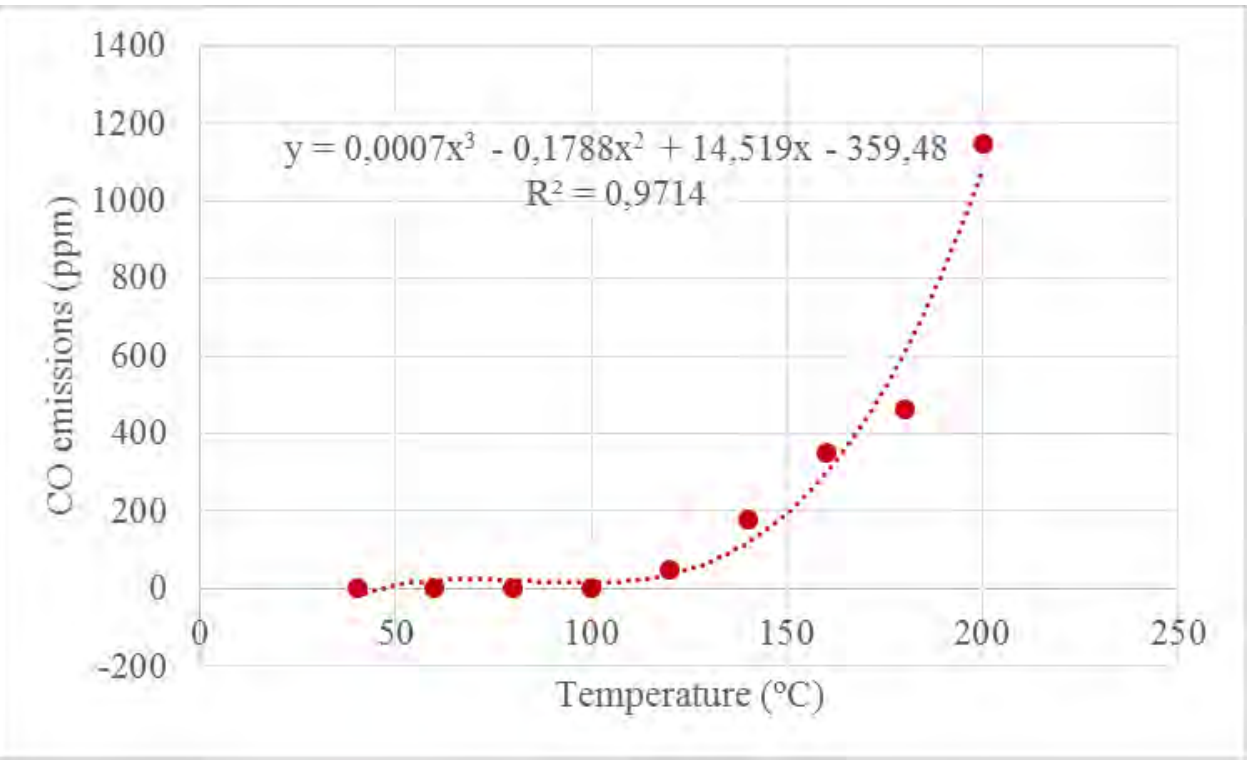

NFA-7 fine compacted 

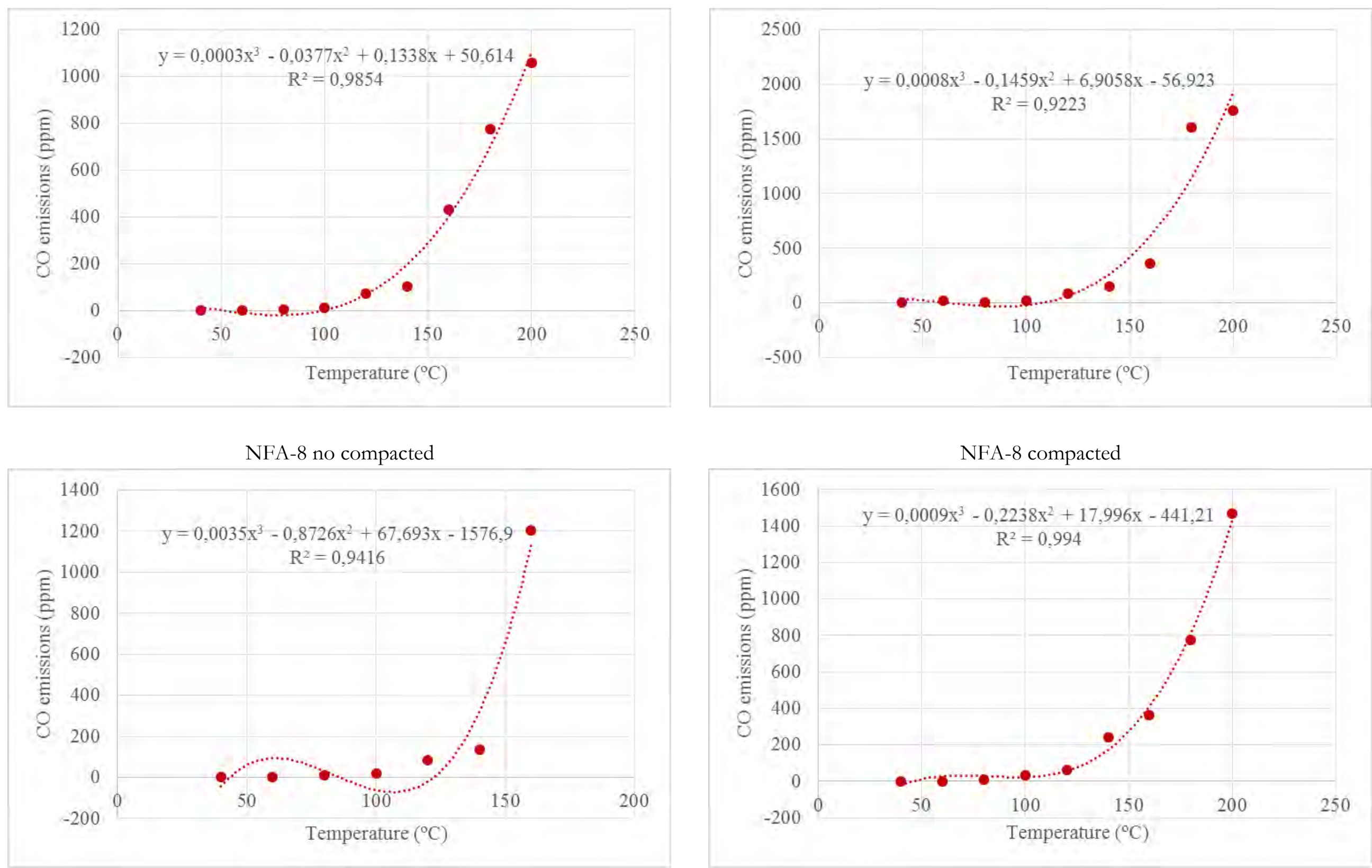

NFA-9 no compacted

NFA-9 compacted 

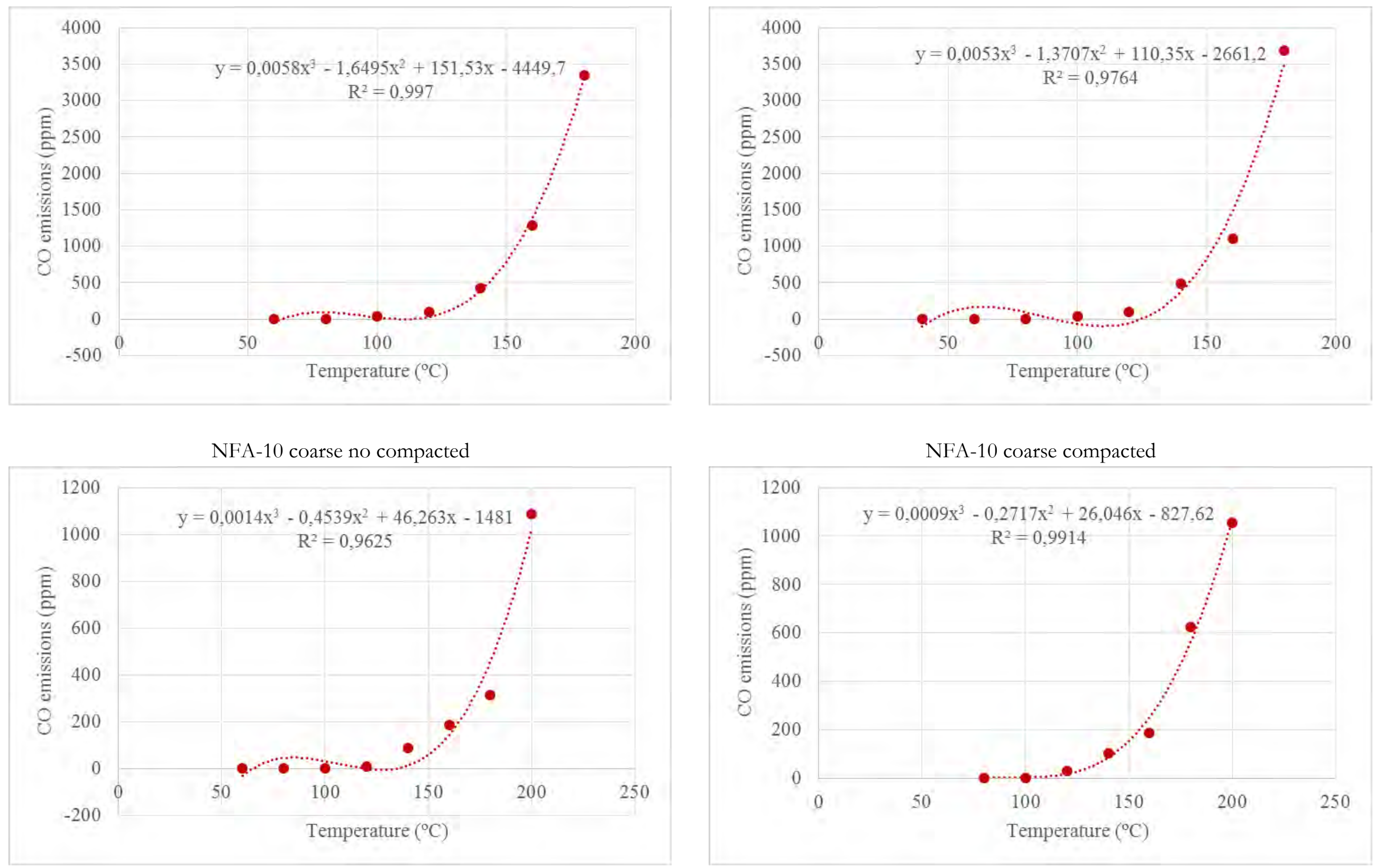

NFA-10 fine no compacted

NFA-10 fine compacted 

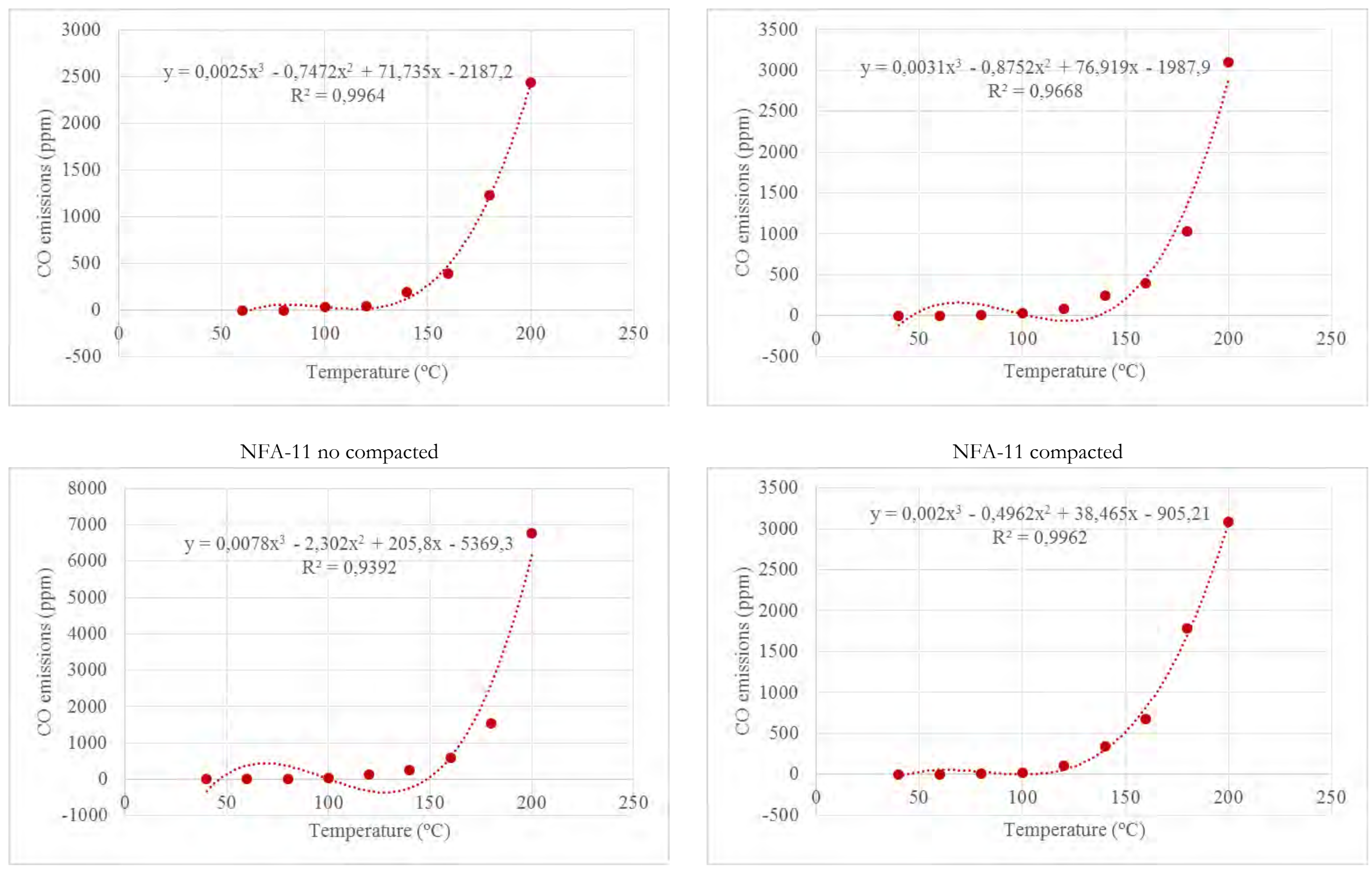

NFA-12 no compacted

NFA-12 compacted 

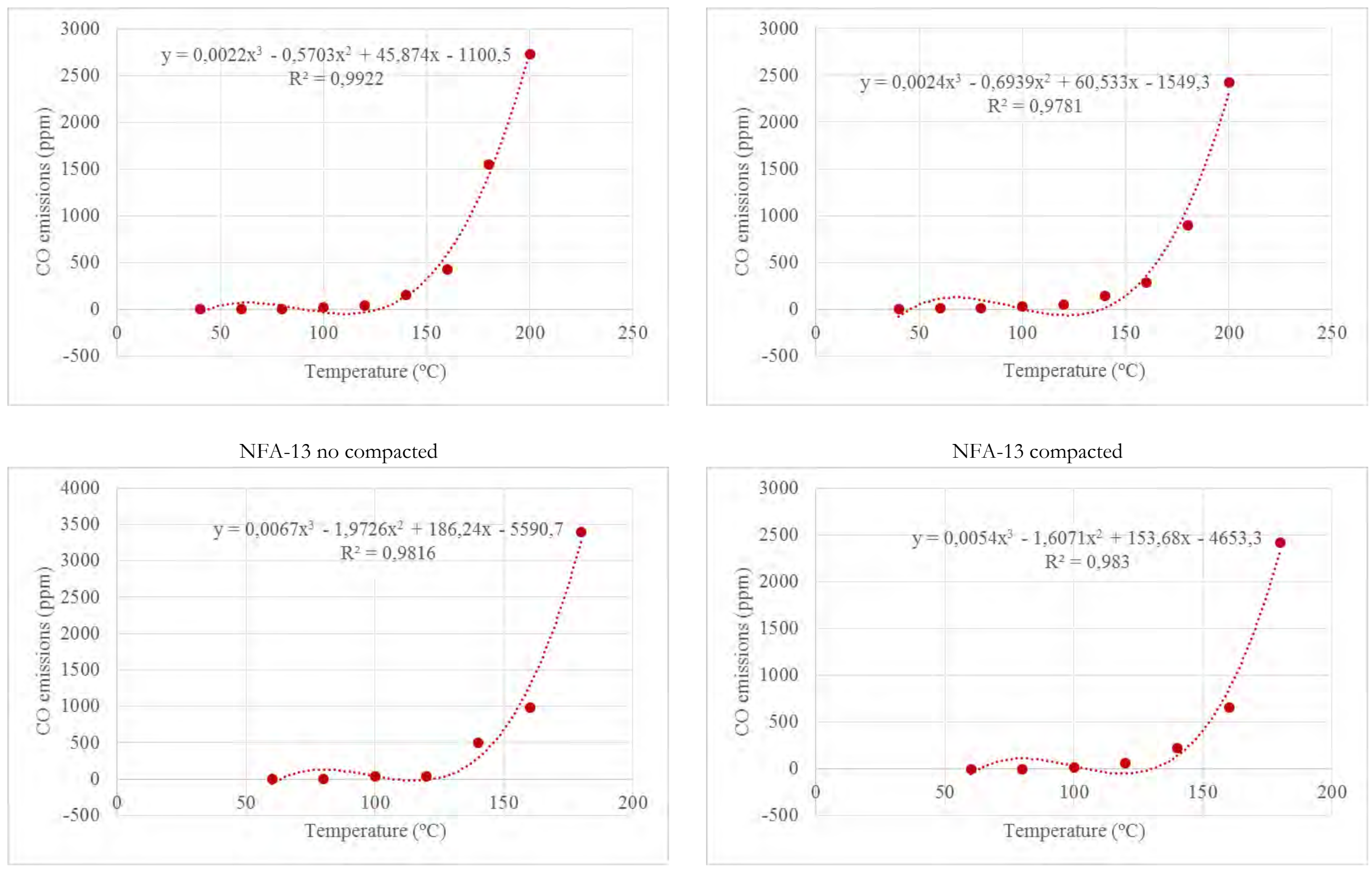

NFA-14 coarse no compacted

NFA-14 coarse compacted 

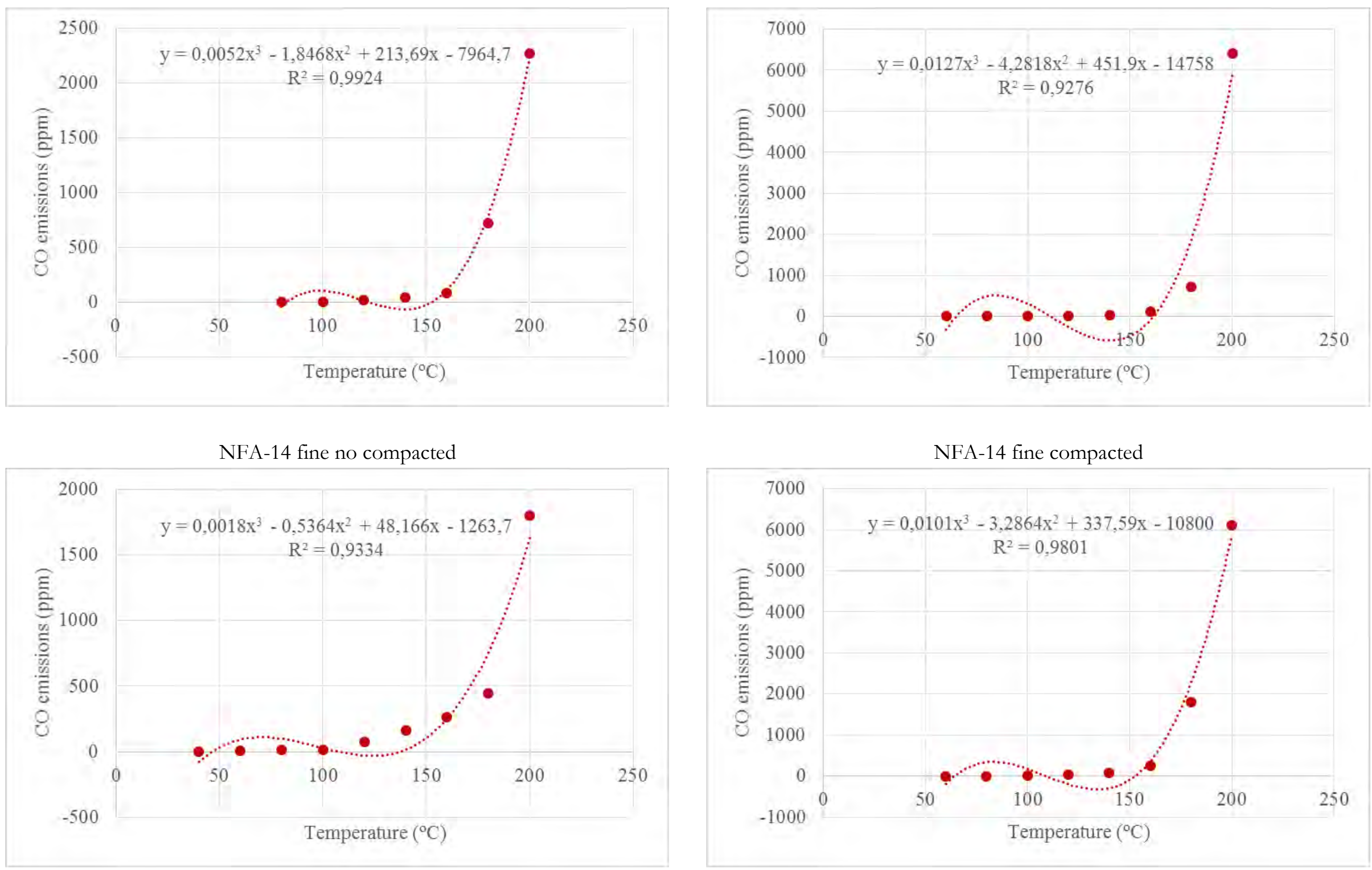

NFA-15 coarse no compacted

NFA-15 coarse compacted 

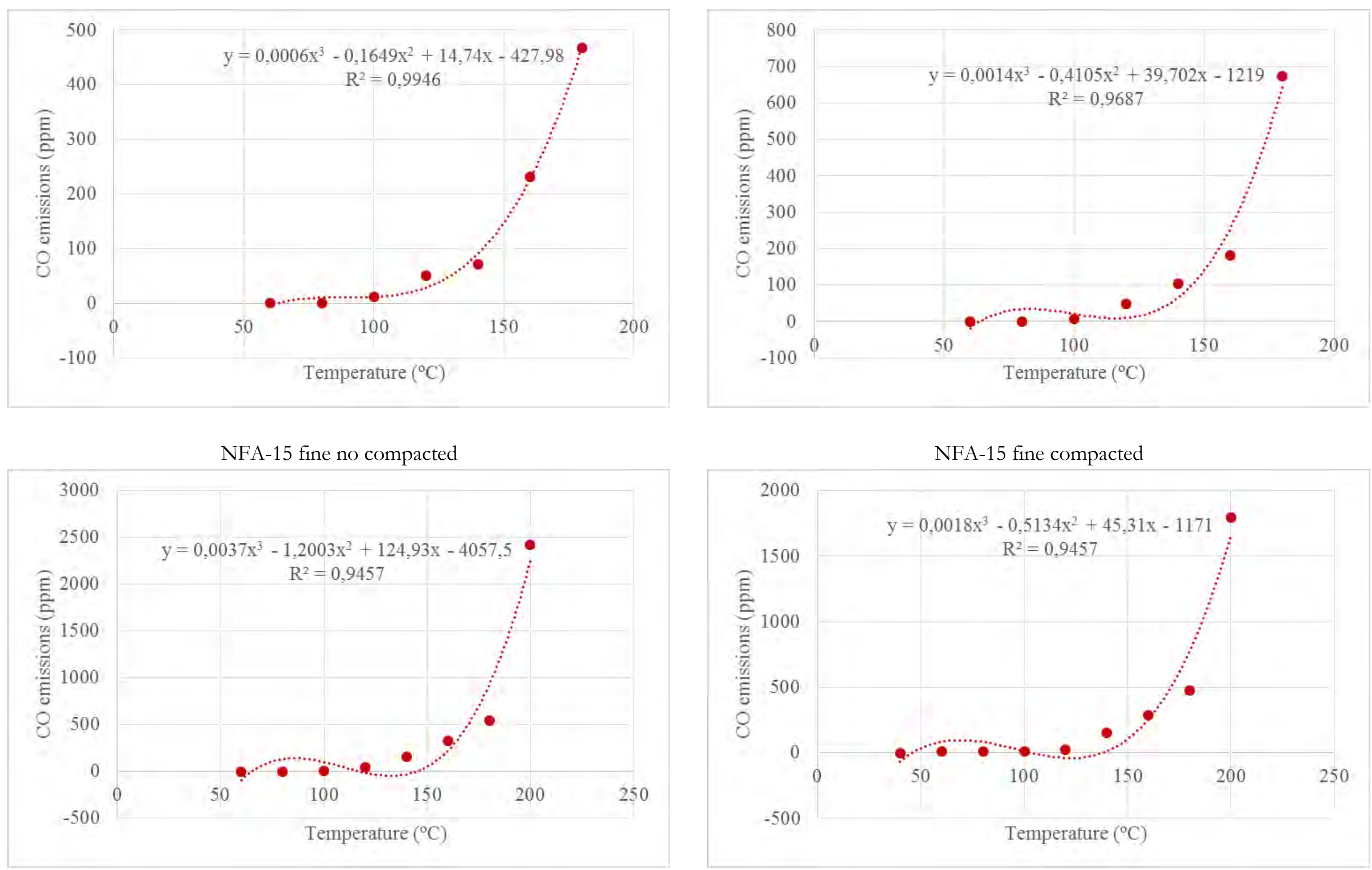

NFA-16 coarse no compacted

NFA-16 coarse compacted 

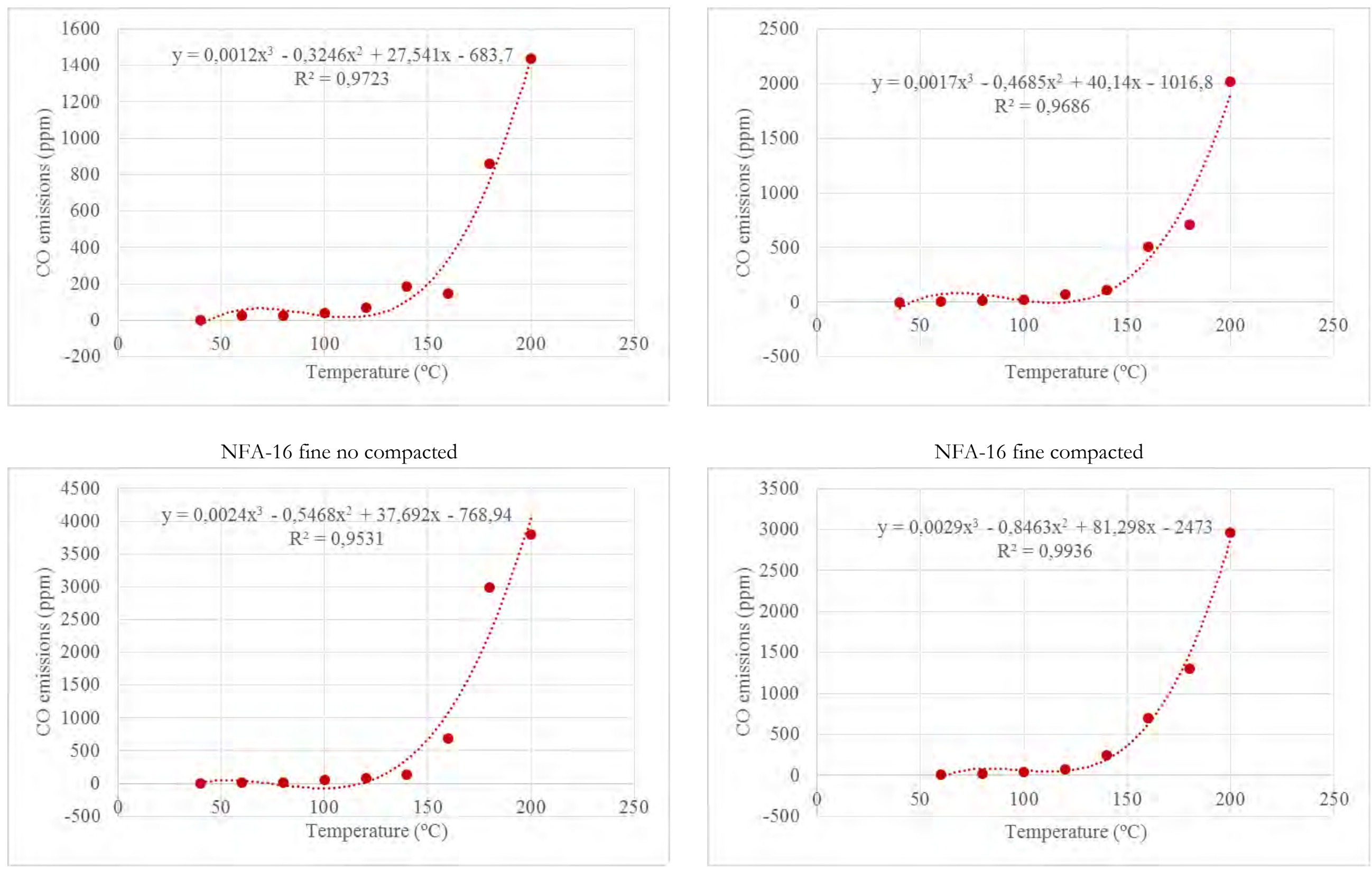


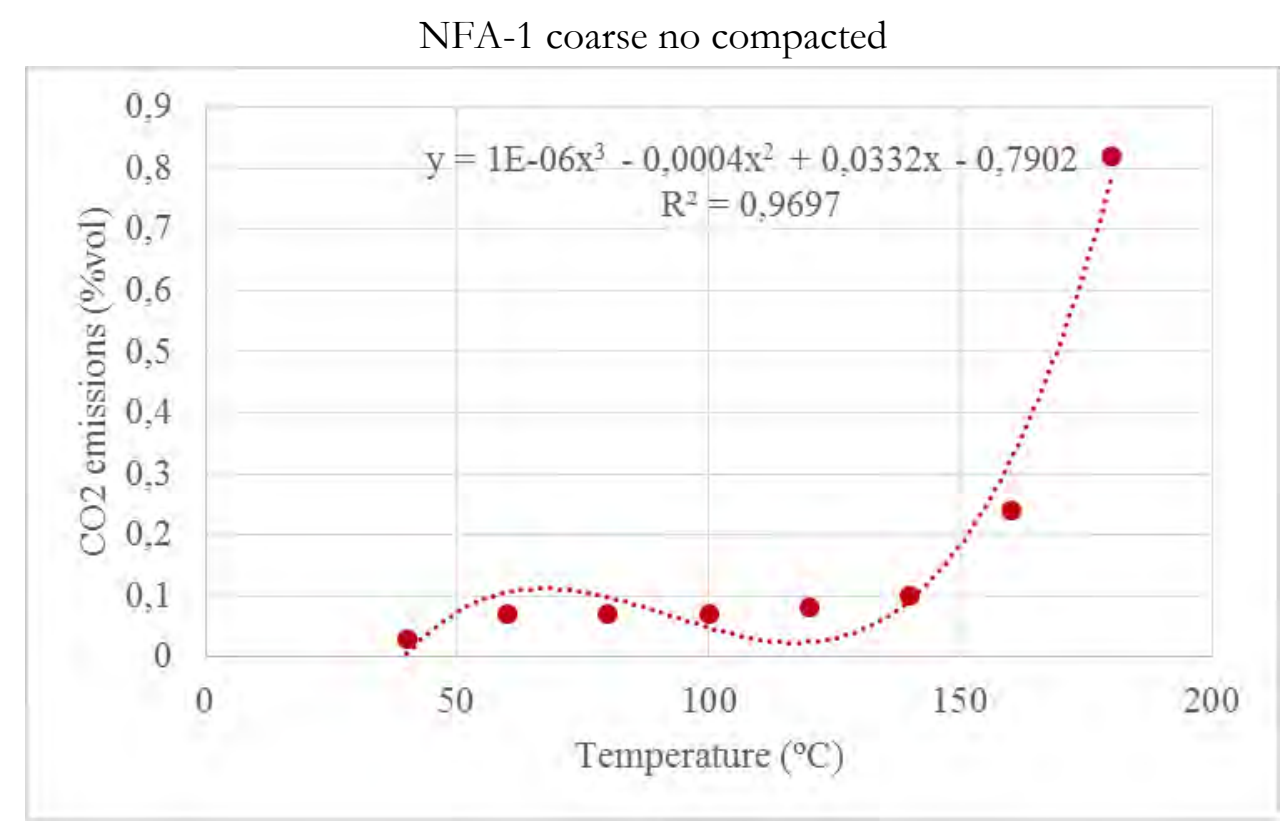

NFA-1 fine no compacted
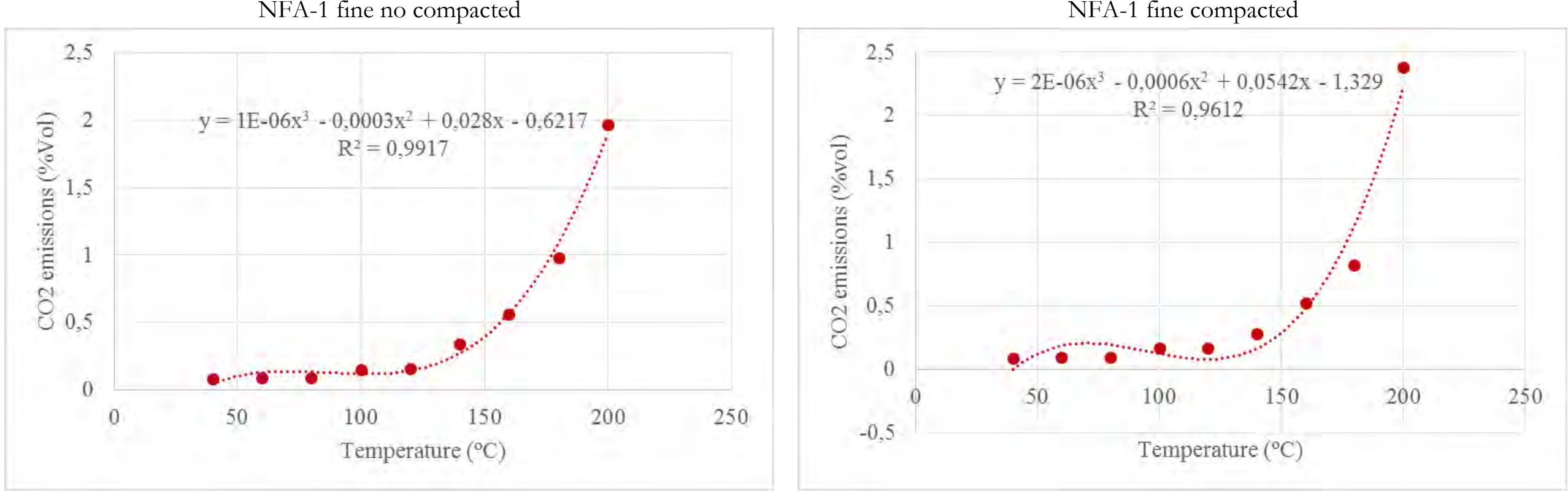

NFA-2 no compacted

NFA-2 compacted 

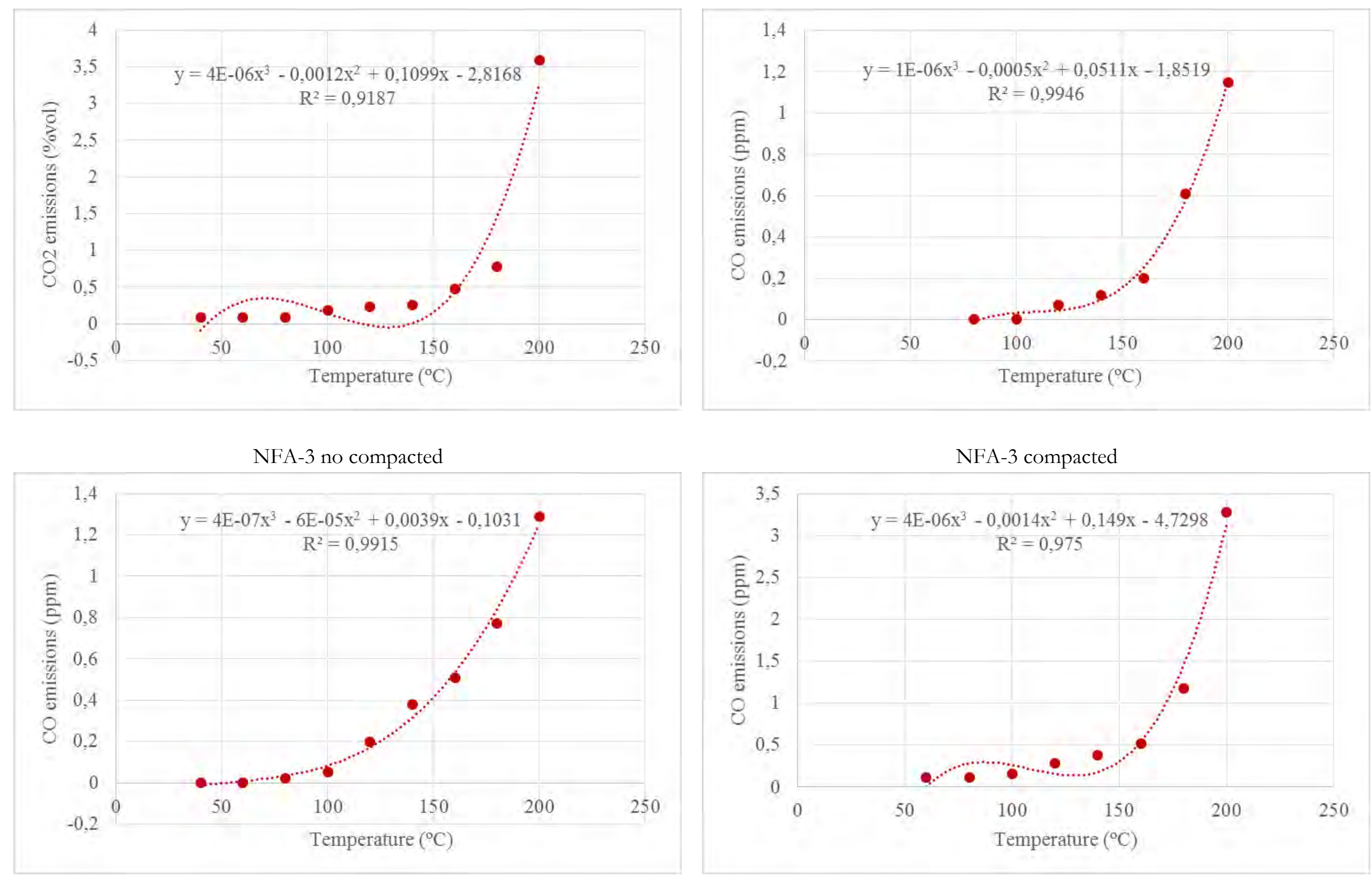

NFA-4 coarse no compacted

NFA-4 coarse compacted 

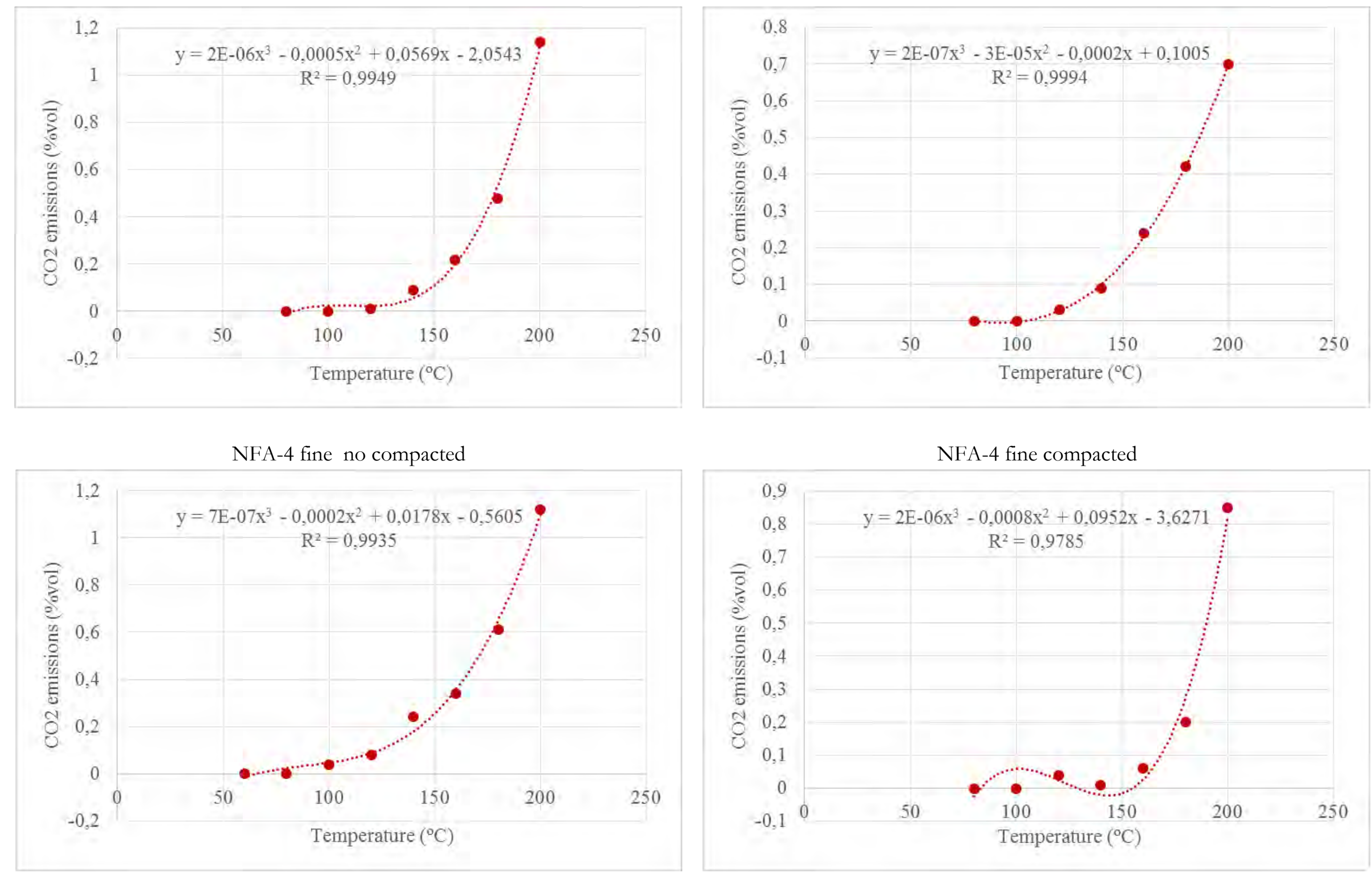

NFA-5 no compacted

NFA-5 compacted 

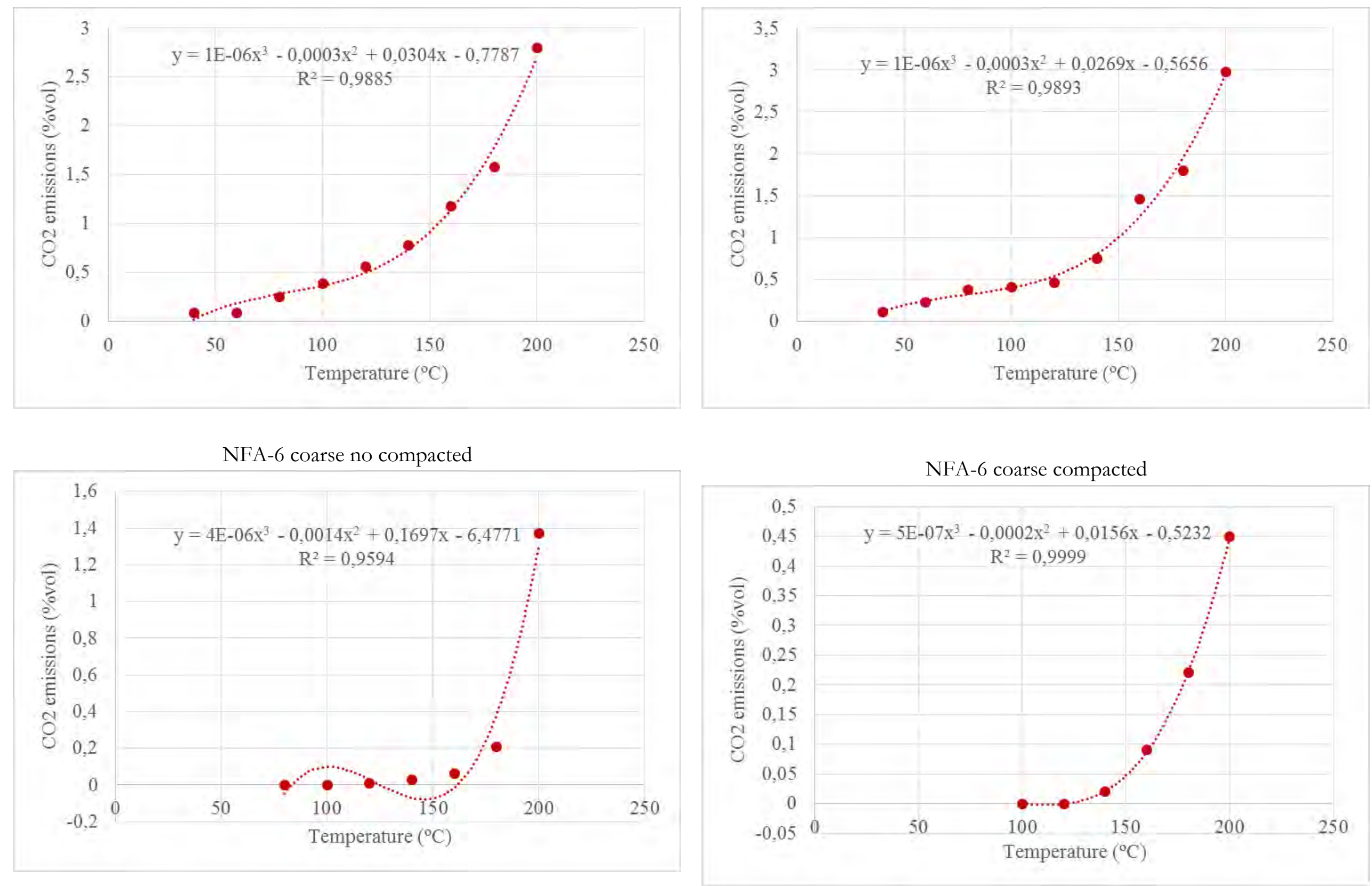

NFA-6 fine no compacted

NFA-6 fine compacted 

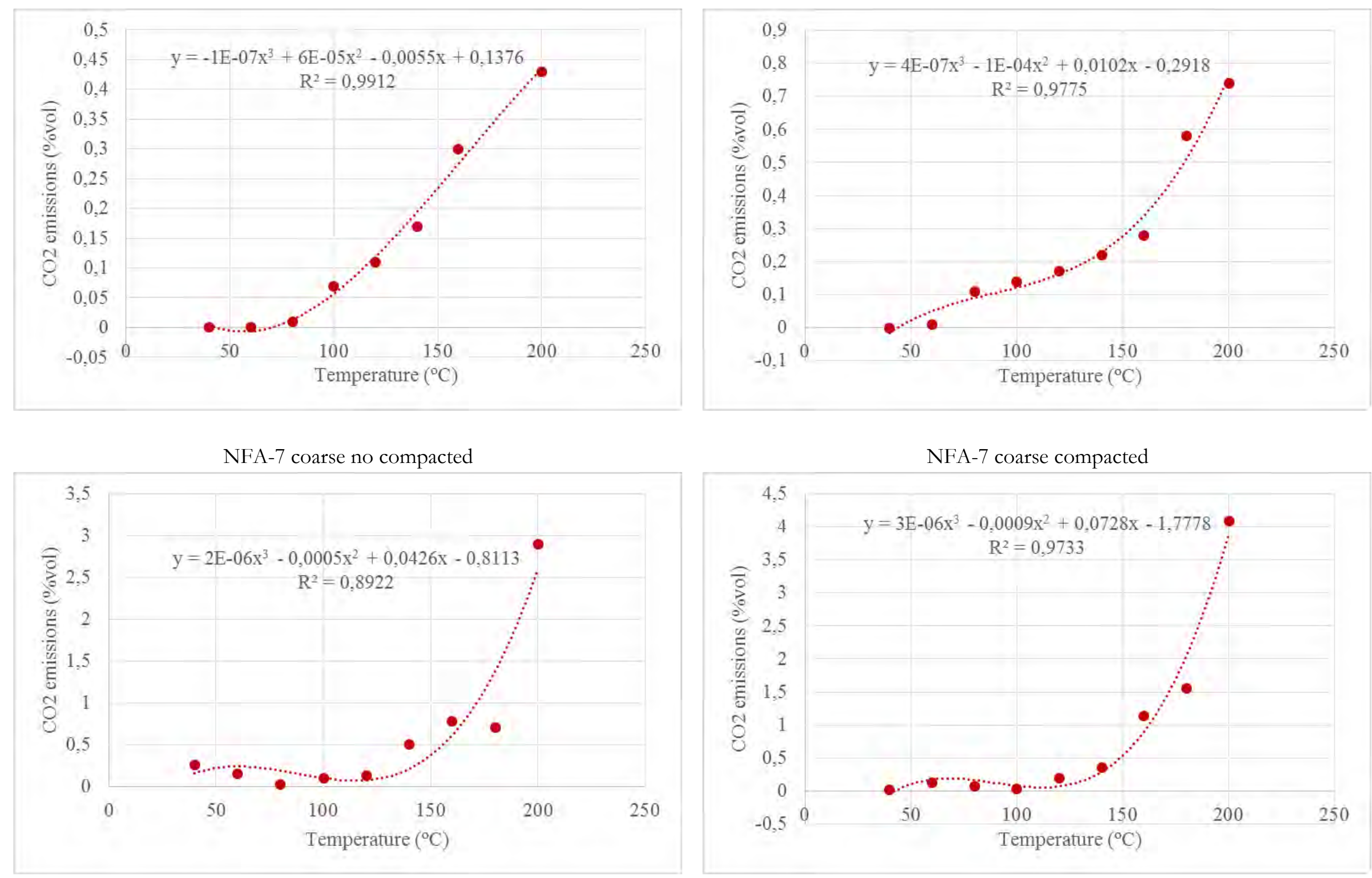

NFA-7 fine no compacted

NFA-7 fine compacted 

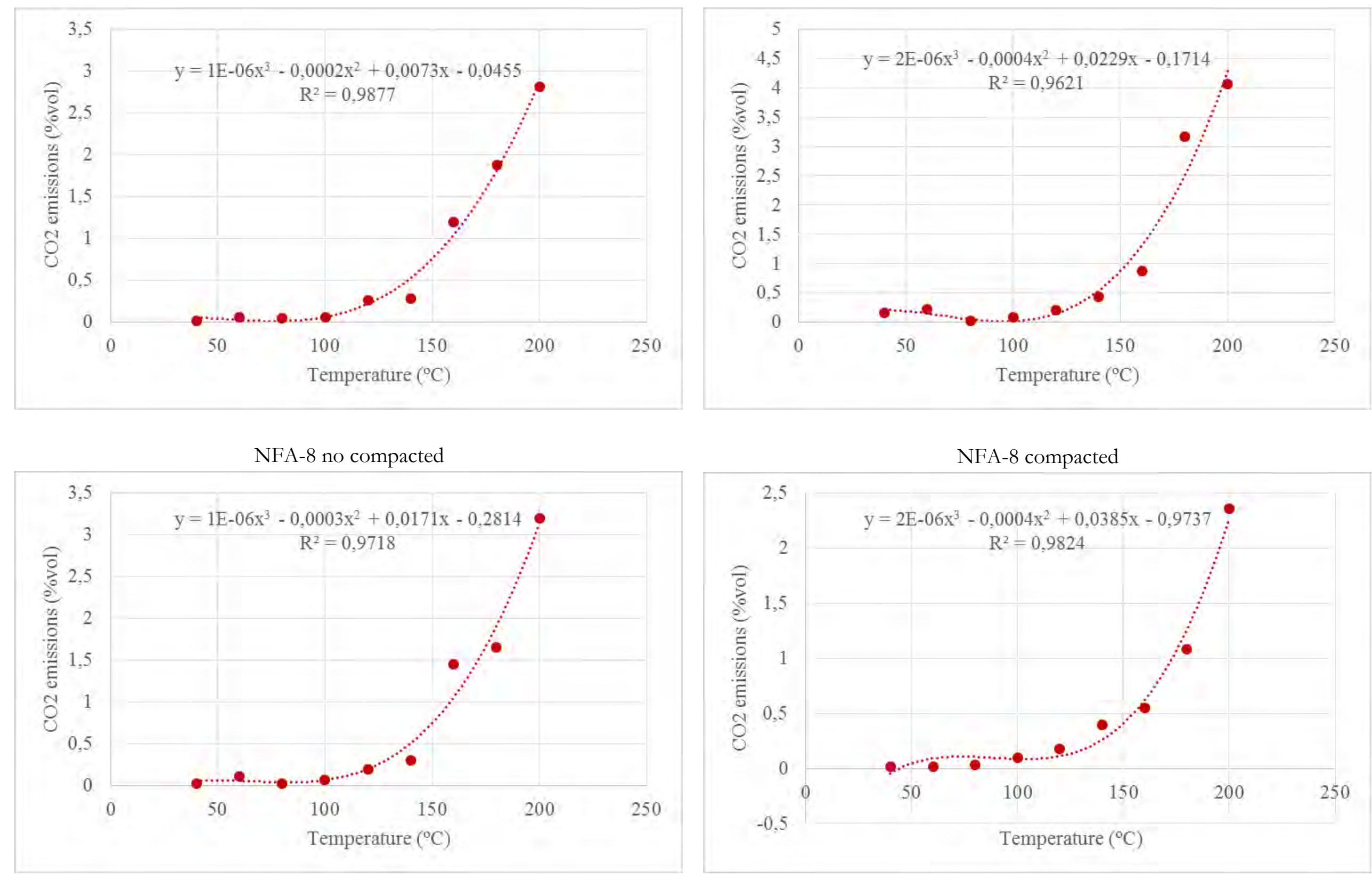

NFA-9 no compacted

NFA-9 compacted 

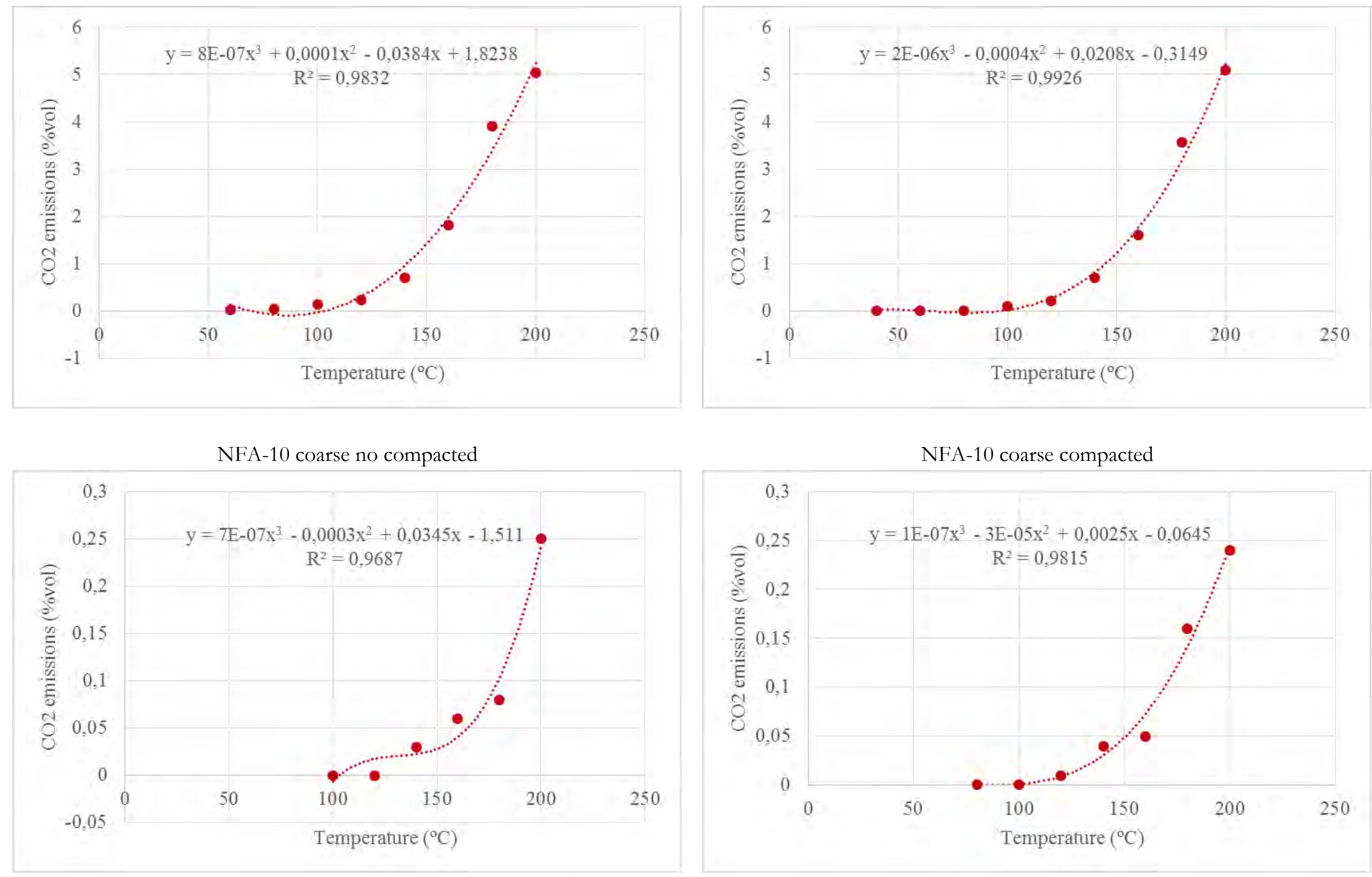

NFA-10 fine no compacted

NFA-10 fine compacted 

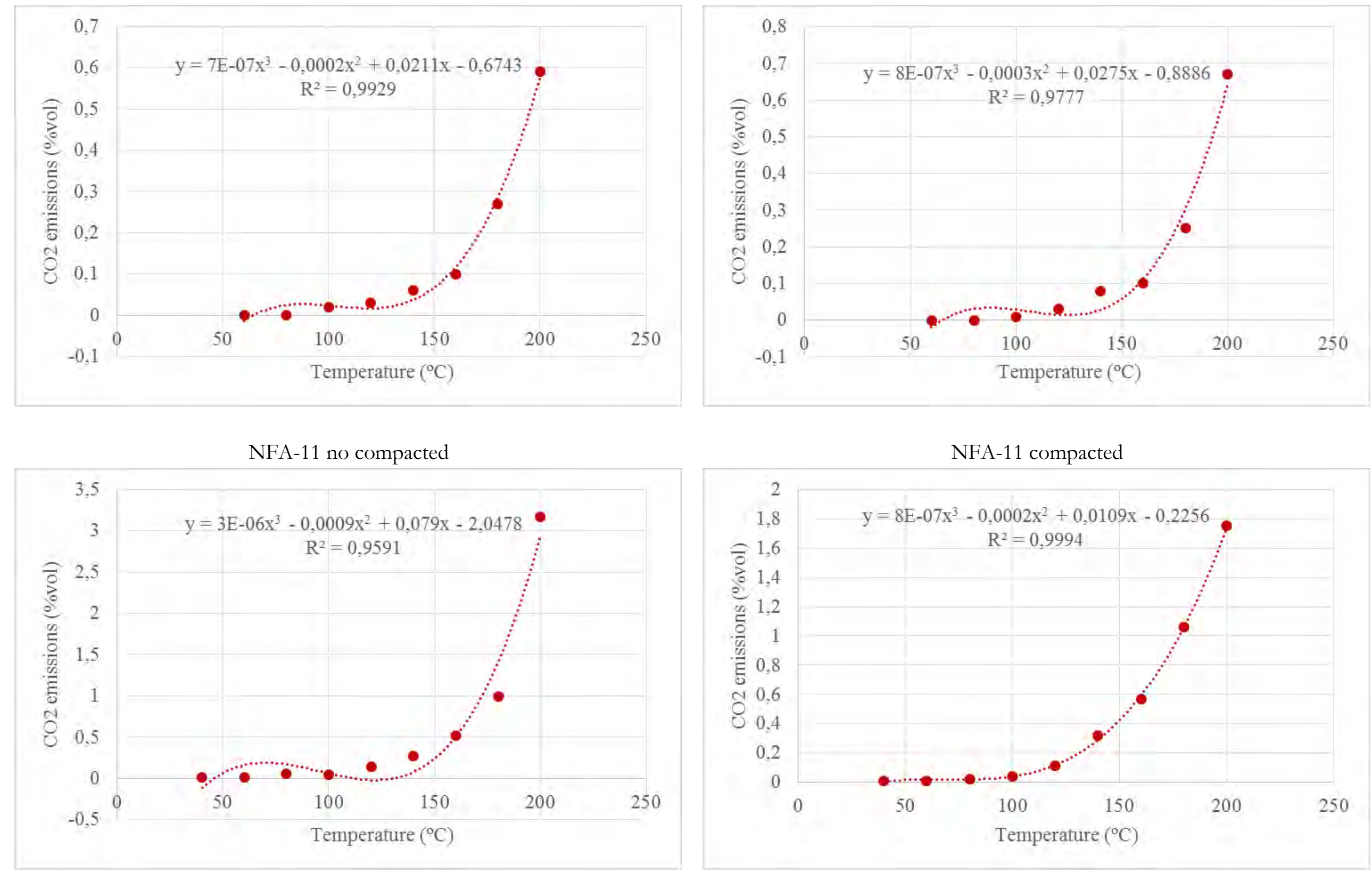

NFA-12 no compacted

NFA-12 compacted 

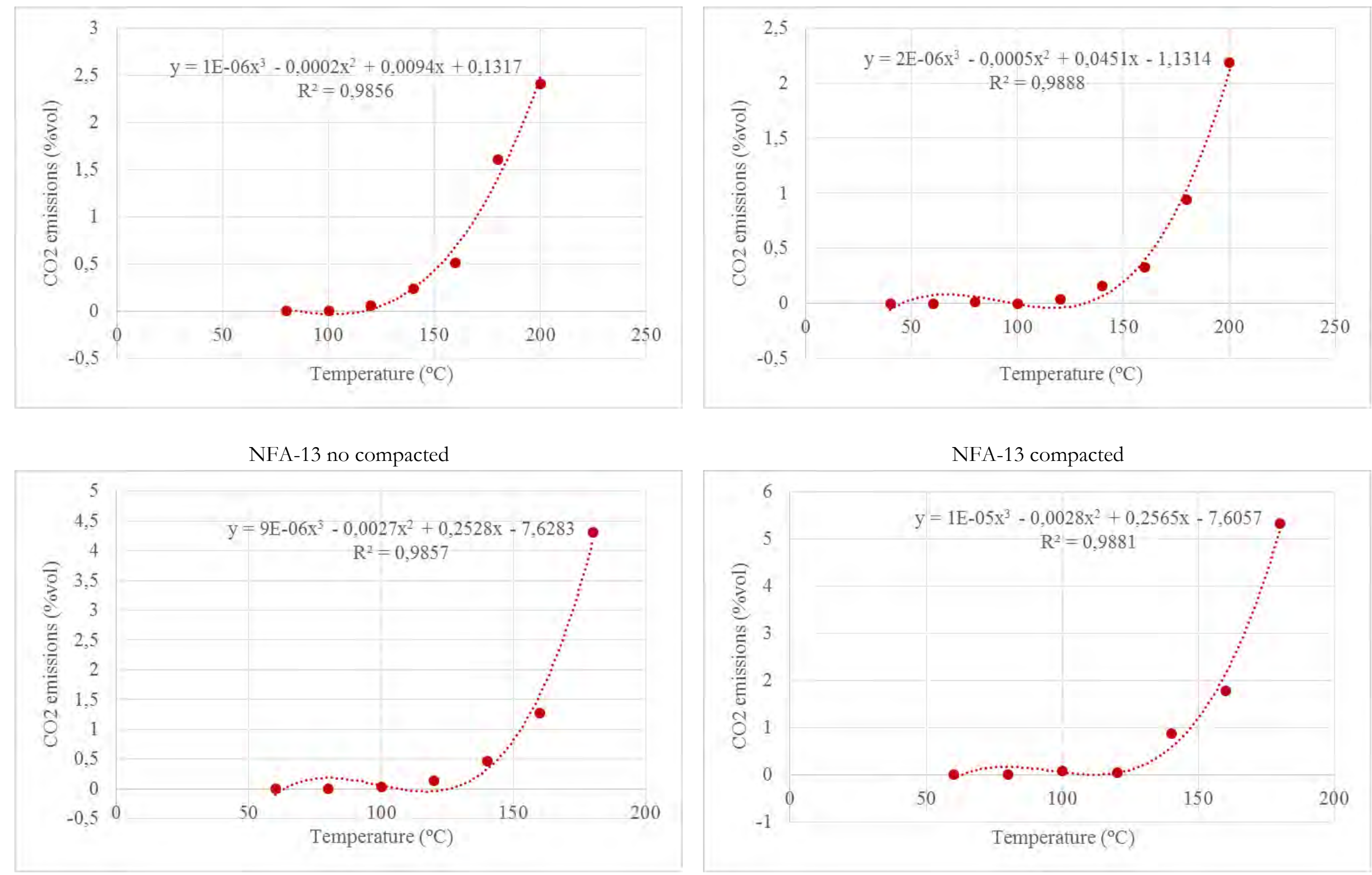

NFA-14 coarse no compacted

NFA-14 coarse compacted 

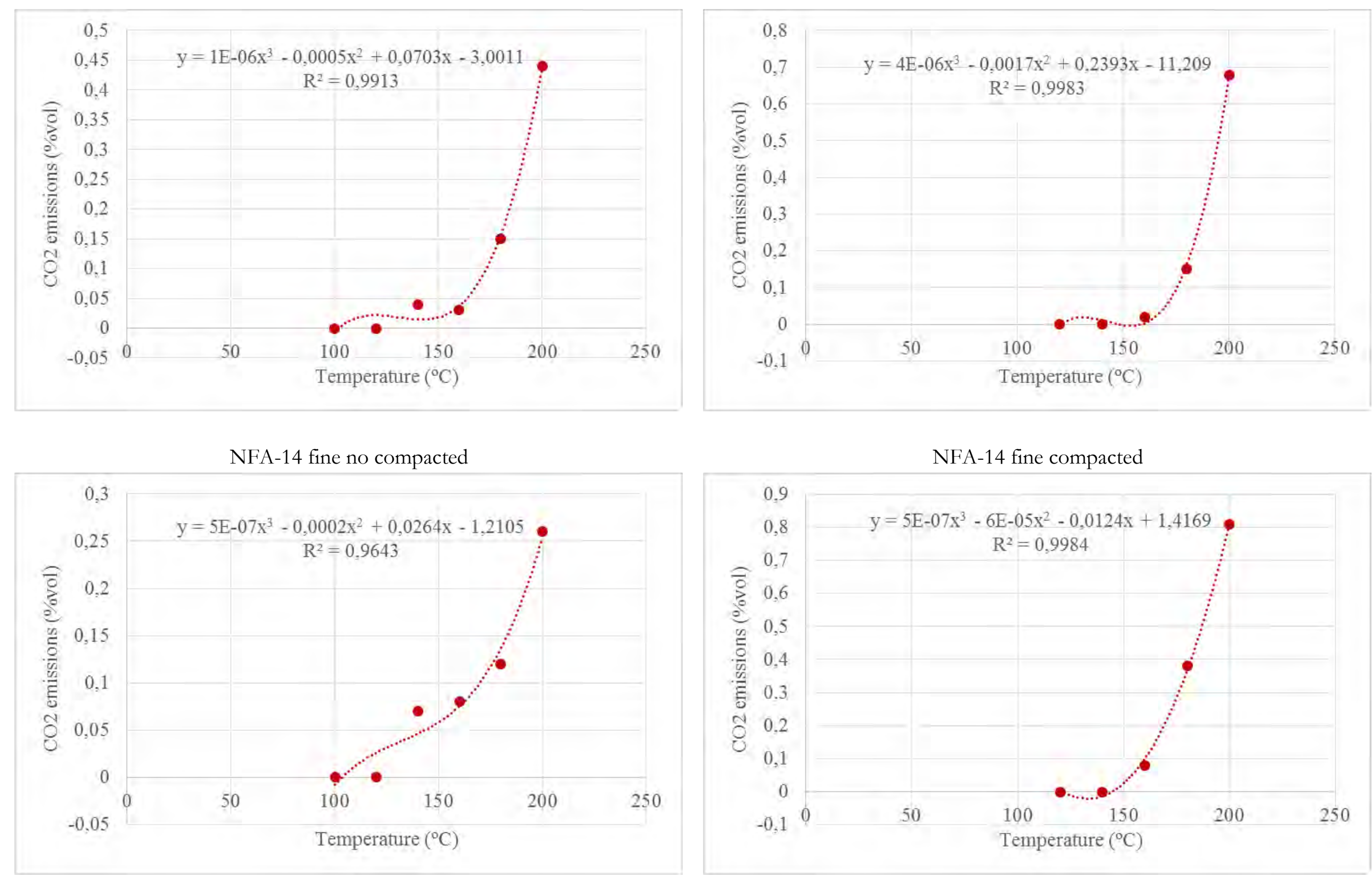

NFA-15 coarse no compacted

NFA-15 coarse compacted 

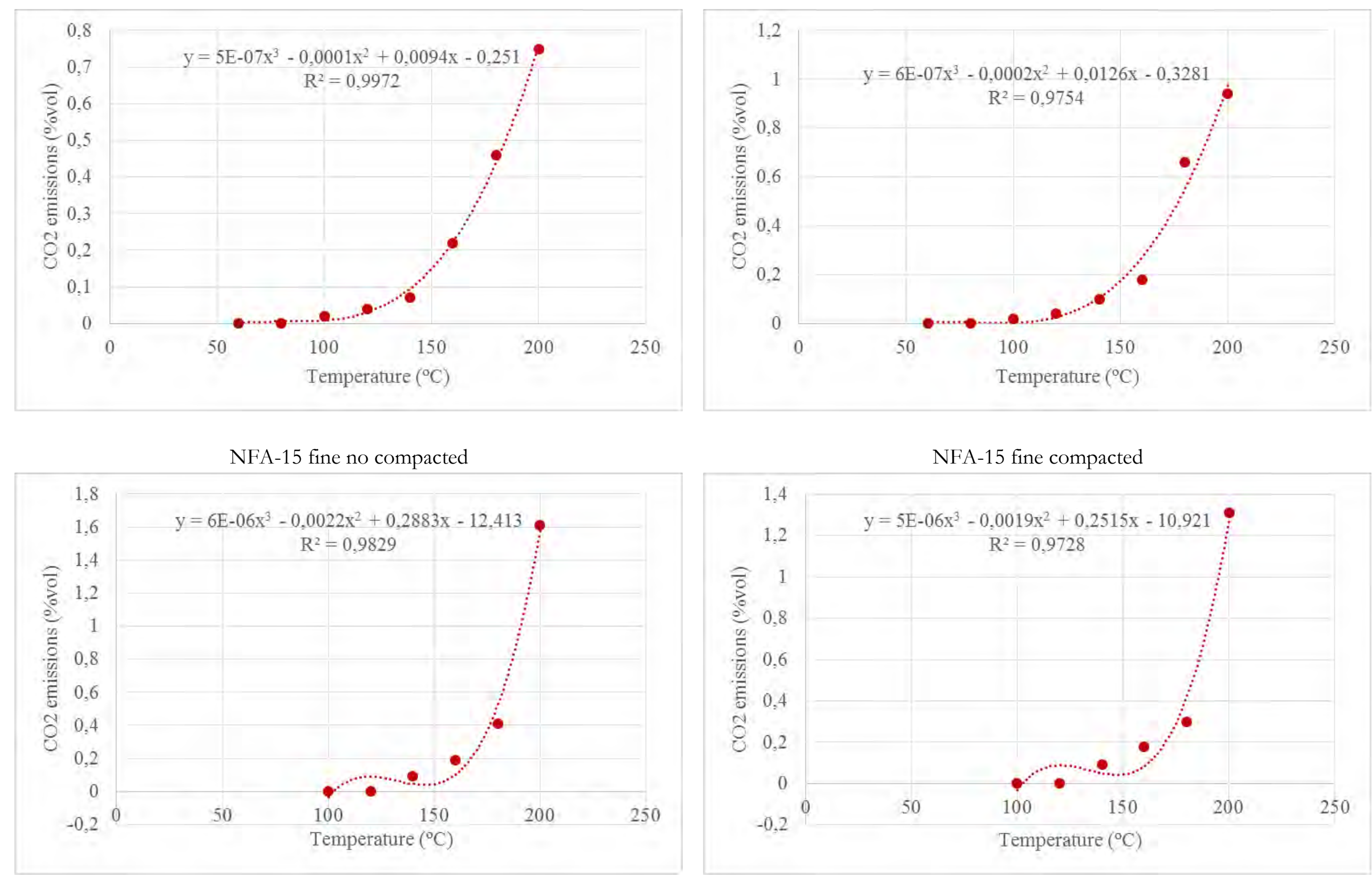

NFA-16 coarse no compacted

NFA-16 coarse compacted 

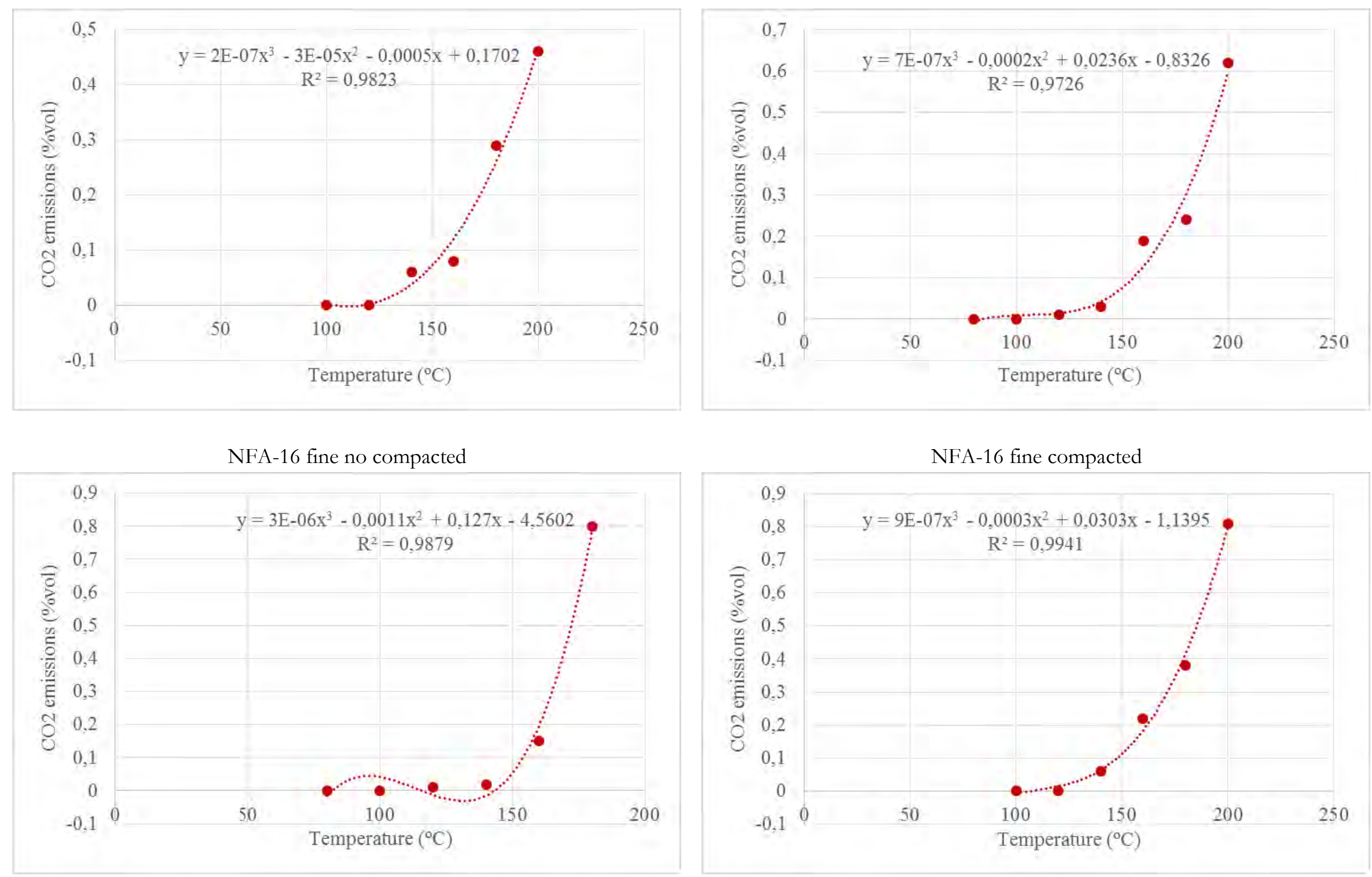


\section{Elemental analysis thermally dried sewage sludge}

\begin{tabular}{|c|c|c|c|c|c|}
\hline Sample & C ( $\%$ d.b. $)$ & H (\% d.b.) & N (\% d.b.) & S (\% d.b.) & $O$ ( $\%$ diff.) \\
\hline LRET-101 & 37.43 & 4.91 & 3.01 & 0.61 & 54.04 \\
\hline LRET-102 & 28.48 & 3.56 & 2.96 & 0.84 & 64.16 \\
\hline LRET-103 & 33.72 & 4.94 & 5.00 & 1.63 & 54.71 \\
\hline LRET-104 & 34.72 & 4.70 & 4.46 & 1.24 & 54.88 \\
\hline LRET-105 & 35.76 & 4.74 & 4.52 & 1.31 & 53.67 \\
\hline LRET-106 & 33.83 & 4.52 & 4.75 & 1.61 & 55.29 \\
\hline LRET-107 & 31.90 & 4.77 & 5.01 & 1.21 & 57.11 \\
\hline LRET-108 & 29.57 & 4.45 & 4.70 & 1.31 & 59.97 \\
\hline LRET-110 & 31.73 & 4.69 & 4.89 & 1.14 & 57.55 \\
\hline LRET-111 & 30.23 & 4.50 & 4.83 & 1.49 & 58.95 \\
\hline LRET-112 & 36.13 & 5.19 & 4.51 & 4.90 & 49.27 \\
\hline LRET-113 & 34.72 & 4.96 & 5.13 & 2.24 & 52.95 \\
\hline LRET-114 & 35.28 & 4.96 & 4.11 & 2.18 & 53.47 \\
\hline LRET-115 & 32.28 & 4.67 & 4.65 & 1.96 & 56.44 \\
\hline LRET-116 & 44.81 & 6.69 & 5.36 & 1.30 & 41.84 \\
\hline LRET-117 & 38.30 & 6.33 & 3.72 & 1.08 & 50.57 \\
\hline LRET-118 & 34.80 & 6.45 & 5.20 & 1.39 & 52.16 \\
\hline LRET-119 & 31.90 & 5.63 & 4.27 & 0.89 & 57.31 \\
\hline LRET-120 & 38.20 & 6.53 & 4.67 & 1.44 & 49.16 \\
\hline LRET-121 & 33.40 & 6.24 & 4.37 & 1.23 & 54.76 \\
\hline
\end{tabular}




\section{Proximate analysis thermally dried sewage sludge}

\begin{tabular}{|c|c|c|c|c|}
\hline Sample & Moisuture (\%) & Volatiles (\% d.b.) & Ashes (\% d.b.) & $\begin{array}{c}\text { Fixed carbon }(\% \\
\text { diff.) }\end{array}$ \\
\hline LRET-101 & 6.10 & 62.30 & 32.20 & 5.50 \\
\hline LRET-102 & 2.70 & 52.50 & 48.10 & -0.60 \\
\hline LRET-103 & 11.10 & 59.90 & 43.90 & -3.80 \\
\hline LRET-104 & 4.80 & 54.40 & 44.80 & 0.80 \\
\hline LRET-105 & 6.50 & 53.50 & 45.00 & 1.50 \\
\hline LRET-106 & 7.80 & 52.90 & 45.00 & 2.10 \\
\hline LRET-107 & 5.60 & 55.40 & 41.70 & 2.90 \\
\hline LRET-108 & 7.10 & 54.60 & 46.10 & -0.70 \\
\hline LRET-110 & 4.40 & 57.80 & 41.80 & 0.40 \\
\hline LRET-111 & 6.20 & 54.20 & 44.30 & 1.50 \\
\hline LRET-112 & 5.70 & 62.30 & 37.10 & 0.60 \\
\hline LRET-113 & 3.00 & 60.40 & 38.10 & 1.50 \\
\hline LRET-114 & 3.90 & 57.60 & 40.40 & 2.00 \\
\hline LRET-115 & 14.10 & 56.60 & 40.00 & 3.40 \\
\hline LRET-116 & 5.80 & 73.90 & 20.20 & 5.90 \\
\hline LRET-117 & 2.40 & 57.40 & 38.50 & 4.10 \\
\hline LRET-118 & 9.80 & 60.20 & 36.40 & 3.40 \\
\hline LRET-119 & 1.30 & 51.50 & 45.40 & 3.10 \\
\hline LRET-120 & 3.60 & 58.40 & 34.50 & 7.10 \\
\hline LRET-121 & 6.20 & 57.00 & 41.70 & 1.30 \\
\hline
\end{tabular}




\section{Thermogravimetric curves thermally dried sewage sludge}

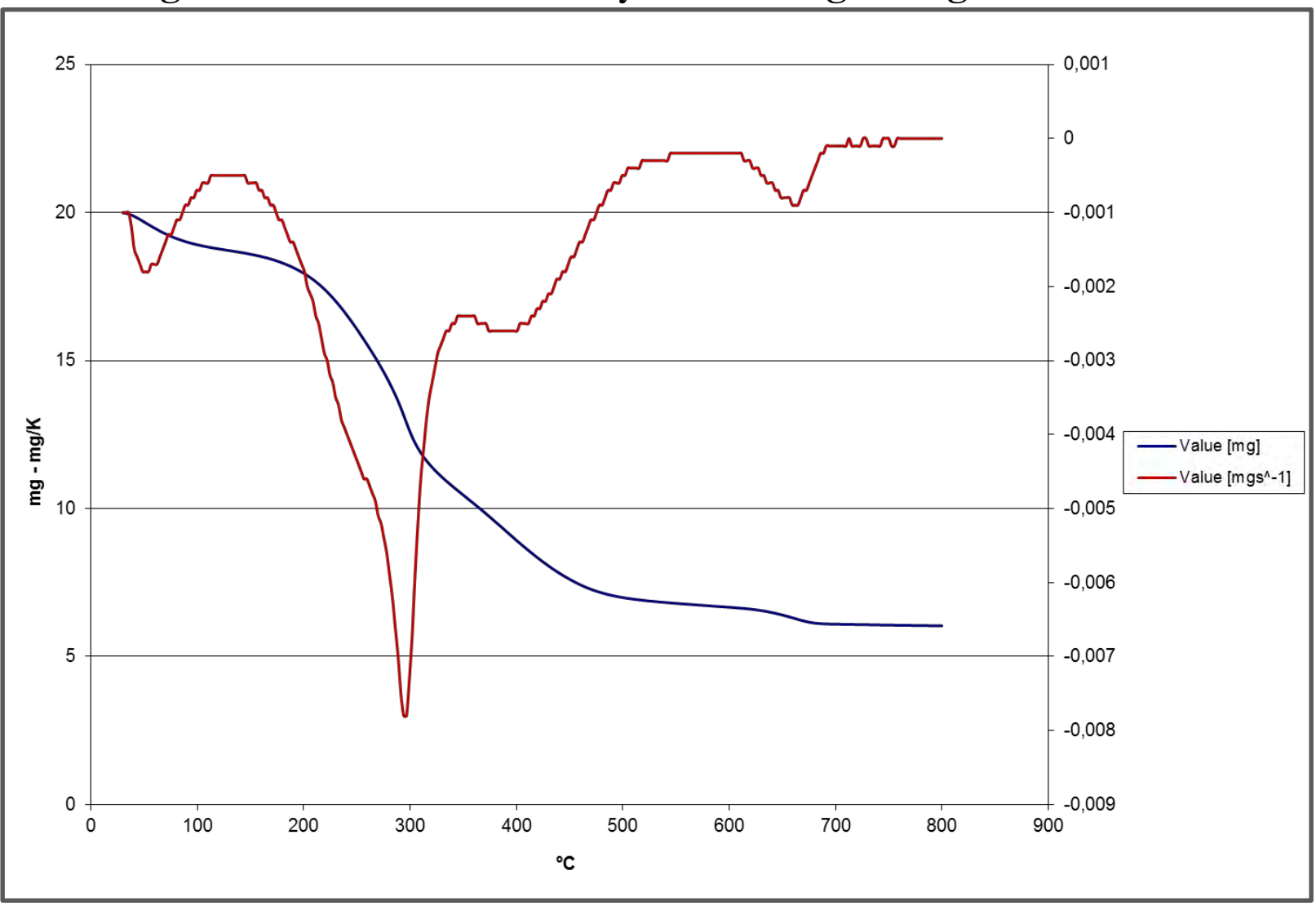

Figure 8-1. LRET-101

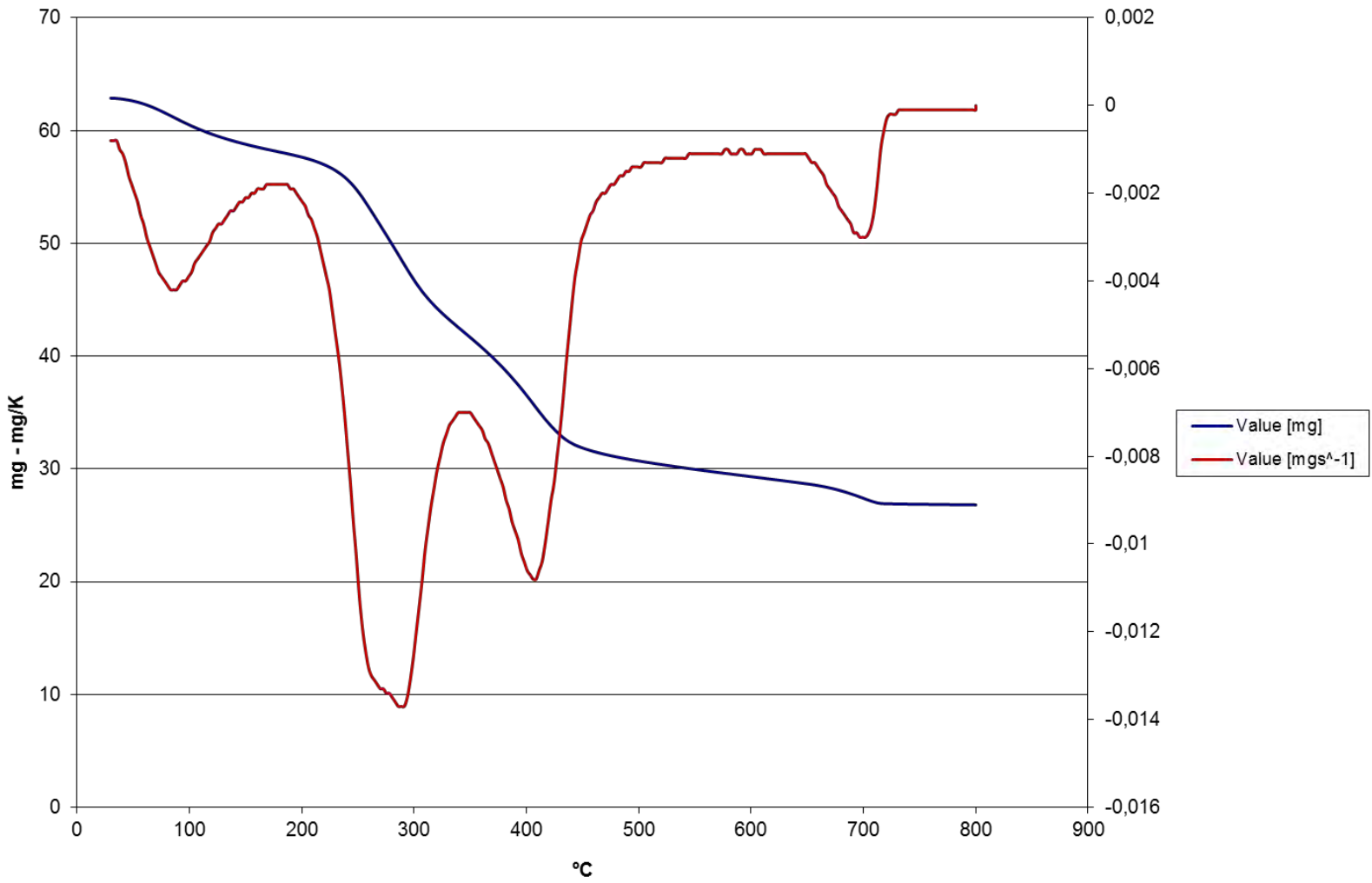

Figure 8-2. LRET-102 


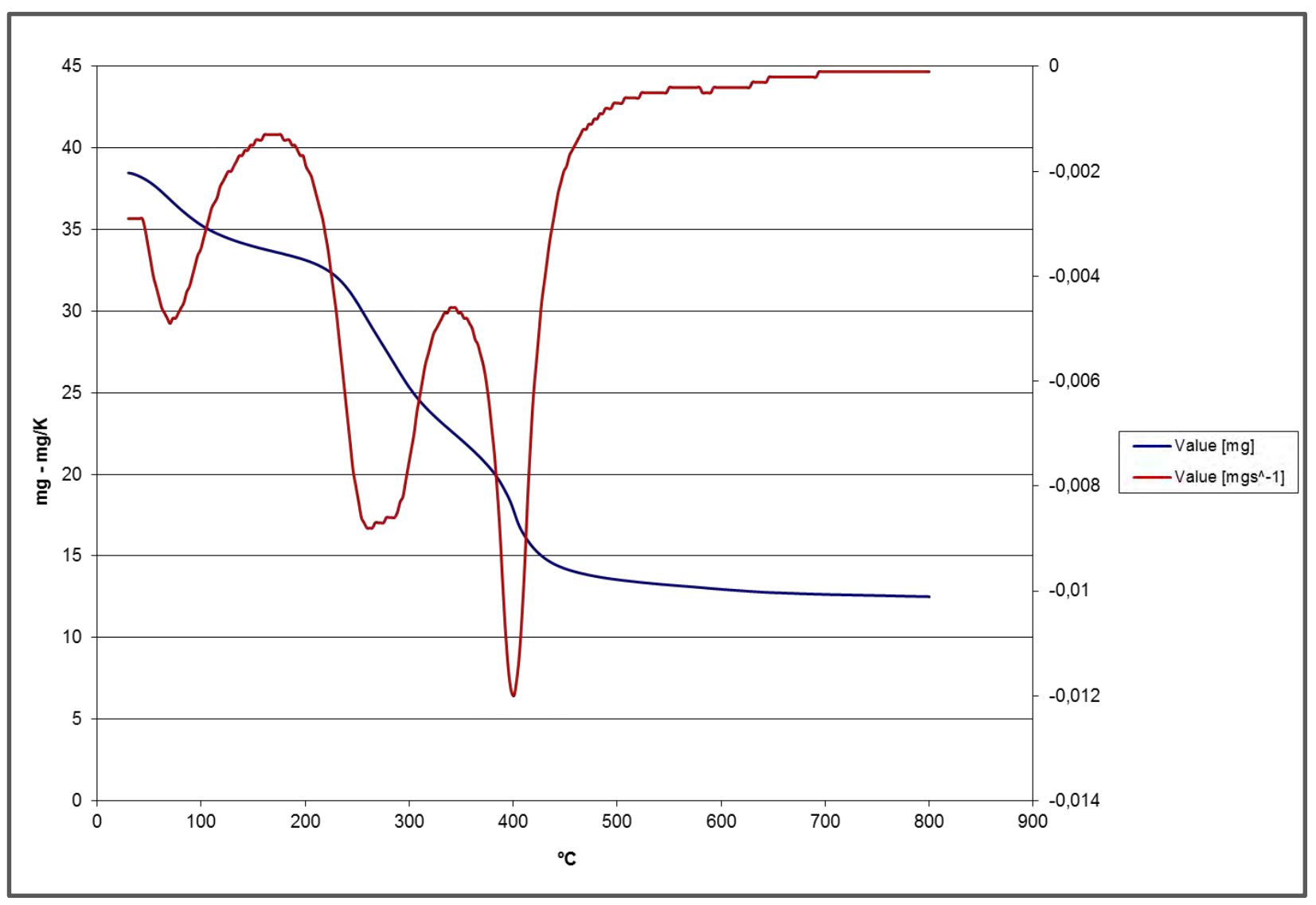

Figure 8-3. LRET-103

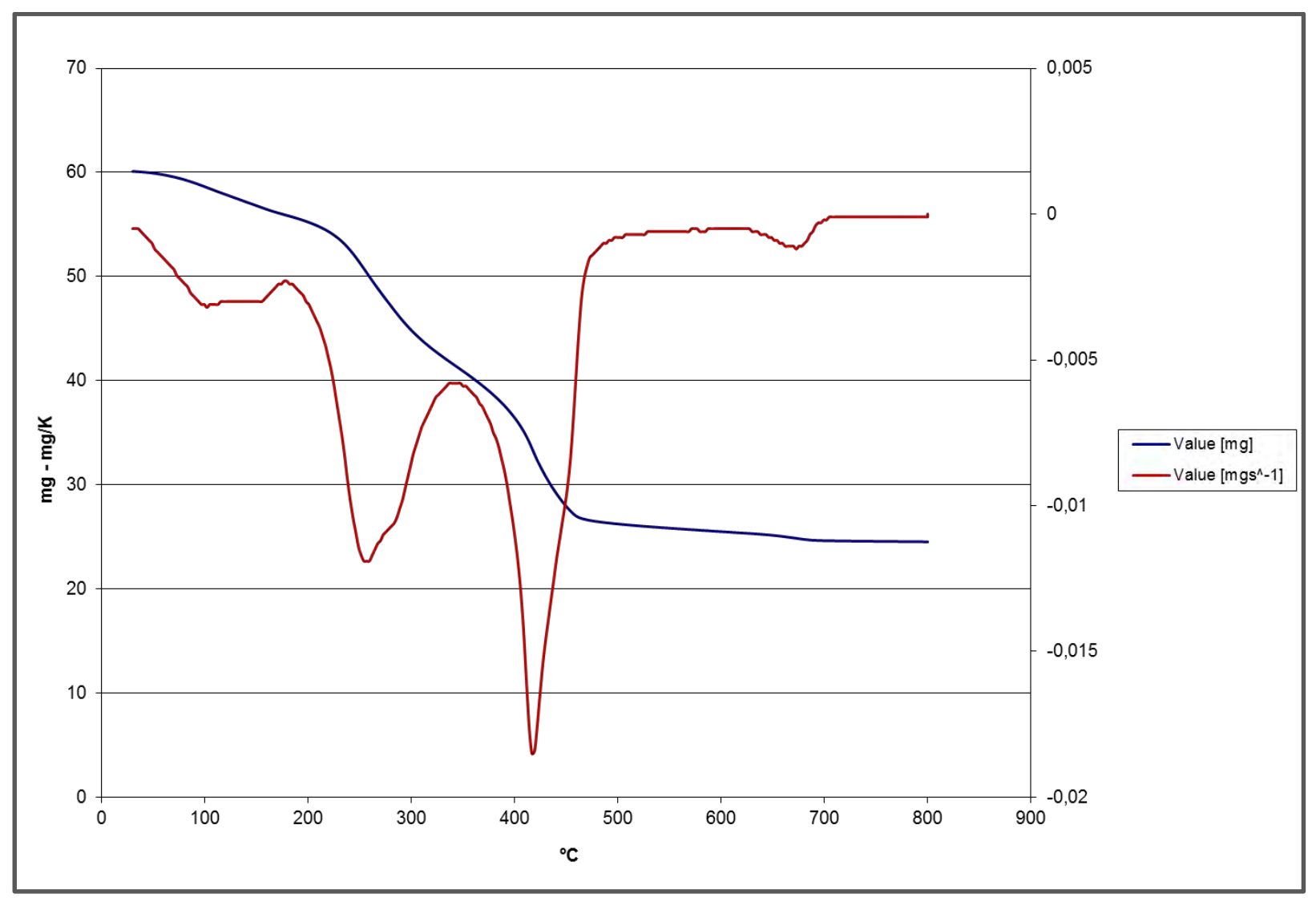

Figure 8-4. LRET-104 


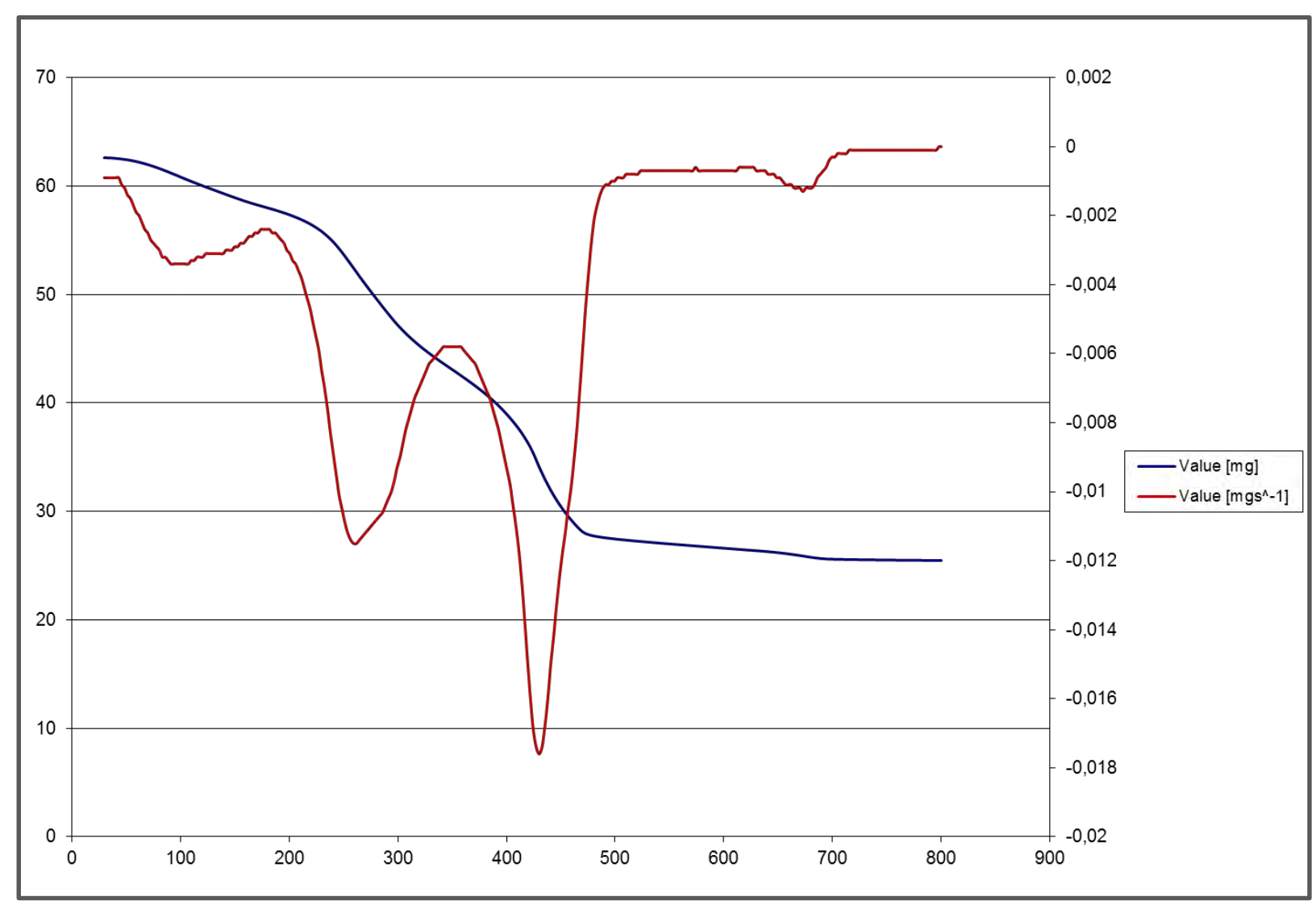

Figure 8-5. LRET-105

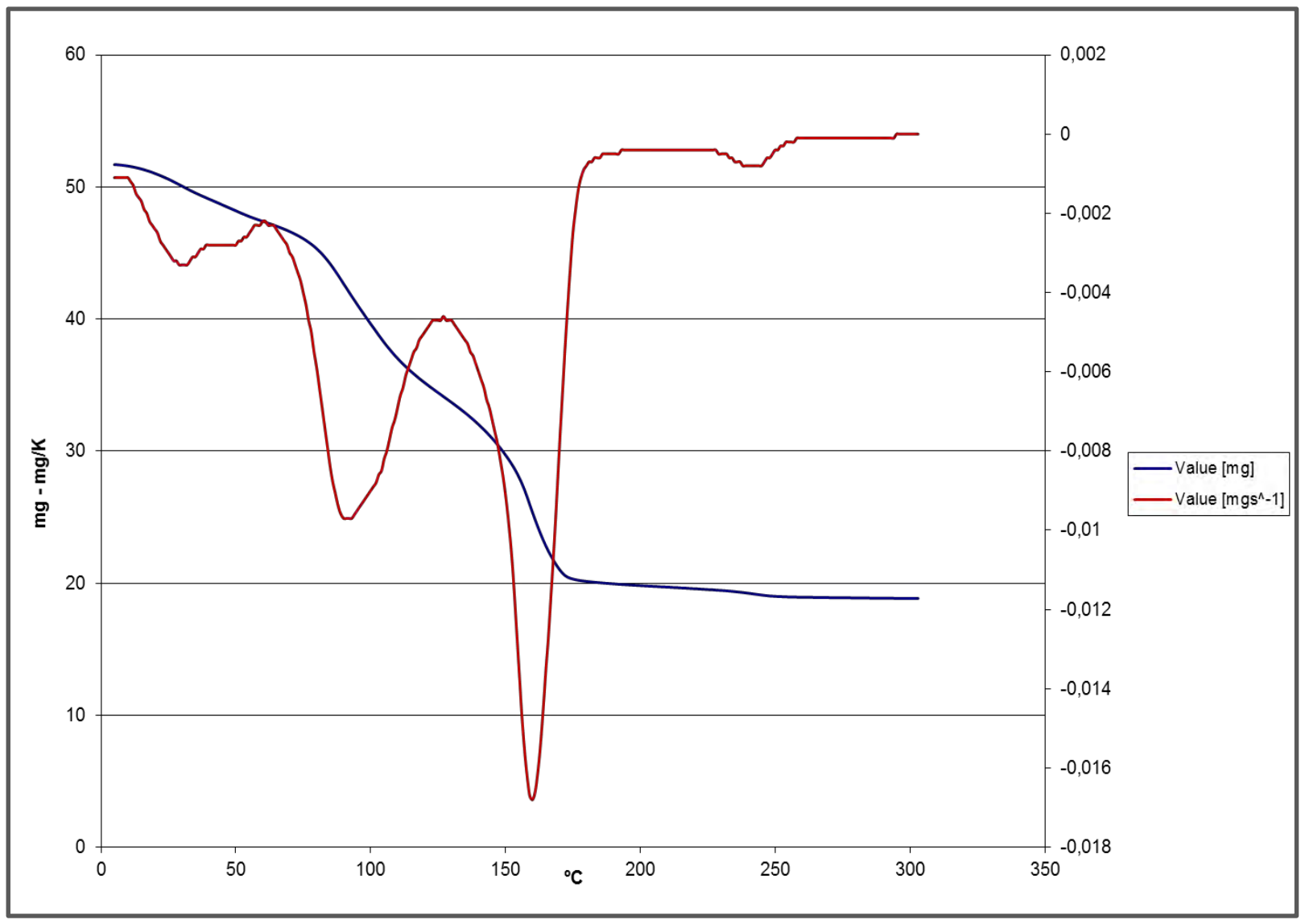

Figure 8-6. LRET-107 


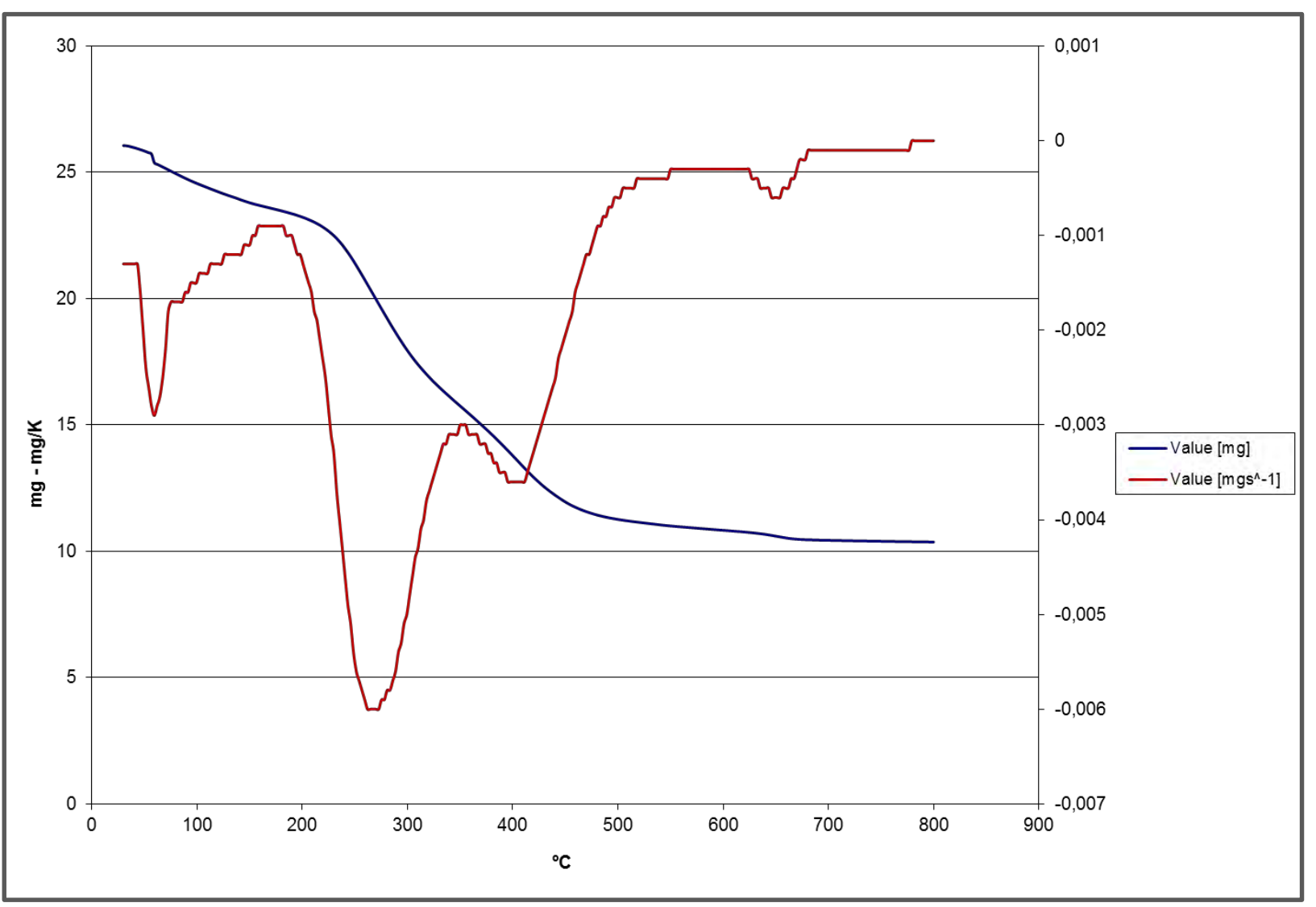

Figure 8-7. LRET-108

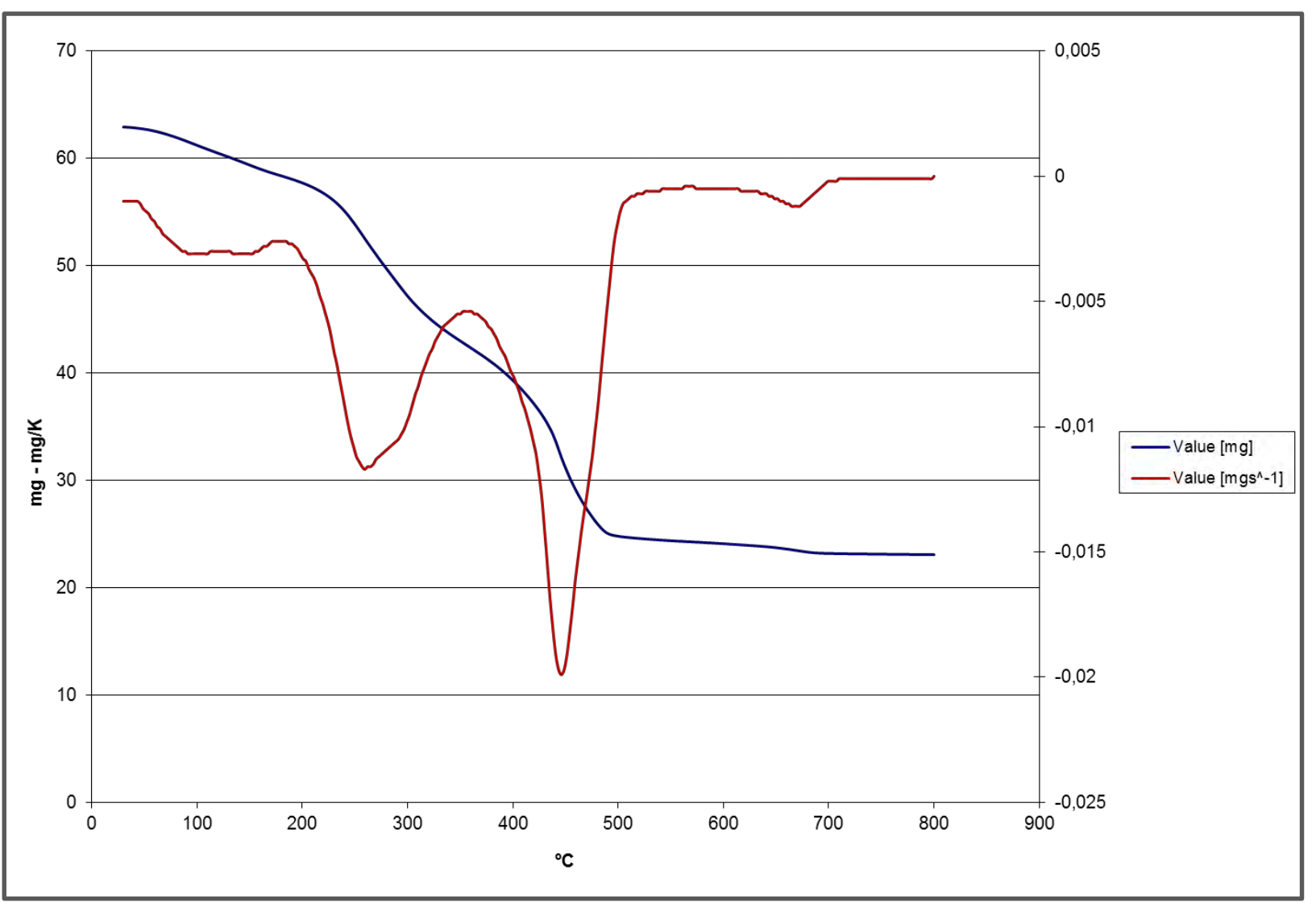

Figure 8-8. LRET-110 


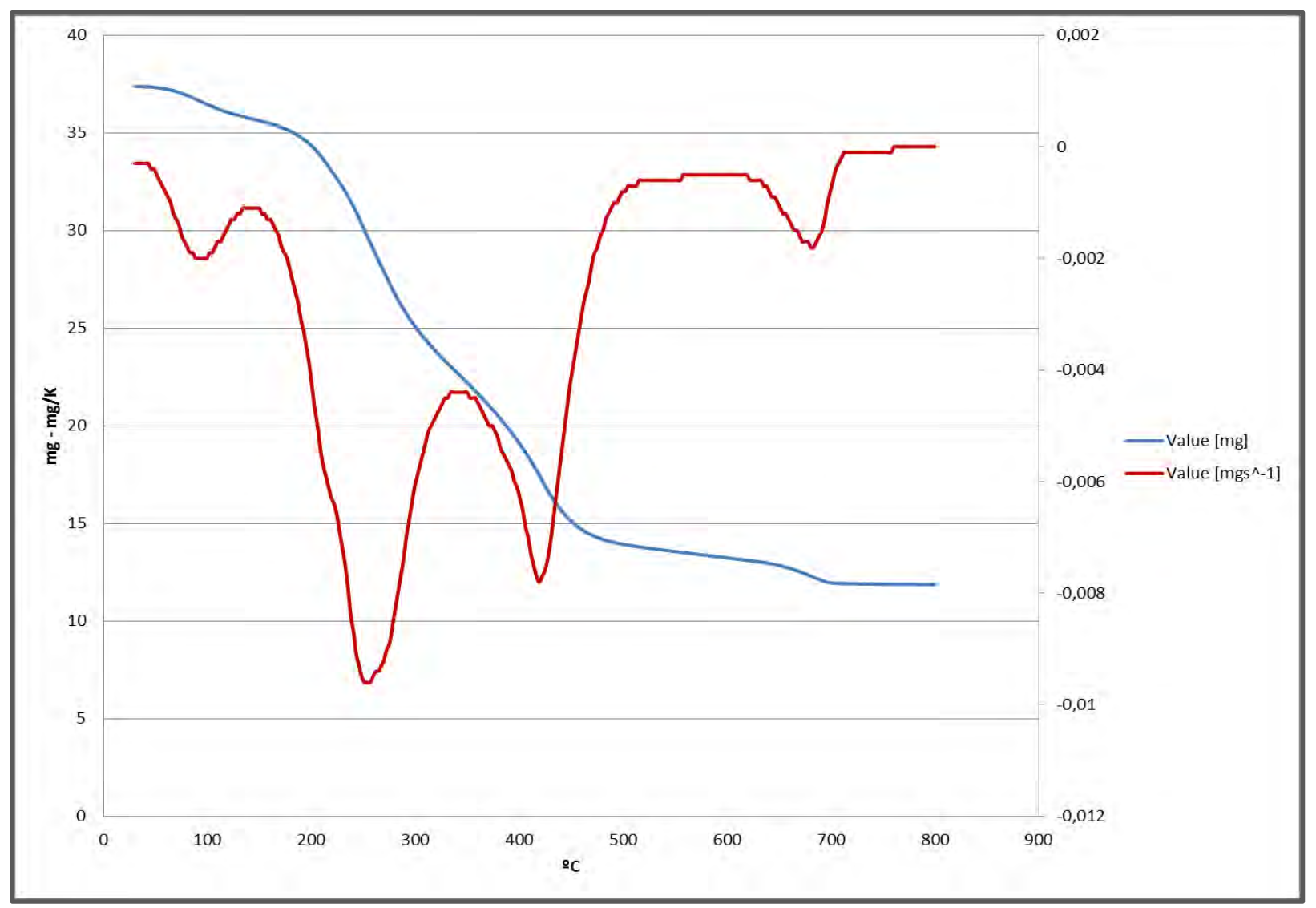

Figure 8-9. LRET-112

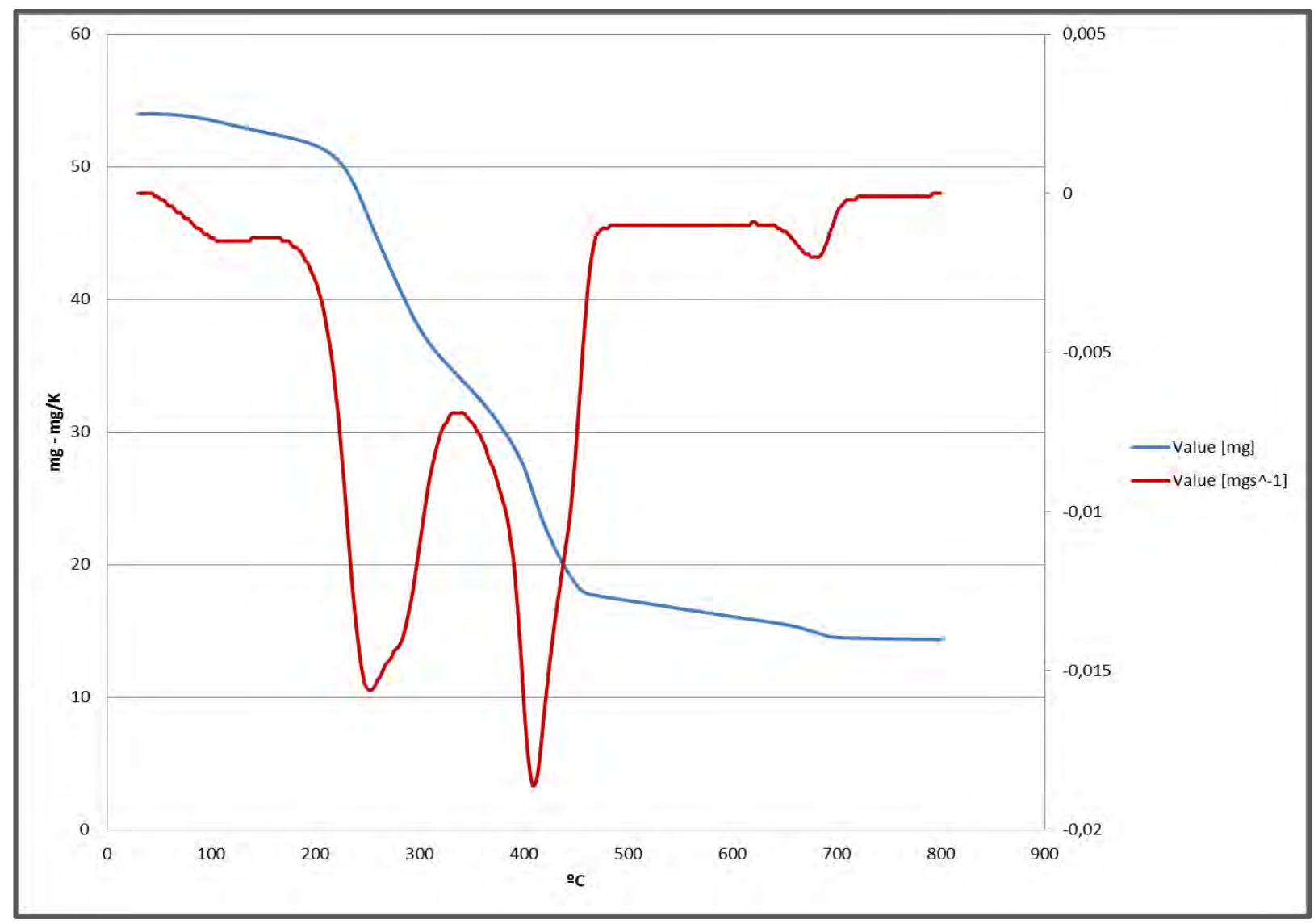

Figure 8-10. LRET-117 


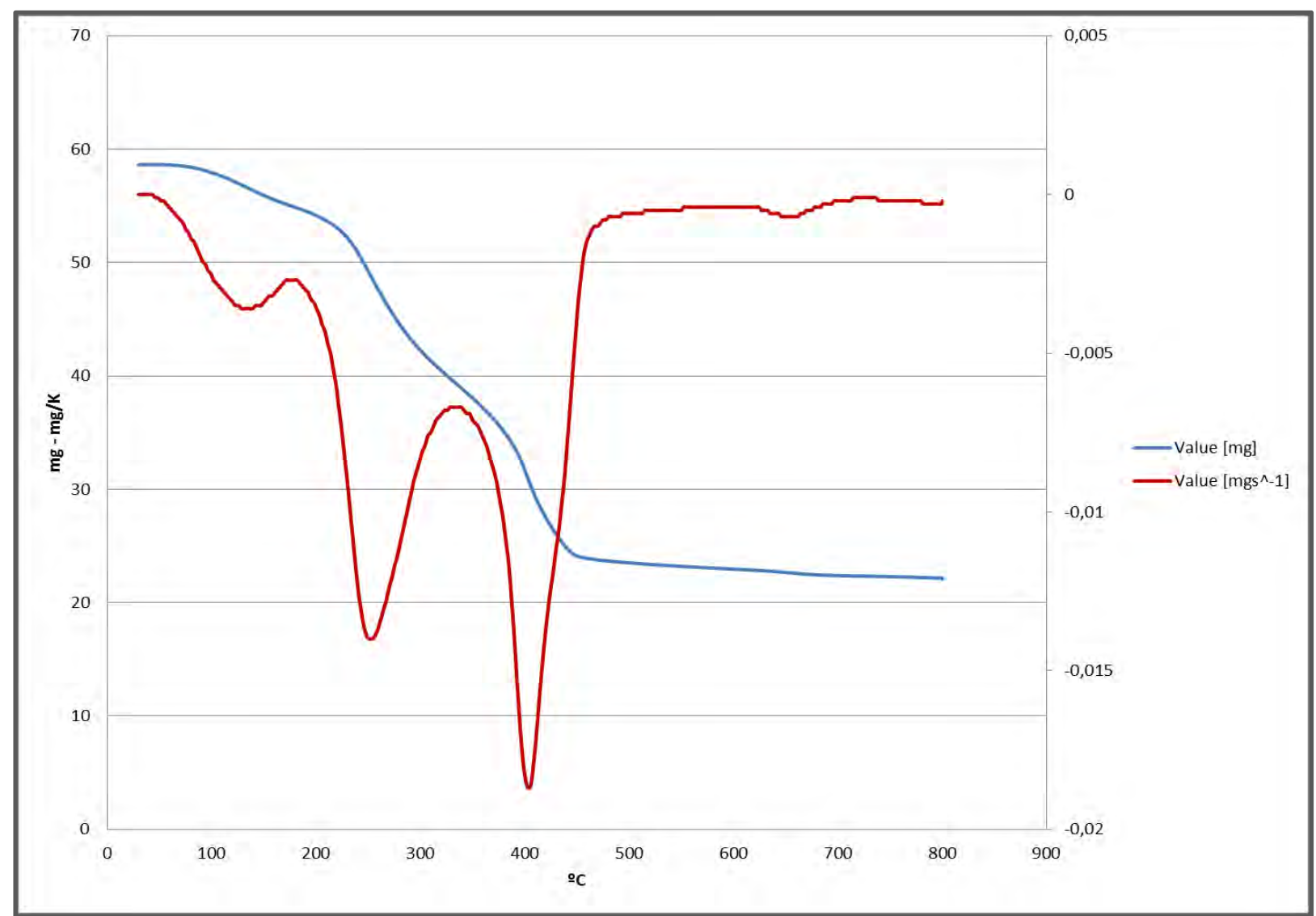

Figure 8-11. LRET-121 
9. Thermogravimetric with oxygen stream curves thermally dried sewage sludge

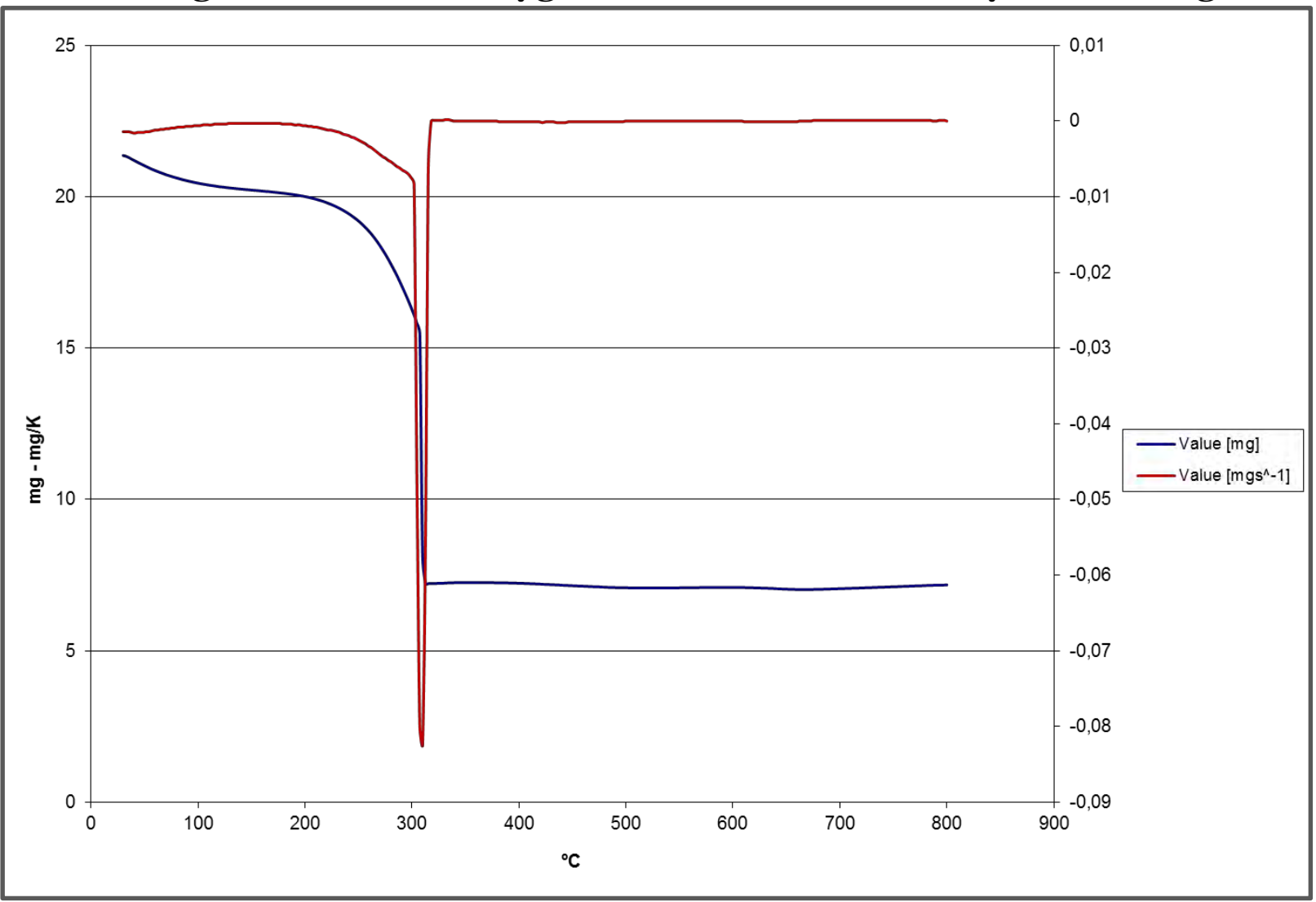

Figure 9-1. LRET-101

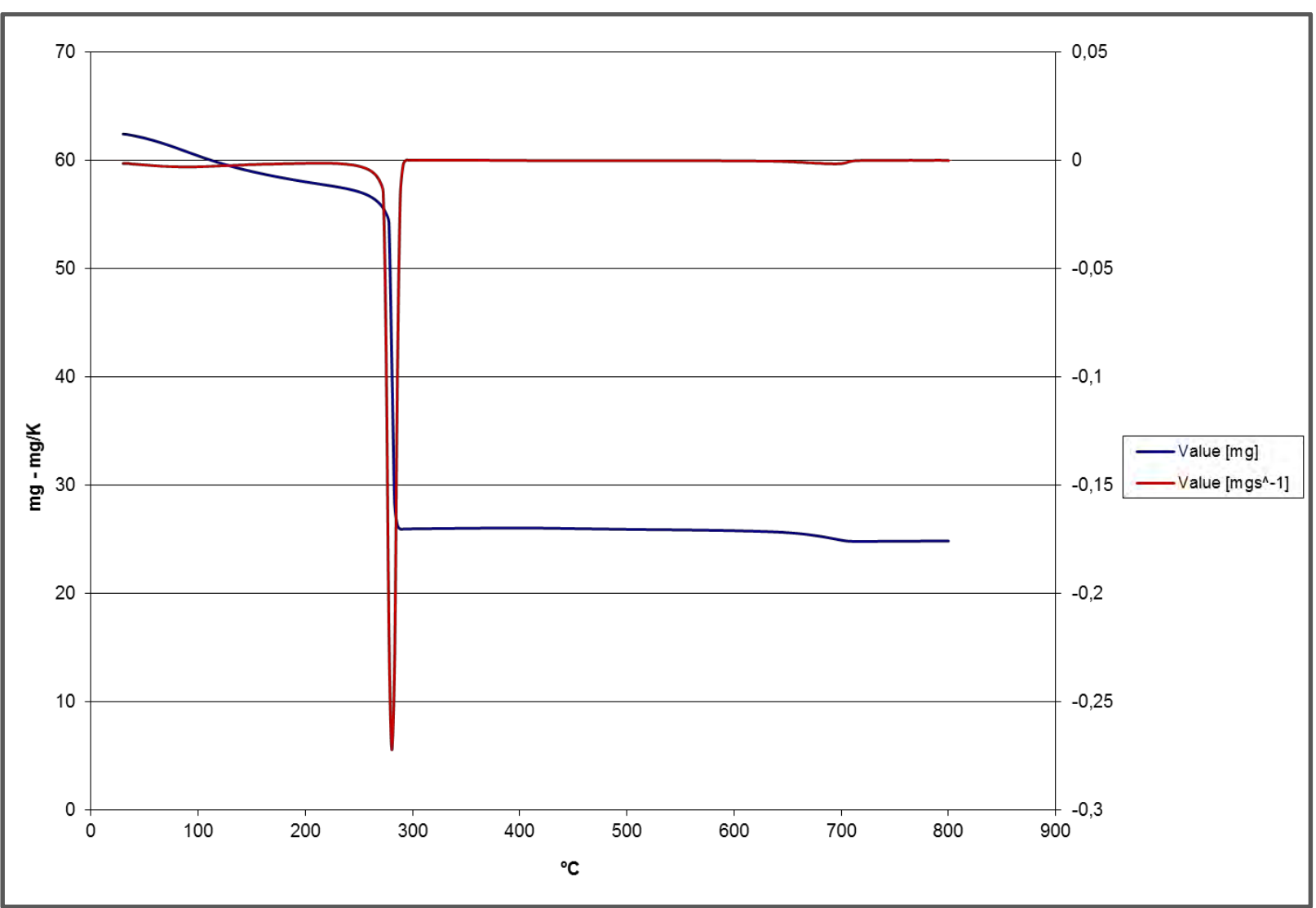

Figure 9-2. LRET-102 


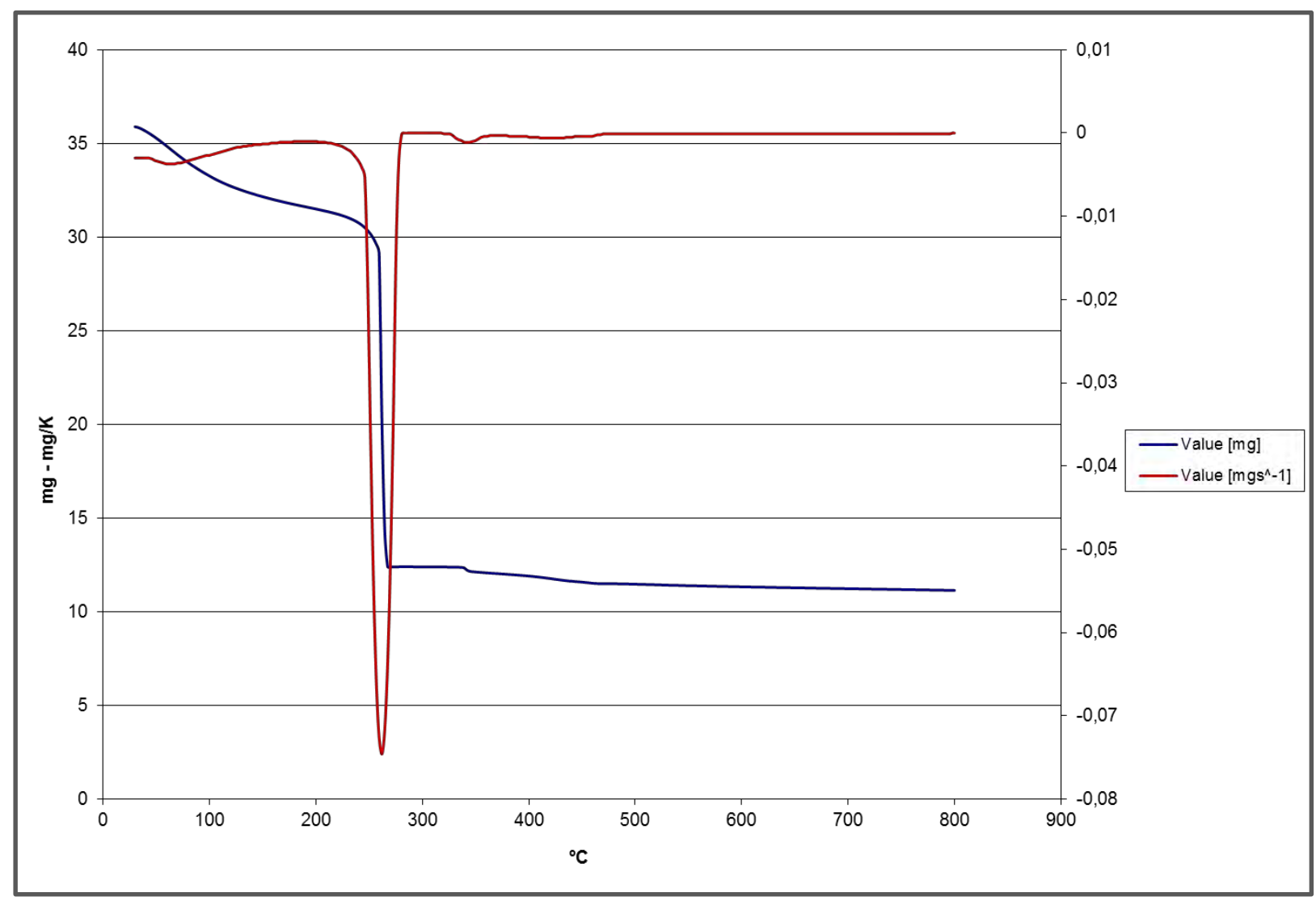

Figure 9-3. LRET-103

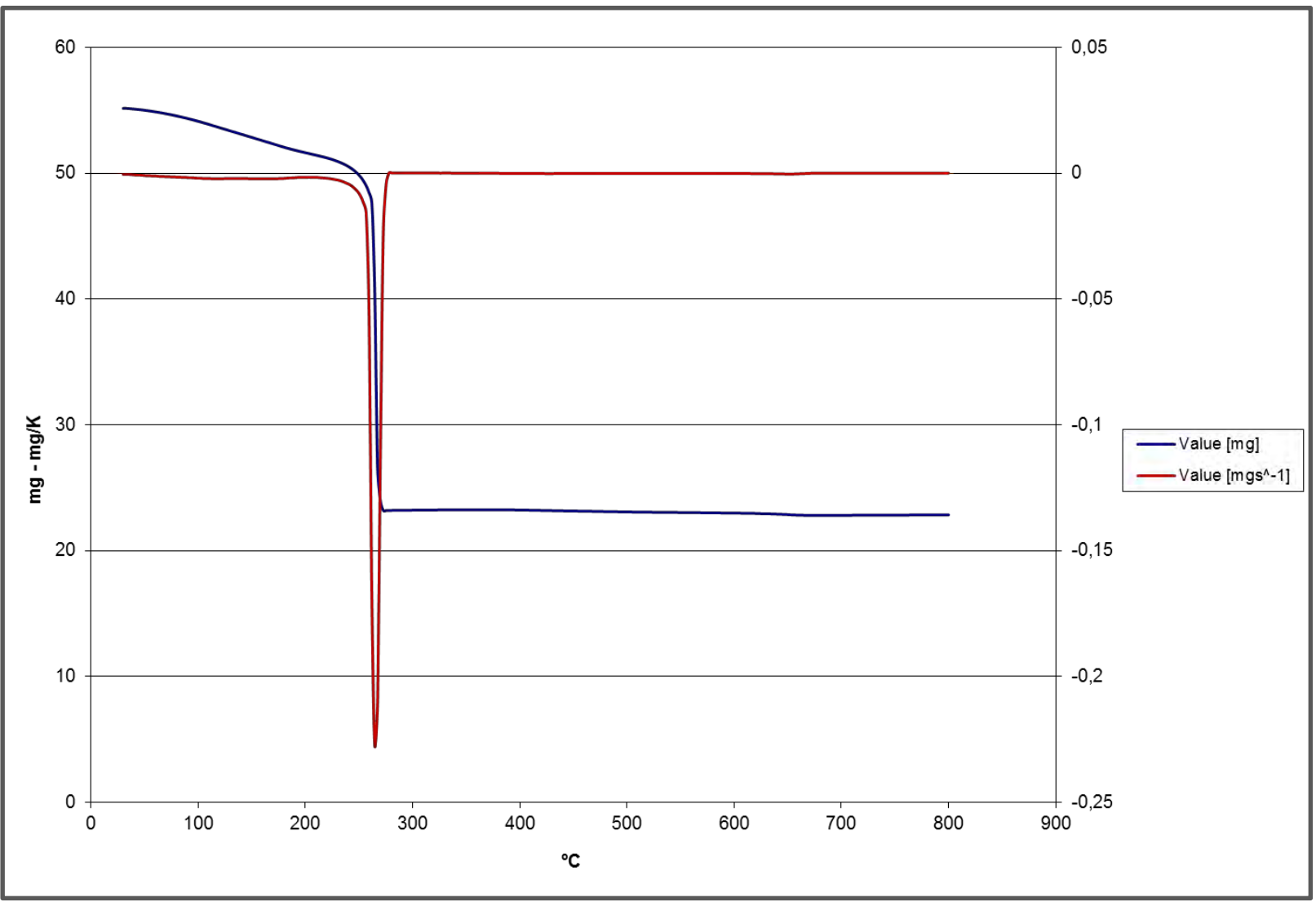

Figure 9-4. LRET-104 


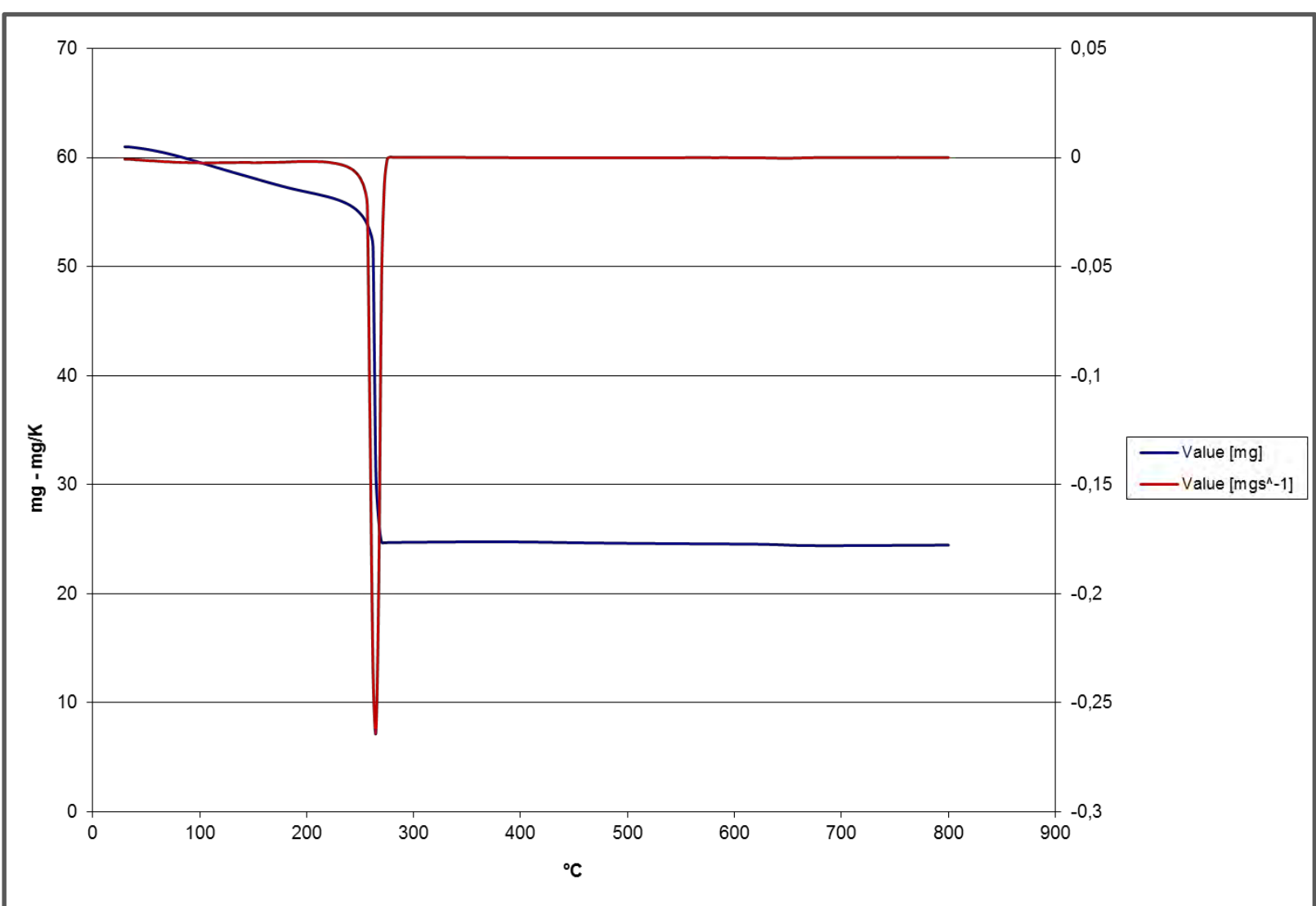

Figure 9-5. LRET 105

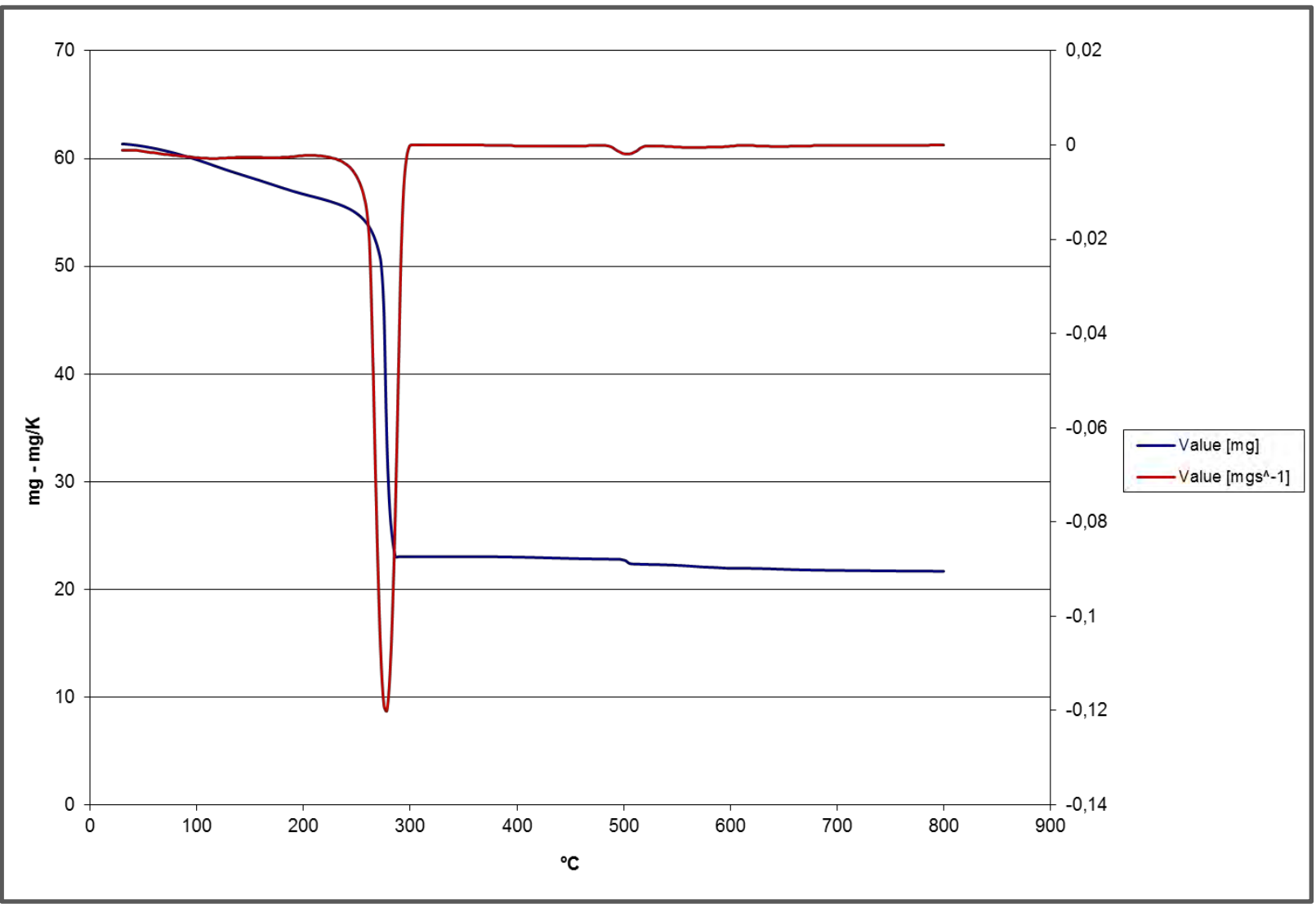

Figure 9-6. LRET 107 


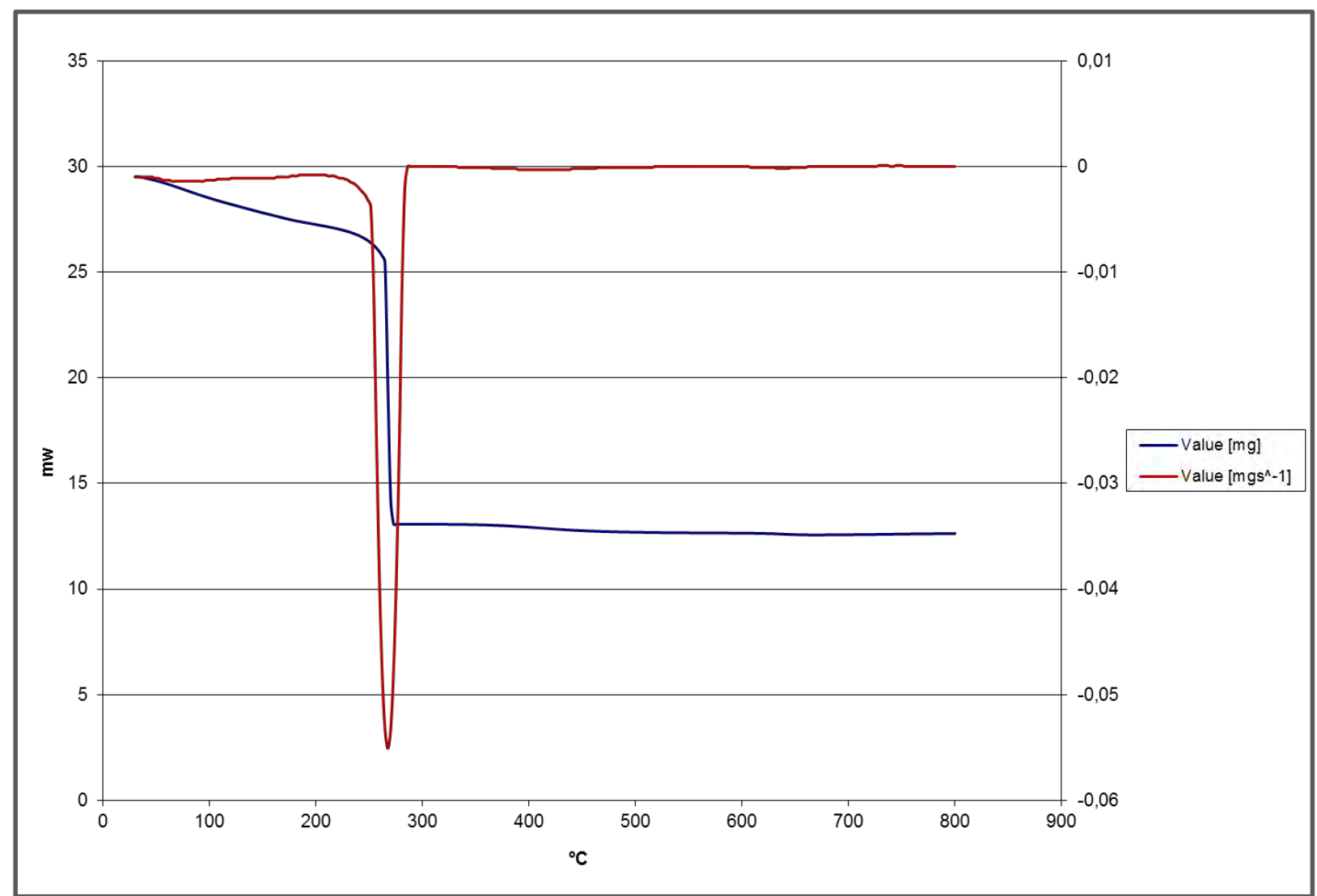

Figure 9-7. LRET 108

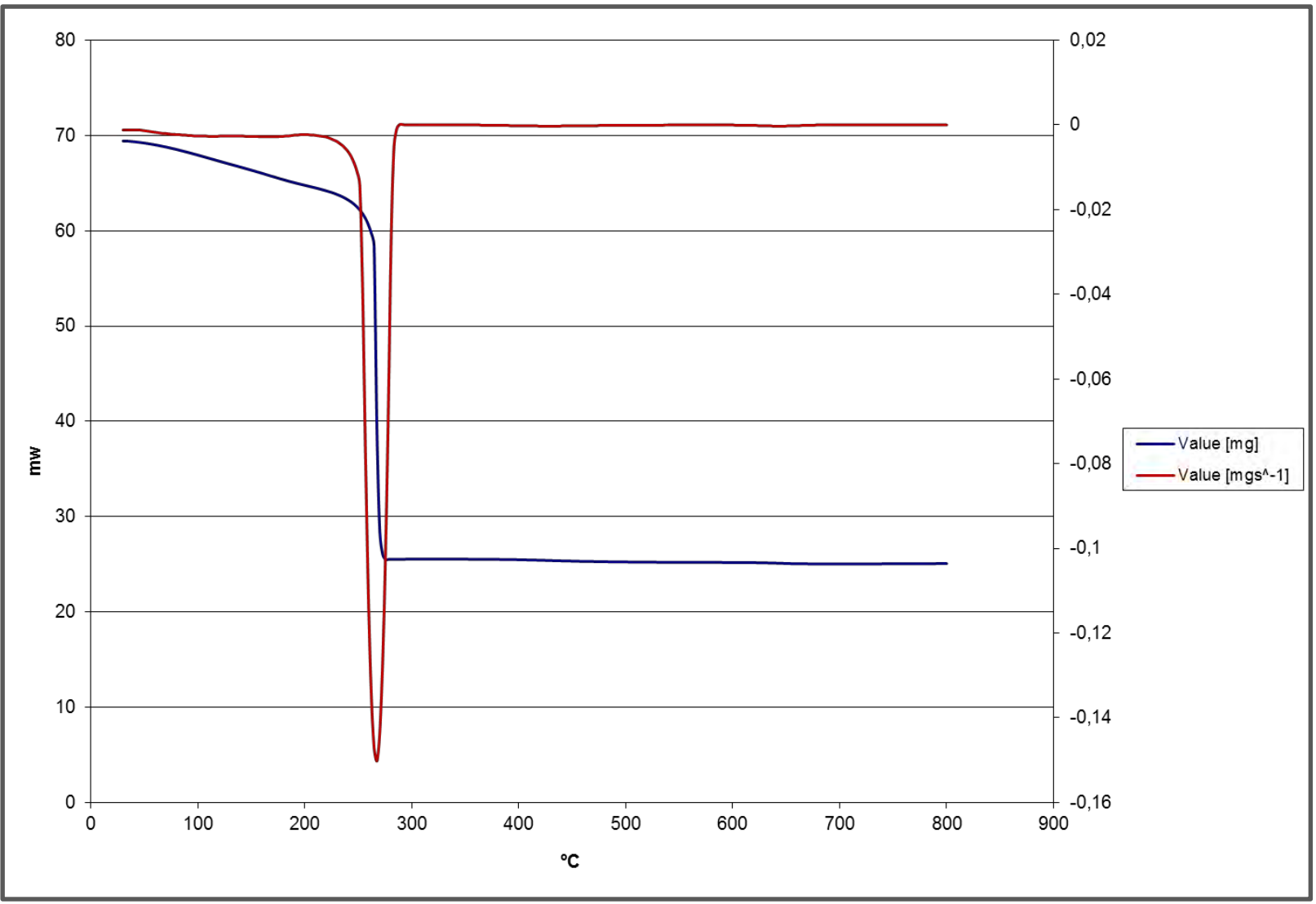

Figure 9-8. LRET 110 


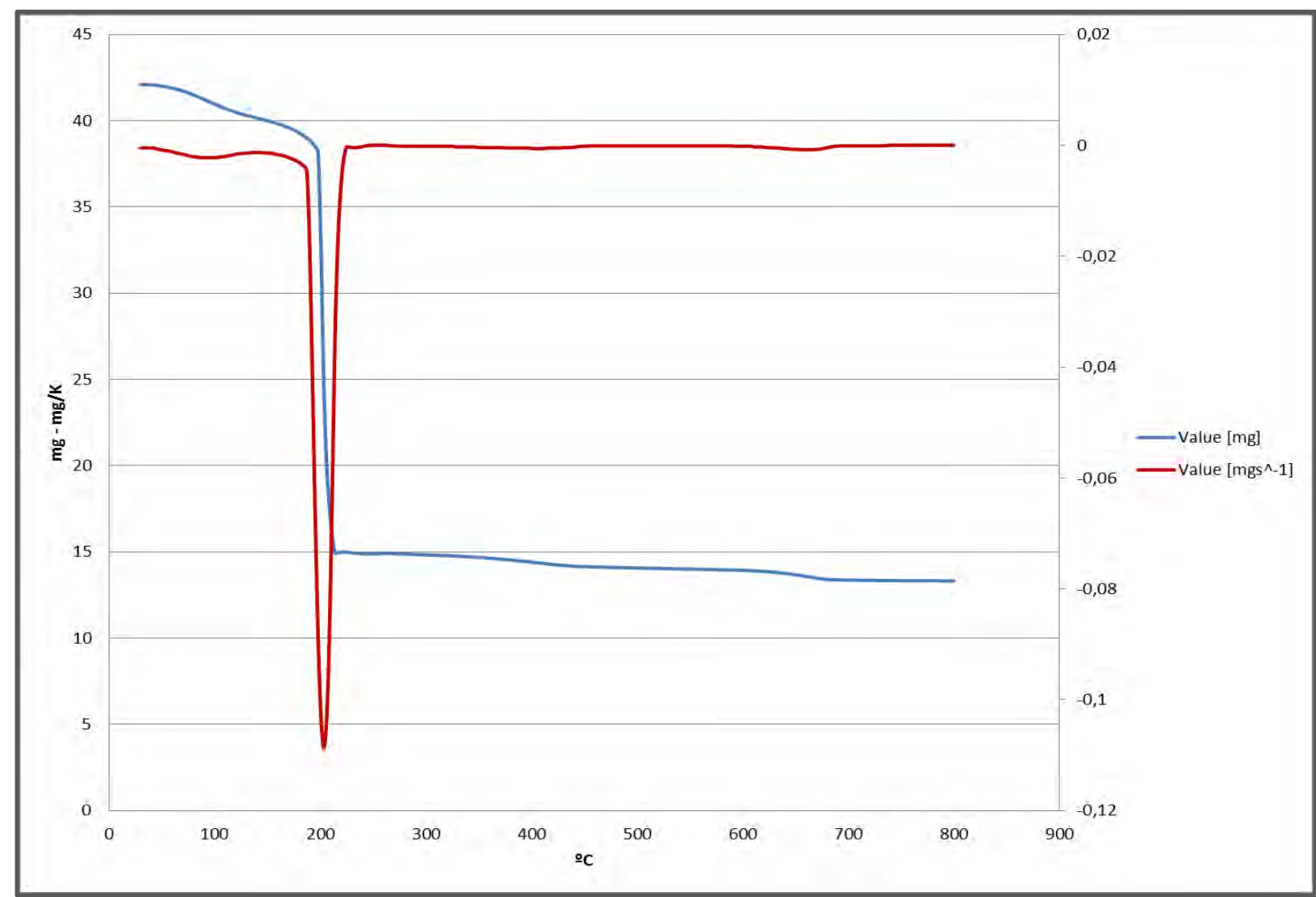

Figure 9-9. LRET 112

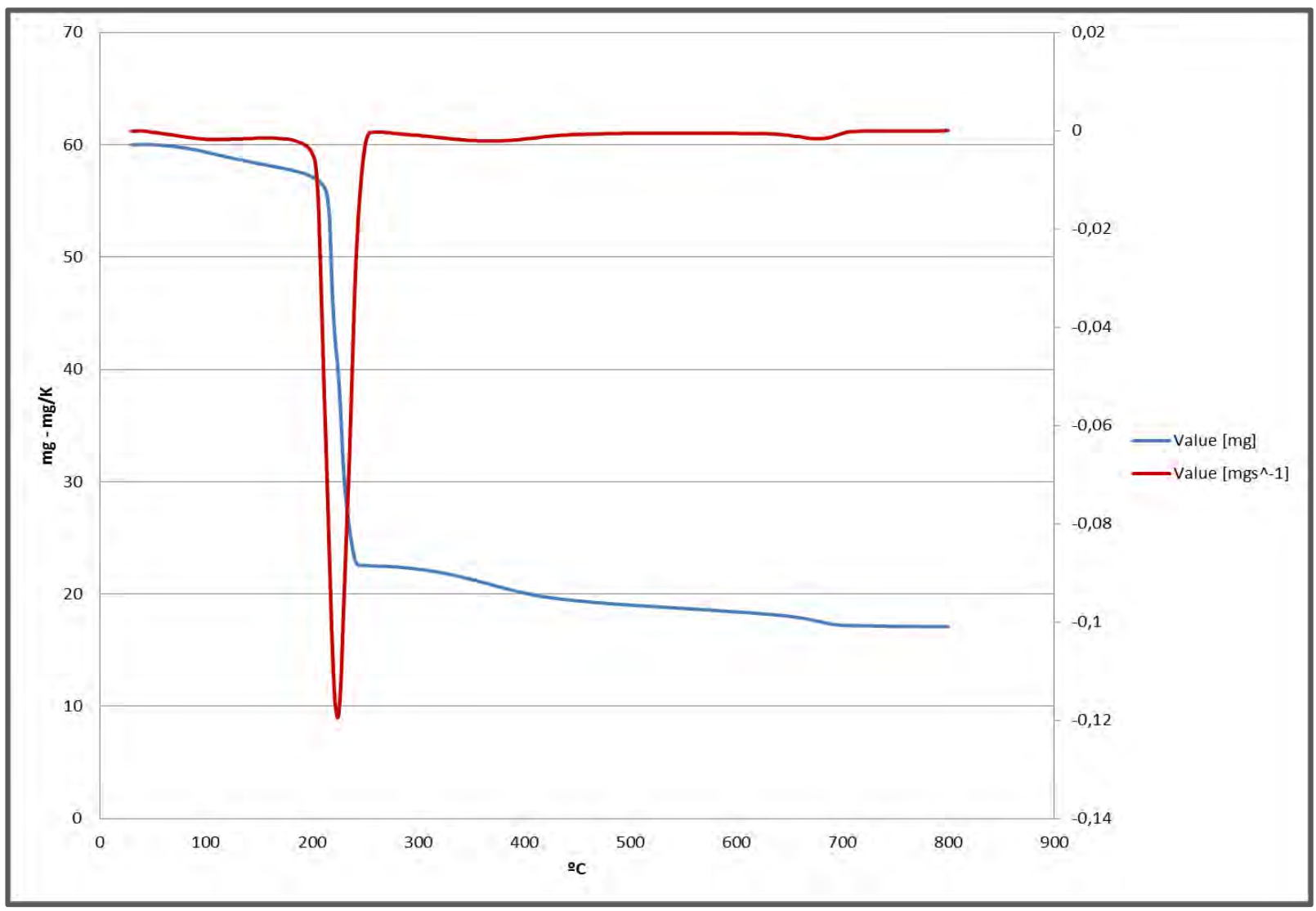

Figure 9-10. LRET 117 


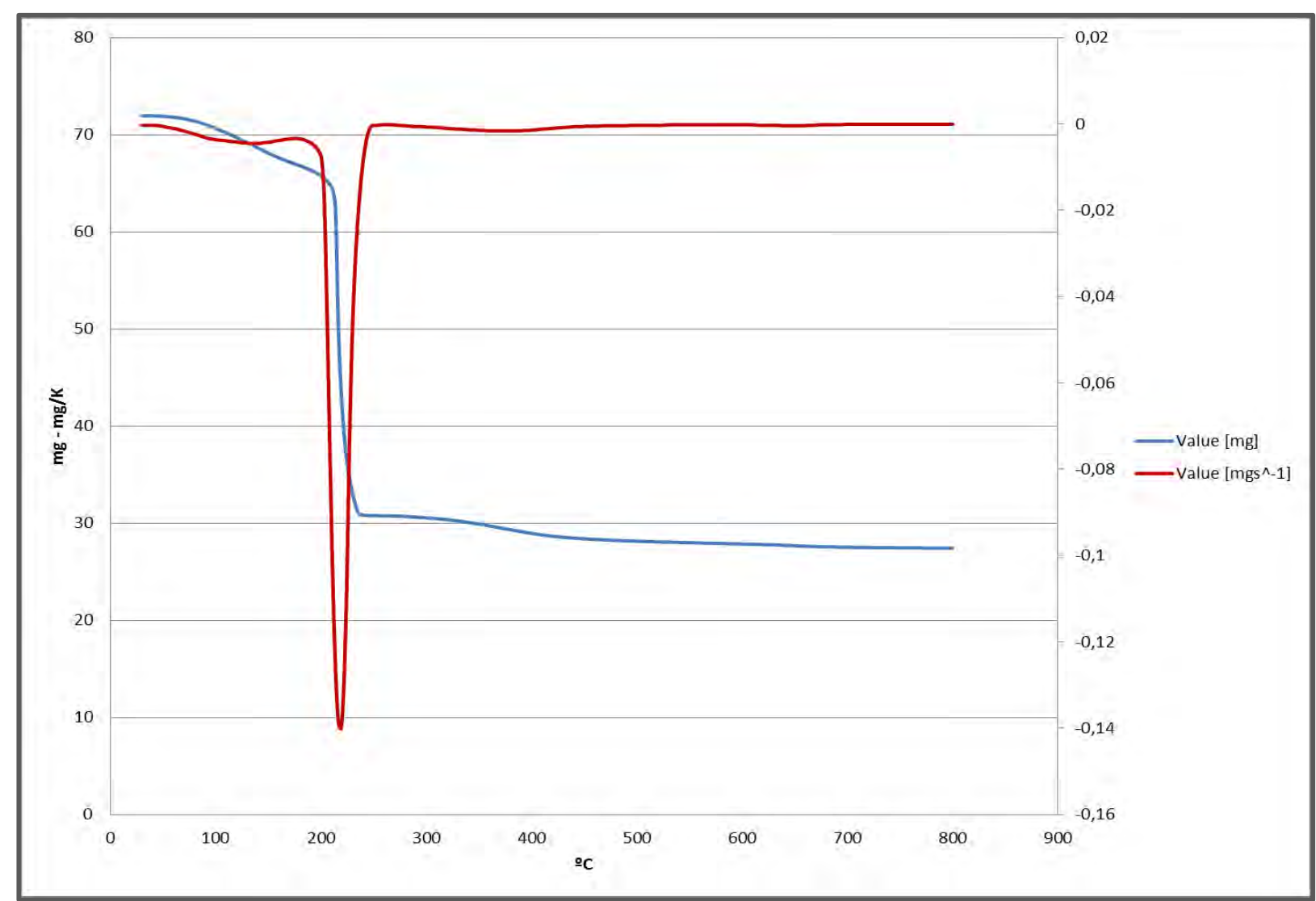

Figure 9-11. LRET 121 
10. Differential scanning calorimetry curves thermally dried sewage sludge

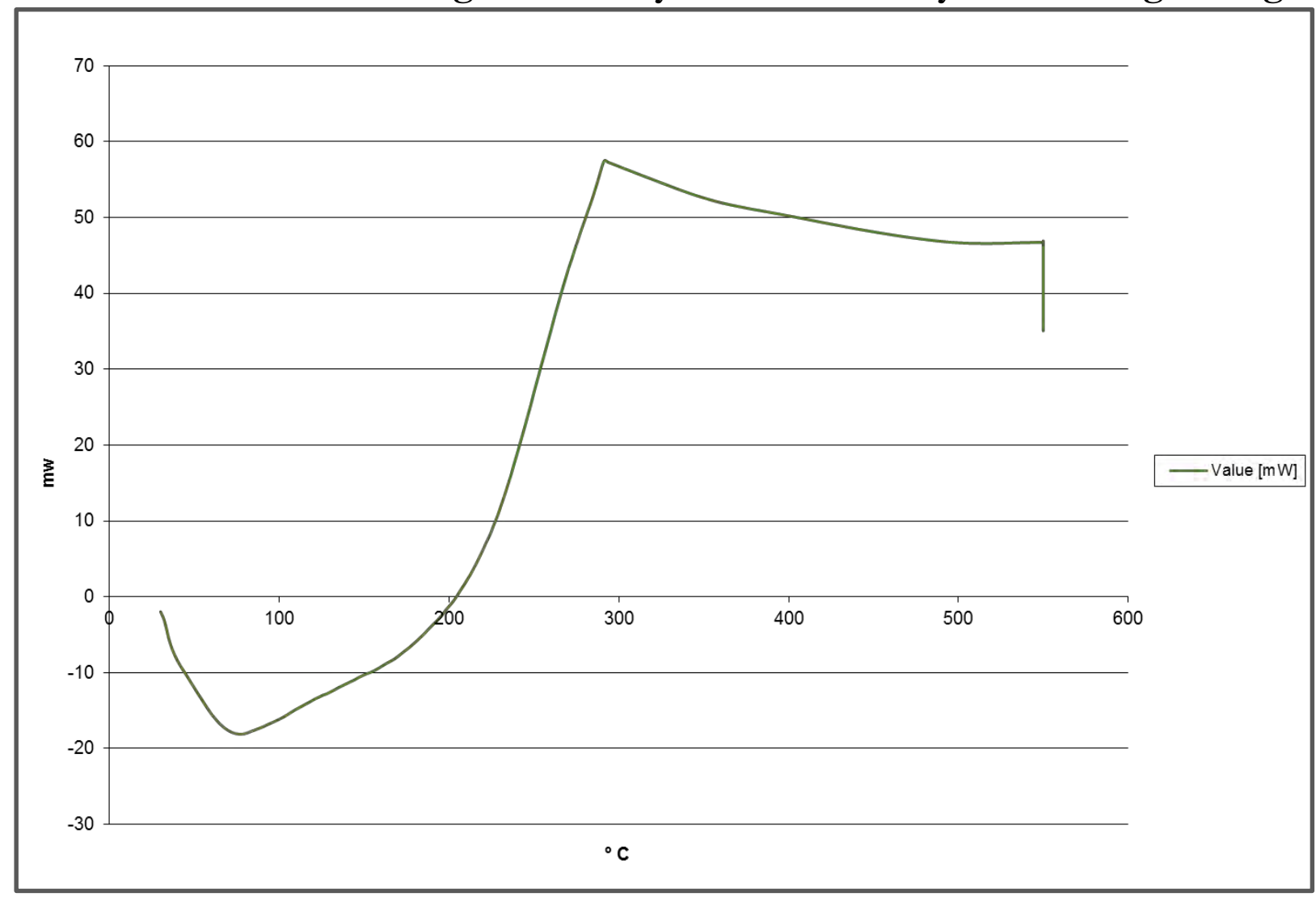

Figure 10-1. LRET 101

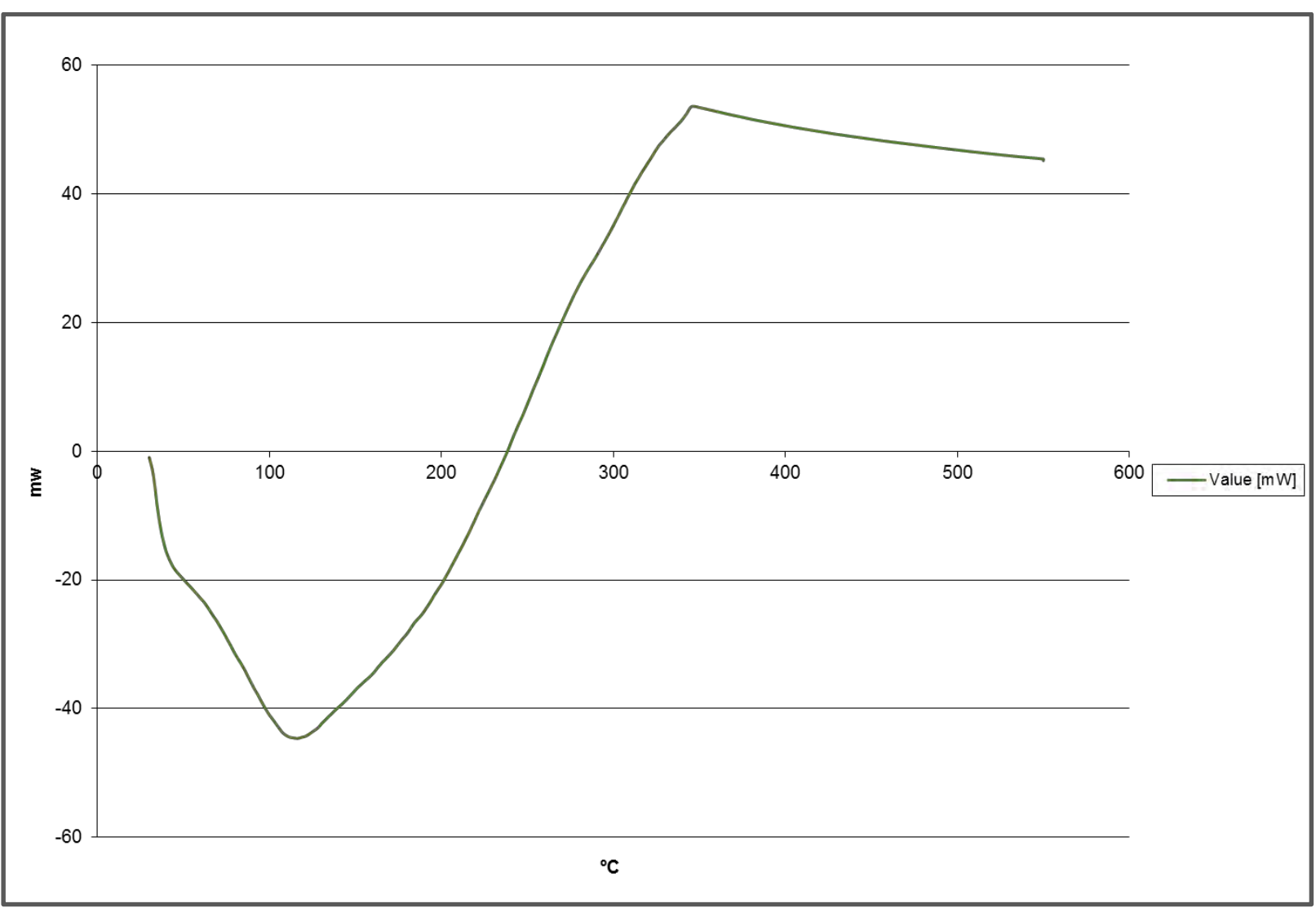

Figure 10-2. LRET 102 


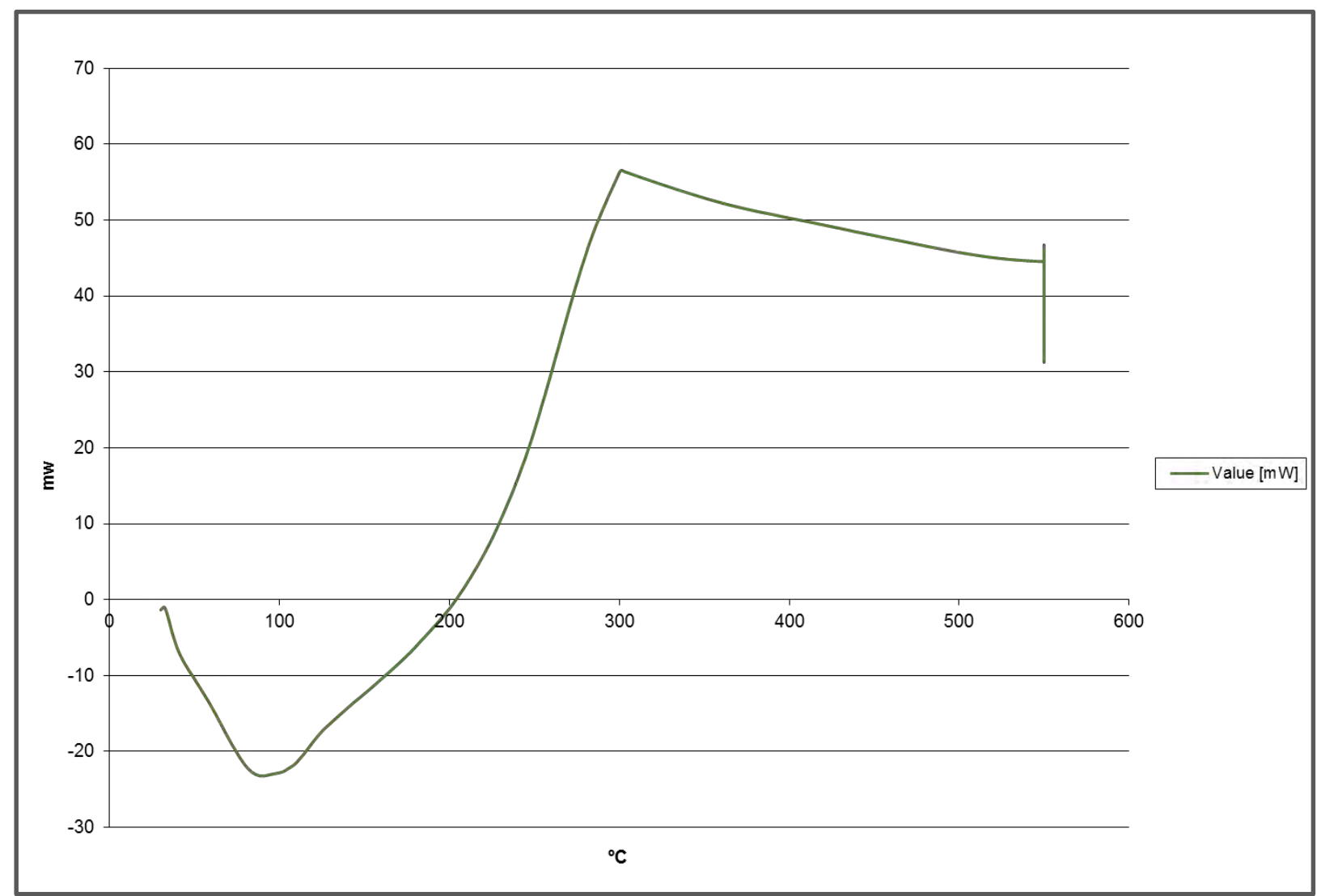

Figure 10-3. LRET 103

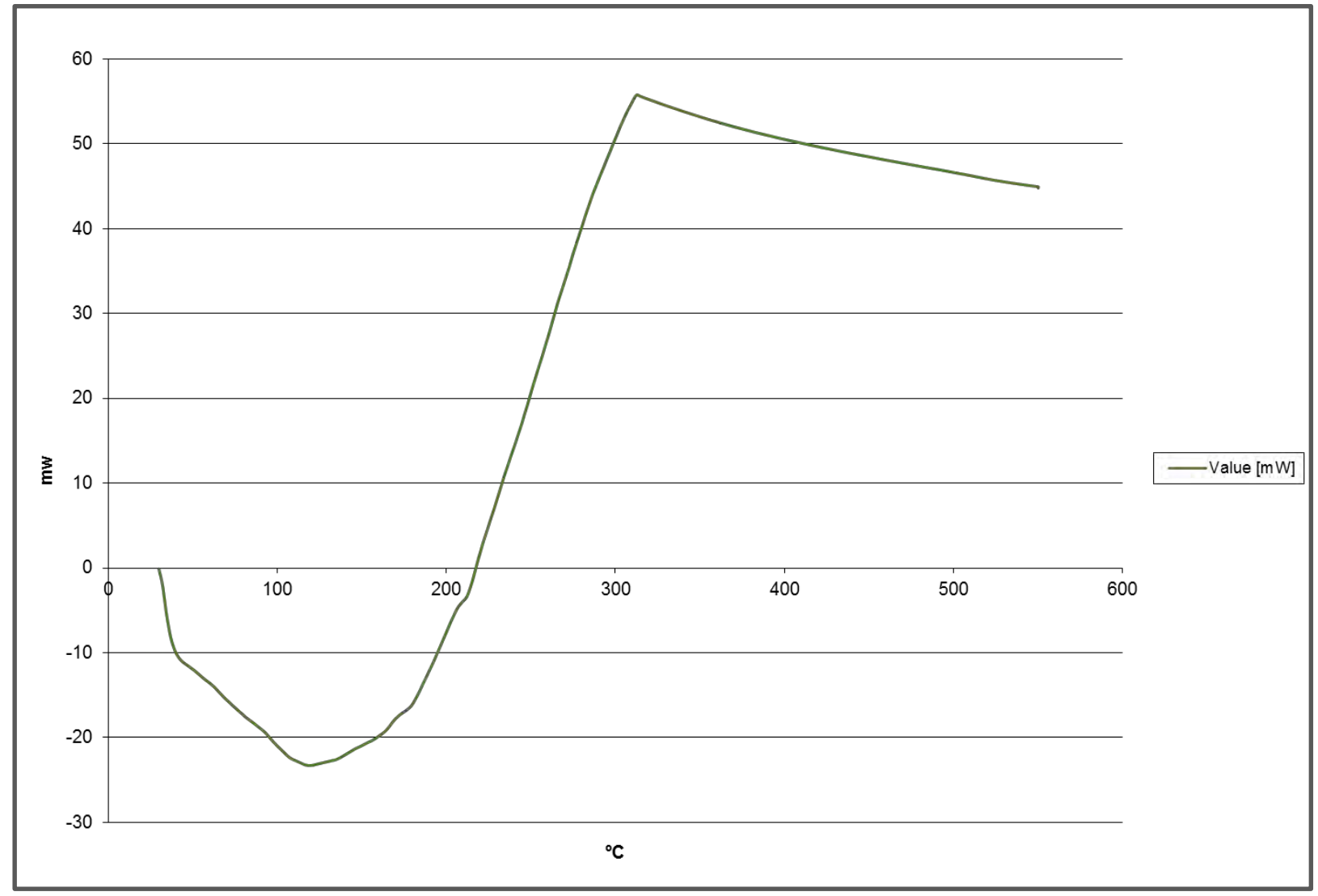

Figure 10-4. LRET 104 


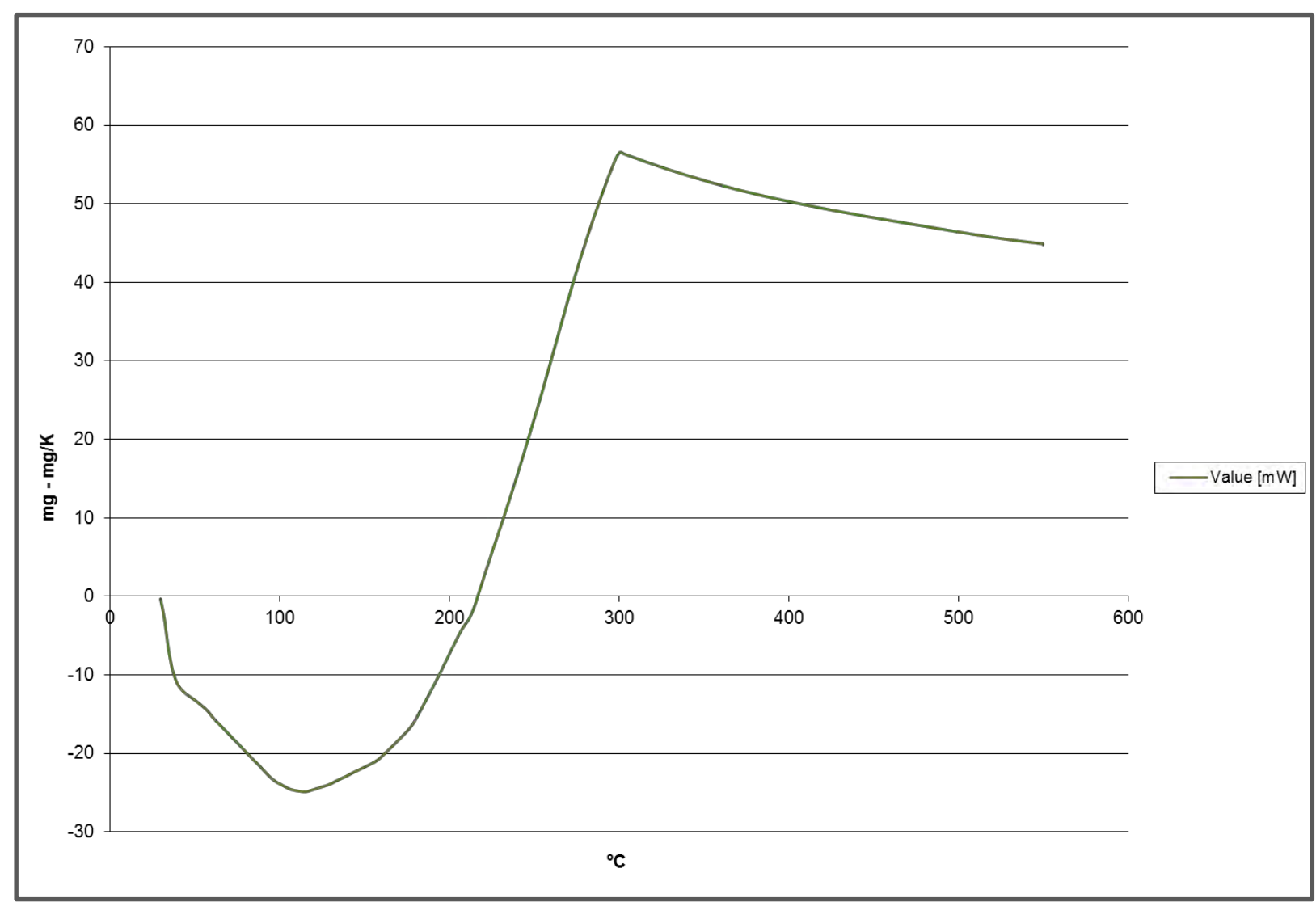

Figure 10-5. LRET 105

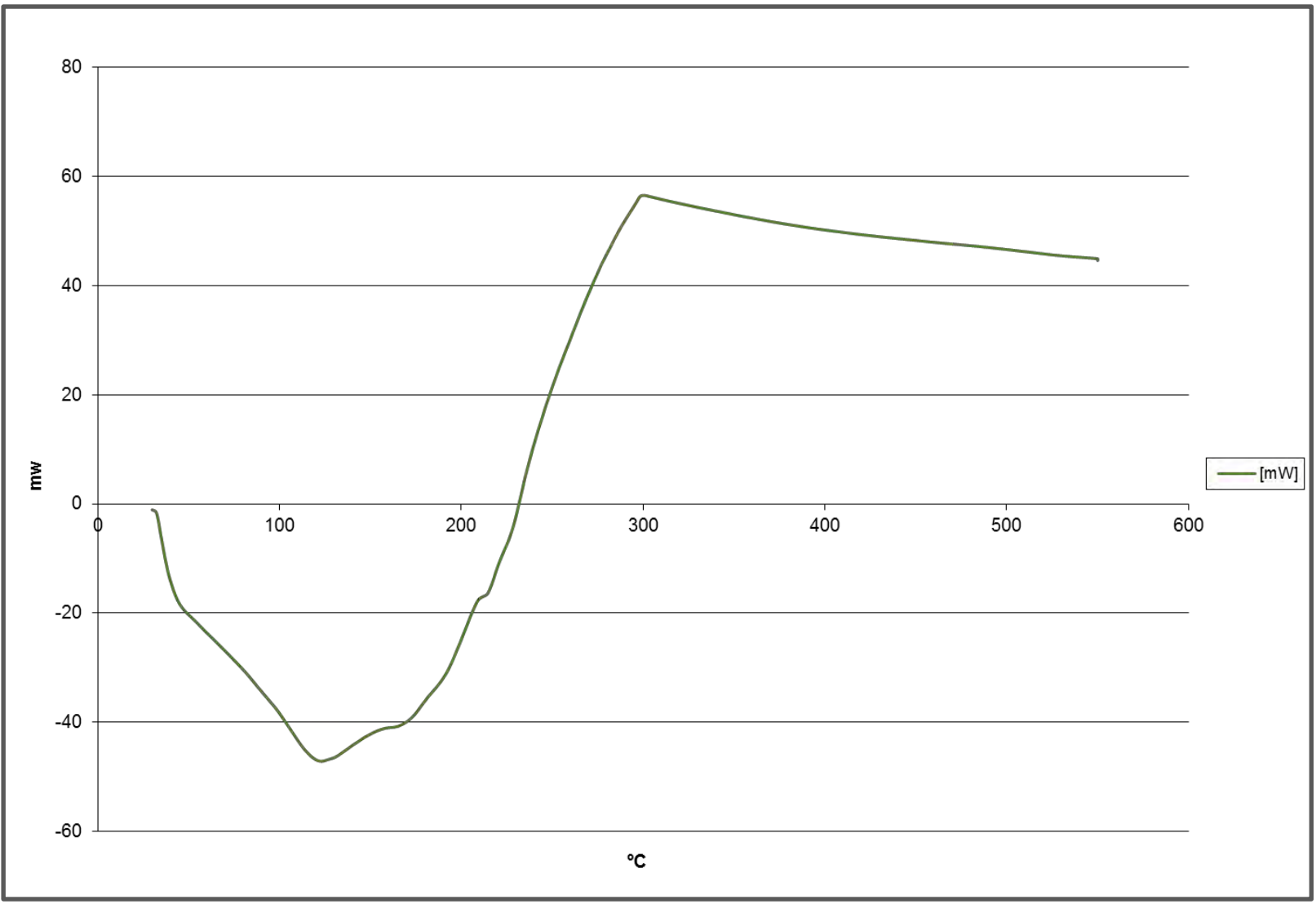

Figure 10-6. LRET 107 


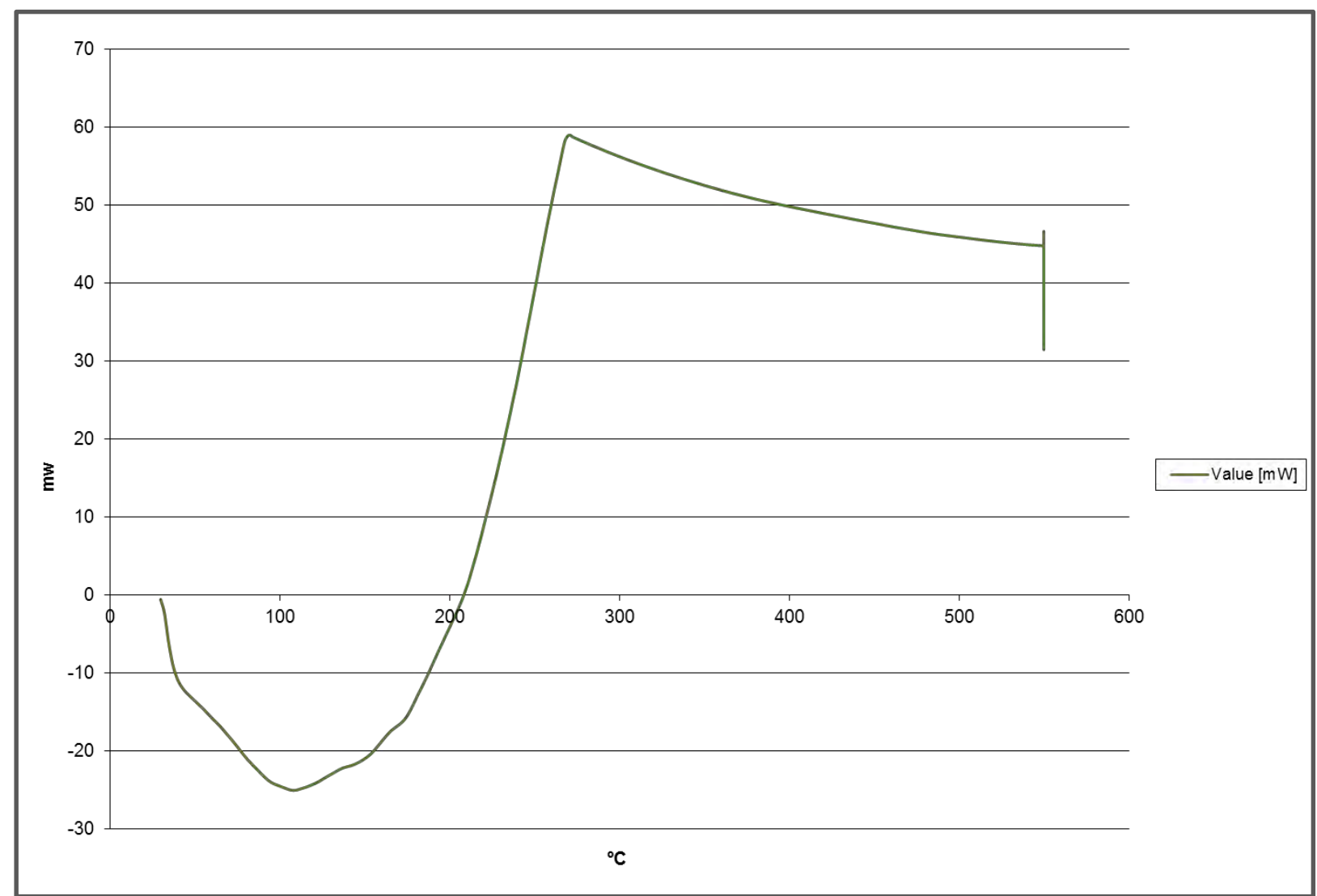

Figure 10-7. LRET 108

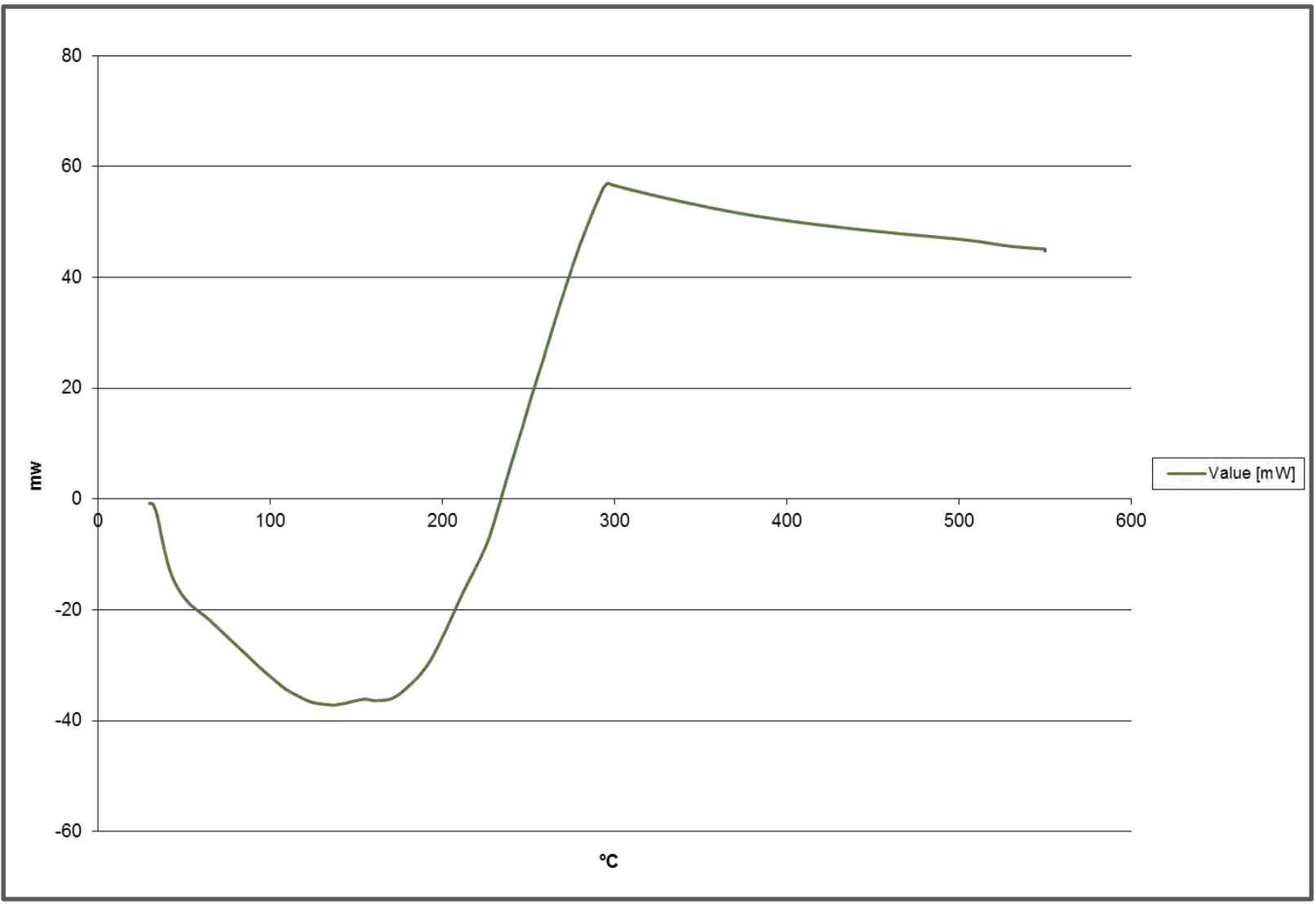

Figure 10-8. LRET 110 


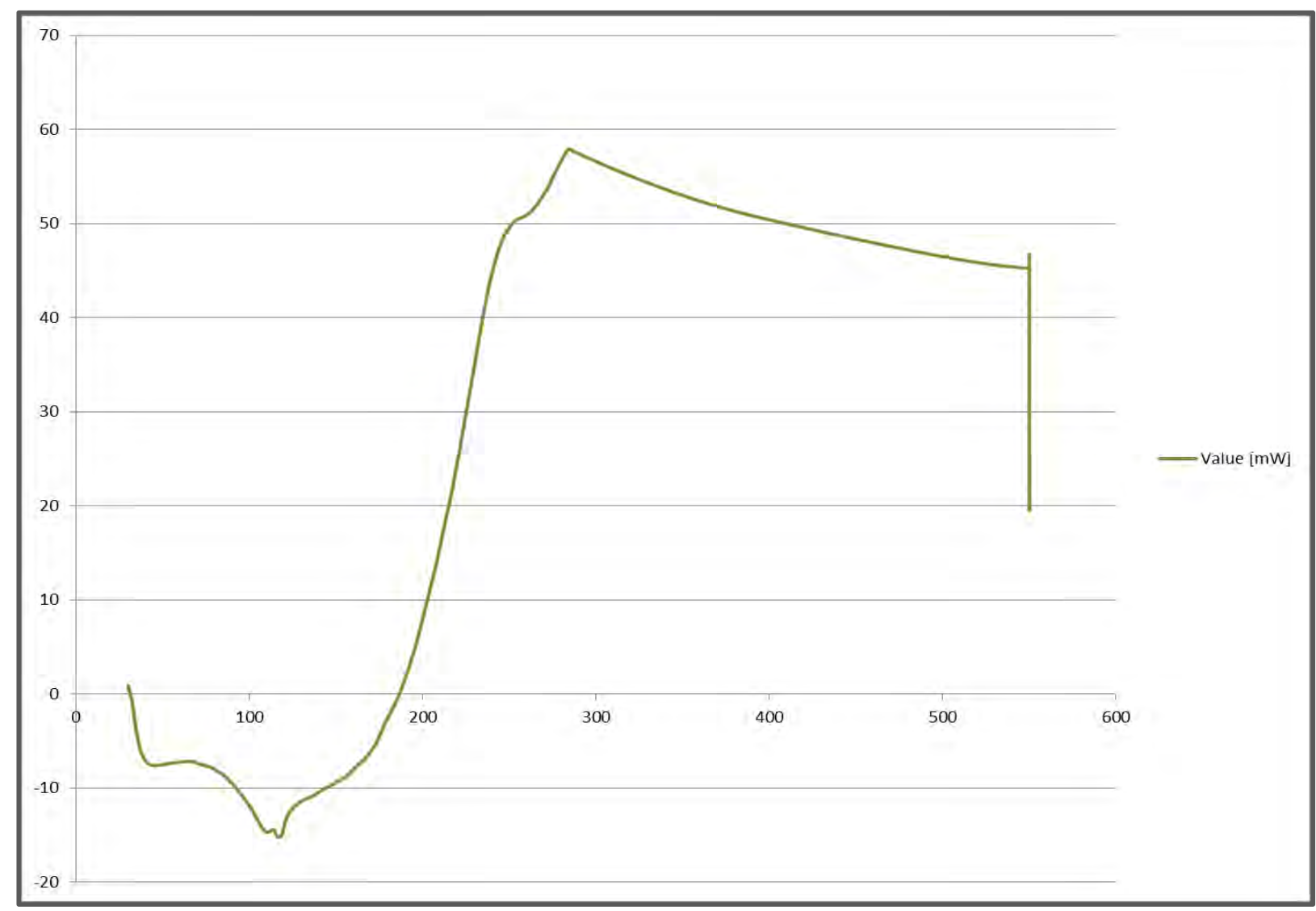

Figure 10-9. LRET 112

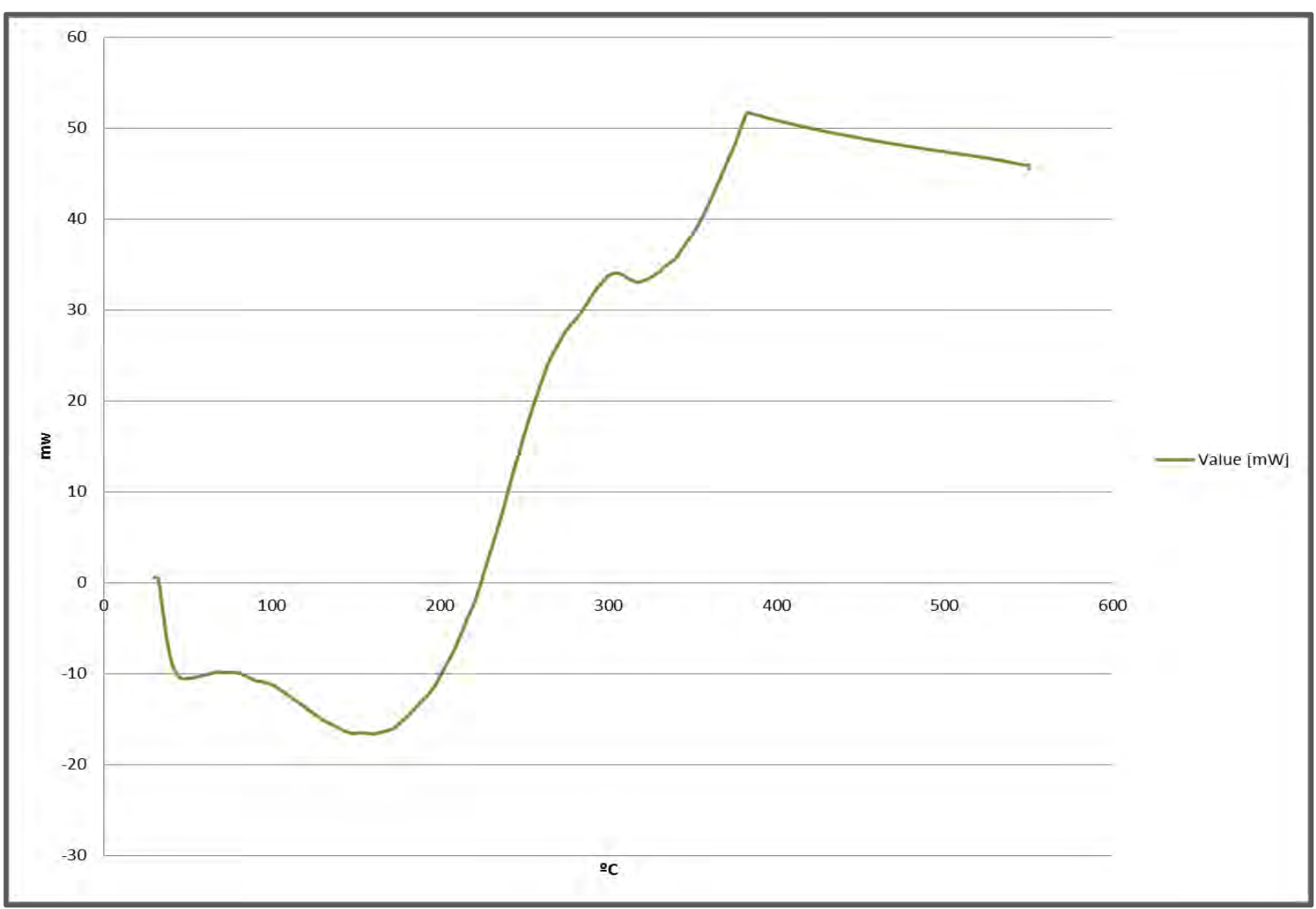

Figure 10-10. LRET 117 


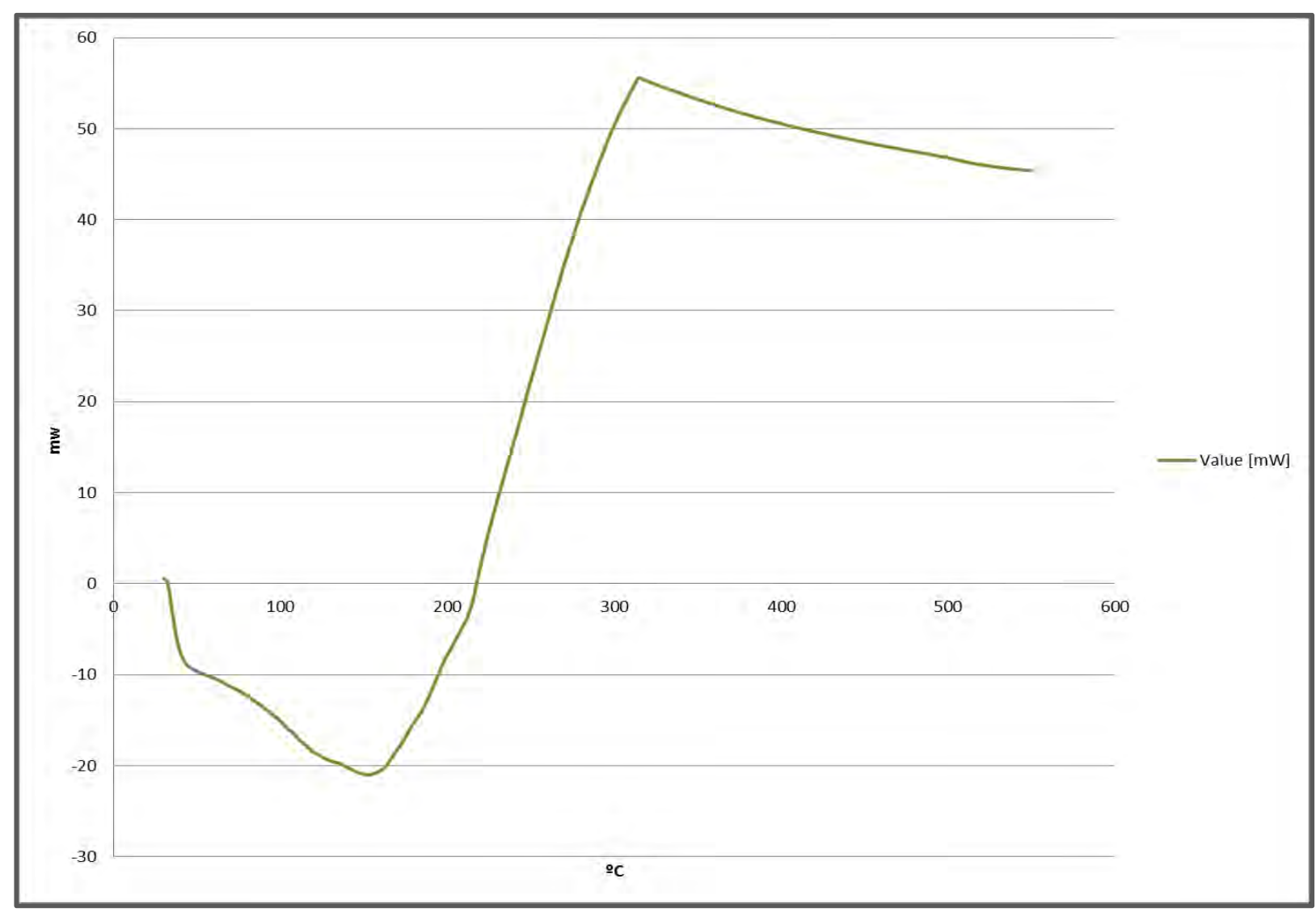

Figure 10-11. LRET 121 
11. Self-ignition temperature thermally dried sewage sludge (LRET-121)

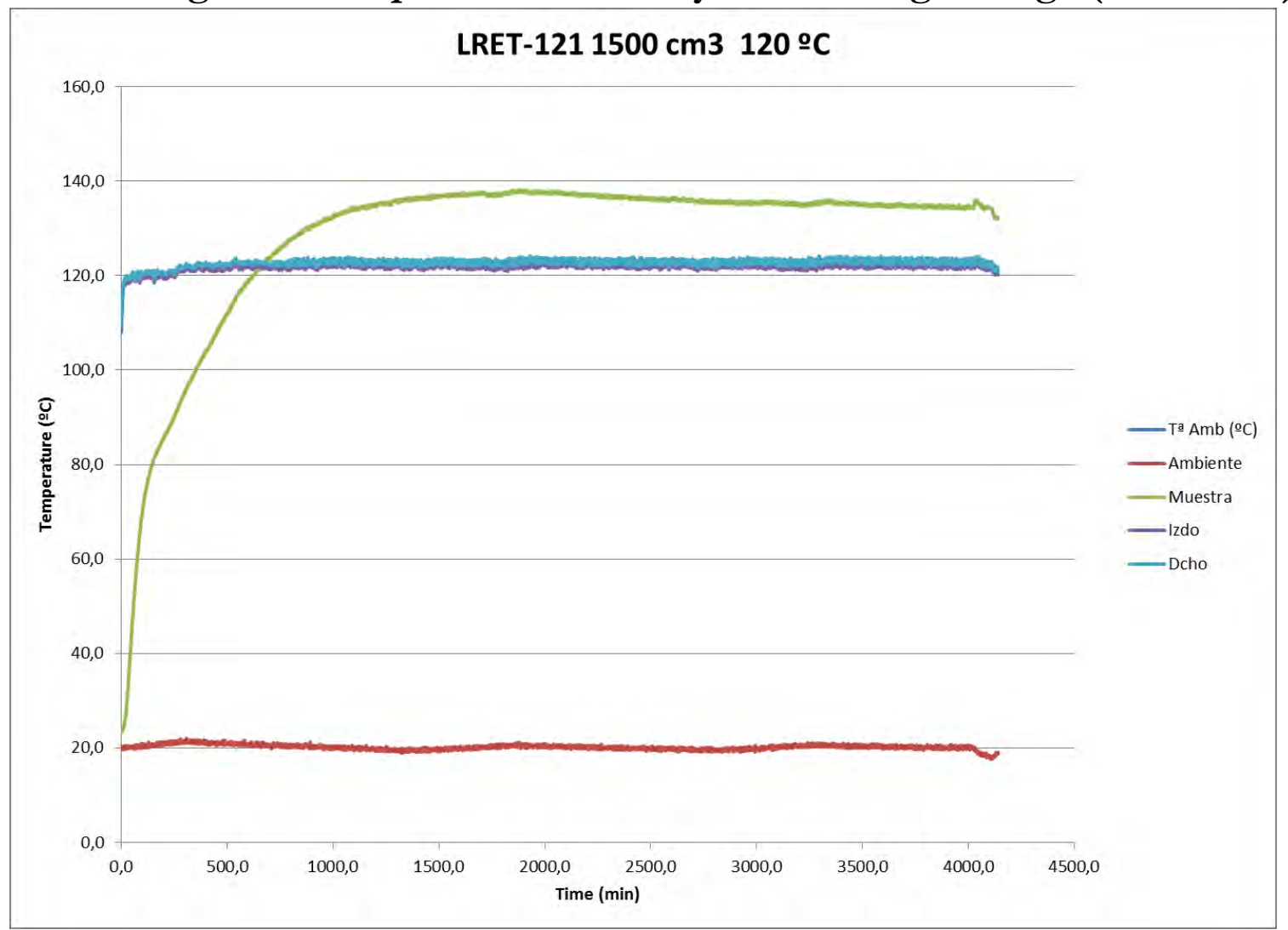

Figure 11-1. Self-ignition temperature test LRET-121 $1500 \mathrm{~cm}^{3} 120^{\circ} \mathrm{C}$

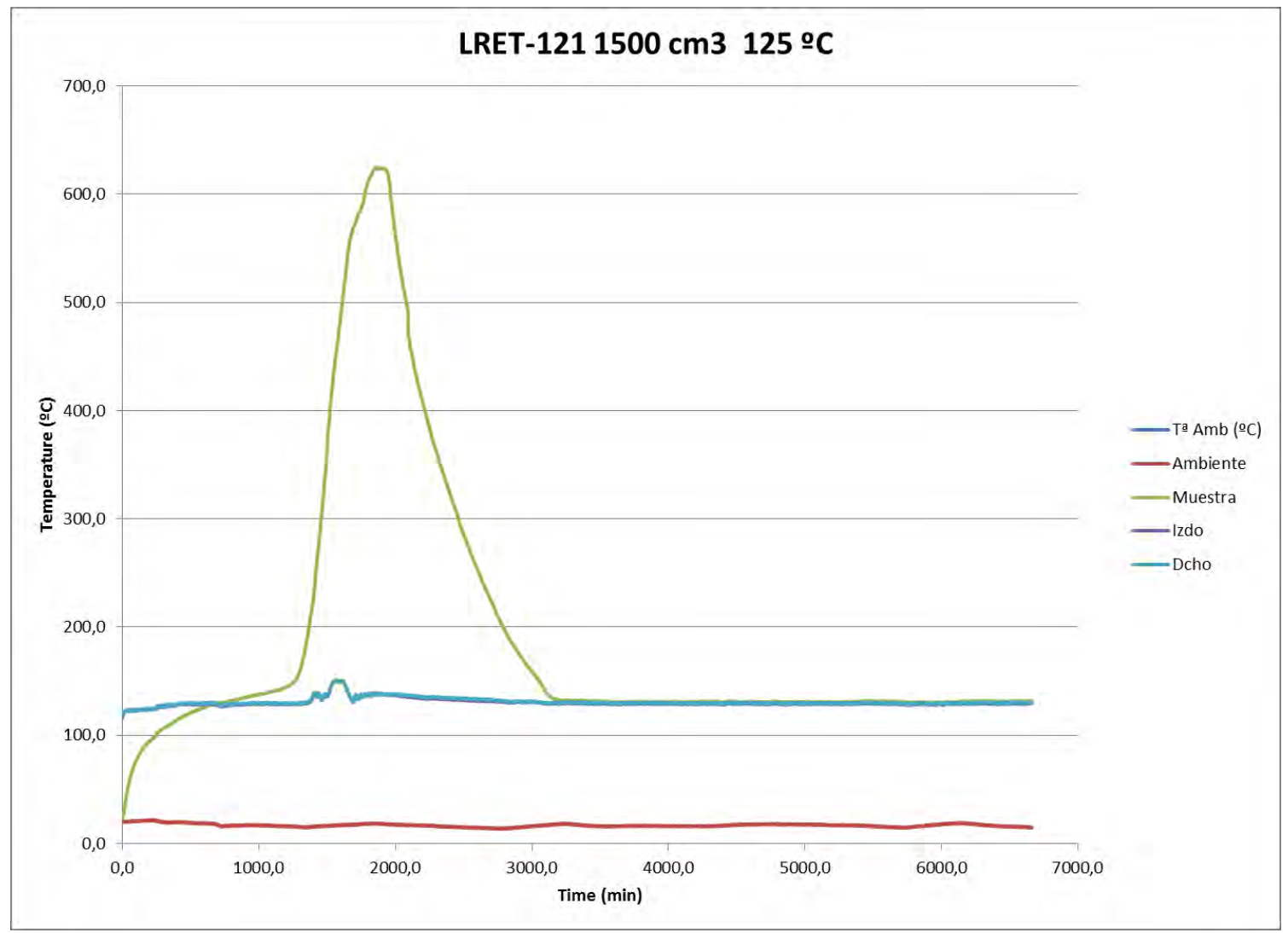

Figure 11-2. Self-ignition temperature test LRET-121 $1500 \mathrm{~cm} 3125^{\circ} \mathrm{C}$ 


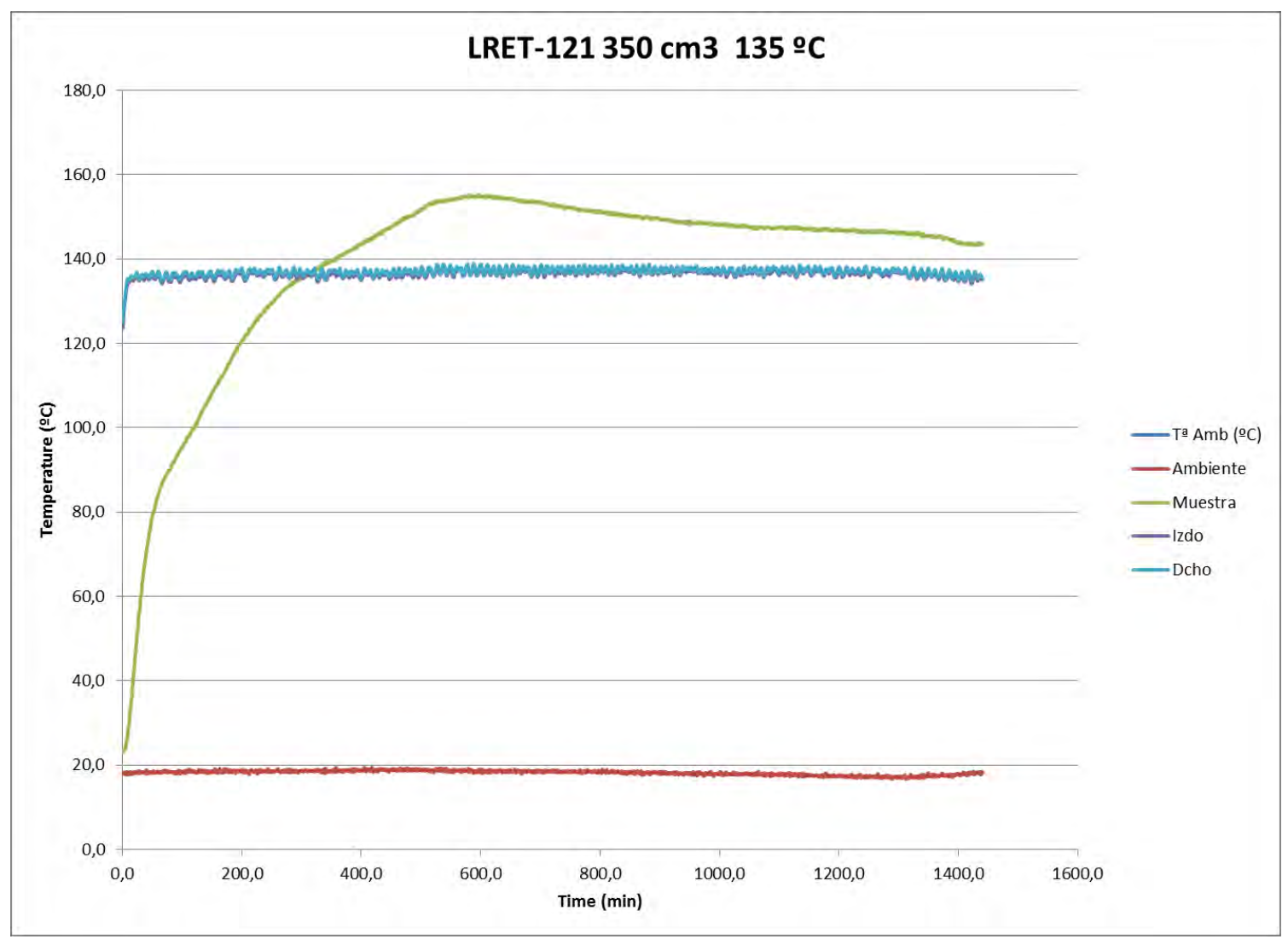

Figure 11-3. Self-ignition temperature test LRET-121 $350 \mathrm{~cm}^{3} 135^{\circ} \mathrm{C}$

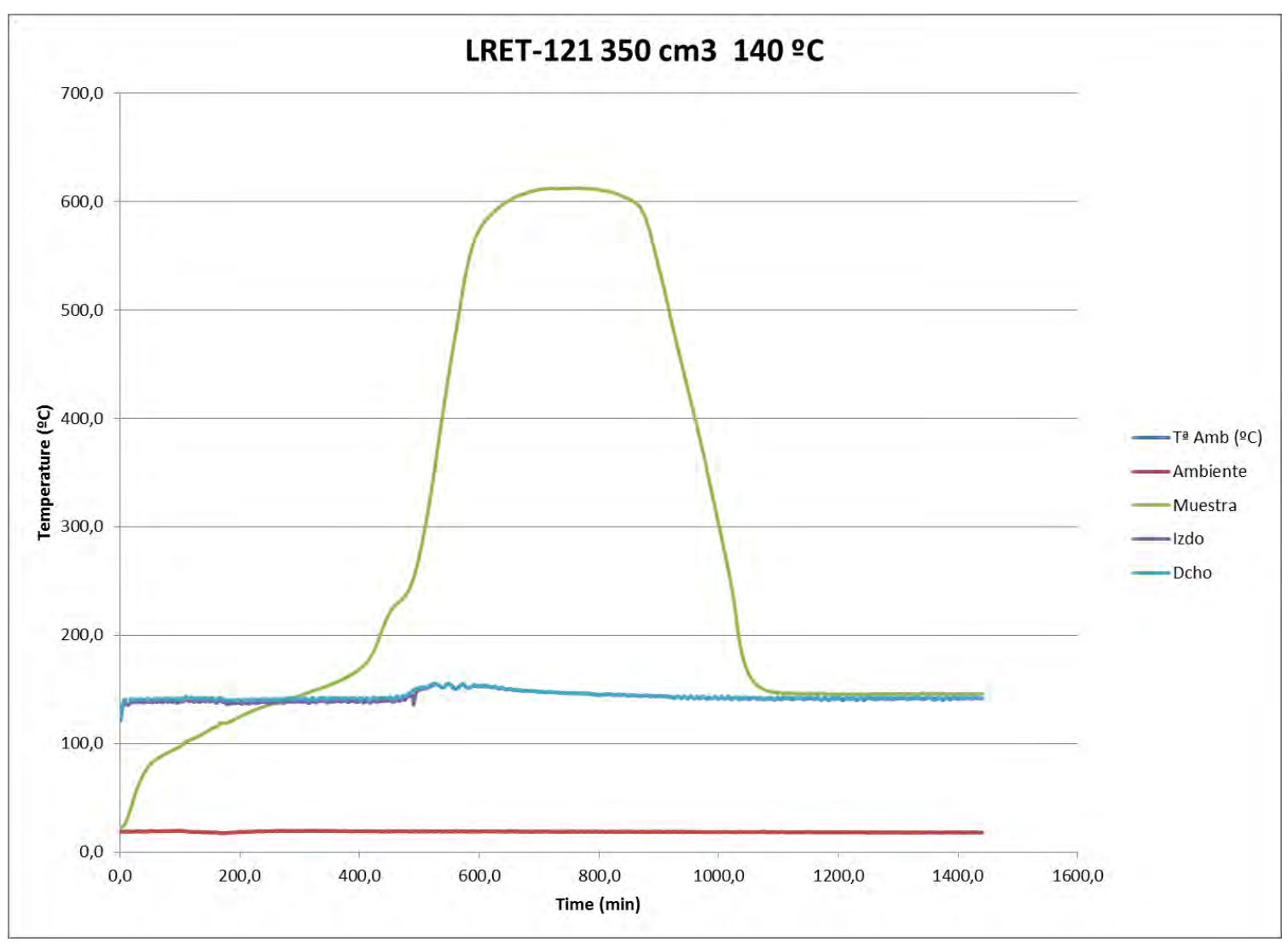

Figure 11-4. Self-ignition temperature test LRET-121 $350 \mathrm{~cm}^{3} 140^{\circ} \mathrm{C}$ 


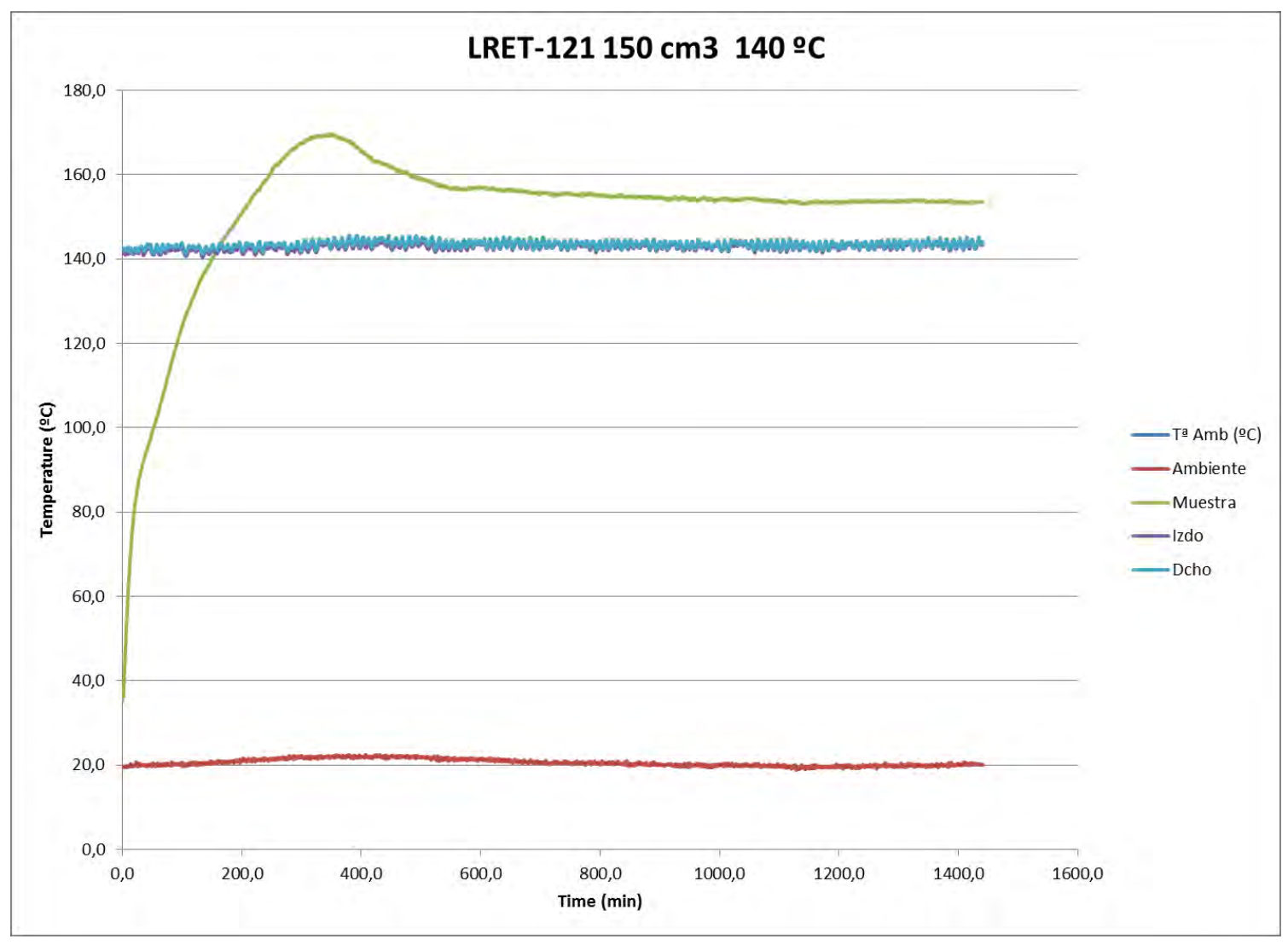

Figure 11-5. Self-ignition temperature test LRET-121 $150 \mathrm{~cm}^{3} 140^{\circ} \mathrm{C}$

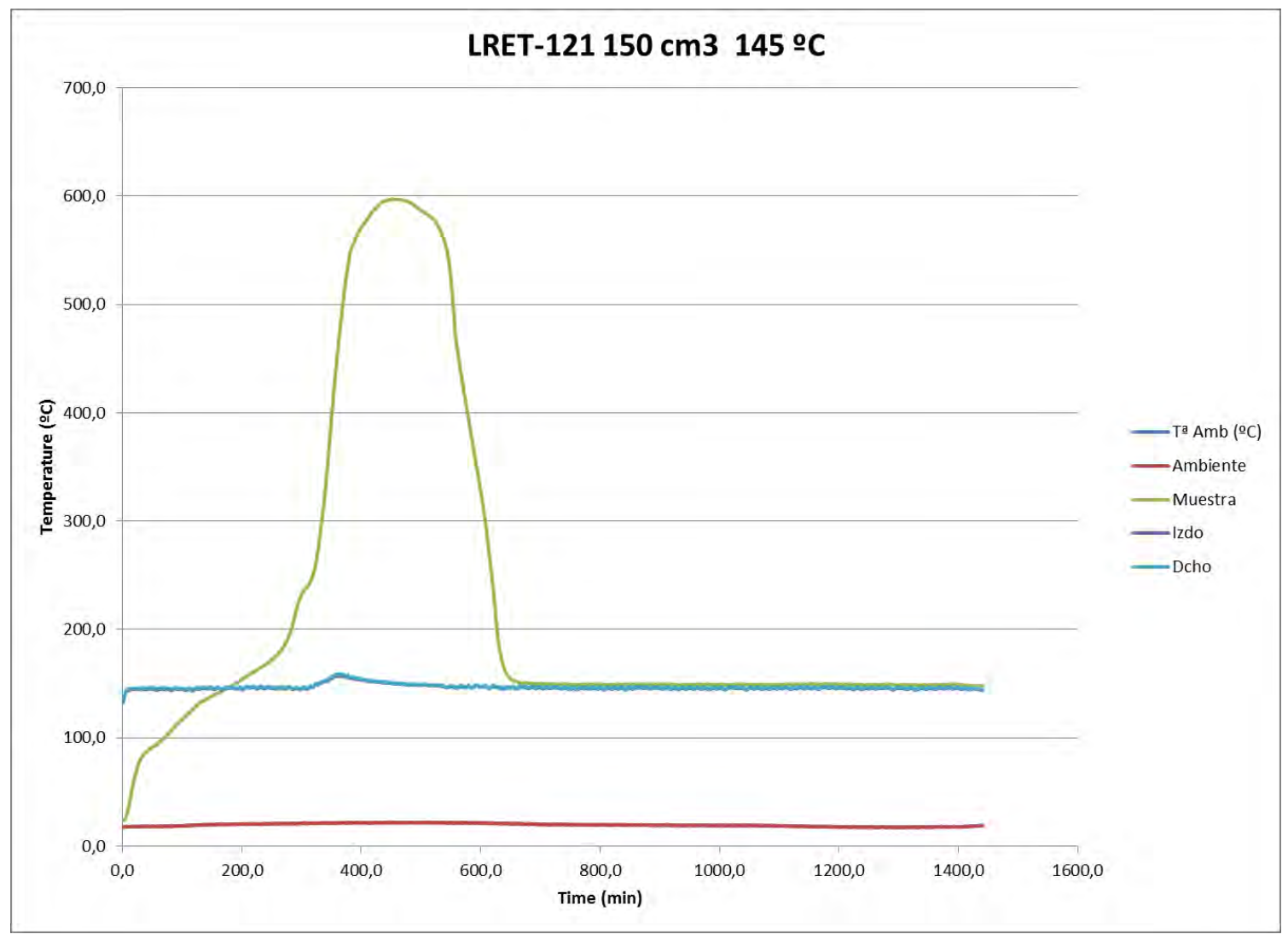

Figure 11-6. Self-ignition temperature test LRET-121 $150 \mathrm{~cm}^{3} 145^{\circ} \mathrm{C}$ 


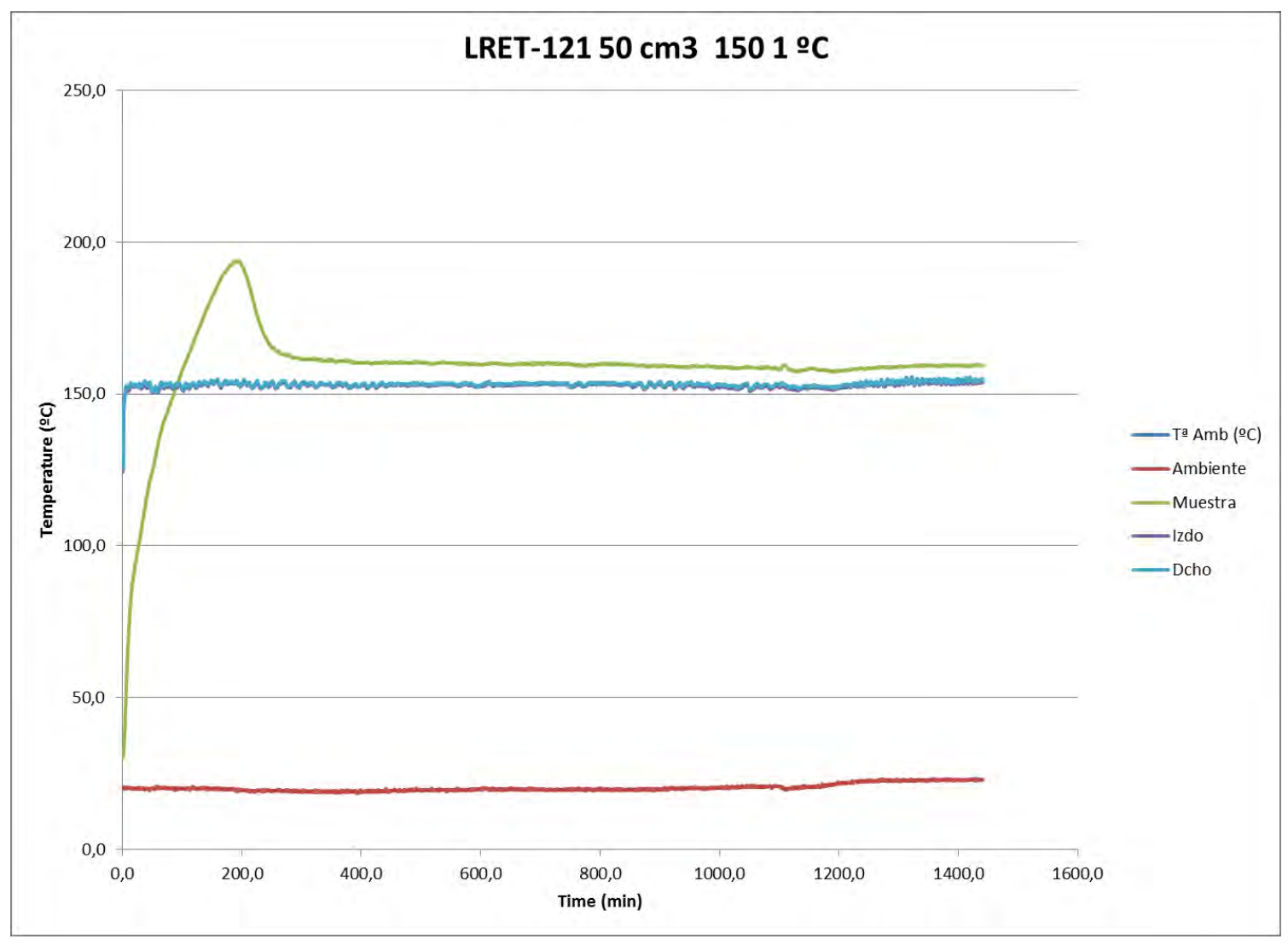

Figure 11-7. Self-ignition temperature test LRET-121 $50 \mathrm{~cm}^{3} 150^{\circ} \mathrm{C}$

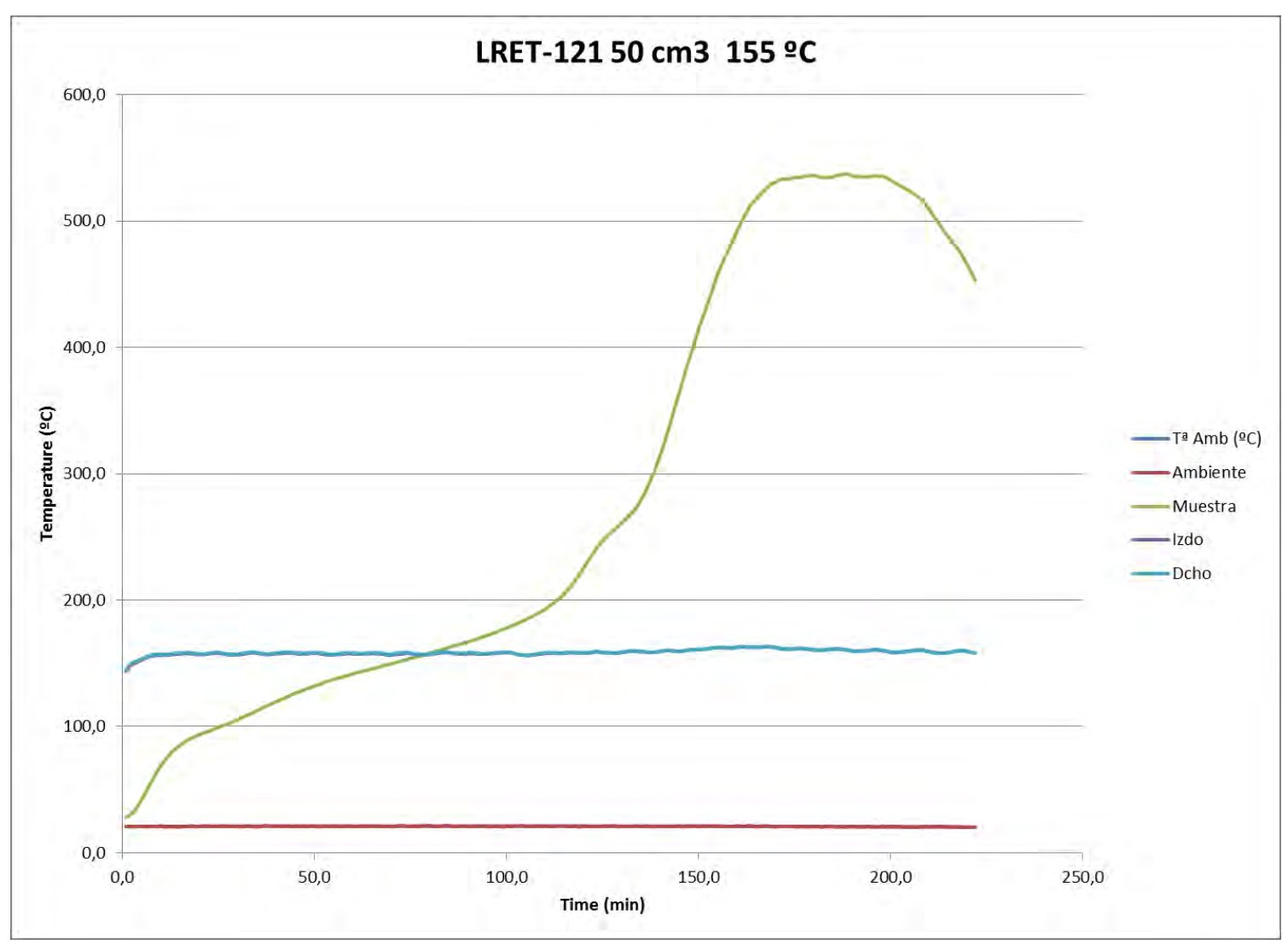

Figure 11-8. Self-ignition temperature test LRET-121 $50 \mathrm{~cm}^{3} 155^{\circ} \mathrm{C}$ 
12. Elemental analysis of mixtures

\begin{tabular}{|c|c|c|c|c|c|}
\hline Sample & $\mathrm{C}(\%)$ & $\mathrm{H}(\%)$ & $\mathrm{N}(\%)$ & $\mathrm{S}(\%)$ & $\mathrm{O}(\%)$ (diff.) \\
\hline NFA-101 & 62.7 & 5.2 & 4.8 & 9.9 & 17.3 \\
\hline NFA-102 & 57.9 & 6.4 & 5.4 & 7.9 & 22.4 \\
\hline NFA-103 & 57.6 & 6.8 & 5.4 & 5.6 & 24.5 \\
\hline NFA-104 & 60.6 & 4.8 & 3.6 & 8.1 & 22.9 \\
\hline NFA-105 & 59.6 & 5.0 & 3.3 & 4.3 & 27.8 \\
\hline NFA-106 & 57.3 & 5.0 & 2.0 & 1.8 & 33.9 \\
\hline NFA-107 & 52.6 & 6.6 & 2.7 & 1.2 & 36.9 \\
\hline NFA-108 & 53.7 & 6.8 & 1.9 & 0.5 & 37.1 \\
\hline NFA-109 & 54.5 & 5.8 & 1.7 & 0.2 & 37.8 \\
\hline NFA-110 & 57.2 & 5.9 & 1.8 & 4.0 & 31.1 \\
\hline
\end{tabular}

\section{Proximate analysis mixtures}

\begin{tabular}{|c|c|c|c|c|}
\hline Sample & Moisture (\%) & Volatiles (\%) & Ashes (\%) & Fixed carbon (\%) \\
\hline NFA-101 & 6.4 & 46.5 & 35.9 & 17.6 \\
\hline NFA-102 & 5.9 & 46.5 & 39.5 & 14.0 \\
\hline NFA-103 & 8.1 & 50.2 & 40.9 & 9.0 \\
\hline NFA-104 & 4.7 & 50.3 & 26.7 & 23.0 \\
\hline NFA-105 & 5.2 & 58.5 & 18.1 & 23.3 \\
\hline NFA-106 & 6.0 & 71.4 & 9.9 & 18.7 \\
\hline NFA-107 & 6.5 & 57.8 & 31.4 & 19.8 \\
\hline NFA-108 & 7.1 & 64.6 & 20.9 & 14.6 \\
\hline NFA-109 & 8.0 & 70.0 & 10.6 & 19.4 \\
\hline NFA-110 & 6.1 & 56.2 & 26.5 & 17.2 \\
\hline
\end{tabular}




\section{Annex III. Flammability properties of thermally dried sewage sludge}




\title{
Flammability properties of thermally dried sewage sludge
}

\author{
Nieves Fernandez-Anez ${ }^{\mathrm{a}, *}$, Javier Garcia-Torrent ${ }^{\mathrm{a}, \mathrm{b}}$, Ljiljana Medic-Pejic ${ }^{\mathrm{a}}$ \\ ${ }^{a}$ Department of Chemical Engineering and Fuels (UPM Technical University of Madrid, Spain), C/Alenza 4, 28003 Madrid, Spain \\ ${ }^{\mathrm{b}}$ Laboratorio Oficial Madariaga, LOM (UPM Technical University of Madrid, Spain), C/Eric Kandel, 1 - (TECNOGETAFE), Parque Científico y Tecnológico de la UPM, Getafe, \\ 28906 Madrid, Spain
}

\section{H I G H L I G H T S}

- Flammability parameters of sludge are presented.

- Relationships between chemical and flammability properties of sludge are analyzed.

- Physical and chemical properties of sludge dusts affects their explosibility.

- Seasons and origins of sludge should lead to a differentiation among samples.

\section{A R T I C L E I N F O}

\section{Article history:}

Received 18 March 2014

Received in revised form 29 May 2014

Accepted 3 June 2014

Available online 18 June 2014

\section{Keywords:}

Sewage sludge

Flammability

Self-combustion

Thermal stability

\begin{abstract}
A B S T R A C T
The treatment and disposal of sewage sludge is becoming an urgent need whereby different technologies were developed and integrated into the waste cycle all over the world. One of the most used technologies is the thermal drying of the sludge. Thermally dried sewage sludge has interesting properties that allow its use as an alternative fuel, but also needs some consideration from the point of view of its safe operation.

The aim of this study was the research on the flammability properties of sewage sludge, including ignition sensitivity, explosion severity, thermal sensitivity and thermal stability. Furthermore relationships among those properties and composition parameters have been determined, added to the study of their variation depending on their origin or season. Finally, properties related to spontaneous combustion were determined. To study these relationships and characteristics sludge samples were selected from different locations in Spain and taken during different seasons.
\end{abstract}

(C) 2014 Elsevier Ltd. All rights reserved.

\section{Introduction}

Due to the arise of consumption and the need to preserve water as an essential resource of life, there has been an increase of the existing wastewater treatment plants (WWTP) in order to collect the wastewater from a population or industry and, after a series of treatments and processes, return it to a receiving stream [1,2].

Actually, many actions are being carried out focused on the reuse of the waste produced by these WWTP [3]. One of the most developed reusing methods is thermal drying. This is an attractive alternative and it also provides the opportunity for an economical resource recovery [4]. Actually, thermal drying of sewage sludge is the most common method used in 2 countries of the 27 forming the EU members, a common method on 12 countries and a rare method in 1 country [5].

\footnotetext{
* Corresponding author. Tel.: +34 9133641 73; fax: +34 913366948 .

E-mail address: nieves.fernandez@upm.es (N. Fernandez-Anez).
}

Most occupational hazards in wastewater treatment, including methane production, are well known [6]. Focusing on the thermal drying process, there is a general risk understudied that produces serious consequences: the risk of generation of explosive atmospheres (ATEX) caused by dusts and a possible consequent explosion [7]. This risk is present in all the industrial plants, and may be well studied to avoid accidents [8].

Dust generated in the thermal drying of sewage sludge is a fuel product [9] and it can produce an explosion due to the chemical reaction: fuel + oxygen $=$ oxides + heat $[10]$.

To design the prevention and protection measurements needed in all the industrial plants a complex methodology is necessary to take into account all the existing hazards [11]. Several researchers have demonstrated that it is essential to characterize the sewage sludge [12,13]. Characterization of new fuels, mainly biomass, has experience an important advance through various researches in recent years [14,15], trying to have a complete scenario of their hazards likes the one nowadays existing for coal [16]. 
First of all, it is necessary to take into account the chemical composition of the sewage sludge. This chemical composition varies among different samples but it is always formed by organic matter, inorganic matter and gases [17] and approximately $75 \%$ of suspended solids and $40 \%$ of filterable solids are organic in nature [18]. As an example of the influence of the chemical composition in the explosibility of dusts, it is shown that the inorganic matter of coal has a negative correlation with the self-heating rate [19].

Other relations that are observed in other substances are those existing among different flammability parameters and the particle size distribution and concentration [20,21], the humidity [22] and the dustiness [23].

All these parameters depend on the sewage sludge studied, and some seasonal and time variability of the composition differences are shown in various studies [24,25].

The aim of this paper is to determine the relations among different explosibility parameters and also among them and the chemical parameters to try to avoid these risks. Also the variability due to seasonal and geographical parameters is studied. Finally, the selfheating of sewage sludge is studied, since this product may be stored for long periods and self-ignition temperature is an important parameter [26].

\section{Materials and methods}

Twenty sewage sludge thermally dried samples have been studied. Those samples have been chosen in order to study seasonal and regional variations, so the samples come from different places and also from different seasons. The samples have been collected in eight WWTP belonging to three regions in Spain: Barcelona, Madrid and Málaga. According to the season when the samples have been collected, they are classified in summer samples or winter samples. If the samples have been collected between May and September, they are classified as summer samples. Otherwise, they have been classified as winter samples. The samples collected are detailed in Table 1.

For all the samples, ultimate and proximate analyses have been conducted and granulometry have been determined. Depending on the results of these tests, ten samples have been selected to develop the ignition sensibility, explosion severity and thermal susceptibility analyses. Finally, due to these results the thermal stability analyses have been done to three samples.

Among all these tests, some are standardized and well known tests, such as ignition sensibility (flammability), explosion severity

Table 1

Collected samples.

\begin{tabular}{lllccc}
\hline Sample & Origin & Season & $\mathrm{d} 10(\mu \mathrm{m})$ & $\mathrm{d} 50(\mu \mathrm{m})$ & $\mathrm{d} 90(\mu \mathrm{m})$ \\
\hline LRET-101 & Barcelona & Summer & 15.4 & 67.9 & 355.3 \\
LRET-102 & Barcelona & Summer & 111.9 & 339.5 & 815.8 \\
LRET-103 & Barcelona & Winter & 23.4 & 100.4 & 289.2 \\
LRET-104 & Madrid & Summer & 96.7 & 382.2 & 818.6 \\
LRET-105 & Madrid & Summer & 88.6 & 397.2 & 844.1 \\
LRET-106 & Madrid & Summer & 13.2 & 77.7 & 371.2 \\
LRET-107 & Madrid & Winter & 69.2 & 385.9 & 853.9 \\
LRET-108 & Madrid & Winter & 10.9 & 30.2 & 160.5 \\
LRET-110 & Madrid & Winter & 88.2 & 382.5 & 839.7 \\
LRET-111 & Madrid & Winter & 10.3 & 43.0 & 383.9 \\
LRET-112 & Málaga & Winter & 7.5 & 27.3 & 62.2 \\
LRET-113 & Málaga & Winter & 81.3 & 517.6 & 1150.7 \\
LRET-114 & Barcelona & Summer & 69.7 & 298.9 & 664.3 \\
LRET-115 & Barcelona & Summer & 152.3 & 492.5 & 1098.7 \\
LRET-116 & Barcelona & Winter & 52.3 & 531.6 & 1218.2 \\
LRET-117 & Barcelona & Winter & 34.1 & 74.4 & 348.3 \\
LRET-118 & Madrid & Winter & 7.4 & 20.6 & 178.9 \\
LRET-119 & Madrid & Winter & 110.3 & 214.4 & 653.5 \\
LRET-120 & Barcelona & Winter & 3.5 & 19.9 & 75.2 \\
LRET-121 & Madrid & Summer & 32.1 & 286.3 & 919.7 \\
\hline
\end{tabular}

(explosibility) or limiting oxygen concentration. Table 2 shows the European Standards followed to determine them.

Thermal susceptibility analyses are less-known in terms of the lack of standardized procedures. They consist of thermogravimetric analysis (TG), differential scanning calorimetric analysis (DSC), Maciejasz Index (MI), characteristic temperature ( $\left.T_{\text {charact }}\right)$ and volatiles emission temperature (TEV).

Finally thermal stability can be explained in terms of the tendency to self-heating. There are standard methods intended to the classification of goods for transportation, according to the ONU-N4 Division 4.2, or intended to the determination of the self-ignition temperature (TSI), according to EN 15188.

\subsection{Test procedures}

In thermogravimetric analysis (TG) the weight of the sample is measured as a function of its temperature when heated following a programmed heating rate. Fig. 1 shows a typical TG plot, with the derivative curve dTG superimposed, where some significant parameters can be defined, such as the combustion induction temperature (IT) and the maximum weight loss temperature (MLT).

In the case of Differential Scanning Calorimetry (DSC) the sample is heated at a regular rate, previously established and a reference inert product is placed in another crucible. The difference in temperature between the sample and the reference is measured and recorded against the temperature of the oven and the exchanges of heat in the sample are determined. Fig. 2 shows a typical DSC record. The parameters used to characterize different substances are the minimum temperature at which the exothermic reaction begins (initial temperature, IET), the maximum temperature reached during the exothermic reaction (final temperature, FET) and the temperature at which the fast exothermic reaction commences (change of slope temperature, CST).

The characteristic temperature $\left(T_{\text {charact }}\right)$ [27] is determined by thermogravimetric tests adding an oxygen stream. The oxygen accelerates the oxidation process so that the sample suffers a sudden loss of weight. This loss happens at a different characteristic temperature for each sample, the lower the temperature, the higher thermal susceptibility to oxidation. According to this parameter samples can be classified by its self-ignition risk [28].

Maciejasz Index (MI) measures the required time $(t)$ to produce a temperature increase of $65 \mathrm{~K}$ in the sample, when it is attacked by hydrogen peroxide. The Maciejasz index is calculated as $\mathrm{MI}=100 / t$. It determines the susceptibility to the self-combustion due to the oxidation of some compounds in the substance that show avidity to react with oxygen, for instance pyrites in coals. This method is frequently used for coals, especially when their sulfur content is high.

The ignition temperature of emitted volatile matter (TEV) can be considered as a kind of flash point for solids. When a sample

Table 2

Properties determined and European Standards followed to determine.

\begin{tabular}{ll}
\hline Property & $\begin{array}{l}\text { European } \\
\text { Standard }\end{array}$ \\
\hline Elemental analysis $(\mathrm{C}, \mathrm{H}, \mathrm{N})$ & EN 15104 \\
Ash content & EN 14775 \\
Volatiles content & EN 15148 \\
Humidity & EN 14774 \\
Minimum ignition temperature (layer: MITl, cloud: & EN 50281-2-1 \\
$\quad$ MITc) & EN 14034-3 \\
Lower explosion limit (LEL) & EN 13821 \\
Minimum ignition energy (MIE) & EN 14034-1 \\
Maximum explosion pressure $\left(P_{\max }\right)$ & EN 14034-2 \\
Dust specific constant $\left(K_{\max }\right)$ & EN 14034-4 \\
Limiting oxygen concentration $($ LOC) & \\
\hline
\end{tabular}




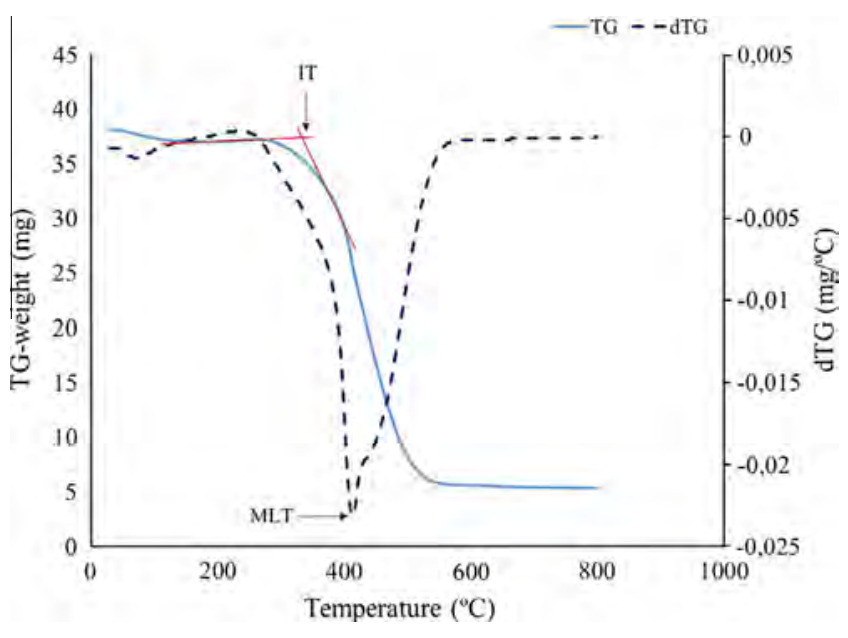

Fig. 1. Thermogravimetric analysis plot.

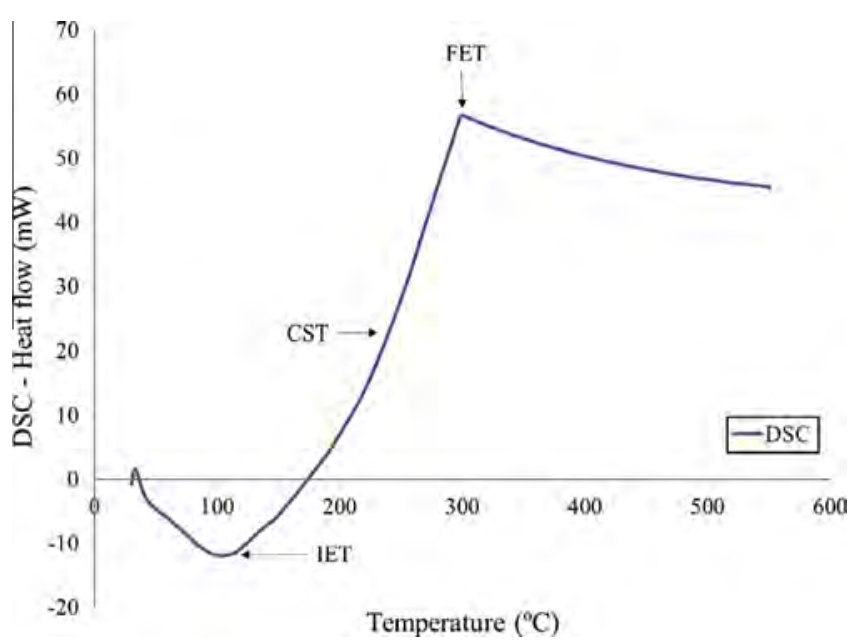

Fig. 2. Differential scanning calorimetry record.

is progressively heated it can decompose and release different gases, some of them being flammable. When an ignition source is applied to the volatile matter released from the sample, the appearance of flames can be observed. It provides an interesting safety issue for organic products that can release flammable combustion products, making the product more hazardous.

Isothermal Oven Tests are useful to detect substances liable to spontaneous combustion. Such substances are classified as Division 4.2 according to the UN recommendations on the transport of dangerous goods. The classification procedure should be undertaken before a product is offered for transport. Tests are performed to determine if substances in a $25 \mathrm{~mm}$ or $100 \mathrm{~mm}$ sample cube, at test temperatures of $100^{\circ} \mathrm{C}, 120^{\circ} \mathrm{C}$ and $140{ }^{\circ} \mathrm{C}$, undergo spontaneous ignition or dangerous self-heating, which is indicated by a $60 \mathrm{~K}$ rise in temperature over the oven temperature within $24 \mathrm{~h}$. These criteria are based on the self-ignition temperature of charcoal, which is $50^{\circ} \mathrm{C}$ for a sample cube of 27 cubic meters.

Self-ignition temperature (TSI) is the temperature at which a given volume of dust will ignite. The experimental basis for describing the self-ignition behavior of a given dust is the determination of the self-ignition temperatures of differently-sized bulk volumes of the dust by isothermal hot storage experiments (storage at constant ambient temperatures) in commercially available drying ovens. The results reflect the dependence of self-ignition temperatures upon dust volume.
The self-ignition temperature may be extrapolated for different volumes, so it represents a generalization of UN tests to any volume. Particularly SIT can be extrapolated to the volumes used in UN tests.

\subsection{Collecting data}

A number of samples have been subjected to those test procedures, measuring many parameters and obtaining a large number of experimental data. Statistical analysis has been applied to these data with a first aim of understanding the behavior of sludge, where correlations between those parameters can provide useful information. The second aim was to determine the similarity between the samples collected based on two parameters: the location where the samples were collected and the season when the samples were collected.

This statistical analysis includes correlation analyses, discriminant analyses and principal component analysis. The study was carried out in two distinct stages: first the chemical composition was studied for a number of samples, selecting some of them for the detailed tests carried out in the second stage. The first stage included all twenty collected samples, whose chemical composition was determined. The second stage corresponded to the selected ten samples whose flammability, explosibility and thermal behavior were analyzed.

\section{Results}

Ultimate and proximate analyses on a dry basis were done to all the twenty samples, as detailed in Table 3. Hydrogen, nitrogen and sulfur content values have a low standard deviation, while variations obtained for carbon, ash content, moisture and volatile matter are higher.

According to the results of the previous analyses, ten samples were selected in order to choose the largest range of values. Ignition sensitivity, explosion severity and thermal stability analyses were determined to those ten samples, and results are shown in Tables 4-6. These results show a wide range of variation in almost all the parameters studied. MITl values have a variation of $150 \mathrm{~K}$, consistent with the observed variation of MITc values, $190 \mathrm{~K}$. The other two parameters included in the ignition sensitivity group

Table 3

Chemical analyses.

\begin{tabular}{|c|c|c|c|c|c|c|c|}
\hline \multirow[t]{2}{*}{ Sample } & \multicolumn{4}{|c|}{ Ultimate analysis (wt\%) } & \multicolumn{3}{|c|}{ Proximate analysis (wt\%) } \\
\hline & C & $\mathrm{H}$ & $\mathrm{N}$ & $\mathrm{S}$ & $\mathrm{Ash}^{\mathrm{a}}$ & Moisture & Volatiles $^{\mathrm{a}}$ \\
\hline LRET-101 & 37.43 & 4.91 & 3.01 & 0.61 & 32.20 & 6.10 & 62.30 \\
\hline LRET-102 & 28.48 & 3.56 & 2.96 & 0.84 & 48.10 & 2.70 & 52.50 \\
\hline LRET-103 & 33.72 & 4.94 & 5.00 & 1.63 & 43.90 & 11.10 & 59.90 \\
\hline LRET-104 & 34.72 & 4.70 & 4.46 & 1.24 & 44.80 & 4.80 & 54.40 \\
\hline LRET-105 & 35.76 & 4.74 & 4.52 & 1.31 & 45.00 & 6.50 & 53.50 \\
\hline LRET-106 & 33.83 & 4.52 & 4.75 & 1.61 & 45.00 & 7.80 & 52.90 \\
\hline LRET-107 & 31.90 & 4.77 & 5.01 & 1.21 & 41.70 & 5.60 & 55.40 \\
\hline LRET-108 & 29.57 & 4.45 & 4.70 & 1.31 & 46.10 & 7.10 & 54.60 \\
\hline LRET-110 & 31.73 & 4.69 & 4.89 & 1.14 & 41.80 & 4.40 & 57.80 \\
\hline LRET-111 & 30.23 & 4.50 & 4.83 & 1.49 & 44.30 & 6.20 & 54.20 \\
\hline LRET-112 & 36.13 & 5.19 & 4.51 & 4.90 & 37.10 & 5.70 & 62.30 \\
\hline LRET-113 & 34.72 & 4.96 & 5.13 & 2.24 & 38.10 & 3.00 & 60.40 \\
\hline LRET-114 & 35.28 & 4.96 & 4.11 & 2.18 & 40.40 & 3.90 & 57.60 \\
\hline LRET-115 & 32.28 & 4.67 & 4.65 & 1.96 & 40.00 & 14.10 & 56.60 \\
\hline LRET-116 & 44.81 & 6.69 & 5.36 & 1.30 & 20.20 & 5.80 & 73.90 \\
\hline LRET-117 & 38.30 & 6.33 & 3.72 & 1.08 & 38.50 & 2.40 & 57.40 \\
\hline LRET-118 & 34.80 & 6.45 & 5.20 & 1.39 & 36.40 & 9.80 & 60.20 \\
\hline LRET-119 & 31.90 & 5.63 & 4.27 & 0.89 & 45.40 & 1.30 & 51.50 \\
\hline LRET-120 & 38.20 & 6.53 & 4.67 & 1.44 & 34.50 & 3.60 & 58.40 \\
\hline LRET-121 & 33.40 & 6.24 & 4.37 & 1.23 & 41.70 & 6.20 & 57.00 \\
\hline
\end{tabular}

a Dry basis. 
Table 4

Ignition sensitivity and explosion severity.

\begin{tabular}{|c|c|c|c|c|c|c|c|}
\hline \multirow[t]{2}{*}{ Sample } & \multicolumn{4}{|l|}{ Sensitivity } & \multicolumn{3}{|l|}{ Severity } \\
\hline & $\operatorname{MITl}\left({ }^{\circ} \mathrm{C}\right)$ & $\operatorname{MITc}\left({ }^{\circ} \mathrm{C}\right)$ & $\operatorname{LEL}\left(\mathrm{g} / \mathrm{cm}^{3}\right)$ & $\operatorname{MIE}(\mathrm{mJ})$ & $P_{\max }$ (bar) & $K_{\max }(\operatorname{bar} \mathrm{m} / \mathrm{s})$ & LOC (\%) \\
\hline LRET-101 & 260 & 460 & 60 & 67 & 7.0 & 124 & 13 \\
\hline LRET-102 & 360 & 480 & 500 & $>1000$ & 5.0 & 77 & 20 \\
\hline LRET-103 & 300 & 480 & 60 & $>1000$ & 6.1 & 125 & 15 \\
\hline LRET-104 & 370 & 440 & 500 & $>1000$ & 5.5 & 108 & 13 \\
\hline LRET-105 & 370 & 420 & 125 & $>1000$ & 5.7 & 98 & 14 \\
\hline LRET-107 & 390 & 510 & 30 & $>1000$ & 6.3 & 178 & 14 \\
\hline LRET-110 & 390 & 510 & 125 & $>1000$ & 6.4 & 145 & 13 \\
\hline LRET-112 & 240 & 320 & 60 & 170 & 6.4 & 157 & 16 \\
\hline LRET-117 & 340 & 420 & 60 & 220 & 6.1 & 161 & 16 \\
\hline LRET-121 & 320 & 460 & 125 & $>1000$ & 6.1 & 161 & 19 \\
\hline
\end{tabular}

Table 5

Thermogravimetry.

\begin{tabular}{|c|c|c|c|c|c|c|}
\hline \multirow[b]{2}{*}{ Sample } & \multirow[b]{2}{*}{$\operatorname{TEV}\left({ }^{\circ} \mathrm{C}\right)$} & \multirow[b]{2}{*}{$\mathrm{MI}\left(\mathrm{s}^{-1}\right)$} & \multicolumn{2}{|c|}{ Thermogravimetry } & \multicolumn{2}{|c|}{ Characteristics } \\
\hline & & & $\operatorname{MLT}\left({ }^{\circ} \mathrm{C}\right)$ & IT $\left({ }^{\circ} \mathrm{C}\right)$ & $T_{\text {charact }}\left({ }^{\circ} \mathrm{C}\right)$ & $E_{\mathrm{a}}(\mathrm{kJ} / \mathrm{mol})$ \\
\hline LRET-101 & 380 & 0 & 295.0 & 225 & 70.7 & 309 \\
\hline LRET-102 & 340 & 29 & 288.0 & 240 & 72.0 & 281 \\
\hline LRET-103 & 310 & 0 & 262.0 & 230 & 67.8 & 262 \\
\hline LRET-104 & 360 & 10 & 256.0 & 240 & 68.5 & 266 \\
\hline LRET-105 & 330 & 3 & 260.5 & 227 & 69.0 & 264 \\
\hline LRET-107 & 320 & 0 & 259.8 & 226 & 53.3 & 277 \\
\hline LRET-110 & 320 & 0 & 260.0 & 228 & 69.0 & 267 \\
\hline LRET-112 & 260 & 0 & 253.0 & 203 & 66.6 & 203 \\
\hline LRET-117 & 330 & 7 & 253.0 & 221 & 66.1 & 224 \\
\hline LRET-121 & 310 & 25 & 253.0 & 230 & 66.8 & 218 \\
\hline
\end{tabular}

Table 6

Differential scanning calorimetry.

\begin{tabular}{lccl}
\hline \multirow{2}{*}{ Sample } & \multicolumn{3}{c}{ Differential scanning calorimetry } \\
\cline { 2 - 4 } & IET $\left({ }^{\circ} \mathrm{C}\right)$ & FET $\left({ }^{\circ} \mathrm{C}\right)$ & CST $\left({ }^{\circ} \mathrm{C}\right)$ \\
\hline LRET-101 & 77 & 296 & 212 \\
LRET-102 & 114 & 345 & 194 \\
LRET-103 & 89 & 305 & 219 \\
LRET-104 & 118 & 317 & 193 \\
LRET-105 & 114 & 304 & 210 \\
LRET-107 & 120 & 303 & 206 \\
LRET-110 & 135 & 299 & 218 \\
LRET-112 & 117 & 288 & 182 \\
LRET-117 & 160 & 387 & 209 \\
LRET-121 & 153 & 319 & 209 \\
\hline
\end{tabular}

also have high variations, being of special interest that only three of the ten studied samples have a MIE under $1000 \mathrm{~mJ}$. Instead explosion severity parameters have a lower range of variation, and the $P_{\max }$ of the samples do not vary substantially among the studied samples. Finally, the values of the LOC show also a remarkable range of variation, from $13 \%$ to $20 \%$.

The parameters obtained from the thermogravimetry and the differential scanning calorimetry provide a range of variation narrower than chemical analyses, ignition sensitivity and explosion severity. The temperatures obtained from these tests do not vary in a range as wide as the ignition temperatures do, so the initial heating process of all the samples studied can be considered as quite similar. However, one of the most significant differences among the samples studied is the variation of the MI values. Only three samples produced a significant reaction, leading to a value higher or equal to 10 , and those samples are not the same as the samples with MIE lower than $1000 \mathrm{~mJ}$.

According to the data obtained for these ten samples, three of them were selected due to their diversity and thermal stability was studied for them. Two samples, LRET-102 and LRET-110, were analyzed according to the Division 4.2 tests and TSI was determined for the third sample, LRET-121. The results for LRET-102 and LRET-110 showed that they were exempted of hazardous classification when transported in packages of less than $3 \mathrm{~m}^{3}$. Test results for sample LRET-121 are shown in Table 7.

\section{Discussion}

\subsection{Relations among parameters}

To determine the relationships existing between chemical composition and explosibility parameters and also among the parameters within these two groups, a correlation analysis was done. The objective of this analysis was to determine the relations existing and define the parameters that could be easily modified by preventive measures and may cause a decrease on the explosion risk on this kind of industrial plants. With this analysis it is possible to see the similarity of the samples with other materials well-known as coal and biomass, and design prevention and protection systems based on those developed and widely experienced in other industrial plants.

To carry out these analyses, two groups of parameters have been analyzed. In the first group chemical and granulometry parameters were analyzed for 20 samples (twenty-sample group). In the second group, besides chemical composition and granulometry, also ignition sensitivity, explosion severity and thermal stability were studied for 10 samples (ten-sample group). From the data obtained from the analyses developed at laboratory, a correlation matrix has been determined in each case, and a Pearson's correlation analysis has been developed to each matrix, with a significant coefficient of 0.05 . Those correlations are studied in two groups, firstly the relationships existing among chemical parameters, and secondly between these parameters and flammability parameters or inside this last group. 
Table 7

Self-ignition temperature of sample LRET-121.

\begin{tabular}{|c|c|c|c|c|}
\hline Sample & Volume & Lower temperature leading to an ignition $\left({ }^{\circ} \mathrm{C}\right)$ & Higher temperature without ignition $\left({ }^{\circ} \mathrm{C}\right)$ & TSI $\left({ }^{\circ} \mathrm{C}\right)$ \\
\hline \multirow[t]{4}{*}{ LRET-121 } & $1500 \mathrm{cc}$ & 125 & 120 & 122.5 \\
\hline & $350 \mathrm{cc}$ & 140 & 135 & 137.5 \\
\hline & $150 \mathrm{cc}$ & 145 & 140 & 142.5 \\
\hline & $50 \mathrm{cc}$ & 155 & 150 & 152.5 \\
\hline
\end{tabular}

\subsubsection{Chemical composition}

Looking only to the chemical parameters determined in this study, two main correlations groups have been observed.

The first group of parameters significantly correlated is formed by four composition parameters: carbon, hydrogen, volatiles and ashes content, as shown in Fig. 3. Added to the correlations, also histograms of each one of the parameters are represented, being the $Y$-axe the frequency of occurrence, the number of samples whose values are included inside the range represented in the $X$-axe. The correlations existing between carbon, hydrogen and volatiles are positive, unlike that observed between ash content and these three parameters. These correlations are due to the chemical composition of the sewage sludge. The first three parameters represent the organic content of the samples, while the ash content can be assimilated as the inorganic matter contained in the samples. As the organic matter of the samples is higher, the inorganic is lower.

The second group of significant correlations is observed between the three studied particle size parameters and it means that the tested samples have a high tendency to homogeneity as necessary in this tests. These correlations are illustrated on Fig. 4 besides the histograms of each parameter.

\subsubsection{Chemical composition and flammability}

Volatiles and ashes contents have a main influence on the flammability and explosibility of dusts. The main relations observed
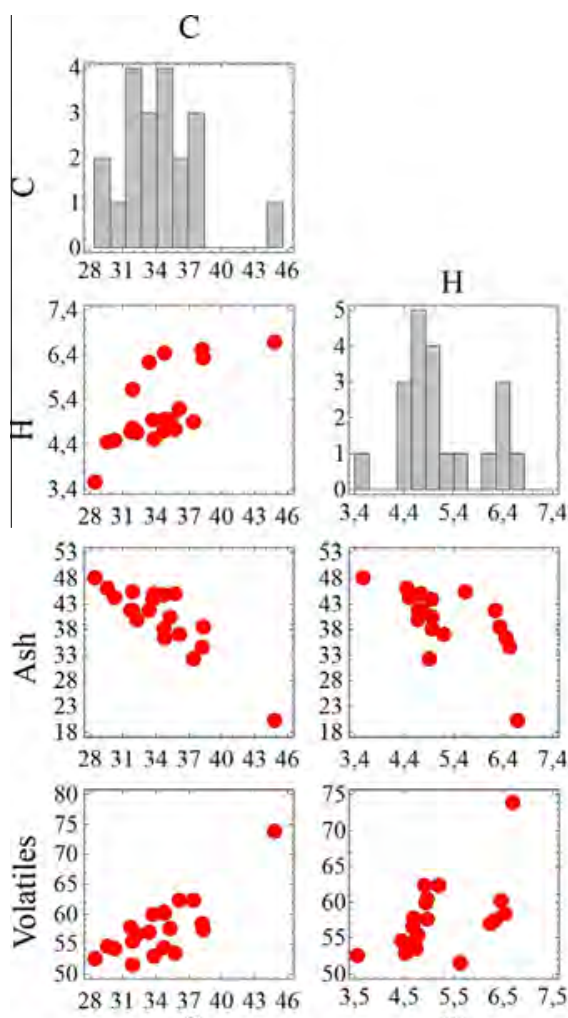

C
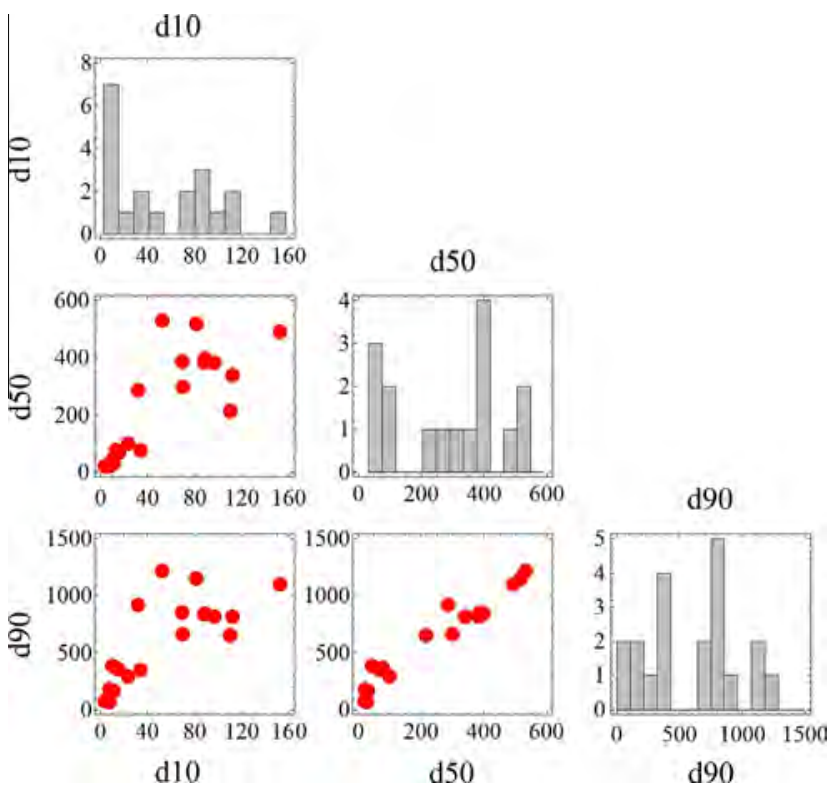

Fig. 4. Relations between $\mathrm{d} 10, \mathrm{~d} 50$ and $\mathrm{d} 90(\mu \mathrm{m})$.
Ash

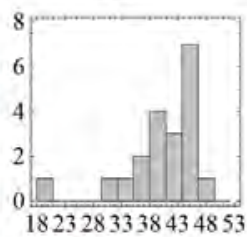

Volatiles
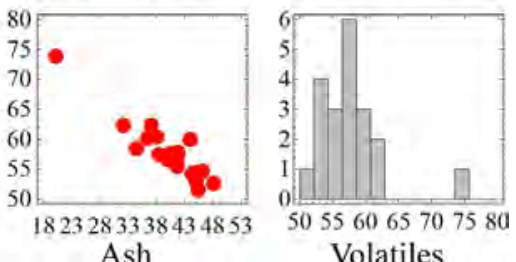

Volatiles

Fig. 3. Relations between $\mathrm{C}, \mathrm{H}$, ash and volatile content (\%). 
dealing these two parameters are those existing with MITl, MIE and $P_{\max }$, as shown in Fig. 5 . As can be seen by the visible alignment formed by the data, the higher the volatiles content, the easier is the flammability of the samples (lower ignition temperatures and energies) and also higher explosibility (higher explosion pressures). However, ash content has a negative influence on the flammability so that higher ignition temperatures and higher ignition energies are required to ignite sludge samples containing a higher inorganic fraction and the obtained explosion pressure is lower.

The addition of inert dust to some combustible products is usually done to avoid the explosion, and this effect can be explained by these correlations among ashes content and the different parameters shown in Fig. 5. These correlations supply a method to decrease the ignition risk of the sewage sludge incorporating into the sample inert dust.

Hydrogen and sulfur showed a strong relation to the flammability parameters and this can be explained by the oxidation tendency of these components that are present in the sewage sludge.

Relationships were also observed between the decreasing particle size and an increase on the flammability of dusts and on the explosion severity. These relationships are observed in these samples between the medium diameter (d50) and the MIE, MITl and IT as shown on Fig. 6.

The relationship existing between particle size and MITl has a double effect. In one hand, when the particle size is bigger, the gaps between the particles full of oxygen are larger, so the ignition easiness is higher. But in the other hand, the ignition is more difficult because the air is less conductive than the own substance. In this case, the second effect is stronger than the first one and by enlarging the particle size it is possible to increase the MITl and the ignition of a dust layer is more difficult. The same effect occurs with the IT, the higher the particle size, the higher the IT so the combustion of the sample starts at higher temperatures. Increasing the particle size and preventing the production of dust of extremely small particle size is also in this case a possibility to prevent the ignition risk in this kind of industrial plants.

Correlations with MIE do not lead to a line like in the other cases. Those are significant correlations because samples are grouped in two groups, one for these samples with less than $1000 \mathrm{~mJ}$ of MIE and another with more. Generally, the group with more than $1000 \mathrm{~mJ}$ has less volatile content, more ash content, more MITl and less $P_{\max }$. These relations are expected, but more samples are needed to ensure them.

In addition, looking at the relations existing among different flammability parameters, it is also observed a significant correlation among several temperatures studied. When a combustible substance is heated by a heat source, it begins to oxidize, and as the temperature increases it oxidizes more rapidly. At a certain point, the heat generated by the oxidation is sufficient to maintain the ignition without the aid of external sources. This point is the self-ignition temperature. Therefore, the three temperatures related to this ignition point (MITl, MITc and TEV) vary in the same direction as IT. Correlations related with MIE are similar as in the previous case, forming two groups of samples.
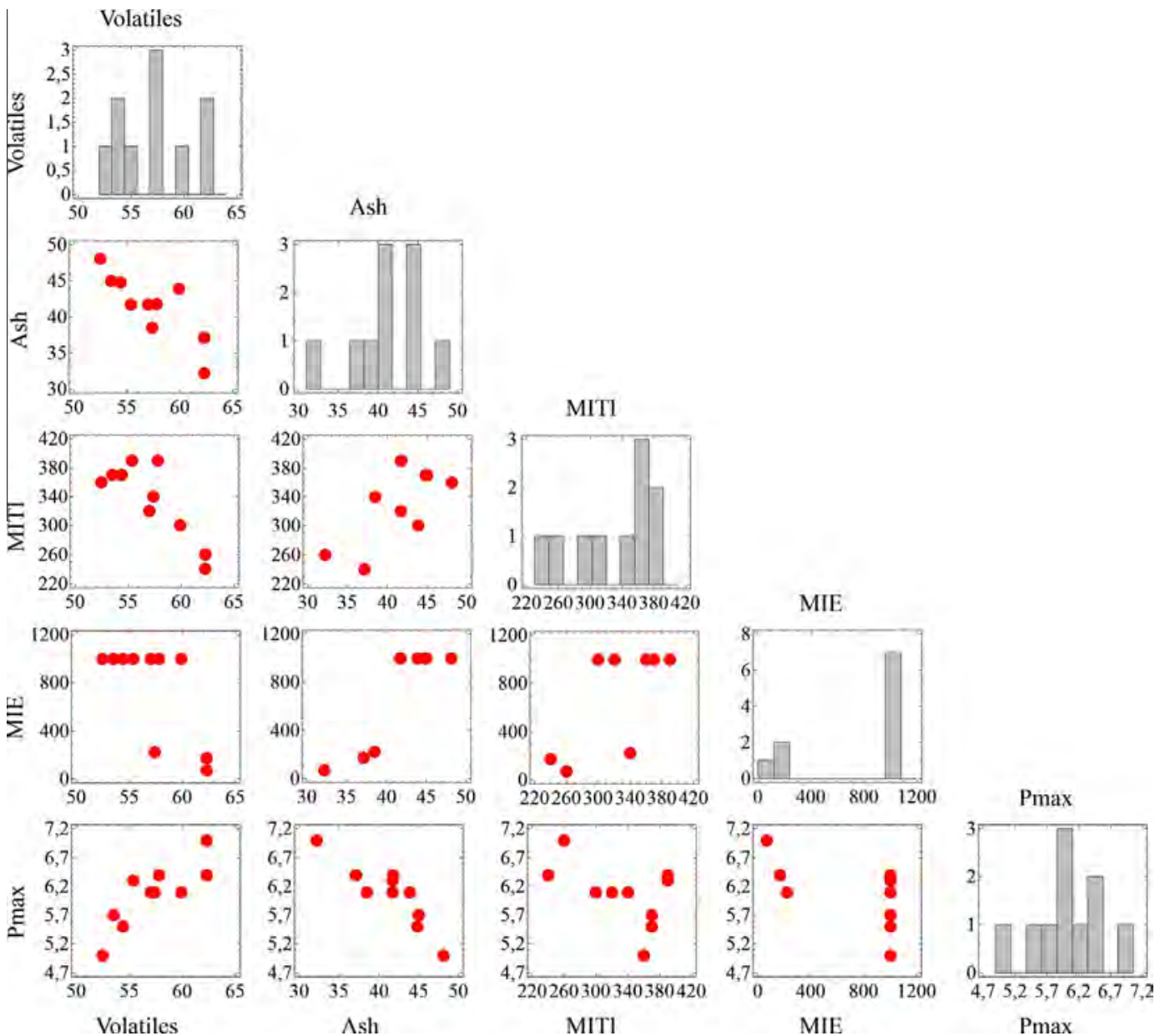

Fig. 5. Relations between volatile and ash content $(\%)$ and $\operatorname{MITl}\left({ }^{\circ} \mathrm{C}\right), \operatorname{MIE}(\mathrm{mJ})$ and $P_{\max }$ (bar). 

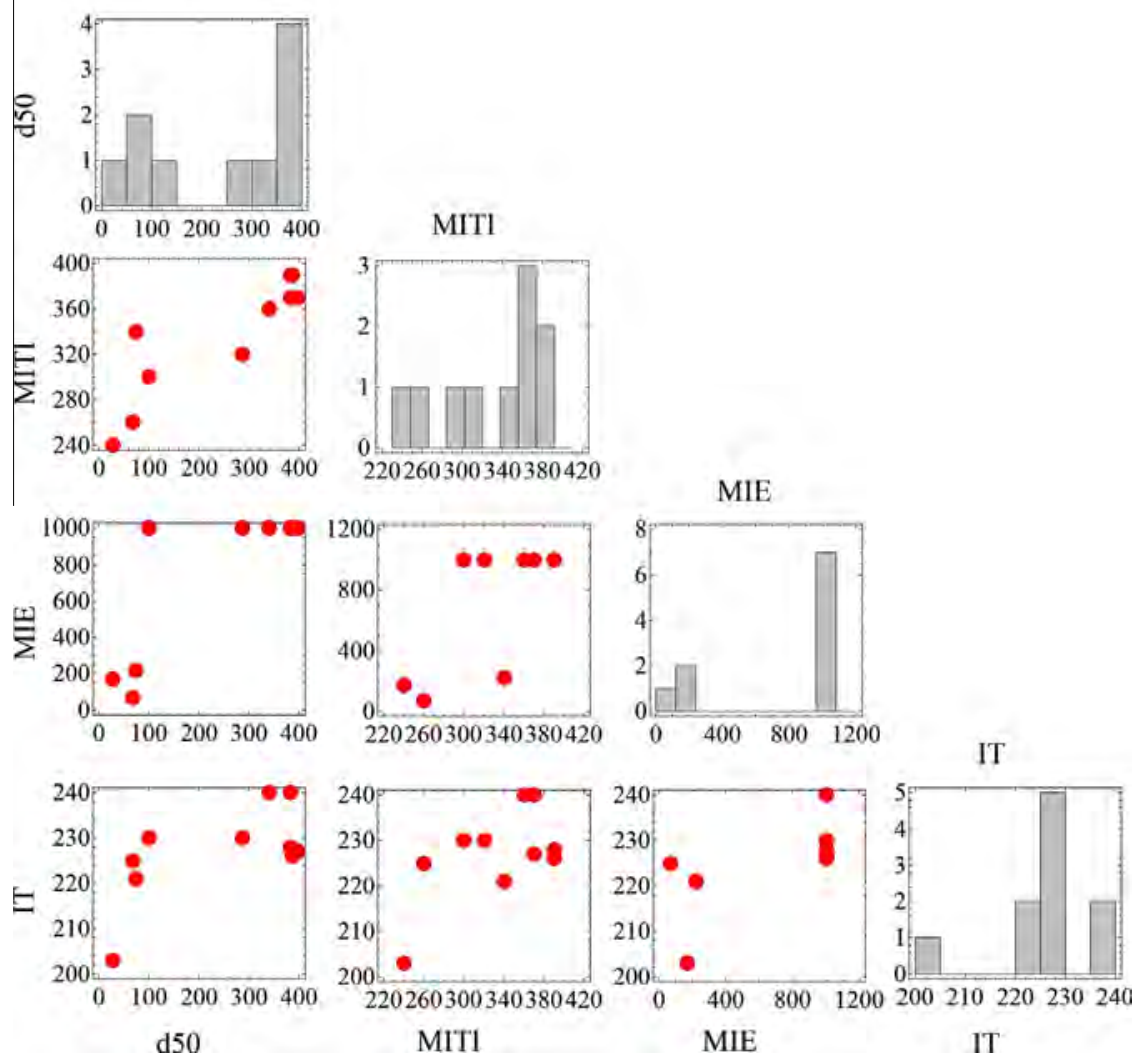

Fig. 6. Relations between medium diameter $(\mu \mathrm{m})$ and $\operatorname{MITl}\left({ }^{\circ} \mathrm{C}\right)$, $\operatorname{MIE}(\mathrm{mJ})$ and $\operatorname{IT}\left({ }^{\circ} \mathrm{C}\right)$.

Other relations among temperatures are those more related with the volatiles content of the sample. It was found that the higher the volatiles content the more easily it ignites. Because of it, when the $T_{\text {charact }}$ increases, also other temperatures associated with those volatiles (MITc, TDM and TEV) increase, due to the $T_{\text {charact }}$ represents the temperature at which a quick combustion occurs. The exothermic reaction starts at lower temperatures as the reactivity of the substances increases (lower TDM) and the ignition of a dust cloud is easier (lower MITc). And in substances in which the quick exothermic reaction starts at low temperatures (lower TCP), the ignition of a cloud of sample is also easier.

Furthermore a relation was observed between ignition sensitivity and explosion severity, so that samples which need less dust concentration to ignite are those that produce the highest explosion pressures.

Finally, looking at the self-ignition risk of the sewage sludge, it was observed that when this risk is higher, the explosion severity is also higher.

\subsection{Influence of the origin and the season}

A discriminant analysis has been developed based on two different factors: the origin of the samples and the season when they were collected. This analysis was applied to the two groups of data previously described: chemical analysis (twenty-sample group) and flammability data (ten-sample group). In the second analysis, due to the linearity existing among the parameters of these ten samples, a principal component analysis (PCA) was developed.

In both groups, the discriminant analyses according to the origin of the sample showed that the $100 \%$ of the samples are correctly classified. In the first group, no significant discriminant function is observed. However, in the second group a significant discriminant function is determined, and the moisture of the sample is the main parameter that causes the classification, followed by its sulfur content.

The analysis according to the season shows that $95 \%$ of the samples included on the twenty-sample group and $90 \%$ on the tensample group are classified in the right group and only one of the samples is incorrectly classified in each case. In the first analysis realized to the twenty-sample data, one significant discriminant function has been determined. In this function, the parameters with more weight are the volatiles content and the carbon content. No significant discriminant function is observed in this case in the analysis done to the twenty-sample data.

\section{Conclusions}

The relations observed between the composition parameters depend on many factors, but they are not due to the drying process of the sewage sludge, otherwise they depend on the wastes treated and on the process followed in the wastewater treatment plant before the drying process.

The composition parameters that mainly affect to the explosibility of these dusts are chemical composition (volatiles and ashes) and particle size. These influences were expected since they were observed for many different materials in other studies, such as coal and biomass. These relations showed that in thermally drying sewage sludge plants it is possible to decrease the explosion risks or its effects applying similar actions as in coal and biomass treatment plants. For example, it is shown that the ashes content makes the sample less dangerous in terms of ignition, while the opposite occurs with the volatiles content, so it is possible to decrease the risk by increasing the inert part of the dust. 
Relations between the different measured temperatures showed the high dependency existing between different groups of parameters, and how the ignition, self-ignition and reactivity of the samples are related. It was also observed that the temperatures related with these actions vary together showing the same tendency. These relations show that by decreasing the risk of one of the parameters it is possible to decrease also others. For example, by increasing the particle size it is possible to heighten MIE, MITl and TIC because of the direct correlations observed, but also MITc, TEV, $T_{\text {charact }}$ and TDM will increase.

By the comparison of the discriminant analysis depending on the origin and on the sampling season, it is shown that the discrimination due to the origin is more accurate than the one due to the season. This shows that the sewage sludge ignition depends more of the origin of the sample than of the season. Even so, the percentage of correctly classified samples in order to the season is quite high, so the season is also an important parameter to classify the ignition tendency of sewage sludge. Also it is shown that the parameter that causes the differentiation of the samples according to their origin is the moisture of the samples, so this parameter varies greatly depending on the origin of the sample. And looking at the season when samples were collected, volatiles and carbon contents are the main reason for differentiating samples, which shows that the organic composition of the samples varies according to the season.

\section{Acknowledgment}

The authors gratefully acknowledge the Lloyd's Register Educational Trust for funding this study through the project Safety conditions against ATEX risk in the water industry.

\section{References}

[1] Daigger GT. Wastewater management in the 21st century. J Environ Eng ASCE 2007:133:671-80

[2] Daigger GT. Evolving urban water and residuals management paradigms: water reclamation and reuse, decentralization, and resource recovery. Wate Environ Res 2009;81:809-23.

[3] Bixio D, Thoeye C, De Koning J, Joksimovic D, Savic D, Wintgens T, et al Wastewater reuse in Europe. Desalination 2006;187:89-101.

[4] Spinosa L, Vesilind PA. Sludge into biosolids, processing disposal and utilization. London: IWA Publishing; 2001.

[5] Kelessidis A, Stasinakis AS. Comparative study of the methods used for treatment and final disposal of sewage sludge in European countries. Waste Manage (Oxford) 2012:32:1186-95.

[6] Brophy MO. Hazards in Sewage (Waste) Treatment Plants. Encyclopedia of Occupational Health and Safety. Geneva: International Labour Organization 2011. <http://www.ilo.org/oshenc/part-xvii/public-and-government-services/ item/831-hazards-in-sewage-waste-treatment-plants>.
[7] Joseph G. Combustible dusts: a serious industrial hazard. J Hazard Mater 2007;142:589-91.

[8] American Institute of Chemical Engineers. Is sugar an explosion hazard? J Fail Anal Preven 2008;8:311-2.

[9] Fodor Z, Klemeš JJ. Waste as alternative fuel-minimising emissions and effluents by advanced design. Process Saf Environ 2012;90:263-84.

[10] Eckhoff RK. Dust explosions in the process industries. Oxford: ButterworthHeinemann; 2003.

[11] Lebecki K. Functional safety in industrial explosion protection. Transactions 2012:44-8.

[12] Amyotte PR, Eckhoff RK. Dust explosion causation, prevention and mitigation: an overview. J Chem Health Saf 2010;17:15-28.

[13] Ramírez Á, García-Torrent J, Aguado PJ. Determination of parameters used to prevent ignition of stored materials and to protect against explosions in food industries. J Hazard Mater 2009;168:115-20.

[14] Huéscar Medina C, Phylaktou H, Sattar H, Andrews G, Gibbs B. The development of an experimental method for the determination of the minimum explosible concentration of biomass powders. Biomass Bioenergy 2013:53:95-104.

[15] López-González D, Fernandez-Lopez M, Valverde J, Sanchez-Silva L. Thermogravimetric-mass spectrometric analysis on combustion of lignocellulosic biomass. Bioresour Technol 2013;143:562-74.

[16] Cashdollar KL. Coal dust explosibility. J Loss Prevent Process 1996;9:65-76.

[17] Harrison EZ, Oakes SR, Hysell M, Hay A. Organic chemicals in sewage sludges. Sci Total Environ 2006;367:481-97.

[18] Metcalf L, Eddy HP, Tchobanoglous G. Wastewater engineering: treatment, disposal, and reuse. McGraw-Hill; 1972.

[19] Beamish B, Arisoy A. Effect of mineral matter on coal self-heating rate. Fuel 2008;87:125-30.

[20] Calle S, Klaba L, Thomas D, Perrin L, Dufaud O. Influence of the size distribution and concentration on wood dust explosion: experiments and reaction modelling. Powder Technol 2005;157:144-8.

[21] Eckhoff RK. Understanding dust explosions. The role of powder science and technology. J Loss Prevent Process 2009;22:105-16.

[22] Traoré M, Dufaud O, Perrin L, Chazelet S, Thomas D. Dust explosions: how should the influence of humidity be taken into account? Process Saf Environ 2009;87:14-20.

[23] Klippel A, Scheid M, Krause U. Investigations into the influence of dustiness on dust explosions. J Loss Prevent Process 2013;26:1616-26.

[24] Fuentes MJ, Font R, Gómez-Rico MF, Moltó J. Multivariant statistical analysis of PCDD/FS in sewage sludges from different areas of the Valencian Community (Spain). Chemosphere 2007;67:1423-33.

[25] García-Delgado M, Rodríguez-Cruz M, Lorenzo L, Arienzo M, Sánchez-Martín M. Seasonal and time variability of heavy metal content and of its chemical forms in sewage sludges from different wastewater treatment plants. Sci Total Environ 2007;382:82-92.

[26] Ramírez Á, García-Torrent J, Tascón A. Experimental determination of selfheating and self-ignition risks associated with the dusts of agricultural materials commonly stored in silos. J Hazard Mater 2010;175:920-7.

[27] García Torrent J, Cámara Rascón Á, Querol Aragón E. New thermogravimetric techniques applications for characterizing the susceptibility of coal to selfcombustion. In: XI Congreso Internacional de Industria, Minería y Metalurgia, Zaragoza; 2002.

[28] García Torrent J, Medic Pejic L, Querol Aragón E. A self-combustion characterisation index based in thermogravimetric and differential scanning calorimetry techniques, presented at the $\mathrm{V}$ International Symposium on Hazards, Prevention and Mitigation of Industrial Explosions, Cracow (Poland); 2004. 


\section{Annex IV. Determination of spontaneous combustion of thermally dried sewage sludge}




\title{
Determination of spontaneous combustion of thermally dried sewage sludge
}

\author{
Ljiljana Medic Pejic a , Nieves Fernandez Anez ${ }^{\text {a, * }}$, Javier García Torrent ${ }^{\text {a, b }}$, \\ Álvaro Ramírez-Gómez ${ }^{\mathrm{C}}$ \\ a Department of Energy and Fuels (UPM Technical University of Madrid, Spain), C/ Alenza 4, 28003 Madrid, Spain \\ ${ }^{\mathrm{b}}$ Laboratorio Oficial Madariaga, LOM (UPM Technical University of Madrid, Spain), C/ Eric Kandel, 1 - (TECNOGETAFE), Parque Científico y Tecnológico de \\ la UPM, 28906, Getafe, Madrid, Spain \\ ${ }^{c}$ BIPREE Research Group (UPM Technical University of Madrid, Spain), Ciudad Universitaria s/n, 28040 Madrid, Spain
}

\section{A R T I C L E I N F O}

\section{Article history:}

Received 9 September 2014

Received in revised form

8 January 2015

Accepted 13 January 2015

Available online 14 January 2015

Keywords:

Spontaneous combustion

Sludge

Self-ignition

Flammability

\begin{abstract}
A B S T R A C T
The general purpose of this research was the determination of self-ignition tendency of thermally dried sewage sludge. Eight Spanish plants located in Madrid, Barcelona and Málaga were selected to develop this study and ten samples were collected. Three different testing methodologies for studying the selfignition of dusts have been undertaken. Thermogravimetric techniques, self-ignition temperature analyses and UN Division 4.2 tests were developed. The results of these analyses showed the risk of selfignition during storage and transportation of these substances.
\end{abstract}

(C) 2015 Elsevier Ltd. All rights reserved.

\section{Introduction}

The volume of wastewater produced worldwide has increased dramatically due to the large global population growth and industrialization (Eurostat, 2013). Dried sewage sludge is a product of high interest in the near future due to the different potential uses, including its use as a fuel (Fodor and Klemes, 2012; Rulkens, 2008). However, some cautions must be considered since dusts show high risk of self-ignition (García-Torrent et al., 2012), and produce explosive atmospheres as a dust-air mixture (Proust, 2006).

In 2006 the explosion of the sewage treatment plant in Besós, Barcelona, killed a worker and seriously injured two others (Europa Press, 2006). In this plant, sludge from purification of wastewater is subjected to a dehydration treatment using centrifuges and subsequent drying and pelletization. Cause of explosion in sludge dryer still unknown.

In the particular case of the wastewater treatment there are present risks of explosive atmospheres in different phases of the

\footnotetext{
* Corresponding author.

E-mail address: nieves.fernandez@upm.es (N. Fernandez Anez).
}

process due to the digestion gases generated in the treatment of wastewater that can form explosive gas-air mixtures. The dry sludge solids can also generate explosive dust clouds.

Chemical properties of sewage sludge are related to ignition parameters and the ignition risk may be reduced by means of preventive measures (Nifuku et al., 2005). It is well known that the main influential parameter on ignition risk is the particle size: the smaller the particle size, the greater ignition hazard (Eckhoff, 2009).

During the process of thermal drying, sewage sludge humidity sharply diminishes below $10 \%$ or even less, so that storage of sludge is facilitated for long periods. However, the drier the product, the larger quantities of fines are produced and the ignition risks associated to the powdered products generated in the process greatly increase (Rulkens, 2008; Zerlottin et al., 2013).

Flammability and explosibility properties of sewage sludge samples from different origins in Spain collected at different seasons were determined by measuring ignition and explosion parameters: Minimum ignition temperature with the dust forming a cloud (MITc) or deposited in a layer (MITl), Lower explosive limit (LEL), Minimum ignition energy (MIE), Maximum explosion pressure (Pmax), Characteristic constant (Kmax), Limiting oxygen concentration (LOC) (Fernandez-Anez et al., 2014) 
Self-heating and self-ignition risks associated with dusts have been evaluated for agricultural materials by Ramírez et al. (2009), due to the importance of the characterization of those materials to avoid these risks. Several experimental techniques can be used to characterize the thermal behaviour of materials, taking into account that the thermal behaviour of sewage sludge presents several differences with other well-studied materials as coal, as the weight loss during sludge combustion takes place not in one step as for coal but in two (Otero et al., 2002). Due to this differences several studies were conducted showing that due to the devolatilization of sewage sludge, in the co-combustion of coal and sewage sludge, the activation energy may decrease with the addition of sewage sludge (Folgueras et al., 2003). Furthermore, the devolatilization of materials depends on several parameters, being the main one the presence of hydrogen inside the structure of the samples (Arenillas et al., 2003).

These relations and the variability of these parameters on sewage sludge have been studied. In addition, the risk of selfignition during the transport of sewage sludge has been also studied following the procedure for classification of dangerous goods for transportation developed by the United Nations (United Nations, 2009).

\section{Experimental methodology}

Ten samples have been collected in eight wastewater treatment plants from three regions in Spain: Catalonia, Madrid and Málaga, The origin of the samples collected, together with their moisture contents and average particle sizes are detailed on Table 1.

The chemical composition is detailed on Table 2. Carbon (C), hydrogen $(\mathrm{H})$ and nitrogen $(\mathrm{N})$ were measured as percentages following EN 15104:2011 standard and sulphur (S) content was determined following the A method of ASTM D4239 standard. Oxygen content $(\mathrm{O})$ was determined as the complementary part of these values, taking into account that the sum of these five elements has to represent one hundred percent.

As stated, dried sewage sludge con produce explosive atmospheres and give rise to fires and explosions. Among possible ignition sources are exothermic reactions, including self-ignition of dusts. A number of experimental techniques can be used to characterize the thermal susceptibility of bulk solids and their thermal stability.

\subsection{Thermal susceptibility}

Thermal susceptibility is the term used to group the diverse parameters that allow the study of the thermal behaviour of solids and to determine their spontaneous combustion tendency (Querol Aragón et al., 2000). Parameters included in this group are: Maciejasz Index (MI) as a measure of reactivity and avidity for

Table 1

Collected samples.

\begin{tabular}{llcc}
\hline Sample & Origin & Apparent moisture $(\%)$ & $\mathrm{d} 50(\mu \mathrm{m})$ \\
\hline SEW-1 & Barcelona & 7.3 & 67.9 \\
SEW-2 & Barcelona & 7.0 & 339.5 \\
SEW-3 & Barcelona & 12.1 & 100.4 \\
SEW-4 & Madrid & 6.2 & 382.2 \\
SEW-5 & Madrid & 6.5 & 397.2 \\
SEW-6 & Madrid & 7.2 & 385.9 \\
SEW-7 & Madrid & 6.2 & 382.5 \\
SEW-8 & Malaga & 6.9 & 27.3 \\
SEW-9 & Barcelona & 4.1 & 74.4 \\
SEW-10 & Madrid & 8.3 & 286.3 \\
\hline
\end{tabular}

Table 2

Chemical composition.

\begin{tabular}{lllllr}
\hline Sample & $\mathrm{C}(\%)$ & $\mathrm{H}(\%)$ & $\mathrm{N}(\%)$ & $\mathrm{S}(\%)$ & $\mathrm{O}(\%)$ \\
\hline SEW-1 & 37.43 & 4.91 & 3.01 & 0.61 & 21.84 \\
SEW-2 & 28.48 & 3.56 & 2.96 & 0.84 & 16.06 \\
SEW-3 & 33.72 & 4.94 & 5.00 & 1.63 & 10.81 \\
SEW-4 & 34.72 & 4.70 & 4.46 & 1.24 & 10.08 \\
SEW-5 & 35.76 & 4.74 & 4.52 & 1.31 & 8.67 \\
SEW-6 & 31.90 & 4.77 & 5.01 & 1.21 & 15.41 \\
SEW-7 & 31.73 & 4.69 & 4.89 & 1.14 & 15.75 \\
SEW-8 & 36.13 & 5.19 & 4.51 & 4.90 & 12.17 \\
SEW-9 & 38.30 & 6.33 & 3.72 & 1.08 & 12.07 \\
SEW-10 & 33.40 & 6.24 & 4.37 & 1.23 & 13.06 \\
\hline
\end{tabular}

oxygen when sample is attacked with oxygen peroxide, Temperature of emission of flammable volatiles (TEV) as a sort of flash point for solids, Thermogravimetry test (TG), Differential Scanning Calorimetry (DSC), Activation energy (Ea) and Characteristic oxidation temperature (Tcharact.). The meaning and the experimental procedures for these parameters are described in detail by Ramírez et al. (2009). The DSC analysis allows determining the characteristics of the combustion reaction of solid fuels as shown in Fig. 1.

Three characteristic parameters are obtained with this analysis, the Initial Exothermic Temperature (IET), the Final Exothermic Temperature (FET) that is the starting point and the end of the combustion reaction and the Change of Slope Temperature (CST), representing the temperature at which the slow combustion changes to a quick combustion. Before the IET, dehydration of the sample takes place. Afterwards, combustion starts as a slow reaction between IET and CST and quicker until FET.

Through conventional thermogravimetry test, another parameter can be determined in order to better define the thermal susceptibility of dusts: their apparent activation energy (Ea). The Ea of the sample is calculated at the point of maximum weight loss by means of a simple mathematical model applied to a set of points around that of maximum weight loss in a suitable representation of the recorded test points. The activation energy is related to the rate of weight loss, leading to the estimate of an "apparent activation energy" from the slope of least-squares line fitted to the selected test data. Thermodynamic and mathematical basis of Cumming's equation, based on first order reaction characteristic equations, simplifies and provides the estimate and use of this activation energy, turning it into a typical parameter of the sample representing the easiness for the reaction to take place.

Additionally, thermogravimetric technique is also applied to the study of self-ignition susceptibility by modifying test conditions when an oxygen stream is introduced. As a consequence of this oxidant contribution, sample behaviour can be very different during testing and a step or sudden loss of weight is observed, associated to a rapid combustion and produced at a characteristic temperature in every substance. Thus, from this unique value of the "characteristic temperature" powdered substances can be easily classified.

\subsection{Classification of substances liable to spontaneous combustion}

Transportation or storage of large quantities of products showing thermal susceptibility can lead to self-ignition. The classification of substances liable to spontaneous combustion according to the recommendations on the transport of dangerous goods comes from ONU $\mathrm{N}_{2}+\mathrm{N}_{4}$ tests (United Nations, 2009), so that substances classified as Division 4.2 are considered as liable to undergo dangerous self-heating processes. The classification 


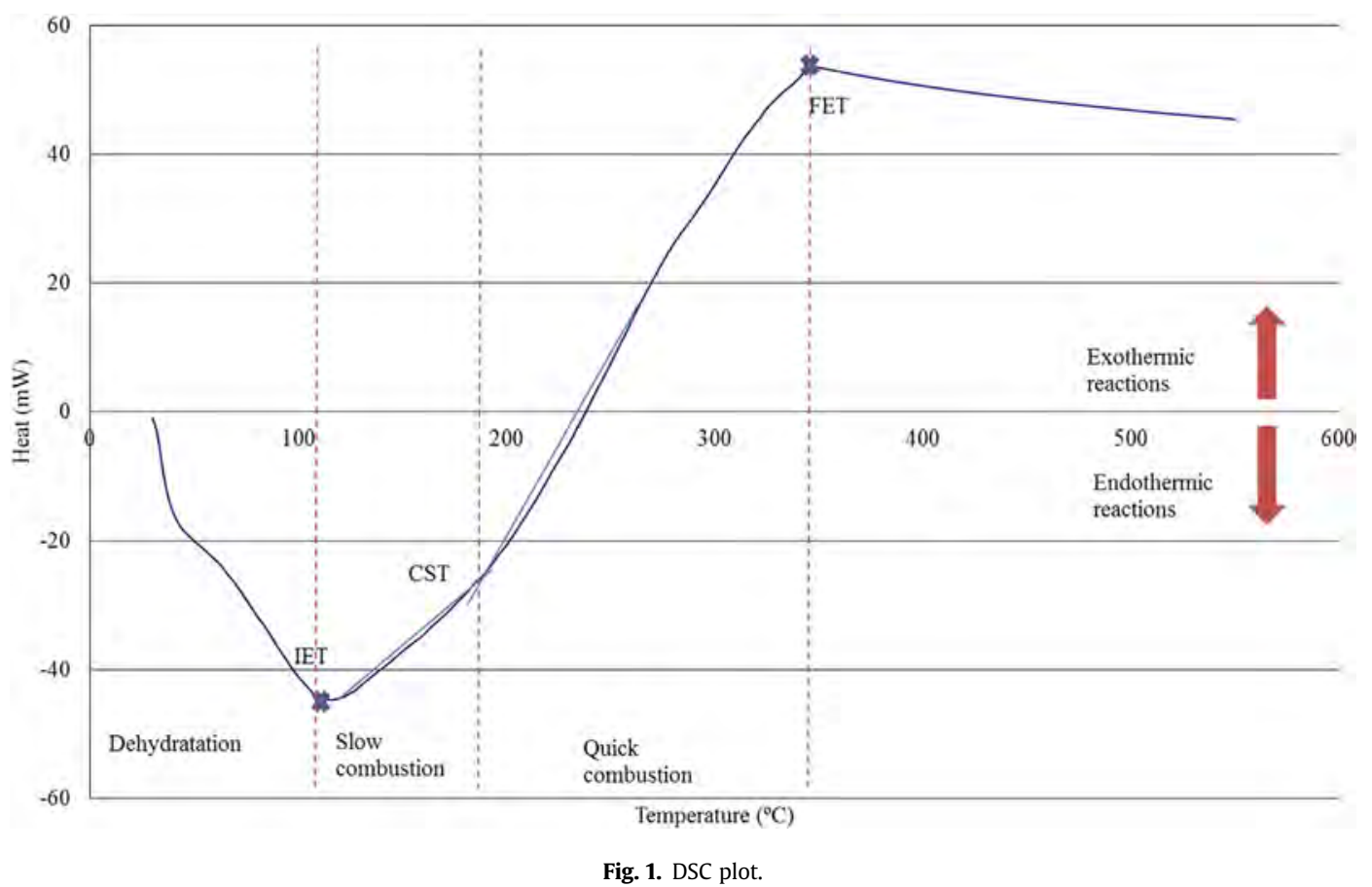

criterion is based on the self-ignition temperature of charcoal, which is $50{ }^{\circ} \mathrm{C}$ for a sample cube of $27 \mathrm{~m}^{3}$.

To determine if the material is susceptible to self-heating, a cubic sample container of $100 \mathrm{~mm}$ side is introduced in an oven at $140^{\circ} \mathrm{C}$ and held for $24 \mathrm{~h}$, recording the sample temperature. If no ignition is observed and the temperature does not exceed $200{ }^{\circ} \mathrm{C}$, the material is not classified in Class 4.2. If there is ignition or the temperature exceeds $200^{\circ} \mathrm{C}$, the test is repeated with a sample cube of $25 \mathrm{~mm}$ side. If there is ignition or exceeds $200{ }^{\circ} \mathrm{C}$, is assigned a packing group II of Division 4.2. If there is no ignition, the test is repeated using the cubic cell of $100 \mathrm{~mm}$ side within the oven set to $120^{\circ} \mathrm{C}$. If no ignition is observed, the material is considered exempt if shipped in packages of less than $3 \mathrm{~m}^{3}$. If there is ignition the test is repeated with the cell $100 \mathrm{~mm}$ side with oven at $100{ }^{\circ} \mathrm{C}$. If there is no ignition, it is considered exempt if shipped in packages of less than $450 \mathrm{~L}$. If there is ignition a packing group III of Division 4.2 is assigned.

\subsection{Thermal stability}

The thermal stability of a material is based on the determination of self-ignition temperatures in samples of different volumes in an isothermal oven that reproduces environmental temperatures. Self-Ignition Temperature (SIT) is the temperature at which a given volume of dust will ignite. Plotting volume/sources ratios against the reciprocal of the temperature, it is possible to characterise the self-ignition behaviour of dust deposits and piles. The results reflect the dependence of self-ignition temperatures upon dust volume.

Tests are carried out using four different volumes of sample, ranging from $50 \mathrm{~cm}^{3}$ to $1500 \mathrm{~cm}^{3}$ and subjecting the samples to increasing oven temperatures, both the lower temperature leading to an ignition and the higher temperature without ignition can be determined, so that the self-ignition temperature can be defined as the medium value among those temperatures.

\section{Results and discussion}

\subsection{Thermal susceptibility}

\subsubsection{Differential scanning calorimetry}

Values of the characteristics parameters for the ten studied samples are shown in Table 3.

\subsubsection{Activation energy (Ea) and oxidation temperature (Tcharact)}

Table 4 shows the obtained values for the determination of the thermal susceptibility of sludge.

The determined activation energies and characteristic temperatures of oxidation in oxygen flow are plotted in Fig. 2 as an experimental comparative graph. This kind of graphs was previously used for other materials, such as agricultural products and also different types of coals (García Torrent et al., 2002), allowing the definition of four regions depending on the ease of the oxidation process.

Cut-off values defining the different regions in this plot were taken considering the clustering observed in various typical samples previously studied, including different rank coals.

As can be seen, one sample is placed in the medium risk zone, six samples in the high risk zone and three samples in the very high risk zone.

Table 3

DSC results.

\begin{tabular}{llll}
\hline Sample & IET $\left({ }^{\circ} \mathrm{C}\right)$ & FET $\left({ }^{\circ} \mathrm{C}\right)$ & CST $\left({ }^{\circ} \mathrm{C}\right)$ \\
\hline SEW-1 & 76.5 & 296 & 212 \\
SEW-2 & 114 & 345 & 194 \\
SEW-3 & 89 & 305 & 219 \\
SEW-4 & 118 & 317 & 193 \\
SEW-5 & 114 & 304 & 210 \\
SEW-6 & 120 & 303 & 206 \\
SEW-7 & 135 & 299 & 218 \\
SEW-8 & 117 & 288 & 182 \\
SEW-9 & 160 & 387 & 209 \\
SEW-10 & 153 & 319 & 209 \\
\hline
\end{tabular}


Table 4

Evaluation of thermal susceptibility.

\begin{tabular}{lllll}
\hline Sample & $\begin{array}{l}\text { Temperature } \\
\text { of flammable } \\
\text { volatiles } \\
\text { TEV }\end{array}$ & $\begin{array}{l}\text { Maciejasz } \\
\text { Index } \\
\text { MI }\end{array}$ & $\begin{array}{l}\text { Activation } \\
\text { energy } \\
\text { Ea }\end{array}$ & $\begin{array}{l}\text { Characteristic } \\
\text { oxidation } \\
\text { temperature } \\
\text { Tcharact }\end{array}$ \\
\hline SEW-1 & 380 & 0 & 70.7 & 309 \\
SEW-2 & 340 & 29 & 72.0 & 281 \\
SEW-3 & 310 & 0 & 67.8 & 262 \\
SEW-4 & 360 & 10 & 68.5 & 266 \\
SEW-5 & 330 & 3 & 69.0 & 264 \\
SEW-6 & 320 & 0 & 53.3 & 277 \\
SEW-7 & 320 & 0 & 69.0 & 267 \\
SEW-8 & 260 & 0 & 66.6 & 203 \\
SEW-9 & 330 & 8 & 66.1 & 224 \\
SEW-10 & 310 & 25 & 66.8 & 218 \\
\hline
\end{tabular}

The three samples that are located inside the very high risk zone are those three with hydrogen contents over $5 \%$ and whose slow combustion reaction is shorter. This location proved that the hydrogen concentration of sewage sludge produces the same effect as the release of volatiles during devolatilisation previously observed in other organic materials, such as different types of coals. For different rank coals, a higher spontaneous combustion risk is observed for low rank coals when volatile contents are higher, as it is the case of subbituminous coals.

This relation is not observed in the other direction for sewage sludge, since the sample that is located in the medium risk (SEW-1) is not the sample with less hydrogen content. This suggests that the hydrogen content is not the only parameter causing this differentiation and it is proved thanks to the discriminant analysis developed. This analysis shows the importance of nitrogen and sulphur

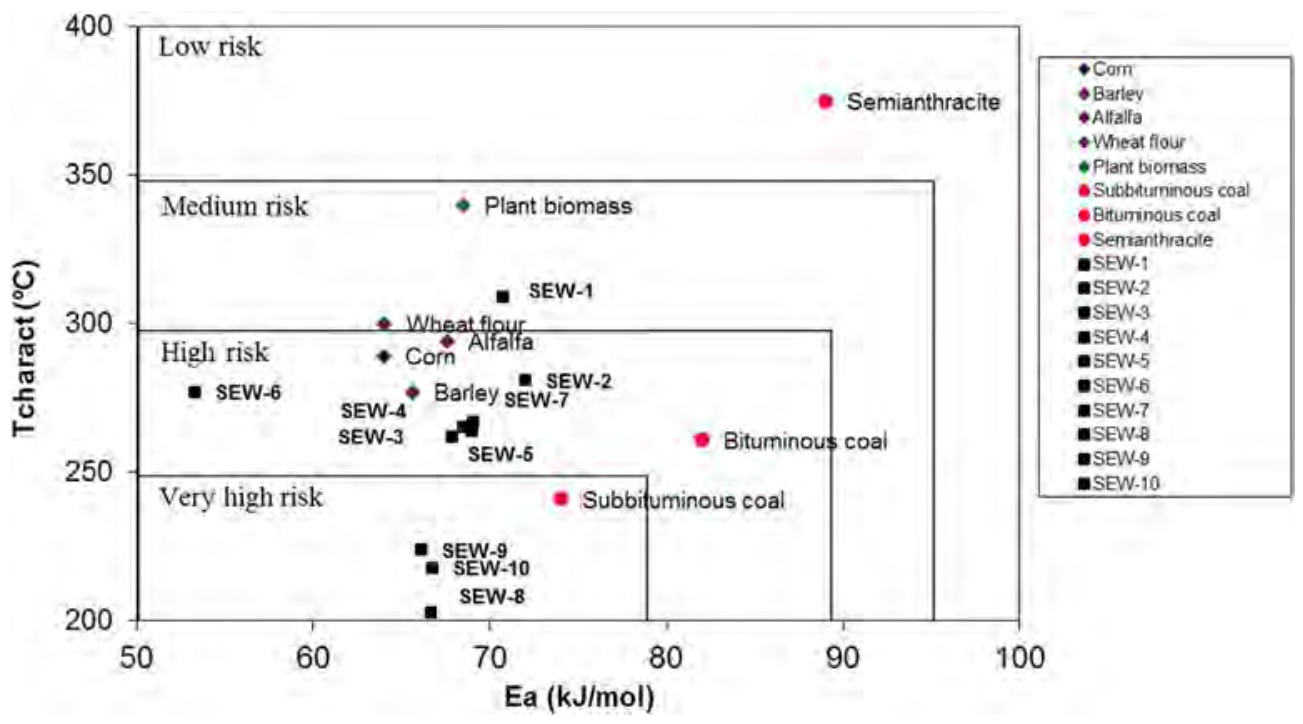

Fig. 2. Spontaneous combustion tendency of sewage sludge.

As shown in the analysis, the Ea did not vary in great degree for these, unlike for coals. Coals from different ranges are located in different regions of self-ignition risk, but all the thermally dried sewage sludge and biomass present an activation energy of less than $79 \mathrm{~kJ} / \mathrm{mol}$. This situation is also observed for biomasses, which cannot be classify according to their Ea but for their Tcharact. The Ea lower values of biomasses and sewage sludge do not mean a lower risk, but this risk might be determined through Tcharact.

By doing a correlation analysis it is shown that Tcharact has significant correlation with $\mathrm{H}, \mathrm{S}$ and TEV. A discriminant analysis has also developed, and it was observed that $100 \%$ of the samples are well classified. Two significant equations are determined where $\mathrm{H}, \mathrm{N}$ and $\mathrm{S}$ are the main parameters causing the differentiation of the samples.

The three samples that are located in the Very high risk, SEW-8, SEW-9 and SEW-10, area are those that have lower difference between IET and CST in the DSC analysis, and the one that is in the Medium risk area is the one with the highest range. This means that the first stage of the self-heating process, consisting of the initial exothermic reaction (slow oxidation) is shorter for samples SEW-8, SEW-9 and SEW-10 than for the other samples. The second stage of the self-heating process that takes place when CST is reached (quick oxidation) starts very near to the initial point of the exothermic reaction.
Table 5

ONU N.4. Division 4.2.test.

\begin{tabular}{|c|c|c|c|c|c|}
\hline Sample & $\begin{array}{l}\text { Self-heating } \\
\text { in a } 100 \mathrm{~mm} \\
\text { cube at } \\
140{ }^{\circ} \mathrm{C}\end{array}$ & $\begin{array}{l}\text { Self-heating } \\
\text { in a } 25 \mathrm{~mm} \\
\text { cube at } \\
140{ }^{\circ} \mathrm{C}\end{array}$ & $\begin{array}{l}\text { Self-heating } \\
\text { in a } 100 \mathrm{~mm} \\
\text { cube at } \\
120^{\circ} \mathrm{C}\end{array}$ & $\begin{array}{l}\text { Self-heating } \\
\text { in a } 100 \mathrm{~mm} \\
\text { cube at } \\
120^{\circ} \mathrm{C}\end{array}$ & Classification \\
\hline SEW-2 & Yes & No & No & - & $\begin{array}{l}\text { Exempted if } \\
\text { transported in } \\
\text { packages } \leq 3 \mathrm{~m}^{3}\end{array}$ \\
\hline SEW-7 & Yes & No & No & - & $\begin{array}{l}\text { Exempted if } \\
\text { transported in } \\
\text { packages } \leq 3 \mathrm{~m}^{3}\end{array}$ \\
\hline
\end{tabular}

Table 6

Self-ignition temperature test.

\begin{tabular}{llll}
\hline $\begin{array}{l}\text { Sample } \\
\text { volume } \\
\left(\mathrm{cm}^{3}\right)\end{array}$ & $\begin{array}{l}\text { Lower temperature } \\
\text { leading to ignition }\left({ }^{\circ} \mathrm{C}\right)\end{array}$ & $\begin{array}{l}\text { Higher temperature } \\
\text { without ignition }\left({ }^{\circ} \mathrm{C}\right)\end{array}$ & $\begin{array}{l}\text { Self-ignition } \\
\text { temperature }(\mathrm{SIT}) \\
\left({ }^{\circ} \mathrm{C}\right)\end{array}$ \\
\hline 1500 & 125 & 120 & 122.5 \\
350 & 140 & 135 & 137.5 \\
150 & 145 & 140 & 142.5 \\
50 & 155 & 150 & $152: 5$ \\
\hline
\end{tabular}




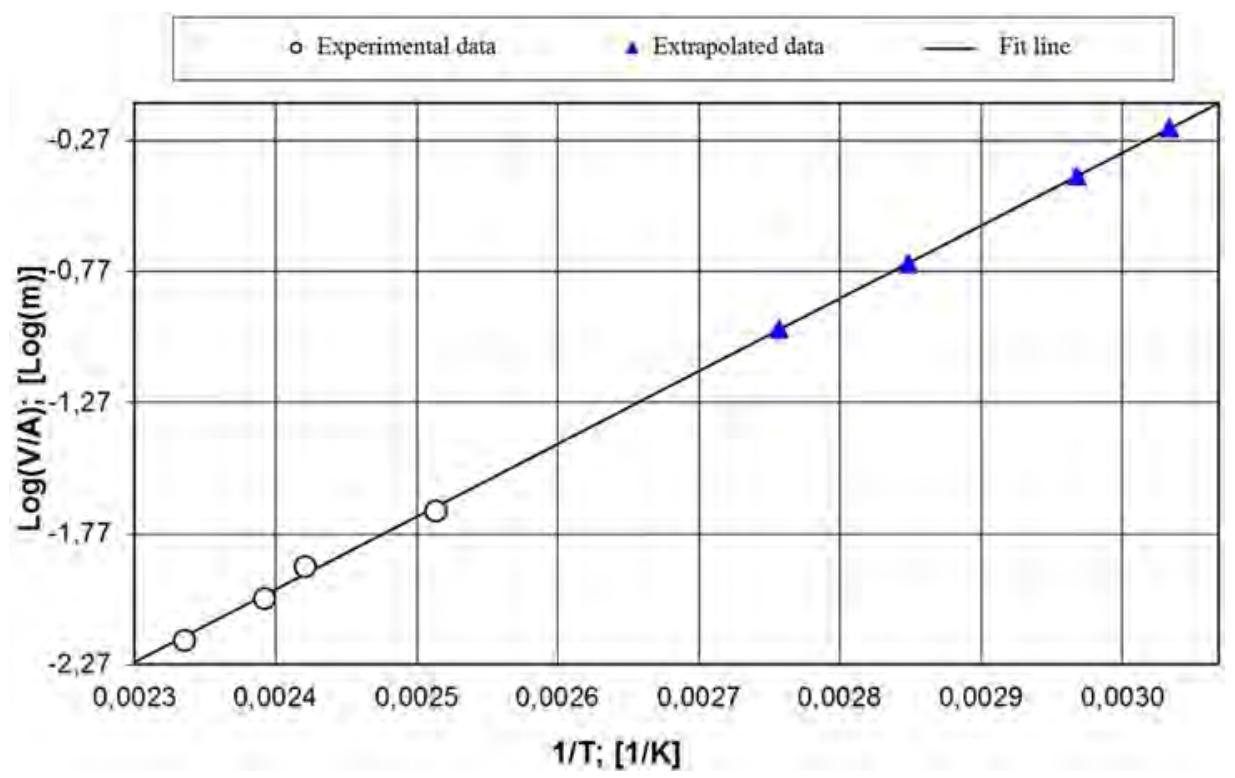

Fig. 3. Extrapolation of SIT. Temperature $[1 / T]$ versus size $[\log (\mathrm{V} / \mathrm{A})]$.

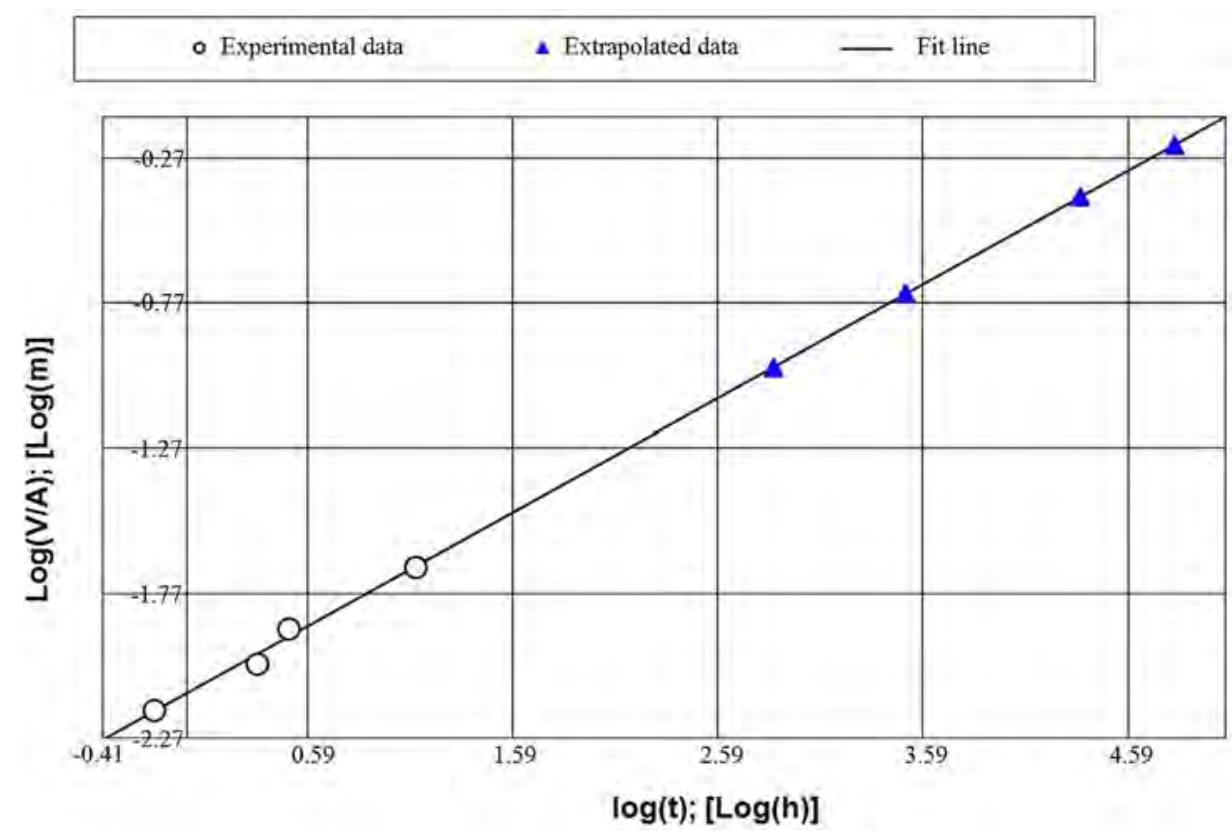

Fig. 4. Extrapolation of SIT. Time $[\log (\mathrm{t})]$ versus size $[\log (\mathrm{V} / \mathrm{A})]$.

content of the samples. It is shown that SEW-1 is the sample with the lowest sulphur content and the highest value of Tcharact, while with SEW-8 the opposite occurs.

\subsection{Transport classification}

Table 5 shows the results obtained for two samples, which were selected by their different origin, one from Madrid and the other from Barcelona. As can be seen, both samples are identically classified.

\subsection{Thermal stability}

A more detailed testing has been done for sample SEW-10 in order to determine its self-ignition temperature. Using four different volumes of sample, ranging from $50 \mathrm{~cm}^{3}$ to $1500 \mathrm{~cm}^{3}$ and subjecting the samples to increasing oven temperatures, both the lower temperature leading to an ignition and the higher temperature without ignition can be determined, so that the self-ignition temperature can be defined as the medium value among those temperatures.

Table 6 shows the results of the thermal stability tests.

Figs. 3 and 4 represent the size of the sample versus the inverse 
of temperature and versus time. Extrapolating these results it can be deduced that a volume of $1 \mathrm{~m}^{3}$ will reach self-ignition at $76{ }^{\circ} \mathrm{C}$ after 4.4 months; for $10 \mathrm{~m}^{3}$, the temperature would drop to $62{ }^{\circ} \mathrm{C}$, but the required time would increase to 3 years.

These results were also extrapolated to determine the classification of SEW-10 according to ONU N.4 Division 4.2 and results show that this sample is also exempted of classification if it is transported in packages of less than 3 cubic meters.

Transport classification tests of the two samples tested and the interpolation of results for the third one show that there is no distinction between samples from different origins and that belonging to different spontaneous combustion risk zone. These results indicate that transport classification tests produce a broad grouping of samples, which is a reasonable finding for samples that have some similarities in their composition. More samples should be further studied to verify this behaviour and provide a general rule about safe transportation of dried sewage sludge. Nevertheless, a more precise distinction among samples has been obtained by the evaluation of susceptibility procedure (Ea, Tcharact) as shown in Fig. 2.

\section{Conclusions}

Dried sewage sludge are flammable products that present a selfignition risk. Those samples having a shorter initial exothermic reaction, characterized by a lower difference among IET and CST values produce a higher self-ignition tendency. The content in $\mathrm{H}$ is positively correlated to this behaviour.

The procedure to evaluate thermal susceptibility based on the activation energy and the characteristic oxidation temperature provides a more detailed analysis of samples than the transport classification tests alone.

The knowledge of ignition properties of sewage sludge will improve the design of prevention and protection measures to decrease the hazards associated with the management, transport and storage of sewage sludge. Chemical composition of sludge has a great influence on their spontaneous combustion properties, so a good study of these parameters may provide a guide to design these measures. As a general rule, prevention measures similar to those extensively used for coals would be applicable to sludge.

Some parameters can be controlled during normal operation of plants. It is recommended to avoid the accumulation of large amounts of dust in industrial facilities, since they can promote the initiation of self-heating processes and also they mean always an increase in the risk of dust explosions. This goal can be also obtained by adding certain percentages of inert materials.
A continuous monitoring of temperatures, or even better, of $\mathrm{CO}$ emissions from dust accumulations will allow the early detection of self-heating processes, providing more time for the protective measures to act properly.

\section{Acknowledgements}

The authors gratefully acknowledge the Lloyd's Register Educational Trust for funding the project Safety conditions against ATEX risks in the water industry providing all the data for this paper.

\section{References}

Arenillas, A., Rubiera, F., Pis, J.J., Cuesta, M.J., Iglesias, M.J., Jiménez, A., Suárez-Ruiz, I., 2003. Thermal behaviour during the pyrolysis of low rank perhydrous coals. J. Anal. Appl. Pyrolysis 371-385.

Eckhoff, R., 2009. Understanding dust explosions. The role of powder science and technology. J. Loss Prev. Process Ind. 22, 105-116.

Europa Press, 2006, July 8. Un muerto y dos heridos tras una explosión en una depuradora en Barcelona (Barcelona, Catalonia, Spain).

Eurostat, 06.11.2013. Eurostat. Retrieved fromhttp://appsso.eurostat.ec.europa.eu/ nui/show.do?dataset=env_ww_spd\&lang=en.

Fernandez-Anez, N., García-Torrent, J., Medic-Pejic, L., 2014. Flammability properties of thermally dried sewage sludge. Fuel 134, 636-643.

Fodor, Z., Klemes, J.J., 2012. Waste as alternative fuel - Minimising emissions and effluents by advanced design. Process Saf. Environ. Prot. 263-284.

Folgueras, M.B., Díaz, R.M., Xiberta, J., Prieto, I., 2003. Thermogravimetric analysis of the co-combustion of coal and sewage sludge. Fuel 82, 2051-2055.

García Torrent, J., Cámara Rascón, A., Querol Aragón, E., 2002. New thermogravimetric techniques applications for characterizing the susceptibiliy of coal selfcombustion. In: XI Congreso Internacional de Industria, Minería y Metalurgia, pp. 469-471 (Zaragoza).

García-Torrent, J., Ramírez-Gómez, Á., Querol-Aragón, E., Grima-Olmedo, C., MedicPejic, L., 2012. Determination of the risk of self-ignition of coals and biomass materials. J. Hazard. Mater. 213-214, 230-235.

Nifuku, M., Tsujita, H., Fujino, K., Takaichi, K., Barre, C., Hatori, M., , et al.Paya, E., 2005. A study on the ignition characteristics for dust explosion of industrial wastes. J. Electrost. 63, 455-462.

Otero, M., Díez, C., Calvo, L.F., García, A.I., Morán, A., 2002. Analysis of the cocombustion of sewage sludge and biomass by TG-MS. Biomass \& Bioenergy 22, 319-329.

Proust, C., 2006. A few fundamental aspects about ignition and flame propagation in dust clouds. J. Loss Prev. Process Ind. 19, 104-120.

Querol Aragón, E., García Torrent, J., Cámara Rascón, A., 2000. Spontaneous combustion testing. In: Congress Safety net Seminar on Explosion Prevention. Hamm (Germany). Retrieved from. www.safetynet.de/publications/.

Ramírez, A., García Torrent, J., Tascón, A., 2009. Experimental determination of selfheating and self-ignition risks associated with the dusts of agricultural materials commonly stored in silos. J. Hazard. Mater. 175, 920-927.

Rulkens, W., 2008. Sewage Sludge as a Biomass Resource for the Production of Energy: Overview and Assessment of the Various Options. American Chemical Society.

United Nations, 2009. Recommendations on the Transport of Dangerous Goods (Manual of Tests and Criteria. New York and Geneva).

Zerlottin, M., Refosco, D., Della Zassa, M., Biasin, A., Canu, P., 2013. Self-heating of dried wastewater sludge. Waste Manag. 129-137. 


\section{Annex V. Detection of incipient self- ignition process in solid fuels through gas emissions methodology}




\title{
Detection of incipient self-ignition process in solid fuels through gas emissions methodology
}

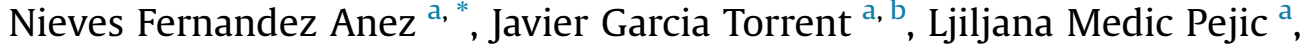 \\ Carlos Grima Olmedo ${ }^{\mathrm{c}}$ \\ ${ }^{a}$ Department of Energy and Fuels (UPM Technical University of Madrid, Spain), C/ Alenza 4, 28003 Madrid, Spain \\ ${ }^{\mathrm{b}}$ Laboratorio Oficial Madariaga, LOM (UPM Technical University of Madrid, Spain), C/ Eric Kandel, 1 - (TECNOGETAFE), Parque Científico y Tecnológico de \\ la UPM, 28906 Getafe, Madrid, Spain \\ ${ }^{c}$ Department of Geological and Mining Engineering (UPM Technical University of Madrid, Spain), C/ Alenza 4, 28003 Madrid, Spain
}

\section{A R T I C L E I N F O}

\section{Article history:}

Received 9 September 2014

Received in revised form

19 February 2015

Accepted 19 February 2015

Available online 21 February 2015

\section{Keywords:}

Self-ignition

Spontaneous combustion

Gas emission

Solid fuels

\begin{abstract}
A B S T R A C T
The aim of this study is to propose an experimental methodology to detect incipient self-ignition processes in solid fuels. This methodology is based on the gases emissions of different solid fuels, varying the degree of compaction and the grain size of the materials. To achieve this goal, a procedure for the collection and analysis of the gases emitted by samples of various fuels has been developed, analysing the temperatures at which these emissions begin. The results obtained for different materials show that it is possible to detect incipient spontaneous combustion processes using measurements of $\mathrm{CO}$ and $\mathrm{CO}_{2}$ emissions during heating process, and then to set alarm thresholds based on the concentrations of these gases. Those results have been compared with results from conventional thermogravimetry and differential scanning calorimetry tests and it is shown that the proposed methodology detect the self-ignition process start point in advance.
\end{abstract}

๑) 2015 Elsevier Ltd. All rights reserved.

\section{Introduction}

Currently over $80 \%$ of the energy source used in the world comes from the combustion of fossil fuels (International Energy Agency, 2013). Historically, coal is the fossil fuel most used to produce energy and nowadays it is still one of the most used fuels all over the world, with a total world consumption of 8,123,601 thousand tons in 2011 (U.S. Energy Information Administration). Thus, coal storage is a common practice and the associated hazards, its harmful effects to the environment and human health (Fabiano et al., 2013) and its self-ignition and spontaneous combustion risks are commonly studied (Sipilä et al., 2012). But coal production is gently being reduced (World coal association, 2013) and replaced by other products, such as biomass.

The United Nations Framework Convention on Climate Change ((UNFCCC)) defines biomass as the "non-fossilized and biodegradable organic material originating from plants, animals and microorganisms. This shall also include products, by-products, residues

\footnotetext{
* Corresponding author.

E-mail address: nieves.fernandez@upm.es (N. Fernandez Anez).
}

and waste from agriculture, forestry and related industries as well as the non-fossilized and biodegradable organic fractions of industrial and municipal wastes. Biomass also includes gases and liquids recovered from the decomposition of non-fossilized and biodegradable organic material". One of the most used biomass is the one derived from wood, as pellets or chips, but new biomasses from waste are being developed also nowadays (Kothari et al., 2010).

Benefits of substituting coal by biomass are well studied and known (Heller et al., 2004), but other options, as using trees for carbon sequestration, are also possible to achieve the objectives (Baral and Guha, 2004). Existing beliefs about the no-gas emissions of biomass are not exactly true (Wibe, 2012) (Kallio et al., 2013), and the use of biomass generate several hazards. Two of the main hazards of this kind of substances are highly related. Those are the gas emissions associated to the heating and oxidation of the biomass (Goode and Yokelson, 1999) (Hegg et al., 1990), and the heating and oxidation their selves, which are the cause of the selfignition of these storages (García-Torrent et al., 2012) (Veznikova et al., 2014).

Thermogravimetric and differential scanning calorimetric analyses are useful tools for a first and fast assessment of the 


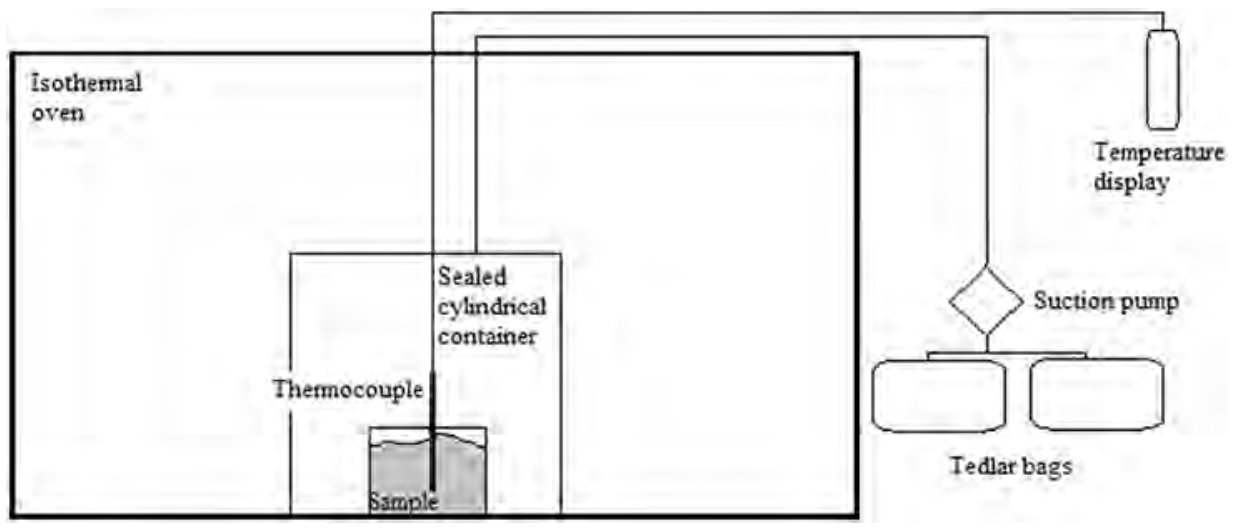

Fig. 1. Equipment for gas emissions test.

combustion properties of fuels (Magdziarz and Wilk, 2013) (Montenegro Mateos et al., 2013) and they are also used to initially evaluate the behaviour of the combustion on larger scale. But these techniques have a main disadvantage that is the difficulty of testing different parameters of the samples and different operating conditions, such as particle porosity, gas velocity magnitude and direction or oxygen concentration, that condition the smouldering and flaming combustion of the samples (Aldushin et al., 2006) (Bakhman et al., 2002).

A number of studies has been developed to determine the main parameters obtained from thermogravimetric and differential scanning calorimetric analyses, but this is not the only way to predict the combustion properties of materials (Everard et al., 2014). The combustion process of a sample starts even before the point at which is determined by these analyses, and the first indicator of this combustion is the gas emissions associated.

Adding this conviction with the necessity of studying several different parameters, a new test for the detection of the incipient self-ignition process in solid fuels has been developed and tested with coal and biomass samples (Fernandez-Anez et al., 2014) (Laboratorio Oficial Madariaga (LOM), 2013).

\section{Experiments}

\subsection{Gas emissions tests}

The equipment used to carry out these experiments is detailed below (Fig. 1):

- $10 \mathrm{~L}$ sealed cylindrical container.

- Isothermal oven P-Selecta.

- Type K thermocouple.

- Digital temperature display Testo 925.

- 1 L Tedlar sampling bags Sigma-Aldrich.

- Gas analyser Rosemount Analytical NGA-2000.

The sample is introduced inside a $1000 \mathrm{~cm}^{3}$ cubical wired basket according to different arrangements (compacted and noncompacted) and this basket is introduced inside the sealed container. The container is closed and connected with the temperature display through a K-thermocouple that is placed inside the sample, approximately at its centre. Before introducing the container, the oven is preheated at the tested temperature.

The sealed container is situated inside the oven to carry out the sample heating. The container has a narrow fitting $3 \mathrm{~mm}$ diameter on top where it connects to a plastic tube closed with a Mohr wrench.
Once the desired temperature inside the sample is reached, the plastic tube is connected with the sampling bags by opening the Mohr wrench and they are filled with the gas driven by a suction pump. Due to the small volume of the samples tested, temperature quickly stabilizes and it is considered constant during the sampling time. When the bags are full, they are disconnected from the plastic tub and connected to the analysers. Gases emitted during combustion are measured, starting at the connection between bag and analyser, until gas emission is zero.

The gas analyser Rosemount Analytical NGA-2000 measured emission data of $\mathrm{CO}$ and $\mathrm{CO}_{2}$. Also some $\mathrm{H}_{2} \mathrm{O}$ has been observed to condensate inside the tube, but it is not measured because it is not significant for the present research.

To determine the point at which emissions started, the relative percentage of emissions have been determined for each $20 \mathrm{~K}-$ interval. These relative percentages have been calculated according to the following procedure.

First of all, relative differences (RD) for each $20 \mathrm{~K}$ - interval have been calculated as shown in Equation (1).

$R D=\frac{e_{T 2}-e_{T 1}}{e_{T 1}}$

Where $\mathrm{e}_{\mathrm{T} 1}$ means the emissions at the lowest temperature of the interval and $\mathrm{e}_{\mathrm{T} 2}$ are the emissions at the highest temperature of the interval.

After that, relative percentages (RP) are determined by Equation (2) as the division between the relative difference of the interval and the sum of all the relative differences of the experiment, multiplied by 100 .

$R P=\frac{R D}{\Sigma R D_{i}} \cdot 100$

\subsection{Thermogravimetry and differential scanning calorimetry analyses}

In Thermogravimetric analysis (TG) the weight loss of a sample is measured when the sample is heated at a constant rate in air as

Table 1

Moisture and granulometry of studied samples.

\begin{tabular}{llccc}
\hline Sample & Moisture $(\%)$ & $\mathrm{d} 10(\mu \mathrm{m})$ & $\mathrm{d} 50(\mu \mathrm{m})$ & $\mathrm{d} 90(\mu \mathrm{m})$ \\
\hline Wood chips (fine) & 6.9 & 43 & 153 & 379 \\
Wood chips (coarse) & 7.2 & 115 & 600 & 1150 \\
Sewage sludge & 7.2 & 290 & 638 & 1210 \\
Coal & 4.0 & 8 & 46 & 166 \\
\hline
\end{tabular}




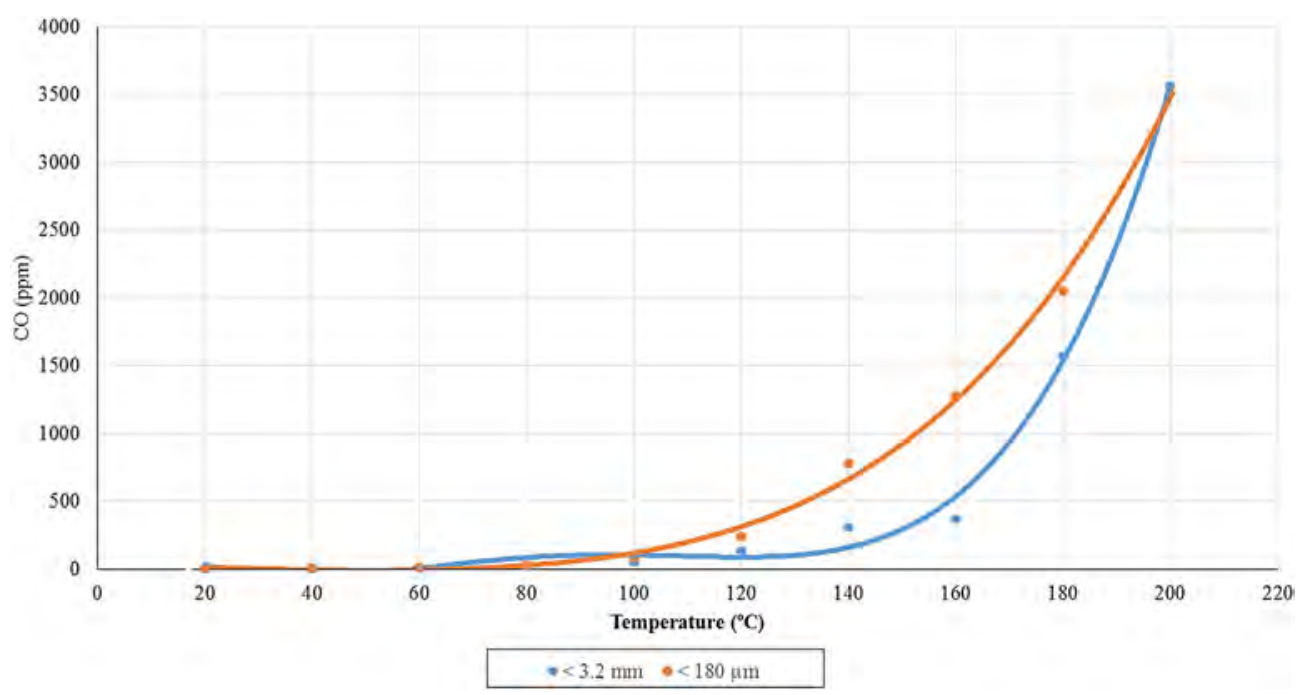

Fig. 2. CO emissions from wood chips.

well as the derivation of the weight by time. Test begins at $30{ }^{\circ} \mathrm{C}$ and ends at $800{ }^{\circ} \mathrm{C}$ using a heating rate of $5 \mathrm{~K} / \mathrm{min}$ and remaining at the final temperature for $10 \mathrm{~min}$. The resultant graph (weight vs temperature) gives information about the reactions occurred. Normally, it has three phases: loss of humidity, oxygen adsorption and combustion. Using this graph, two characteristics parameters are determined: the combustion induction temperature (IT), that is the temperature at the beginning of the combustion profiles; and the maximum weight loss temperature (MLT) that represents the volatile matter yield by the pyrolysis process. The MLT is used as an index of reactivity of the sample. The higher this temperature, the lower reactivity of the sample (Montenegro Mateos et al., 2013).

In the Differential Scanning Calorimetric analysis (DSC) the sample is placed in a crucible and heated from $30^{\circ} \mathrm{C}$ to $550{ }^{\circ} \mathrm{C}$ at a constant rate of $20 \mathrm{~K} / \mathrm{min}$. The difference in temperature between the sample and one of reference is measured and recorded against the temperature of the oven and the exchanges of heat in the sample are determined. Heat fluxes are characterized and exo and endothermic processes are determined. The parameters used to characterize different substances are: minimum temperature at which the exothermic reaction begins (initial temperature, IET), maximum temperature reached during the exothermic reaction (final temperature, FET) and temperature at which the fast exothermic reaction commences (change of slope temperature, CST) (Montenegro Mateos et al., 2013).

Those analyses have been done using a TG-DSC Mettler Toledo TG-50 apparatus.

\subsection{Samples}

Three samples have been tested, pinus silvestris wood chips from Sweden, thermally dried sewage sludge from Madrid (Spain) and British coal. The weight of the samples tested was $50 \mathrm{~g}$ in all the tests. Temperatures studied were between $20^{\circ} \mathrm{C}$ and $200{ }^{\circ} \mathrm{C}$, measurements being taken every $20 \mathrm{~K}$.

Wood chips of two different sizes were analysed, one below $180 \mu \mathrm{m}$ and another one below $3.2 \mathrm{~mm}$.

Both sewage sludge and coal were received as small particle size samples, so they were studied as received in two arrangements, compacted and no compacted. Compaction is done by placing a $10 \mathrm{~kg}$ weight on the sample surface. Moisture and particle size of the studied samples are shown in Table 1.

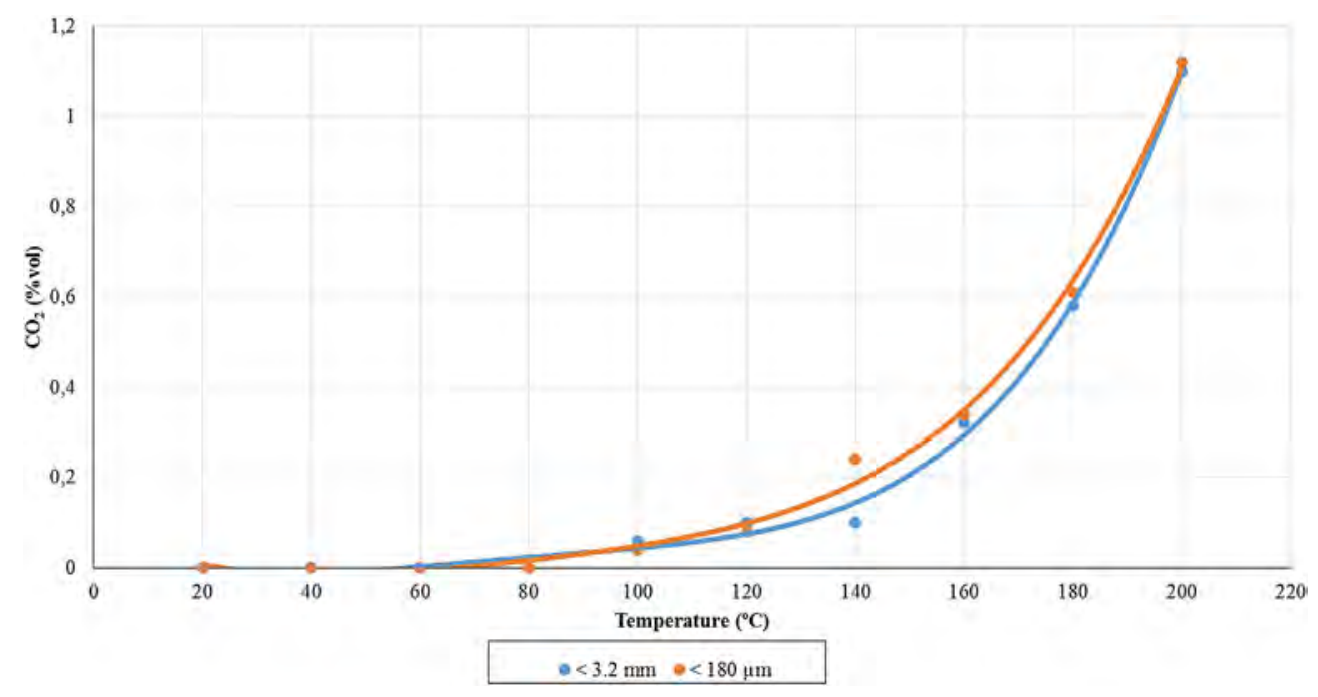

Fig. 3. $\mathrm{CO}_{2}$ emissions from wood chips. 


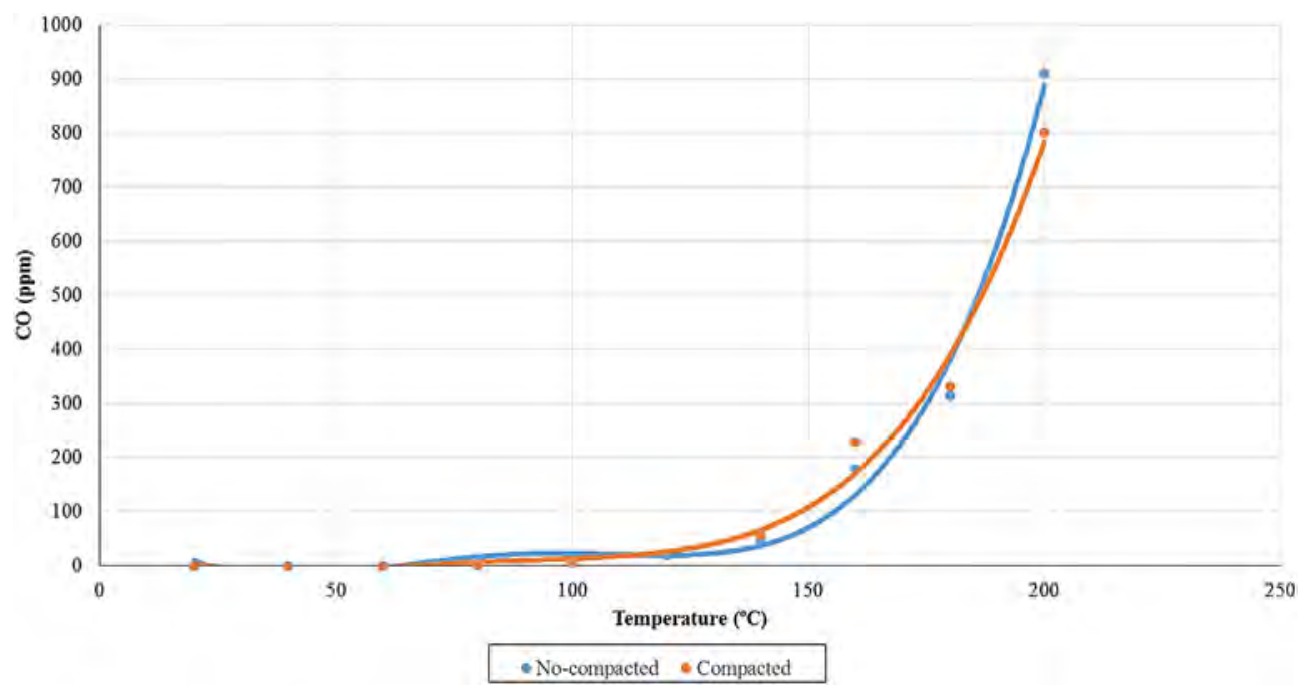

Fig. 4. CO emissions from sewage sludge.

\section{Results}

\subsection{Gas emissions test}

Three different solid fuels have been selected with the objective of a high diversity. Gas emissions for wood chips, sewage sludge and coal samples have been determined in the temperature range between $20^{\circ} \mathrm{C}$ and $200{ }^{\circ} \mathrm{C}$, with measurements each $20 \mathrm{~K}$.

Wood chips have been studied with two different granulometries, and results of $\mathrm{CO}$ and $\mathrm{CO}_{2}$ emissions are shown in Figs. 2 and 3.

It is observed that the rise of the temperature produces an increase on the gas emissions. Looking at the particle size, in the midrange temperature, gas emissions for the small one are higher than for the big one, but the starting point of the emissions seems to be similar.

With these data, it is considered that the emissions start at the interval where relative percentage is higher than $10 \%$. So as shown in Table 2, in this case CO emissions start in the $60-80{ }^{\circ} \mathrm{C}$ interval.

Doing the same calculation for $\mathrm{CO}$ and $\mathrm{CO}_{2}$ and each granulometry, it is observed that the first gas emitted is $\mathrm{CO}$ at the interval of $60-80{ }^{\circ} \mathrm{C}$ for both granulometries. Secondly, $\mathrm{CO}_{2}$ is emitted at $100-120^{\circ} \mathrm{C}$ for both granulometries.

Thermally dried sewage sludge and coal samples have been studied according to two arrangements, compacted and no compacted.

Gases emissions of thermally dried sewage sludge show a small difference between compacted and no compacted samples. $\mathrm{CO}_{2}$ emissions start before than $\mathrm{CO}$ in this case, and the interval of start point according to $\mathrm{CO}_{2}$ is $60-80^{\circ} \mathrm{C}$ while for $\mathrm{CO}$ is $80-100{ }^{\circ} \mathrm{C}$ (see Figs. 4 and 5).

Looking at the results of coal, showed on Figs. 6 and 7, a significant rise of emissions due to the compaction is observed. Compacted sample emits a higher amount of gases than nocompacted at high temperatures, but the starting point of both samples is located in the range of $80-100{ }^{\circ} \mathrm{C}$ according to $\mathrm{CO}$ emissions. Looking at $\mathrm{CO}_{2}$ emissions, this point is located on the $100-120^{\circ} \mathrm{C}$.

Compaction affects differently to the samples depending both on the particle size and the moisture of the sample. The lower these parameters, the more efficient the compaction is, so the more different are the results between compacted and no-compacted samples.

\subsection{Thermogravimetric and differential scanning calorimetric analyses}

Thermogravimetric (TG) and differential scanning calorimetric (DSC) analyses have been also done. Fig. 8 presents thermogravimetric plot for wood chips sample (blue-coloured), with the overlapping derivative curve (red-coloured). This sample has two stages of loss of weight instead of one like coal sample. As can be seen, the sample undergoes a first loss of weight process that has the maximum value at $312{ }^{\circ} \mathrm{C}$ (MLT). At $450{ }^{\circ} \mathrm{C}$ a second peak of the derivative is recorded, probably due to a later stage of the reaction.

Fig. 9 shows the calorimetric curve of the sample. Descending lines correspond to endothermic processes and ascending lines to exothermic processes. The first descending peak represents moisture loss of the sample while the ascending one represents its oxidation. Wood chips sample begins the exothermic process at $82{ }^{\circ} \mathrm{C}$ (IET), accelerating from $205{ }^{\circ} \mathrm{C}$ (CST), showing a clear exothermic process that continues up to $346{ }^{\circ} \mathrm{C}$ (FET).

Showing TG results of sewage sludge (Fig. 10), two stages of loss of weight are also observed. In this case the first peak has less loss of weight than the second one, unlike for the wood chips sample. The heating process starts at $242{ }^{\circ} \mathrm{C}$ (IT) and there are two maximum values, the first one at $277^{\circ} \mathrm{C}$ (MLT) and the second one at $480{ }^{\circ} \mathrm{C}$.

The DSC plot for sewage sludge has some differences with the one for wood chips, as shown in Fig. 11. The descending peak that appears after the final point of the exothermic temperature represents the decomposition of the sample.

Unlike the previous cases, TG plot for coal has only one stage of weight loss as shown in Fig. 12 . The heating process starts at $375^{\circ} \mathrm{C}$

Table 2

Calculation example for $\mathrm{CO}$ emissions start point for wood chips.

\begin{tabular}{lll}
\hline Temperature interval $\left({ }^{\circ} \mathrm{C}\right)$ & Relative difference $(-)$ & Relative percentage $(\%)$ \\
\hline $20-40$ & 0.2 & 1.9 \\
$40-60$ & 0.6 & 5.9 \\
$60-80$ & 2.2 & 20.2 \\
$80-100$ & 1.8 & 16.2 \\
$100-120$ & 1.8 & 16.9 \\
$120-140$ & 2.3 & 21.0 \\
$140-160$ & 0.6 & 5.8 \\
$160-180$ & 0.6 & 5.6 \\
$180-200$ & 0.7 & 6.5 \\
Sum & 10.9 & 100.0 \\
\hline
\end{tabular}




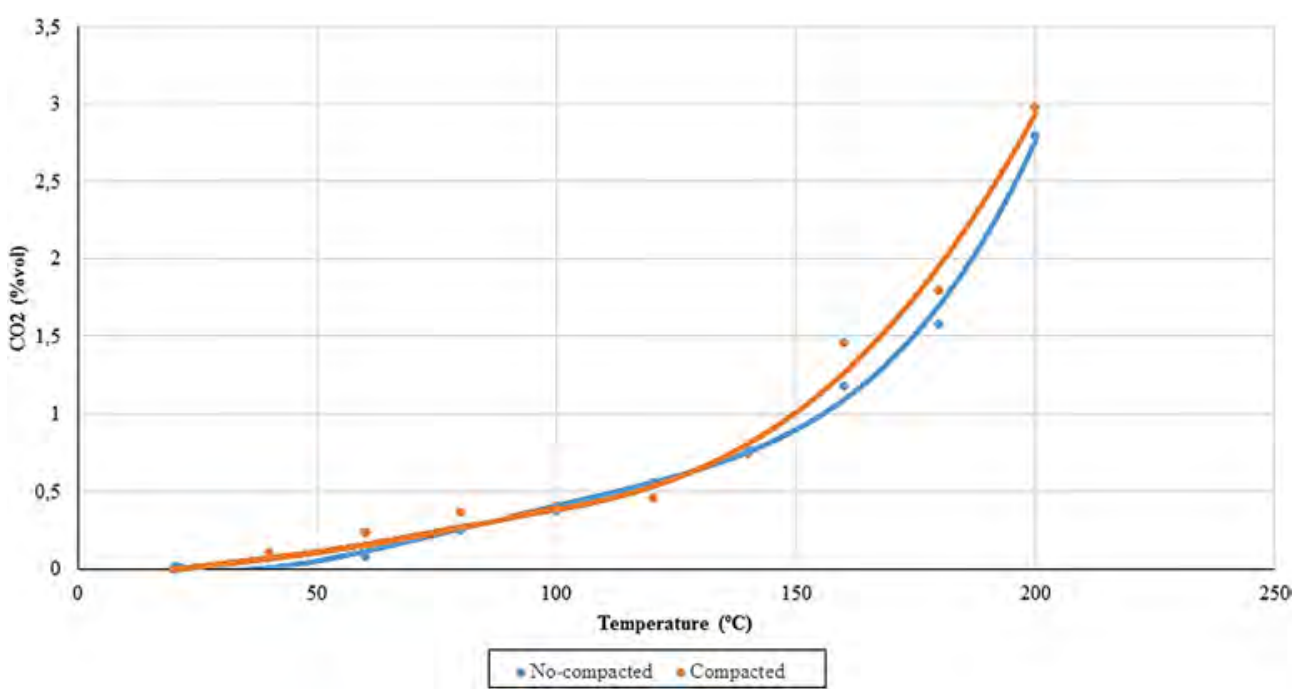

Fig. 5. $\mathrm{CO}_{2}$ emissions from sewage sludge.

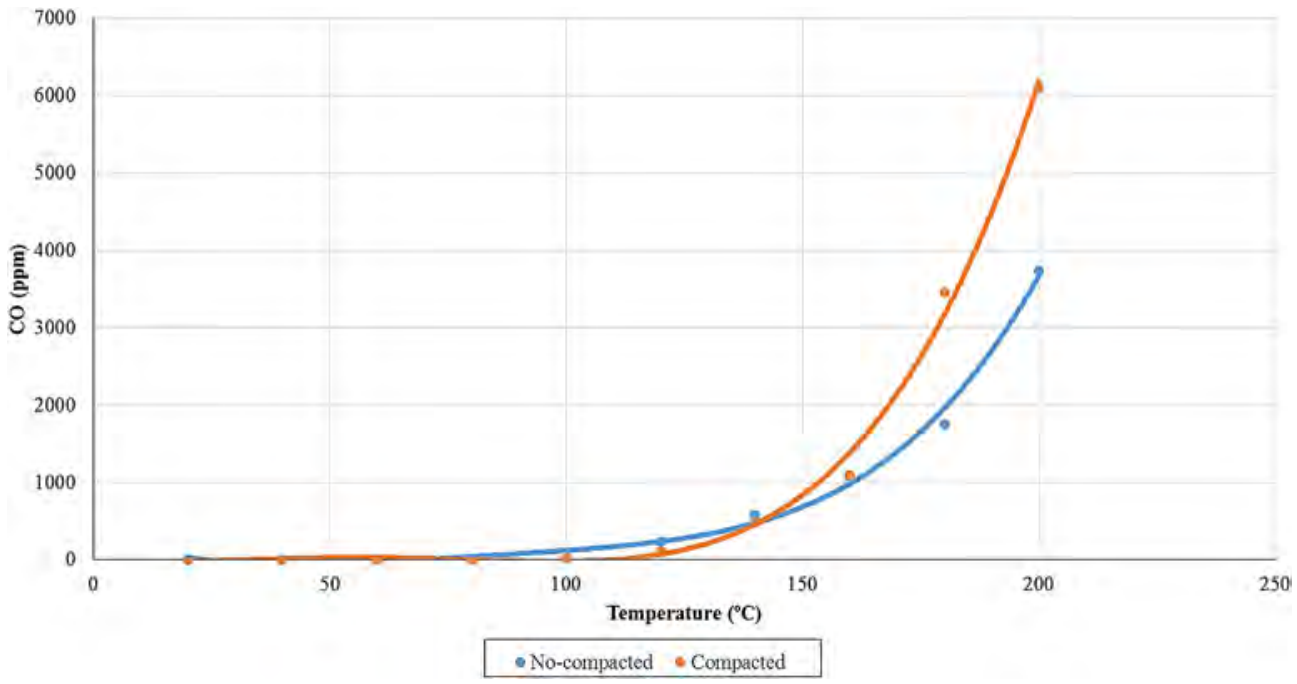

Fig. 6. CO emissions from coal.

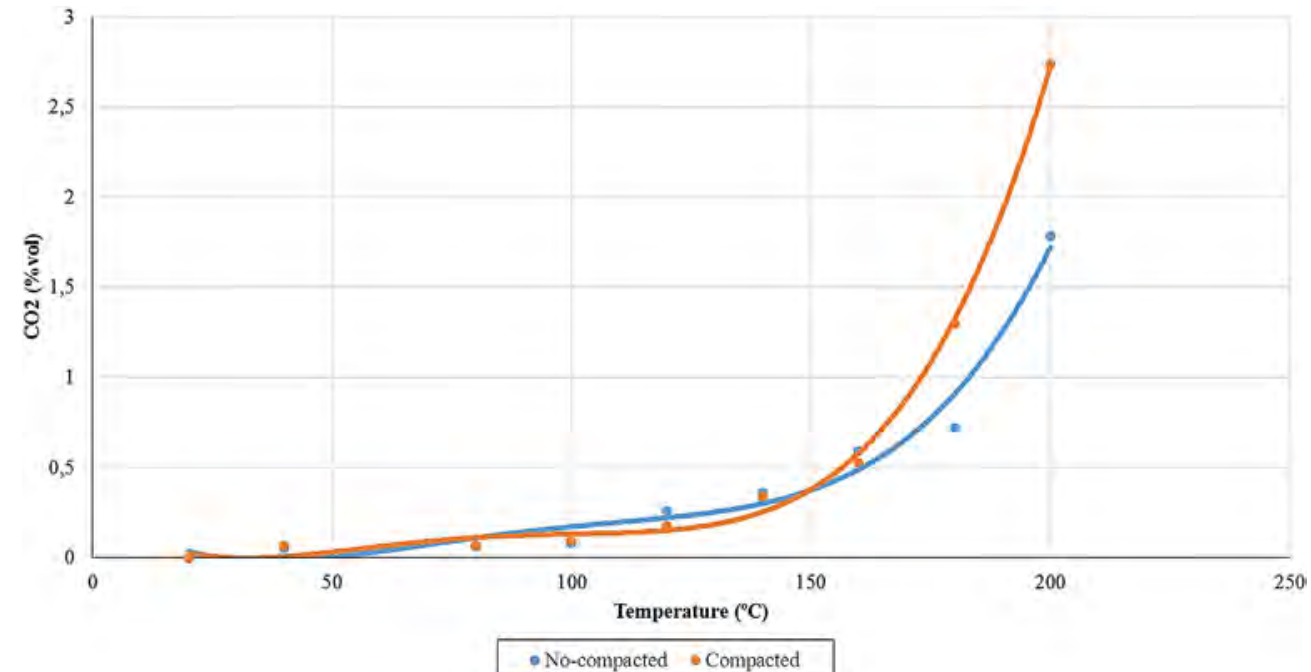

Fig. 7. $\mathrm{CO}_{2}$ emissions from coal. 


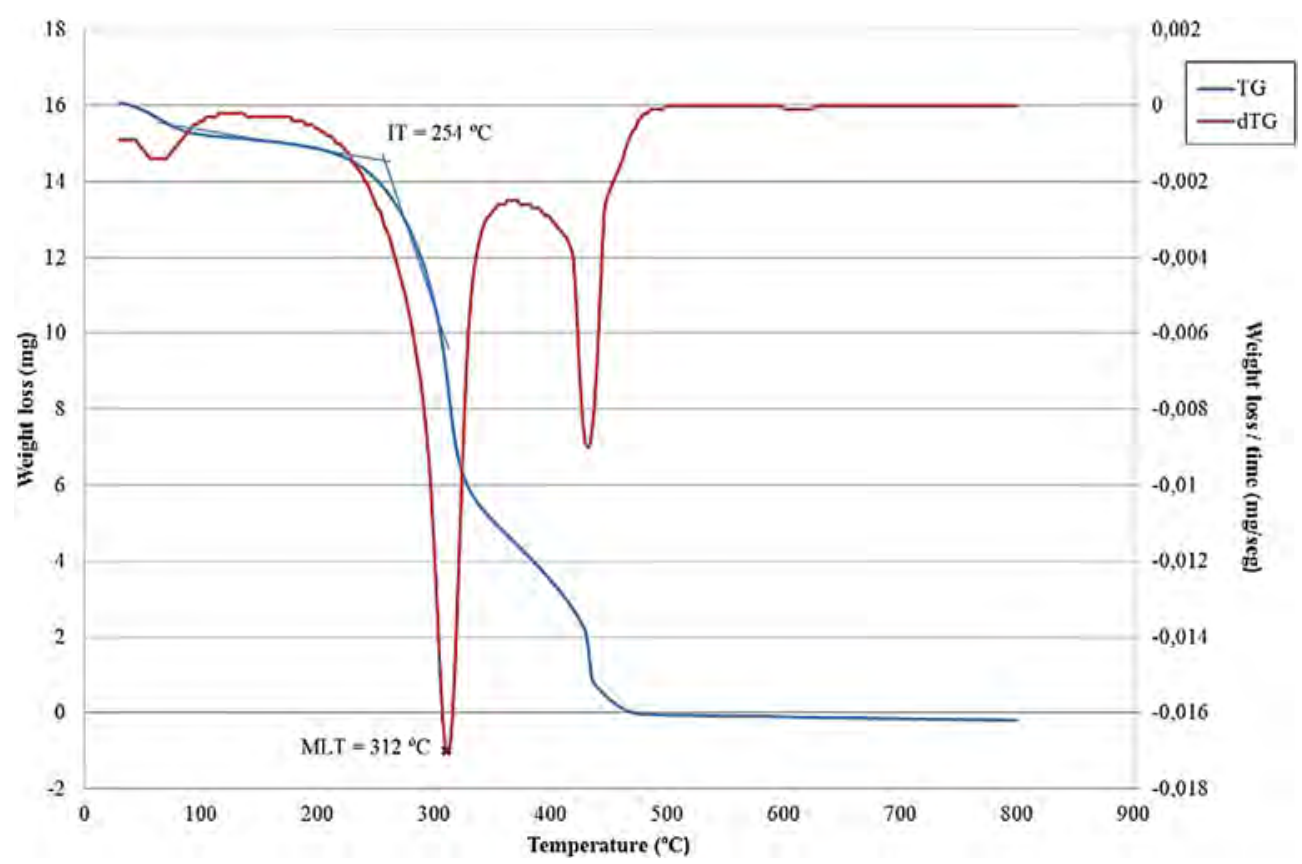

Fig. 8. TG analysis for wood chips.

(IT) and its maximum value is observed at $413^{\circ} \mathrm{C}$ (MLT).

The DSC plot for the coal sample, shown in Fig. 13, is similar to the one obtained for the wood chips sample, both presenting an acceleration of the exothermic process up to the FET. From this temperature significant changes are no longer produced, unlike what happens for the sludge, as shown in Fig. 11.

The IET obtained from the DSC analysis is the minimum starting temperature of the exothermic reaction, and the value of this parameter for the wood chips sample is $82^{\circ} \mathrm{C}$, for sewage sludge is $110{ }^{\circ} \mathrm{C}$ and for coal is $104^{\circ} \mathrm{C}$.

\subsection{Comparison of results}

Comparing the results obtained from both methods (Table 3), it can be inferred that the gas emissions method detects self-heating in advance.

\section{Discussion}

The results clearly indicate that increasing the temperature the total emissions of gas increase, which is fully expected as higher temperature implies an increased rate to the oxidation reaction.

This reaction occurs on the surface of the solid particles of the material, so that since it is an exothermic reaction, a heat source is generated. Upon oxidation of the dust material with the air is a spontaneous exothermic reaction, heat is being released. This phenomenon is called self-heating and is the first step in a process that might finally result in spontaneous combustion. An increase in temperature due to exothermic reaction on the solid surface will produce an increase in the reaction rate, releasing more heat, and

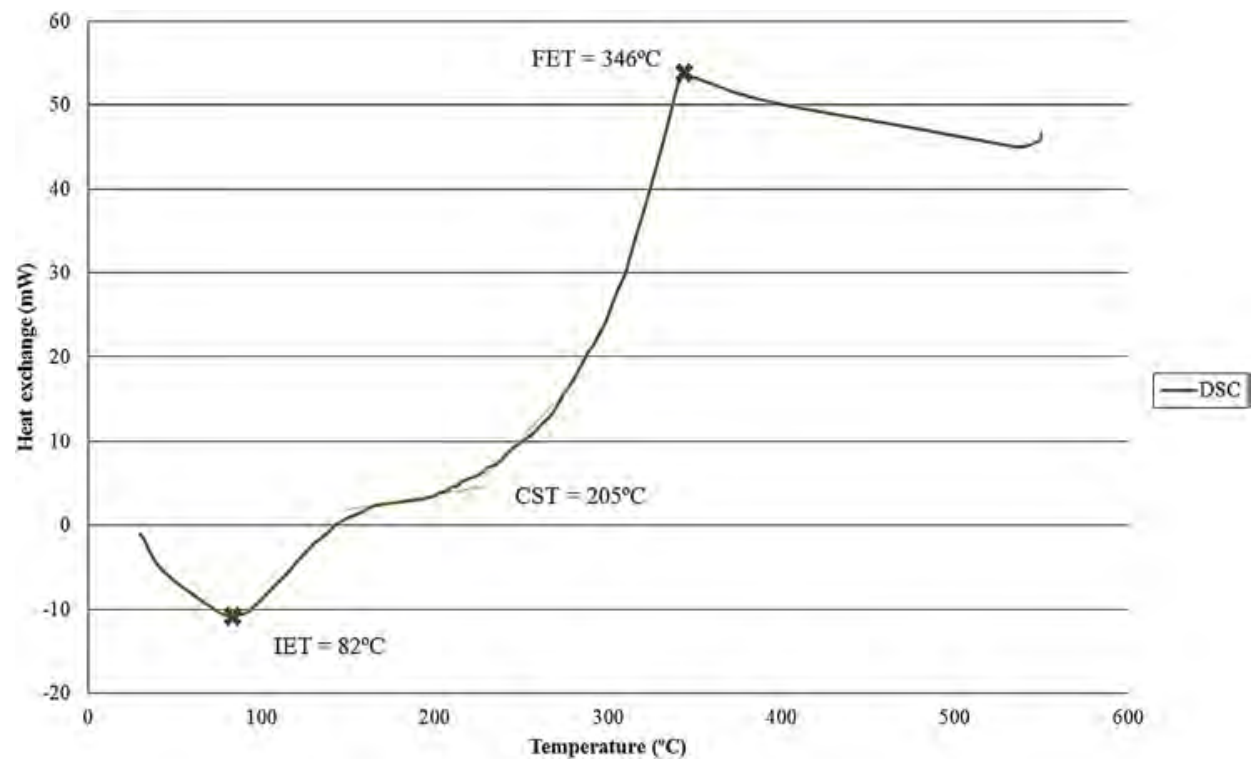

Fig. 9. DSC for wood chips. 


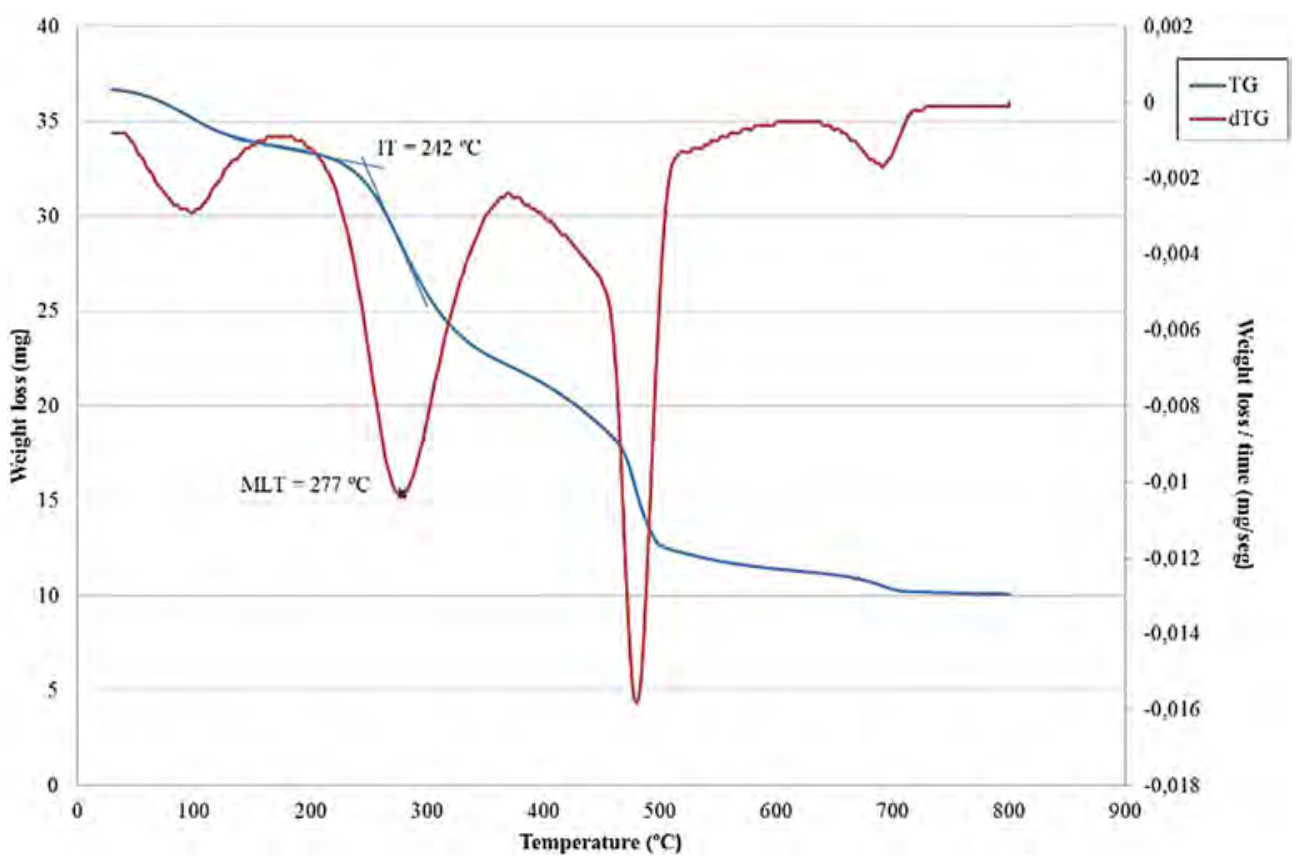

Fig. 10. TG for sewage sludge.

this process rapidly accelerates to high temperatures, leading to self-ignition.

The spread of the reaction is affected by the availability of oxygen, and this is related both to particle size and compaction.

In the case of wood chips, a smaller particle size causes a slight increase in gas emissions, but does not change the temperature at which the process begins. More emission from the sample with larger particles could be expected because oxygen in the air would have better access to the surface of the particles. The fine sample behaves somewhat like a compacted sample, because the oxygen access is reduced, but the larger specific surface due to smaller particles will probably have a greater influence on the reaction.

As for the compaction, it is evident that a compacted sample has a smaller spacing between the particles, which hinders the oxygen access to the area. In the case of the sample of sludge, compacting does not result in a difference in emissions, which can be analysed because the sludge had a large particle size, so that compaction is not significant. In the case of coal, however, a notable difference is observed, so that the compacted coal emits a greater amount of gas at higher temperatures, but the onset temperature of the process remains unchanged. In this case it should be noted that density and thermal conductivity are higher for compacted samples and it is well known that an increase in the thermal conductivity decreases the tendency to begin the self-heating process.

Somehow there is a competition between different phenomena (access of oxygen and thermal conductivity) and temperature will

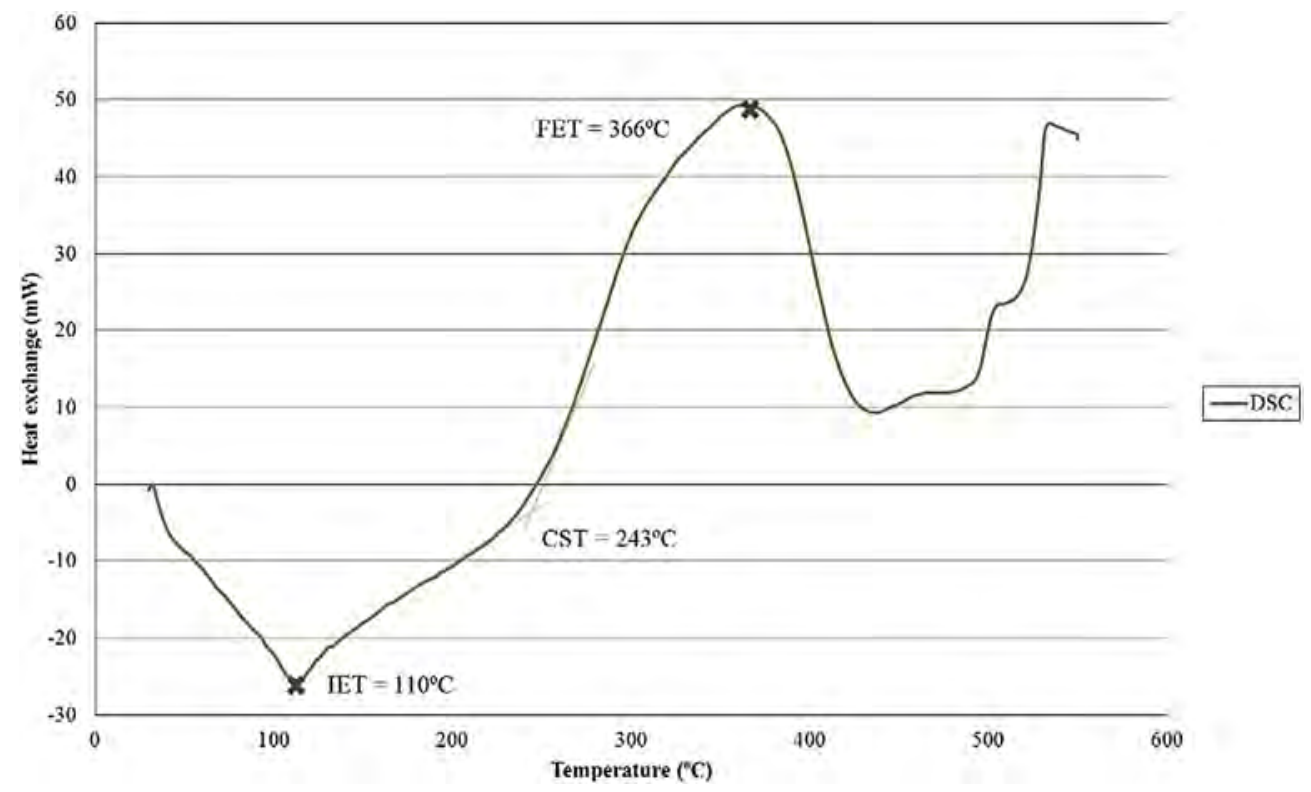

Fig. 11. DSC for sewage sludge. 


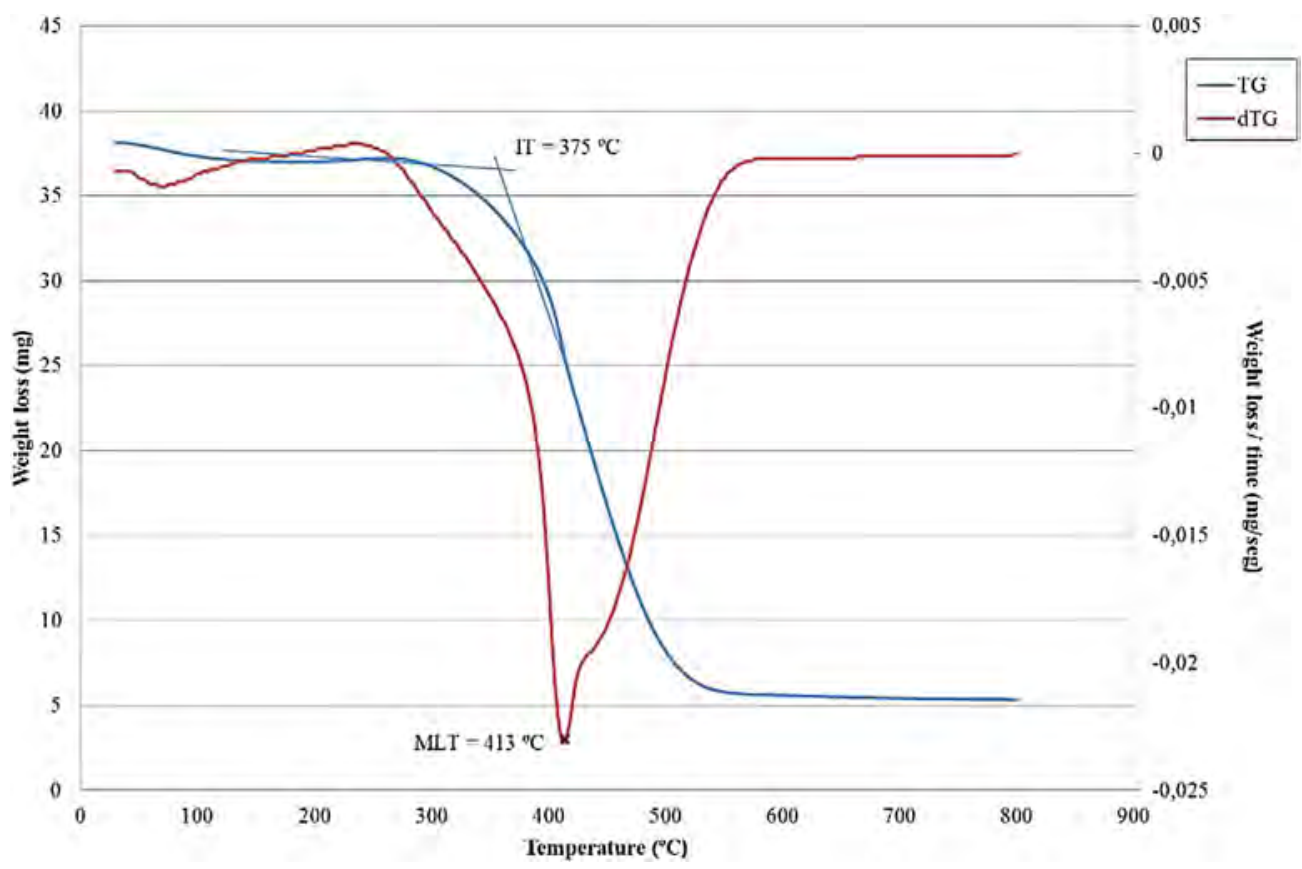

Fig. 12. TG for coal.

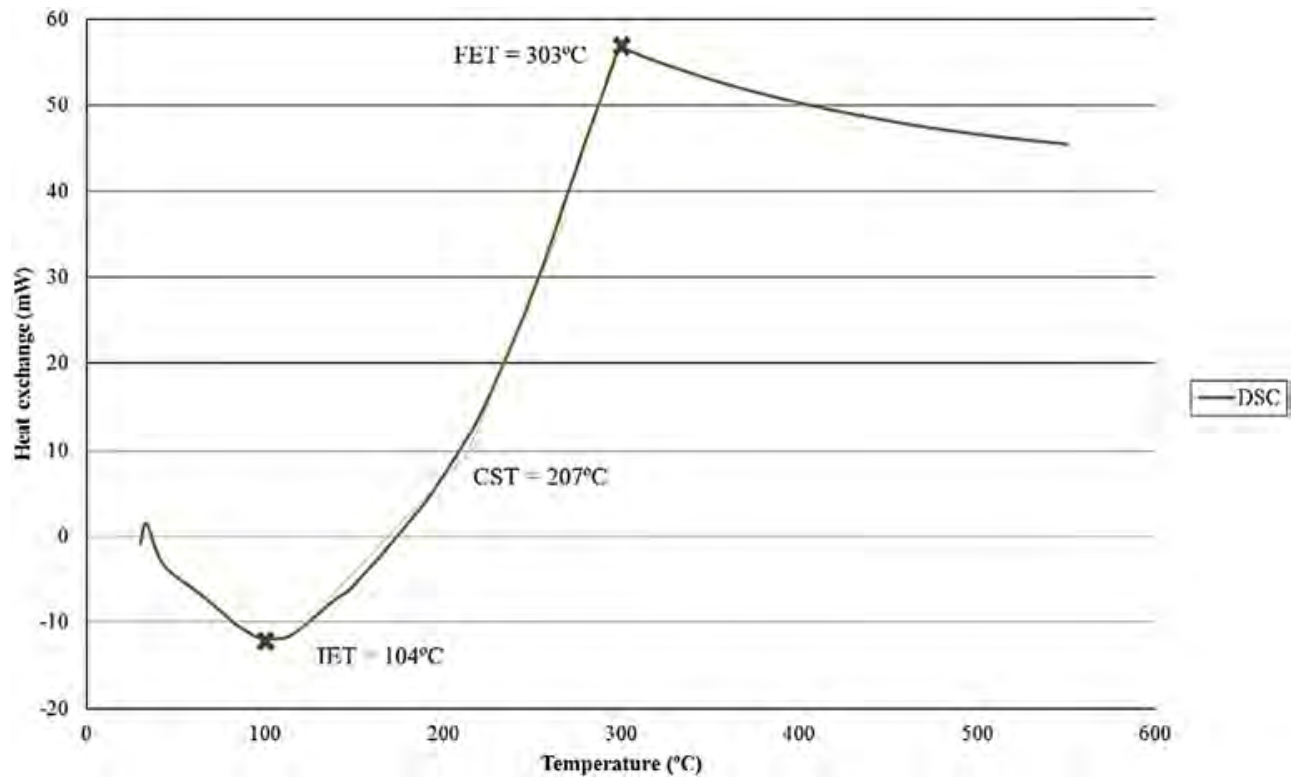

Fig. 13. DSC for coal.

have a decisive influence on which variable predominates. At low temperature, at the time of starting the self-heating, compaction delays the start of the process because it makes access to the solid surface difficult for oxygen: the solid-gas interaction is reduced. However, when the temperature rises enough, the initial oxidation is guaranteed and what influences the development process is the propagation of the reaction, which is now favoured by increasing the thermal conductivity. The self-heating process depends on both the heating and cooling and a high conductivity at the initial time favours heat dissipation and delay the process. Conversely, when the process is underway and the temperature rises, the highest conductivity promotes the heating of the particles close to the heat source.
This change observed with increasing temperature can be seen very well in the DSC curves. Upon reaching the IET (initial temperature exothermic reaction), still at low temperature, the process is still slow and the access of oxygen to the surface is the dominant mechanism for the development of self-heating. However, once the CST (slope change of temperature) is exceeded, the process is faster and will be conditioned by the spread of the reaction, which is favoured by a higher thermal conductivity.

\section{Conclusions}

Firstly, it is observed that the total amount of gas emissions from the studied samples heavily depends on the temperature of the 
Table 3

Comparison of results.

\begin{tabular}{|c|c|c|c|}
\hline \multirow[t]{2}{*}{ Sample } & \multirow{2}{*}{$\begin{array}{l}\text { Differential } \\
\text { scanning } \\
\text { calorimetry } \\
\text { IT }\left({ }^{\circ} \mathrm{C}\right)\end{array}$} & \multicolumn{2}{|c|}{ Gas emissions methodology } \\
\hline & & $\begin{array}{l}\text { Range according to } \\
\text { CO emissions }\left({ }^{\circ} \mathrm{C}\right)\end{array}$ & $\begin{array}{l}\text { Range according } \\
\text { to } \mathrm{CO}_{2} \text { emissions }\left({ }^{\circ} \mathrm{C}\right)\end{array}$ \\
\hline Wood chips & 82 & $60-80$ & $100-120$ \\
\hline Sewage sludge & 110 & $80-100$ & $60-80$ \\
\hline Coal & 104 & $80-100$ & $100-120$ \\
\hline
\end{tabular}

sample. Compaction also affects to emissions, but it depends on the particle size and the moisture of the sample. The lower values of these parameters, the more efficient the compaction is.

Secondly, it is observed that the combustion process of the sample is earlier detected by gas emissions than by the TG-DSC analyses. $\mathrm{CO}$ emissions are detected at lower temperatures than IT, while it happens occasionally with $\mathrm{CO}_{2}$. This means that $\mathrm{CO}$ emissions are more effective for this methodology.

Therefore, gas emission measurements allow to observe the self-ignition tendency of a solid fuel at lower temperatures than TG-DSC analyses. Also different heating stages existing in the combustion process which can be easily detected with the TG-DSC analyses may be also defined with the gas emission test.

This test is designed at laboratory scale, so data are measuring point by point. To apply this test for an industrial practice it is recommended to apply online gas analysis to have a continuous data measurement.

\section{References}

Aldushin, A., Bayliss, A., Matkowsky, B., 2006. On the transition from smoldering to flaming. Combust. Flame 145, 579-606.

Bakhman, N., Kuznetsov, G., Puchkov, V., 2002. Effect of airflow direction and velocity on smoldering waves in combustible porous layers. Combust. Explos. Shock Waves 38 (5), 518-524.

Baral, A., Guha, G.S., 2004. Trees for carbon squestration or fossil fuel substitution: the issue of cost vs. carbon benefit. Biomass \& Bioenergy 27, 41-55.

Everard, C., Schmidt, M., McDonnell, K., Finnan, J., 2014. Heating processes during storage of Miscanthus chip piles and numerical simulations to predict selfignition. J. Loss Prev. Process Ind. 30, 188-196.
Fabiano, B., Currò, F., Reverberi, A., Palazzi, E., 2013. Coal dust emissions: from environmental control to risk minimization by underground transport. An applicative case-study. Process Saf. Environ. Prot. Retrieved from http://dx.doi. org/10.1016/j.psep.2013.01.002.

Fernandez-Anez, N., Garcia Torrent, J., Medic Pejic, L., Grima Olmedo, C., 2014. New tests for the detection of incipient self-ignition process in soluid fuels. In: Tenth International Symposium on Hazards, Prevention, and Mitigation of Industrial Explosion (X ISHPMIE). Bergen, Norway.

García-Torrent, J., Ramírez-Gómez, Á., Querol-Aragón, E., Grima-Olmedo, C., MedicPejic, L., 2012. Determination of the risk of self-ignition of coals and biomass materials. J. Hazard. Mater. 230-235.

Goode, J.G., Yokelson, R.J., 1999. Trace gas emissions from laboratory biomass fires measured by open-path Fourier transform infrared spectroscopy: fires in grass and surface fuels. J. Geophys. Res. 104 (D17), 21,237-21,245.

Hegg, D.A., Radke, L.F., Hobbs, P.V., 1990. Emissions of some trace gases grom biomass fires. J. Geophys. Res. 95 (D5), 5669-5675.

Heller, M.C., Keoleian, G.A., Mann, M.K., Volk, T.A., 2004. Life cycle energy and environmental benefits of generating electricity from willow biomass. Renew. Energy 29, 1023-1042.

International Energy Agency, 2013. Key World Energy Statistics. Retrieved from. http://www.iea.org/publications/freepublications/publication/KeyWorld2013. pdf.

Kallio, A., Salminen, O., Sievänen, R., 2013. Sequester or substitute - consequenves of increased production of wood based energy on the carbon balance in Finland. J. For. Econ. http://dx.doi.org/10.1016/j.jfe.2013.05.001.

Kothari, R., Tyagi, V., Pathak, A., 2010. Waste-to-energy: a way from renewable energy sources to sustainable development. Renew. Sustain. Energy Rev. 14, 3164-3170.

Laboratorio Oficial Madariaga (LOM), 2013. Estudio de un sistema avanzado de seguridad para la prevención y control de los fenómenos de autocombutión en almacenamientos prolongados. Madrid.

Magdziarz, A., Wilk, M., 2013. Thermogravimetric study of biomass, sewage sludge and coal combustion. Energy Convers. Manag. 75, 425-430.

Montenegro Mateos, L., Garcia Torrent, J., Castilla Gomez, J., Fernandez Anez, N. Medic Pejic, L., 2013. Physical characteristics of biomass and its influence in selfcombustion. In: 13th International Multidisciplinary Scientific Geoconference SGEM 2013. Energy and Clean Technologies. Albena Co., Bulgaria: International Multidisciplinary Scientific Geoconference SGEM, pp. 169-176.

Sipilä, J., Auerkari, P., Heikkilä, A.-M., Tuominen, R., Vela, I., Itkonen, J., , et al.Aaltonen, K., 2012. Risk and mitigation of self-heating and spontaneous combustion in underground coal storage. J. Loss Prev, Process Ind. 25, 617-622.

U.S. Energy Information Administration. (n.d.). Retrieved December 03, 2013, from http://www.eia.gov/cfapps/ipdbproject/iedindex3.cfm? tid $=1 \&$ pid $=1 \&$ aid $=2 \&$ cid $=w w, \&$ syid $=2008 \&$ eyid $=2012 \&$ unit=TST .

Veznikova, H., Perdochova, M., Bernatik, A., Binkau, B., 2014. Safe storage of selected fuels with regard to their tendency to spontaneous combustion. J. Loss Prev. Process Ind. 29, 295-299.

Wibe, S., 2012. Carbon dioxide emissions from wood fuels in Sweden 1980-2100. J. For. Econ. 18, 123-130.

World coal association, 2013, August. World Coal Association. Retrieved December 02, 2013, from. http://www.worldcoal.org/resources/coal-statistics/. 